
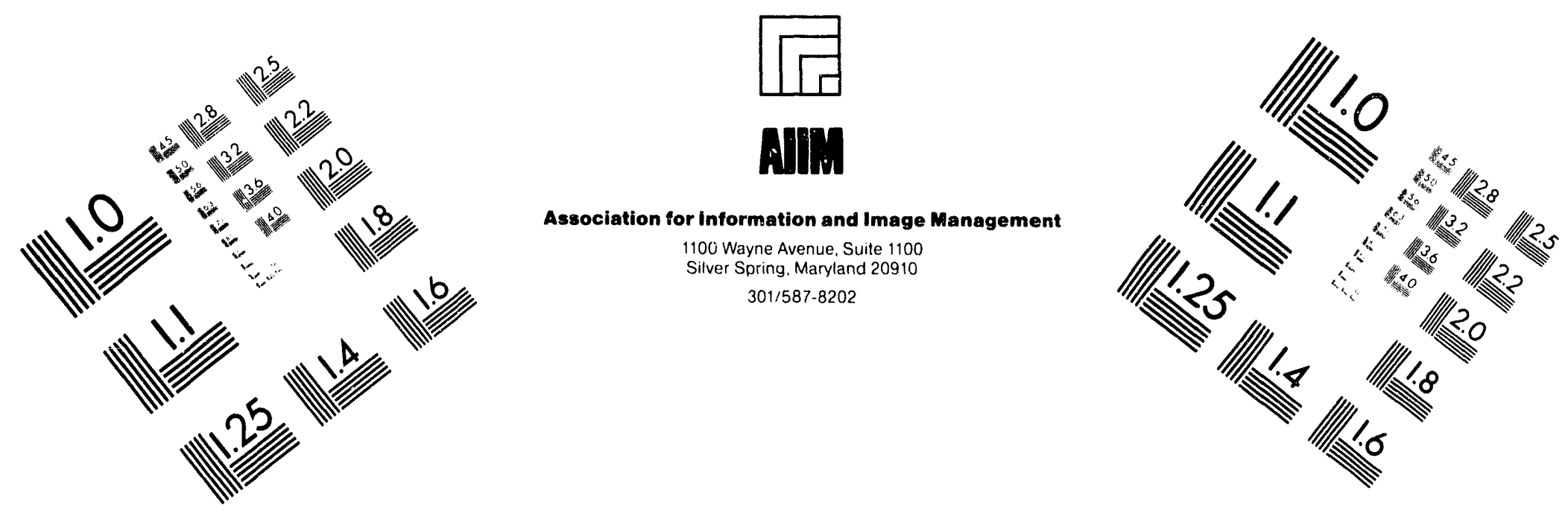

\title{
Centimeter
}

| Inches
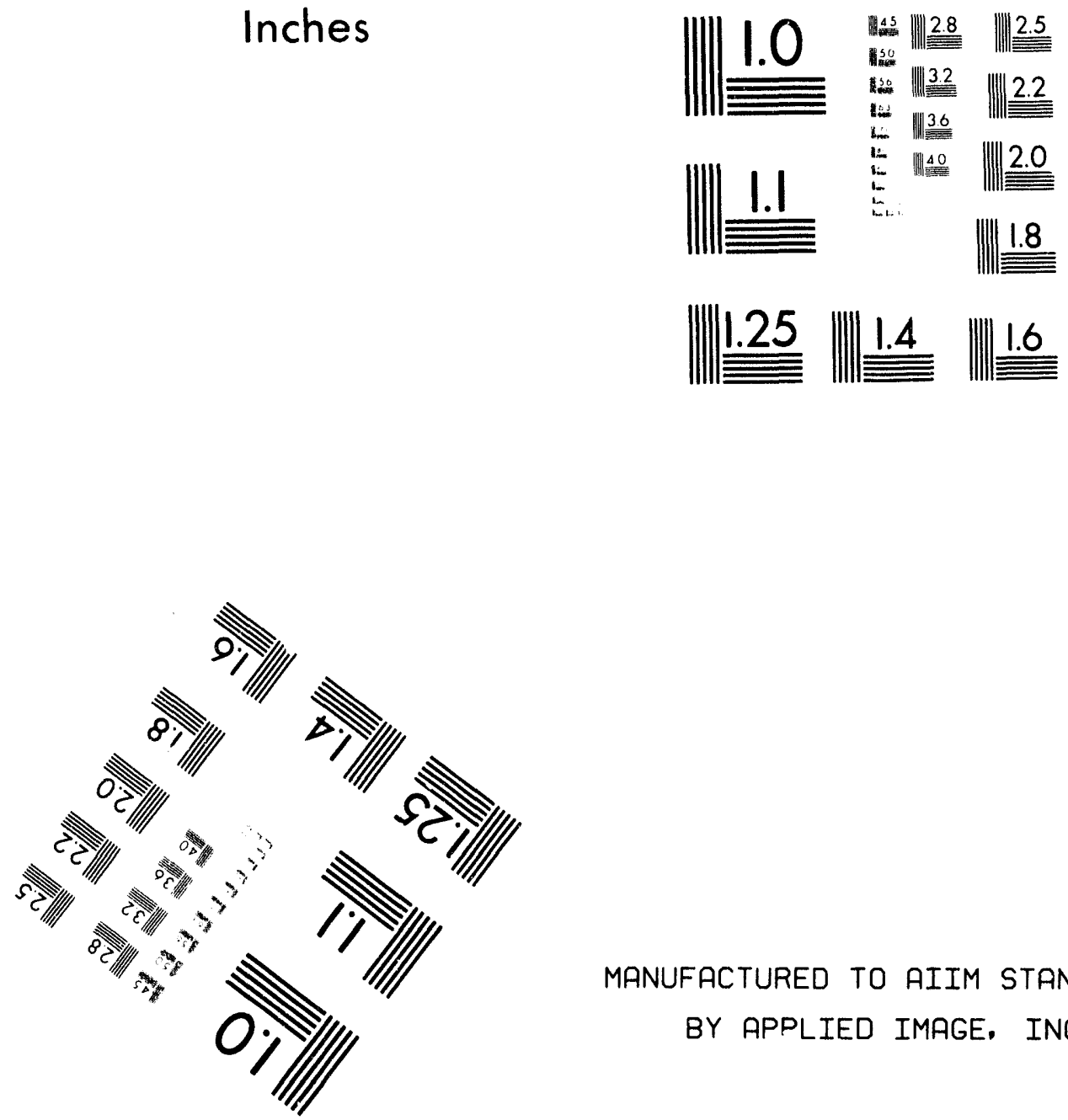

MANUFACTURED TO AIIM STANDARDS

BY APPLIED IMAGE, INC.

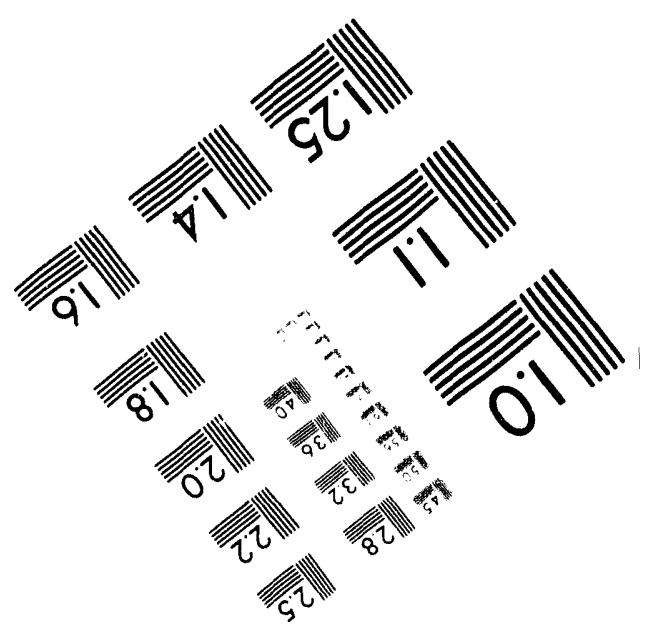



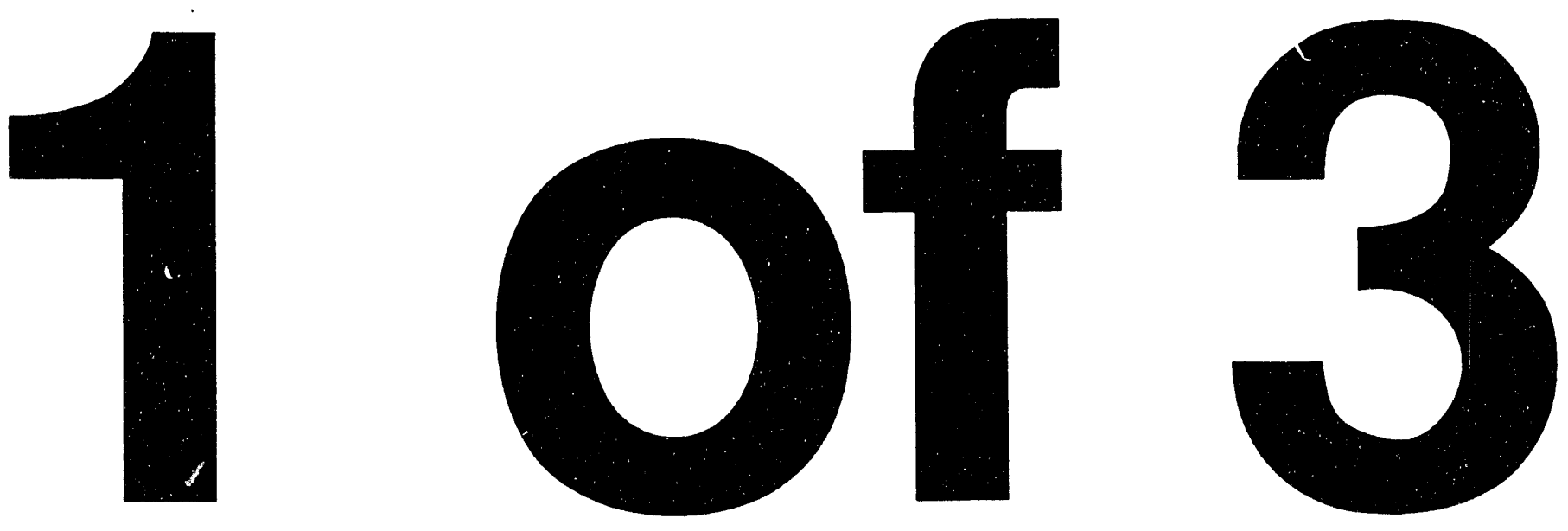
NUREG/CR-6234

ANL-94/22

BMI-2178

\section{Validation of Analysis Methods \\ for Assessing Flawed Piping \\ Subjected to Dynamic Loading}

Manuscript Completed: June 1994

Date Published: August 1994

Prepared by

R. J. Olson, R. L. Wolterman, G. M. Wilkowski, C. A. Kot*

Battelle

505 King Avenue

Columbus, OH 43201

\section{Prepared for}

Division of Engineering

Office of Nuclear Regulatory Research

U.S. Nuclear Regulatory Commission

Washington, DC 20555-0001

NRC FIN L1673

\footnotetext{
*Argonne National Laboratory 9700 South Cass Avenue

Argonne, IL 60439
} 


\section{ABSTRACT}

Argonne National Laboratory and Battelle have j jintly conducted a research program for the USNRC to evaluate the ability of current engineering analysis methods and one state-of-the-art analysis method to predict the behavior of circumferentially surface-cracked pipe system water-hammer experiments. The experimental data used in the evaluation were from the HDR Test Group E31 series conducted by the Kernforschungszentrum Karlsruhe (KfK) in Germany. The incentive for this evaluation was that simplified engineering methods, as well as newer "state-of-the-art" fracture analysis methods, have been typically validated only with static experimental data. Hence, these dynamic experiments were of high interest. High-rate dynamic loading can be classified as either repeating, e.g., seismic, or nonrepeating, e.g., water hammer. Development of experimental data and validation of cracked pipe analyses under seismic loading (repeating dynamic loads) are being pursued separately within the NRC's International Piping integrity Research Group (IPIRG) program.

This report describes developmental and validation efforts to predict crack stability under waterhammer loading, as well as comparisons using currently used analysis procedures. Current fracture analysis methods use the elastic stress analysis loads decoupled from the fracture mechanics analysis, while state-of-the-art methods employ nonlinear cracked-pipe time-history finite element analyses. The results showed that the current decoupled methods were conservative in their predictions, whereas the cracked pipe finite element analyses were more accurate, yet slightly conservative. The nonlinear time-history cracked-pipe finite element analyses conducted in this program were also attractive in that they were done on a small Apollo DN5500 workstation, whereas other cracked-pipe dynamic analyses conducted in Europe on the same experiments required the use of a CRAY2 supercomputer, and were less accurate. 


\section{CONTENTS}

Page

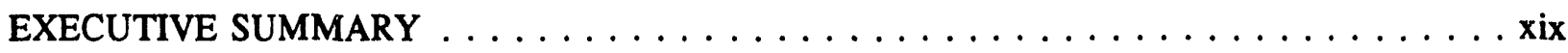

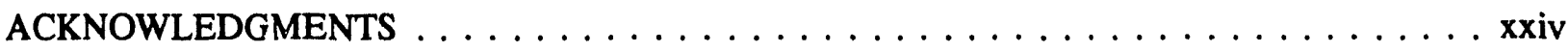

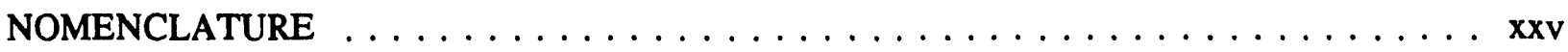

PREVIOUS REPORTS IN SERIES $\ldots \ldots \ldots \ldots \ldots \ldots \ldots \ldots \ldots \ldots \ldots \ldots$ xxiii

1. INTRODUCTION $\ldots \ldots \ldots \ldots \ldots \ldots \ldots \ldots \ldots \ldots \ldots \ldots \ldots \ldots \ldots$

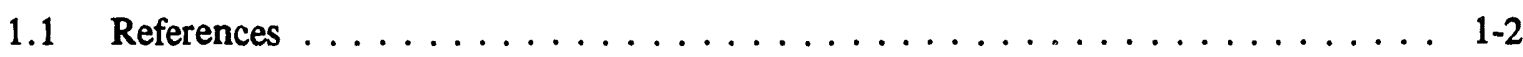

2. CURRENT ENGINEERING FRACTURE MECHANICS ANALYSES . . . . . . . . 2-1

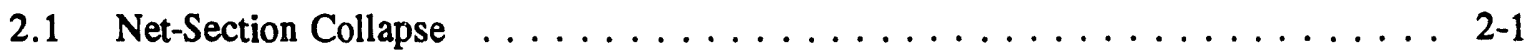

$2.2 \quad$ ASME Section XI $\ldots \ldots \ldots \ldots \ldots \ldots \ldots \ldots \ldots \ldots \ldots$

2.2.1 Ferritic Pipe Fracture Analysis $\ldots \ldots \ldots \ldots \ldots \ldots \ldots \ldots \ldots$

2.3 Dimensionless Plastic-Zone Parameter $\ldots \ldots \ldots \ldots \ldots \ldots \ldots$

2.4 R6 Revision 3, Option 1 Analysis $\ldots \ldots \ldots \ldots \ldots \ldots \ldots \ldots \ldots \ldots$

2.4.1 R6 Rev. 3 Option 1 Calculational Procedure . . . . . . . . . . 2-7

$2.5 \mathrm{~J}$-Estimation Scheme Analysis $\ldots \ldots \ldots \ldots \ldots \ldots \ldots \ldots \ldots \ldots$

2.5.1 J-Estimation Scheme Analysis Procedures . . . . . . . . . . . . 2-11

2.5 .2 Modification for Pressure . . . . . . . . . . . . . . . . 2-12

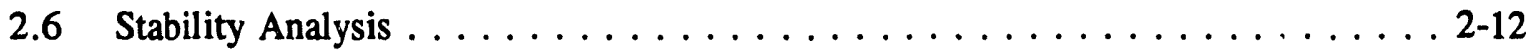

2.6.1 Fully Plastic J/T Stability Analysis . . . . . . . . . . . . 2-13

2.6.2 Energy Balance Stability Analysis . . . . . . . . . . . . . 2-14

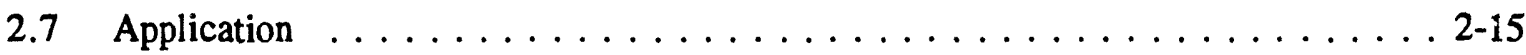

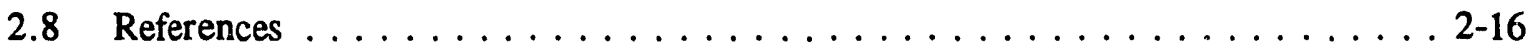


CONTENTS

$\underline{\text { Page }}$

3. NONLINEAR FEA FRACTURE MECHANICS ANALYSES $\ldots \ldots \ldots \ldots \ldots$

3.1 Prior State-Of-The-Art $\ldots \ldots \ldots \ldots \ldots \ldots \ldots \ldots \ldots \ldots \ldots \ldots$

3.1.1 Nonlinear Spring Dynamic Analysis Options . . . . . . . . . . . . 3-2

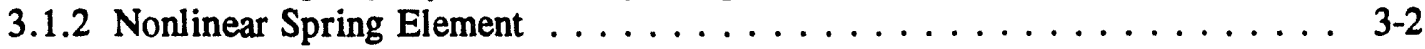

3.1.3 Nonlinear Spring Performance $\ldots \ldots \ldots \ldots \ldots \ldots \ldots \ldots$. . . . . . . .

3.2 Advancements in the State-Of-The-Art $\ldots \ldots \ldots \ldots \ldots \ldots \ldots \ldots$

3.2.1 Prediction of Flaw Behavior Past Maximum Moment . . . . . . . . . 3-4

3.2.1.1 Model $\ldots \ldots \ldots \ldots \ldots \ldots \ldots \ldots \ldots \ldots \ldots \ldots \ldots$ 3-5

3.2.1.2 Validation .................... $3-6$

3.2.1.3 Summary of Analysis of Cracked-Pipe Behavior

Beyond Maximum Load . . . . . . . . . . . . . 3-8

3.2.2 Prediction of SC to TWC Transitions . . . . . . . . . . . . . . 3-9

3.2.2.1 Model . . . . . . . . . . . . . . . . . 3-9

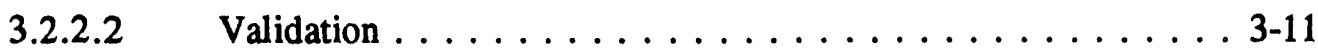

3.2.2.3 Summary of Dynamic Surface to Through-Wall Crack

Transition Behavior . . . . . . . . . . . . . 3-12

3.2.3 Cyclic Loading with Reinitiation $\ldots \ldots \ldots \ldots \ldots \ldots$ 3-12 . . . . . . .

3.2.3.1 Model . . . . . . . . . . . . . . . 3-12

3.2.3.2 Validation . . . . . . . . . . . . . . . . 3-14

3.2.3.3 Summary of Analytical Cyclic Loading with Reinitiation . . . 3-15

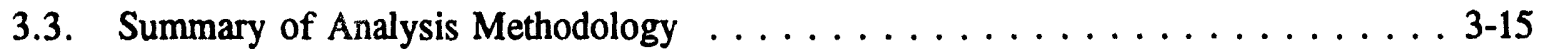

3.4 References ............................... . . . . . . . .

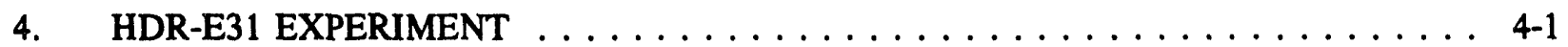

4.1 Experimental Facility $\ldots \ldots \ldots \ldots \ldots \ldots \ldots \ldots \ldots \ldots \ldots \ldots \ldots$

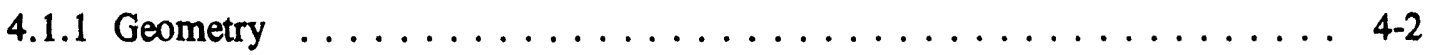

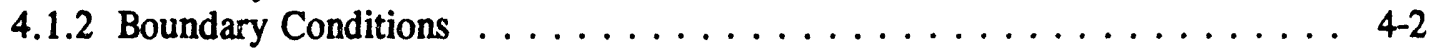

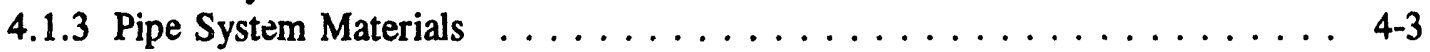

4.1.4 Instrumentation/Measurements $\ldots \ldots \ldots \ldots \ldots \ldots \ldots \ldots \ldots$ 
4.2 Loading $\ldots \ldots \ldots \ldots \ldots \ldots \ldots \ldots \ldots \ldots \ldots \ldots \ldots \ldots \ldots \ldots \ldots$

4.2 .1 Initial Test Conditions $\ldots \ldots \ldots \ldots \ldots \ldots \ldots \ldots \ldots$ 4-5

4.2.2 Rupture Disc Assembly and Check Valve . . . . . . . . . . . 4-5

4.2.3 Pipe System Pressure-Time Histories . . . . . . . . . . . . . . . . 4-6 . . . . . . .

4.2.4 Elbow Pressures, Forces, and Moments $\ldots \ldots \ldots \ldots \ldots \ldots$. . . . . . .

4.3 Flaws $\ldots \ldots \ldots \ldots \ldots \ldots \ldots \ldots \ldots \ldots \ldots \ldots \ldots \ldots \ldots \ldots$

4.3.1 Test Section . . . . . . . . . . . . . . . . . . 4-7

4.3.2 Test Section Materials $\ldots \ldots \ldots \ldots \ldots \ldots \ldots \ldots \ldots \ldots$. . . . . . . . .

4.4 References . . . . . . . . . . . . . . . . . . . . 4-8

5. PREDICTIONS OF THE HDR-E31 EXPERIMENTS $\ldots \ldots \ldots \ldots \ldots \ldots \ldots \ldots$. . . . $\ldots$.

5.1 Finite Element Modeling $\ldots \ldots \ldots \ldots \ldots \ldots \ldots \ldots \ldots \ldots \ldots \ldots$

5.1 .1 Finite Element Models $\ldots \ldots \ldots \ldots \ldots \ldots \ldots \ldots \ldots \ldots \ldots$. . . . . . . .

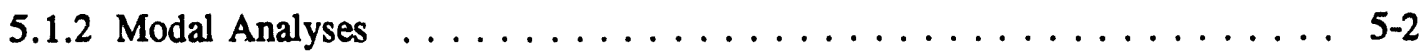

5.1 .3 Static Analyses . . . . . . . . . . . . . . . . . 5-3

5.1 .4 Linear Dynamic Analysis $\ldots \ldots \ldots \ldots \ldots \ldots \ldots \ldots \ldots$

5.2 Engineering Fracture Predictions $\ldots \ldots \ldots \ldots \ldots \ldots \ldots \ldots$

5.2 .1 Analysis Assumptions $\ldots \ldots \ldots \ldots \ldots \ldots \ldots \ldots \ldots \ldots$

5.2.1.1 R6 Assumptions . . . . . . . . . . . . 5-6

5.2.1.2 J-Estimation Scheme Assumptions . . . . . . . . 5-6

5.2.1.3 Energy Balance Stability Analysis Assumptions . . . . . . 5-7

5.2 .2 Predictions $\ldots \ldots \ldots \ldots \ldots \ldots \ldots \ldots \ldots \ldots \ldots \ldots \ldots$

5.3 Nonlinear FEA Fracture Predictions . . . . . . . . . . . . . . . . 5-9

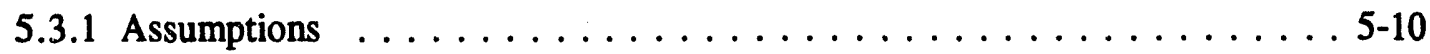

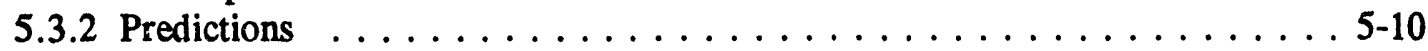

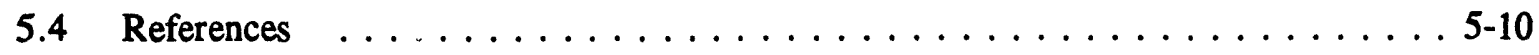

6. COMPARISONS OF PREDICTIONS AND THE HDR-E31 EXPERIMENTS $\ldots \ldots$. . 6-1

6.1 Structural Behavior Comparisons $\ldots \ldots \ldots \ldots \ldots \ldots \ldots \ldots \ldots \ldots \ldots$ 


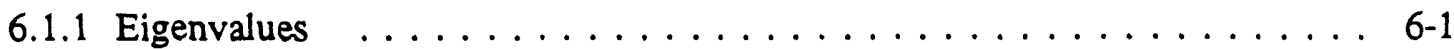

6.1 .2 Static Behavior .......................... 6-1

6.1 .3 Dynamic Time-History Response ................... 6-1

6.1.3.1 Displacement Comparisons . . . . . . . . . . . . 6-2

6.1.3.2 Moment Comparisons Remote from the Test Section . . . . . . 6 6-2

$6.2 \quad$ Fracture Mechanics Comparisons . . . . . . . . . . . . . . . . . 6-2

6.2 .1 Loads and Stresses at Cracked Section . . . . . . . . . . . . . . . 6-2

6.2 .2 Crack Response . . . . . . . . . . . . . . . . . . . . . 6-3

6.2.3 Comparison of Calculations and Test Results . . . . . . . . . . . . 6-4

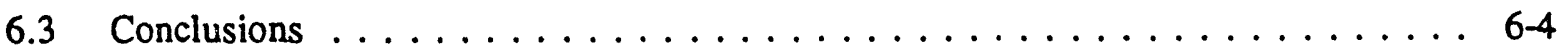

6.4 References . . . . . . . . . . . . . . . . . . . . $6-5$

7. SUMMARY, DISCUSSION, AND CONCLUSIONS $\ldots \ldots \ldots \ldots \ldots \ldots$

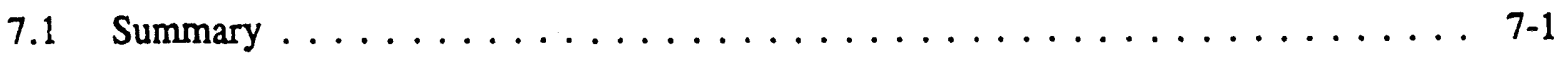

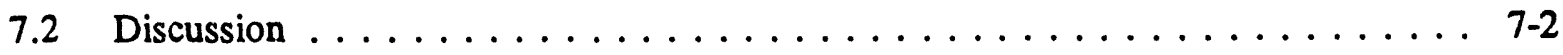

7.2.1 Accuracy of the Elastic Stress Analysis . . . . . . . . . . . . 7-2

7.2 .2 Accuracy of the Fracture Analyses . . . . . . . . . . . . . 7-3

7.2.3 Limitations in Engineering Methods Stability Analyses . . . . . . . . . . . 7-4

7.2.4 Limitations in Nonlinear FEA Fracture Analysis Methods . . . . . . . . 7-5

7.2.5 The HDR-E31 Experiments as an Analysis Validation Tool . . . . . . . . . 7-6

7.2 .6 Other HDR-E31 Analysis Efforts $\ldots \ldots \ldots \ldots \ldots \ldots \ldots$. . . . . . . .

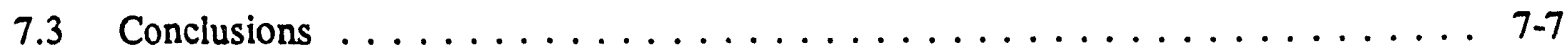

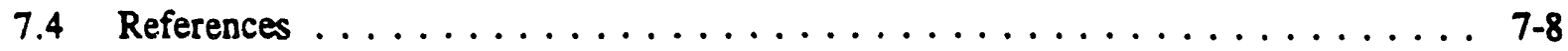


FIGURES

\section{FIGURES}

Figure

$\underline{\text { Page }}$

2.1 Net-Section-Collapse criteria $\ldots \ldots \ldots \ldots \ldots \ldots \ldots \ldots \ldots \ldots \ldots \ldots \ldots$

2.2 Nomenclature and loading system for the application of the Net-Section-Collapse criterion to a pipe with a circumferential through-wall crack . . . . . . . . . . . 2-19

2.3 Nomenclature and loading for the application of the Net-Section-Collapse criterion to a pipe with a circumferential surface crack subjected

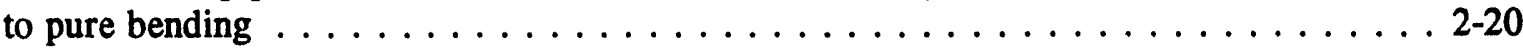

2.4 Nomenclature and loading for the application of the Net-Section-Collapse criterion to a pipe with a circumferential surface crack subjected

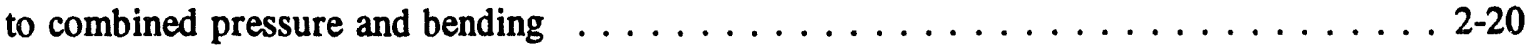

2.5 Dimensionless Plastic-Zone Parameter data $\left[\sigma_{\mathrm{f}}=\left(\sigma_{\mathrm{y}}+\sigma_{\mathrm{u}}\right) / 2\right] \ldots \ldots \ldots \ldots \ldots \ldots$

2.6 R6, Option 1 failure assessment diagram $\ldots \ldots \ldots \ldots \ldots \ldots \ldots \ldots \ldots \ldots \ldots$

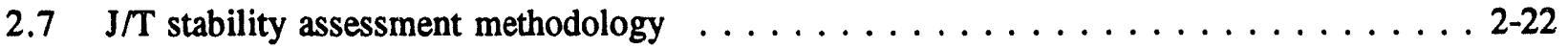

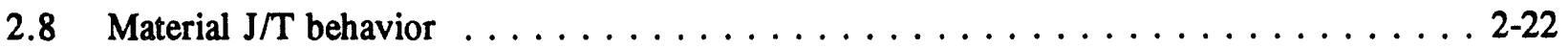

2.9 Energy available for driving an instability $\ldots \ldots \ldots \ldots \ldots \ldots \ldots \ldots \ldots \ldots \ldots$

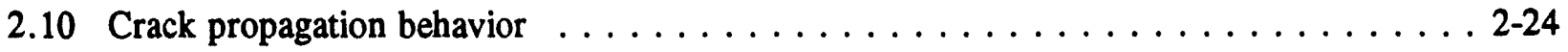

2.11 Energy Balance diagram showing balanced available and absorbed energies $\ldots \ldots \ldots 2-24$

3.1 Cracked pipe analysis beam and shell piping system model of

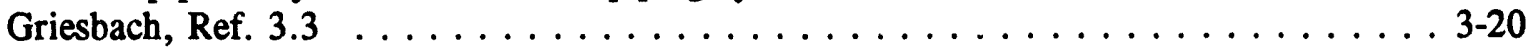

3.2 LBB.ENG reduced section for modeling cracked piping response $\ldots \ldots \ldots \ldots$. . . . . 3-20

3.3 Basic spring-slider element $\ldots \ldots \ldots \ldots \ldots \ldots \ldots \ldots \ldots \ldots \ldots \ldots \ldots \ldots$

3.4 Modeling of a multi-linear load-displacement curve with spring slider elements $\ldots \ldots$. . 3-21

3.5 Spring-slider model of a crack under reversed loading without crack closure $\ldots \ldots \ldots$. . 3-22

3-6 IPIRG-1 Subtask 1.1 inertial loading cracked pipe experimental facility $\ldots \ldots \ldots$. . . . 3-22

3-7 IPIRG-1 Experiment $1.1-3$ forcing function $\ldots \ldots \ldots \ldots \ldots \ldots \ldots \ldots \ldots$ 
FIGURES

Figure

Page

3-8 Comparison of experiment and pretest design analysis for moment versus

time for IPIRG-1 Experiment 1.1-3, inertially loaded stainless steel

through-wall crack, (analysis valid only up to maximum moment) $\ldots \ldots \ldots \ldots$. . . . 3-24

3-9 Comparison of experiment and pretest design analysis for inertial mass

displacement for IPIRG-1 Experiment 1.1-3, (inertially loaded stainless

steel through-wall crack $\ldots \ldots \ldots \ldots \ldots$. . . . . . . . . . . . . . . . . . . . . . . .

3-10 Comparison of experiment and pretest design analysis for moment versus total rotation for IPIRG-1 Experiment 1.1-3 (inertially loaded stainless steel through-wall crack) (analysis valid only up to maximum moment) $\ldots \ldots \ldots$. . . . . 3-26

3-11 Artist's conception of the IPIRG pipe loop test facility $\ldots \ldots \ldots \ldots \ldots \ldots \ldots$

3-12 Dimensions of the IPIRG pipe loop test facility $\ldots \ldots \ldots \ldots \ldots \ldots \ldots \ldots$

3-13 IPIRG-1 Experiment 1.1-3 (pipe system stainless steel surface crack experiment)

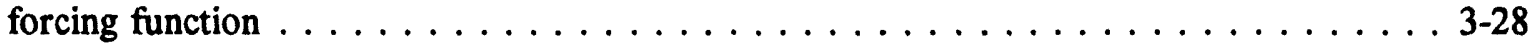

3-14 Flaw location moment for IPIRG-1 Experiment 1.3-3

(pipe system stainless steel base metal experiment) $\ldots \ldots \ldots \ldots \ldots \ldots \ldots \ldots$. . . . . . .

3-15 Crack section moment-rotation for IPIRG-1 Experiment 1.1-3

(pipe system stainless steel base metal experiment) . . . . . . . . . . . . . . . 3-29

3-16 Global pipe loop displacement at the crack location for IPIRG-1

Experiment 1.3-3 (stainless steel base metal experiment) $\ldots \ldots \ldots \ldots$. . . . . . . 3-29

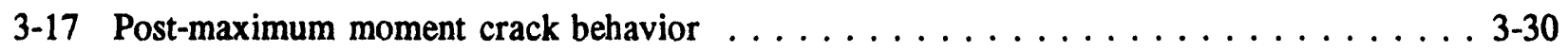

3-18 ANSYS STIF39 (nonlinear force-deflection element) response under

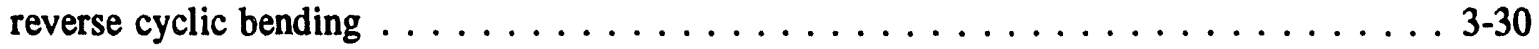

3-19 Model for analysis of post-maximum moment crack behavior $\ldots \ldots \ldots \ldots \ldots$. . . . . .

3.20 Input moment-rotation response for a through-wall crack in a pipe $\ldots \ldots \ldots \ldots$ 3-31

3.21 Nonlinear truss model analysis of a through-wall crack without unloads

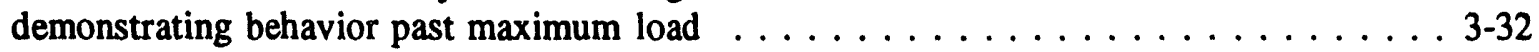

3.22 Nonlinear truss model analysis of a through-wall crack with unloads exhibiting absence of ratcheting and proper kinematic hardening response $\ldots \ldots \ldots 3-32$ 
FIGURES

Figure

Page

3.23 Schematic of DTRC compliant instability pipe experiments $\ldots \ldots \ldots \ldots \ldots$ 3-33

3.24 Comparison of experimental results (DTRC Test Number 7) and predicted behavior (LBB.ENG2) showing the high quality of the predictions $\ldots \ldots \ldots \ldots \ldots$

3.25 LBB.ENG2 through-wall crack J-estimation scheme predictions of momentrotation behavior for selected DTRC experiments $\ldots \ldots \ldots \ldots \ldots \ldots \ldots \ldots$

3.26 Stable crack growth behavior for DTRC Experiment 7 with

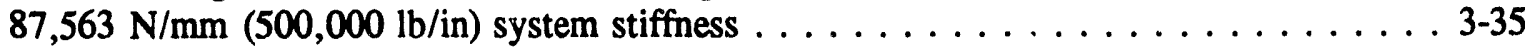

3.27 Limited instability behavior for DTRC Experiment 7 with $2,627 \mathrm{~N} / \mathrm{mm}(15,000 \mathrm{lb} / \mathrm{in})$ system stiffness $\ldots \ldots \ldots \ldots \ldots$. . . . . . . . . . . . . .

3.28 Completely unstable behavior for DTRC Experiment 13 with measured system stiffness of $6,480 \mathrm{~N} / \mathrm{mm}(37,000 \mathrm{lb} / \mathrm{in}) \ldots \ldots \ldots \ldots$ 3-37

3.29 Energy balance for DTRC Experiment 13 with $6,480 \mathrm{~N} / \mathrm{mm}(37,000 \mathrm{lb} / \mathrm{in})$

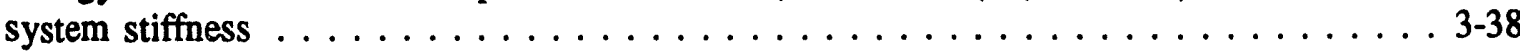

3.30 Energy balance for DTRC Experiment 13 with $12,959 \mathrm{~N} / \mathrm{mm}(74,000 \mathrm{lb} / \mathrm{in})$

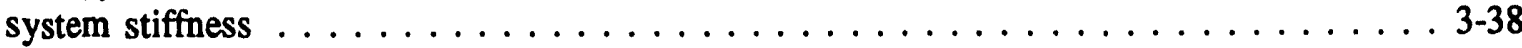

3.31 Energy balance for DTRC Experiment 13 with $15,761 \mathrm{~N} / \mathrm{mm}(90,000 \mathrm{lb} / \mathrm{in})$

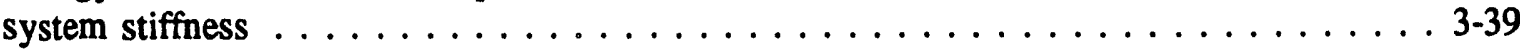

3.32 $\mathrm{J} / \mathrm{T}$ assessment for DTRC Experiment 13 using Zahoor EPFM formulation at various system stiffnesses $(1.0 \mathrm{lb} / \mathrm{in}=0.17513 \mathrm{~N} / \mathrm{mm}) \ldots \ldots \ldots 39 \ldots \ldots \ldots$

3.33 Model of surface crack to through-wall crack transition using plastic trusses $\ldots \ldots \ldots$. . . . .

3.34 Model of surface crack to through-wall crack transition using spring-sliders and one plastic truss $\ldots \ldots \ldots \ldots \ldots \ldots \ldots \ldots$

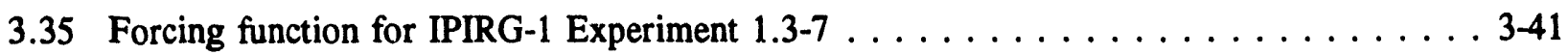

3.36 Input moment-rotation response for IPIRG-1 Experiment 1.3-7 from

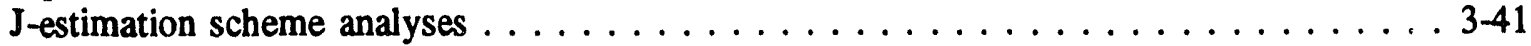

3.37 Comparison of crack section moment as a function of cime for IPIRG-1

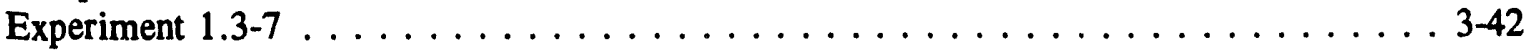

3.38 Crack section cyclic moment-rotation for IPIRG-1 Experiment $1.3-7 \ldots \ldots \ldots$. . . . . . . . 
FIGURES

Figure

3.39 Ideas for incorporating crack growth in a cyclically loaded pipe specimen

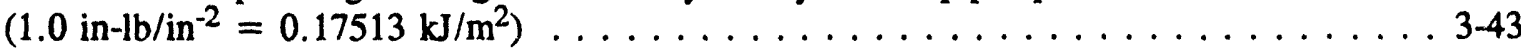

3.40 Kinematic hardening behavior at large rotations when the tangent stiffness is negative (Note inflection on compressive loading is incorrect modelling $\ldots \ldots \ldots \ldots \ldots \ldots \ldots \ldots \ldots \ldots \ldots \ldots \ldots \ldots$

3.41 Crack unloading and compressive behavior model $\ldots \ldots \ldots \ldots \ldots \ldots \ldots$

3.42 IPIRG-1 Experiment 1.2-4 (displacement iontrolled loading, carbon steel through-wall crack) $R=-1$ moment-rotation response . . . . . . . . . . . . . . . . . 3-44

3.43 Unloading model performance using measured crack growth data (solid curves are selected cycles from IPIRG-1 Experiment 1.2-4 and dashed curves are predicted unloading response) $\ldots \ldots \ldots \ldots \ldots \ldots \ldots$

3.44 Unloading model performance using LBB.ENG2 J-estimation scheme predicted crack with $\mathrm{J}-\mathrm{R}$ curve derived from an $\eta$-factor analysis of the pipe experiment data (solid curves are selected cycles from IPIRG-1 Experiment $1.2-4$ and dashed curves are predicted unloading response) $\ldots \ldots \ldots \ldots$. . . . . .

4.1 HDR-E31 test system with flawed section $\ldots \ldots \ldots \ldots \ldots \ldots \ldots \ldots \ldots$

4.2 Isometric of the HDR-31 test system (Units in $\mathrm{mm}) \ldots \ldots \ldots \ldots \ldots \ldots \ldots$

4.3 S-nozzle at the reactor pressure vessel (RPV) (Units in $\mathrm{mm}) \ldots \ldots \ldots \ldots \ldots$

4.4 Fixed Point support (Units in $\mathrm{mm}) \ldots \ldots \ldots \ldots \ldots \ldots \ldots \ldots \ldots \ldots$

4.5 Pipe restraint section at the Fixed Point (Units in $\mathrm{mm}) \ldots \ldots \ldots \ldots \ldots$

4.6 Rupture disc assembly support (Units in $\mathrm{mm}) \ldots \ldots \ldots \ldots$. . . . . . . . . . . . . . . .

4.7 Comparison of measured mechanical properties of the HDR-E31 pipe components with data sheet values at $240 \mathrm{C}(464 \mathrm{~F}) \ldots \ldots \ldots \ldots$. . . . . . . . . .

4.8 Stress-strain curves from tensile tests for the HDR-E31 pipe system materials

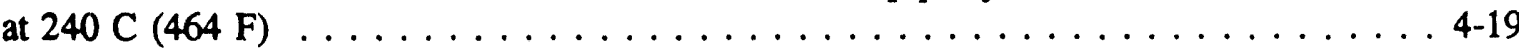

4.9 Strain measurement locations for the HDR-E31 tests $\ldots \ldots \ldots \ldots \ldots \ldots \ldots \ldots$

4.10 Typical strain gage installation in a straight pipe section (cross-section Q91 shown) . . . . . . . . . . . . . . . . . . . . 4-21 
4.11 HDR-E31 piping coordinate systems $\ldots \ldots \ldots \ldots \ldots \ldots \ldots \ldots \ldots \ldots \ldots$

4.12 Pressure gage locations for HDR-E31 tests $\ldots \ldots \ldots \ldots \ldots \ldots \ldots \ldots$. . . . . . . . . . .

4.13 Displacement measurement locations for the HDR-E31 tests and

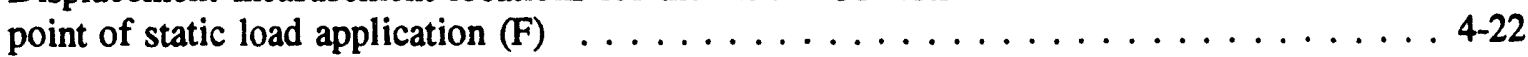

4.14 Rupture disc assembly nominal $450 \mathrm{~mm}$ diameter (Units in $\mathrm{mm}$ ) . . . . . . . . 4-23

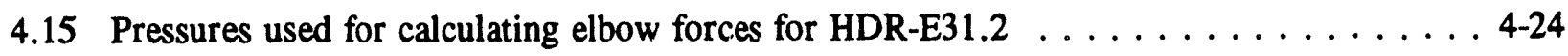

4.16 Pressures used for calculating elbow forces for HDR-E31.3 $\ldots \ldots \ldots \ldots \ldots \ldots$

4.17 Procedure for calculating equivalent elbow forces from elbow pressures . . . . . . . . 4-26

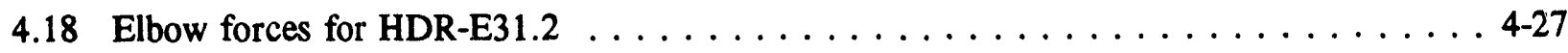

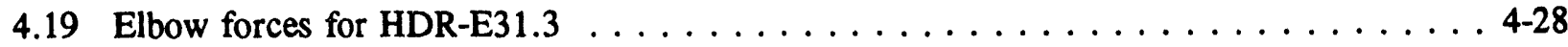

4.20 Test section with circumferential flaw for the HDR-E31 tests (numbers in parenthesis indicate values for HDR-E31.3)

Units in $\mathrm{mm} \ldots \ldots \ldots \ldots \ldots \ldots \ldots \ldots \ldots \ldots$. . . . . . . . . . . . . . . . . . . . .

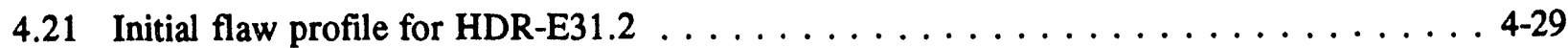

4.22 Initial flaw profile for HDR-E31.3 $\ldots \ldots \ldots \ldots \ldots \ldots \ldots$

4.23 Typical J-R curve for test section material 20 MnMoNi 5 ,

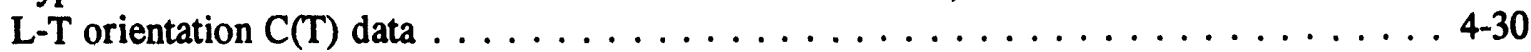

4.24 Charpy energy-temperature curves for test section material 20 MnMoNi 55 at various sample orientations $\ldots \ldots \ldots \ldots \ldots \ldots \ldots \ldots \ldots \ldots \ldots \ldots \ldots$

5.1 HDR-E31 experimental facility schematic (Units in $\mathrm{mm}) \ldots \ldots \ldots \ldots \ldots$

5.2 ANSYS finite element model of the HDR-E31 system $\ldots \ldots \ldots \ldots \ldots \ldots \ldots$

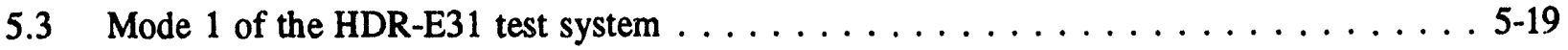

5.4 Mode 2 of the HDR-E31 test system $\ldots \ldots \ldots \ldots \ldots \ldots \ldots \ldots \ldots$

5.5 Mode 3 of the HDR-E31 test system $\ldots \ldots \ldots \ldots \ldots \ldots \ldots \ldots \ldots$

$5.6 \mathrm{M} \quad 4$ the HDR-E31 test system $\ldots \ldots \ldots \ldots \ldots \ldots \ldots \ldots \ldots \ldots$ 
FIGURES

Figure $\quad$ Page

5.7 Mode 5 of the HDR-E31 test system

5.8 Selected nodes and elements in the engineering model $\ldots \ldots \ldots \ldots \ldots \ldots \ldots \ldots$

5.9 Selected nodes and elements in the refined system models $\ldots \ldots \ldots \ldots \ldots \ldots \ldots$

5.10 Moments at Section Q02 (Element 5) in the engineering model

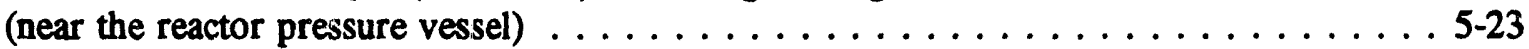

5.11 Moments at Section QP1 (Element 8) in the engineering model (crack location) . . . . . 5-24

5.12 Moments at Section Q9! (Element 38) in the engineering model (near the Fixed Point support) $\ldots \ldots \ldots \ldots \ldots \ldots \ldots \ldots \ldots \ldots \ldots \ldots \ldots$

5.13 Displacements at Transducer MN461 (Node 14) in the engineering model (at the first elbow from the reactor pressure vessel) $\ldots \ldots \ldots \ldots \ldots \ldots \ldots \ldots$

5.14 Displacements at Transducer MN471 (Node 25) in the engineering model (at the second elbow from the reactor pressure vessel) . . . . . . . . . . . . 5-27

5.15 Displacements at Transducer MN481 (Node 35) in the engineering model (at the third elbow from the reactor pressure vessel) $\ldots \ldots \ldots \ldots \ldots \ldots \ldots \ldots$

5.16 Moments at Section Q02 (Element 26) in the refined system models (near the reactor pressure vessel) . . . . . . . . . . . . . . . . . . 5-29

5.17 Moments at Section QP1 (Element 43) in the refined system models

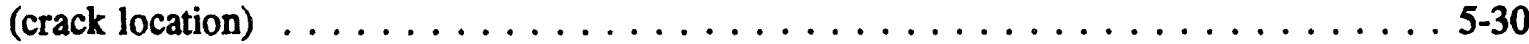

5.18 Moments at Section Q91 (Element 194) in the refined system models

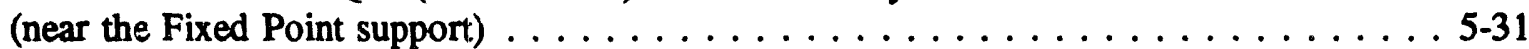

5.19 Displacements at Transducer MN461 (Node 93) in the refined system models (at the first elbow from the reactor pressure vessel) $\ldots \ldots \ldots \ldots \ldots \ldots \ldots \ldots$

5.20 Displacements at Transducer MN471 (Node 142) in the refined system models (at the second elbow from the reactor pressure vessel) $\ldots \ldots \ldots \ldots \ldots \ldots \ldots$. . . . . . . .

5.21 Displacements at Transducer MN481 (Node 171) in the refined system models (at the third elbow from the reactor pressure vessel) $\ldots \ldots \ldots \ldots \ldots \ldots \ldots \ldots$ 5-34

5.22 Stress-strain curve used in the J-estimation scheme analysis for

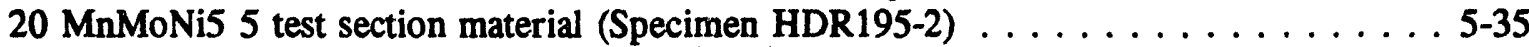


FIGURES

Figure

$5.23 \mathrm{~J}-\mathrm{R}$ curve used in the J-estimation scheme analysis for $20 \mathrm{MnMoNi} 55$

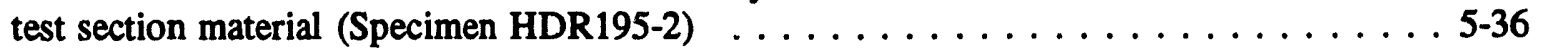

5.24 SC.TNP J-estimation scheme prediction accuracy for Degraded Piping Program experiments (Scatter due to Ramberg-Osgood fits in different

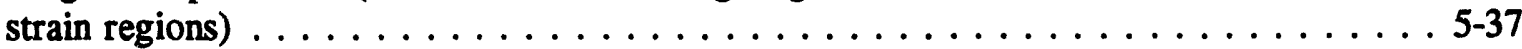

5.25 Dynamic strain-aging screening test data for $20 \mathrm{MnMoNi} 55$ test section material (Lack of a peak hardness indicates that the material is not sensitive to dynamic strain aging) $\ldots \ldots \ldots \ldots \ldots \ldots \ldots$

5.26 Predicted crack behavior from J-estimation scheme analyses (Rotation

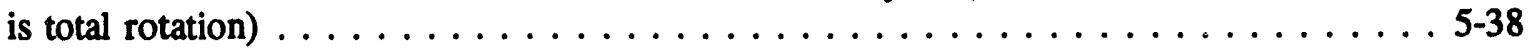

5.27 Load-controlled $\mathrm{J} / \mathrm{T}$ stability analysis of HDR-E31 experiments $\ldots \ldots \ldots \ldots \ldots$. . . . 5-39

5.28 Energy Balance stability analysis of HDR-E31.2 (Rotation is total rotation) $\ldots \ldots \ldots$. . 5-39

5.29 Energy Balance stability analysis of HDR-E31.3 (Rotation is total rotation) $\ldots \ldots$. . 5-40

5.30 Nonlinear FEA fracture mechanics prediction of the moment-time response of the E31.2 flaw (Rotation is total rotation) . . . . . . . . . . . 5-40

5.31 Nonlinear FEA fracture mechanics prediction of the moment-rotation

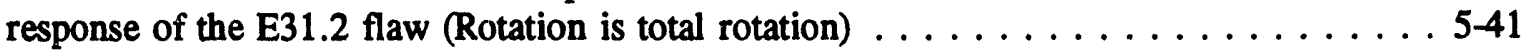

5.32 Nonlinear FEA fracture mechanics prediction of the moment-time

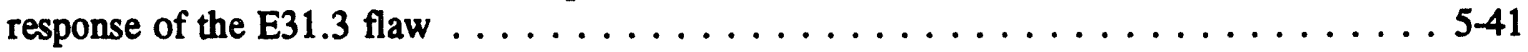

5.33 Nonlinear FEA fracture mechanics prediction of the moment-rotation response of the E31.3 flaw (Rotation is total rotation) . . . . . . . . . . . 5-42

6.1 Displacements at Transducer MN461 (Node 93) for E31.2 (at the first elbow from the reactor pressure vessel)

6.2 Displacements at Transducer MN471 (Node 142) for E31.2 (at the second elbow from the reactor pressure vessel)

6.3 Displacements at Transducer MN481 (Node 171) for E31.2 (at the third elbow from the reactor pressure vessel) $\ldots \ldots \ldots \ldots \ldots \ldots \ldots \ldots$. . . . . . .

6.4 Displacements at Transducer MN461 (Node 93) for E31.3 (at the first elbow from the reactor pressure vessel) $6-13$ 
6.5 Displacements at Transducer MN471 (Node 142) for E31.3

(at the second elbow from the reactor pressure vessel) $\ldots \ldots \ldots \ldots \ldots \ldots$. . . . . . . . .

6.6 Displacements at Transducer MN481 (Node 171) for E31.3

(at the third elbow from the reactor pressure vessel) $\ldots \ldots \ldots \ldots \ldots \ldots \ldots$

6.7 Moments at Section Q02 (Element 26) for E31.2

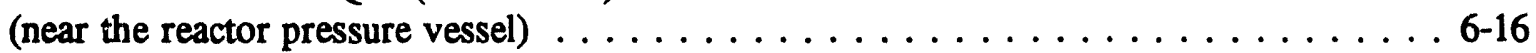

6.8 Moments at Section Q91 (Element 194) for E31.2

(near the Fixed Point support) $\ldots \ldots \ldots \ldots \ldots \ldots \ldots \ldots \ldots$ 6 .17

6.9 Moments at Section Q02 (Element 26) for E31.3

(near the reactor pressure vessel) $\ldots \ldots \ldots \ldots \ldots \ldots \ldots \ldots \ldots \ldots \ldots \ldots$

6.10 Moments at Section Q91 (Element 194) for E31.3 (near the Fixed Point support) . . . . 6-19

7.1 Net-Section-Collapse analysis predictions, with and without considering induced

bending effects for through-wall cracks $\ldots \ldots \ldots \ldots \ldots \ldots \ldots \ldots$. $\ldots \ldots \ldots$

7.2 Experimental surface crack moment-displacement behavior showing the difference between maximum moment and surface crack penetration (From Ref. 7.6) $\ldots \ldots \ldots \ldots \ldots \ldots \ldots \ldots \ldots \ldots$ 


\section{TABLES}

Table

Page

3.1 Test matrix for instability assessments of A106 steel pipes subjected to four-point bending

3.2 Comparison of experimental and predicted maximum moments $\ldots \ldots \ldots \ldots$. . . . . .

3.3 Stability comparison for DTRC compliant instability experiments . . . . . . . . 3-18

3.4 Stability comparison for DTRC compliant instability Experiment 13 with various hypothetical stiffnesses $\ldots \ldots \ldots \ldots \ldots \ldots \ldots \ldots \ldots$ 3-18

3.5 Crack size data for unloading stiffness calculations $\ldots \ldots \ldots \ldots \ldots \ldots \ldots$. . . . . . . . .

4.1 Table of the individual HDR E31 test system pipe sections $\ldots \ldots \ldots \ldots \ldots \ldots \ldots$

4.2 Mechanical and physical properties of the pipe materials, from data sheets: $20 \mathrm{MnMoNi} 55 \ldots \ldots \ldots \ldots \ldots \ldots \ldots \ldots$. . . . . . . . . . .

4.3 Mechanical and physical properties of the pipe materials, from data sheets: $15 \mathrm{MnNi} 63 \ldots \ldots \ldots \ldots \ldots \ldots \ldots \ldots$. . . . . . . . . . . . .

4.4 Mechanical and physical properties of the pipe materials, from data sheets: WB $36 \ldots \ldots \ldots \ldots \ldots \ldots \ldots \ldots$. . . . . . . . . . . . . . .

4.5 Mechanical and physical properties of the pipe materials, from data sheets: 15 Mo $3 \ldots \ldots \ldots \ldots \ldots \ldots \ldots$. . . . . . . . . . . . . .

4.6 Mechanical and physical properties of the reactor pressure

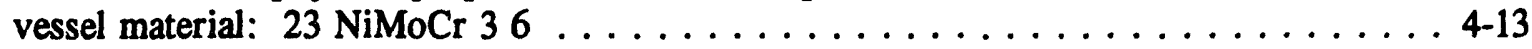

4.7 Initial thermohydraulic test conditions - comparison of measured

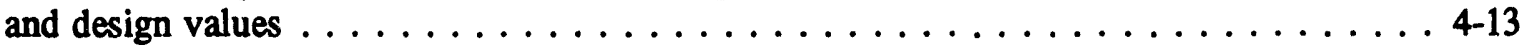

4.8 Initial geometrical parameters of test sections $\ldots \ldots \ldots \ldots \ldots \ldots \ldots \ldots$

4.9 Mechanical characteristics from tensile tests of test section material 20 MnMoNi $55 \ldots \ldots \ldots \ldots \ldots \ldots \ldots \ldots \ldots$. . . . . . . . . . . . . .

5.1 Predicted natural frequencies of the HDR pipe system $\ldots \ldots \ldots \ldots \ldots \ldots \ldots \ldots$. . . . . . . .

5.2 Fixed point stiffness values for Experiment E31.2 . . . . . . . . . . . 5-12

5.3 Mode frequencies for Experiment E31.2 ... . . . . . . . . . . . 5-13 
TABLES

Table

5.4 Summary of displacements due to static loading $\ldots \ldots \ldots \ldots \ldots \ldots \ldots \ldots$

5.5 Moment and displacement results for the engineering finite element

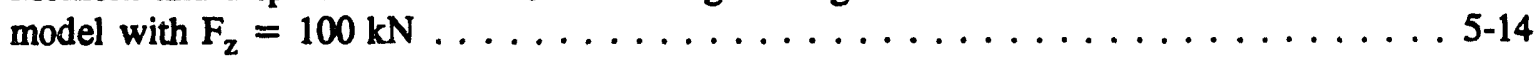

5.6 Moment and displacement results for the E31.2 finite element

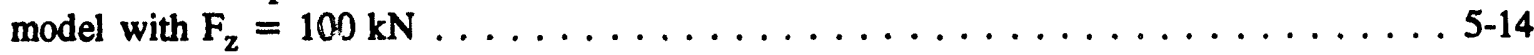

5.7 Moment and displacement results for the engineering finite element

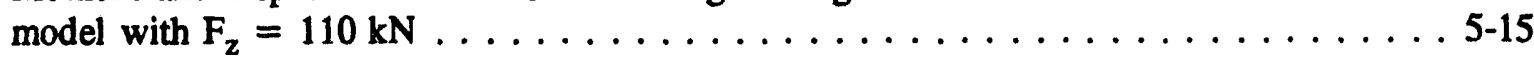

5.8 Moment and displacement results for the E31.3 finite element

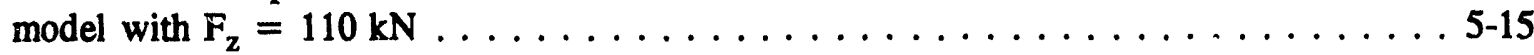

5.9 Linear finite element piping stress analysis moment summary

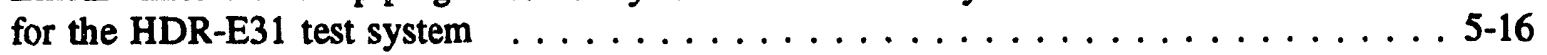

5.10 Flaw sizes used in the HDR-E31 fracture assessments $\ldots \ldots \ldots \ldots \ldots \ldots$

5.11 Engineering methods predictions $\ldots \ldots \ldots \ldots \ldots \ldots \ldots \ldots$

5.12 Comparison of IWB-3650 maximum moments for the HDR-E31 experiments with various flaw and material assumptions

6.1 Natural frequencies of the HDR pipe system $\ldots \ldots \ldots \ldots \ldots$

6.2 Static loading results for Experiment E31.2, $\mathrm{F}_{\mathrm{applied}}=100 \mathrm{kN} \ldots \ldots \ldots$

6.3 Static loading results for Experiment E31.3, $\mathrm{F}_{\text {applied }}=110 \mathrm{kN} \ldots \ldots \ldots$

6.4 Crack section behavior in the E31 experiments inferred from remote strain gage data . . . 6-7

6.5 E31 experiment post-test crack examination results $\ldots \ldots \ldots \ldots \ldots \ldots$

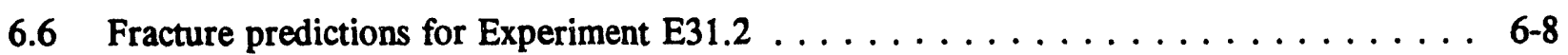

6.7 Fracture predictions for Experiment E31.3 . . . . . . . . . . . . . 6-9

6.8 Flaw stability predictions for the $\mathrm{E} 31$ experiments $\ldots \ldots \ldots \ldots \ldots \ldots$

7.1 Elastic stress analysis moment ratio at maximum moment for the HDR-E31 experiments . 7-9

7.2 Experiment/predicted maximum moments for the HDR-E31 experiments . . . . . . . 7-9

7.3 SC.TNP predicted maximum moments for HDR-E31 experiments $\ldots \ldots \ldots \ldots \ldots$ 
Executive Summary

\section{EXECUTIVE SUMMARY}

The behavior of flawed piping under accident conditions is a major concern in the nuclear power industry, with significant resources devoted to developing and improving tools to predict such events. Simplified engineering methods have been developed as well as newer "state-of-the-art" fracture analysis methods. However, most of these analysis methods have only been validated with static experimental data. High-rate dynamic loading comparisons are rare because high-rate experimental data are scarce. High-rate dynamic loading can be classified as either repeating, e.g., seismic, or nonrapeating, e.g., water hammer. Development of experimental data and validation of cracked pipe under seismic loading is being conducted within the NRC's International Piping Integrity Research Group (IPIRG) program. The Test Group E31 series, part of a study of the behavior of flawed piping subjected to dynamic loads in the HDR Safety Program (PHDR) Phase III conducted by the Kernforschungszentrum Karlsruhe (KfK) in Germany, provided a unique opportunity to validate analytical and computational methods used in predicting the behavior of flawed piping under waterhammer loading. Argonne National Laboratory and Battelle have jointly conducted a research program for the USNRC to evaluate the ability of current engineering analyses methods and one stateof-the-art analysis method to predict the behavior of the E31 water-hammer experiments.

In this effort, typically used engineering fracture mechanics analyses were assessed. For dynamic loading cases, the peak dynamic load from an elastic uncracked pipe stress analysis is typically used along with the fracture mechanics predicted failure load, i.e., the stress analysis and fracture predictions are decoupled. The alternative is to embed the fracture mechanics analysis into the dynamic piping stress analyses. This was done in the NRC's IPIRG-1 program. In the current joint Argonne-Battelle program, there were three major advances in nonlinear FEA fracture analysis. The improvements made to the IPIRG-1 developments were: modeling of crack behavior past maximum moment, modelling the surface-crack to through-wall-crack transition, and modeling of cyclic ductile tearing with reinitiation on subsequent cyclic loads. These improvements were validated by comparisons with various pipe fracture experiments from other programs. The following summarizes the accuracy of the analyses, limitations of the methods, and comparisons with other European analysis efforts on the same experiments.

Accuracy of the Elastic Stress Analysis. The ANSYS code was employed in the calculations conducted at Battelle for this project. In general, the predicted static, eigenvalue, and predicted global dynamic responses under elastic loading were quite similar to the measured behavior. The accuracy of the elastic stress analysis for the fracture experiments was determined by dividing the moment from an elastic analysis at maximum load by the experimentally determined moment at the crack location. The moment ratio was greater than one but less than 1.5. This suggests that the elastic analysis overpredicts the actual moment. The moment ratios for the HDR-E31 tests are far less that the ratio of 15 to 30 observed in the EPRI/NRC Piping and Fitting Dynamic Reliability program on uncracked pipe, but are close to the results observed in the IPIRG-1 pipe system experiments. The reasons why these different programs have different moment or stress ratios are:

The IPIRG-1 program employed large cracks in the piping system, so that the failure loads would be near yield in the uncracked pipe. Furthermore, the pipe system was mostly made 
from a high strength material so that it would behave elastically, and hence, be reusable for multiple tests.

For the HDR E31 experiments, the cracks were much smaller than the IPIRG-1 program pipe system cracks, but the material used had a much higher yield to ultimate strength ratio so that yielding of the unflawed pipe was less likely to occur. Additionally, the cracked pipe section had a reduced pipe wall thickness (16-mm-thick pipe in the flawed section versus 25 -mm-thick pipe in the rest of the HDR pipe loop), so fracture occurred at nominal stresses which were slightly below yield in the pipe loop except in the cracked pipe section.

In the EPRI/NRC Piping Reliability Program there were no cracks in the piping system, so the failure loads were very high.

Experiments with smaller cracks in pipe systems with low yield to ultimate strength ratio piping materials (typical of U.S. materials), where yielding may occur other than at the crack section, have yet to be done. This is in part due to the expense of having to replace major portions of the pipe loop in every test. Hence, the margin in elastic stress analysis that might exist under higher stresses for shorter cracks has not been assessed experimentally by any of these programs. This could be assessed analytically, to some degree, with the capabilities developed in this and the IPIRG programs. This may be a more important issue with the potential changes to ASME Section III that propose to increase the maximum Service Level D elastic design stresses from $3 S_{m}$ to $4.5 S_{m}$.

Accuracy of the Fracture Analyses. The inherent accuracy of the various fracture analyses was calculated by dividing the maximum moment in the experiment by the predicted maximum moment. This accuracy may be thought of as the margin on the pipe to resist fracture, whereas the elastic stress analysis ratio (elastically calculated to actual moments) may be thought of as a margin on the applied stress or the crack driving force. The following observations can be made about the various analyses.

- The Net-Section-Collapse analysis predicted moment was 20 percent higher than the experimental moments. This is because the toughness is sufficiently low with the higher strength material, and the pipe diameter is sufficiently large, that elastic-plastic failure is a possibility.

- The ASME Section XI flaw evaluation procedures for ferritic piping (IWB-3650) using the Code values of $S_{m}$ and Section XI flaw size definition, has the highest fracture ratio, i.e., it is the most conservative of all the analyses used. This fracture ratio does not include the ASME Code applied safety margins of 2.78 for normal and test conditions or 1.39 for emergency and faulted conditions. Inclusion of these factors would further increase the conservatism for this method. This large fracture ratio for the ASME Ferritic Pipe Flaw Evaluation criteria is consistent with past results in the IPIRG-1 and Degraded Piping Programs.

- The Dimensionless Plastic-Zone Parameter analysis is one of the simplest means of modifying the Net-Section-Collapse analysis for elastic-plastic fracture considerations. The fracture ratio was slightly greater than 1.0 for the two experiments, showing this 
method was fairly accurate, yet slightly conservative in predicting the maximum moments.

- The R6 Revision 3. Option 1 analysis overpredicted the experimental failure stresses for Experiment E31.2 and underpredicted the failure moment for Experiment E31.3. In the past, the R6 Option 1 method was found to generally underpredict the failure stresses, since like the ASME criteria, it is a failure avoidance method not necessarily intended to be an accurate predictor. Hence, the overprediction for Experiment E31.2 was surprising.

- The SC.TNP J-estimation analysis tended to give values which slightly underpredicted the maximum load for both experiments. The predicted maximum moments are very close to the Dimensionless Plastic-Zone Parameter analysis values.

A common thread with all these predictions was that the fracture ratios were lower for Experiment E31.2 than for Experiment E31.3. In examining the experimental data, there is the discrepancy that the reported experimental moment is lower for the shallower surface crack in Experiment E31.2 than for the deeper crack in Experiment E31.3. This fact, along with the applied dynamic forces being about 10 percent higher in Experiment E31.3 than Experiment E31.2, raises the question of the accuracy of the experimental moment data. The HDR moment data were recently reassessed in Germany because of this concern, but it was concluded that the although there were some experimental difficulties, the moments of the E31.2 and E31.3 experiments were approximately the same as initially reported. The only explanation for a lower maximum moment in the shaliower Experiment E31.2 flaw is a reduced material toughness or strength in that test pipe relative to the E31.3 test pipe.

Crack Stability Analyses. Three different crack stability analyses were evaluated. These were the fully plastic J/T analyses, the Energy Balance Stability approach developed at Battelle, and nonlinear time-history cracked-pipe finite element analyses. The Energy Balance Stability method has some advantages over ine $\mathrm{J} / \mathrm{T}$ approach in that it can: (1) handle surface-crack to through-wall crack transition, (2) handle combined bending and tension loads, (3) handle different ratios of loadcontrolled and displacement-controlled stresses, and (4) predict not only the start of a crack instability, but whether or not the crack will arrest or result in a double-ended guillatine break, DEGB. The fully plastic J/T and Energy Balance Stability analyses are quasi-static based analyses that assume that the loads or displacements remain essentially constant during the fracture event. During the HDR-E31 water-hammer experiments, the hoop stress at the crack sections remained relatively constant during the fracture event (the pressure transient at the crack section occurred before the large bending stresses), but dynamic bending stresses were created in the pipe loop that decreased after surface crack penetration. Neither the $J / T$ nor the Energy Balance Stability analyses can handle time-varying load predictions, and hence are conservative in predicting the dynamic crack stability behavior since they use the peak value. The nonlinear time-history cracked-pipe finite element analysis considers the loads as they are applied in time and can predict crack growth and arrest, and crack reinitiation and further growth during subsequent dynamic repeating loads. In validating the nonlinear time-history cracked-pipe finite element analysis, the David Taylor Research Center compliant instability pipe tests were analyzed, and crack velocity and dynamic crack opening predictions were made for the first time. 
Nonlinear Finite Element Fracture Analysis. The nonlinear finite element fracture analysis method predicted the HDR-E31 experiments better than any of the engineering fracture analysis methods. The nonlinear finite element fracture analysis models the crack as a nonlinear spring in the momentrotation degree of freedom, while the remainder of the pipe system is modeled with standard finite elements. All of the standard capabilities of finite element programs are available (dynamic timehistory analysis, plasticity, etc.). The fact that so many of the first order effects in the fracture process and loading are an inherent part of the method accounts for the quality of the predictions.

However, in spite of the superior accuracy of the nonlinear finite element fracture analysis, there are limitations that need to be mentioned. First, the moment-rotation curves generated using the SC.TNP J-estimation scheme were scaled to remove known conservatism. Second, predicted crack rotation has not been fully validated. Further development efforts on circumferential surface-cracked pipe Jestimation schemes are in progress as part of the NRC's Short Cracks in Piping and Piping Welds program. Lastly, surface-crack penetration is assumed to occur at maximum moment, even though some stable crack growth often occurs after maximum load, but before surface-crack penetration.

Comparison with Other HDR-E31 Analysis Efforts. The HDR-E31 experiments have been analyzed by other researchers. Brosi, et al., performed extensive elastic and plastic global analysis of the piping system under static, modal, and dynamic loading. His elastic calculations, like ours, tend to be slightly stiffer than the measured values. In general, he found reasonably good agreement between predictions and the global response in his plastic calculations. Brosi modeled the crack in a separate 3-D brick element substructure analysis, using bending loads from the global structural analysis. Using approximately 2400 nodes and in excess of 400 elements, he predicted J-integral values along the crack front and predicted that the crack would initiate in Experiment E31.3 and grow only $0.5 \mathrm{~mm}$ radially, and that it would not even initiate in Experiment E31.2. Neither of these predictions was correct, and his errors were on the nonconservative side. One of the interesting findings from Brosi was that $\mathrm{J}$ along the crack front was not symmetric with respect to the centerline of the crack. The moment at 90 -degrees to the principal bending plane caused this.

Kussmaul, et al., also did extensive finite element analysis of the global behavior of the system and found good agreement with the measured values. Like our nonlinear finite element fracture analysis model, Kussmaul, et al., included the crack directly in their finite element piping system, after they had completed a series of uncracked piping analyses. In their case, shell elements and line-spring (surface crack) elements were used to model the crack. Their cracked-pipe analyses showed that Experiment E31.2 would initiate. Experiment E31.3 was problematic for them because large compression loading of the crack prior to the large crack-opening moment caused the elements to cease correctly evaluating J. Kussmaul et al., also did a 3D-brick substructure analysis of the crack area and essentially duplicated Brosi's asymmetric $\mathbf{J}$ behavior.

It is interesting to note that neither of the other researchers that have analyzed the E31 experiments have predicted the behavior as accurately as the nonlinear finite element fracture method that we have used. This is especially significant in light of the fact that Kussmaul et al. indicates that CRAY2 supercomputers were used in both Brosi's and their work, and that several investigations had to be abandoned because costs were getting unmanageable. Our analyses were easily performed on a small Apollo DN5500 work station, basically a desk-top computer. Hence, the nonlinear FEA fracture analysis, in spite of its relative simplicity, when compared with 3-D brick and shell models of cracks, 
does a good job of predicting crack behavior. Additionally, the nonlinear FEA fracture analysis is the only method that currently can be used to assess the propensity for a DEGB, i.e., growth and possible arrest of the through-wall crack after surface crack penetration. This dynamic circumferentially cracked pipe finite element fracture analysis would allow realistic assessments of dynamic crack speeds, crack opening, resulting leakage and thrust loads to be made in the future. 


\section{ACKNOWLEDGMENTS}

This report was conducted under funding by the Materials Engineering Branch of the Office of Research of the U.S. Nuclear Regulatory commission. The FIN number was L1673. Battelle's contract was with Argonne National Laboratory, contract number 13052401 . We would like to thank Mr. Allen Hiser of the Materials Engineering Branch for his support and interest in this effort.

We would also like to thank Mr. Dieter Schrammel and Dr. Gustav Katzenmeier of KfK in Germany for their assistance in providing the necessary experimental test data. We would also like to thank Dr. Harald Diem and Mr. Eike Kobes of MPA-Stuttgart for information on the material properties, supplying a piece of the material for dynamic strain aging evaluation, and their insight in evaluating the experiments. We would also like to thank Mr. Stefan Brosi of Paul Scherrer Institut in Switzerland for insight from his finite element analysis of these experiments.

The Battelle staff are most grateful to Dr. Christian A. Kot for his assistance in translating documents and coordination with KfK and MPA staff, and to Drs. M. G. Srinivasan and B. J. Hsieh of Argonne in their assistance in solving a stress analysis problem during the program. We would also like to thank Mrs. V. Kreachbaum and Ms. Adele Armitage of Battelle for their assistance in preparation of this report, as well as Mr. D. Hayes for drafting assistance. 


\section{NOMENCLATURE}

\section{SYMBOLS}

A

$A_{p}$

Aps

$A_{\text {ac }}$

a

C

D

$\mathrm{D}_{\mathrm{i}}$

$D_{m}$

d

E

$F_{\text {applied }}$

$F_{b}$

$F_{k}$

$F_{\mathrm{m}}$

$F_{\text {slide }}$

$\mathrm{F}_{\mathrm{T} 1}, \mathrm{~F}_{\mathrm{T} 2}, \mathrm{~F}_{\mathrm{T} 3}$

$F_{1}$

g

$\mathrm{H}_{1}$

$h_{1}$
Parameter in Z-factor exprassion in IWB-3650

Cross-sectional area of pipe at I.D.

Area under M- $\phi$ curve or energy of pipe system

Area under $M-\phi_{c}$ curve for surface crack

Half crack length at mean radius

Statistically-based parameter from plastic-zone size screening criteria

Nominal pipe diameter

Inside pipe diameter

Mean pipe diameter

Crack depth

Elastic modulus

Applied force

Bending stress elastic function

Resolved force from pressure data at elbow in HDR experiments

Membrane stress elastic function

Limiting force in spring-slider element

Forces used in modeling multilinear crack behavior

Elastic f-function in GE/EPRI method

Gravity

Function in SC.TNP J-estimation scheme

Function in EPRI/GE J-estimation scheme to calculate plastic contribution of $\mathrm{J}$ 
Area moment of inertia

J

J-integral fracture parameter

$\mathrm{J}_{\text {applied }}$

Applied crack driving force in terms of $\mathbf{J}$

$\mathbf{J}_{\mathbf{D}}$

$\mathrm{J}$ based on deformation theory

Jelastic

Elastic component of $\mathbf{J}$

$\mathbf{J}_{\mathbf{i}}$

$\mathrm{J}$ at crack initiation

$\mathbf{J}_{\mathrm{Ic}}$

Plane strain $\mathrm{J}$ at crack initiation by ASTM E813

J material

Material's fracture resistance in terms of $\mathbf{J}$

$\mathbf{J}_{\mathbf{m}}$

Modified form of $\mathrm{J}$

$J_{r}$

Ratio of $J_{\text {app }}$ to $J_{\text {material }}$ for $R 6$ analysis

$\mathbf{J}_{\text {plastic }}$

Plastic component of $\mathbf{J}$

$J_{\text {total }}$

Total J applied, i.e., Jelastic plus $\mathrm{J}_{\text {plastic }}$

$\mathbf{K}_{\mathbf{I}}$

Applied linear elastic stress intensity factor

$\mathbf{K}_{\text {Ib }}$

Bending component of $K_{l}$

$\mathbf{K}_{\text {Im }}$

Membrane component of $K_{I}$

$\mathbf{K}_{\mathbf{r}}$

Ratio of $K_{I}$ to $K_{r}$ (a) from $R 6$ analysis

$\mathbf{k}_{\mathrm{sc}}$

Stiffness of surface-cracked pipe

$\mathbf{k}_{\mathrm{tw}}$

Stiffness of through-wall-cracked pipe

L

Outer span length of pipe in four-point bend test

$\mathrm{L}_{\mathbf{r}}$

Load ratio in $\mathbf{R} 6$ analysis

$1_{0}, 1_{1}, 1_{2}$,

Length terms used in resolving pressure data into force components at elbows in HDR experiments

$\mathbf{M}$

Moment

$\mathbf{M}_{\mathbf{b}}$

Net-Section-Collapse analysis calculated moment at failure for pure bending 
$\mathbf{M}_{\mathrm{b}+\mathrm{p}}$

$\mathbf{M}_{\text {ep }}$

$M_{\text {exp }}$

$M_{i}$

$\mathbf{M}_{\mathrm{o}}$

$\mathrm{M}_{\mathrm{sc}}$

$M_{\text {(SP el. })}$

$\mathbf{M}_{\text {(Tot. el.) }}$

$M_{\text {(Tot. exp.) }}$

$\mathbf{M}_{\mathrm{tw}}$

$M_{\text {tw-u }}$

n

$\mathbf{P}$

$\mathbf{P}_{\mathrm{m}}$

$P_{\text {nsc }}$

$P_{\text {o }}$

$\mathrm{P}_{1}, \mathrm{P}_{2}, \mathrm{P}_{\mathrm{k}}$

p

$\mathbf{R}_{\mathbf{i}}$

$\mathbf{R}_{\mathbf{m}}$

$\mathbf{R}_{\text {o }}$

Net-Section-Collapse analysis calculated moment at failure for combined pressure and bending

Equivalent bending moment

Experimental moment

Moment at crack initiation

Limit moment for a cracked pipe under pure bending in the GE/EPRI method where the flow stress is $\sigma_{o}$

Moment for surface-cracked pipe

Moment from static push analysis

Calculated elastic moment at crack section at time of maximum moment from the experiment

Experimental maximum moment

Moment for through-wall-cracked pipe

Moment for through-wall-cracked pipe unpressurized

Ramberg-Osgood parameter

Total failure stress

Membrane stress

Net-Section-Collapse predicted tension and bending stress

Reference stress in J-estimation schemes

Pressure terms used to resolve pressure into force components in HDR experiments

Pressure

Inside pipe radius

Mean pipe radius

Outside pipe radius 
Moment arm in four-point bend test

SF

$\mathbf{S}_{\mathbf{m}}$

$S_{m \text { (Actual) }}$

$S_{m \text { (Code) }}$

$\mathbf{S}_{\mathbf{r}}$

$\mathbf{T}$

$T_{\text {applied }}$

$T_{\text {material }}$

$\mathbf{t}$

$\mathbf{Z}$

$\boldsymbol{\alpha}$

$\beta$

$\beta_{\text {ASME }}$

$\beta_{\mathrm{sc}-\mathrm{u}}$

$\beta_{\mathrm{sc}-\mathrm{p}}$

$\beta_{\text {tw-u }}$

$\Delta \mathbf{a}$

$\epsilon$

$\epsilon_{\mathrm{o}}$
Safety factor

ASME code design stress

$S_{m}$ based on measured tensile properties using ASME Section III Article 2110 criteria

$S_{m}$ based on ASME code properties

Stress ratio in $\mathbf{R} 6$ analysis

Tearing modulus

Applied tearing modulus

Tearing modulus of the material

Pipe wall thickness

Stress multipliers in Section XI to account for low toughness

Ramberg-Osgood parameter

Angle from bottom of pipe to neutral bending axis in circumferential crack limitload analyses

Angle from bottom of pipe to neutral bending axis used in ASME Section XI circumferential crack limit-load solution

Angle from bottom of pipe to neutral bending axis used for surface-cracked unpressurized pipe in original Net-Section-Collapse analysis

Angle from bottom of pipe to neutral bending axis for surface-cracked pressurized pipe in original Net-Section-Collapse analysis

Angle from bottom of pipe to neutral bending axis for through-wall-cracked unpressurized pipe in original Net-Section-Collapse analysis

Change in crack length or depth, i.e., crack growth

Strain

Ramberg-Osgood reference strain, $\sigma_{0} / E$ 
$\eta$

$\phi$

$\phi_{c}$

$\phi_{\text {ci }}$

$\sigma$

$\sigma_{\mathrm{b}}$

$\sigma_{\mathrm{bNSC}}$

$\sigma_{f}$

$\sigma_{0}$

$\sigma_{\text {nsc:sc-u }}$

$\sigma_{\text {nsc:tw-u }}$

$\sigma_{\mathrm{t}}$

$\sigma_{\text {(Tot. el.) }}$

$\sigma_{\mathrm{u}}$

$\sigma_{y}$

$\theta$

$\theta_{\mathbf{i}}$

$\xi$

Geometric constant used in general analytical procedure where $\mathrm{J}_{\text {plastic }}$ is calculated using experimental load, displacement, and crack growth data

Pipe rotation

Rotation due to the crack

Rotation at crack initiation

Stress

Bending stress

Net-Section-Collapse predicted bending stress at maximum load

Flow stress

Ramberg-Osgood reference stress

Net-Section-Collapse predicted failure stress for a surface-cracked pipe unpressurized

Net-Section-Collapse predicted failure stress for TWC pipe unpressurized

Axial tensile stress

Total calculated elastic stresss; calculated elastic bending stress plus pressure induced axial tension stress

Ultimate strength

Yield strength

Half circumferential crack angle

Initial circumferential half crack angle

Angular position around pipe circumference

2. ACRONYMS AND INITIALISMS

ANL Argonne National Laboratories

ASME

American Society of Mechanical Engineers 
BMFT

CEA

CEGB

$\mathrm{C}(\mathrm{T})$

DEGB

DPZP

DTRC

EPFM

EPRI

FEA

GE

HDR

ID

IPIRG-1

J-R

$J_{D}-\mathbf{R}$

$\mathbf{J}_{\mathrm{m}}-\mathbf{R}$

$\mathrm{J} / \mathrm{T}$

KfK

L-C

LEFM

L-T
German Ministry of Research and Technology

Commissariat A L'Energie Atomique, France

Central Electric Generating Board, United Kingdom (now Nuclear Electric)

Compact (Tension)

Double-ended guillotine break

Dimensionless plastic-zone parameter

David Taylor Research Center

Elastic-plastic fracture mechanics

Electric Power Research Institute, USA

Finite element analysis

General Electric

Heissdampfreaktor (An experimental reactor facility in Germany)

Inside diameter

First International Piping Integrity Research Group

J-resistance

$\mathrm{J}$-resistance based on deformation theory form of $\mathrm{J}$

$\mathrm{J}$-resistance based on modified form of $\mathrm{J}$

Tearing instability approach

Kernfortschangszantran Karlsruhe

Orientation code that indicates crack plane is normal to longitudinal axis (L) and crack growth direction is circumferential (C)

Linear elastic fracture mechanics

Orientations code that indicates crack plane is normal to longitudinal or rolling direction $(\mathrm{L})$ and crack growth direction is transverse $(\mathrm{T})$ to plate rolling directions LVDT Linear variable differential transformer 
MPA

NPS

NRC

NRC-RES

NSC

OD

PC

PVP

RPV

RVDT

SASI

SC

T/C

TWC

USNRC
Materialprüfungsanstalt (Stuttgart), Germany

Nominal pipe size

Nuclear Regulatory Commission

Nuclear Regulatory Commission - Office of Nuclear Reactor Research

Net-Section-Collapse

Outside diameter

Personal Computer

Pressure Vessel and Piping

Reactor Pressure Vessel

Rotary-variable-differential transformer

Swanson Analysis Systems, Inc.

Surface crack

Thermocouple

Through-wall crack

United States Nuclear Regulatory Commission 


\section{PREVIOUS REPORTS IN SERIES}

\section{Previous Reports from Short Cracks in Piping and Piping Welds Program}

"Short Cracks in Piping and Piping Welds," First Semiannual Report, NUREG/CR-4599, Vol. 1, No. 1, March 1991.

"Short Cracks in Piping and Piping Welds," Second Semiannual Report, NUREG/CR-4599, Vol. 1, No. 2, April 1992.

"Short Cracks in Piping and Piping Welds," Third Semiannual Report, NUREG/CR-4599, Vol. 2, No. 1, September 1992.

"Short Cracks in Piping and Piping Welds," Fourth Semiannual Report, NUREG/CR-4599, Vol. 2, No. 2, February 1993.

"Short Cracks in Piping and Piping Welds," Fifth Semiannual Report, NUREG/CR-4599, Vol. 3, No. 1, October, 1993.

"Short Cracks in Piping and Piping Welds," Sixth Semiannual Report, NUREG/CR-4599, Vol. 3, No. 2, March, 1994.

\section{Previous Related Documents from NRC's Degraded Piping Program}

"Degraded Piping Program - Phase 1!," Semiannual Report, NUREG/CR-4082, Vol. 1, October 1984.

"Degraded Piping Program - Phase II," Semiannual Report, NUREG/CR-4082, Vol. 2, June 1985.

"Degraded Piping Program - Phase II," Semiannual Report, NUREG/CR-4082, Vol. 3, March 1986.

"Degraded Piping Program - Phase II," Semiannual Report, NUREG/CR-4082, Vol. 4, July 1986.

"Degraded Piping Program - Phase II," Semiannual Report, NUREG/CR-4082, Vol. 5, December 1986.

"Degraded Piping Program - Phase II," Semiannual Report, NUREG/CR-4082, Vol. 6, April 1988.

"Degraded Piping Program - Phase II," Semiannual Report, NUREG/CR-4082, Vol. 7, March 1989.

"Degraded Piping Program - Phase II," Semiannual Report, NUREG/CR-4082,

Vol. 8, March 1989. 
Previous Reports in Series

"NRC Leak-Before-Break (LBB.NRC) Analysis Method for Circumferentially Through-Wall Cracked Pipes Under Axial Plus Bending Loads," Topical Report, NUREG/CR-4572, March 1986.

"Elastic-Plastic Finite Element Analysis of Crack Growth in Large Compact Tension and Circumferentially Through-Wall-Cracked Pipe Specimen-Results of the First Battelle/NRC Analysis Round Robin," Topical Report, NUREG/CR-4573 September 1986.

"An Experimental and Analytical Assessment of Circumferential Through-Wall Cracked Pipes Under Pure Bending," Topical Report, NUREG/CR-4574, June 1986.

"Predictions of J-R Curves With Large Crack Growth From Small Specimen Data," Topical Report, NUREG/CR-4575, August 1986.

"An Assessment of Circumferentially Complex-Cracked Pipe Subjected to Bending," Topical Report, NUREG/CR-4687, September 1986.

"Analysis of Cracks in Stainless Steel TIG Welds," Topical Report, NUREG/CR4806, November 1986.

"Approximate Methods for Fracture Analyses of Through-Wall Cracked Pipes," Topical Report, NUREG/CR-4853, January 1987.

"Assessment of Design Basis for Load-Carrying Capacity of Weld-Overlay Repair," Topical Report, NUREG/CR-4877, February 1987.

"Analysis of Experiments on Stainless Steel Flux Welds," Topical Report, NUREG/CR-4878, February 1987.

"Experimental and Analytical Assessment of Circumferentially Surface-Cracked Pipes Under Bending," Topical Report, NUREG/CR-4872, April 1987.

Previous Related Documents from NRC's International Piping Integrity Research Group (IPIRG) Program

"Evaluation and Refinement of Leak-Rate Estimation Models," NUREG/CR-5128, April 1991.

"Loading Rate Effects on Strength and Fracture Toughness of Pipe Steels Used in Task 1 of the IPIRG Program," Topical Report, NUREG/CR-6098, October 1993. 


\section{INTRODUCTION}

A major concern with the safety and operation of nuclear power plants is the reliability of piping in general and, more specifically, the behavior of flawed piping under accident conditions. The U.S. Nuclear Regulatory Commission (USNRC), in conjunction with the nuclear industry, has devoted significant resources to address this concern (Refs. 1.1 through 1.5). While simplified engineering methods exist to predict the behavior of flawed piping and newer "state-of-the-art" methods have been developed as part of the International Piping Integrity Research Group (IPIRG) Program (Ref. 1.4), these analysis methods have only been partially validated with experimental data. In particular, the capabilities of these techniques to predict the response of flawed piping under high loading rates has not been extunsively verified, i.e., no comparisons between predictions and experiments under waterhammer loading conditions have been conducted to date.

As part of the HDR Safety Program (PHDR) Phase III conducted by the Kernforschungszentrum Karlsruhe (KfK) in Germany, a series of experiments was conducted on the behavior of flawed piping subjected to dynamic loadings. A series of experiments, Test Group E31, were concerned with the behavior of flawed piping subjected to blowdown loadings. The data and results from these experiments provide a unique opportunity to validate analytical and computational methods used in predicting the response and behavior of flawed piping. The results from these experiments were made available to the USNRC and Argonne National Laboratory (ANL) as part of an agreement between the USNRC, the KfK, and the German Federal Ministry of Research and Technology (BMFT) on cooperative research in the HDR Safety Program. Of particular interest to this program were Experiments E31.2 and E31.3, in which straight pipe sections with circumferential flaws were. subjected to high level water- hammer loads following blowdown.

The effort described herein was part of a USNRC-sponsored program at ANL. The specific objective was to evaluate the capabilities of the current engineering and state-of-the-art methods for predicting the response and structural integrity of flawed piping subjected to high-rate dynamic loadings. Battelle conducted the fracture analyses, while ANL provided the interface with the HDR Safety Program personnel. This report documents both the ANL and Battelle contributions to this program.

The following discussion presents the work performed on this program by the project team. Six subjects are addressed:

- A brief review of current engineering fracture mechanics analyses

- Discussion of a state-of-the-art fracture analysis method

- A description of the HDR-E31 experiments

- Predictions of the HDR-E31 experimental results

- Comparison of the predictions and the experiments

- A summary and discussion. 


\subsection{References}

1.1 Kanninen, M. F., et al, "Instability Predictions for Circumferentially Cracked Type 304 Stainless Steel Pipes Under Dynamic Loadings", Final Report on EPRI Project T118-2, by Battelle Columbus Laboratories, EPRI Report Number NP-2347, April 1982.

1.2 Wilkowski, G. M., et al, "Degraded Piping Program - Phase II", Summary of Technical Results and Their Significance to Leak-Before-Break and In-Service Flaw Acceptance Criteria, March 1984-January 1989, NUREG/CR-4082, Vol. 8, March 1989.

1.3 Vassilaros, M. G., et al, "J-Integral Testing Instability Analysis for 8-inch Diameter ASTM A106 Steel Pipe", U.S. David W. Taylor Naval Ship Research and Development Laboratory, NUREG/CR-2347, April 1984.

1.4 R. A. Schmidt, G. M. Wilkowski, and M. Mayfield, "The International Piping Integrity Research Group (IPIRG) Program-An Overview", SMiRT-11 Proceedings, August 1991, Paper G23/1.

1.5 Wilkowski, G., et al, "Short Cracks in Piping and Welds, Semiannual Progress Report April 1992 - September 1992", NUREG/CR-4599, Vol. 3 No. 1, June 1993. 


\section{CURRENT ENGINEERING FRACTURE MECHANICS ANALYSES}

The moment-carrying capacity of flawed pipe has been a subject of study for many years. Through the years, cracked-pipe behavior hypotheses have been advanced which have been verified or refuted with carefully executed experiments. Based on these results, theories have been refined, empirical factors have been incorporated to bring predicted behavior into reasonable agreement with observed test results, and eventually, several of the assessment methodologies matured so that they are now seeing routine application. Parallel to the development of the pipe flaw assessment methodologies, general piping stress analysis has been advanced from simplified "rule of thumb" design to routine use of linear finite element response spe.trum and/or time-history analysis. Coupling the fracture mechanics analysis with linear finite element piping stress analyses, the expected behavior of a flaw under a specific loading can be assessed.

In the section that follows, a brief discussion of six engineering fracture mechanics analyses is presented. The six analyses are:

- $\quad$ Net-Section Collapse (NSC)

- $\quad$ ASME Section XI

- Dimensionless Plastic-Zone Parameter (DPZP)

- $\quad$ R6 Revision 3, Option 1

- J-Estimation Schemes

- $\quad \mathrm{J} / \mathrm{T}$ and Energy Balance Flaw Stability.

These analyses form the core of currertly "accepted" and routinely used fracture mechanics analyses for flawed piping. The discussion of each method will, of necessity, be brief, but suitable references will be given so that the full details of any method can be examined.

\subsection{Net-Section Collapse}

The Net-Section-Collapse (NSC) analysis is a limit-load analysis for predicting the failure of pipes under bending loads, Ref. 2.1. One major assumption in the Net-Section-Collapse analysis is that the material toughness is sufficiently high that failure is governed by the strength of the material (that is, flow stress or collapse stress) and is not sensitive to the material's toughness. The flow stress is a value between the material's yield strength and ultimate strength and represents an average critical net-section stress reached throughout the flawed ligament of the structure, Figure 2.1. Also, crack growth is not taken into account, i.e., crack initiation occurs at the maximum load. 
For an unpressurized pipe with a circumferential through-wall crack subjected to pure bending, an idealized bending stress is assumed in the plane of the crack as shown in Figure 2.2. Axial equilibrium analysis shows that the point of stress inversion, $\beta$ in Figure 2.2, is

$$
\beta_{\mathrm{tw}-\mathrm{u}}=\frac{\pi-\theta}{2}
$$

The bending moment predicted by the Net-Section-Collapse analysis for an unpressurized pipe with a through-wall crack, developed by integrating the stresses around the pipe circumference and assuming the pipe retains a circular cross section, is

$$
M_{t w-u}=2 \sigma_{f} R_{m}^{2} t\left(2 \sin \beta_{t w-u}-\sin \theta\right)
$$

where

$$
\begin{array}{ll}
\mathbf{M}_{\mathrm{tw-u}}= & \text { predicted bending moment for an unpressurized through-wall crack } \\
\boldsymbol{\sigma}_{\mathrm{f}}= & \text { flow stress or collapse stress } \\
\mathbf{R}_{\mathrm{m}}=\text { mean radius of the pipe } \\
\mathbf{t}=\text { wall thickness of the pipe } \\
\theta=\text { half the initial crack angle. }
\end{array}
$$

From the bending moment in Equation 2.2, one can calculate the nominal bending stress, $\mathrm{Mc} / \mathrm{I}$, predicted by Net-Section-Collapse analysis for an unpressurized through-wall crack,

$$
\sigma_{\text {nac }: t w-u}=\frac{2}{\pi} \sigma_{f}\left(2 \sin \beta_{t w-u}-\sin \theta\right)
$$

For an unpressurized pipe with a circumferential surface crack subjected to pure bending, an idealized bending stress is assumed in the plane of the crack as shown in Figure 2.3. Again, considering axial equilibrium, the point of stress inversion is

$$
\beta_{u-u}=\frac{\pi-(d / t) \theta}{2}
$$

assuming that the circumferential crack length, $\theta$, is less than $\beta$; that is, the surface crack does not extend into the compressively stressed side of the pipe. The unpressurized pipe surface crack bending moment is then given by 


$$
M_{x-u}=2 \sigma_{f} R_{m}^{2} t\left(2 \sin \beta_{\infty c-u}-(d / t) \sin \theta\right)
$$

where

d $=$ depth of the surface crack.

From the bending moment in Equation 2.5, the nominal bending stress predicted by Net-SectionCollapse analysis for an unpressurized surface-cracked pipe is

$$
\sigma_{\text {nec: }: c-u}=\frac{2}{\pi} \sigma_{f}\left(2 \sin \beta_{x c-u}-(d / t) \sin \theta\right)
$$

For a pressurized pipe with a circumferential part-through surface crack subjected to bending, that is, combined pressure and bending, an idealized bending stress is assumed in the plane of the crack as shown in Figure 2.4. Axial equilibrium shows that the point of stress inversion in this case is

$$
\beta_{x c-p}=\frac{\pi-(d / t) \theta}{2}-\frac{\pi R_{i}^{2} p}{4 R_{m} t \sigma_{f}}
$$

where

$$
\begin{array}{ll}
\mathbf{R}_{\mathbf{i}}= & \text { inside radius of the pipe } \\
\mathbf{p}=\text { internal pipe pressure. }
\end{array}
$$

Again, this assumes that the circumferential crack length, $\theta$, is less than $\beta$.

Knowing $\beta$, the predicted stress using the Net-Section-Collapse analysis can be calculated as above using Equation 2.6. Thus, the only difference between surface crack Net-Section-Collapse formulations for the pure bending case and the combined pressure and bending case is the stress inversion angle $\beta$. The pressure term shifts the neutral axis down away, from the crack, thus lowering the predicted moment.

Net-Section-Collapse was first proposed for application to stainless steel pipe with circumferential through-wall cracks, Ref. 2.1. It was subsequently verified for different diameter stainless steel pipes with circumferential surface and through-wall cracks, Ref. 2.2. The solutions developed in Ref. 2.2 have several assumptions embedded in their formulation. First, the analysis is based on thin-shell theory. Thick-shell formulations exist, but are not generally used. Second, it is assumed that the pipe remains circular. At high loads surface-cracked pipe will ovalize, and will lose moment-carrying 
capacity. This has been documented experimentally, Refs. 2.2 and 2.3, but analytical corrections do not presently exist. (Such corrections are the objective of a current NRC program entitled "Short Cracks in Piping and Piping Welds", Ref. 2.4.) Finally, another limitation in the original NetSection-Collapse formulation is that the pressure contribution on the crack faces is not considered. Pressure corrections exist, but have been found to be small for most experiments of interest.

A key aspect of the Net-Section-Collapse analysis is that it assumes that the material is sufficiently tough so that there is negligible crack growth prior to reaching maximum load. It also assumes, for simplicity, that the pipe cross section becomes fully plastic and the net-section stress reaches a constant value. The critical net-section stress at maximum load is called the flow stress.

Several different definitions of flow stress have been used in the Net-Section-Collapse analysis. The most frequently used value is the average of the yield and ultimate strengths. Results from the Degraded Piping Program pipe fracture experiments, Ref. 2.5, have shown that if the value of flow stress is defined as 1.15 times the average of the yield and ultimate strengths, then the experimental results match the predictions better. Using just the average of the yield and ultimate strengths gives a predicted failure stress approximately two standard deviations below the average pipe test results. Consequently, using the average of the yield and ultimate strengths for the flow stress is slightly conservative. Per the original Net-Section-Collapse equations in Reference 2.1, the average of yield and ultimate is taken as the flow stress for this study.

Another definition of flow stress comes from the ASME Section XI flaw evaluation procedures, Refs. 2.6 and 2.7. Here, the flow stress is defined as $2.4 S_{m}$ for ferritic steels and $3 S_{m}$ for austenitic steels, where $S_{m}$ is the design stress intensity from Section III of the ASME Boiler and Pressure Vessel code. One also has the option to calculate an $S_{m}$ based on actual properties. This $S_{m}$ value, called $S_{m \text { (Actual) }}$, is the lowest of: $\sigma_{u} / 3$ at temperature, $0.9 \sigma_{y}$ at temperature, or $2 \sigma_{y} / 3$ at room temperature, per the ASME definitions for ferritic steels. Using the $S_{m \text { (Actual) }}$ would account for material variability, and essentially would evaluate every pipe as if the test specimen for that experiment had the minimum ASME Code properties.

Although there are controversies associated with modifications to the Net-Section Collapse analysis for either short through-wall cracks (see Refs. 2.2 and 2.8), or for deep surface cracks (see Refs. 2.9 and 2.10 ), the basic equations are believed to be reasonably applicable for pipes with relatively large surface cracks.

\subsection{ASME Section XI}

Within Section XI of the ASME Boiler and Pressure Vessel Code, flaw evaluation procedures for cracks in austenitic and ferritic piping have been developed. The austenitic pipe flaw evaluation procedures are in Article IWB-3640 and Code Case 436. These were developed first in 1985, and have been modified to include procedures for evaluation of cracks in lower toughness welds, Ref. 2.6. The ferritic pipe flaw evaluation procedures are given in the ASME Code as Code Case $\mathbf{N}$ 463, Ref. 2.7, as well as Article IWB-3650. Only the ferritic pipe criteria is discussed in this report because there were no austenitic pipe experiments in the HDR E31 test series. 


\subsubsection{Ferritic Pipe Fracture Analysis}

The ASME ferritic pipe flaw evaluation procedure is essentially the same as the Net-Section-Collapse analysis procedure with modifications to account for failure being below Net-Section-Collapse stresses for flaws in base metal. The major differences between the ASME ferritic pipe flaw evaluation procedure and the Net-Section-Collapse analysis are:

- The flow stress used for ferritic pipe is $2.4 \mathrm{~S}_{\mathrm{m}}$ in the ASME Code,

- For combined tension and bending, the Net-Section-Collapse analysis and the ASME $\beta$ terms differ slightly:

For the ASME analysis:

$$
\beta_{\text {ASME }}=\frac{\pi-(d / t) \theta}{2}-\frac{\pi P_{m}}{2 \sigma_{f}}
$$

For the Net-Section-Collapse analysis:

$$
\beta_{c-p}=\frac{\pi-(d / t) \theta}{2}-\frac{\pi R_{i}^{2} p}{4 R_{m} t \sigma_{f}}
$$

- There is a screening criterion used to assess if limit-load, elastic-plastic fracture, or linear-elastic fracture analyses should be used in the ASME procedure, and

- There is a simple stress multiplier used for the elastic-plastic analysis method to account for the lower stresses.

The stress multiplier, Z, used for a crack in base metal (Material Category 1 for base metals and shielded metal arc welds in Ref. 2.7) is

$$
Z=1.20[1+0.021 A(N P S-4)]
$$

where

$$
\begin{aligned}
A & =\left[0.125\left(R_{m} / t\right)-0.25\right]^{0.25}, 5 \leq R_{m} / t \leq 10 \\
& =\left[0.4\left(R_{m} / t\right)-3.0\right]^{0.25}, 10<R_{m} / t \leq 20 \\
R_{m} & =\text { mean pipe radius } \\
t & =\text { pipe thickness } \\
N P S & =\text { nominal pipe size (diameter), inches. }
\end{aligned}
$$


Unlike the other engineering fracture analysis methods, ASME Section XI prescribes how crack size is to be established for the evaluation; the crack depth is taken as the maximum depth and circumferential length is taken as the length on the inner circumference.

\subsection{Dimensionless Plastic-Zone Parameter}

In order to differentiate cases where contained plasticity exists from cases where fully plastic conditions exist (that is, where the NSC analysis should be appropriate), a screening criterion was developed as part of the Degraded Piping Program, Ref. 2.5. The Dimensionless Plastic-Zone Criterion is a semi-empirical relationship in which the ratio of the maximum predicted stress to the calculated NSC stress is a function of a Dimensionless Plastic-Zone Parameter (DPZP). The DPZP is a simplified ratio of the plastic-zone size, using Irwin's relationship, to the distance from the crack tip to the neutral axis. This relationship is shown in Figure 2.5 with a large amount of experimental data. In this figure, the NSC stress is based on a flow stress equal to the average of the actual yield and ultimate strengths of the material.

Four curves are shown in Figure 2.5. For the curves shown in Figure 2.5, the relationship between the ratio of the experimental stress to the predicted NSC stress and the DPZP is given as

$$
\begin{gathered}
\frac{P}{P_{n e c}}=\frac{2}{\pi} \arccos \left(e^{-C(D P Z P)}\right) \\
D P Z P=\frac{2 E J_{i}}{\pi^{2} \sigma_{f}^{2} D_{m}} .
\end{gathered}
$$

where

$$
\begin{array}{lll}
\mathbf{P} & = & \text { total failure stress } \\
\mathbf{P}_{\text {nac }} & = & \text { NSC predicted tension and bending stress } \\
\mathbf{E} & = & \text { elastic modulus } \\
\mathbf{J}_{\mathrm{i}} & \left.=\mathrm{J} \text { at crack initiation (may be } \mathrm{J}_{\mathrm{Ic}}\right) \\
\boldsymbol{\sigma}_{\mathrm{f}} & =\text { flow stress }=\left(\sigma_{\mathrm{y}}+\sigma_{\mathrm{u}}\right) / 2 \\
\mathbf{D}_{\mathrm{m}} & =\text { mean pipe diameter } \\
\mathrm{C} & =\text { statistically based parameter. }
\end{array}
$$

The factor " $C$ " is selected based on a statistical fit of the data. The three upper curves in Figure 2.5 are for different values of " $\mathrm{C}$ " based on three different statistical fits of the data. The solid curve shows a 95-percent confidence level curve for all the data for which the DPZP was less than one. The value of " $\mathrm{C}$ " for this curve is 3.0. For the best fit of the through-wall-cracked pipe and surfacecracked pipe data, the values of $C$ were statistically determined to be 4.62 and 21.8 , respectively. 


\subsection{R6 Revision 3, Option 1 Analysis}

The R6 method is a fracture prevention design criteria developed by CEGB, Refs. 2.11, 2.12 and 2.13. The most recent refinew.ent is referred to as R6 Revision 3, Ref. 2.13. Within this version there are three options for performing a flaw assessment. In all three options, a failure assessment diagram is used; points falling inside the failure assessment curve are deemed safe, points outside the curve are unsafe. The first R6 analysis option is the simplest, and does not require the use of the material stress-strain curve input. The second option requires the use of the material stress-strain curve, and hence is slightly more complicated. The third option allows the use of any appropriate elastic-plastic fracture mechanics analysis, i.e., GE/EPRI, to create the appropriate failure assessment curve. In this last option, the R6 method is essentially identical to the J-estimation methods that are discussed in Section 2.5 of this report.

Option 1 requires the least material property information, but it can be applied to virtually any cracked-pipe. The obvious penalty for ease of use, however, is conservatism. Using the more advanced options, conservatism is reduced at the price of a more complex analysis. To get some sense of the failure assessment diagram methodology, and the upper limit uf conservatism inherent in R6, Option 1 is considered in some detail.

\subsubsection{R6 Rev. 3 Option 1 Calculational Procedure}

In the Option 1 procedure, a fixed failure assessment curve is used for any material, crack or structural geometry. The failure assessment curve has a load or stress ratio $\left(L_{r}\right.$ or $\left.S_{r}\right)$ axis along the abscissa, and toughness ratio using either the $K$ or $J$ fracture parameter $\left(K_{t}\right.$ or $\left.J_{r}\right)$ on the ordinate, see Figure 2.6.

The load ratio or $\mathrm{L}_{\mathrm{r}}$ term is the applied load divided by the limit load, the limit load being the NetSection-Collapse predicted load for circumferentially cracked pipe. For a pipe under pressure and bending, such as the HDR pipe system experiments, one could interpret this ratio as being the total applied stress (bending plus tension from the pressure) divided by the Net-Section-Collapse analysis predicted bending stress plus the pressure induced axial tension stress,

$$
L_{R}=\frac{\sigma_{b}+\sigma_{t}}{\sigma_{b N S C}+\sigma_{t}}
$$

or, the ratio of just the bending stress divided by the Net-Section-Collapse analysis predicted bending stress,

$$
\mathrm{L}_{\mathrm{R}}=\frac{\sigma_{\mathrm{b}}}{\sigma_{\mathrm{bNSC}}}
$$


where

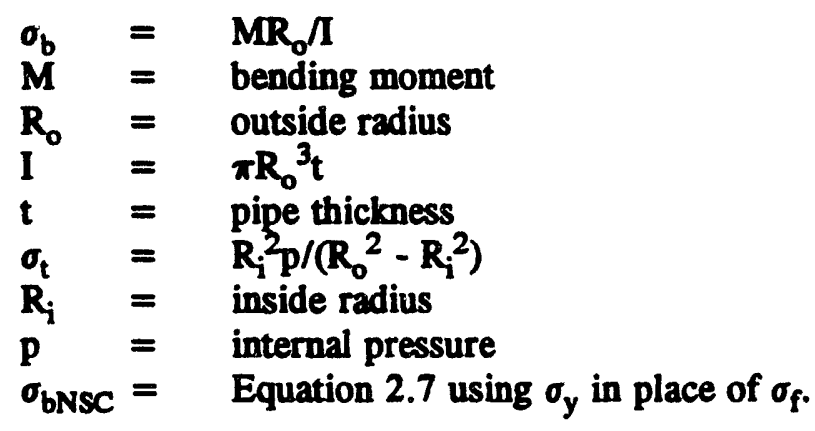

Unlike the Net-Section-Collapse analysis which uses flow stress, the R6 method uses the yield strength in the limit-load equation. The ratio of the flow stress to the yield strength can be used as the cut-off point along the $L_{r}$ axis to be consistent with Net-Section-Collapse analyses.

The toughness or $K_{T}$ term is the ratio of the applied linear elastic stress intensity factor, $K_{I}$, to the toughness of the material, $K_{T}$ (a), where $K_{\Gamma}$ (a) can be a function of crack growth from the J-R curve of the material

$$
\begin{aligned}
K_{r} & =\frac{K_{1}}{K_{r}(a)} \\
K_{r}(a) & =(J E)^{0.5}
\end{aligned}
$$

where

$$
\begin{aligned}
& J=\text { the value of } J \text { for the corresponding } \Delta a \text { from the } J-R \text { curve } \\
& \text { of the material } \\
& \mathrm{E}=\text { elastic modulus. }
\end{aligned}
$$

The linear elastic stress intensity, $\mathrm{K}_{\mathrm{I}}$, is composed of two parts

$$
\mathbf{K}_{\mathrm{I}}=\mathbf{K}_{\mathrm{Im}}+\mathbf{K}_{\mathrm{lb}}
$$

where $\mathrm{K}_{\mathrm{Im}}$ and $\mathrm{K}_{\mathrm{Ib}}$ are taken in this report to be the solutions given in the ASME Section XI ferritic pipe flaw evaluation criteria, Article IWB-3650, Ref. 2.7, 


$$
\begin{aligned}
& K_{I m}=F_{m}(\pi d)^{0.5} \sigma_{t} \\
& K_{I b}=F_{b}(\pi d)^{0.5} \sigma_{b}
\end{aligned}
$$

where

$$
\begin{aligned}
& F_{m}=1.1+\left(\frac{d}{t}\right)\left\{0.15241+16.772\left[\left(\frac{d}{t}\right)\left[\frac{\theta}{\pi}\right]\right]^{0.855}-14.944\left(\frac{d}{t}\right)\left(\frac{\theta}{\pi}\right)\right\} \\
& F_{b}=1.1+\left(\frac{d}{t}\right)\left\{-0.09967+5.0057\left[\left(\frac{d}{t}\right)\left[\frac{\theta}{\pi}\right]\right]^{0.565}-2.8329\left(\frac{d}{t}\right)\left(\frac{\theta}{\pi}\right)\right\}
\end{aligned}
$$

The Option 1 failure assessment curve, $K_{r}-L_{r}$ curve, has the following relationship:

$$
K_{r}=\left(1-0.14 L_{r}^{2}\right)\left[0.3+0.7 e^{-0.65 L_{r}^{6}}\right]
$$

The failure assessment curve for Option 1 is illustrated in Figure 2.6. Note that on the $L_{r}$ axis, there is a cut-off stress, that is frequently defined as the ratio of the flow stress to the yield strength.

Using the failure assessment diagram, moment at crack initiation and maximum load can be calculated. In the maximum load calculations, the crack growth is incremented causing the $\mathrm{K}_{r}$ (a) to increase, $K_{I}$ to increase, and $\sigma_{b N s c}$ to decrease.

Normally in a design situation, one would take the applied stress, yield strength, etc. and calculate a $L_{r}$ and $K_{r}$. This point would be plotted on the failure assessment diagram. If the point fell under the curve it would be considered safe. If it was above the curve, it would be a failure. The safety margin is generally calculated as the ratio of the distance from the origin of the graph through the point to the failure assessment curve to the distance from the origin to point being assessed, i.e., the ratio of the distance $O B$ to the distance $O A$ in Figure 2.6. This assumes that all stresses are proportional, which may not be true for the combined pressure and bending pipe system experiments being evaluated in this report.

For some experiments, one may be interested in the margin of safety on moment with the pressure remaining constant. This makes the definition of the $L_{r}$ term important. In this case, the definition 
of the $L_{r}$ term shown in Equation 2.14 should be used. Using this definition, the margin of safety on the moment can be determined as described above with one exception; a second calculation to determine the $y$-intercept of the $K_{1} L_{r}$ line is required, because at zero bending stress, a low toughness pipe or pipe with a large flaw could fail under the internal pressure, i.e., the point would be along the $y$-axis of the failure assessment diagram.

\subsection{J-Estimation Scheme Analysis}

In the event that limit-load analysis predictions are higher than actual loads, due to low toughness and/or large diameter pipe, elastic-plastic analysis may be needed to obtain a more accurate estimate of the loads at crack initiation and maximum load.

Various methods exist to predict the maximum loads for circumferentially cracked pipe in pure bending. This can be accomplished by detailed finite element analyses or by simpler approximate closed-form solutions. Detailed finite element analysis could be used in an application phase type of calculation along with the material fracture resistance curve to determine the strength of the cracked pipe during crack growth. Many different fracture mechanics parameters have been proposed, but the J-integral parameter is the most frequently used parameter in the nuclear industry. Several closedform solutions exist to give approximate elastic-plastic fracture mechanics solutions for circumferentially cracked pipe. These are frequently referred to as J-estimation schemes.

There are a number of finite-length circumferential through-wall-cracked pipe J-estimation schemes. Some of the existing methods are:

GE/EPRI, Ref. 2.14

LBB.NRC, Ref. 2.15

LBB.ENG1 and LBB.ENG2, Refs. 2.16 and 2.17, respectively.

The GE/EPRI scheme uses the finite element method to develop tables of generalized functions, so called $h$-functions, for calculating the plastic contribution to $J$ from an applied load. The LBB series of solutions were developed in the NRC Degraded Piping Program. LBB.NRC interpolates between known linear elastic and known rigid plastic solutions for planar fracture specimens, adapted to through-wall-cracked pipe geometry, to find $\mathrm{J}$ at an applied load, and includes material strain hardening. The LBB.ENG methods basically use the GE/EPRI h-functions to define plastic displacements, but integrates numerically to find the plastic contribution to J from the applied load. LBB.ENG2 modifies the h-function plastic crack displacements using an engineering estimate of the reduced pipe compliance due to crack tip plasticity.

Likewise, there exist only a few finite-length circumferential surface-cracked pipe J-estimation scheme analyses. Methods available include:

GE/EPRI, Ref. 2.14 
R6, Ref. 2.13

SC.TNP and SC.TKP, Ref. 2.18.

The SC.TNP and SC.TKP solutions were developed in the NRC Degraded Piping Program, Ref. 2.18. The SC.TNP solution is based on thin-shell theory, while SC.TKP is based on thick-shell theory. These solutions use the GE/EPRI 360-degree surface-cracked pipe solution for pure tension to develop new h-functions for calculation of the plastic component of $J$ for finite-length surfacecracked pipe in bending.

\subsubsection{J-Estimation Scheme Analysis Procedures}

J-estimation schemes are a way of analytically estimating the applied $J$ that can be precisely calculated by finite element analyses. Because finite element analyses are time consuming and expensive to conduct for all the possible cases of interest, J-estimation schemes are more frequently used. In a generic sense, the GE/EPRI method is typical of J-estimation scheme analyses. In this method, the applied $J$ value is determined by separating $J$ into an elastic and a plastic component, i.e.,

$$
\mathrm{J}_{\text {total }}=\mathrm{J}_{\text {elartic }}+\mathrm{J}_{\text {plastic }}
$$

Elastic component solutions typically exist from handbook solutions, but the plastic component of $\mathrm{J}$ is more complicated. The GE/EPRI method of calculating J Jartic is to use finite element analyses to define a function that relates the $J_{\text {plaxic }}$ to the applied load as per the following general form

$$
J_{\text {plastic }}=\alpha \epsilon_{0} \sigma_{0} a\left[P / P_{0}\right]^{n+1} h_{1}
$$

where parameters $\alpha, \epsilon_{0}, \sigma_{0}$, and $\mathrm{n}$ are from the Ramberg-Osgood representation of the material's stress-strain curve

$$
\frac{\epsilon}{\varepsilon_{0}}=\frac{\sigma}{\sigma_{0}}+\alpha\left(\frac{\sigma}{\sigma_{0}}\right)^{n}
$$

The term $a$ is the crack length, and $P_{0}$ is the limit load using $\sigma_{0}$ as the flow stress of the material. The term $h_{1}$ is a function of the crack size, the geometry of the structure, and the strain-hardening exponent, $n$. This $h_{1}$ term is determined from elastic-plastic finite element analyses.

Similarly, there are relationships between the pipe displacement or rotation of the pipe as a function of load. The general form for such displacement functions is 


$$
\delta_{\text {plastic }}=\alpha \epsilon_{0} \sigma_{0} a\left[\mathrm{P} / \mathrm{P}_{0}\right]^{\mathrm{n}} \mathrm{h}_{2}
$$

where for crack-opening displacement the $h_{2}$ function is defined, and for load-point displacement or pipe rotation $h_{3}$ or $h_{4}$ functions are defined.

Hence, for any given load, one can calculate the applied $J$ and the pipe displacement or pipe rotations. If the applied $J$ is greater than the $J_{k c}$ of the material, then the crack length is incremented and the $J$ value from the appropriate $J-R$ curve for the corresponding crack growth is then used in subsequent calculations.

The basic inputs to a J-estimation scheme analysis are the stress-strain behavior of the material, the J versus crack growth curve (J-R curve) for the material, and the pipe and flaw geometry. Given these data and some prescribed loading, the applied J, pipe displacements (rotations), crack extension, and crack-opening displacement can all be estimated. As appropriate, the crack length is incremented and, eventually, the load at crack initiation and maximum load can be determined. Because the calculations are very intensive and repetitive, they are generally implemented in computer programs.

As mentioned previously, there are very few finite-length through-wall or surface-cracked J-estimation scheme analyses. Battelle's NRCPIPE computer program contains a rather complete selection of the available through-wall-cracked pipe J-estimation scheme solutions. Surface-cracked J-estimation scheme analyses are contained in the companion program NRCPIPES.

\subsubsection{Modification for Pressure}

The prediction of initiation and maximum moment for circumferentially cracked-pipe experiments is complicated by combined pressure and bending loads. At present, Battelle's J-estimation scheme analyses appear to be the most detailed pipe flaw analysis procedures, short of full three-dimensional finite-element analysis. Even so, these methods do not currently include the effect of internal pressure on $\mathrm{J}$.

The effect of internal pressure is addressed in an approximate way, by ignoring possible (but suspected to be insignificant) loading path effects on plastic deformation, and replacing the axial tension in the uncracked ligament ahead of the crack by an additional applied moment. The equivalent moment, $\mathbf{M}_{\mathrm{eq}}$, from the pressure induced axial tension stress is calculated as being approximately equal to the difference of the Net-Section-Collapse analysis predicted stress under pure bending and the Net-Section-Collapse analysis predicted stress under combined bending and tension for the internal pressure.

\subsection{Stability Analysis}

The previously discussed engineering flaw assessment methodologies predict the initiation and maximum load-carrying capacity of cracks in pipes. They do not, however, make any assessment of the stability of the flaws when the flaws reach maximum load unless all stresses are load-controlled, 
which is not typical for real piping systems. Stability in this context means the absence of large amounts of rapid crack growth. If a crack has a large maximum moment capacity, and the piping system that contains the crack is very compliant, the applied load that would cause the crack to propagate will cause a great deal of elastic deformation in the pipe system. The elastic deformation of the pipe system will result in a large amount of stored energy in the pipe system which may be released in the form of rapid, unstable crack growth after maximum load. Less compliance in the test system or lower moment-carrying capacity of the crack tend to enhance stability.

There currently are two engineering analysis flaw stability assessment strategies, J/T stability analysis and Energy Balance stability analysis. In both cases, the methods are founded on the idea of determining the energy stored in the pipe system that can be made available to drive the crack, and comparing this available energy to the energy that is needed to grow the crack.

\subsubsection{Fully Plastic J/T Stability Analysis}

The $\mathrm{J}$-integral/tearing modulus, fully plastic $\mathrm{J} / \mathrm{T}$, analysis is a method currently used to make an assessment of the stability of cracked structures. Paris and his co-workers popularized the methodology, Ref. 2.19. A rather extensive compilation of $\mathrm{J} / \mathrm{T}$ solutions for various loading modes (displacement-controlled and load-controlled) and assumed material behavior can be found in Ref. 2.20 .

Simply stated the $\mathrm{J} / \mathrm{T}$ instability criteria for cracked pipe can be expressed as:

$$
\mathrm{J}_{\text {applied }}>\mathrm{J}_{\mathrm{Ic}}
$$

and

$$
T_{\text {applied }}>T_{\text {material }}
$$

If the applied $\mathrm{J}$ is greater than $\mathrm{J}_{\mathrm{lc}}$, the crack will grow. Then, if the applied tearing modulus becomes greater than the material's tearing resistance, crack growth instability will occur.

Graphically, the J/T methodology is shown in Figures 2.7 and 2.8. In the left-hand part of Figure 2.7, applied $\mathrm{J}$ is computed as a function of load for the given pipe, crack, and material. Applied $\mathrm{J}$ is also calculated as a function of applied $\mathrm{T}$ and plotted on the right-hand side of the figure. Next, a J/T curve representing the material's crack growth resistance, as developed from a compact tension or pipe specimen J-R curve, is plotted on the right-hand portion of the figure from data shown in Figure 2.8. $\mathrm{J}_{\text {applied }}$ and $\mathrm{T}_{\text {appliod }}$ solutions, as a function of load, can be found in Ref. 2.20. Instability is predicted to occur when the applied and material $\mathrm{J} / \mathrm{T}$ curves intersect. 
$\mathrm{J} / \mathrm{T}$ analyses can be performed for surface crack or through-wall cracks under assumed load-controlled or displacement-controlled stresses with various assumed material behaviors (LEFM, small-scale yielding, fully plastic, EPFM, etc.). J/T analysis can predict the occurrence of an instability, but it does not predict how severe the instability will be. In addition, $J / T$ analysis is limited to the bounding cases of fully displacement-controlled or fully load-controlled stresses.

\subsubsection{Energy Balance Stability Analysis}

The Energy Balance Stability Method is a technique that was developed in the Degraded Piping Program (Ref. 2.21) to predict the onset of crack instability and to estimate the crack length at arrest of a limited instability for either a through-wall or surface-cracked pipe. It uses an elastic-plastic Jestimation scheme to calculate the force-deflection response of a cracked pipe to determine the energy absorbed in the fracture process, and the elastic energy in the pipe system to determine the energy available to drive the instability. It has been verified for some limited cases by quasi-static compliant surface-cracked pipe fracture experiments.

The basic process used to conduct an energy balance stability assessment is shown in Figures 2.9 through 2.11. Although the process is described in moment-rotation coordinates and refers to a surface crack transitioning to a through-wall crack, the concept is perfectly general and applies equally well to load-displacement coordinates and pure through-wall cracks.

In Figure 2.9a, the moment-rotation behavior of a surface crack is shown. The crack is assumed to be a circumferential plane of zero axial length, with all effects of the pipe on either side excluded. At any point on the loading curve, the shaded area describes the elastic energy that is stored in the cracked pipe. In Figure $2.9 \mathrm{~b}$, the elastic energy stored in the attached piping is shown, assuming that all of the piping remote from the crack remains elastic and that the loading and unloading compliances are equal and linear. Figure $2.9 \mathrm{c}$ is the sum of the energies shown in Figures $2.9 \mathrm{a}$ and $2.9 \mathrm{~b}$. This is the total energy available to drive a crack.

The energy absorbed by a through-wall crack growing from length $\theta_{\mathrm{i}}$, the original length of the surface crack, to some final length $\theta_{\text {tot }}$ is shown in Figure 2.10. Figure 2.11 shows the energy being absorbed to propagate the through-wall crack being made equal to the available elastic energy from the crack and the attached piping system. Stability is determined by how far out on the through-wall crack curve the energies balance.

In contrast to the J/T analysis, the Energy Balance analysis can estimate how far the crack will propagate; given that the energies balance at a given crack rotation that is above zero moment, the companion J-estimation scheme can be used to find the crack length at that rotation. Energy Balance can also, in a rough way, deal with combined displacement- and load-controlled stresses. If the applied moment on the crack due to pressure and dead weight, for instance, is greater than the moment where the energies balance (see the horizontal load-controlled $r$ toment line in Figure 2.11), the crack will not arrest but would be expected to grow to a DEGB. 


\subsection{Application}

In application, the fracture analysis methods described above are used in conjunction with a linear elastic stress analysis. Flaws are postulated to exist at various locations, the applied moments or stresses at the flaw locations are extracted from the elastic stress reports, and then capacity of the flaw is compared to the applied load. If the flaw capacity is less than the applied load, a stability analysis is then performed. 


\subsection{References}

2.1 Kanninen, M. F., and others, "Mechanical Fracture Predictions for Sensitized Stainless Steel Piping with Circumferential Cracks", Final Report, EPRI NP-192, September 1976.

2.2 Kanninen, M. F., and others, "Instability Predictions for Circumferentially Cracked Type 304 Stainless Steel Pipes Under Dynamic Loadings", Final Report on EPRI Project T118-2, by Battelle Columbus Laboratories, EPRI Report Number NP-2347, April 1982.

2.3 Wilkowski, G. M., and others, "Degraded Piping Program -Phase II", Summary of Technical Results and Their Significance to Leak-Before-Break and In-Service Flaw Acceptance Criteria, March 1984-January 1989, by Battelle Columbus Division, NUREG/CR-4082, Vol. 8, March 1989.

2.4 Wilkowski, G., et al, "Short Cracks in Piping and Welds, Semiannual Progress Report April 1992 - September 1992", NUREG/4599, Vol. 3, No. 1, June 1993.

2.5 Wilkowski, G. M., and Scott P. M., "A Statistical Based Circumferentially Cracked Pipe Fracture Mechanics Analysis for Design or Code Implementation", Nuclear Engineering and Desien, 1989, pp 173-187.

2.6 American Society of Mechanical Engineers Boiler and Pressure Vessel Code, Edition July 1989, Section XI Article IWB-3640.

2.7 American Society of Mechanical Engineers Boiler and Pressure Vessel Code, Edition July 1989, Code Case N-463.

2.8 Maricchiolo, C., and Milella, P. P., "Fracture Behavior of Carbon Steel Pipes Containing Circumferential Cracks at Room Temperature and $300 \mathrm{C}^{n}$, Nuclear Enginearing and Desion, 111,1989 , pp. 35-46.

2.9 Wilkowski, G. M. and Eiber, R. J., "Evaluation of Tensile Failure of Girth Weld Repair Grooves in Pipe Subjected to Offshore Laying Stresses", ASME Journal of Energy Resources Technology, Vol. 103, March 1981.

2.10 Kurihara, R., Ueda, S. and Sturm, D., "Estimation of the Unstable Fracture of Pipe with a Circumferential Surface Crack Subjected to Bending", Nuclear Engineerine and Desien, 106 (1988), pp. 265-273.

2.11 Harrison, R. P., Loosmore, K., Milne, I., and Dowling, A. R., "Assessment of the Integrity of Structures Containing Defects", CEGB Report R/H/R6, 1976: R/H/R6-Rev. 1, 1977.

2.12 Milne, I., "Failure Assessment Diagrams and J Estimates: A Comparison for Ferritic and Austenitic Steels", CEGB Report RD/L/2208N81, 1982. 
2.13 Milne, I., Ainsworth, R. A., Dowling, A. R., and Stewart, A. T., "Assessment of the Integrity of Structures Containing Defects", R/H/R6-Rev. 3, Published by Central Electric Generating Board, England, May 1986.

2.14 Kumar, V., and German, M. D., "Elastic-Plastic Fracture Analysis of Through-Wall and Surface Flaws in Cylinders", EPRI report NP-5596, January 1988.

2.15 R. Klecker, F. Brust, and G. Wilkowski, "NRC Leak-Before-Break (LBB.NRC) Analysis Method for Circumferentially Through-Wall Cracked Pipe Under Axial Plus Bending Loads", NUREG/CR-4572, BMI-2134, May, 1986.

2.16 Brust, F. W., "Approximate Methods for Fracture Analyses of Through-Wall Cracked Pipes", NUREG/CR-4853, February 1987.

2.17 P. Gilles and F. W. Brust, "Approximate Methods for Fracture Analysis of Tubular Members Subjected to Combined Tensile and Bending Loads", ASME 8th OMAE Conference, The Hague, Netherlands, March 1989.

2.18 Scott, P. M. and Ahmad, J., "Experimental and Analytical Assessment of Circumferentially Surface-Cracked Pipes Under Bending", NUREG/CR-4872, April 1987.

2.19 Tada, H., and Paris, P., "Tearing Instability Handbook," NUREG/CR-1221, January 1980.

2.20 Zahoor, A., "Ductile Fracture Handbook," EPRI Report NP-6301-D, June 1989.

2.21 G. M. Wilkowski and G. Kramer, "An Energy Balance Approach to Estimate the Initiation and Arrest of Ductile Fracture Instability in Circumferentially Cracked Pipe", ASME Special Technical Publication, Vol. 167, July 1989, pp 103-114. 

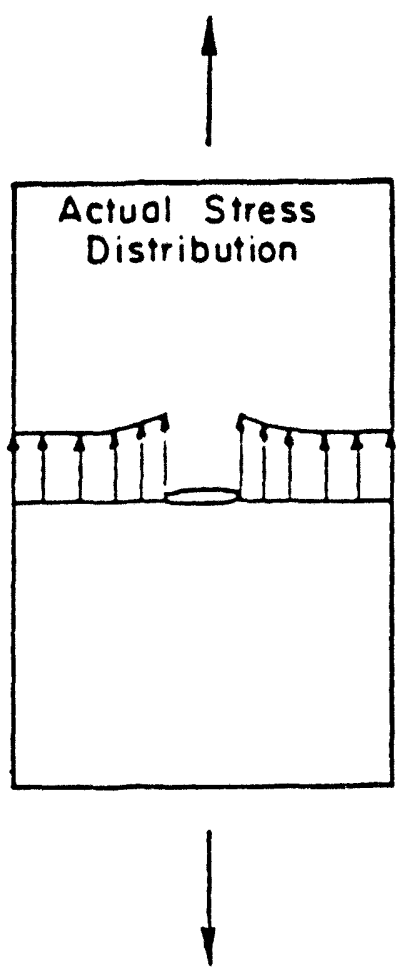

Plate

in Tension
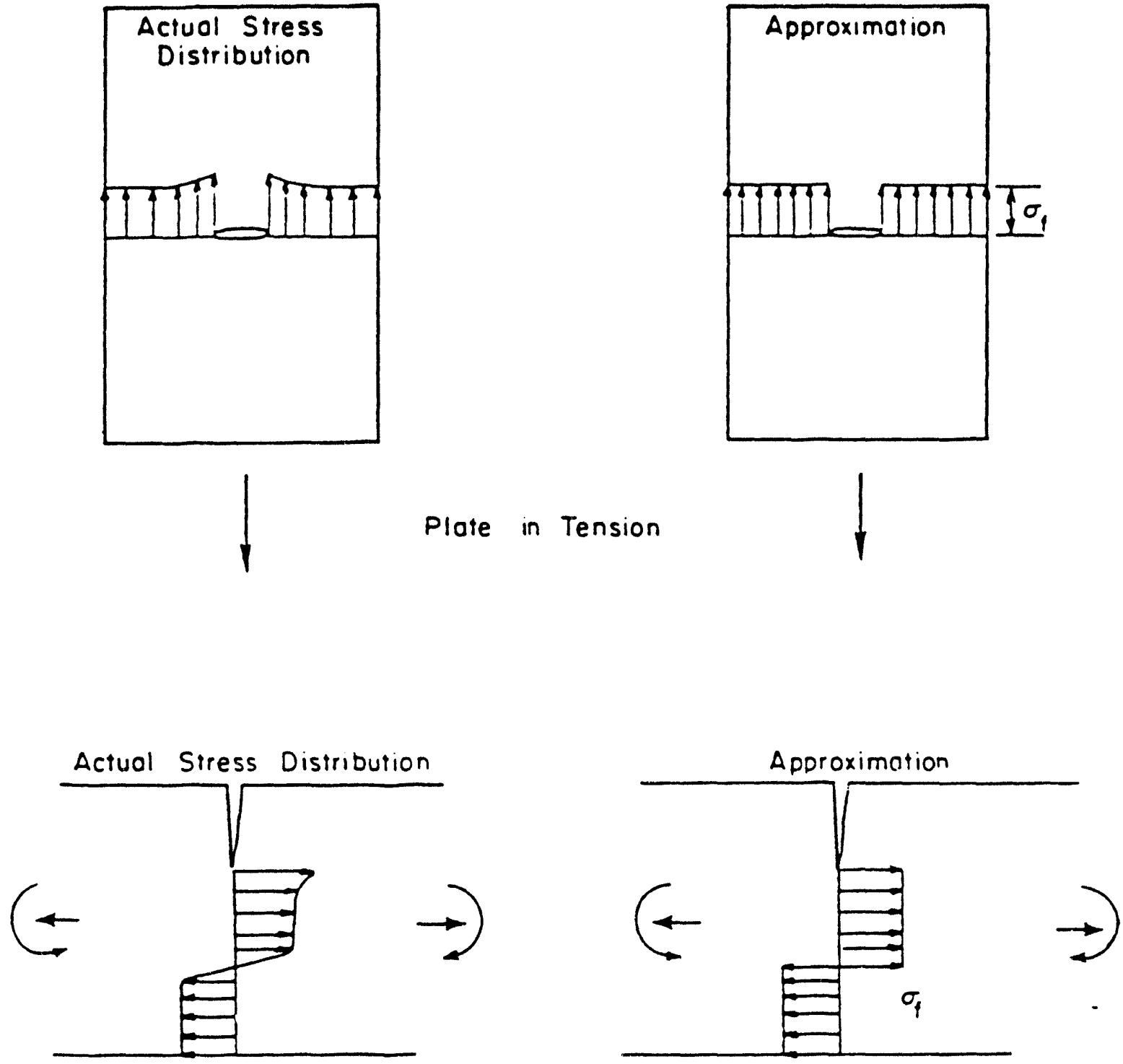

Pipe Under Bending

Figure 2.1 Net-Section-Collapse criteria 

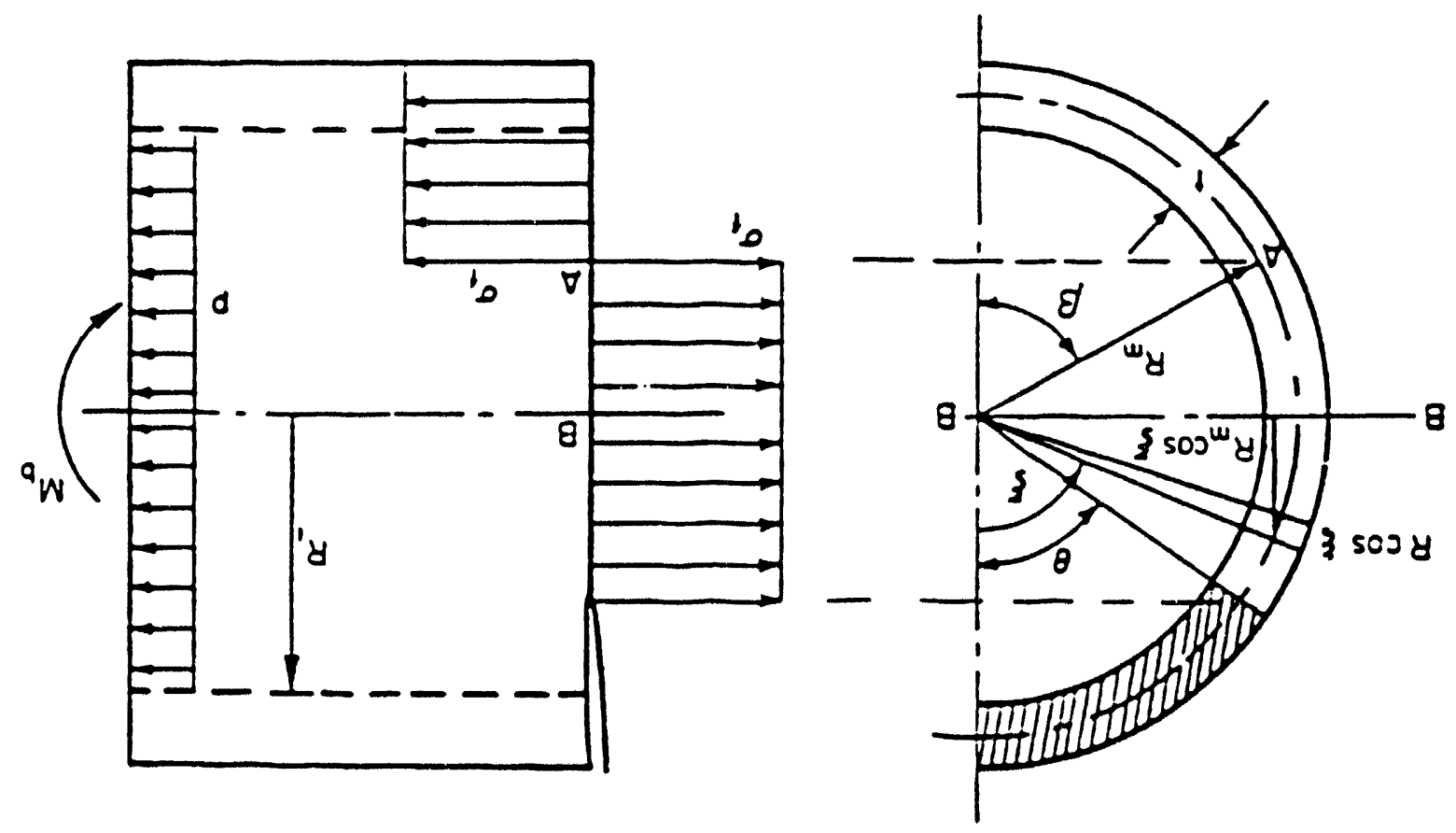

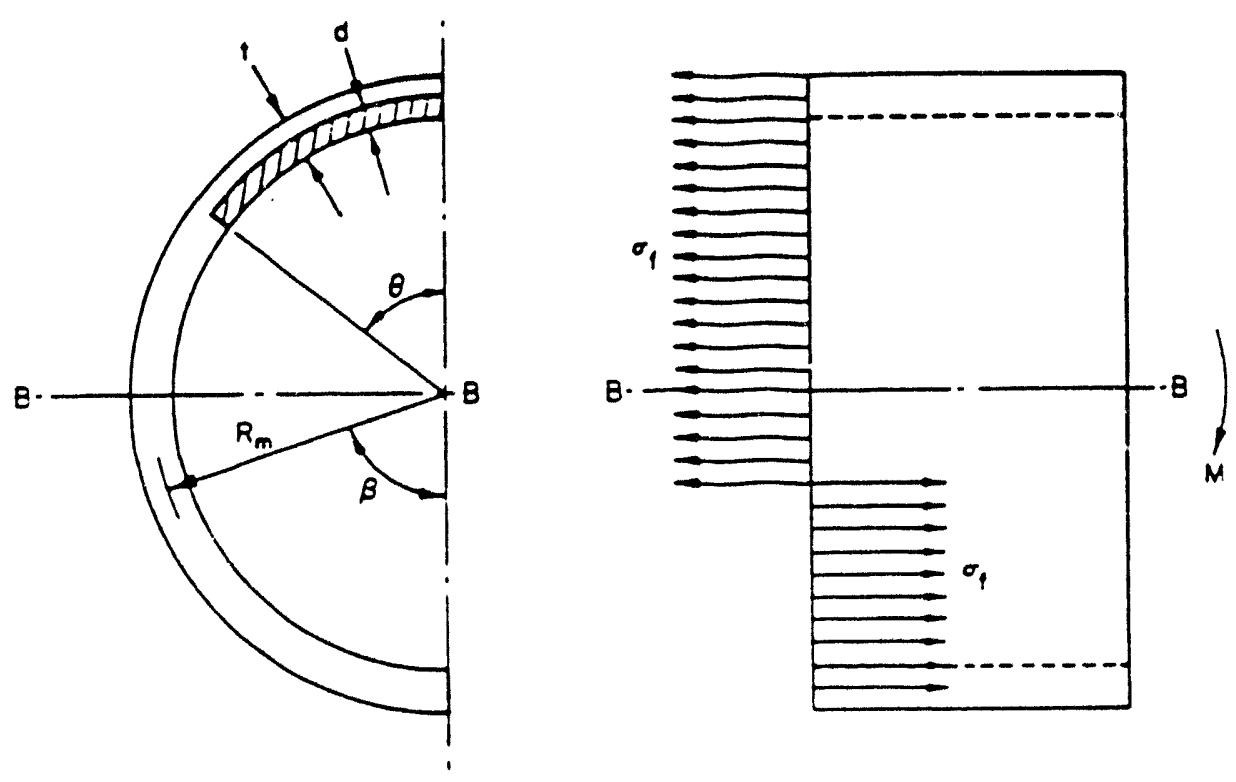

Figure 2.3 Nomenclature and loading for the application of the Net-Section-Collapse criterion to a pipe with a circumferential surface crack subjected to pure bending
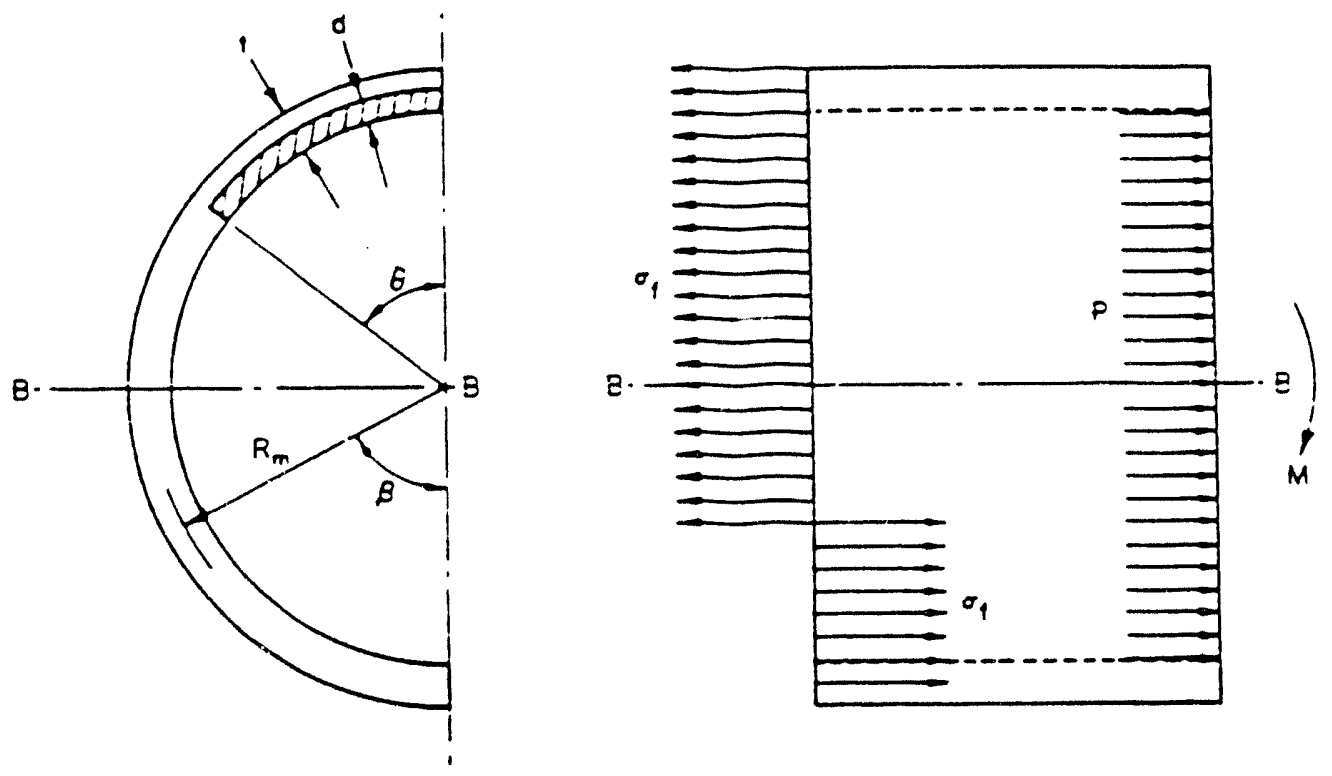

Figure 2.4 Nomenclature and loading for the application of the Net-Section-Collapse criterion to a pipe with a circumferential surface crack subjected to combined pressure and bending 


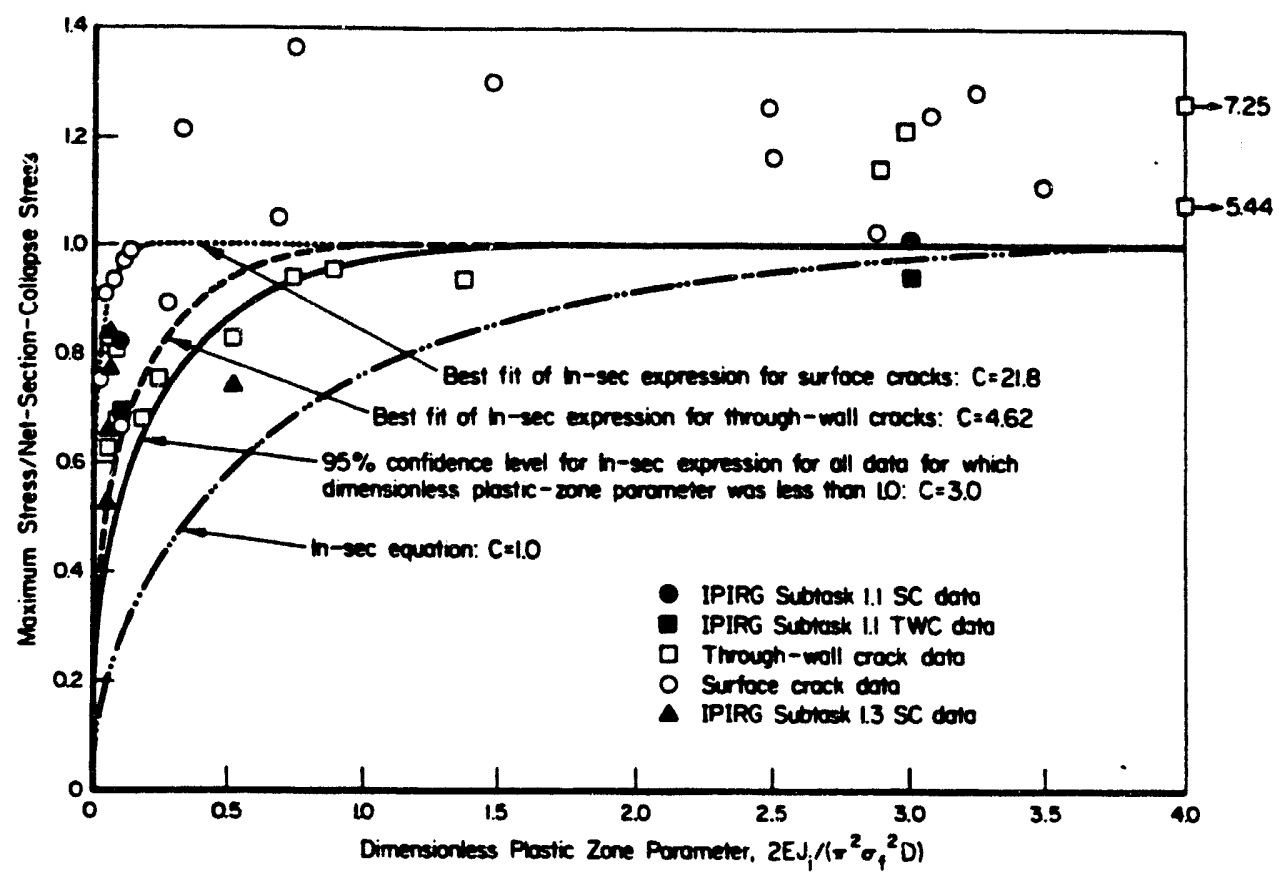

Figure 2.5 Dimensionless Plastic-Zone Parameter data $\left[\sigma_{\mathrm{f}}=\left(\sigma_{\mathrm{y}}+\sigma_{\mathrm{v}}\right) / 2\right]$

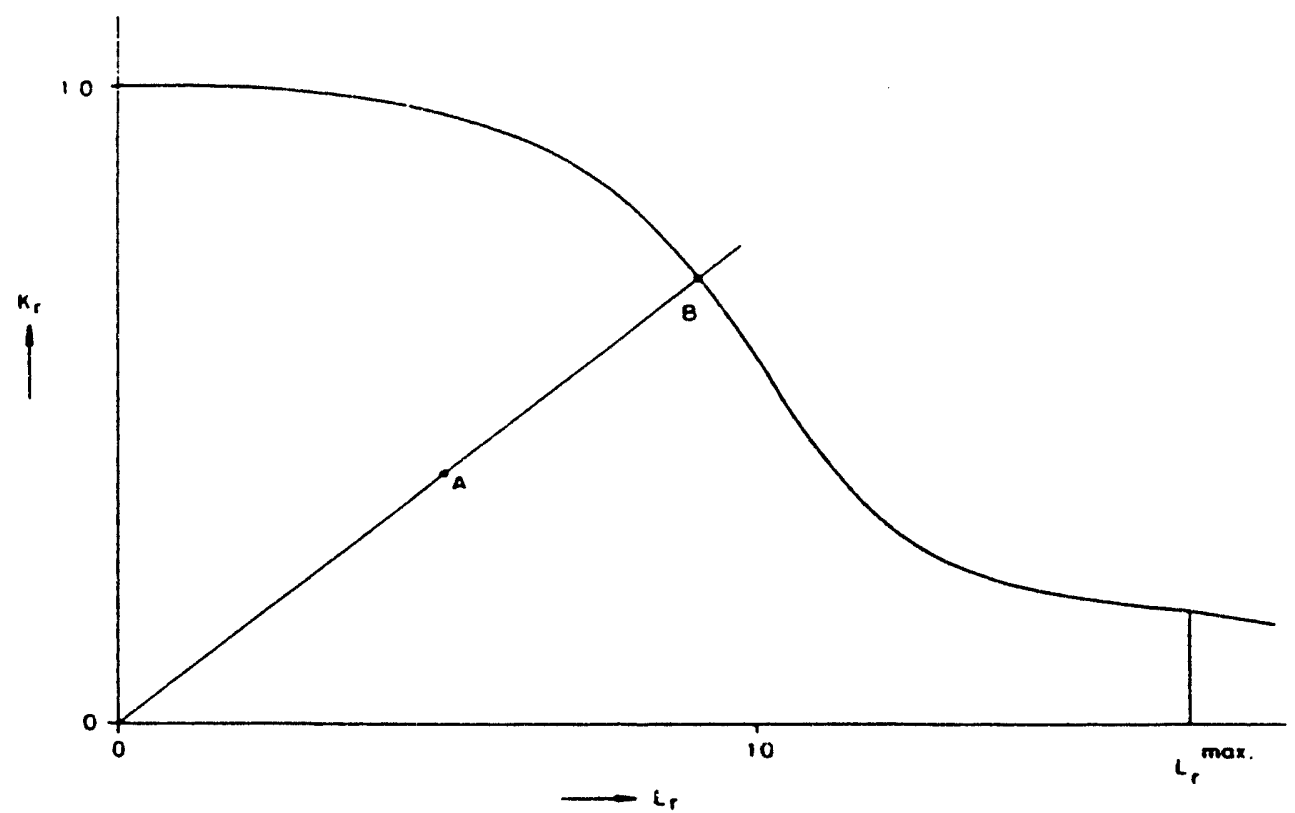

Figure 2.6 R6, Option 1 failure assessment diagram 


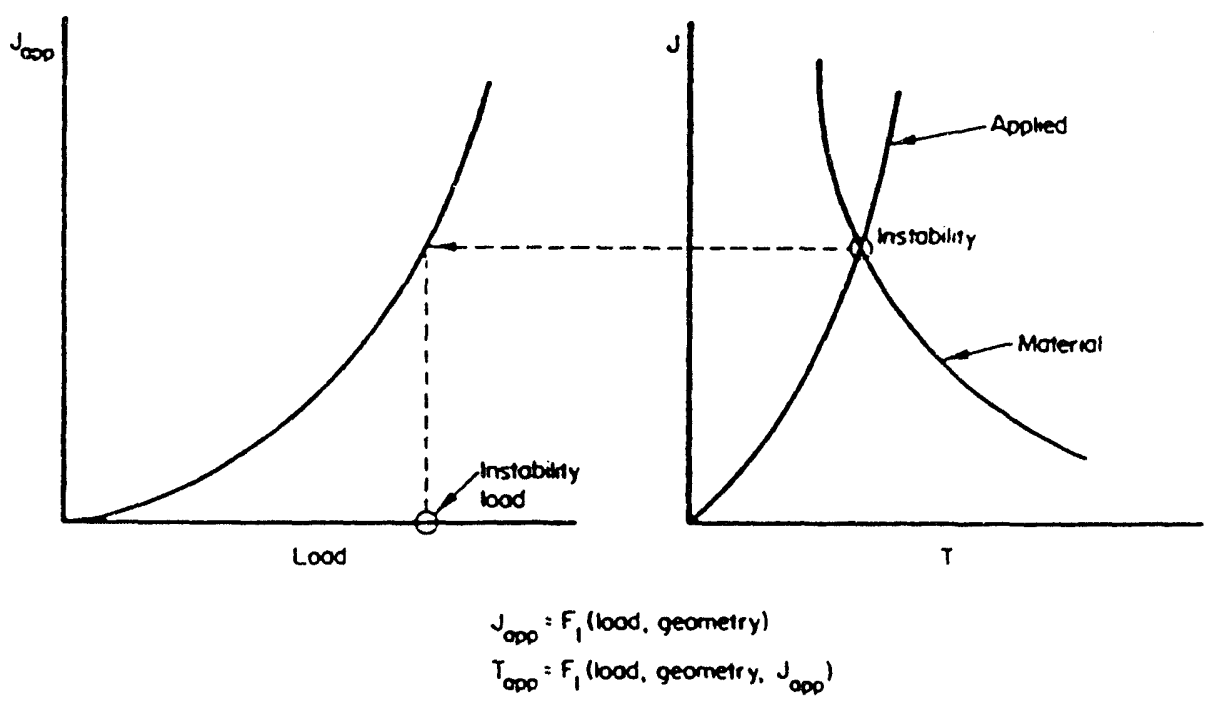

Figure 2.7 J/T stability assessment methodology

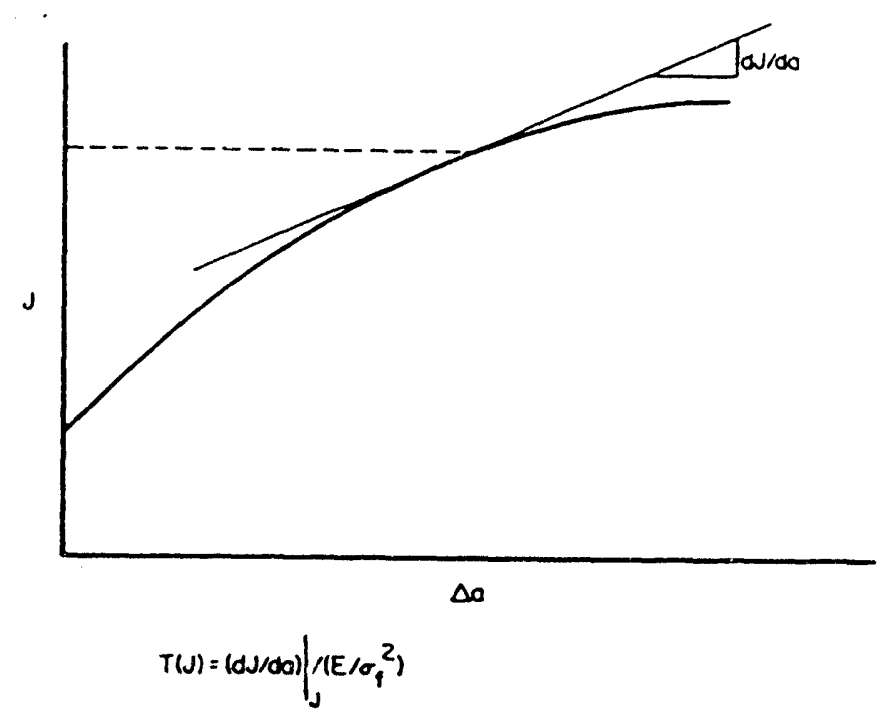

Figure 2.8 Material J/T behavior 


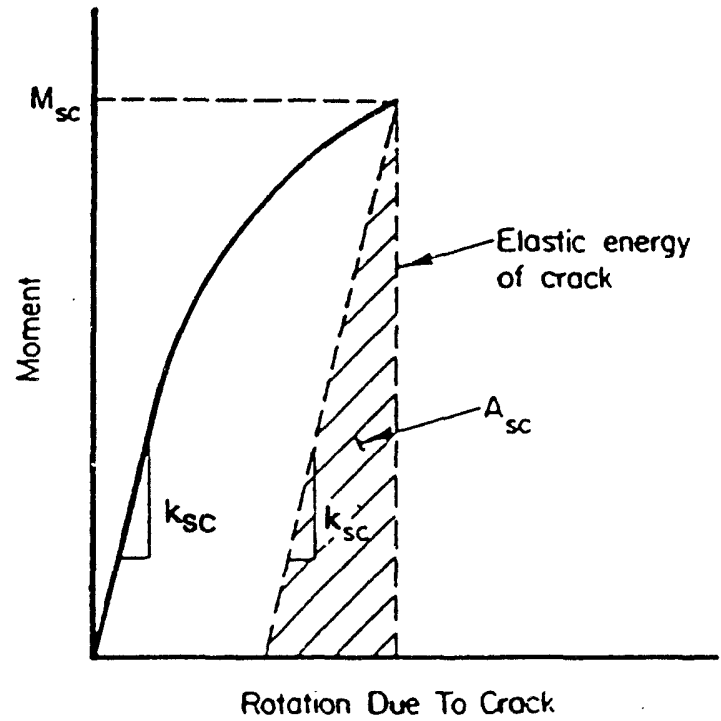

(a) Surface crack behavior

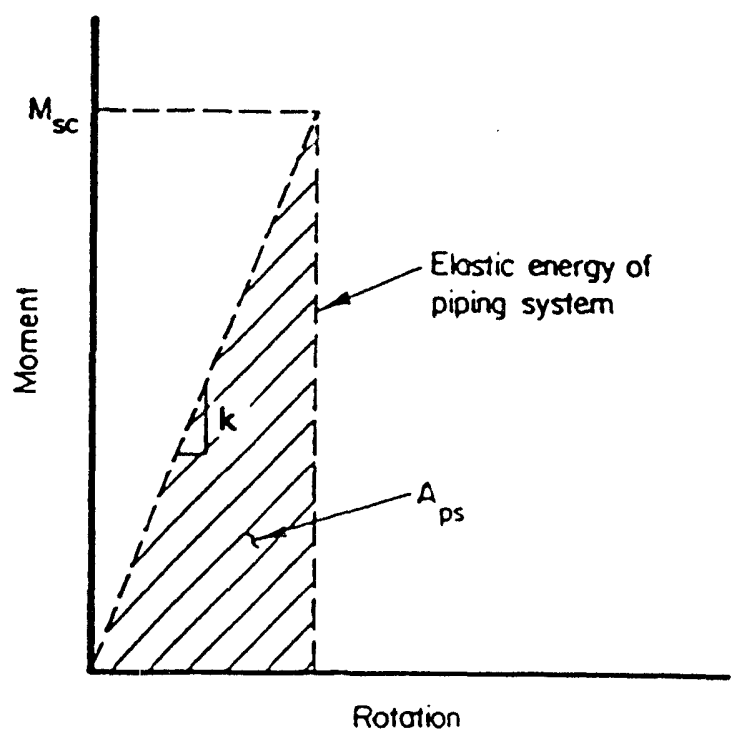

(b) Pipe system behavior

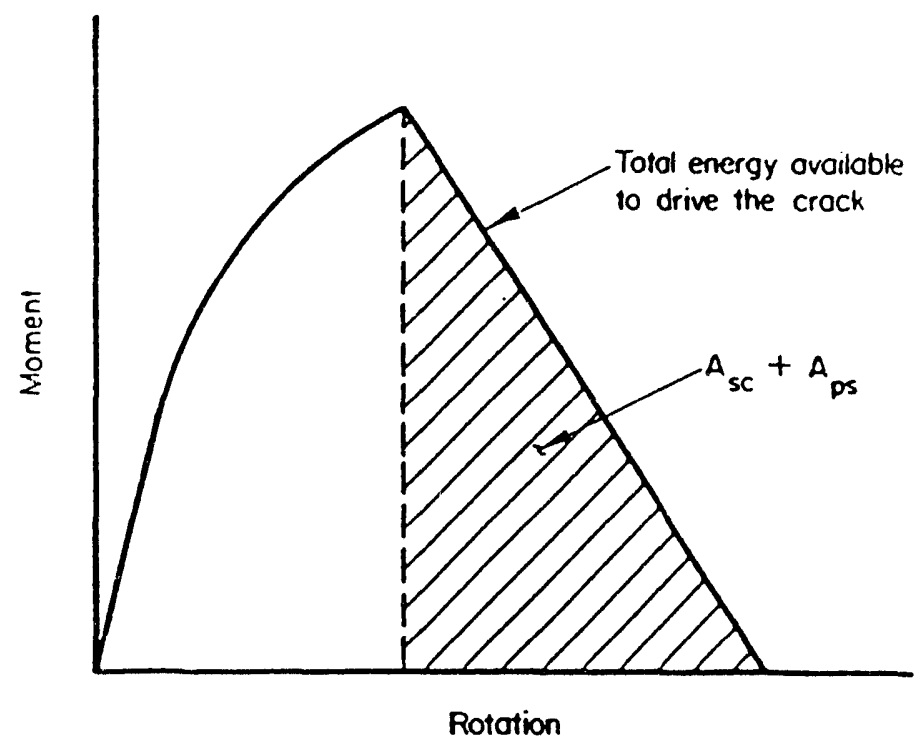

(c) Combined energy

Figure 2.9 Energy available for driving an instability 


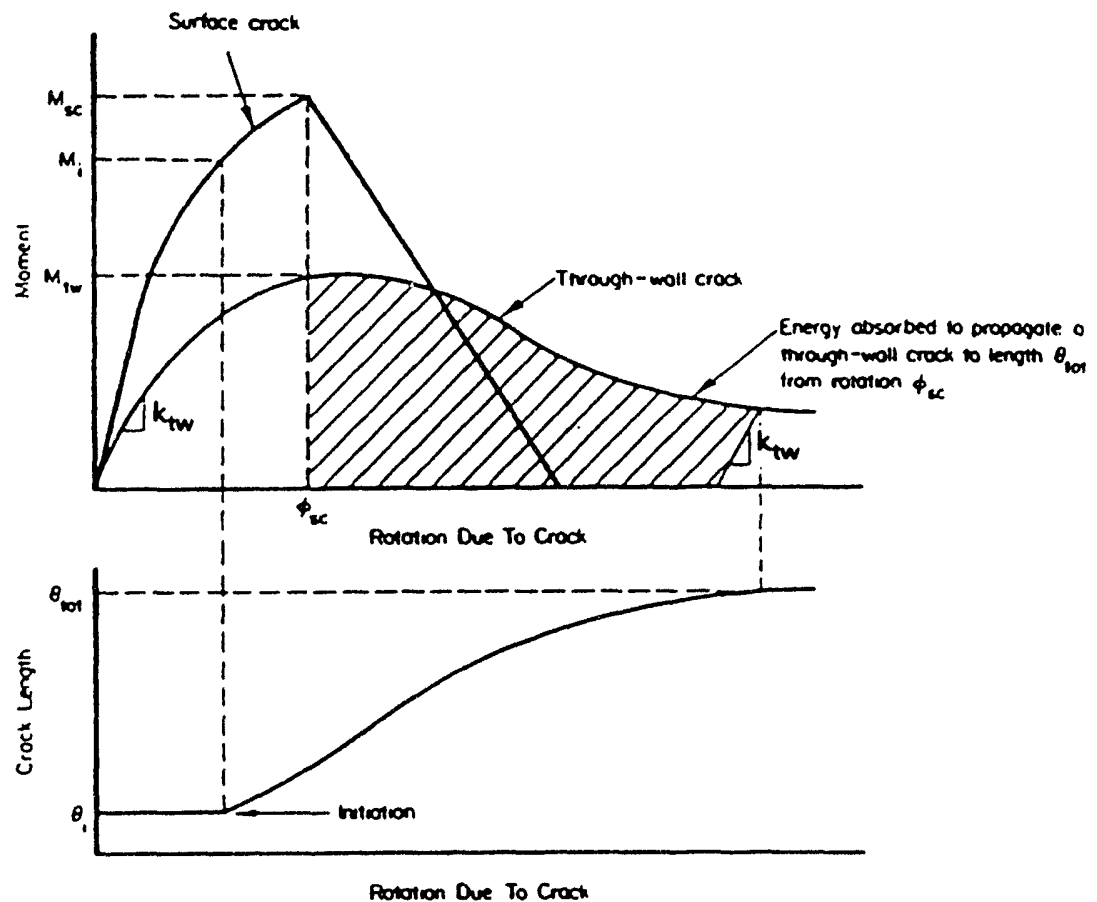

Figure 2.10 Crack propagation behavior

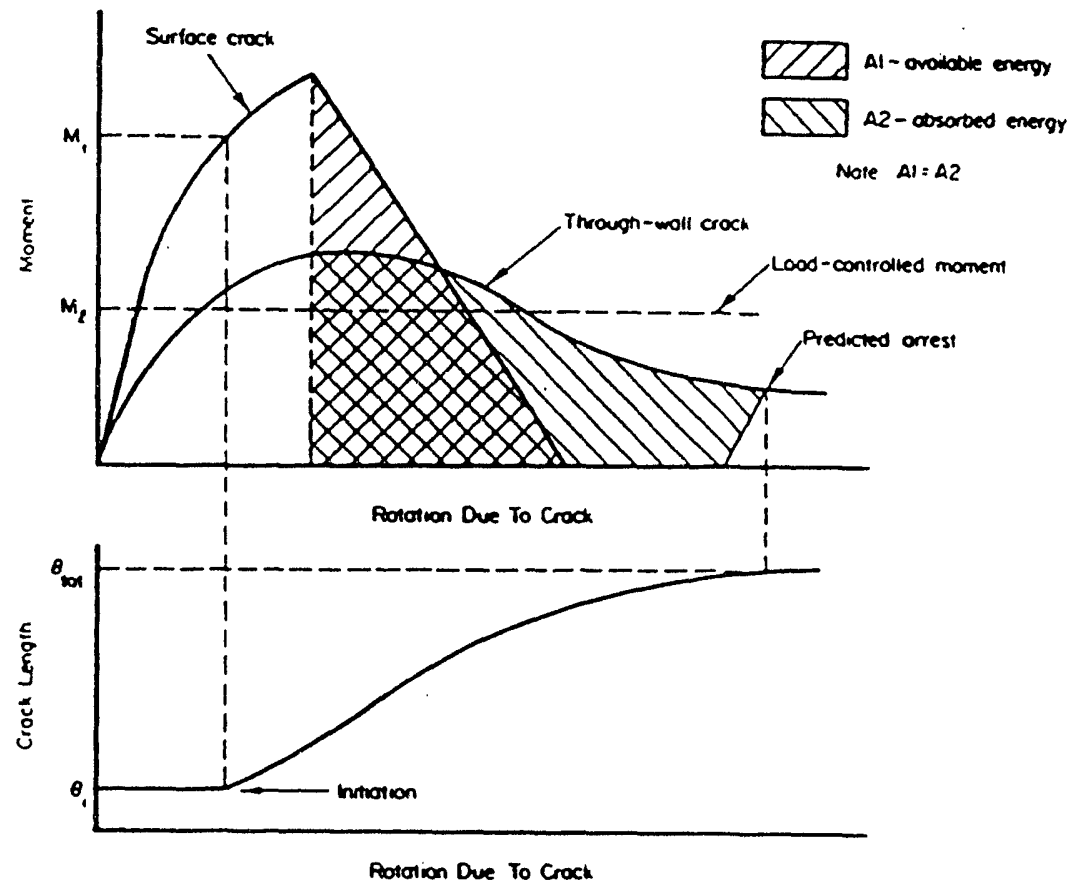

Figure 2.11 Energy Balance diagram showing balanced available and absorbed energies 


\section{NONLINEAR FEA FRACTURE MECHANICS ANALYSES}

The analyses described in the previous section make liberal use of engineering assumptions to intentionally induce conservative estimates of flaw behavior. Foremost among the assumptions that contribute to the conservatism are:

(1) The fracture and pipe response are assumed to be decoupled

(2) An elastic stress analysis is used

(3) The transient nature of dynamic loads is ignored, i.e., stresses are applied statically and in a load-controlled manner

(4) "Design" values for material properties are used in a number of the methods.

From a plant design and operation perspective, this conservatism is generally desirable. From the point of view of analysis margin assessment, or the point of view of pipe fracture experiment design, the inherent conservatism of the engineering fracture mechanics analyses is not appropriate. To address this issue, a state-of-the-art nonlinear FEA pipe fracture analysis method that directly deals with the four points listed above was developed in the IPIRG-1 program, Ref. 3.1. In the current program, the state-of-the-art has been refined to incorporate additional known dynamic pipe fracture phenomena.

\subsection{Prior State-Of-The-Art}

Prior to starting this program in January 1992, the state-of-the-art in dynamic fracture analysis had been advanced to the point where the time to failure and maximum moment of a surface-cracked test section in a dynamically loaded expansion loop could be predicted with reasonable accuracy, Ref. 3.2. Because the development of this basic capability formed the foundation for the advancements needed to analyze the HDR-E31 experiments, a review of the state-of-the-art at the beginning of this program will be useful.

There are at least three different categories of cracked-pipe dynamic analyses. These are;

- Complete three-dimensional finite element modeling

- Substructuring, using beam elements for the uncracked pipe and three-dimensional elements at the crack location

- Using beam elements for the uncracked pipe and a nonlinear spring element to simulate the crack response. 
Complete three-dimensional, elastic-plastic, dynamic analysis is extremely costly, time consuming, and is not a practical engineering tool. Substructuring with beam elements and three-dimensional elements at the crack is more practical, but for a surface-crack problem, the finite element mesh is very complicated. Griesbach, Ref. 3.3, conducted a substructured dynamic analysis for a throughwall crack with a relatively coarse shell element mesh, see Figure 3.1. Mesh development and computer time for a more detailed analysis, particularly for surface cracks, makes such an approach very expensive.

The final approach, the one used by Battelle during the IPIRG-1 program, has proven to be very economical, and is possibly the most accurate approach. In this approach, the crack response is represented by a nonlinear spring and the dynamic response of the pipe system becomes an inherent part of the fracture analysis.

\subsubsection{Nonlinear Spring Dynamic Analysis Options}

There are several different approaches which could be used to simulate the response of a cracked pipe using a nonlinear spring. Some of these are:

- Reduce the thickness of a short length of pipe and/or change the stress-strain curve to give the proper nonlinear response that the crack would cause. This is similar to the engineering approach used in developing the Battelle's through-wall-crack J-estimation scheme LBB.ENG method, Refs. 3.4 and 3.5, see Figure 3.2.

- Completely embed one of the J-estimation schemes within the beam element code.

- Determine a nonlinear stiffness and implement it with a nonlinear spring element.

Of these, the first two require more computational time than the third. The first approach requires that the constitutive equations be solved for the simulated cracked pipe section. The second requires that an estimation scheme such as LBB.ENG, GE/EPRI, LBB.NRC, LBB.GE, Refs. 3.4, 3.6 and 3.7, for through-wall-cracked pipe or SC.TKP or SC.TNP for surface-cracked pipe, Ref. 3.8, be solved at every matrix update. This method was pursued by CEA in France, Ref. 3.9, but to date only a rigid-elastic, perfectly-plastic fracture element has been incorporated. The last method was adopted by Battelle for the IPIRG-1 program and has proven to be efficient, reliable, and accurate.

\subsubsection{Nonlinear Spring Element}

The method that Battelle pursued and refined in the IPIRG-1 program for the dynamic analysis of flawed piping established the stiffness (moment-rotation relationship) of a nonlinear spring representation of a cracked pipe using the J-estimation schemes described in Section 2.5. Although experimental data (i.e., results from a quasi-static pipe fracture experiment with the same material and flaw size) might be available, the J-estimation scheme approach for predicting the moment-rotation response is more consistent with data that are likely to be available for a flaw evaluation, i.e., specimen material properties. In calculating the stiffness of a cracked-pipe section using a J-estimation scheme, the material properties and crack section geometry (i.e., pipe diameter, 
thickness, crack length, and crack depth) need to be well defined. In addition, several assumptions are made in generating the crack stiffness:

- For low-cycle high amplitude loading, the cyclic load effects on the circumferential crack growth are assumed to be small; crack growth is dominated by ductile tearing under increasing load amplitude.

- High strain rate effects on crack growth and on the constitutive relationship are typically ignored, even though they may tend to influence crack growth and the plastic flow for some materials. Rarely, however, will one have access to dynamic material property data (i.e., dynamic tensile or J-R curve data).

- Only a separation mode (Mode I) of crack propagation under bending is assumed. This implies that the crack section is considered to be rigid in all degrees of freedom except the rotation corresponding to the crack opening.

- The rotational deformation due to the crack and relevant plastic deformations are confined to the crack section.

The nonlinear cracked section model developed in the IPIRG-1 program was implemented using spring-slider elements (STIF40, Combination Element) in the ANSYS Version 4.4a computer program. The spring-slider element, one of which is shown in Figure 3.3, is a two node, two degree-of-freedom element with a linear spring and a friction slider in series. At low loads, the slider is locked and the two nodes behave as if they have a linear spring between them. When the spring load reaches a magnitude of $\pm F_{\text {slide }}$, the force between Nodes I and $J$ remains constant. If the spring-slider reaches the limiting force and then is unloaded, a permanent displacement will remain when the load is brought back to zero. Putting two or more spring-slider elements in parallel with different stiffnesses and $F_{\text {slide }}$ values allows one to model a multi-linear load-deflection curve. Figure 3.4 illustrates the modeling of a 3-segment curve.

Under monotonically increasing load, a multi-linear spring-slider representation of a crack follows the curve shown in Figure 3.5. With load reversals, compressive yield and hysterisis effects are exhibited. Referring to Figure 3.5, at the point of first unloading, the spring-slider model unloads along a line parallel to the slope of the initial segment of the defined moment-rotation curve. Unloading continues along this line until the load reaches a value of $2 \mathrm{~F}_{\mathrm{TI}}$ below the load at which unloading took place. At this point, the system unloads along a line parallel to the slope of the second segment. If the system continues unloading to a load level that is $2\left(F_{T 2}-F_{T 1}\right)$ below the slope change (yield), the system unloads along a line parallel to the third segment. Subsequent yielding and load reversals continue with the same pattern. The behavior of the spring-slider elements described above is a model of the Baushinger effect, i.e., kinematic hardening in a plasticity analysis. The implication of using a model like this is that energy is absorbed at the crack under cyclic loading.

The multi-linear spring-slider model is attached to a pair of coincident nodes at the crack location in the pipe model, coupling the two nodes together in the relative rotation bending degree-of-freedom of the attached pipe elements. The remaining five degrees of freedom; the two shears, the torsion, the 
tension, and the remaining bending degree-of-freedom, are rigidly coupled with constraint equations. To accommodate crack closure in the nonlinear spring model, a very stiff spring is inserted that is "activated" when the rotations try to become negative.

\subsubsection{Nonlinear Spring Performance}

The nonlinear spring model discussed above was used to design the IPIRG-1 pipe system and inertial loading experiments. Figure 3.6 shows the configuration of the IPIRG-1 cracked pipe inertial loading test facility. In these experiments, a straight pipe with large masses at each end and a crack in the middle is supported at two points near the middle of the span. Load is applied to the crack when the support points are moved vertically. If the frequency of the imposed motion is near the first resonant frequency of the pipe, the inertial masses will oscillate in the vertical plane, and thus load the crack. Figure 3.7 shows a typical applied support displacement for an IPIRG-1 Subtask 1 experiment. Figures 3.8 to 3.10 show a comparison of predictions using the nonlinear spring model and an IPIRG1 inertial loading experiment. Figures 3.11 to 3.16 show the test facility, typical loading, and a comparison of nonlinear spring analysis results and an IPIRG-1 pipe system experiment. The agreement between the analysis and experimental data suggests that the basic cracked section behavior, system dynamics, and flaw-structure interaction have been properly represented.

The model described above is quite simple, and as long as the loading does not take excessively large steps, closed hysterisis loops are traced on unloading and reloading. The primary limitation of the spring-slider representation of the moment-rotation response is that it cannot consider the crack response past maximum load. Consequently, it is not possible to model the behavior of the crack section as a surface crack penetrates the pipe wall and transitions into a through-wall crack, a behavior that is important for analysis of the HDR-E31 experiments.

\subsection{Advancements in the State-Of-The-Art}

The state-of-the-art in dynamic pipe fracture mechanics at the beginning of this program permitted an analyst to calculate the maximum moment and the time required to attain this moment for both surface and through-wall cracks. Energy dissipation, due to cyclic loading of the nonlinear crack prior to initiation, was an inherent part of the time-history analysis. Loading past maximum moment, transition of a surface crack to a through-wall crack, and reinitiation of a crack that has already extended were not possible. Because all of these features were thought to be important for analysis of the HDR-E31 experiments, refinements and enhancements were made to the basic nonlinear spring analysis capability.

\subsubsection{Prediction of Flaw Behavior Past Maximum Moment}

The first refinement of the dynamic nonlinear spring model of cracked pipe that was explored was prediction of flaw behavior past maximum load, including potential flaw instability. The difficulty with making these kind of calculations is that the tangent stiffness of the crack is negative past maximum load, see Figure 3.17. The concept of negative stiffness, i.e., increasing displacement with decreasing load, is somewhat foreign, in that it appears to be a manifestation of perpetual motion; ordinary springs do not generally exhibit this kind of behavior. However, it must be recognized that 
the negative stiffness is local to the crack, because the overall pipe-crack system must have a positive stiffiness or the pipe will be unstable. The spring-slider elements used in IPIRG-1, because they model simple mechanical springs and friction, cannot be used to define a negative local stiffness. Thus, a different model is required to be able to analyze cracked pipe behavior past maximum load.

\subsubsection{Model}

The requirements for a crack model that will permit analysis past maximum load are as follows:

- The ability to model negative local stiffness

- The capability to accommodate unloading into the compressive regime

- Dissipation of energy through kinematic hardening-type plasticity behavior.

At the outset of this program, the plan was to use the nonlinear force-deflection element, STIF39, in ANSYS for modeling cracks past maximum load. This element can use up to $\mathbf{4 0}$ linear segments to describe a nonlinear force-deflection (moment-rotation) response, including portions with negative tangent stiffness. Based on experience with STIF39 in IPIRG-1, the element needed some modifications to meet all of the requirements. Basically, as shown in Figure 3.18, the original STIF39 exhibits a ratcheting phenomenon wherein the moment-rotation curve is reset to the original curve, but with an offset, whenever the element reloads to a positive moment after going below zero moment. Fundamentally, this means that the third requirement for a model for analysis of cracked pipe behavior past maximum load cannot be satisfied. The proposed remedy for the ratcheting-uponreloading problem with STIF39 was to modify the element.

Plans to modify STIF39 to remove the undesirable ratcheting behavior began when the source code for STIF39 was purchased from Swanson Analysis System, Inc. (SASI), the authors of ANSYS. With encouragement from SASI, we were led to believe that the changes were simple, and that we could make them ourselves. Inspection of the source code for STIF39 suggested that the changes needed were more substantial, so modifying STIF39 was abandoned.

Several ideas were proposed to achieve the effect of a modified STIF39 element. The most promising idea was to use the standard kinematic hardening plasticity constitutive law in ANSYS as a vehicle for obtaining the desired behavior, because it can be used to model post-yield behavior. Specifically, rigid offsets from the pipe connected with a plastic pin-connected truss, as shown in Figure 3.19, were proposed for creating the moment-rotation response for a crack. With suitable consideration of the geometry of the offsets and size of the truss, it seemed reasonable that a prescribed nonlinear moment-rotation curve could be converted to an equivalent nonlinear stress-strain curve that ANSYS could inherently use.

Figure 3.20 shows a moment-rotation curve that was modeled as described above, and Figures 3.21 and 3.22 show analysis results for this "element". The "element" traces closed hysterisis loops, it unloads properly below zero moment, it displaces beyond maximum moment, and it unloads and reloads properly even beyond maximum moment. In short, it is the behavior that was sought. The 
only limitation with this approach to crack section modeling is that only five stress-strain segments are permitted.

\subsubsection{Validation}

A critical test of the nonlinear spring element is to see if the element can predict an instability for a simple, quasi-statically loaded pipe in four-point bending, when the moment-rotation response and the system compliance are known. Ideally, the element should also be able to predict bow far the moment would drop if there was a limited crack jump, i.e., the pipe did not break in half.

To make this assessment, five experiments from David Taylor Research Center (DTRC) on 8-inch diameter A106 Grade B pipe have been modeled, Ref. 3.10. The five experiments chosen for this analysis had different crack lengths and test system compliances, but the same pipe material and nominal pipe size. The relevant experimental data are summarized in Table 3.1, while the test system configuration modeled with ANSYS is shown in Figure 3.23.

The objective of the DTRC experiments was to provide data to evaluate the Tada-Paris and Zahoor $\mathrm{J} / \mathrm{T}$ instability analyses. With reference to Figure 3.23, if a crack has a large maximum moment and the belleville springs are relatively soft, the applied load from the pistons will be large and hence, the deflections of the springs will be large. At large spring deflections, there will be a large amount of stored energy in the springs available to drive the crack unstable after maximum load. Less compliance in the test system or lower moment-carrying capacity of the crack tend to enhance stability. The cracks in Experiments 7, 11, and 12 were stable while the cracks in Experiments 13 and 14 were unstable.

Prediction of the DTRC experiments using the post-maximum load feature of the nonlinear FEA fracture analysis is straight forward:

(1) The geometry of the basic pipe system is modeled using ANSYS pipe elements.

(2) A J-estimation scheme analysis is performed to define the moment-rotation response of the crack.

(3) The predicted moment-rotation response of the cracked section is implemented in the ANSYS model using a nonlinear truss.

(4) Dynamic time-history analysis is performed. Any tendency toward instability should be evident in the load-time or load-deflection curves. (It must be noted that dynamic analysis must be used, even though the displacements to load the pipe were applied quasi-statically, because the inertia of the pipe provides a significant restraint to instability, i.e., some of the energy in the springs must be used to accelerate the pipe).

Obviously, the predicted moment-rotation response has a significant influence on crack stability in the analysis of a compliant four-point bend experiment. Therefore, as a preliminary step to actually performing the finite element analyses of the DTRC experiments, a quick check of the quality of the J-estimation scheme predictions was made. Table 3.2 compares the maximum moments for the 
DTRC experiments and the NRCPIPE Version 1.4d predictions made using the LBB.ENG2 Jestimation scheme analysis for a circumferential through-wall crack. Figure 3.24 compares experimental and predicted force-deflection response for the only DTRC experiment with a complete data record in our files, DTRC Experiment 7. From Table 3.2, it is apparent that NRCPIPE does a good job of predicting maximum moments, and from Figure 3.24, it is clear that the load-line displacements and hence, crack rotations are quite good also. (The comparison in Figure 3.24 was the worst of the maximum load predictions in Table 3.2.) The moment-rotation curves for all of the relevant DTRC compliant instability cracks are shown in Figure 3.25. The J-R curve calculated by DTRC from the pipe experiments was used in the LBB.ENG2 analysis.

As indicated previously, crack instability is a function of the compliance of the test system: very stiff (low compliance) test systems tend to be stable, while soft (high compliance) systems promote instability. To determine whether this behavior can be duplicated analytically, several analyses of DTRC Experiment 7 were performed with varying machine stiffnesses. Using the measured stiffness from the experiment, $87,563 \mathrm{~N} / \mathrm{mm}(500,000 \mathrm{lb} / \mathrm{in})$, the finite element analysis predicts complete stability, Figure 3.26. This is consistent with the experimental observation. Reducing the belleville spring stiffness from $87,563 \mathrm{~N} / \mathrm{mm}(500,000 \mathrm{lb} / \mathrm{in})$ to $2,627 \mathrm{~N} / \mathrm{mm}(15,000 \mathrm{lb} / \mathrm{in})$, a crack jump just after maximum load occurs, Figure 3.27. The abrupt drop in applied load for essentially no change in displacement suggests that the crack ran some distance and then arrested. The moment rotation curve in Figure $3.26 \mathrm{~b}$ is identical to Figure $3.27 \mathrm{~b}$, as expected, indicating that the dynamic analysis has not violated the prescribed crack element constitutive relationship and that the predicted equilibrium configuration is valid.

Considering DTRC Experiments 11 through 14 with the measured test machine compliance, all of the dynamic finite element analyses indicate that equilibrium cannot be found after maximum moment. Figure 3.28 illustrates a typical result. Based on the results presented for Experiment 7, the correct interpretation of this is that there is an instability and that it is so severe that the pipes are all predicted to be severed.

Analysis of the DTRC 8-inch nominal diameter A106 Grade B pipe compliant instability tests was concluded by examining the predicted stability of Experiment 7 and Experiments 11 through 13 using the J/T stability analysis method and the Energy Balance stability method. Table 3.3 presents a comparison of the predicted stability using all of the analysis methods and the experimentally observed stability. The prediction of instability for DTRC Experiments 11 and 12 is not consistent with the test observations. With regard to the severity of the instability of the unstable experiments, based on the published report of the DTRC experiments, there are no data concerning how far the crack actually grew when it went unstable. In a conversation with Mr. Richard Hayes who ran the experiments, however, we were told that the magnitude of any instability was artificially limited by stops designed to limit spring extension, probably to keep from throwing the pipe out of the test machine. Thus, there is no way to assess the actual magnitude of instability in the DTRC tests.

Originally, the $\mathrm{J} / \mathrm{T}$ analysis of the DTRC experiments was done using the Tada-Paris $\mathrm{J} / \mathrm{T}$ formulation, Reference 3.11. Unfortunately, this formulation suggested that instability would occur immediately, because at $J_{\text {Ic }}, T_{\text {applied }}$ is greater than $T_{\text {material. }}$. This, of course is nonsensical, because the experiments were conducted under displacement-controlled loading and hence, crack growth is inherently stable at least until maximum load is reached. Efforts to discover an obvious flaw in the 
Tada-Paris formulation were unproductive, so a more recent J/T EPFM analysis by Zahoor was used, Reference 3.12.

The Zahoor EPFM J/T analysis required knowledge of load-displacement-crack growth behavior. Because we did not have the experimental P-\&- $\Delta a$ data, we calculated these values using the LBB.ENG2 option in NRCPIPE using the pipe J-R curve calculated by DTRC. The pipe and C(T) specimen J-R curves were virtually identical, but the pipe J-R curve extends to much larger $\Delta a$ values than the $C(T)$ specimen.

The universal disagreement between all of the predictions and the observed stability for Experiments 11 and 12 raised the issue of the sensitivity of the stability predictions to stiffness changes. The thought was that perhaps the measured stiffnesses were slightly in error, and that this was biasing the predictions. To examine the sensitivity of the stability predictions to stiffiness changes, several hypothetical stiffnesses were considered for Experiment 13.

Figures 3.29 through 3.31 show Energy Balance stability assessments for Experiment 13 at various stiffnesses and Figure 3.32 shows similar results for $\mathrm{J} / \mathrm{T}$ analyses. Table 3.4 compares the experimental and predicted stability results with various stiffinesses using the three stability prediction methods. For Experiment 13, ANSYS predicts imminent stability at a stiffiness of $19,264 \mathrm{~N} / \mathrm{mm}$ $(110,000 \mathrm{lb} / \mathrm{in})$ stiffness, Energy Balance predicts imminent stability at $15,761 \mathrm{~N} / \mathrm{mm}(90,000 \mathrm{lb} / \mathrm{in})$, and the Zahoor $\mathrm{J} / \mathrm{T}$ analysis suggests that stability is imminent at just over $10,508 \mathrm{~N} / \mathrm{mm}(60,000$ $\mathrm{lb} / \mathrm{in})$. The conclusion from this investigation is that slight stiffness measurement errors cannot explain why the stability of Experiments 11 and 12 is incorrectly predicted.

There is no clear explanation for the discrepancies, both in terms of incorrect prediction of some of the DTRC experiments and predicted stiffness changes needed to bring about stability for Experiment 13. Because all of the experiments had the same belleville spring stiffness, however, it is not surprising that the analyses predict Experiments 11 and 12 as unstable, because the predicted momentrotation curves for the stable experiments (see Figure 3.25) are virtually identical to the momentrotation curve for Experiment 13. The root cause of the incorrect prediction of instability for Experiments 11 and 12 is not apparent. To resolve these discrepancies more compliant instability testing will have to be conducted.

\subsubsection{Summary of Analysis of Cracked-Pipe Behavior Beyond Maximum Laad}

The FEA model developed for analysis of cracked-pipe behavior beyond maximum moment is a simple extension of the basic cracked-pipe element developed in the IPIRG-1 program. It incorporates all of the features needed to capture expected crack behavior: the ability to model negative local stiffness, the capability to accommodate unloading into the compressive regime, dissipation of energy through kinematic hardening-type plasticity behavior, and the ability to predict crack instability. Comparison of performance of the post-maximum nonlinear FEA cracked-pipe element predictions with experiments and other prediction methodologies have shown reasonable agreement, although the paucity of data and apparent inconsistencies in the experimental results are problematic. The bounds for use of the element are: (1) it uses standard program capabilities that should be available in any nonlinear finite element program, (2) dynamic analysis must be used so 
that the restraining influence of pipe inertia is included, and (3) the quality of the pipe-flaw system analysis is a direct function of the quality of the J-estimation scheme prediction of the momentrotation behavior.

\subsubsection{Prediction of SC to TWC Transitions}

The second refinement of the basic nonlinear spring model of cracked pipe that was explored was prediction of surface crack to through-wall crack transitions. During loading of a surface crack in a pipe, the surface crack will initiate and propagate radially. Eventually, if the loading continues, the surface crack will penetrate the pipe wall and the crack will become a through-wall crack which can grow in the circumfereatial direction. The transition of the surface crack to a through-wall crack is generally quite abrupt, because surface cracks tend to have a much higher moment capacity than the resulting through-wall cracks, i.e., there is the potential for unstable crack growth during the transition. Ideally, a nonlinear FEA dynamic cracked-pipe analysis should be able to address the following:

- Whether or not the surface crack penetrates the pipe wall

- How far the through-wall crack propagates when we surface crack penetrates the pipe wall

- Whether the resulting through-wall crack propagates during subsequent loading.

Prediction of this type of behavior can be obtained using refinements of the previously discussed spring-slider and nonlinear-truss models.

\subsubsection{Model}

The first and last issues identified above can be addressed with the analysis tools already discussed. A spring-slider model of a surface crack inherently permits one to determine if the surface crack reaches maximum load. The nonlinear-truss model, because it can be used for analysis past maximum load, can be used for predicting both the occurrence of maximum load and crack propagation behavior.

Several concepts for modeling surface-crack to through-wall-crack transitions were explored. These included:

- Multiple parallel nonlinear trusses with a break-away element. In this model, the surface-crack moment-rotation response is modeled with one nonlinear-truss element and the through-wall crack is modeled with another. The transition from surface crack to through-wall crack occurs when a break-away element in series with the surface crack element reaches a prescribed break-away force. Figure 3.33 shows a schematic of this model. 
- Spring-sliders and a break-away element in parallel with a nonlinear truss. This model uses three spring-sliders in parallel to model the basic surface-crack behavior while a nonlinear truss models the through-wall crack. A break-away element "removes" the spring-sliders from the analysis when the surface-crack maximum moment is reached. Figure 3.34 shows a schematic of this crack model.

The results of analyses with the models described above were successful in that surface-crack to through-wall crack transitions could be analytically modeled. The results were somewhat disappointing, however, in that none of the crack models was as convergent as desired. Specifically, if the load on any of the crack models was increased too rapidly, in many cases the break-away element would "break" prematurely. Replacing a force-based break-away feature (ANSYS STIF40, Combination Element) with a displacement-based break-away feature (ANSYS STIF37, Control Element) did not improve the convergence.

After some further investigation, the most successful approach to modeling surface to through-wall crack transitions was found to be the spring-slider with one nonlinear-truss model as shown in Figure 3.34. The crack "element" is actually an assembly of ANSYS elements that give the desired effect. The surface crack is modeled as in the IPIRG-1 program with ANSYS spring-slider elements. Using three spring-slider elements in parallel with appropriately selected stiffnesses and slide forces, one can model the moment-rotation of the surface crack up to the point of maximum moment. The throughwall crack is modeled with a plastic truss connected by rigid links to the pipe. By suitable definition of the nonlinear stress-strain curve for the truss, a through-wall-crack moment-rotation behavior that extends beyond maximum moment can be described. The transition from surface crack to throughwall crack is accomplished using a break-away element. Basically, when the maximum surface-crack moment is achieved, the break-away element takes the surface crack out of the analysis leaving the through-wall crack element.

In theory, one should be able to set the break-aw ay element maximum load to the maximum surfacecrack moment and have everything behave properly. In practice, however, the break-away feature has a propensity to "break" prematurely. Therefore, the procedure that had to be adopted for conducting surface-crack to through-wall-crack transition analyses is as follows:

(1) Set the maximum force of the break-away element to a high value.

(2) Conduct the dynamic analysis and note when the maximum surface-crack moment is achieved.

(3) Restart the analysis at the time step of maximum moment of the surface crack with the correct break-away force in the break-away element. This will "remove" the surface crack from the subsequent load steps.

This procedure, when implemented, works very well. It is not particularly elegant or easy to use, but it is effective. One must be careful when assigning stiffnesses to be certain that all series and parallel springs have been properly considered, otherwise the structure will be too stiff. 
A final note here is that the above procedure works well as long as the through-wall-crack curve is below the surface-crack curve. For very deep and short cracks, the converse can be true (Ref. 3.13 and 3.14), but the current J-estimation schemes cannot predict these cases.

\subsubsection{Validation}

Verification of the surface-crack to through-wall-crack transition element was performed by analyzing one of the IPIRG-1 pipe system test experiments, Ref. 3.1. Specifically, IPIRG-1 Experiment 1.3-7 was analyzed:

- Nominal 16-inch diameter, Sch 100 pipe

- Aged cast stainless steel material

- Initial surface crack: 53 percent deep, 50 percent around the circumference

- $\quad$ Pipe system at PWR conditions, $288 \mathrm{C}$ (550 F) and 15.51 MPa (2,250 psi)

- Growing amplitude sinusoidal excitation.

Figure 3.11 shows a schematic of the IPIRG pipe system, while Figure 3.12 shows its dimensions. The measured forcing function for Experiment 1.3-7 is shown in Figure 3.35.

The input for the crack response for Experiment 1.3-7 consisted of the spring stiffnesses, slide forces, stress-strain curve for the plastic truss, and the associated geometry. These data were generated from J-estimation scheme analyses of the surface crack (SC.TNP) and through-wall crack (LBB.ENG2). Using laboratory specimen J-R and stress-strain data, the J-estimation schemes predict the momentrotation response of the surface crack and resulting through-wall crack to be as shown in Figure 3.36.

Figure 3.37 shows a comparison of the predicted and measured moment-time response at the crack. (The experimental data after 4 seconds are not valid). To the point of maximum moment, the prediction agrees very well with the experiment. The prediction also is quite good during the surface crack to through-wall crack transition. In fact, the analysis properly predicts the first small cyclic load increase after maximum moment. When the through-wall-crack reaches its first positive peak in load, the prediction is also good. In subsequent cycles of loading, however, the prediction shows the crack always attaining a positive moment of about $113 \mathrm{kN}-\mathrm{m}\left(1.0 \times 10^{6} \mathrm{in}-\mathrm{lb}\right)$, while the experiment shows a progressive decrease in peak moment up to about 4 seconds. The predicted behavior is counter intuitive, because as the through-wall crack grows to maximum load on any given cycle, we expect the peak attainable moment to progressively drop off under continued cyclic loading.

To understand the predicted behavior after maximum moment, one need only look at the momentrotation response, Figure 3.38. The predicted through-wall-crack behavior represents classical kinematic hardening, as can be seen in the hysterisis loops that are traced. In a case where there is a stress-strain curve that softens after maximum load, as is the case with our crack model, the kinematic hardening flow rule prescription that the next yield always occurs at $2 \sigma_{y}$ above or below a change in loading direction increases the moment capacity of the crack as it gets to larger and larger cyclic 
rotations. There is no simple remedy for this anomalous behavior, because it is inherent to the kinematic hardening model. The net result of this limitation is that thirough-wall-crack growth after a surface to through-wall-crack transition can be predicted only for the first through-wall loading cycle.

\subsubsection{Summary of Dynamic Surface to Through-wall Crack Transition Behavior}

The analyses discussed indicate that the procedures and elements used to model the crack are quite reasonabic. As a pioneering effort, the results suggest that it is possible to predict dynamic pipe fracture, including the surface to through-wall-crack transition, with better than "good enough" accuracy. Although there still is room for improvement, particularly in the way of defining a new hardening rule for cyclic through-wall-crack growth, a primary concern for design, the propensity for a DEGB, can be addressed with this analysis. Within the context of the HDR-E31 analyses, the approach used here is all that is required because only one large load cycle is expected.

\subsubsection{Cyclic Loading with Reinitiation}

The third refinement of dynamic, nonlinear, cracked-pipe analysis that was examined in this program was the behavior of through-wall cracks under cyclic loading. Up to the time when the validation analyses for the surface-crack to through-wall-crack transitions were being conducted, no systematic consideration of analytical prediction of cyclic ductile tearing had been undertaken. The observation from experiments with through-wall cracks that were unloaded and reloaded several times is that there should be a continuous degradation of maximum moment-carrying capacity with each increment of crack growth. As described above, the kinematic hardening flow rule behavior is inconsistent with this observation.

\subsubsection{Model}

Two technical features dominate modeling of cyclic ductile tearing episodes:

- A methodology to predict the moment-rotation curve of a crack that has previously been extended

- Behavior of the crack when it is unloaded into the compressive regime.

The first feature must be addressed in such a fashion that the model incorporates progressive degradation of maximum moment-carrying capacity and increasing elastic compliance with increasing crack size. The second feature must incorporate only crack section yielding (no crack growth) and crack closure during compressive loading.

Because of the limitations of standard plasticity flow rules (isotropic hardening, kinematic hardening, etc.), reinitiation of previously extended cracks cannot be handled automatically by finite element programs; the programs continue to refer back to the original input curve behavior. Rather, multiple restarts with new through-wall-crack moment-rotation curves have to be used. Basically when a through-wall crack is reloaded, a new moment-rotation curve must be defined that is based on the 
amount of crack growth attained in the previous loading cycle. Implementing this process is quite straight forward, but it is somewhat cumbersome.

As a part of developing this analysis procedure, a rational basis for generating the new momentrotation curve had to be defined. Several ideas were explored before a satisfactory one was found. The first idea that was tested, and the simplest one, used the NRCPIPE J-estimation scheme with the original stress-strain curve and the original J-R curve, but with an updated crack length. The results of this analysis produced maximum moments in the longer crack that were substantially below the noment at which the original crack was unloaded. Based on IPIRG-1 program, Ref. 3.15, results for inrough-wall cracks that were unloaded and subsequently reloaded, the maximum moment upon reloading should be almost the same as the moment at unloading.

The second idea assumed that as the crack gets longer, $J_{i}$ is raised to the value of $J_{\text {applied }}$ before unloading. This assumption satisfies the requirement that the reloaded maximum moment be approximately equal to the moment at unloading. Furthermore, the moment-rotation response after maximum moment for the longer crack is identical to the original moment-rotation curve. Figure 3.39 illustrates the results from using the two different procedures for considering crack growth. The modified length with modified J-R curve is the one that makes the most sense.

The issue of the compressive loading behavior of a cyclically loaded through-wall crack is important, because hysterisis loops traced during unloading of a through-wall crack appear to the pipe system as damping. As a consequence, the shape of the moment-rotation response of a through-wall crack when it unloads will influence the pipe system dynamics, and indirectly, the propensity of the through-wall crack to grow.

The dynamic analysis model discussed in Section 3.2.2 used a kinematic hardening model, with the compressive region being a mirror image of the tensile region. As presented in the discussion of surface-crack to through-wall-crack transition, the kinematic model exhibits an anomaly when one operates out at large rotations where the tangent stiffness is negative: on unloading, the reflected tensile moment-rotation curve goes through a minimum and then moments become more positive, see Figure 3.40. In fact, in the compressive region, the kinematic model implies some sort of "crack growth" behavior, which is not appropriate. What is needed to correct these deficiencies is a moment-rotation response that has distinctly defined tension and compressive moment-rotation curves and some sort of flow rule.

A simple engineering model for pipe crack unloading has been hypothesized to behave as follows:

- The unloading stiffness is equal to the elastic stiffness at the crack length when the crack is unloaded. This implies that if a crack has grown, it will unload with a stiffness less than the elastic stiffness of the crack before it grew. Conversely, if a crack has not grown, it will unload with the initial elastic stiffness.

- The behavior of a crack during unloading is governed only by material stress-strain response and crack size until crack closure occurs. This implies that $\mathrm{J}$ plays no role and that the crack location appears to the remainder of the pipe system as a yielding pipe 
section with reduced wall thickness. When crack closure occurs, the crack location must behave like competent pipe.

- A simple flow rule is postulated: the crack unloads elastically to zero moment, then loads in compression following the moment-rotation response consistent with the nonlinear stress-strain curve as shown in Figure 3.41.

To implement the proposed crack unloading model, the nonlinear FEA cracked-pipe analysis and the NRCPIPE through-wall-crack J-estimation scheme analysis are used as follows:

(1) Conduct a dynamic nonlinear FEA cracked-pipe analysis with a prescribed through-wallcrack moment-rotation response.

(2) At the point of crack unloading, determine the amount of crack growth and save restart files for the dynamic analysis.

(3) At the given amount of through-wall-crack growth, conduct an NRCPIPE through-wallcrack analysis with the new crack length and $J_{i}$ set very high. This has the effect of suppressing crack growth in the analysis, so that only material stress-strain nonlinearity is considered.

(4) At the given amount of through-wall-crack growth, conduct an NRCPIPE through-wallcrack analysis with the new crack length and $J_{i}$ set to the value attained when the crack unloaded. This basically implements the change in compliance caused by the longer crack while retaining the correct moment-rotation response when the crack reinitiates.

(5) Restart the dynamic cracked-pipe analysis with new material properties. The tensile part of the moment-rotation curve comes from Step 4 and the compressive part comes from Step 3.

(6) Recycle to Step 1, as needed.

This model addresses the deficiencies of the kinematic hardening model and increases the quality of dynamic predictions past maximum load.

\subsubsection{Validation}

To test the proposed crack unloading model described above, IPIRG-1 cyclic $R=-1$ through-wallcracked pipe data were used, Ref. 3.15. IPIRG-1 Experiment 1.2-4 was a nominal 6-inch, Schedule 120, A106 Gr B carbon steel pipe loaded quasi-statically in four-point bending under displacementcontrol. The resulting cyclic moment-rotation response is shown in Figure 3.42.

Using the measured crack growth and quasi-static stress-strain properties, the unloading model, as described above, predicts the performance shown in Figure 3.43 for several selected loading cycles. As an alternative to using the measured crack growth data, a J-estimation scheme prediction of crack growth can be utilized. To make the comparison as meaningful as possible, the J-estimation scheme 
(LBB.ENG2) used the J-R curve calculated from the experimental load-displacement and crack growth record. The unloading response for this case is shown in Figure 3.44. The differences between Figure 3.43 and 3.44 exist because the crack length at a given rotation is predicted to be shorter by the J-estimation scheme than was observed in the experiment, see Table 3.5.

\subsubsection{Summary of Analytical Cyclic Loading with Reinitiation}

The crack growth and unloading model described above appears to work reasonably well, in that it agrees fairly well with the limited $R=-1$ pipe test data that are available, and it certainly gets rid of the objectionable behavior of the kinematic hardening model. As a first approximation of a very complex problem, the model is judged be to quite acceptable for engineering applications. There are certainly other issues that could be explored to refine the model such as the impact of cyclic stressstrain behavior, and comparison with other experimental data. These will have to wait until a data base of high temperature cyclic stress-strain data and companion cyclic $R=-1$ pipe test data become available.

\subsection{Summary of Analysis Methodology}

The state-of-the-art in dynamic fracture mechanics at the beginning of this program was advanced to the point that an analyst could calculate the maximum moment and the time required to attain this moment for both surface and through-wall cracks. Energy dissipation, due to cyclic loading of the nonlinear crack prior to initiation, was an inherent part of the time-history analysis. Loading past maximum moment, transition of a surface crack to a through-wall crack, and reinitiation of a crack that had already extended were not possible. Through exploration of the limitations of the available tools within the ANSYS finite element program and with an emphasis on engineering solutions, the boundary of the state-of-the-art has been moved outward to include these new features. Although none of the new features has been fully validated, there is ample justification for their use in research situations, based on the favorable comparison of predictions with experimental data. Although the main intent of the ANL-Battelle HDR program was not to develop analysis tools, these modest pioneering efforts are significant and permit better prediction of the HDR-E31 experiments.

\subsection{References}

3.1 R. A. Schmidt, G. M. Wilkowski, and M. Mayfield, "The International Piping Integrity Research Group (IPIRG) Program-An Overview", SMiRT-11 Proceedings, August 1991, Paper G23/1.

3.2 Olson, R., Scott, F., and Wilkowski, G., "Application of a Nonlinear Spring Element to Analysis of Circumferentially Cracked Pipe Under Dynamic Loading", in Pressure Vessel Fracture, Fatigue, and Life Management, ASME PVP Vol. 233, June 1992, pp. 279-292. 
3.3 Griesbach, T. J., "Dynamic Elastic-Plastic Behavior of Circumferential Cracks in a Pipe Subject to Seismic Loading", ASME, Paper 80-C2/PVP-151, April 1980.

3.4 Brust, F. W., "Approximate Methods for Fracture Analyses of Through-Wall Cracked Pipes". NRC Topical Report by Battelle Columbus Division, NUREG/CR-4853, February 1987.

3.5 Gilles, P., and Brust, F. W., "Approximate Methods for Fracture Analysis of Tubular Members Subjected to Combined Tensile and Bending Loads", ASME 8th OMAE Conference, The Hague, Netherlands, March 1989.

3.6 Kumar, V., and German, M. D., "Elastic-Plastic Fracture Analysis of Through-Wall and Surface Flaws in Cylinders", EPRI report NP-5596, January 1988.

3.7 Klecker, R., Brust, F., and Wilkowski, G., "NRC Leak-Before-Break (LBB.NRC) Analysis Method for Circumferentially Through-Wall-Cracked Pipe Under Axial Plus Bending Loads", NUREG/CR-4572, BMI-2134, May 1986.

3.8 Scott, P. M., and Ahmad, J. A., "Experimental and Analytical Assessment of Circumferentially Surface-Cracked Pipes Under Bending", NUREG/CR-4872, April 1972.

3.9 Brouchard, J., Petit, M., and Millard, A., "A Special Cracked Pipe Element for Leak Before break Application", Transactions of 10th SMiRT, Vol. G, pp. 357-362, August 1989.

3.10 Vassilaros, M. G., et al, "J-Integral Testing Instability Analysis for 8-Inch-Diameter ASTM A106 Steel Pipe", U.S. David W. Taylor Naval Ship Research and Development Laboratory, NUREG/CR-2347, April 1984.

3.11 Paris, P. C. and Tada, H., "The Application of Fracture Proof Design Methods Using Tearing Instability Theory to Nuclear Piping Postulating Circumferential Through-Wall Cracks", NUREG/CR-3464, September 1983.

3.12 Zahoor, A., "Ductile Fracture Handbook, Volume 1 - Section 5.10: Applied Tearing Modulus, Bending Moment, Displacement Control, EPFM", EPRI Report NP-6301-D, June 1989, pp. 551 to $5-60$.

3.13 G. M. Wilkowski and R. J. Eiber, "Evaluation of Tensile Failure of Girth Weld Repair Grooves in Pipe Subjected to Offshore Laying Stresses", ASME Journal of Energy Technology, March, 1981, pp. 48-57.

3.14 Shibata, K., Yasuda, Y., Onizawa, K., and Miyazono, S., "Evaluation of JAERI's Ductile Fracture Test Results on Stainless Steel and Carbon Steel Piping", in Nuclear Engineering and Design, 111 (1989), 1, pp. 135-146.

3.15 G. Wilkowski, P. Vieth, G. Kramer, C. Marschall, and M. Landow, "Results of SeparateEffects Pipe Fracture Experiments", Post-SMiRT-11 Conference, August 1991, Paper 4.2. 
Table 3.1 Test matrix for instability assessments of A106 steel pipes subjected to four-point bending

\begin{tabular}{|c|c|c|c|c|c|c|}
\hline $\begin{array}{c}\text { DTRC Pipe } \\
\text { Experiment } \\
\text { No. }\end{array}$ & $\begin{array}{c}\text { Pipe } \\
\text { Length, } \\
\mathbf{m m}\end{array}$ & $\begin{array}{c}\text { Mean } \\
\text { Radius, } \\
\text { mm* }\end{array}$ & $\begin{array}{c}\text { Mean } \\
\text { Thickness, } \\
\text { mm* }\end{array}$ & $\begin{array}{c}\text { Initial } \\
\text { Crack } \\
\text { Length (2a), } \\
\text { mm* }\end{array}$ & $\begin{array}{c}\text { Moment } \\
\text { Arm } \\
\text { Length } \\
\text { (span), } \\
\text { mm** }\end{array}$ & $\begin{array}{c}\text { Total } \\
\text { Machine } \\
\text { Stifness, } \\
\text { N/mm }\end{array}$ \\
\hline 7 & 1219 & 102 & 13.7 & 210 & 457 & 87,550 \\
\hline 11 & 1067 & 102 & 15.2 & 160 & 381 & 6,480 \\
\hline 12 & 1067 & 102 & 13.9 & 149 & 381 & 6,480 \\
\hline 13 & 1067 & 103 & 13.4 & 138 & 381 & 6,340 \\
\hline 14 & 1067 & 103 & 14.6 & 124 & 381 & 6,480 \\
\hline
\end{tabular}

* $25.4 \mathrm{~mm}=1.0$ inch.

** $0.17513 \mathrm{~N} / \mathrm{mm}=1.0 \mathrm{lb} / \mathrm{in}$.

Table 3.2 Comparison of experimental and predicted maximum moments

\begin{tabular}{|c|c|c|c|}
\hline \multirow{2}{*}{$\begin{array}{c}\text { DTRC } \\
\text { Experiment }\end{array}$} & \multicolumn{2}{|c|}{$\begin{array}{c}\text { Maximum Moment, } \\
\text { kN-m* }\end{array}$} & \multirow[b]{2}{*}{ LBB.ENG2/Actual } \\
\hline & Actual & LBB.ENG2 & \\
\hline 7 & 95.38 & 87.92 & 0.92 \\
\hline 11 & 127.10 & 131.80 & 1.04 \\
\hline 12 & 132.19 & 129.59 & 0.98 \\
\hline 13 & 138.72 & 133.19 & 0.96 \\
\hline 14 & 153.37 & 155.60 & 1.01 \\
\hline
\end{tabular}

* $1.0 \mathrm{kN}-\mathrm{m}=8,851 \mathrm{in}-\mathrm{lb}$. 
Table 3.3 Stability comparison for DTRC compliant instability experiments

\begin{tabular}{|c|c|c|c|c|c|}
\hline $\begin{array}{c}\text { DTRC } \\
\text { Experiment }\end{array}$ & $\begin{array}{l}\text { Spring } \\
\text { Stifrness, } \\
\mathbf{N}^{\prime} \mathbf{m m}^{(0)}\end{array}$ & Experiment & ANSYS & $\begin{array}{l}\text { Energy } \\
\text { Balance }\end{array}$ & $\begin{array}{c}\text { Zahoor } \\
\text { EPFM J/T }\end{array}$ \\
\hline 7 & 87,563 & stable & stable & stable & stable \\
\hline 11 & 6,480 & stable & unstable ${ }^{(b)}$ & unstable ${ }^{(b)}$ & unstable \\
\hline 12 & 6,480 & stable & unstable ${ }^{(b)}$ & unstable ${ }^{(b)}$ & unstable \\
\hline 13 & 6,340 & unstable & unstable & unstable & unstable \\
\hline 14 & 6,480 & unstable & unstable ${ }^{(b)}$ & unstable ${ }^{(b)}$ & unstable \\
\hline
\end{tabular}

(a) $0.17513 \mathrm{~N} / \mathrm{mm}=1.0 \mathrm{lb} / \mathrm{in}$.

(b) Although not analyzed, these experiments are almost certainly unstable due to similarity with Experiment 13.

Table 3.4 Stability comparison for DTRC compliant instability Experiment 13 with various hypothetical stiffnesses

\begin{tabular}{|c|c|c|c|c|}
\hline $\begin{array}{c}\text { Spring } \\
\text { Stiffness } \\
\text { N/mm }\end{array}$ & Experiment & ANSYS & $\begin{array}{c}\text { Energy } \\
\text { Balance }\end{array}$ & $\begin{array}{c}\text { Zahoor } \\
\text { EPFM J/T }\end{array}$ \\
\hline 6,340 & unstable & unstable & unstable & unstable \\
\hline $10,508^{(\mathrm{b})}$ & - & unstable & unstable & stable \\
\hline $12,959^{(\mathrm{b})}$ & - & unstable & $\begin{array}{c}\text { unstable } \\
\text { (limited) }\end{array}$ & stable \\
\hline $15,761^{(\mathrm{b})}$ & - & $\begin{array}{c}\text { unstable } \\
\text { limited })^{(\text {limile }}\end{array}$ & stable & stable \\
\hline $19,264^{(\mathrm{b})}$ & - & stable $^{(\mathrm{d})}$ & stable & stable \\
\hline
\end{tabular}

(a) $0.17513 \mathrm{~N} / \mathrm{mm}=1.0 \mathrm{lb} / \mathrm{in}$.

(b) Not used in experiment.

(c) Although not analyzed, these experiments almost certainly unstable based on comparison with higher stiffness analyses.

(d) Not analyzed, but almost certainly stable based on other Experiment 13 predictions. 
Table 3.5 Crack size data for unloading stiffness calculations

\begin{tabular}{|c|c|c|c|}
\hline \multirow{2}{*}{ Loading Cycle } & $\begin{array}{c}\text { Crack } \\
\text { Rotation } \\
\text { (radians) }\end{array}$ & \multicolumn{2}{|c|}{$\begin{array}{c}\text { Crack Length } \\
(\theta / \pi)\end{array}$} \\
\cline { 3 - 4 } & & Experiment & $\begin{array}{c}\text { J-Estimation } \\
\text { Scheme }\end{array}$ \\
\hline 14 & 0.01073 & 0.405 & 0.380 \\
\hline 20 & 0.02784 & 0.530 & 0.461 \\
\hline 26 & 0.04120 & 0.622 & 0.516 \\
\hline 37 & 0.05541 & 0.746 & 0.576 \\
\hline
\end{tabular}




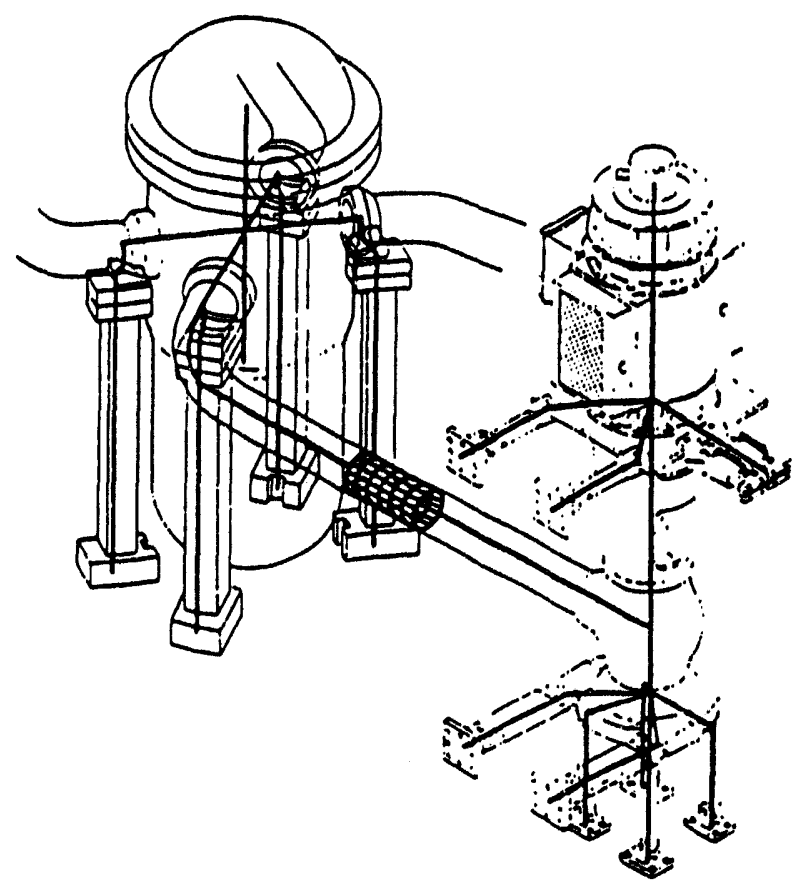

Figure 3.1 Cracked pipe analysis beam and shell piping system model of Griesbach, Ref. 3.3

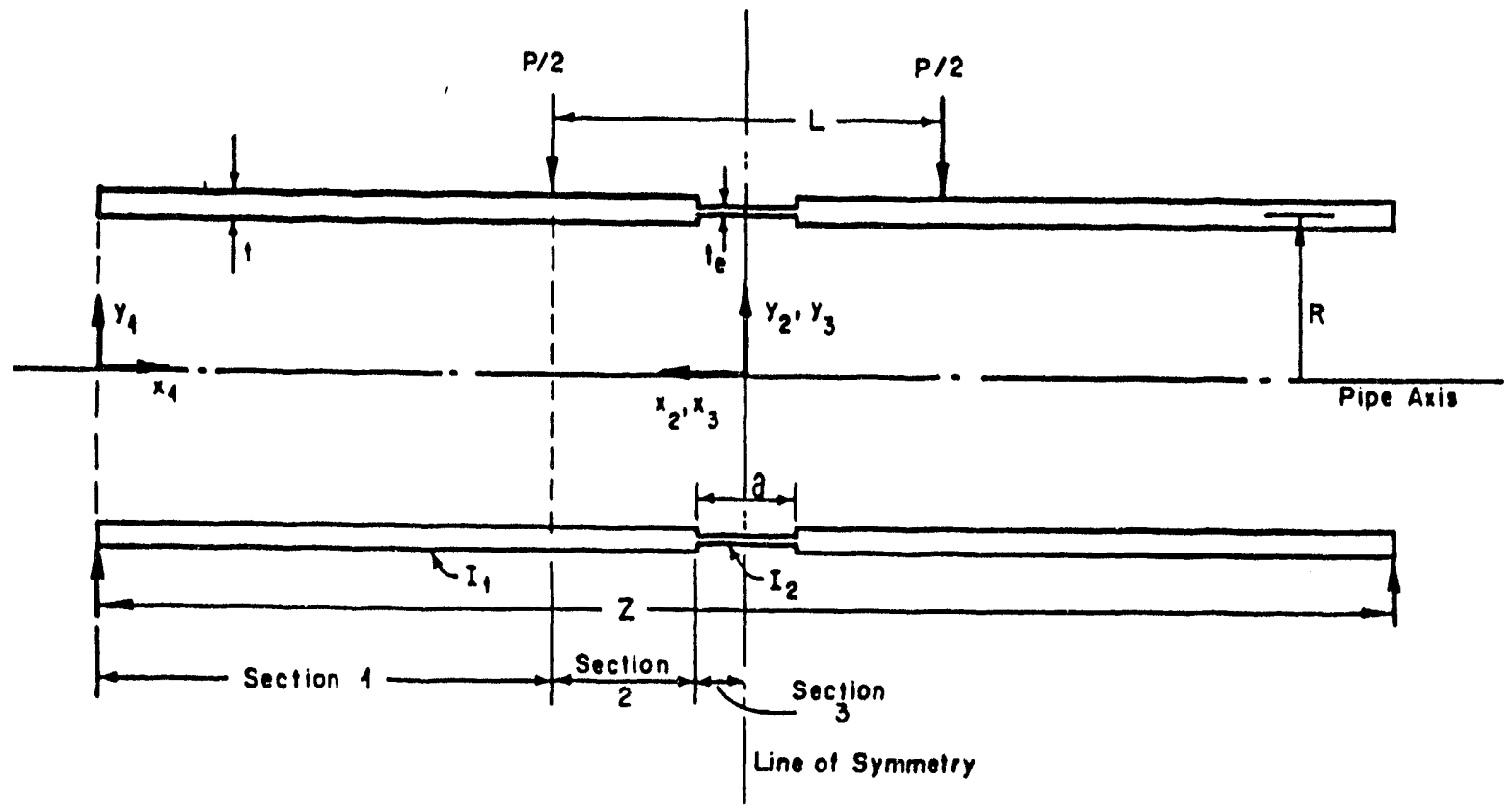

Figure 3.2 LBB.ENG reduced section for modeling cracked pipe response 

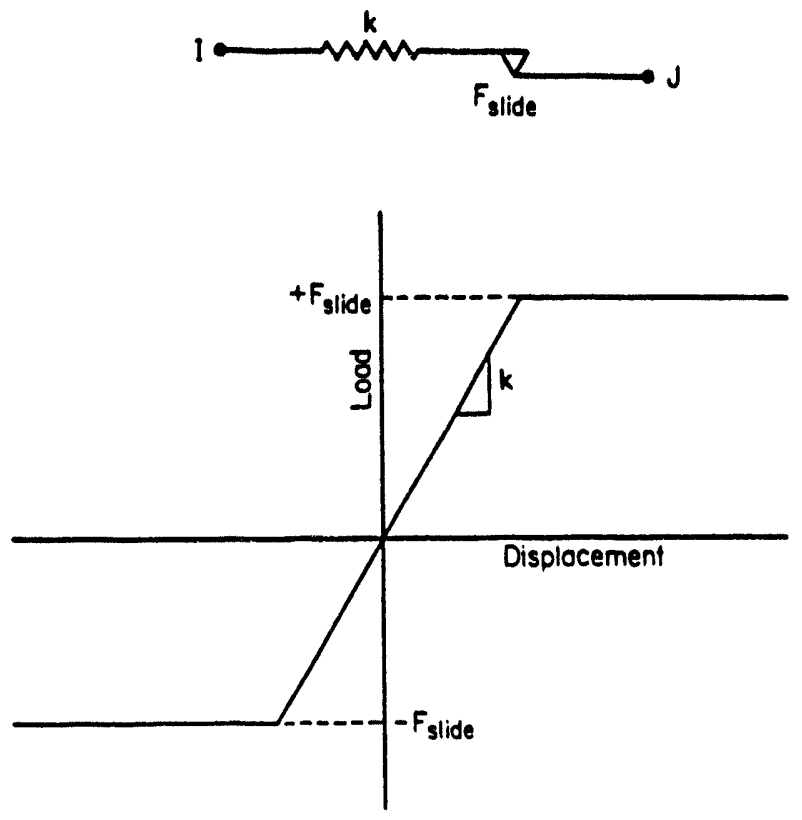

Figure 3.3 Basic spring-slider element
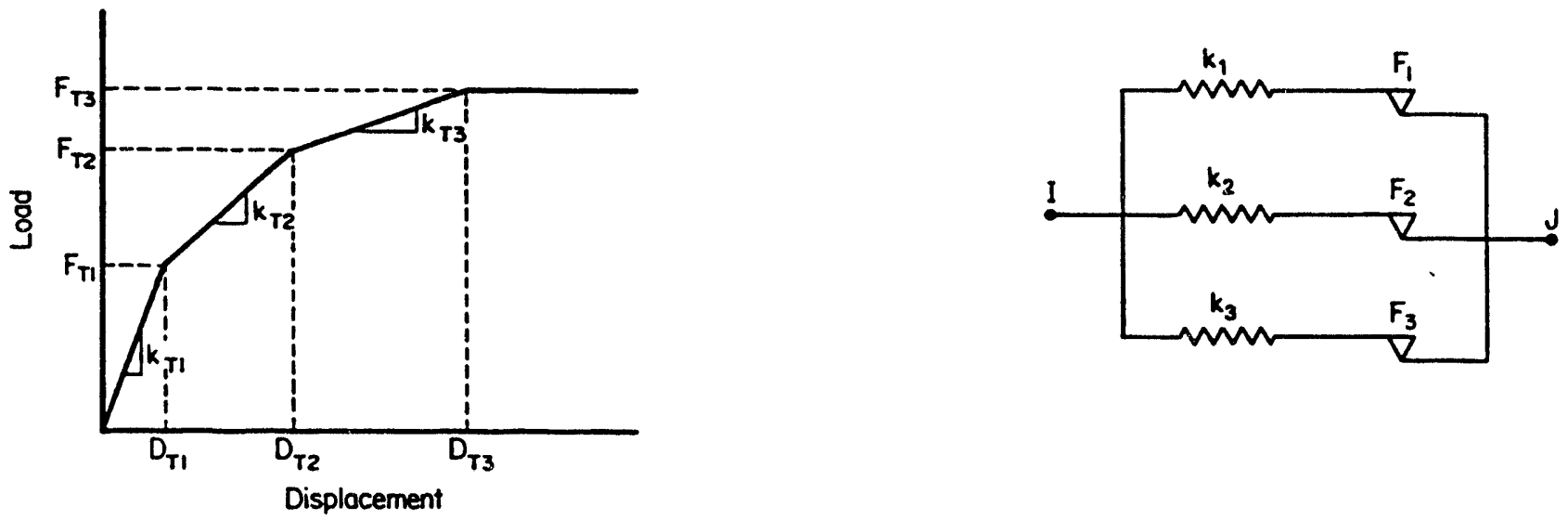

$$
\begin{array}{ll}
k_{1}+k_{2}+k_{3}=k_{T 1} & F_{1}+\left(k_{2}+k_{3}\right) D_{T 1}=F_{T 1} \\
k_{2}+k_{3}=k_{T 2} & F_{1}+F_{2}+k_{3} D_{T 2}=F_{T 2} \\
k_{3}=k_{T 3} & F_{1}+F_{2}+F_{3}=F_{T 3}
\end{array}
$$

Figure 3.4 Modeling of a multi-linear load-displacement curve with spring slider elements 


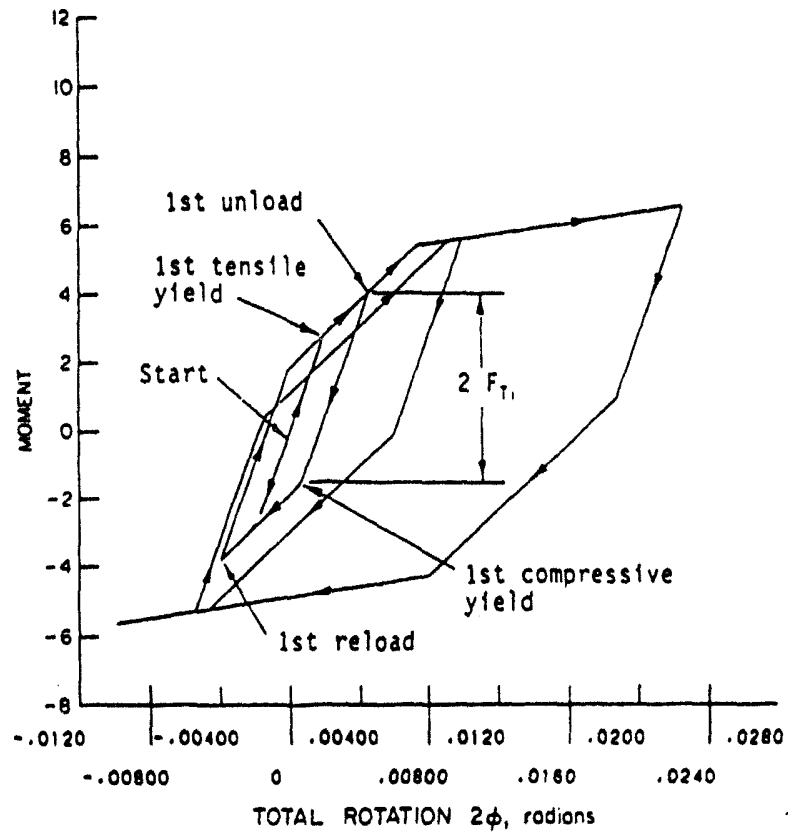

Figure 3.5 Spring-slider model of a crack under reversed loading without crack closure

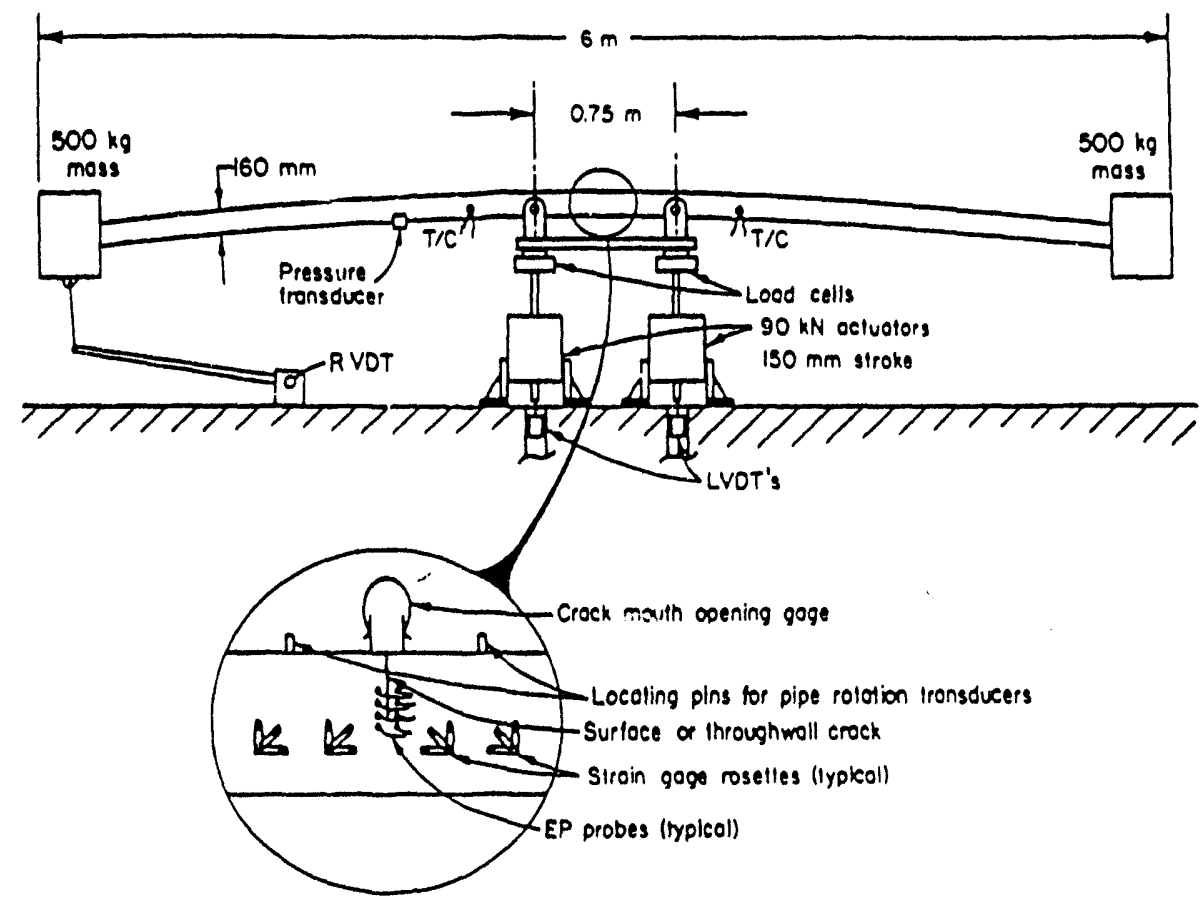

Figure 3.6 IPIRG-1 Subtask 1.1 inertial loading cracked pipe experimental facility 


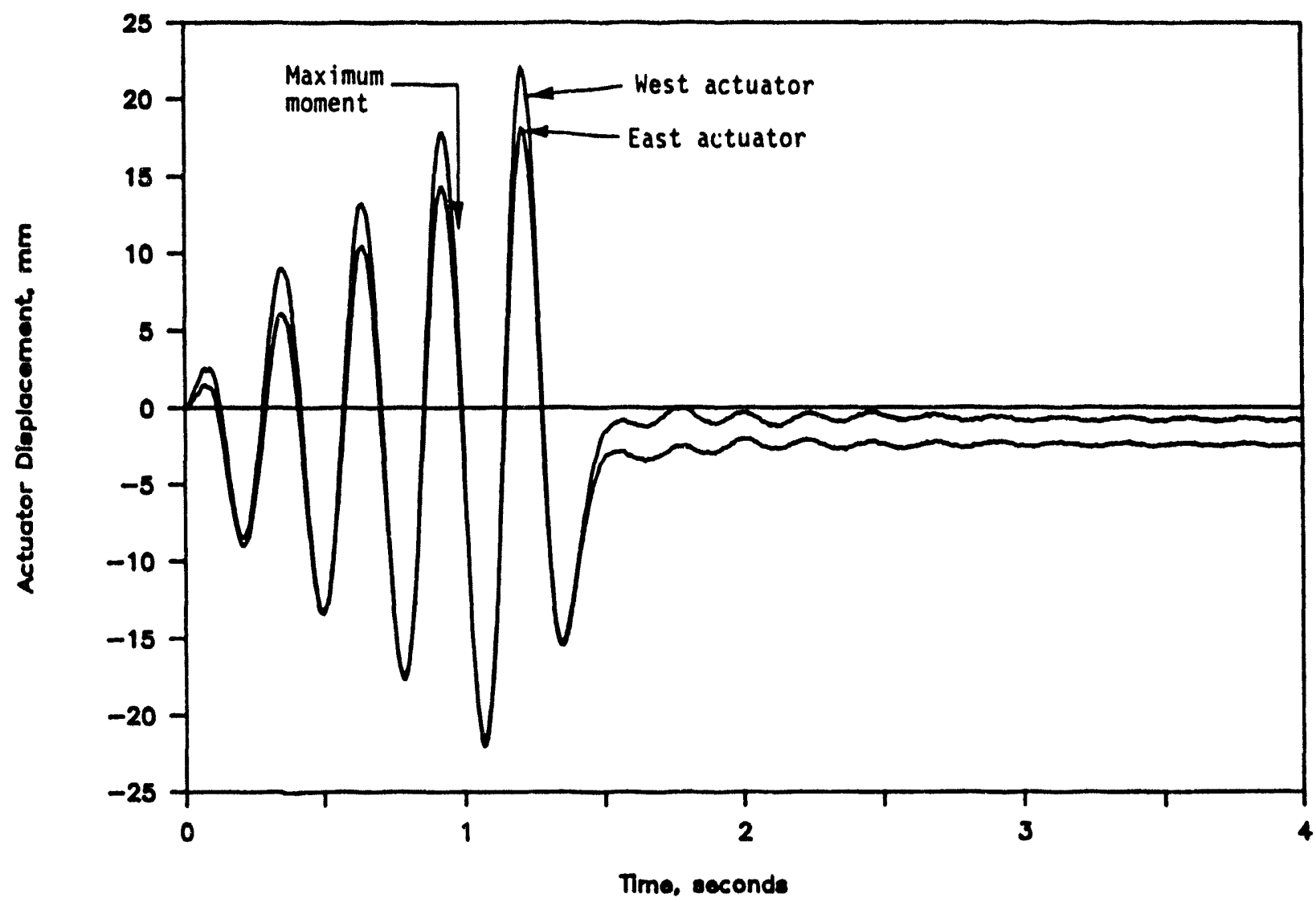

Figure 3.7 IPIRG-1 Experiment 1.1-3 forcing function 


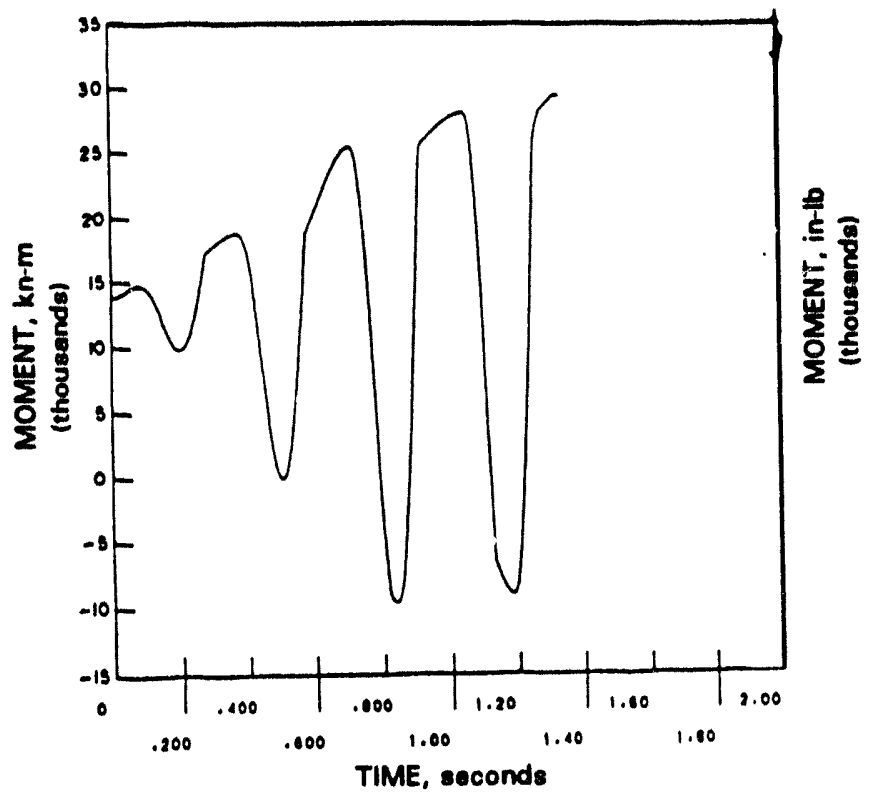

(a) Moment-time from analysis

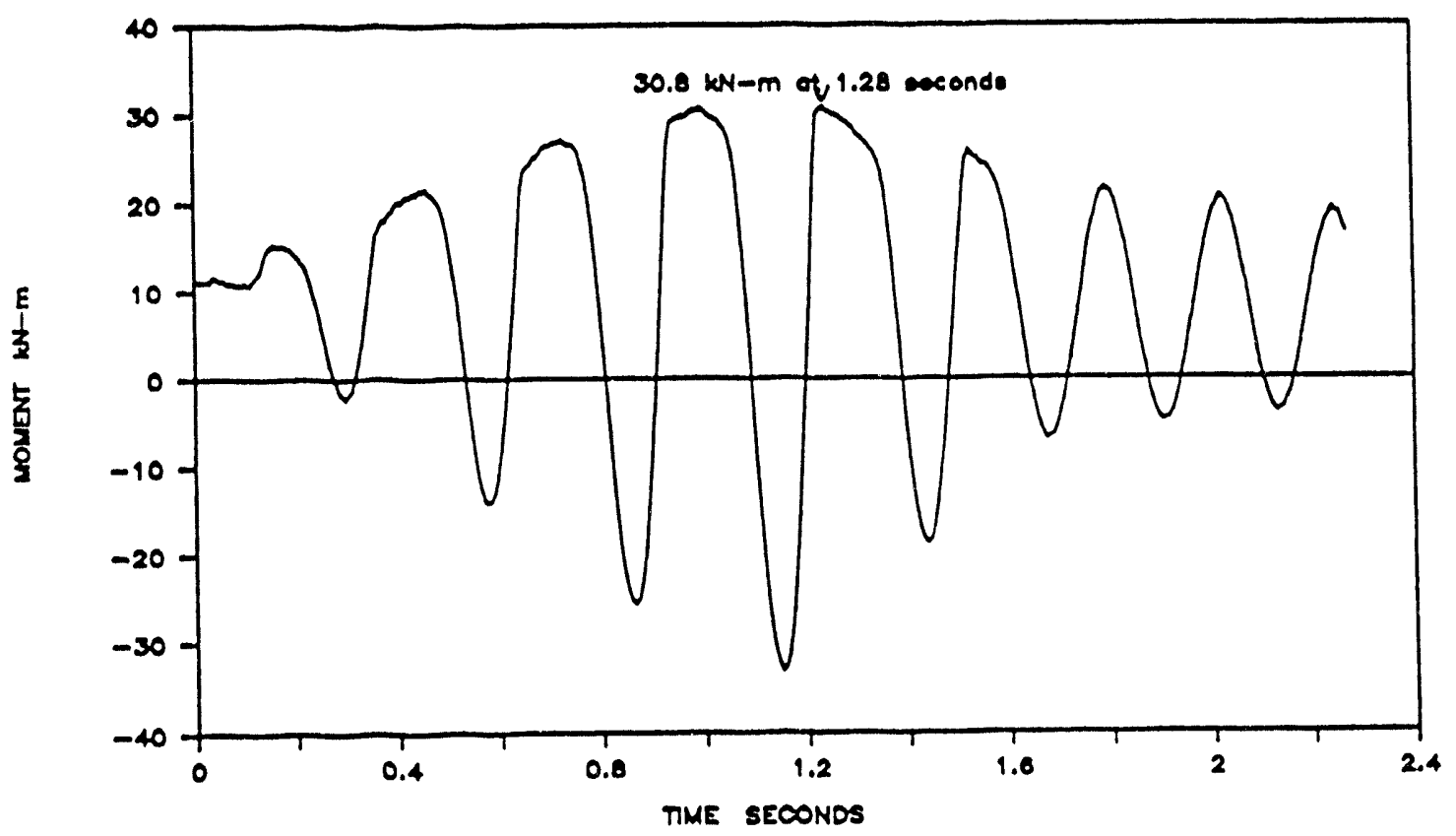

(b) Moment-time from experiment

Figure 3.8 Comparison of experiment and pretest design analysis for moment versus time for IPIRG-1 Experiment 1.1-3 inertially loaded stainless steel through-wall crack (analysis valid only up to maximum moment) 


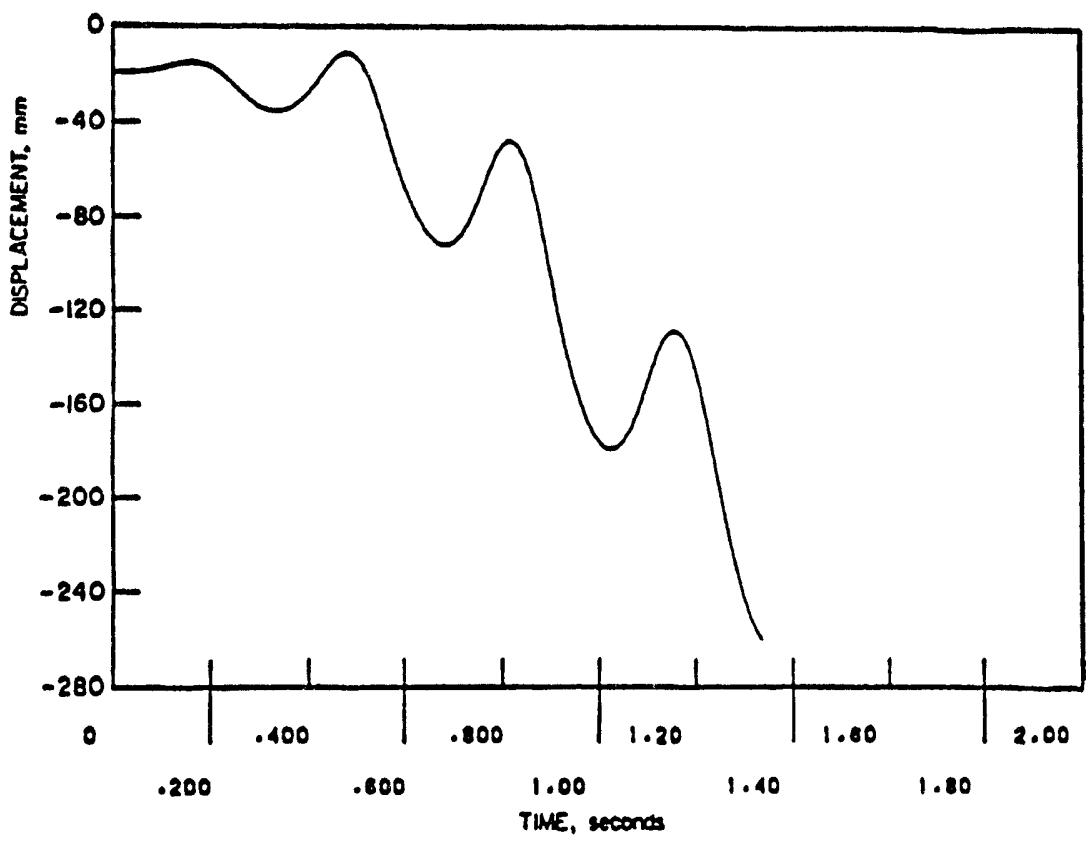

(a) Inertial mass displacement from analysis

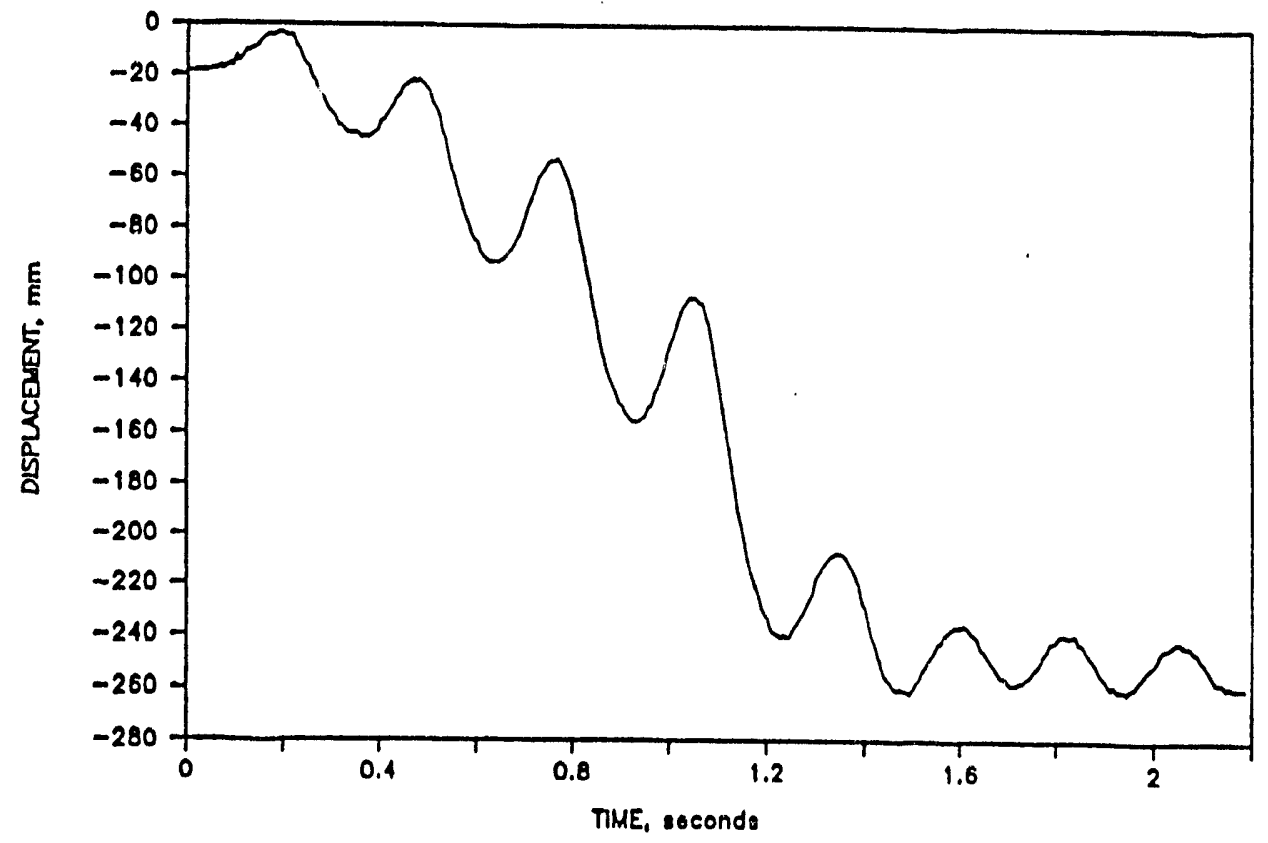

(b) Inertial mass displacements from experiment

Figure 3.9 Comparison of experiment and pretest design analysis for inertial mass displacement for IPIRG-1 Experiment 1.1-3 (inertially loaded stainless steel through-wall crack) 


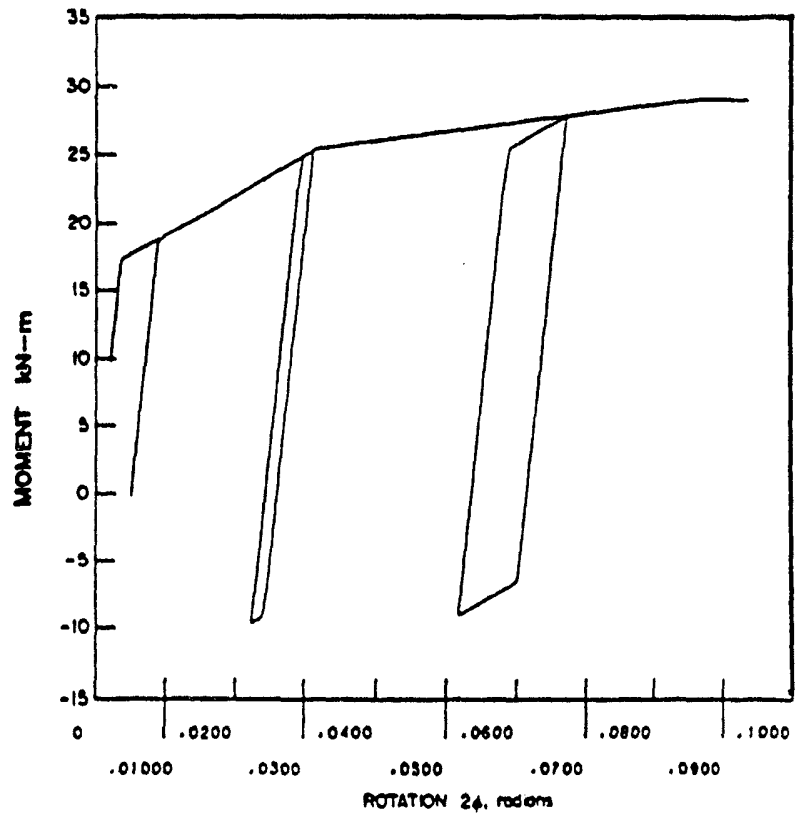

(a) Moment-rotation from analysis

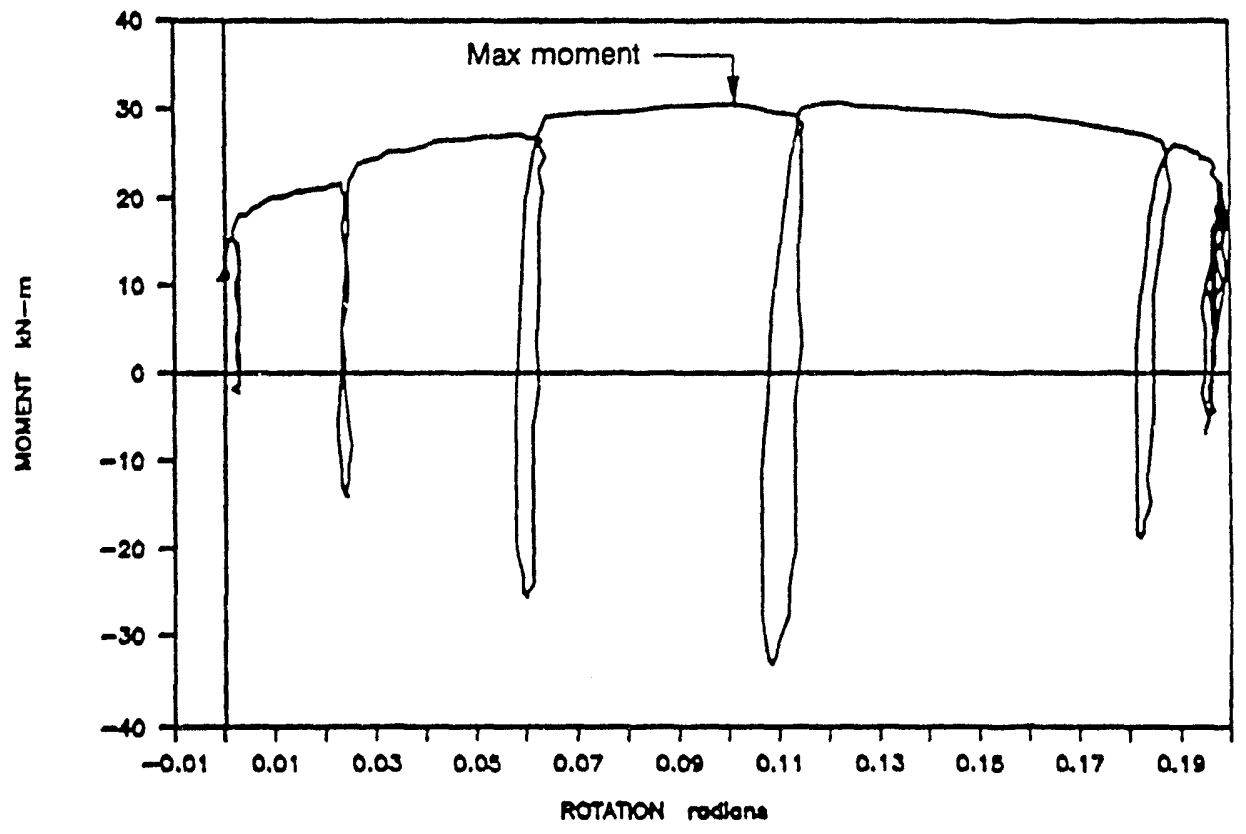

(b) Moment-rotation from experiment

Figure 3.10 Comparison of experiment and pretest design analysis for moment versus total rotation for IPIRG-1 Experiment 1.1-3 (inertially loaded stainless steel through-wall crack) (analysis valid only up to maximum moment) 


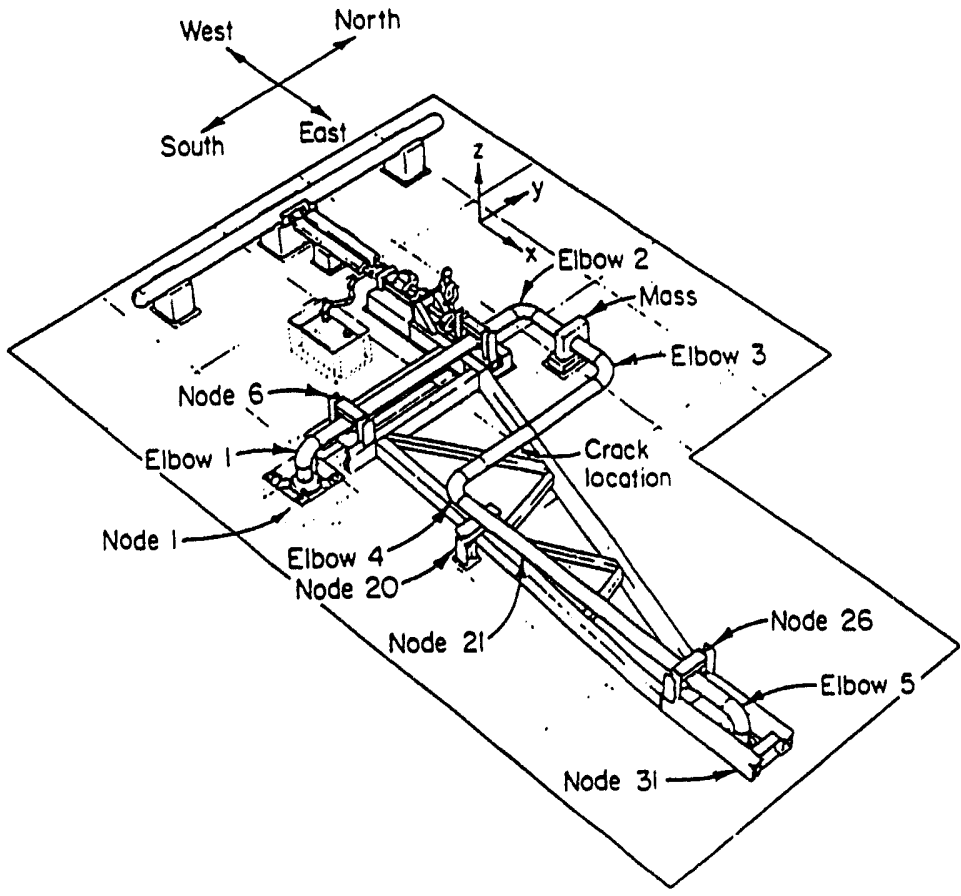

Figure 3.11 Artist's conception of the IPIRG pipe loop test facility

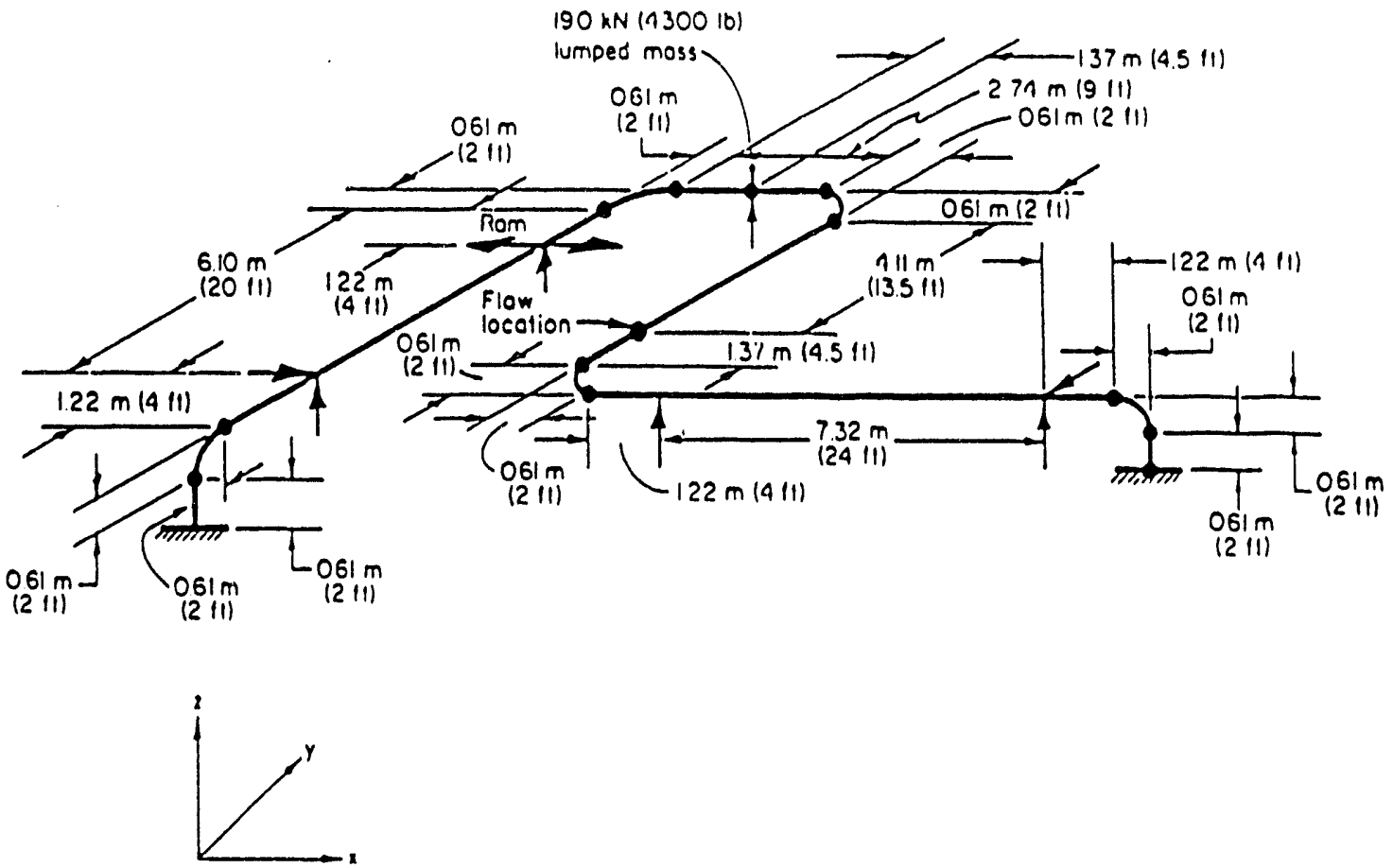

Figure 3.12 Dimensions of the IPIRG pipe loop test facility 


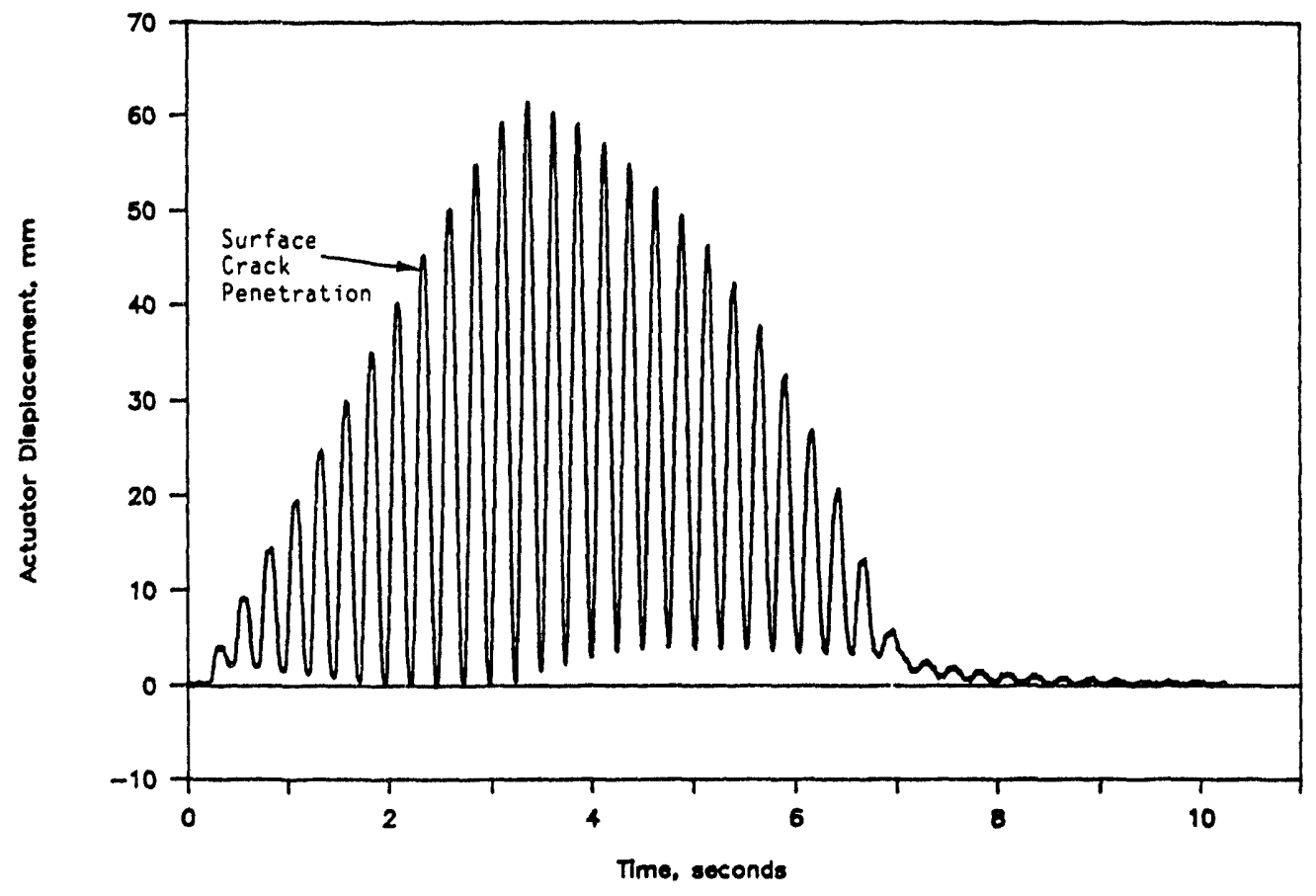

Figure 3.13 IPIRG-1 Experiment 1.3-3 (pipe system stainless steel surface crack experiment) forcing function

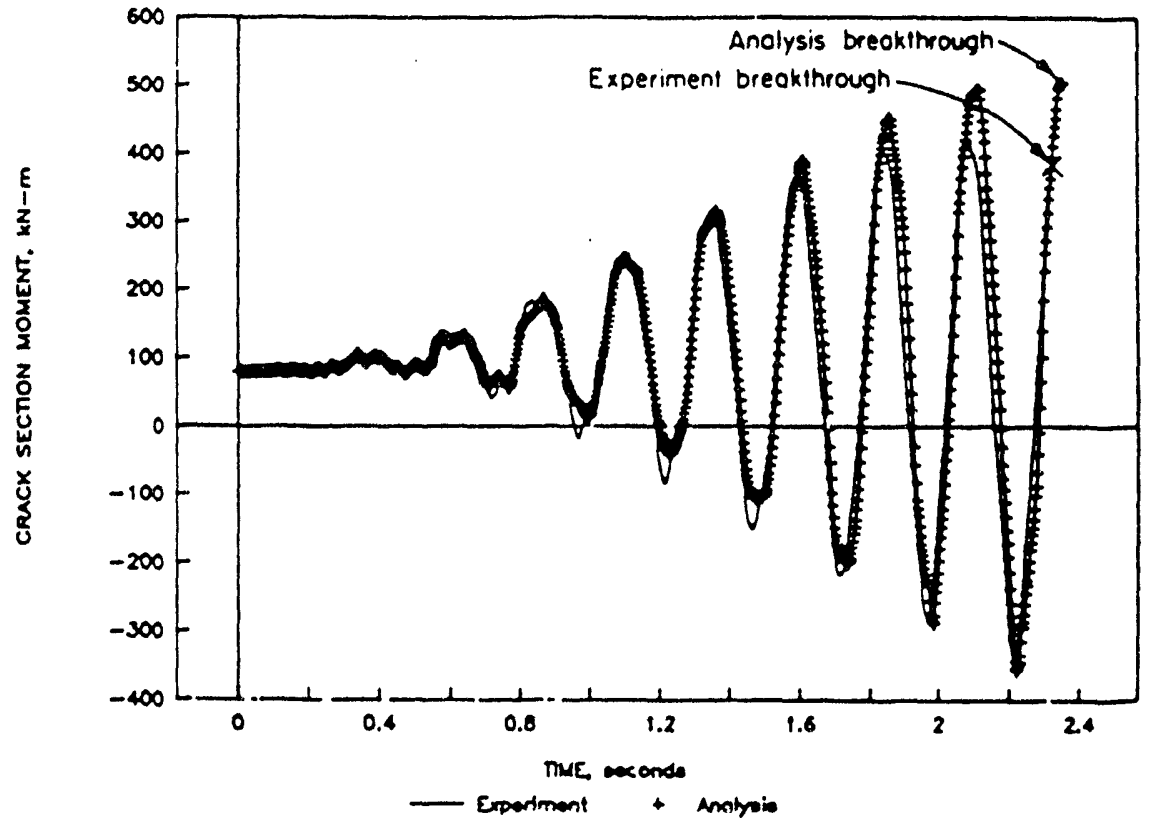

Figure 3.14 Flaw location moment for IPIRG-1 Experiment 1.3-3 (pipe system stainless steel base metal experiment) 


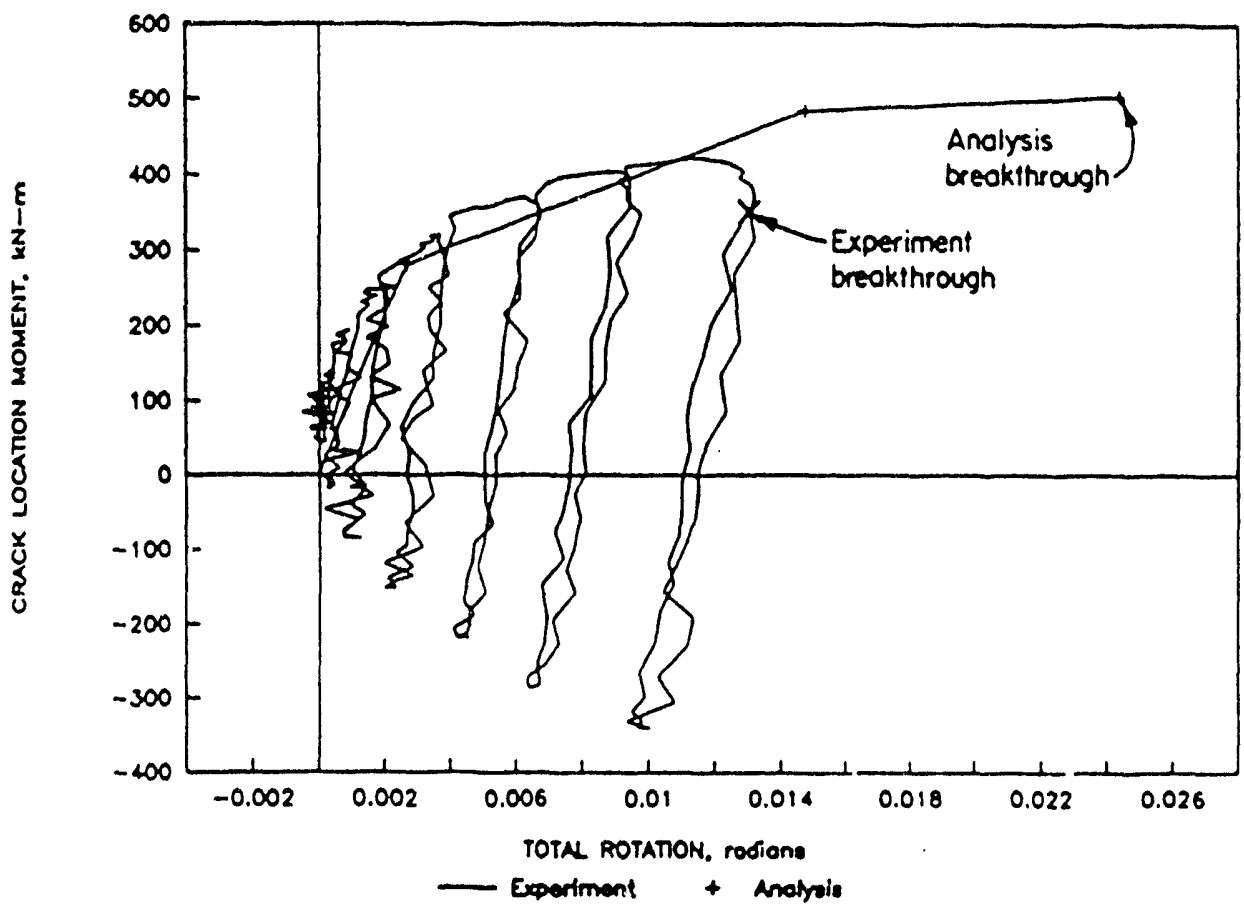

Figure 3.15 Crack section moment-rotation for IPIRG-1 Experiment 1.3-3 (pipe system stainless steel base metal experiment)

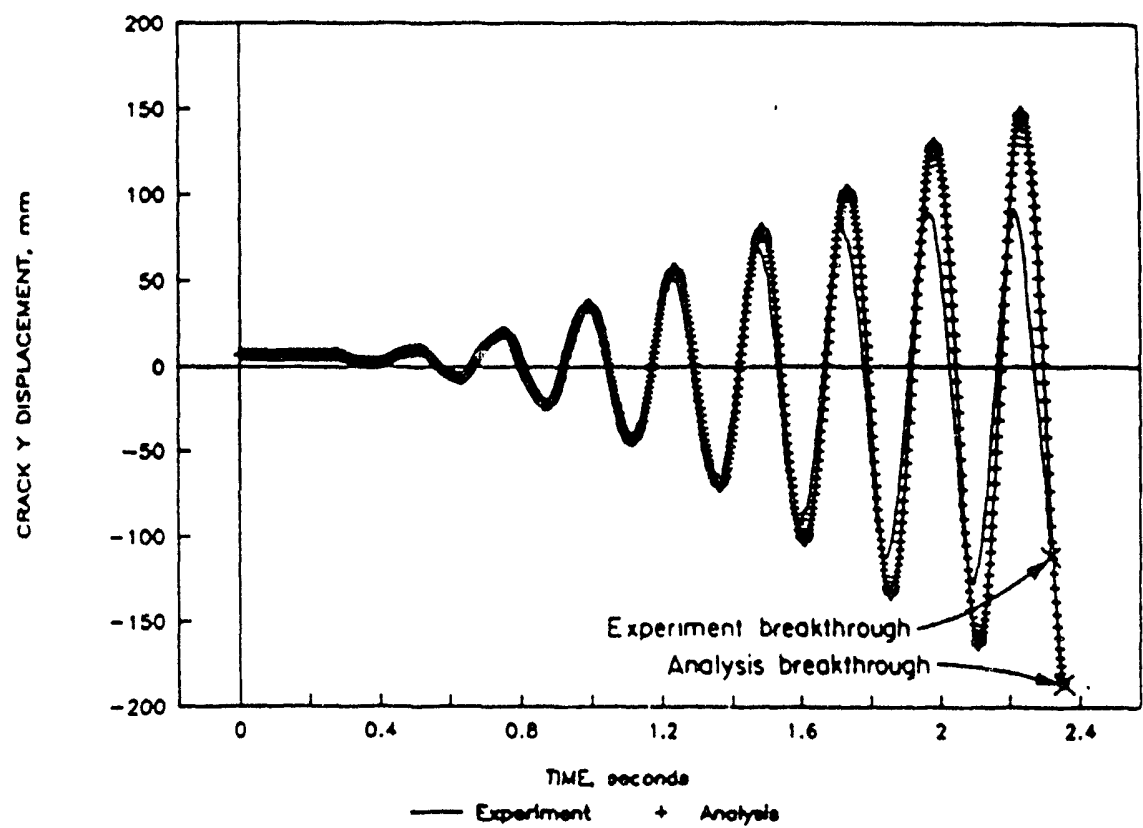

Figure 3.16 Global pipe loop displacement at the crack location for IPIRG-1 Experiment 1.3-3 (stainless steel base metal experiment) 


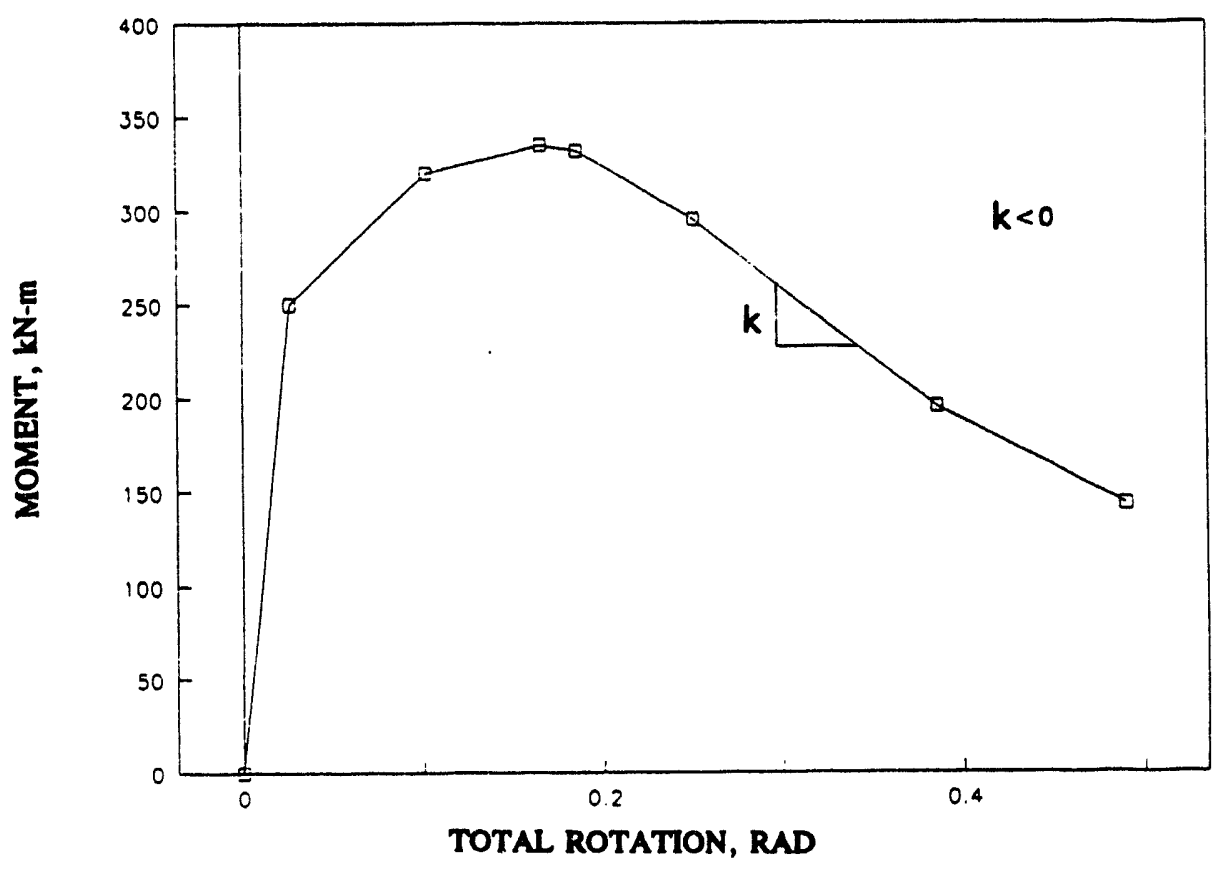

Figure 3.17 Post-maximum moment crack behavior

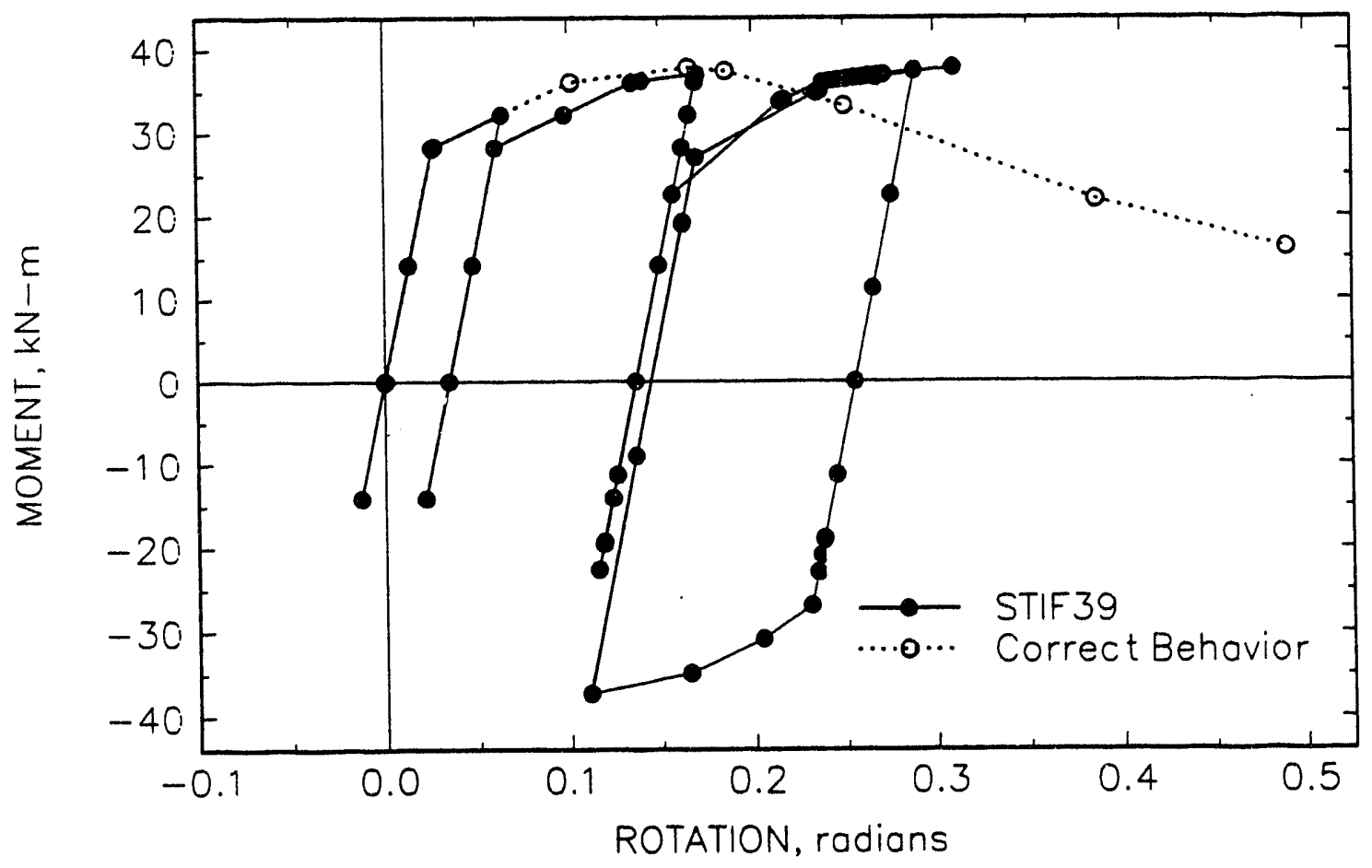

Figure 3.18 ANSYS STIF39 (nonlinear force-deflection element) response under reverse cyclic bending 

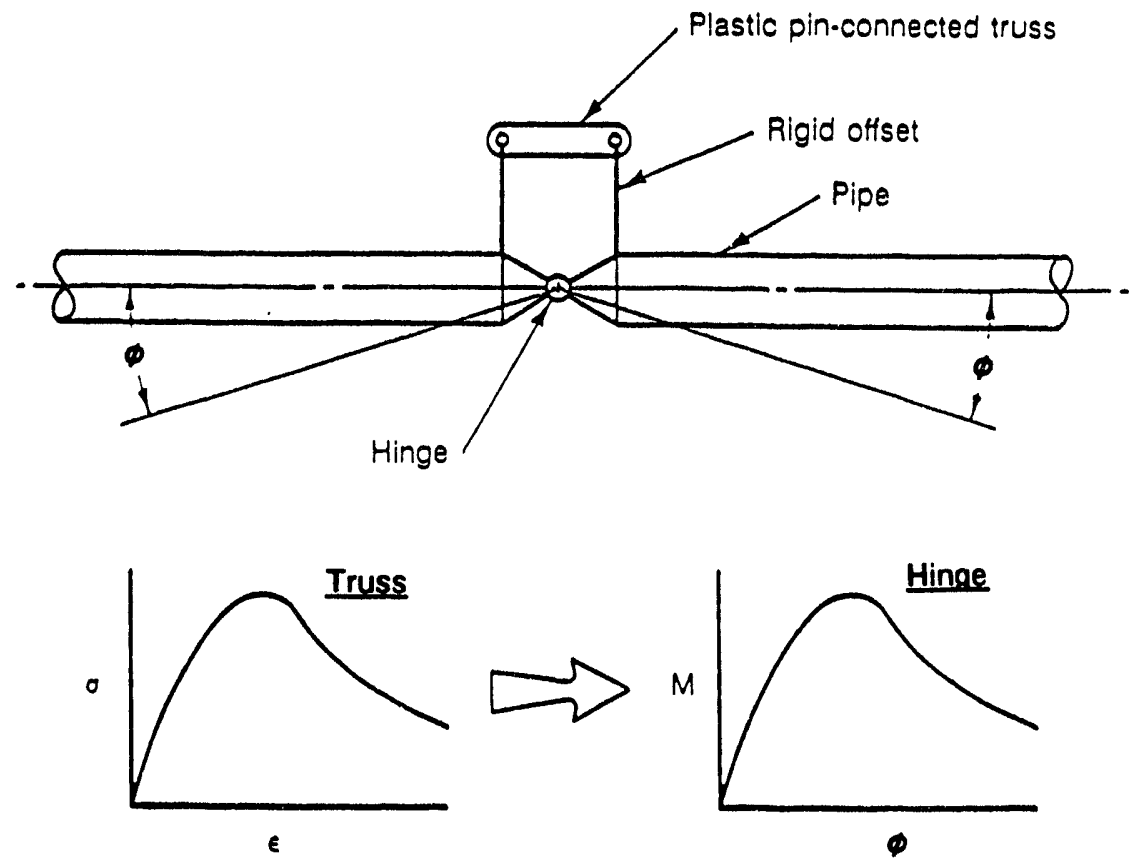

Figure 3.19 Model for analysis of post-maximum moment crack behavior

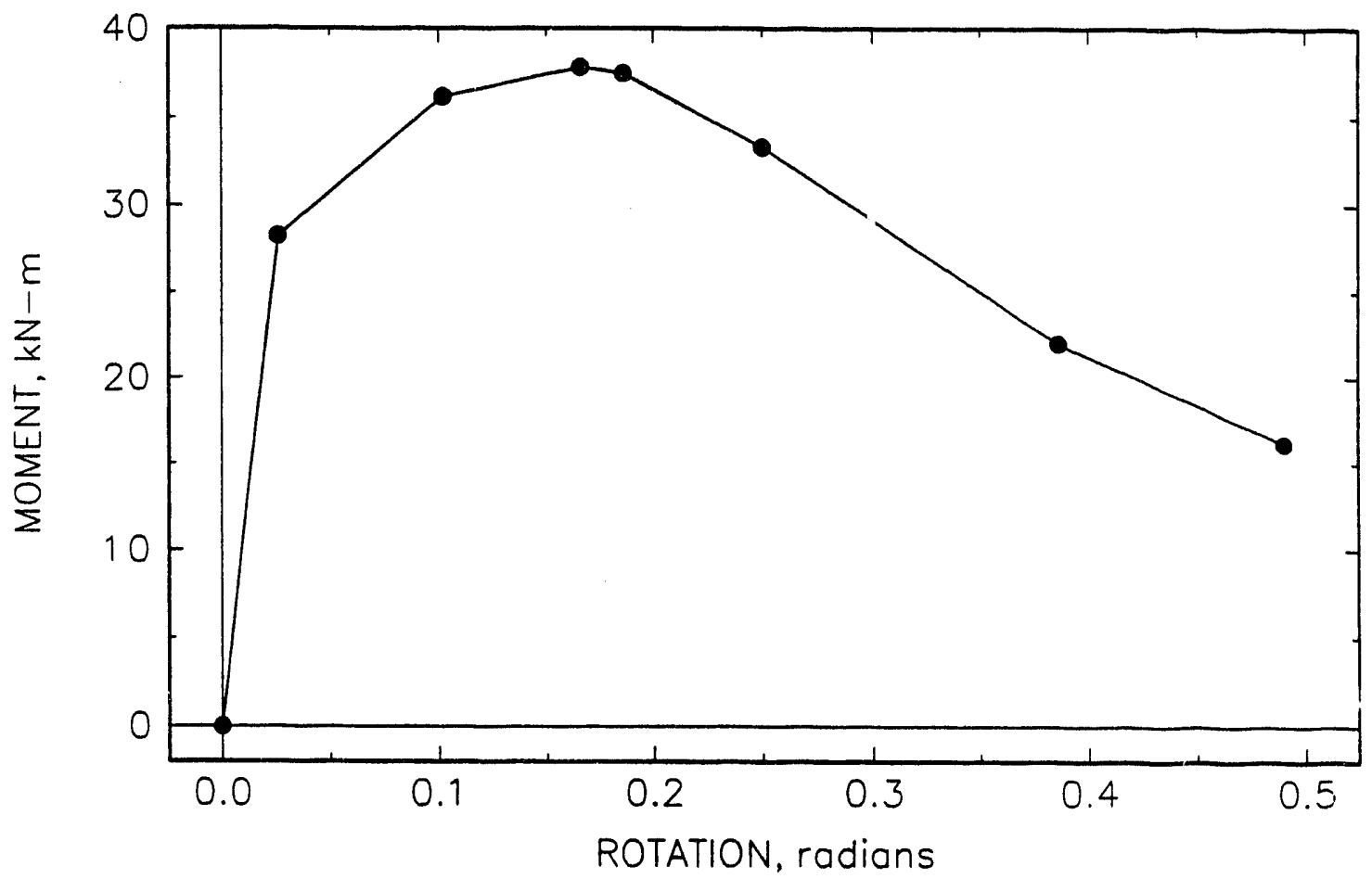

Figure 3.20 Input moment-rotation response for a through-wall crack in a pipe 


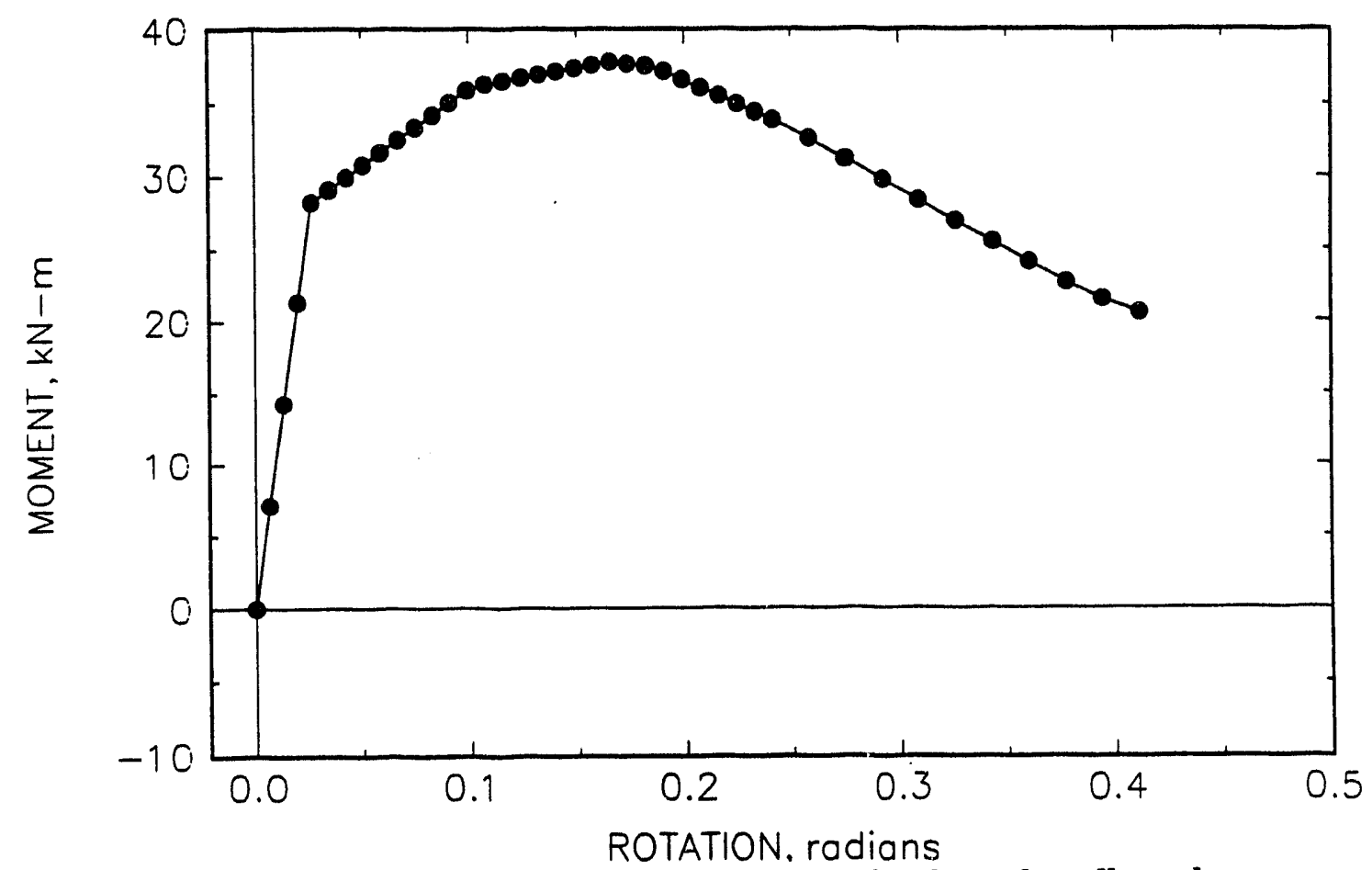

Figure 3.21 Nonlinear truss model analysis of a through-wall crack without unloads demonstrating behavior past maximum load

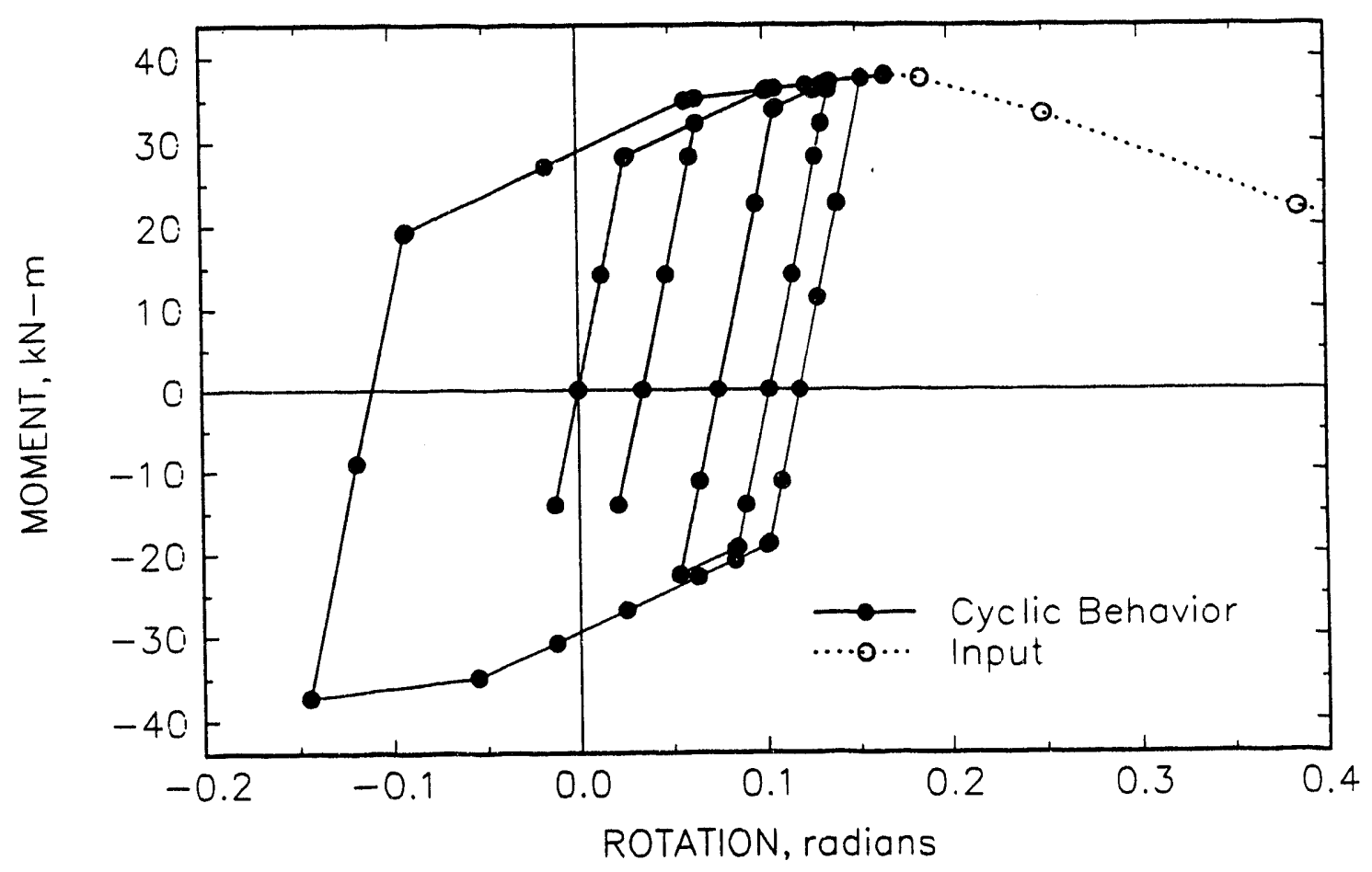

Figure 3.22 Nonlinear truss model analysis of a through-wall crack with unloads exhibiting absence of ratcheting and proper kinematic hardening response 


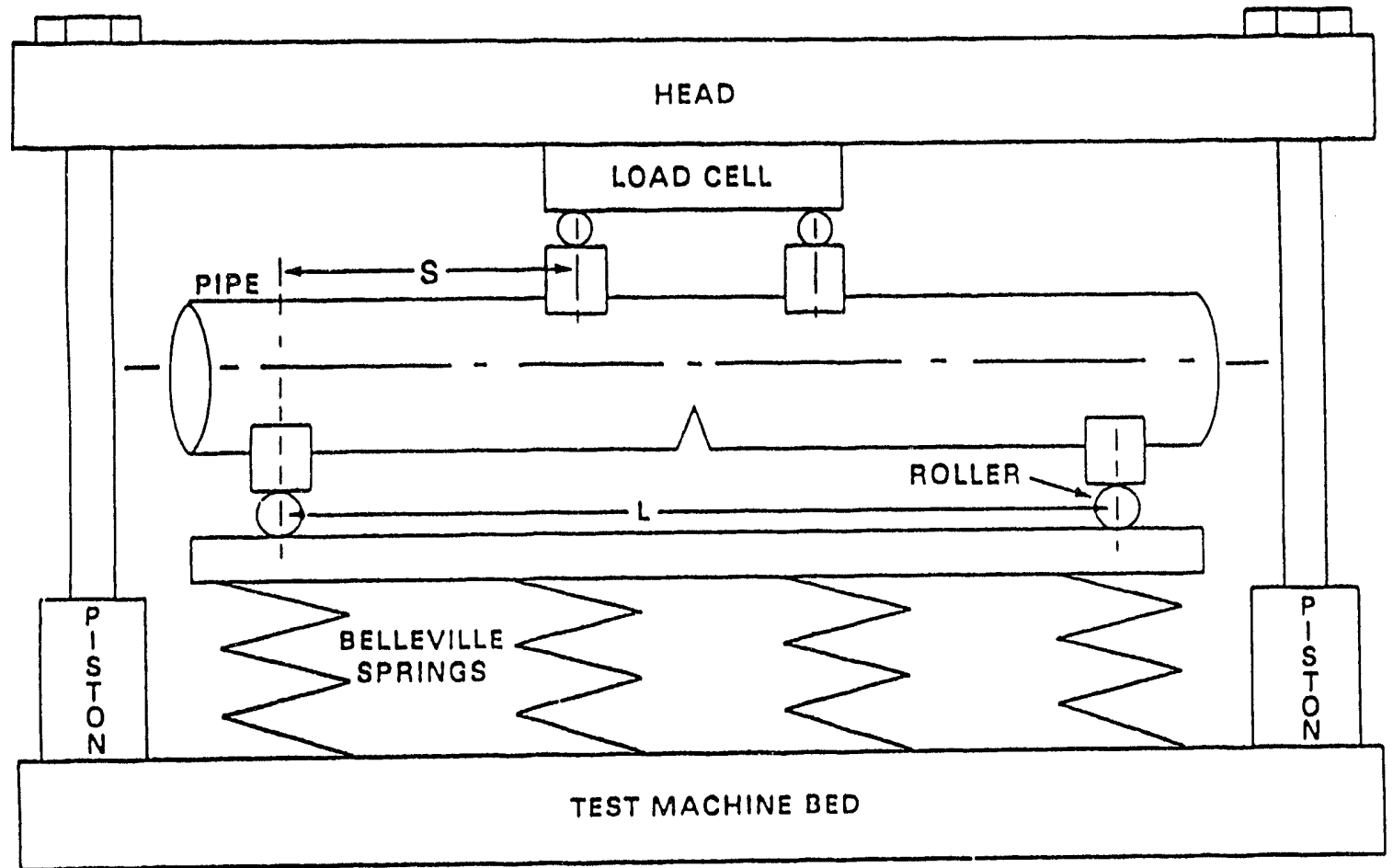

Figure 3.23 Schematic of DTRC compliant instability pipe experiments

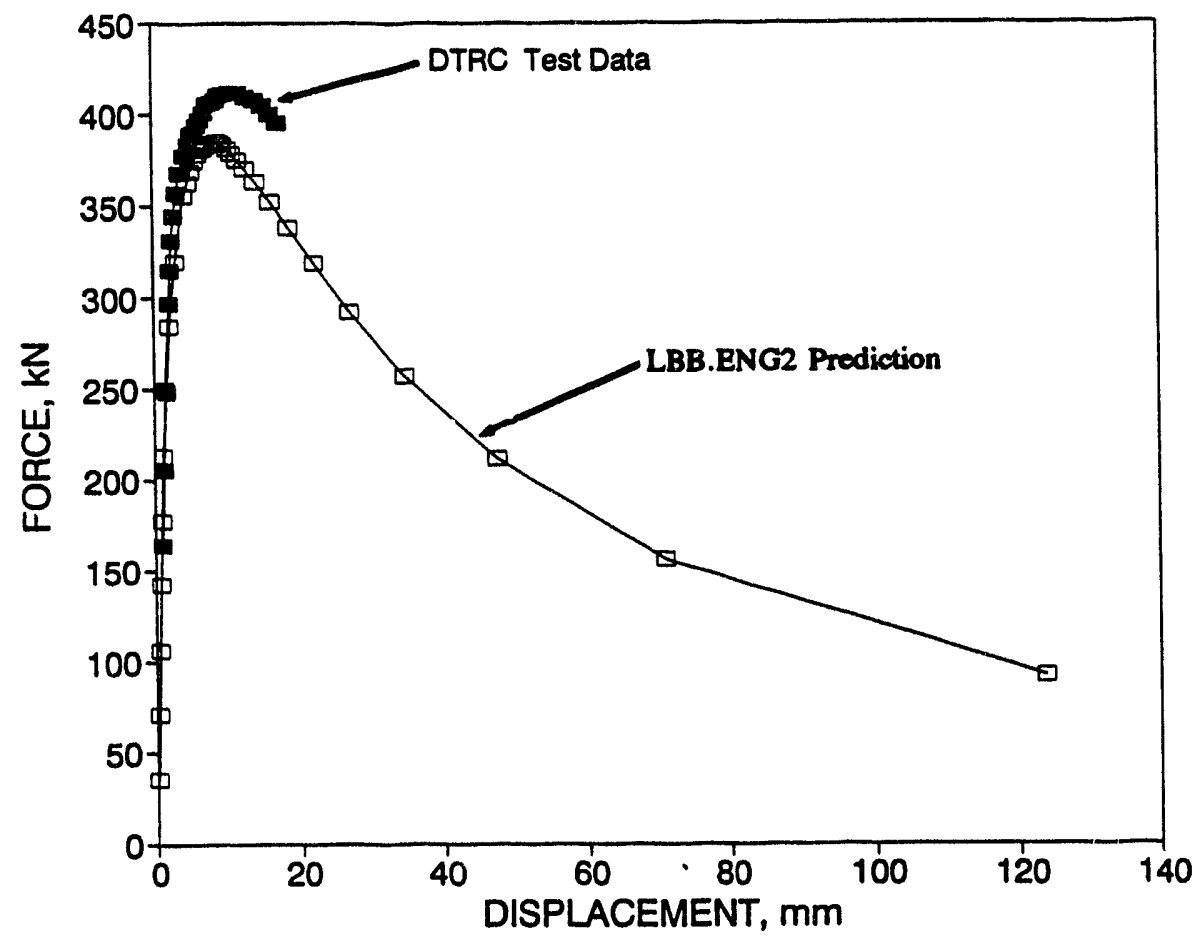

Figure 3.24 Comparison of experimental results (DTRC Test Number 7) and predicted behavior (LBB.ENG2) showing the high quality of the predictions 


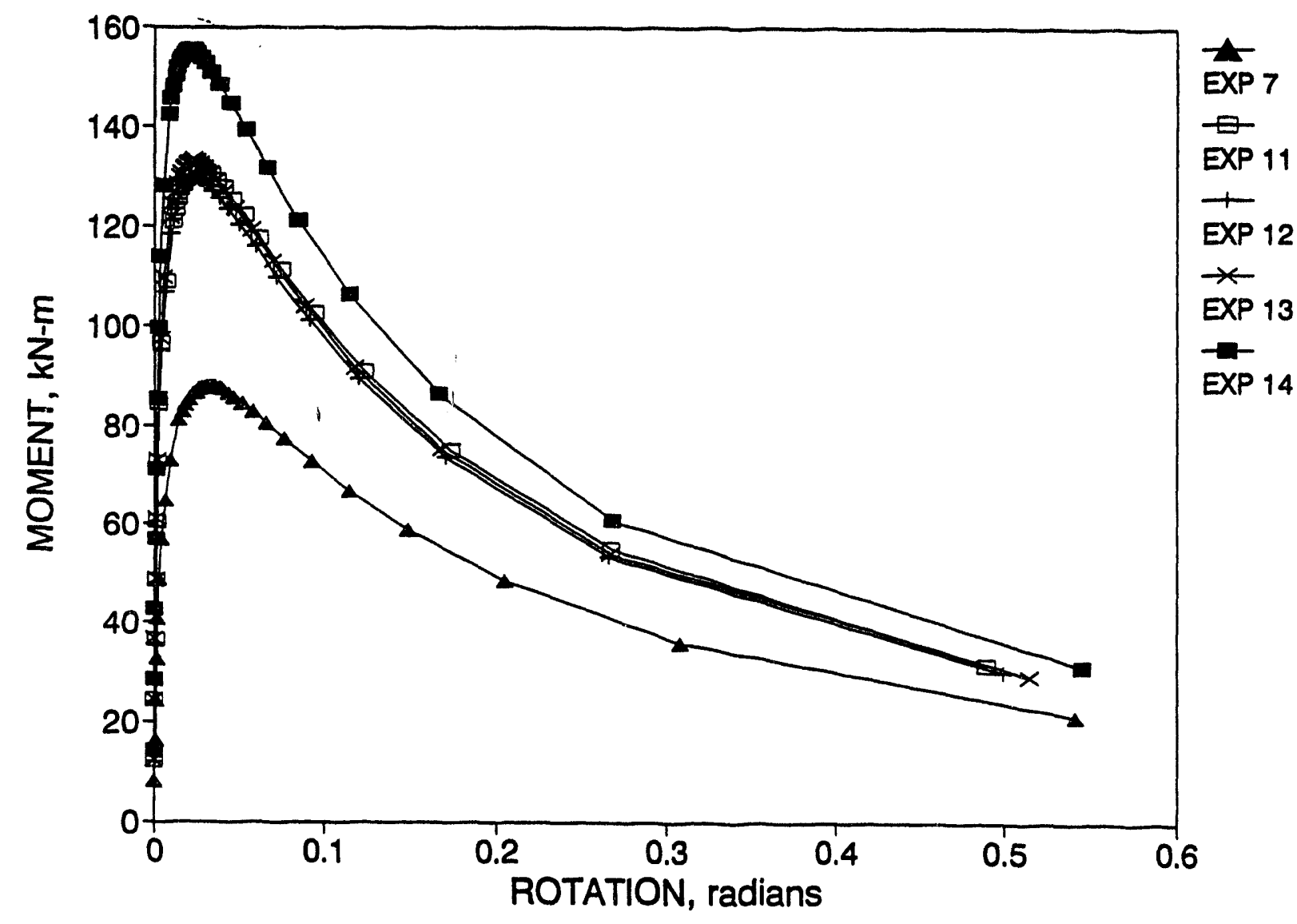

Figure 3.25 LBB.ENG2 through-wall crack J-estimation scheme predictions of moment-rotation behavior for selected DTRC experiments 


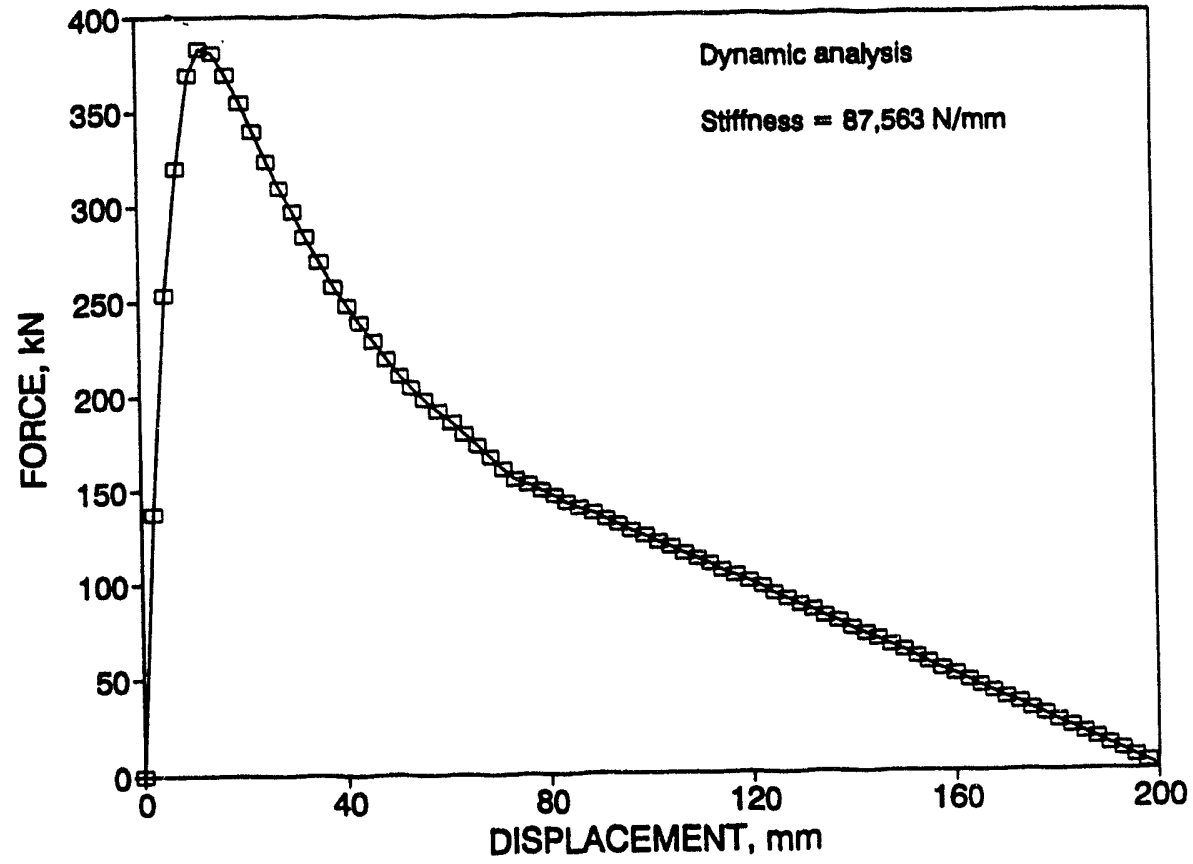

(a)

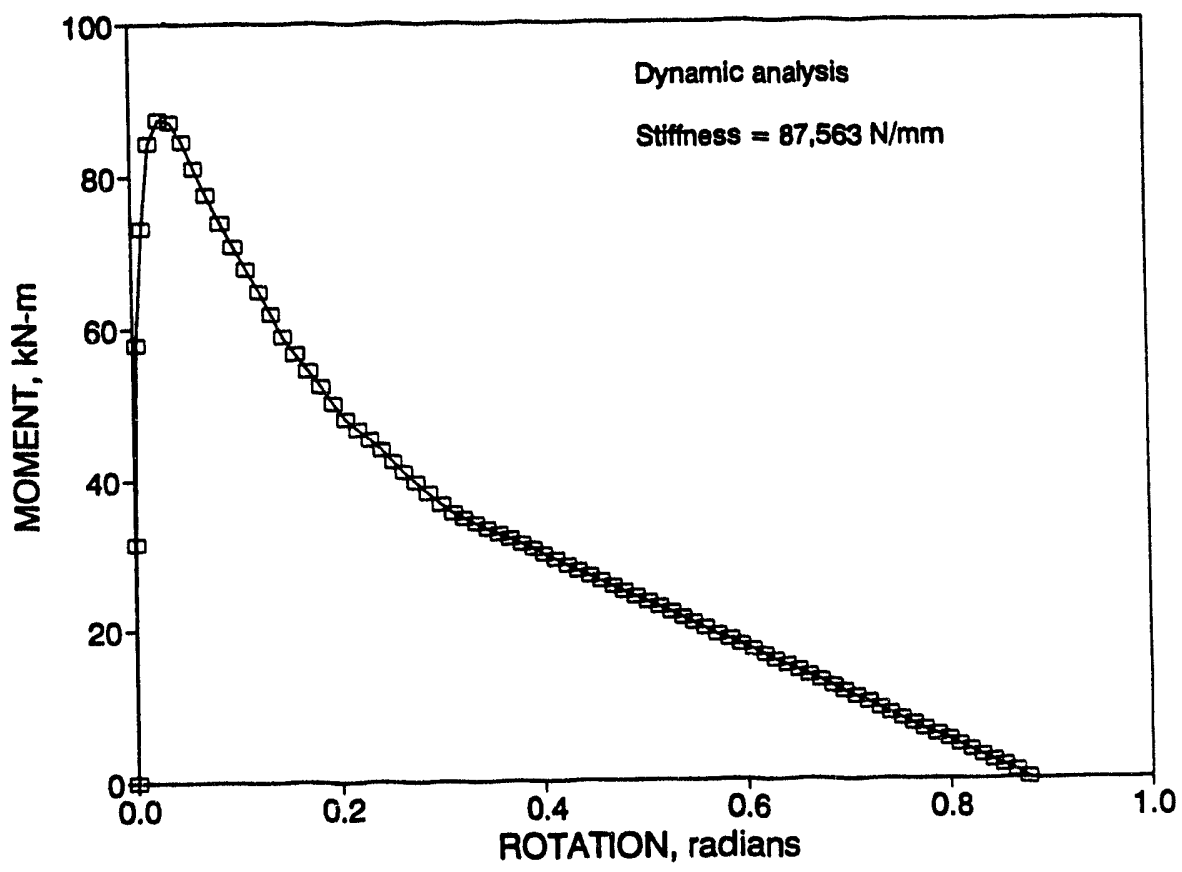

(b)

Figure 3.26 Stable crack growth behavior for DTRC Experiment 7 with 87,563 $\mathrm{N} / \mathrm{mm}(500,000 \mathrm{lb} / \mathrm{in})$ system stiffness 


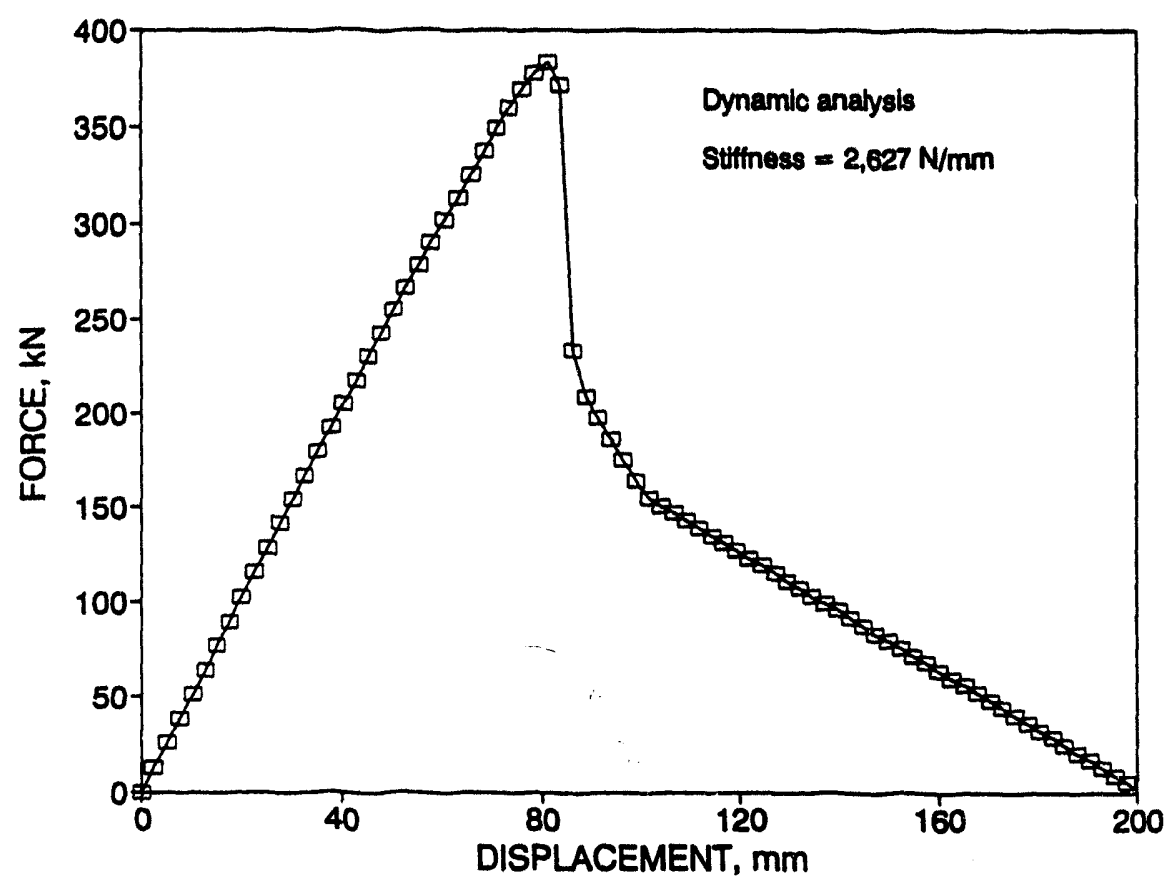

(a)

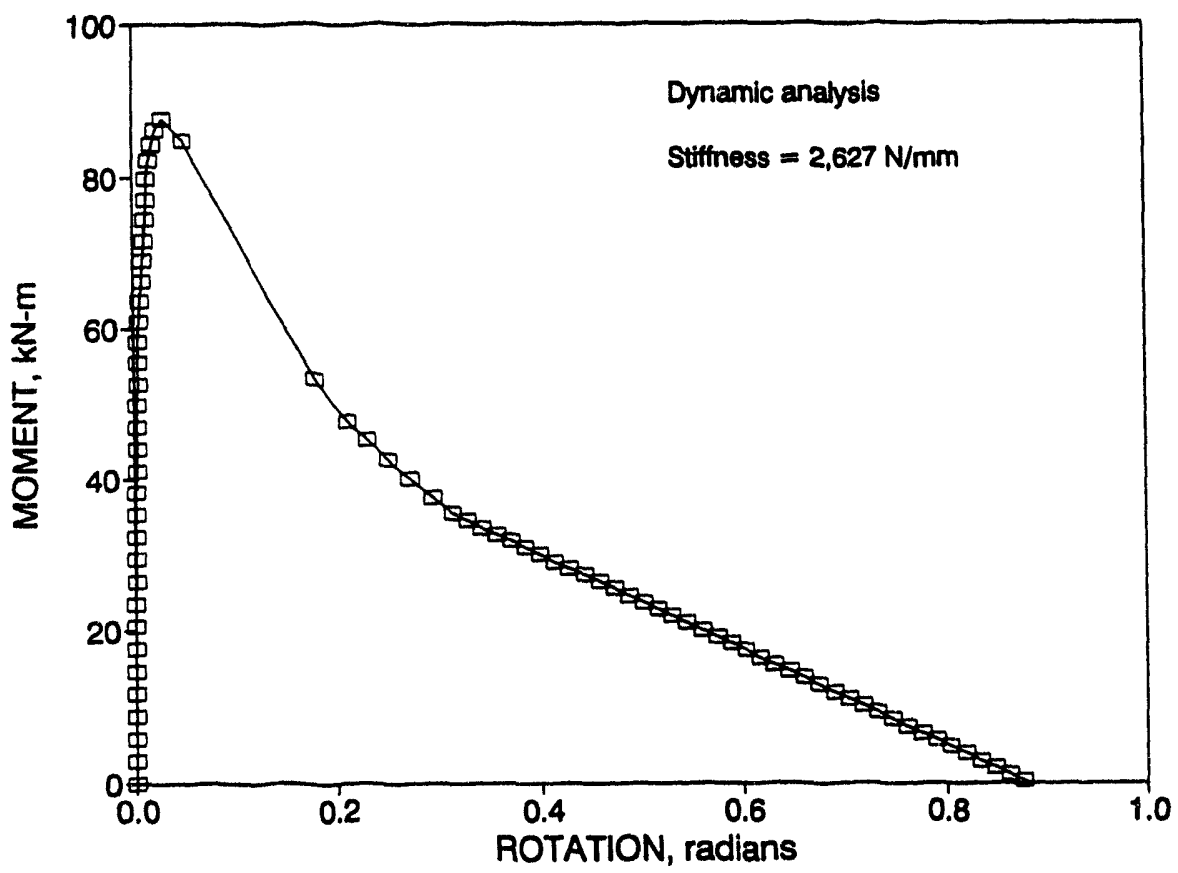

(b)

Figure 3.27 Limited instability behavior for DTRC Experiment 7 with $2,627 \mathrm{~N} / \mathrm{mm}(15,000 \mathrm{lb} / \mathrm{in})$ system stiffness 


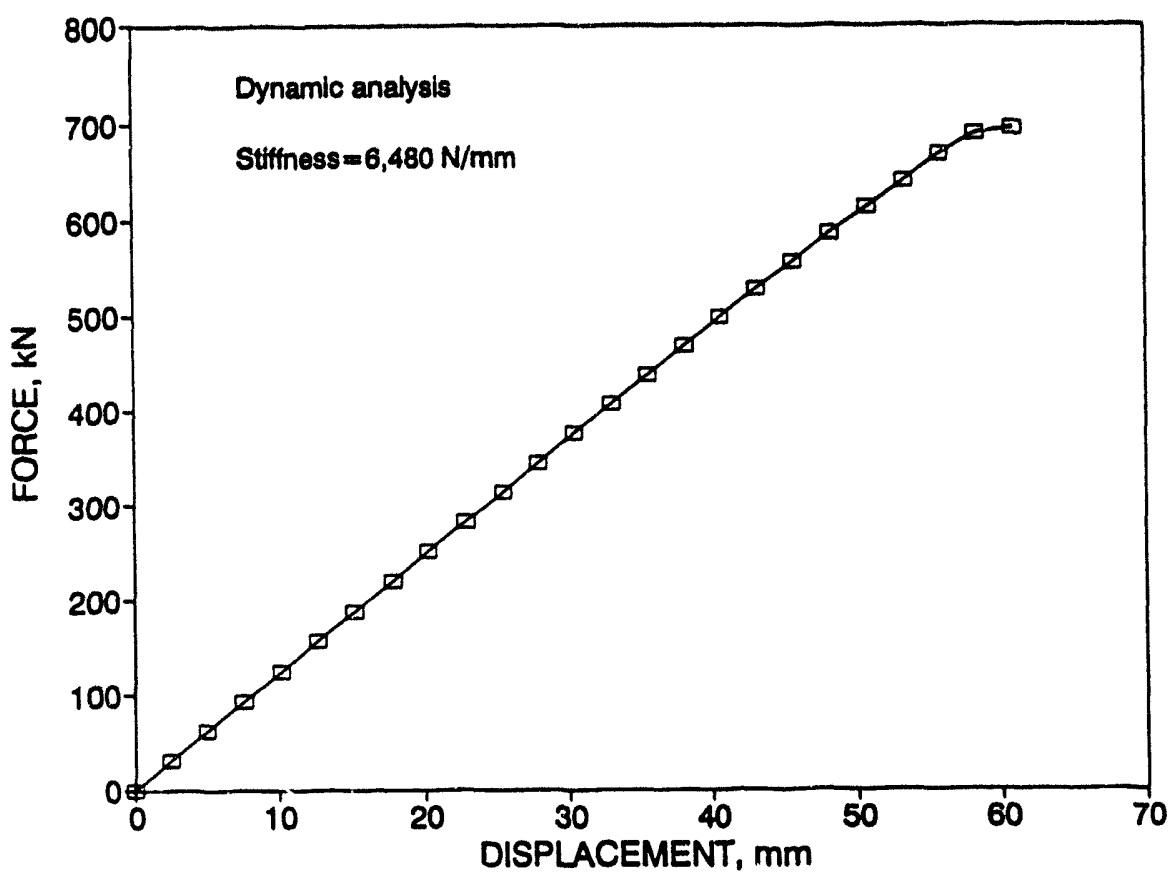

(s)

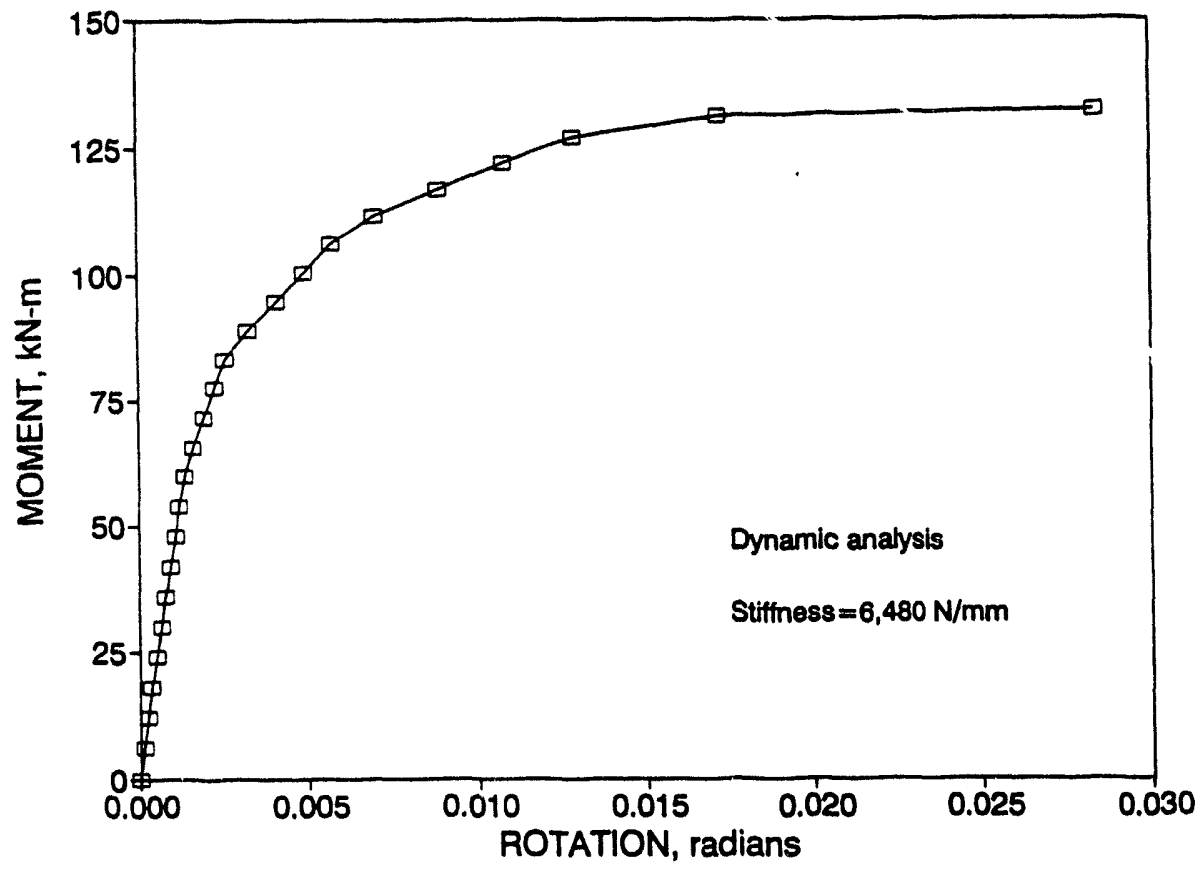

(b)

Figure 3.28 Completely unstable behavior for DTRC Experiment 13 with measured system stiffness of $6,480 \mathrm{~N} / \mathrm{mm}(37,000 \mathrm{lb} / \mathrm{in})$ 


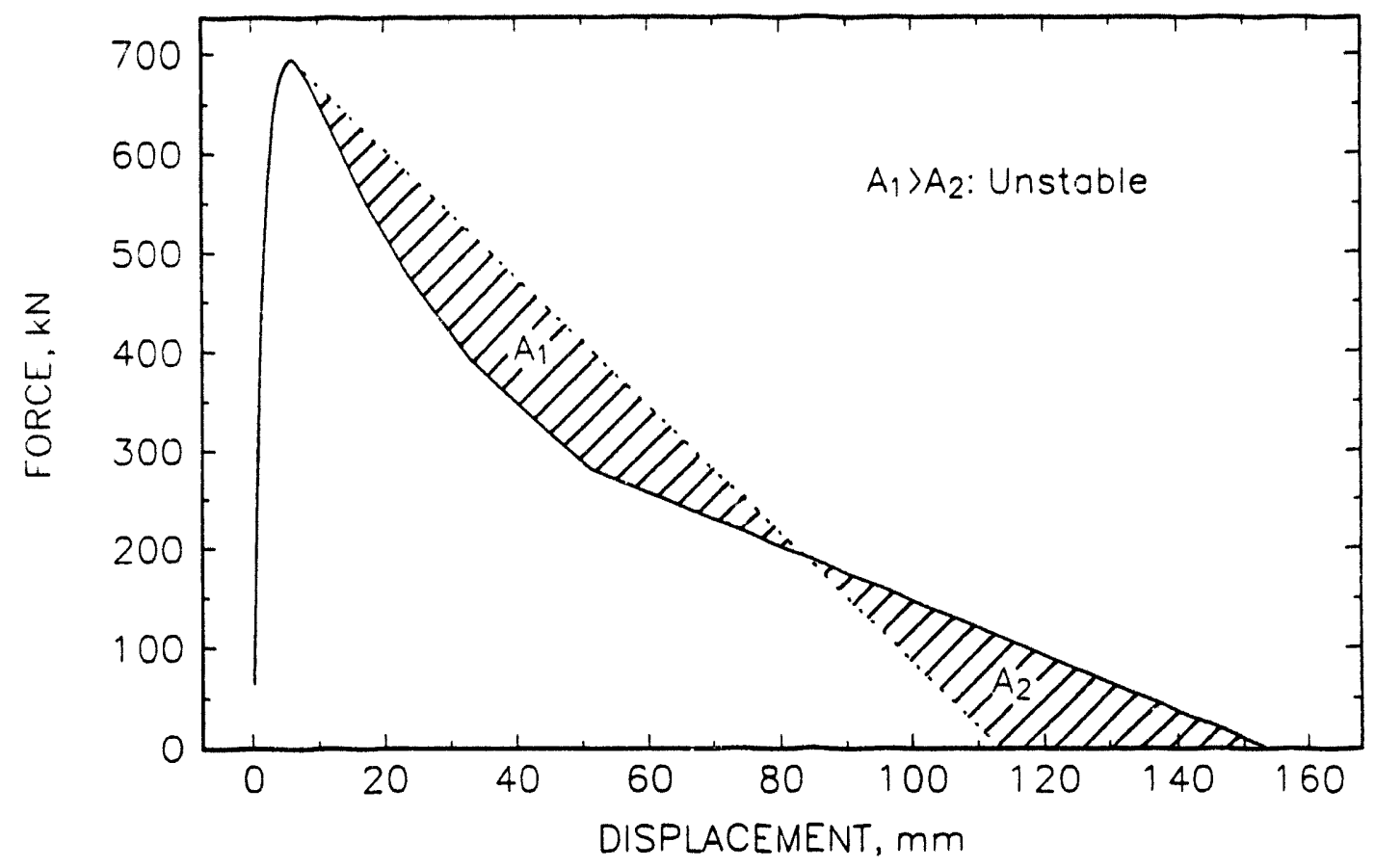

Figure 3.29 Energy balance for DTRC Experiment 13 with $6,480 \mathrm{~N} / \mathrm{mm}(37,000 \mathrm{lb} / \mathrm{in})$ system stiffness

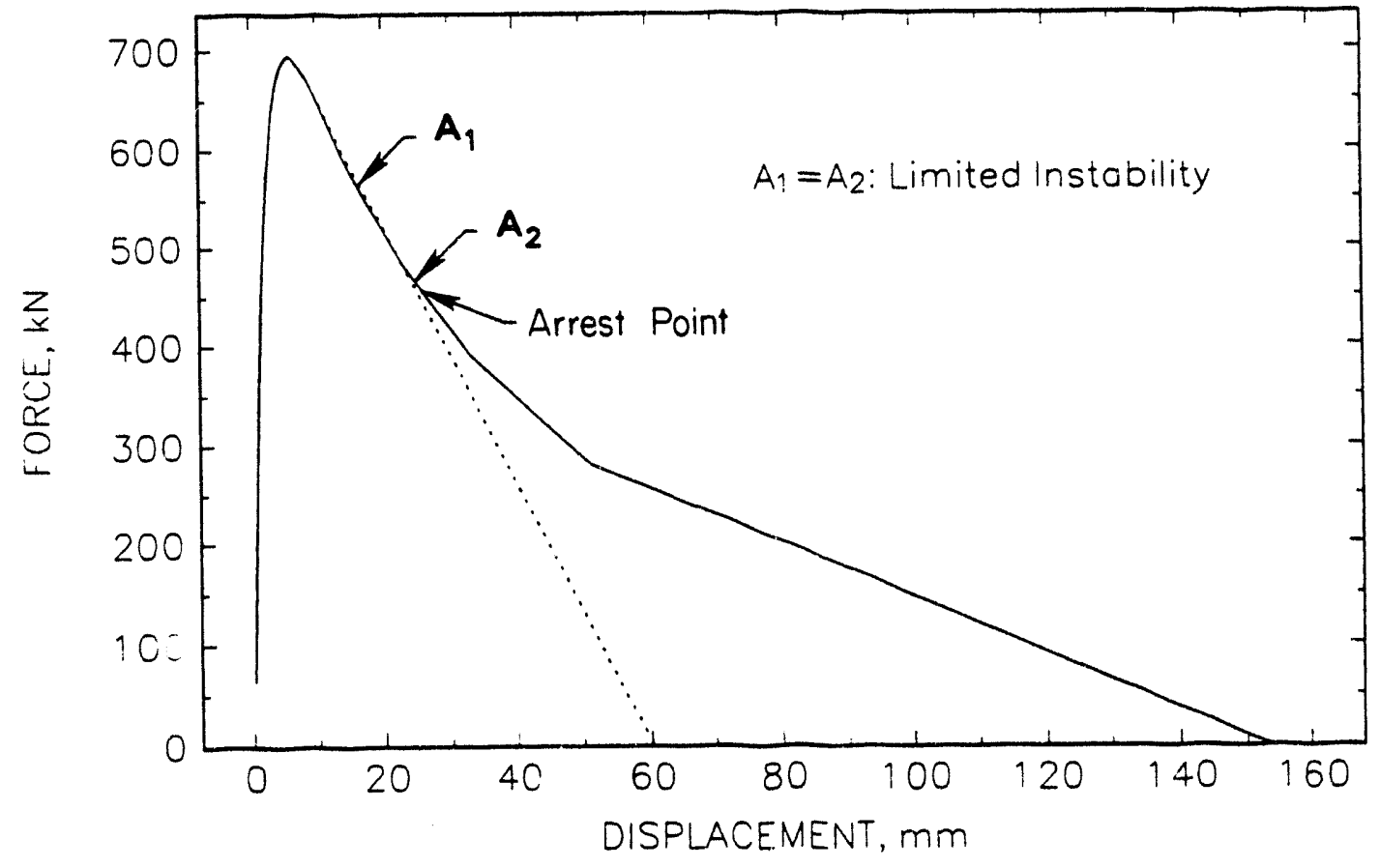

Figure 3.30 Energy balance for DTRC Experiment 13 with $12,959 \mathrm{~N} / \mathrm{mm}(74,000 \mathrm{lb} / \mathrm{in})$ system stiffness 

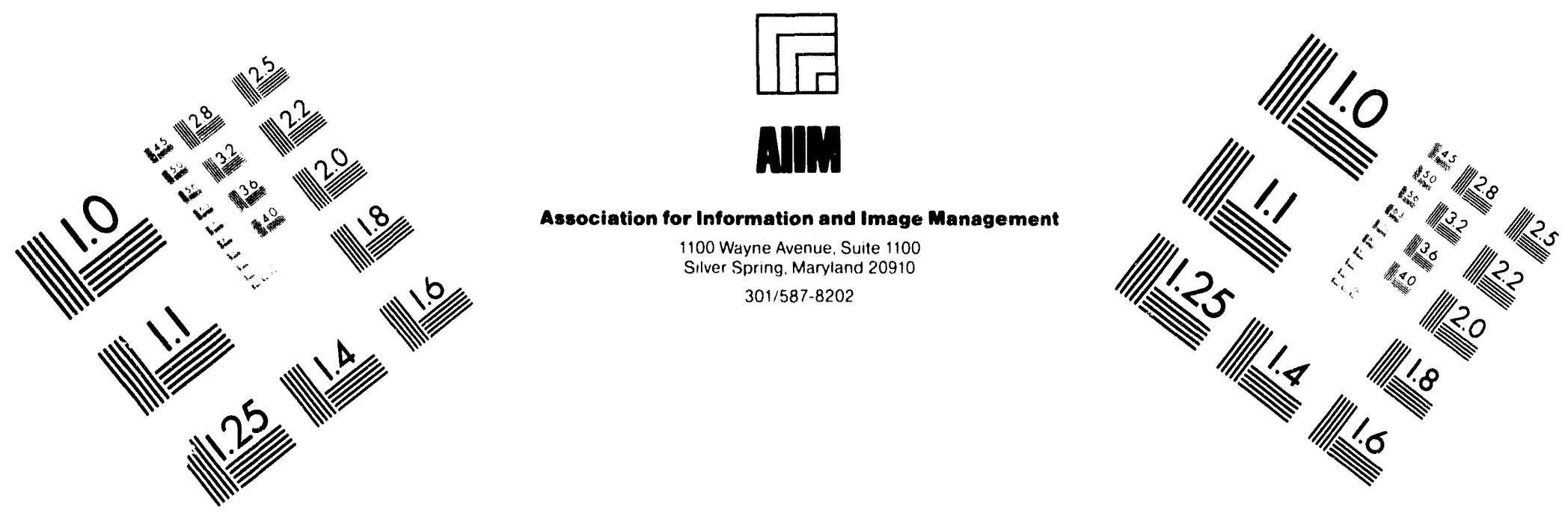

\section{Centimeter}

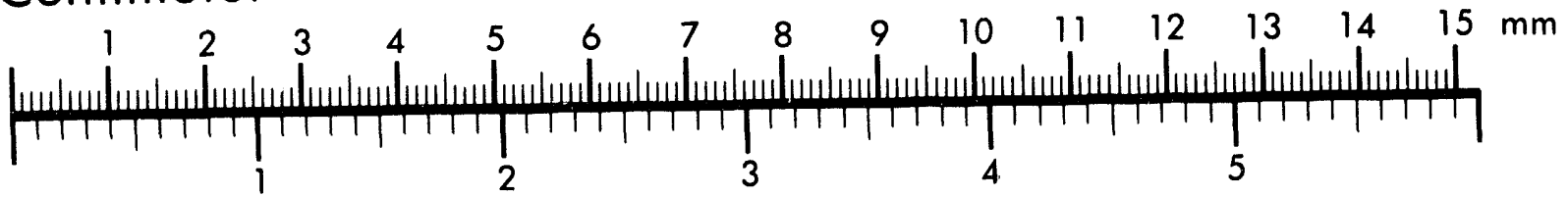
Inches
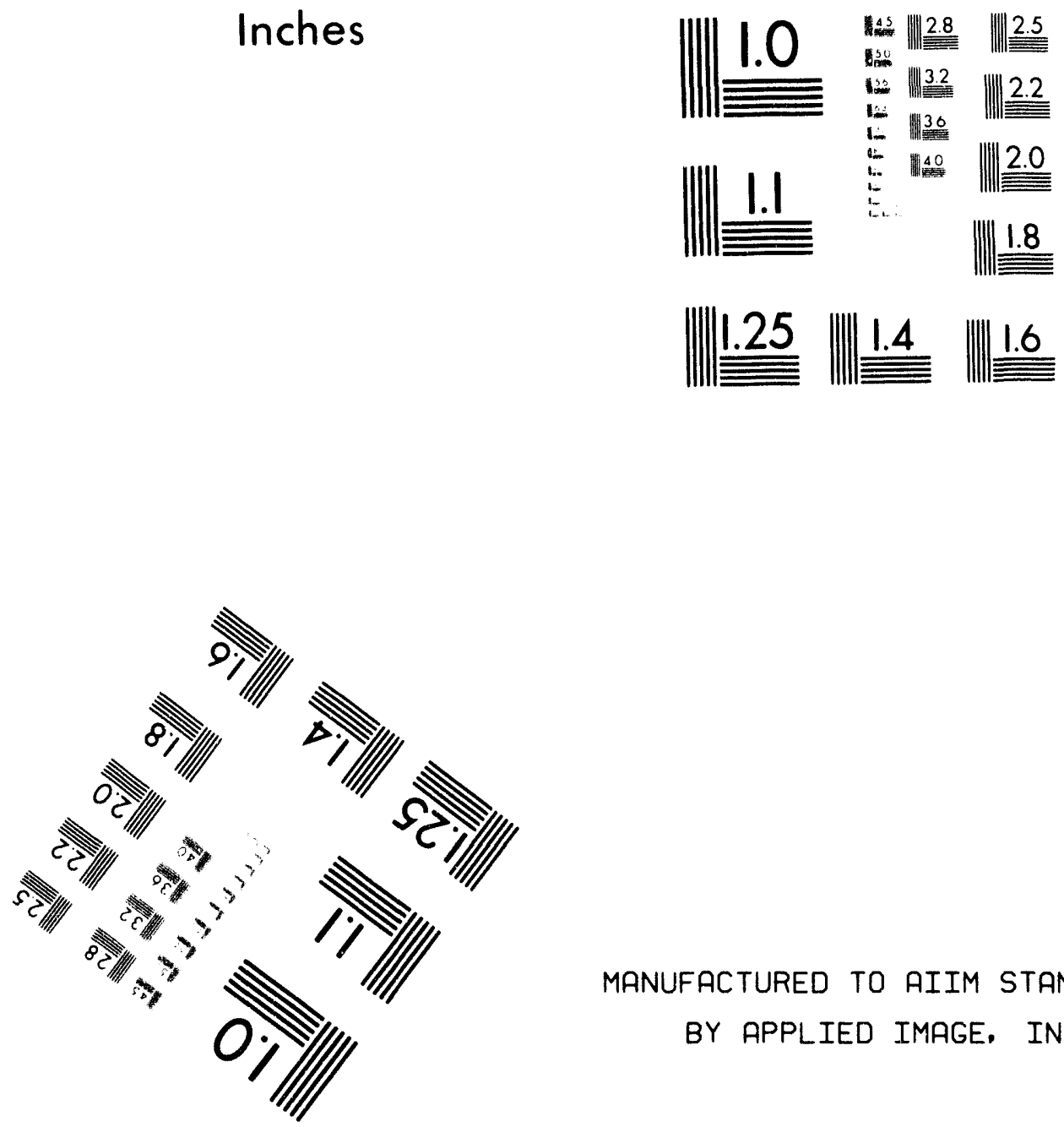

MANUFACTURED TO AIIM STANDARDS

BY APPLIED IMAGE, INC.

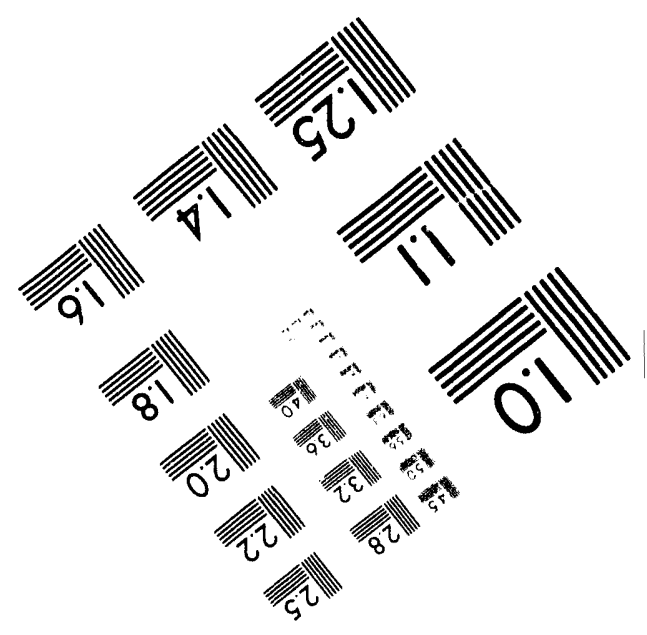



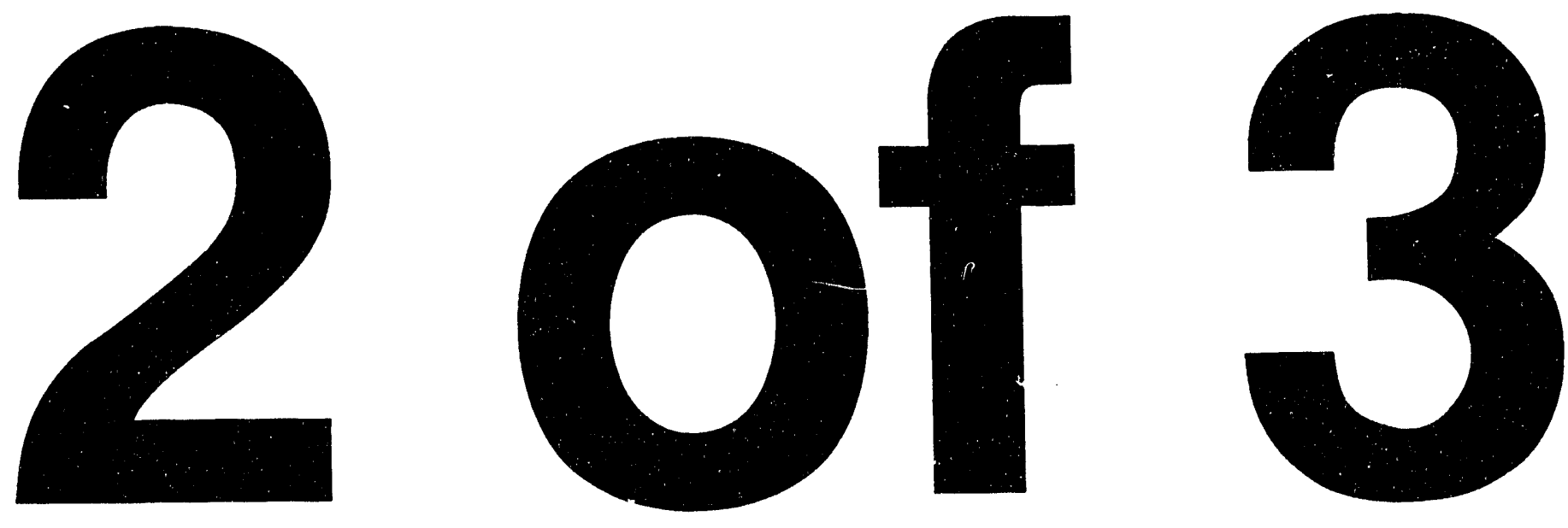


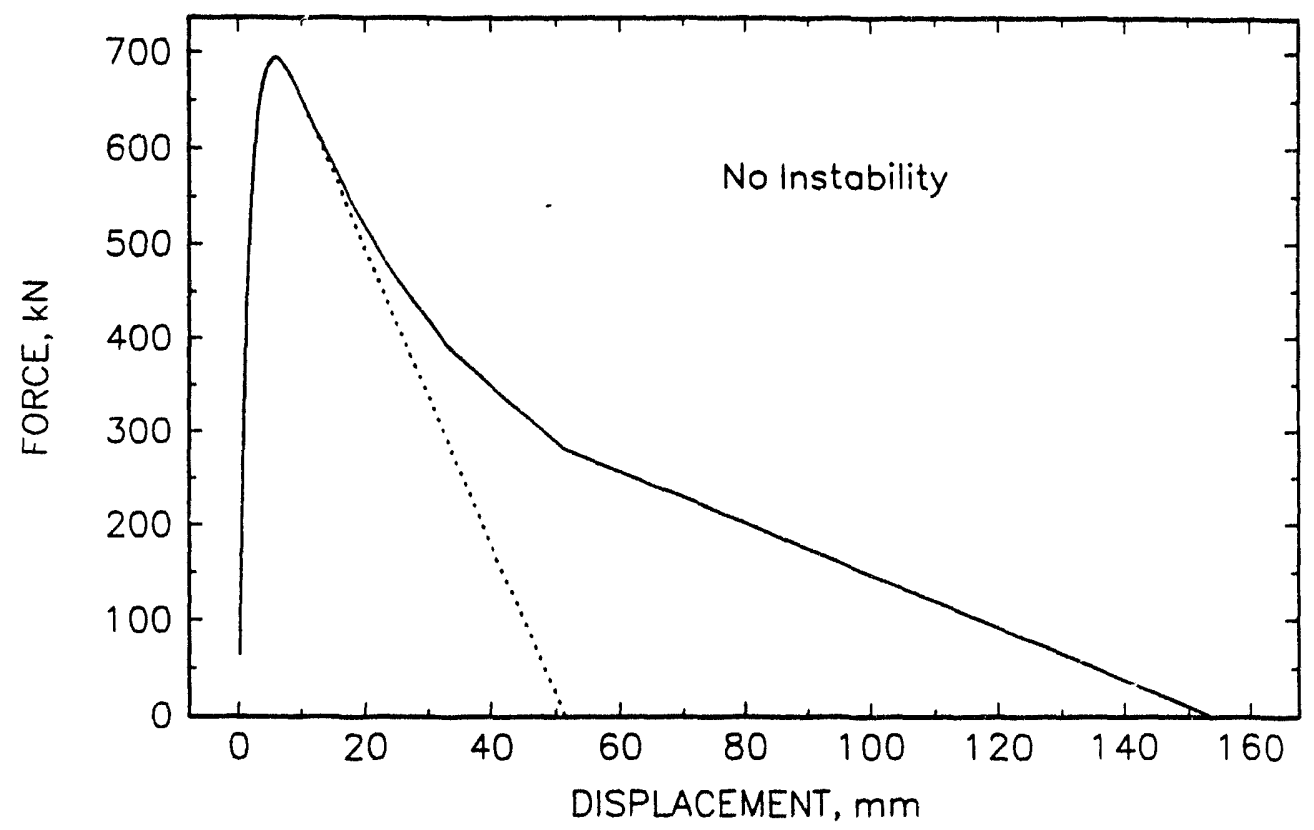

Figure 3.31 Energy balance for DTRC Experiment 13 with 15,761 N/mm $(90,000 \mathrm{lb} / \mathrm{in})$ system stiffiness

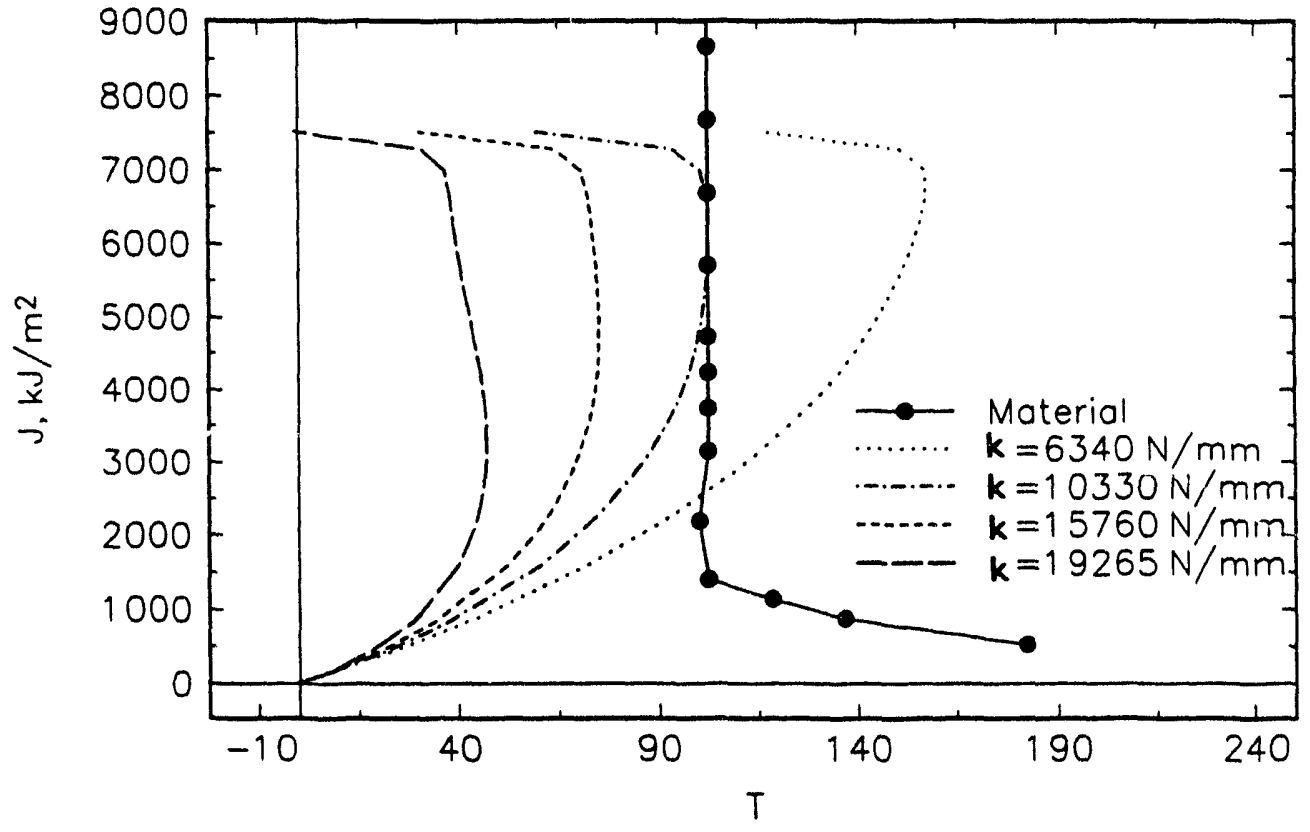

Figure 3.32 J/T assessment for DTRC Experiment 13 using Zahoor EPFM formulation at various system stiffnesses $(1.0 \mathrm{lb} / \mathrm{in}=0.17513 \mathrm{~N} / \mathrm{mm})$ 

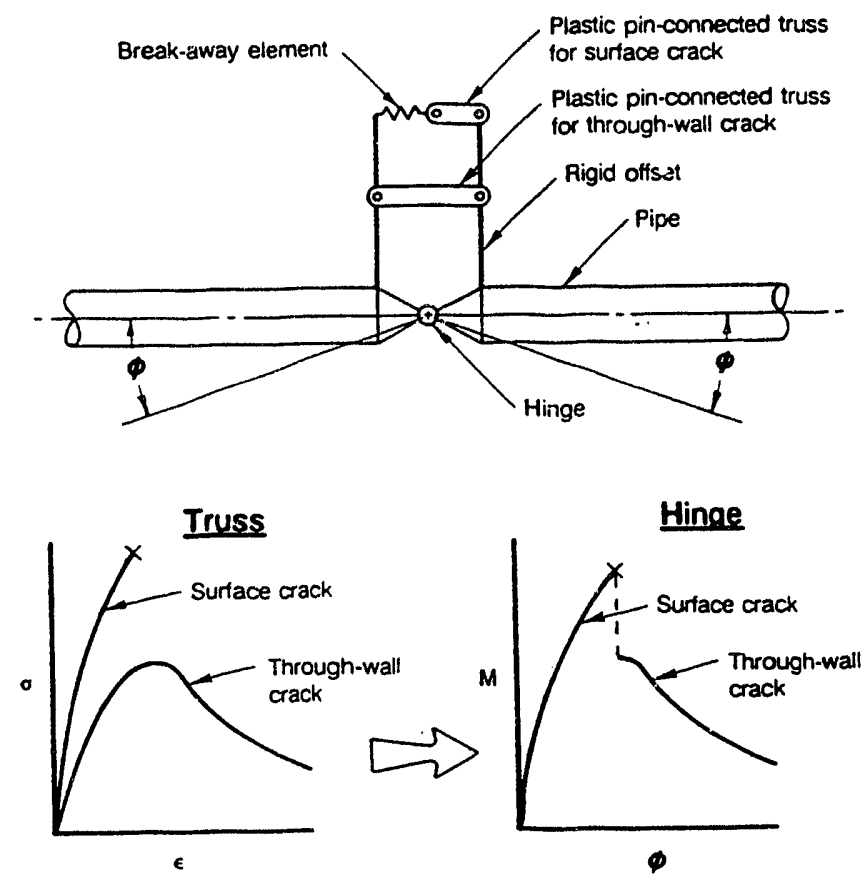

Figure 3.33 Model of surface crack to through-wall crack transition using plastic trusses
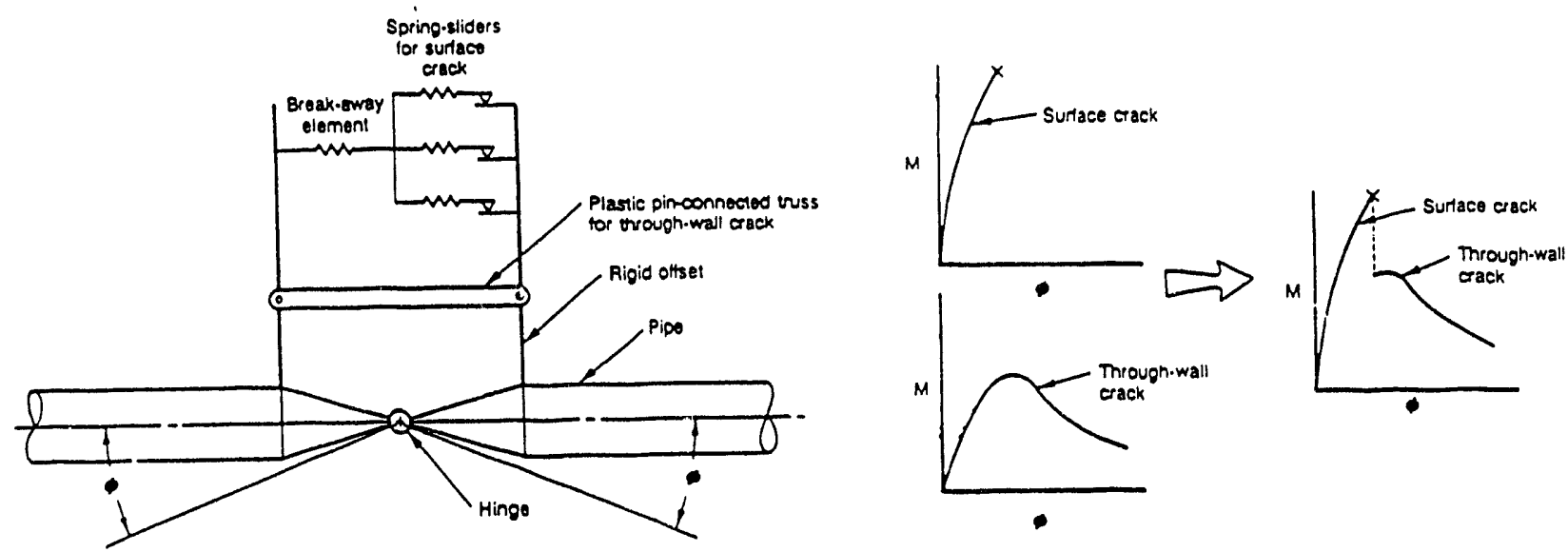

Figure 3.34 Model of surface crack to through-wall crack transition using spring-sliders and one plastic truss 


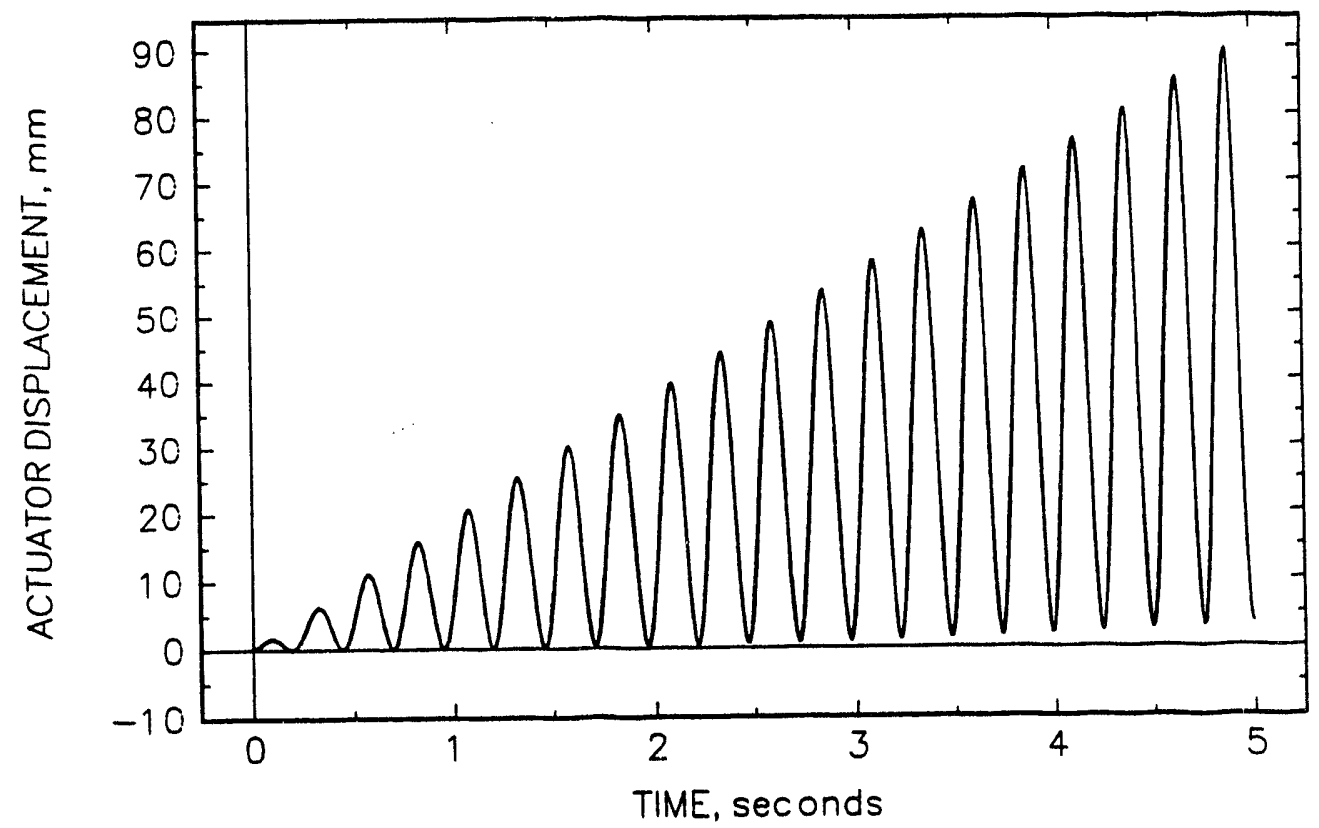

Figure 3.35 Forcing function for IPIRG-1 Experiment 1.3-7

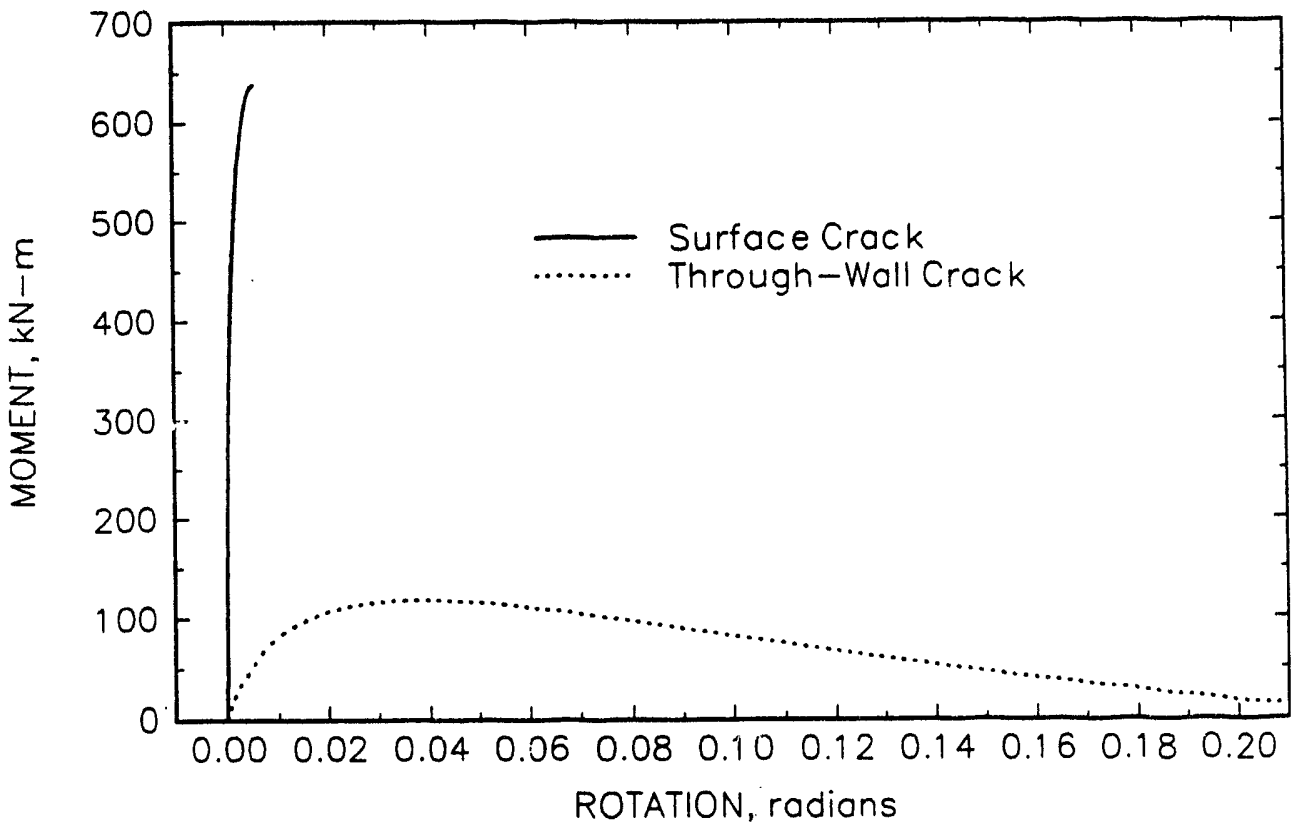

Figure 3.36 Input moment-rotation response for ITRG-1 Experiment 1.3-7 from J-estimation scheme analyses 


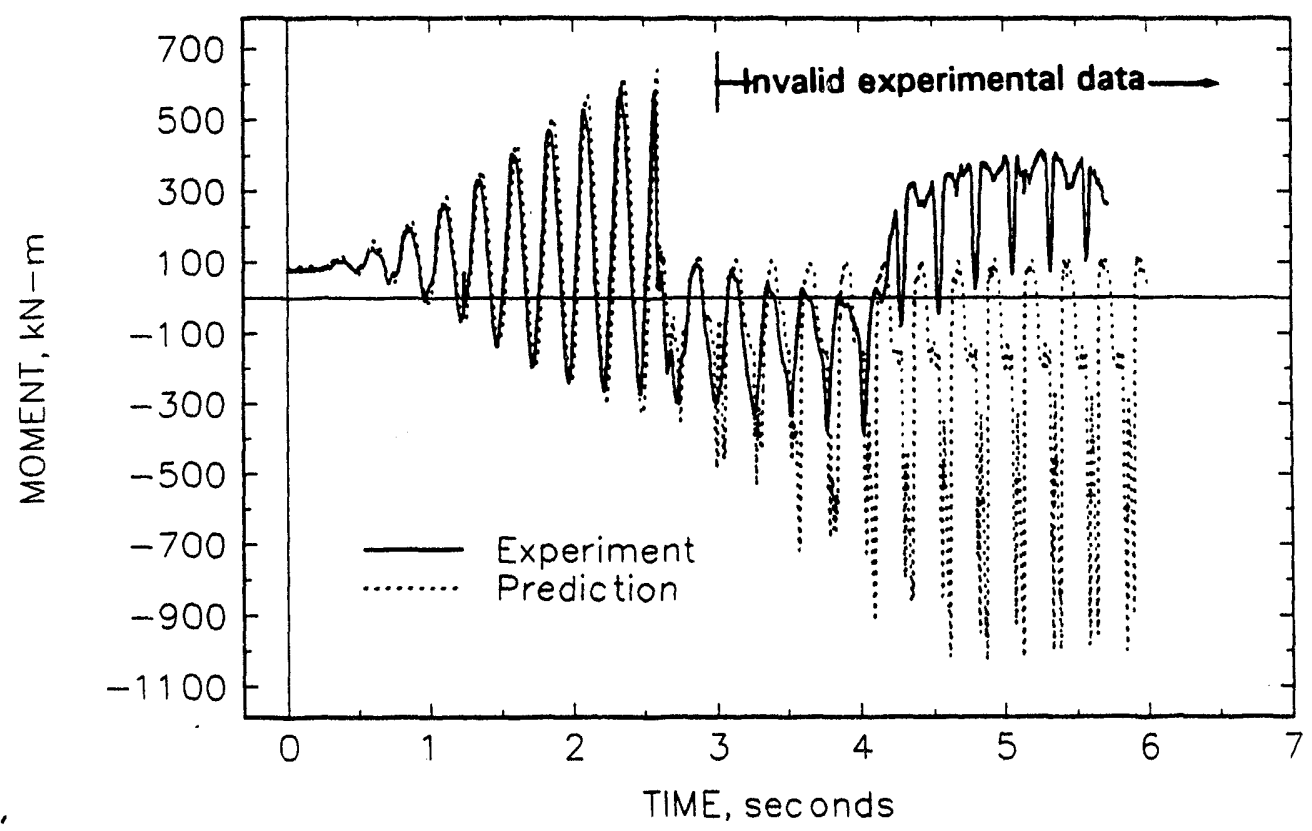

Figure 3.37 Comparison of crack section moment as a function of time for IPIRG-1 Experiment 1.3-7

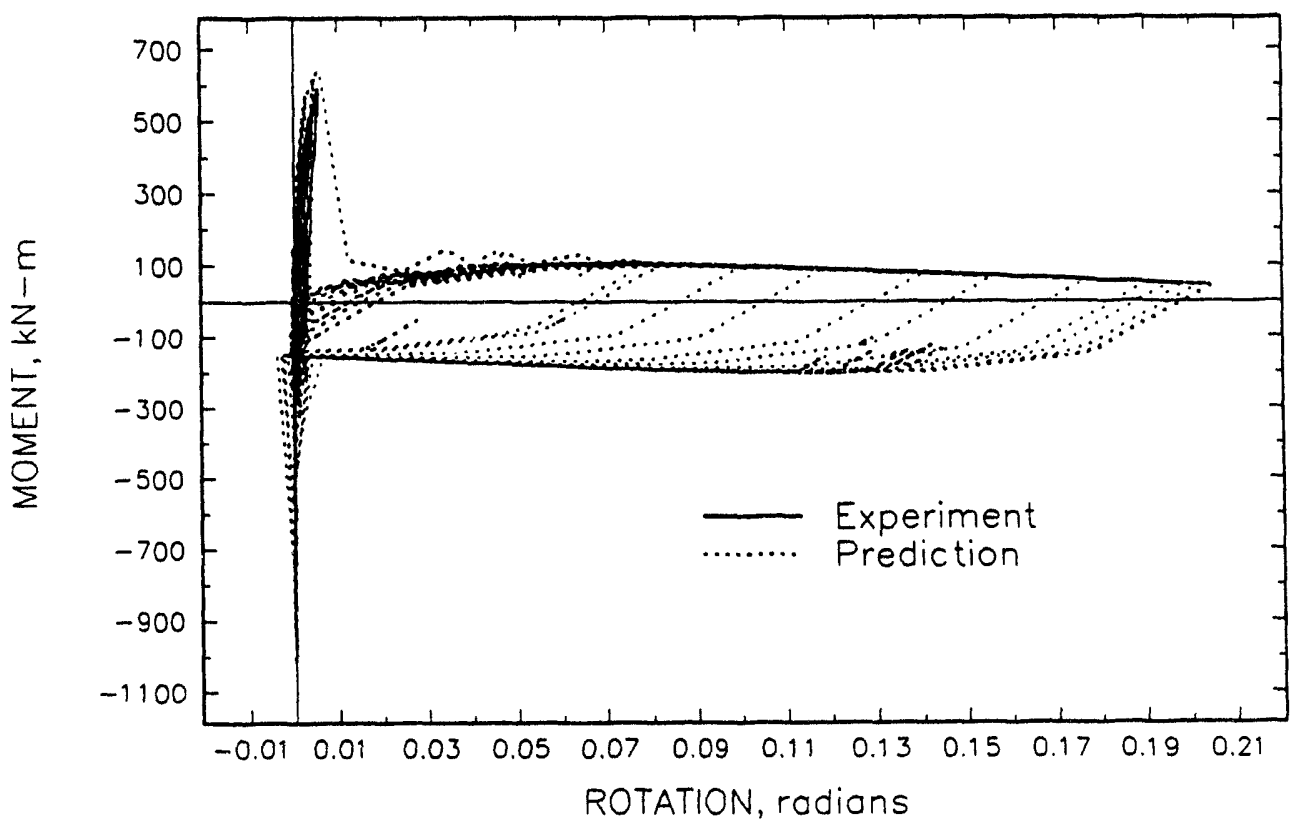

Figure 3.38 Crack section cyclic moment-rotation for IPIRG-1 Experiment 1.3-7 


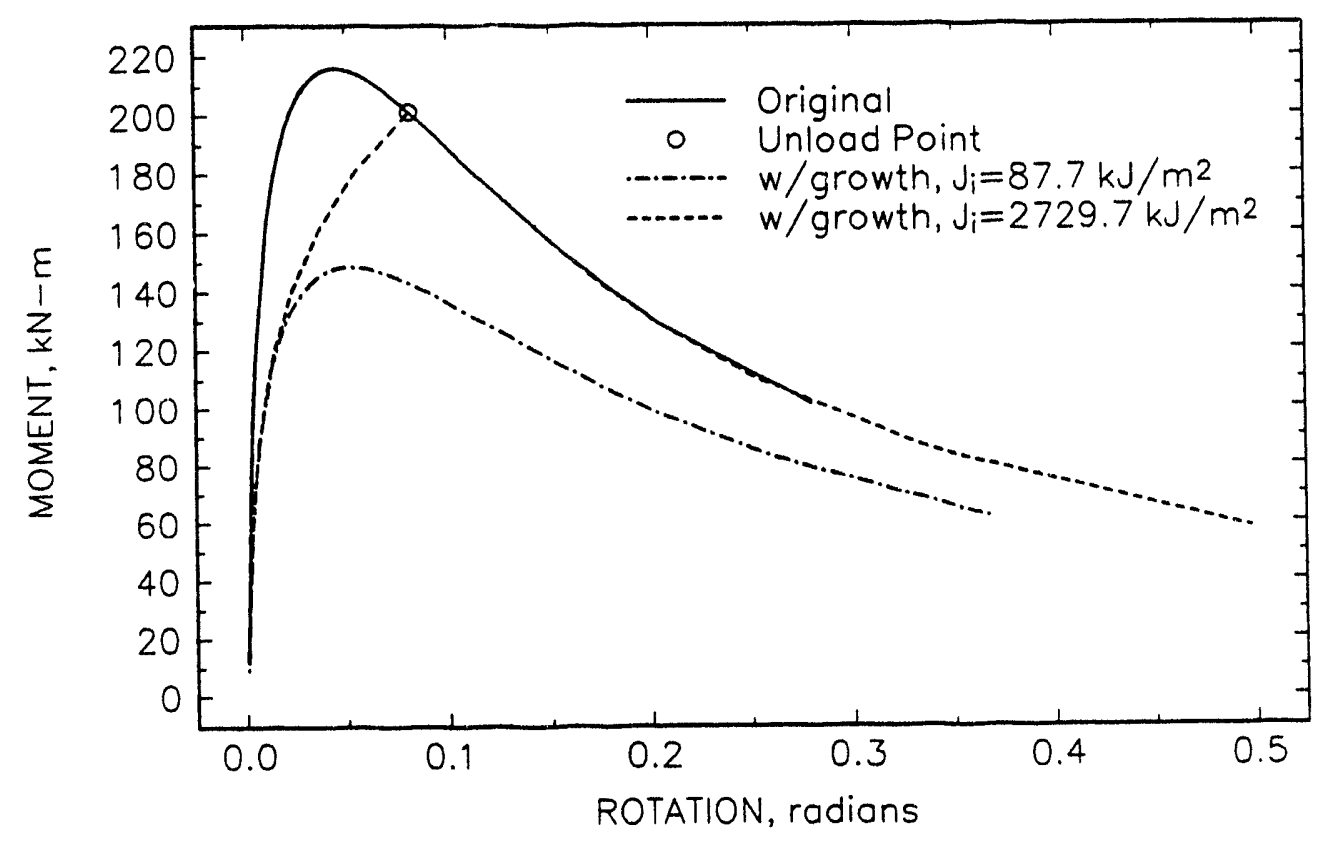

Figure 3.39 Ideas for incorporating crack growth in a cyclically loaded pipe specimen $\left(1.0 \mathrm{in}-\mathrm{lb} / \mathrm{in}^{2}=0.17513 \mathrm{~kJ} / \mathrm{m}^{2}\right)$

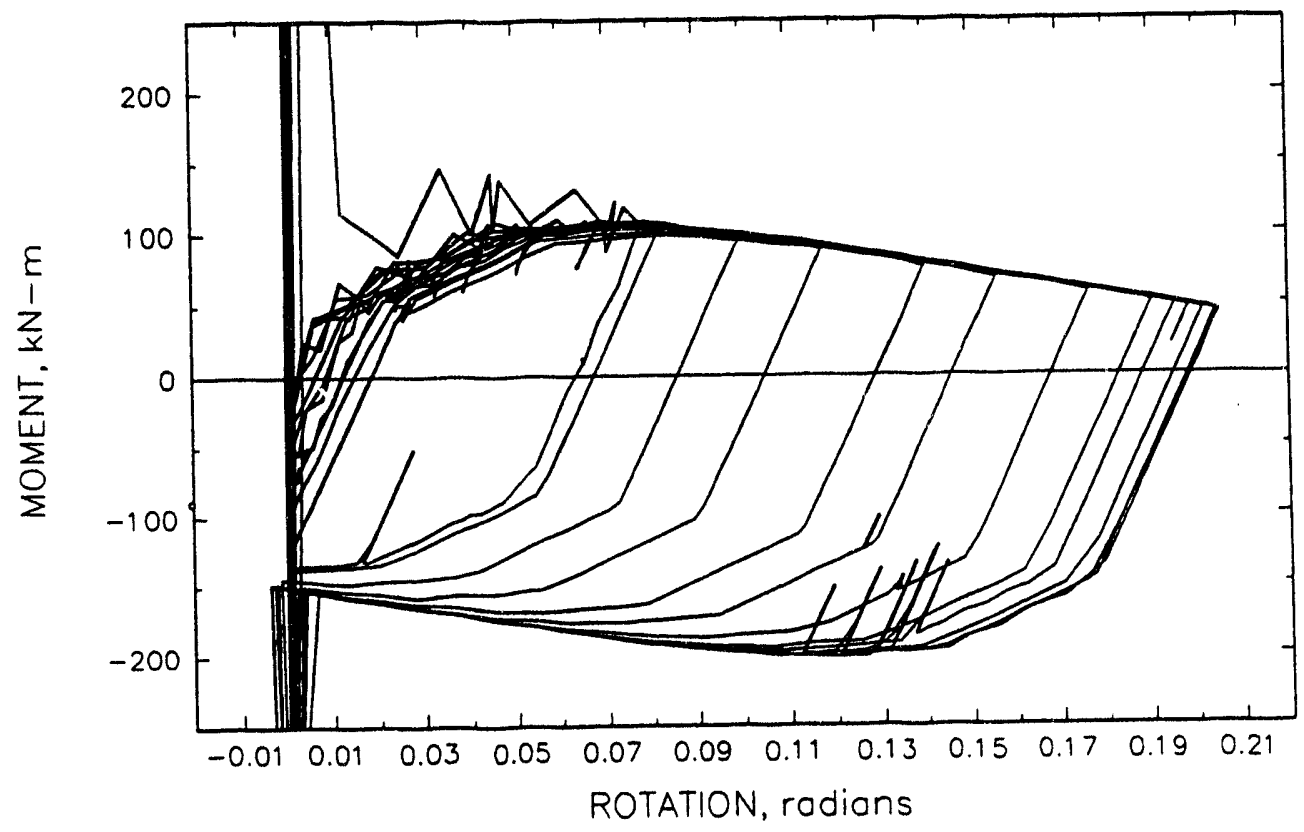

Figure 3.40 Kinematic hardening behavior at large rotations when the tangent stiffness is negative. (Note inflection on compressive loading is incorrect modelling) 
NONLINEAR FEA FRACTURE MECHANICS ANALYSES

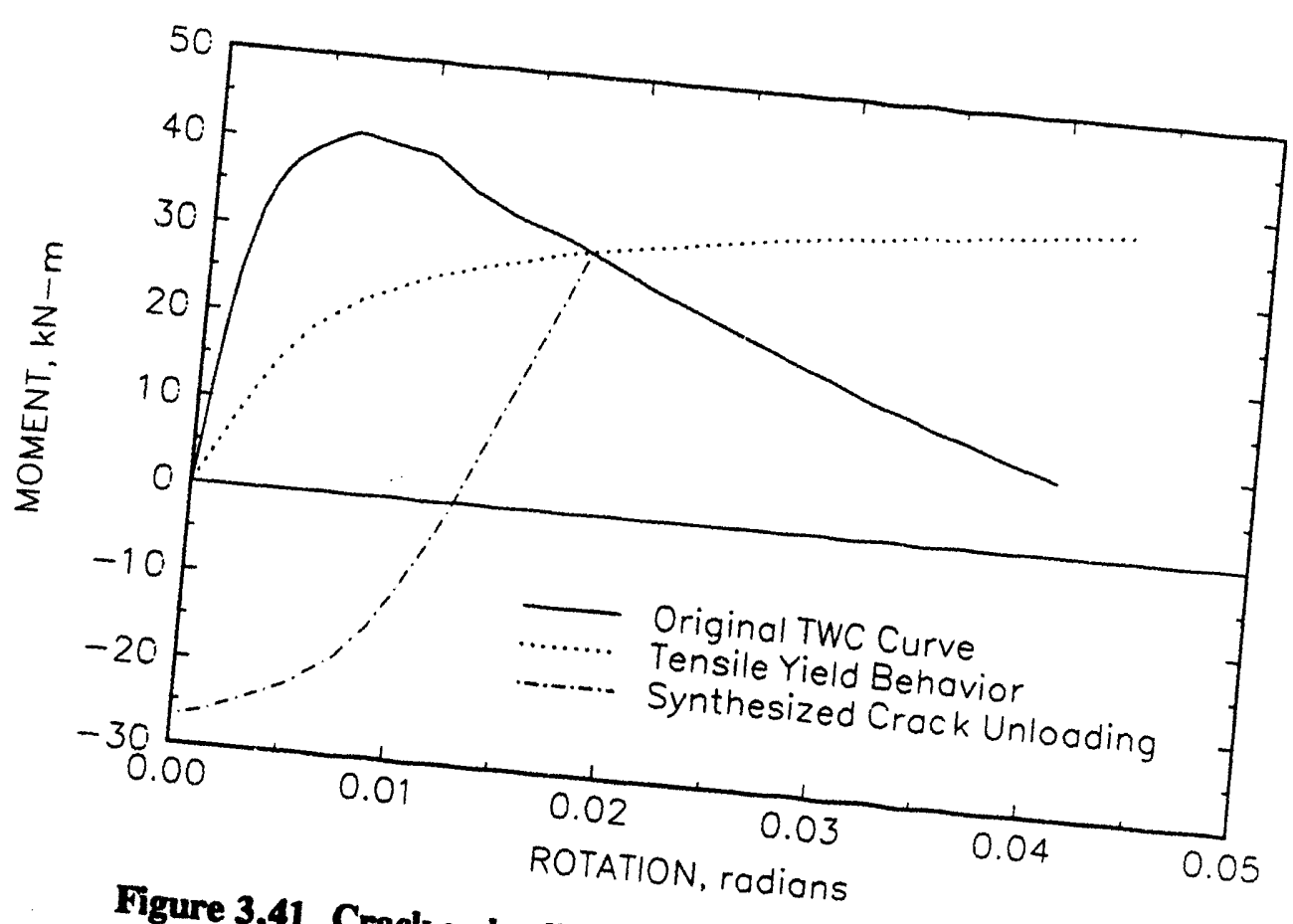

Section 3

Figure 3.41 Crack unloading and compressive behavior model

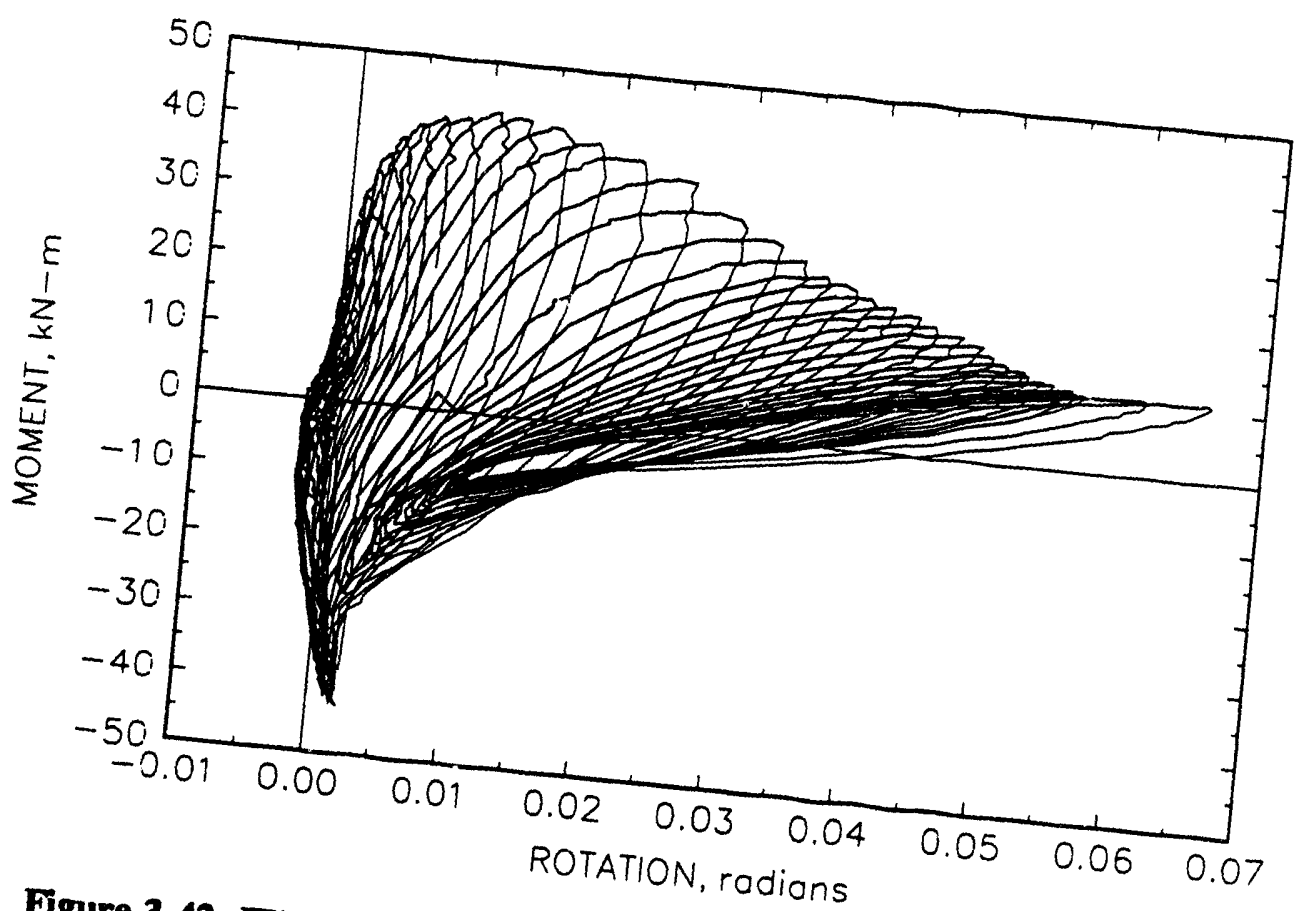

Figure 3.42 IPIRG-1 Experiment carbon steel through-wall crack) $1.2-4$ (displacement controlled loading,

NUREG/CR-6234 


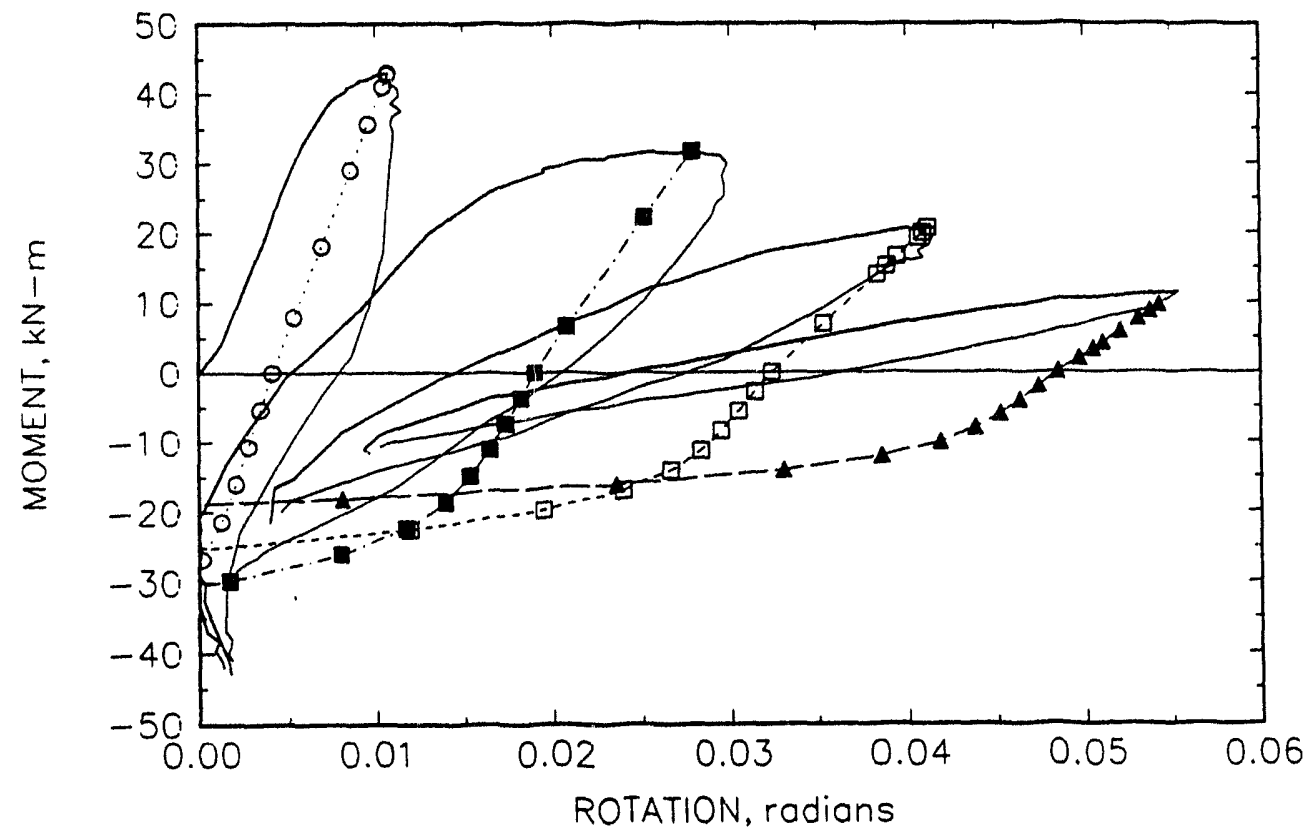

Figure 3.43 Unloading model performance using measured crack growth data (solid curves are selected cycles from IPIRG-1 Experiment 1.2-4 and dashed curves are predicted unloading response)

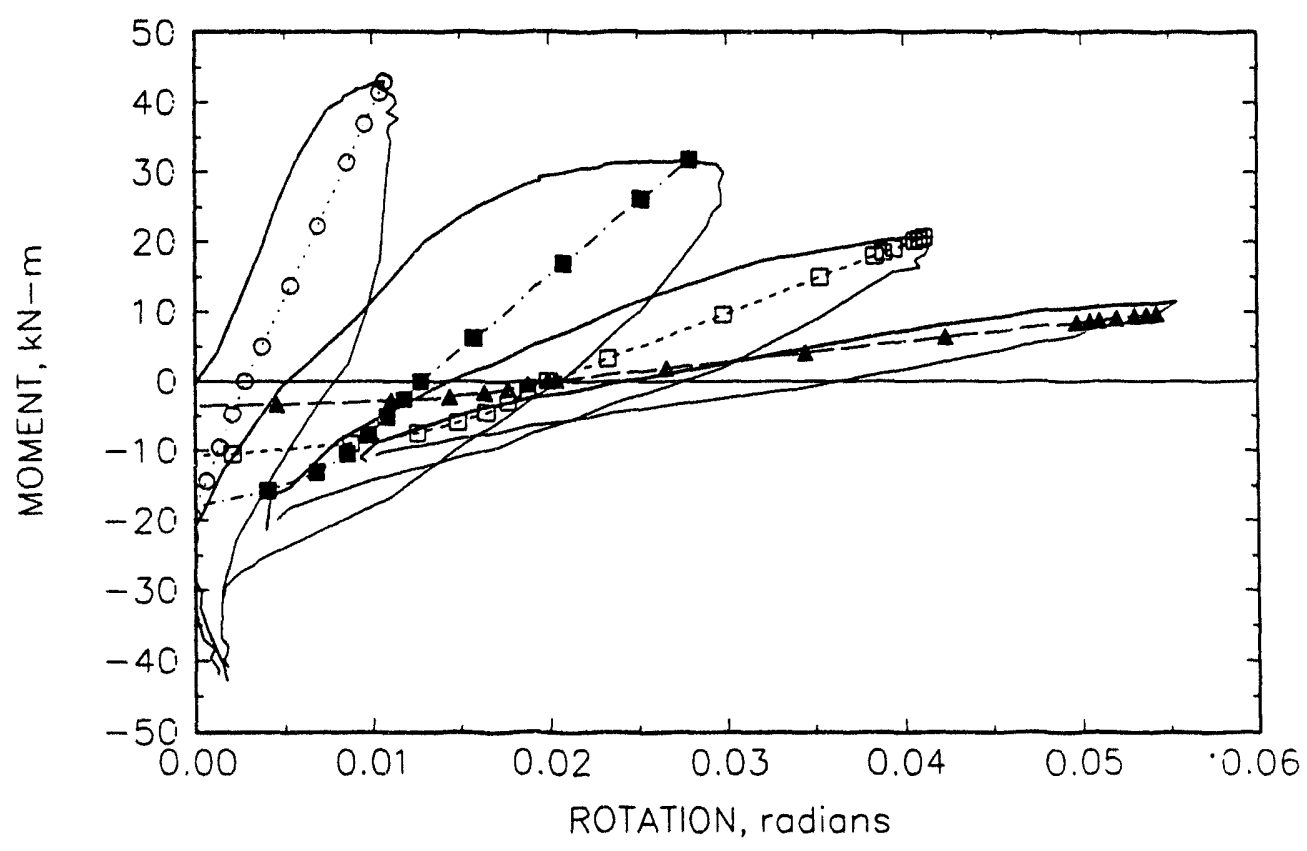

Figure 3.44 Unloading model performance using LBB.ENG2 J-estimation scheme predicted crack with $J-R$ curve derived from an $\eta$-factor analysis of the pipe experiment data (solid curves are selected cycles from IPIRG-1 Experiment 1.2-4 and dashed curves are predicted unloading response) 


\section{HDR-E31 EXPERIMENTS}

In a postulated break and blowdown of a BWR feedwater line, the amount of cooling water outflow is limited by the rapid closing of a check valve. The rapid pressure drop and subsequent water-hammer waves, caused by the valve closure, produce severe structural oscillations of the piping system. Past experience indicates that the resulting loads can usually be sustained by the piping materials used in modern nuclear plants. However, it is not clear that this also holds for a weakened pipe that may have been damaged (cracked) by long term operational stresses. To address this question, two blowdown experiments with predamaged piping were conducted as part of Phase III of the HDR Safety Program. The tests were designated E31.2 and E31.3 (Test Group E31). The overall objectives of these tests included the following:

- Determine the global structurial response of the pipe system subjected to water-hammer loads and estimate the effect of the cracks on this response.

- Determine the failure loads and processes for the predamaged components, i.e., crack growth, possible leaks, etc.

- Ascertain how a dynamically induced event influences the leak-before-break behavior deducsd from static experiments.

- Determine the pipe whip resulting from the possible break of the predamaged components.

- Provide data for the validation and verification of linear and nonlinear analysis models of the structural, fracture-mechanical, and thermohydraulic aspects of the blowdown event.

The next to last item is of primary interest in the current effort. As stated earlier, finite element analysis was used to model both the behavior of the cracked pipe section as well as the overall structural response of the pipe system. The intent is to assess the analyses by comparing predictions with experimentally observed behavior.

To provide the background for performing the structural/fracture assessments, a description of the HDR-E31 test facility is presented. Three topics are included:

- Description of the facility

- Discussion of the loading

- Details of the flaws.

The presentation is made at a level of detail sufficient that other researchers could model the experiments. References from which these data have been extracted are all identified. 


\subsection{Experimental Facility}

The HDR Facility, where the E31 blowdown experiments were conducted in 1990 and 1991, is a decommissioned superheated-steam BWR located in Karlstein, Germany. It is operated by the Kernforschungszentrum Karlsruhe (KfK) and since 1975, has been used for a wide variety of structural/seismic, thermohydraulic, and materials experiments.

\subsubsection{Geometry}

The pipe system used in the E31 tests was newly constructed for this purpose and is a model of a BWR feedwater line. The line is approximately $25 \mathrm{~m}$ (82 feet) long and is attached to the reactor pressure vessel (RPV) at one end as shown schematically in Figure 4.1. A nearly rigid support (Fixed Point) is provided just upstream of the check valve and a second support is located near the end of the rupture disc assembly.

The flawed section was a straight section of pipe in the pipe emanating from the RPV and located close to the vessel. For the E31 experiments, predamaged sections were installed, tested, and then removed for each test. Except for the predamaged section, the pipe system components remained the same for all tests. The pipe system was nominally $425 \mathrm{~mm}$ (16.7 inches) in diameter (DN 425$)$ and ran from the S-nozzle of the RPV about $6 \mathrm{~m}$ (236 inches) in the radial direction, then proceeded approximately $7 \mathrm{~m}$ (276 inches) vertically downwards and continued $3 \mathrm{~m}$ (118 inches) horizontally perpendicular to the $S$-nozzle. Finally, the line continued through two more elbows to the Fixed Point support. From there, the pipe continued with the feedwater check valve to the rupture disc assembly. In contrast to earlier blowdown tests conducted in this facility, the check valve was located behind the Fixed Point support, i.e., outside the region of significant structural response.

The global dimensions of the pipe runs and components are given in the perspective view of Figure 4.2. Details of the pipe system geometry are contained in the experimental Design and Quick-Look Reports for Tests E31.2 and E31.3, Refs. 4.1 to 4.4. The geometry and overall length of the piping for the two experiments was identical, except for some minor length differences in the predamaged pipe component and the immediately adjacent sections. Most of the pipe system had a nominal wall thickness of $25 \mathrm{~mm}$ ( 0.98 inches), but in order to ensure that the test sections were the weakest component, their wall thickness was reduced by machining to $16 \mathrm{~mm}$ (0.63 inches). Table 4.1 summarizes the as-built dimensions of the pipe system.

The pipe system was insulated along its entire length using mats with a thickness of $80 \mathrm{~mm}$ and a density of approximately $100 \mathrm{~kg} / \mathrm{m}^{3}\left(1602 \mathrm{lb} / \mathrm{ft}^{3}\right)$. This gives an additional mass of about $14 \mathrm{~kg} / \mathrm{m}^{3}$ $\left(224 \mathrm{lb} / \mathrm{ft}^{3}\right)$ of pipe length.

\subsubsection{Boundary Conditions}

The pipe system was rigidly supported at the RPV wall, Figure 4.3. The second nearly rigid support was provided by the so called Fixed Point support, which was specifically designed to restrain all six degrees-of-freedom of motion. A massive steel structure made up of beams, columns and plates transmitted the load from the pipe to the building, Figure 4.4. A specially fabricated pipe section with four trunnions welded to it, Figure 4.5, restrained the pipe at the Fixed Point. The trunnions 
were held by plates, which have holes of the same diameter as the trunnions. The plates in turn were welded to the steel structure. This arrangement assured that all six degrees-of-freedom were restrained, but no stresses were generated due to the radial expansion of the pipe during heat-up. All four trunnions together carried the axial force and torsion. The two lateral forces and the bending moments were carried in each case by two opposite trunnions.

Because the feedwater check valve and rupture disc assembly extend another $4.5 \mathrm{~m}$ (177 inch) from the Fixed Point, an additional support was provided near the end of the assembly. This support was designed to restrain horizontal forces of $255 \mathrm{kN}(57,330 \mathrm{lb})$ and vertical forces of $178 \mathrm{kN}(40,020$ lb), Figure 4.6, and suppresses any unwanted oscillations that could possibly influence the functioning of the valve. This support had no effect on the test system proper, because it was located past the Fixed Point.

The design stiffnesses for the Fixed Point support were calculated to be $457 \mathrm{MN}-\mathrm{m} / \mathrm{rad}\left(3.37 \times 10^{8} \mathrm{ft}-\right.$ $\mathrm{lb} / \mathrm{rad})$ for vertical bending and $637 \mathrm{MN}-\mathrm{m} / \mathrm{rad}\left(4.7 \times 10^{8} \mathrm{ft}-\mathrm{lb} / \mathrm{rad}\right)$ for horizontal bending, Ref. 4.1. To estimate the effect of the Fixed Point stiffness on the vibration behavior of the pipe system, the piping was modeled as a beam rigidly supported at the RPV and having the above stiffnesses at the Fixed Point, Ref. 4.5. Taking into account the effect of the piping components downstream of the Fixed Point, as well as of the support at the rupture disc assembly, it was estimated that the first eigen frequency of the pipe system was reduced by 3-percent in comparison to a pipe system supported rigidly at both ends.

Using data from static displacement tests, as well as from the dynamic blowdown tests, it was found (Refs. 4.5 and 4.6) that the actual Fixed Point stiffnesses were only about one half of the values estimated from the design data. Further, it was shown that a slight softening (approximately 10percent) of the Fixed Point support occurred between the first (E31.2) and second (E31.3) blowdown tests. However, the overall effect on the pipe system dynamic behavior of all these aspects is at most a further 1-percent reduction in the fundamental frequency of the pipe system relative to piping rigidly supported at both ends, Refs. 4.5 and 4.6. This clearly demonstrates, that the stiffness of the Fixed Point support has, at best, a minor effect on the global dynamic response of the pipe system.

\subsubsection{Pipe System Materials}

All of the piping materials for the test system were German ferritic steels. Their designation according to German Standards (DIN), as well as their nominal compositions are indicated in Table 4.1, where the various pipe system compunents are listed. The nominal mechanical and physical characteristic, as obtained from standard data sheets, are given at three temperatures $(20 \mathrm{C}, 200 \mathrm{C}$, $300 \mathrm{C}$ [ $68 \mathrm{~F}, 312 \mathrm{~F}$, and $572 \mathrm{~F}]$ ) in Tables 4.2 to 4.6. For specific references to the material property data, Ref. 4.1 should be consulted.

Extensive material characterization tests on the pipe materials were also performed by the Materials Testing Institute of the University of Stuttgart - MPA, Stuttgart, Ref. 4.7. Their tests were, in general, run at room temperature (RT $=20 \mathrm{C}$ [68 F]) and at $240 \mathrm{C}$ (464 F), the latter being comparable to nominal blowdown test temperature. The MPA experiments included tensile tests, some compression tests, notch (Charpy) impact tests, spectral analyses to determine the material composition, and fracture-mechanical tests. In these tests, multiple samples were analyzed from 
various components. Samples were taken from the components longitudirally and circumferentially, both in the axial and radial (thickness) directions.

Comparisons of the yield point, tensile strength and elastic modulus between the MPA tests and the data sheet values for the three most important materials at $240 \mathrm{C}$ (464 F) are given in Figure 4.7. The averaged MPA data for the yield point and tensile strength are significantly higher than the minimum values from the data sheets. There is excellent agreement between the measured elastic modulus values and those given in the data sheets. Some variability in the measured data for a given material was also observed by MPA, depending on the component from which the test sample was obtained. The actual measured stress-strain curves at a temperature of $240 \mathrm{C}$ (464 F) for these materials are shown in Figure 4.8.

\subsubsection{Instrumentation/Measurements}

The pipe system in the E31 tests was fully instrumented to measure all important thermohydraulic and structural response variables, Refs. 4.1 to 4.4. These included pressures, temperatures, flow rates, strains, displacements, and accelerations. For the current application, of greatest significance are the pressure, strain, and displacement measurements. The pressure measurements in the pipe system between the RPV and the Fixed Point support define the loading for the structure. The strain measurements at the various cross-sections are used to determine the moments and forces acting at these locations, Refs. 4.3 and 4.4, and these, in turn, can be compared with the predicted values. Finally, displacement measurements describe the giobal response of the pipe system and can again be used to check the calculations.

The behavior of the predamaged (cracked) sections is primarily inferred from post-test fracturemechanical and metallographic examinations. Details of these studies are given in References 4.8 and 4.9. Because of the large strains occurring at the cracks, the strain gages installed at these locations can only follow the early history of the crack response.

The pipe system cross sections at which strains were measured are shown in Figure 4.9. Typically, at a straight pipe section, six strain gages were installed to allow the computation of all the forces, moments, and stresses, Refs. 4.3 and 4.4. These include four longitudinal (axial) measurements, one circumferential measurement and one diagonal measurement at $\mathbf{4 5}$ degrees, Figure 4.10. At elbows and the cracked pipe section, as many as 22 strain gages were installed, Refs. 4.3 and 4.4. The global cartesian coordinate system, as well as the local (pipe related) polar coordinate systems, are indicated in Figure 4.11. These define the strain and displacement measurement directions, as well as those of derived quantities such as forces and moments.

While dynamic pressure measurements were made throughout the entire system, only those located between the RPV nozzle and the Fixed Point support are essential for determining the blowdown/water hammer loading of the pipe system. Due to gage malfunctions, only three such measurements were made in test E31.2, but as many as six pressure-time histories were recorded in test E31.3. The locations of these measurements are shown schematically in Figure 4.12.

Global displacement measurements were made at three locations. At two of these locations, triaxial measurements were recorded and at the third location, displacements only in two directions were 
obtained. The locations of the displacement measurements are given in Figure 4.13. To check out the instrumentation and global behavior of the pipe system, static displacement tests were performed prior to each of the blowdown experiments. A vertically upward directed force applied in the center of the U-bend, Figure 4.13, was applied in stages up to a maximum of 100 to $110 \mathrm{kN}(22,482$ to $24,730 \mathrm{lbs})$. These measurements can be used for a global check of analytical models.

\subsection{Loading}

\subsubsection{Initial Test Conditions}

The experiments were intended to simulate a feedwater line at thermohydraulic conditions typical for a BWR. Table 4.7 gives a comparison between the thermohydraulic values achieved in the experiments and the intended test design values. For the measured data, the mean value of the appropriate gages are used and standard deviations are given.

\subsubsection{Rupture Disc Assembly and Check Valve}

The blowdown/water hammer event in the E31 tests was initiated by the rapid bursting of double rupture dises located at the end of the rupture disc assembly. The discs were held in a special fixture as shown in Figure 4.14. The two rupture discs were arranged in series and each could sustain only 70 percent of the test starting pressure of 90 bars $(1,320$ psi). Therefore, it was necessary during the pressurization and heat-up to adjust the pressure in the space between the rupture discs such that neither disc exceeded its rupture pressure. Using a nitrogen gas supply and pressure regulators, the pressure in that space was always maintained at one half of the system pressure.

The opening of a valve rapidly depressurizes the space between the rupture disc at the start of the tests. This leads to the rapid bursting of the inner disc. Because the full system pressure now acts on the outer disc, it also bursts out of its fixture. In this manner, the total break cross-section is opened in approximately $3 \mathrm{~ms}$.

The feedwater check valve used in the experiments is designated SRV-350 and had also been used in previous blowdown tests (for details see Refs. 4.1 and 4.2). It was designed to minimize the water hammer effect, by rapidly limiting the outflow and thus preventing the development of high flow velocities, and by providing a soft closure of the valve through hydraulic damping. In the E31 test series, the objective was to produce large pressure waves and pipe system loadings. Hence, the valve was modified to essentially close without damping. In order to allow the valve to remain open prior to the blowdown, even without flow through the pipe, it was installed with its stem at the shallow angle of 15 degrees, relative to the horizontal. During the tests, the valve closed in approximately 51 to $53 \mathrm{~ms}$ (167 to $174 \mathrm{fps}$ ) and its maximum closing velocity was about $13.5 \mathrm{~m} / \mathrm{s}$ ( $44.3 \mathrm{fps})$, Refs. 4.3 and 4.4. In spite of its large weight $(24 \mathrm{kN}[5,396 \mathrm{lb}])$, the valve had no significant influence on the pipe system dynamics because it was installed on the downstream side of the Fixed Point support. 


\subsubsection{Pipe System Pressure-Time Histories}

The pressure-time variations in the pipe system were measured at a number of locations. However, due to gage malfunctions, only three measurements were available in test E31.2, Ref. 4.10, whereas in test E31.3, six measurements could be used, Ref. 4.11. The locations for the pressure measurements are given in Figure 4.12. At all locations, there is first a rapid pressure drop from 92 (1,350 psi) to about 30 bar ( $440 \mathrm{psi})$, due to the rupture disc bursting. This is followed by an oscillation due to pressure wave reflection at the RPV, and then by a very high pressure spike caused by the closure of the valve. The maximum pressures observed in the tests were respectively 237 bar (3,480 psi) in Test E31.2 and 236 bar (3,470 psi) in test E31.3. These pressures are about 15-percent lower than those that are estimated using water hammer equations and the measured maximum mass flow rate, Refs. 4.3 and 4.4. It is thought that these discrepancies are due to the flow measurements overestimating the actual flows.

The three usable pressure-time histories for test E31.2 are given in Figure 4.15, and the dynamic pressures for test E31.3 are presented in Figure 4.16.

\subsubsection{Elbow Pressures, Forces, and Moments}

The pipe system in the E31 tests was essentially rigidly supported at the RPV and at the Fixed Point support. Thus, the only substantial loads that acted on the structure during the blowdown/water hammer event were the loads generated by the pressure waves passing through the elbows. The loads resulting from the blowdown jet were taken-up by the Fixed Point support and have no effect on the piping upstream of this point.

No detailed pressure or flow measurements in the elbows were made during the E31 tests. Even if such information was available, it would still be necessary to derive the resultant time varying elbow forces, either through the momentum equation or by the surface integral of the pressure over the entire elbow. Most piping response analysis codes (and specifically ANSYS) do not have the capability of generating the elbow forces from the surface integral of the pressures. Therefore, in the current application it was necessary to provide as input to the calculations, approximate elbow forces derived from the available pressure measurements.

It has been shown, Refs. 4.12 and 4.13, that a good approximation of an equivalent pressure for the elbow center plane can be derived by arithmetic interpolation between pressure measurements at locations upstream and downstream of the elbow. Multiplying this equivalent pressure by the pipe cross-sectional area, one obtains forces that are applied at the ends of the elbow. The forces determined in this manner are a good approximation of the actual fluid forces, Ref. 4.13. The procedure is illustrated in Figure 4.17. Note that only two pressure measurements ons opposite sides of an elbow are necessary to derive the elbow pressure and hence, the forces acting on the elbow. The force-time histories obtained in this manner for both Experiments E31.2 and E31.3 are shown respectively in Figures 4.18 and 4.19. Although they are nominally identical, the forces from the two experiments are slightly different and thus, the crack driving force is also slightly different. These forces were input into the ANSYS calculations to predict the gross piping response and to generate the moments and forces acting on the cracked pipe section. 
The "measured" cross-sectional forces and moments in the piping can be inferred (calculated) from the measured strains. However, the force and moment caiculations are based on linear-elastic formulas. Hence, the obtained values are only valid at locations which do not experience significant plastic strains.

\subsection{Flaws}

\subsubsection{Test Section}

As indicated earlier, straight pipe test sections with circumferential cracks were subjected to blowdown/water hammer loading in the E31 tests. The overall geometry of the test sections is shown in Figure 4.20. The only difference between Experiments E31.2 and E31.3 is the depth of the initial crack and some minor differences in the overall length of the test sections. The starter cracks were produced by first errosively forming a $2 \mathrm{~mm}(0.079 \mathrm{inch})$ deep, narrow $(0.2 \mathrm{~mm}$ [0.0079 inch]) notch of the desired extent, and then subjecting the test section to cyclic bending, thus obtaining a fatigue crack of the desired depth. The crack depth was controlled by continuous surveillance during the cyclic bending.

The wall thickness of the test sections was reduced by machining from $25 \mathrm{~mm}$ to $16 \mathrm{~mm}(0.98$ to 0.63 inch). This was done to ensure that the test section would experience the highest stresses and that other pipe system components would not be unduly stressed, thus limiting any possible failures to the cracked section.

The important geometrical variables for the test sections in the two experiments are summarized in Table 4.8.

The actual starter crack profiles, as measured ultrasonically prior to the test and as obtained by sectioning after the experiment, are shown in Figure 4.21 for Experiment E31.2. As can be seen, the MPA pretest measurement is in excellent agreement with the post-test measurements. For Experiment E31.3, the ultrasonic pretest measurement of the starter crack profile is given in Figure 4.22. Post-test measurements for E31.3 were not available when these analyses were performed.

\subsubsection{Test Section Materials}

The material for the test sections containing the initial flaws is a German ferritic steel, 20 MnMoNi 5 5, containing about 1.28-percent $\mathrm{Mn}, 0.64$-percent $\mathrm{Ni}$ and 0.46-percent Mo. Other major constituents are 0.17-percent $\mathrm{C}, 0.18$-percent $\mathrm{Si}$, and 0.20-percent $\mathrm{Cr}$, Ref. 4.7. Nominal values of the mechanical and fracture related parameters, taken from standard data sheets, are given in Table 4.2. Density of the test specimen material is about $7.84 \mathrm{Mg} / \mathrm{m}^{3}\left(489 \mathrm{lb} / \mathrm{ft}^{3}\right)$.

Extensive studies on the material were conducted by MPA Stuttgart, Ref. 4.7, and it was shown that the laboratory determined yield stress and tensile strength are considerably higher than the data sheet values, while the elastic moduli are in close agreement. The latter has an average value of $198 \mathrm{GPa}$ $(28,710,000 \mathrm{psi})$ at $240 \mathrm{C}(464 \mathrm{~F})$ and increases to about $208 \mathrm{GPa}(30,160,000 \mathrm{psi})$ at room temperature. Tensile test stress-strain curves, Figure 4.8, indicate that there can be considerable 
variation in the material post yield behavior, depending on the component from which the test specimens were obtained. On the other hand, orientation of the test samples has little influence on the behavior.

The effect. of temperature on the mechanical characteristics of the test section material, as obtained from the tensile testsi, Ref. 4.7, is illustrated in Table 4.9.

It is observed that while temperature has a significant effect on the yield point (0.2-percent offset), there is virtually no influence on the ultimate tensile strength of the material. On the other hand, the strain at rupture is significantly larger at room temperature, when compared to that at $240 \mathrm{C}$ (464 F).

MPA Stuttgart, Ref. 4.7, also conducted extensive tests on the test section material to determine its fracture toughness characteristics. They developed the crack resistance curves using the single

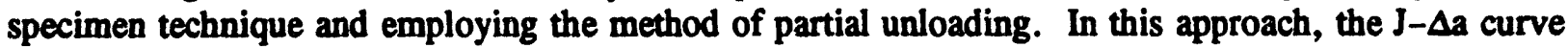
is determined by indirectly calculating the crack growth from the changes in the sample stiffness or compliance function. In addition to developing crack resistance or J-R curves, MPA also obtained crack tip opening curves and determined crack initiation characteristics (energy values) in accordance, with various criteria.

The maximum value for $J$ determined in the tests was about $750 \mathrm{~kJ} / \mathrm{m}^{2}\left(4,282 \mathrm{in}-\mathrm{lb} / \mathrm{in}^{2}\right)$, corresponding to crack elongation of $3.2 \mathrm{~mm}(0.126 \mathrm{inch})$ and a CTOD of $0.75 \mathrm{~mm}$ (19.05 inch). It was shown that the J-R curves are not very sensitive to the sample orientation. This also holds for the $\mathrm{J}$ at crack initiation, $\mathrm{J}_{\mathrm{i}}$. A typical $\mathrm{J}-\mathrm{R}$ curve for the test section materials is given in Figure 4.23.

Finally, notch impact (Charpy) tests were conducted over a range of temperatures for the test section material using samples at various orientations in the pipe component. The results are summarized in a series of impact energy versus temperature curves shown in Figure 4.24 and taken from Ref. 4.7. The results do depend on the orientation of the test sample, with the maximum impact energies ranging from 200 to $250 \mathrm{~J}$ (147 to $184 \mathrm{ft}-\mathrm{lb}$ ).

\subsection{References}

4.1 Schrammel, D. and Brosi, S., "Design Report, Behavior of a Faulted Pipeline Under Blowdown Loading", Test Group E31 (BLORI), (In German), PHDR-Working Report No. 30.018/90, Kernforschungszentrum, Karlsruhe, June 1990.

4.2 Schrammel, D., "Design Report, Behavior of a Faulted Pipeline Under Blowdown Loading", Test Group E31 (BLORI), Blowdown Test E31.3 (In German), PHDR-Working Report No. 30.037/90, Kernforschungszentrum, Karlsruhe, April 1991.

4.3 Schrammel, D., "Behavior of a Faulted Pipeline During a Simulated Loss of Coolant Accident with High Water-hammer Loading", Quick Look Report, Test Group E31, Experiment E31.2 (In German), Technical Report PHDR 106-91, Kernforschungszentrum, Karlsruhe, January 1991. 
4.4 Schrammel, D., "Behavior of a Faulted Pipeline During a Simulated Loss of Coolant Accident with High Water-hammer Loading", Quick Look Report, Test Group E31, Experiment E31.3 (In German), Technical Report PHDR 108-91, Kernforschungszentrum, Karlsruhe, November 1991.

4.5 Schrammel, D., "Estimating the Stiffness of the Fixed Point Support From Experimental Data of the Pipeline in Test Groups E21 and 31", (In German), PHDR-Working Report No. 30.026/90, Kernforschungszentrum, Karlsruhe, August 1990.

4.6 Schrammel, D., "Estimating the Stiffness of the Fixed Point Support of the Test-Pipeline Using Experimental Data From Test E31.3", (In German), PHDR-Working Report No. 30.043/91, Kernforschungszentrum, Karlsruhe, July 1991.

4.7 Eisele, V. and Restemeyer, "Material Investigations for the Pipe Tests E21 and E31", (In German), Test Report 875021 040, MPA Stuttgart, PHDR-Working Report No. 20.060/91, April 1991.

4.8 Diem, H. et al., "Fracture-Mechanical and Metallographic Investigation of the Circumferential Crack in BLORI-Test E31.2", (In German), Test Report 875031 060, MPA Stuttgart, PHDR-Working Report No. 30.039/91, June 1991.

4.9 Diem, H. et al., "Fracture-Mechanical and Metallographic Investigation of the Circumferential Crack in BLORI-Test E31.3", (In German), Test Report 875031 061, MPA Stuttgart, PHDR-Working Report No. 30.050/92, January 1992.

4.10 Schrammel, D., "Calculation of the Elbow Forces From the Measured Pressures for the Blowdown Test E31.2", (In German), PHDR-Working Report No. 30.025/90, Kernforschungszentrum, Karlsruhe, August 1990.

4.11 Schrammel, D., "Calculation of the Elbow Forces From the Measured Pressures for the Blowdown Test E31.3", (In German), PHDR-Working Report No. 30.042/91, Kernforschungszentrum, Karlsruhe, July 1991.

4.12 Meier, D., "Calculation of the Fluid Induced Forces Acting on a Pipe by Means of the Surface Integral and Its Application to a Blowdown Test in the HDR", Transactions of 8th International Conference on Structural Mechanics in Reactor Technology, Vol. F1, Paper F1 3/4, pp. 85-90, Brussels, Belgium, August 19-23, 1985.

4.13 Meier, D. and Hunger, H., "Investigation of the Response and Loading of a Pipeline with a Cooling Water Check Valve During Loss of Coolant Accidents", (In German), Evaluation Report Test Group SRV 350, Tests: V60 and V67, Technical Report PHDR 43-84, Kernforschungszentrum, Karlsruhe, November 1984. 
Table 4.1 Table of the individual HDR E31 test system pipe sections

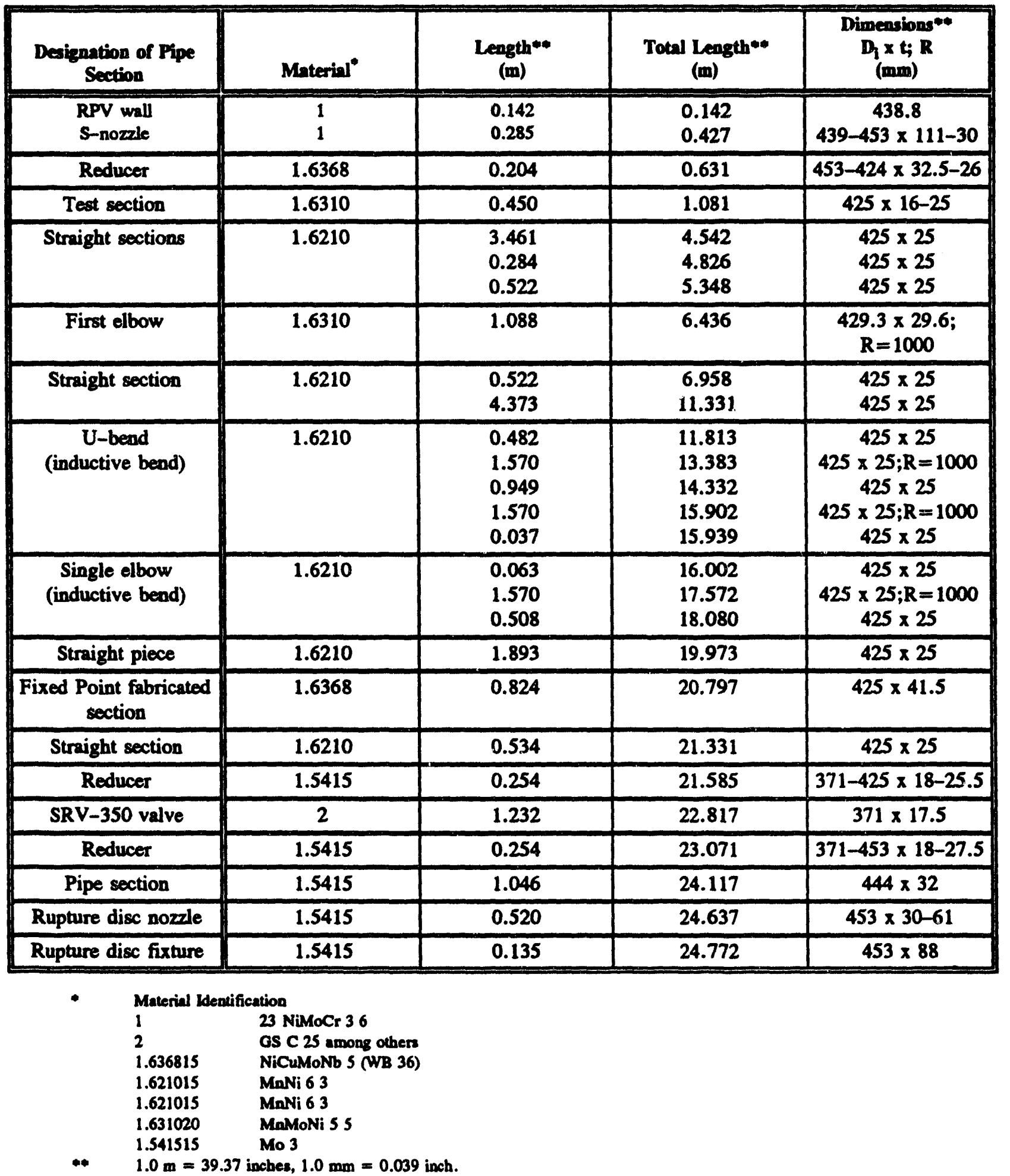


Table 4.2 Mechanical and physical properties of the pipe materials, from data sheets: 20 MnMoNi 55

\begin{tabular}{|c|c|c|c|c|c|}
\hline $\begin{array}{l}\text { Meterial } \\
\text { DN deximation } \\
\text { Meterial No. }\end{array}$ & $\begin{array}{c}\text { Mechanical and physical } \\
\text { characteristics }\end{array}$ & Units & $20 \mathrm{C}$ & $200 \mathrm{C}$ & $300 \mathrm{C}$ \\
\hline \multirow{10}{*}{$\begin{array}{c}20 \text { MnMoNi } 55 \\
1.6310 \\
\text { Tea Piece and Elbow } 1\end{array}$} & Yield poine & $N / \mathrm{mm}^{2}$ (min) & 430 & 392 & 371 \\
\hline & Tensile atrength & $\mathrm{N} / \mathrm{mm}^{2}$ & $570-710$ & 513 & 513 \\
\hline & Elongation at nupture & percent (min) & 19 & - & - \\
\hline & Area reduction & percent (min) & 45 & - & - \\
\hline & Notch impact energy & $J$ (min) & $\begin{array}{c}34 \\
(0 \mathrm{C})\end{array}$ & - & - \\
\hline & Density & $\mathrm{Mg} / \mathrm{m}^{3}$ & 7.84 & - & - \\
\hline & Modulus of elnaticity & $\mathrm{kN} / \mathrm{mm}^{2}$ & 211 & 199 & 192 \\
\hline & Thermal conductivity & $W_{m^{-1}} \mathbf{K}^{-1}$ & 44 & 43 & 41 \\
\hline & Specific beat & $\mathrm{Jg}^{-1} \mathrm{~K}^{-1}$ & 0.46 & 0.52 & 0.56 \\
\hline & $\begin{array}{c}\text { Coefficient of thermal } \\
\text { expanaion }\end{array}$ & $1 / K$ & - & $13.2 * 10^{-6}$ & $13.6 * 10^{-6}$ \\
\hline
\end{tabular}

Table 4.3 Mechanical and physical properties of the pipe materials, from data sheets: 15 MnNi 63

\begin{tabular}{|c|c|c|c|c|c|}
\hline $\begin{array}{l}\text { Material } \\
\text { DIN decignnation } \\
\text { Material No. }\end{array}$ & $\begin{array}{c}\text { Mechanical and physical } \\
\text { characteristics }\end{array}$ & Units & $20 \mathrm{C}$ & $200 \mathrm{C}$ & $300 \mathrm{C}$ \\
\hline \multirow{10}{*}{$\begin{array}{l}\text { Pipe sections except for } \\
\text { the } \\
\text { Tea Piece and } \\
\text { firn Elbow }\end{array}$} & Yield point & $\mathrm{N} / \mathrm{mm}^{2}$ (min) & 330 & 245 & 210 \\
\hline & Tenaile arength & $\mathrm{N} / \mathrm{mm}^{2}$ & $490-610$ & 400 & 400 \\
\hline & Elongation at rupture & percent (min) & 22 & - & - \\
\hline & Area reduction & percent (min) & 45 & - & - \\
\hline & Nolch impact eoergy & $J$ (min) & 100 & - & - \\
\hline & Density & $\mathrm{Mg} / \mathrm{m}^{3}$ & 7.84 & - & - \\
\hline & Modulus of elseticity & $\mathrm{kN} / \mathrm{mm}^{2}$ & 211 & 199 & 191 \\
\hline & Thermal conductivity & $W m^{-1} K^{-1}$ & 42 & 43 & 41 \\
\hline & Specific heal & $\mathbf{J}^{-1} \mathbf{K}^{-1}$ & 0.43 & 0.54 & 0.58 \\
\hline & $\begin{array}{l}\text { Coefficient of thermal } \\
\text { expansion }\end{array}$ & $1 / K$ & - & $12.9 * 10^{-6}$ & $13.5 * 10^{-6}$ \\
\hline
\end{tabular}


Table 4.4 Mechanical and physical properties of the pipe materials, from data sheets: WB 36

\begin{tabular}{|c|c|c|c|c|c|}
\hline $\begin{array}{l}\text { Menterial } \\
\text { DDN defiernion } \\
\text { Meteriel No. }\end{array}$ & $\begin{array}{l}\text { Mechanical and pluyaical } \\
\text { characterietics }\end{array}$ & Units & $20 \mathrm{C}$ & $200 \mathrm{C}$ & $300 \mathrm{C}$ \\
\hline \multirow{10}{*}{$\begin{array}{l}\text { Reducers at the } \\
\text { S-noende and the Fixed } \\
\text { Point chaped } \\
\text { reatraining piece }\end{array}$} & Yield point & $\mathrm{N} / \mathrm{mm}^{2}(\mathrm{~min})$ & 440 & 402 & 382 \\
\hline & Tensile Arength & $\mathrm{N} / \mathrm{mm}^{2}$ & $610-760$ & 520 & 520 \\
\hline & Elongation at rupture & percent (min) & 17 & - & - \\
\hline & Area reduction & percent (min) & - & - & - \\
\hline & Notch impact energy & $J$ (min) & 35 & - & - \\
\hline & Density & $\mathrm{Mg} / \mathrm{m}^{3}$ & 7.84 & - & - \\
\hline & Modulus of elnsticity & $\mathrm{kN} / \mathrm{mm}^{2}$ & 210 & 198 & 190 \\
\hline & Thermal conductivity & $W_{\mathbf{m}^{-1}} \mathbf{K}^{-1}$ & 38 & 42 & 41 \\
\hline & Specific heat & $J_{g^{-1}} K^{-1}$ & 0.46 & 0.52 & 0.56 \\
\hline & $\begin{array}{c}\text { Coefficient of thermal } \\
\text { expantion }\end{array}$ & $1 / x$ & - & $12.8 * 10^{-6}$ & $13.3 * 10^{-6}$ \\
\hline
\end{tabular}

Table 4.5 Mechanical and physical properties of the pipe materials, from data sheets: 15 Mo 3

\begin{tabular}{|c|c|c|c|c|c|}
\hline $\begin{array}{l}\text { Mnterial } \\
\text { DIN decignation } \\
\text { Mnterial No. }\end{array}$ & $\begin{array}{c}\text { Mechamical and physical } \\
\text { characteristics }\end{array}$ & Units & $20 \mathrm{C}$ & $200 \mathrm{C}$ & $300 \mathrm{C}$ \\
\hline \multirow{10}{*}{$\begin{array}{c}\text { Reducers part the Fixed } \\
\text { Point and rupture diec } \\
\text { ascembly }\end{array}$} & Yield point & $\mathrm{N} / \mathrm{mm}^{2}$ (min) & 270 & 225 & 180 \\
\hline & Tensile trength & $\mathrm{N} / \mathrm{mm}^{2}$ & $450-600$ & 390 & 390 \\
\hline & Elongation at rupture & percent (min) & 20 & - & - \\
\hline & Area reduction & percent (min) & - & - & - \\
\hline & Notch impact energy & J (min) & 34 & - & - \\
\hline & Density & $\mathrm{Mg} / \mathrm{m}^{3}$ & 7.85 & - & - \\
\hline & Modulus of elaxticity & $\mathrm{kN} / \mathrm{mm}^{2}$ & 213 & 202 & 193 \\
\hline & Thermal conductivity & $\mathbf{W} \mathbf{m}^{-1} \mathbf{K}^{-1}$ & 49 & 47 & 44 \\
\hline & Specific heat & $J_{g}^{-1} K^{-1}$ & 0.46 & 0.50 & 0.54 \\
\hline & $\begin{array}{c}\text { Coefficient of thermal } \\
\text { expansion }\end{array}$ & $1 / K$ & - & $13.1 * 10^{-6}$ & $13.6 * 10^{-6}$ \\
\hline
\end{tabular}


Table 4.6 Mechanical and physical properties of the reactor pressure vessel material: 23 NiMoCr 36

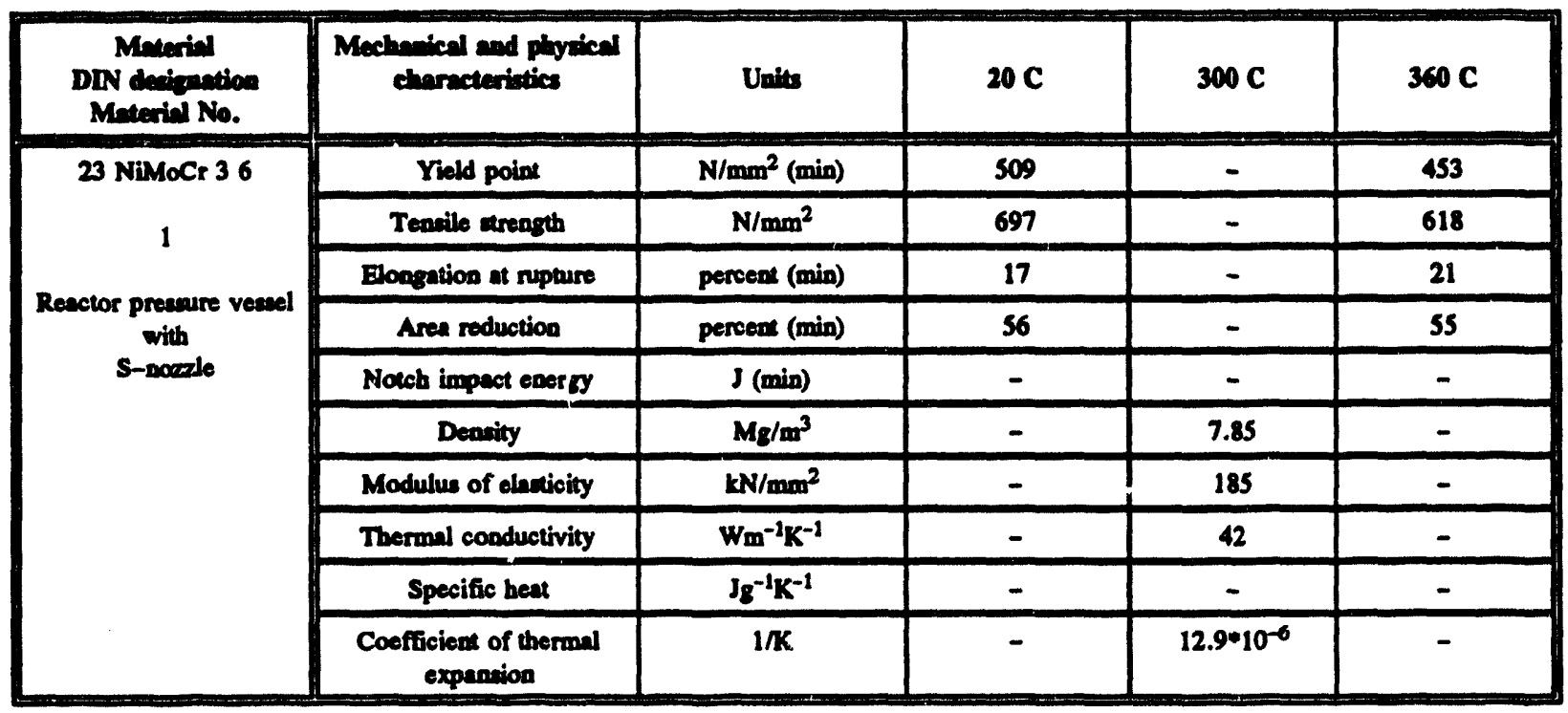

Table 4.7 Initial thermohydraulic test conditions - comparison of measured and design values

\begin{tabular}{|c|c|c|c|}
\hline \multirow{3}{*}{$\begin{array}{l}\text { Tea Variables } \\
\text { (Dimentions) }\end{array}$} & \multicolumn{3}{|c|}{ Initial Test Conditions } \\
\hline & \multirow{2}{*}{$\begin{array}{l}\text { Teat Dexign } \\
\text { Velues }\end{array}$} & \multicolumn{2}{|c|}{ Mearured Mean Value (Standard Deviation) } \\
\hline & & Tet 1312 & Teat $\mathbf{2 3 1 3}$ \\
\hline Syctem presaure (bar) & 90 & $92(1.0)$ & $92(0.5)$ \\
\hline $\begin{array}{c}\text { Temperature of RPV - Upper } \\
\text { Pan (C) }\end{array}$ & 300 & $302(-)$ & $302(-)$ \\
\hline $\begin{array}{c}\text { Temperature of RPV - Lower } \\
\text { Pan (C) }\end{array}$ & 240 & $247(0.6)$ & $246(0.5)$ \\
\hline $\begin{array}{l}\text { Pipe Symem Fluid } \\
\text { Temperature (C) }\end{array}$ & 240 & $239(2.6)$ & $239(3.3)$ \\
\hline $\begin{array}{l}\text { Pipe Syatem Wall Temperature } \\
\text { (C) }\end{array}$ & 240 & $238(3.8)$ & $238(2.9)$ \\
\hline Valve Stroke $(\mathrm{mm})$ & 130 & $130(-)$ & $130(-)$ \\
\hline
\end{tabular}


Table 4.8 Initial geometrical parameters of test sections

\begin{tabular}{|c|c|c|}
\hline Parameter* & Test E31.2 & Test E31.3 \\
\hline Outer Diameter $-D_{o}, \mathrm{~mm}$ & 457 & 457 \\
\hline Wall Thickness $-\mathrm{t}, \mathrm{mm}$ & 16 & 16 \\
\hline Crack Length $-2 \theta$, degrees & 60 & 60 \\
\hline Crack Depth $-\mathrm{d}, \mathrm{mm}$ & 4.8 & 8.0 \\
\hline Depth Ratio, $\mathrm{d} / \mathrm{t}$ & 0.3 & 0.5 \\
\hline
\end{tabular}

* $25.4 \mathrm{~mm}=1.0$ inch.

Table 4.9 Mechanical characteristics from tensile tests of test section material 20 MnMoNi 55

\begin{tabular}{|c|c|c|c|c|c|c|c|}
\hline $\begin{array}{c}\text { Semple } \\
\text { Deaignation }\end{array}$ & $\begin{array}{c}\text { Temperature, } \\
\text { C, (F) }\end{array}$ & $\begin{array}{c}\text { Sample } \\
\text { Orientation }\end{array}$ & $\begin{array}{c}\text { 0.2-Percent } \\
\text { Yield Point, } \\
\text { MPa }\end{array}$ & $\begin{array}{l}\text { Tensile } \\
\text { Strength, } \\
\mathrm{MPa}\end{array}$ & $\begin{array}{c}\text { E-Modulus, } \\
\text { GPa }\end{array}$ & $\begin{array}{l}\text { Rupture } \\
\text { Strain, } \\
\text { percent }\end{array}$ & $\begin{array}{c}\text { Area } \\
\text { Reduction, } \\
\text { percent }\end{array}$ \\
\hline 1 & $240(464)$ & $\mathbf{L}$ & 496 & 662 & 208 & 21.4 & 59.0 \\
\hline 2 & $240(464)$ & $\mathbf{L}$ & 487 & 647 & 200 & 21.0 & 70.8 \\
\hline $\mathbf{Z 2}$ & $20(68)$ & $L$ & 551 & 658 & 208 & 25.0 & 76.0 \\
\hline 7 & $240(464)$ & $\mathbf{T}$ & 488 & 647 & 199 & 19.2 & 65.2 \\
\hline 8 & $240(464)$ & $T$ & 485 & 652 & 192 & 19.0 & 62.8 \\
\hline 27 & $20(68)$ & $\mathbf{T}$ & 554 & 659 & 208 & 23.5 & 71.0 \\
\hline
\end{tabular}

$* 6.895 \mathrm{ksi}=1.0 \mathrm{MPa}=0.001 \mathrm{GPa}$. 


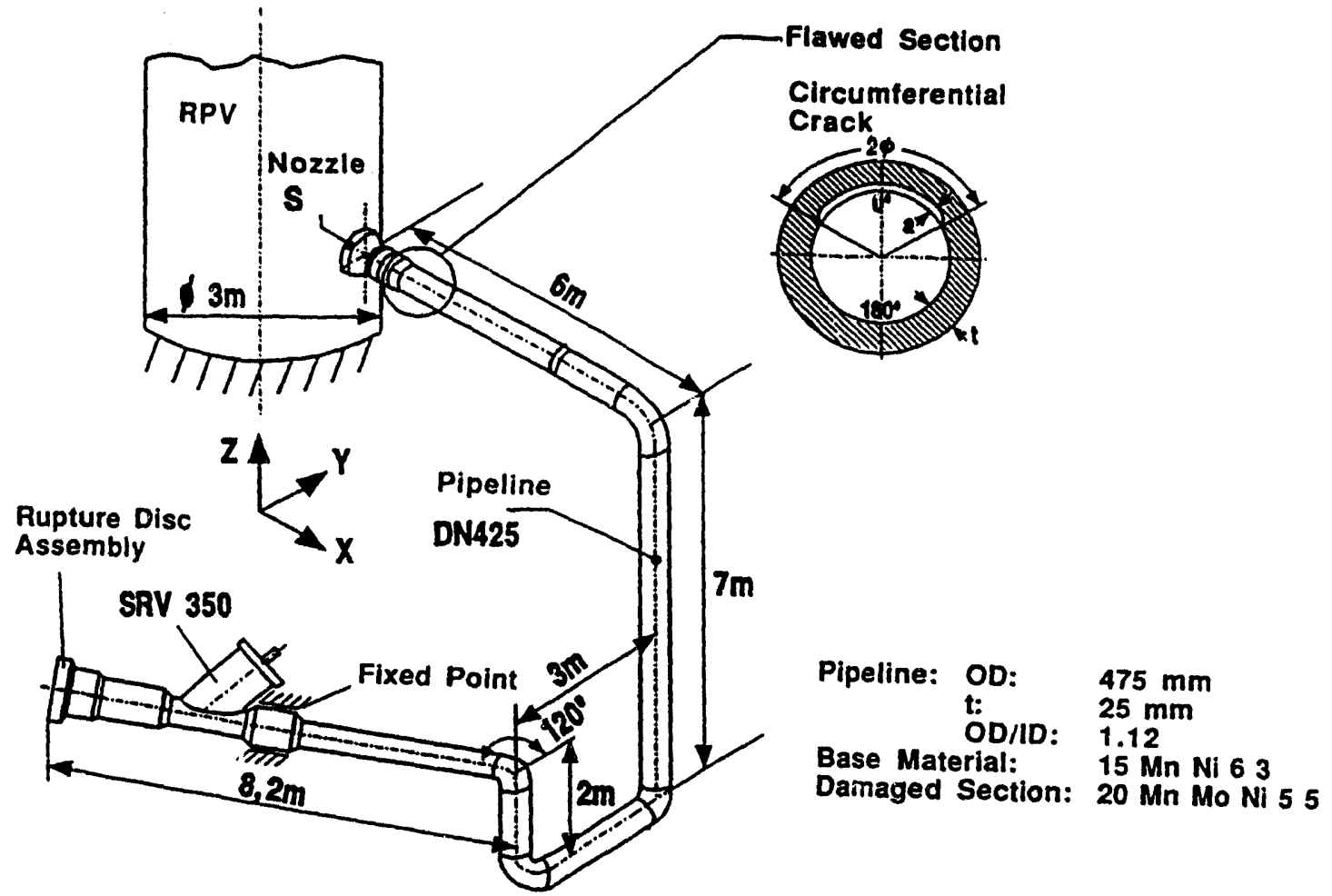

Figure 4.1 HDR-E31 test system with flawed section

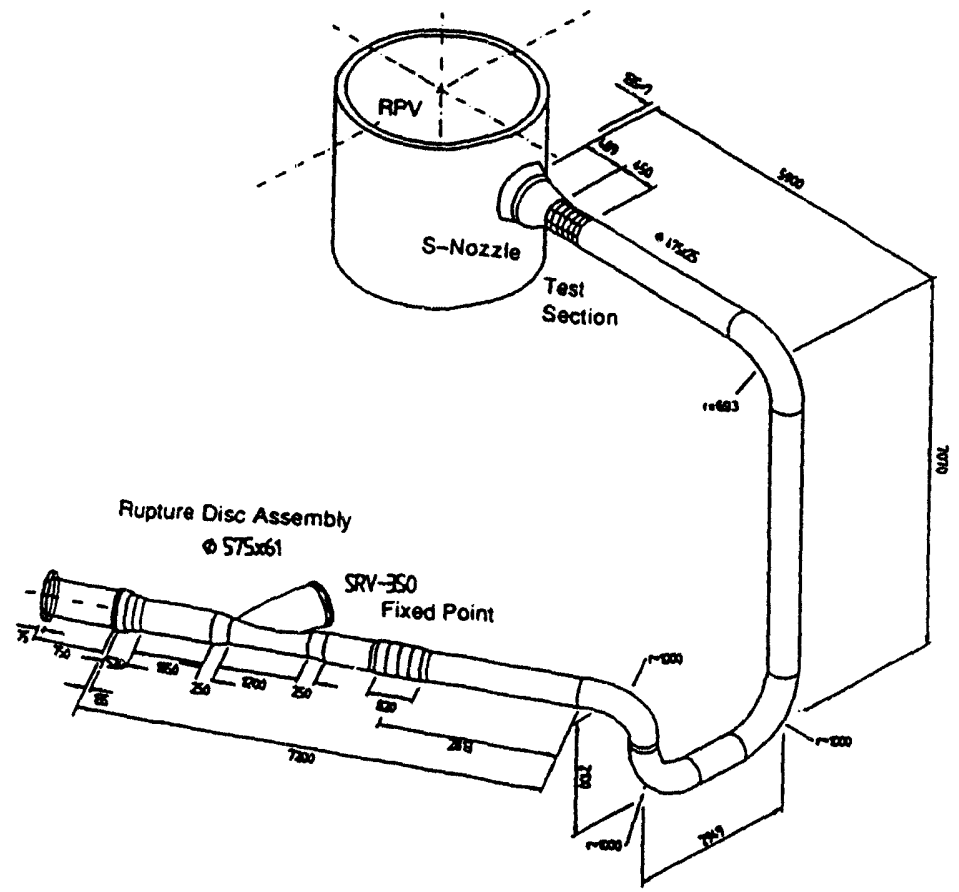

Figure 4.2 Isometric of the HDR-31 test system (Units in mm) 
HDR-E31 EXPERIMENTS

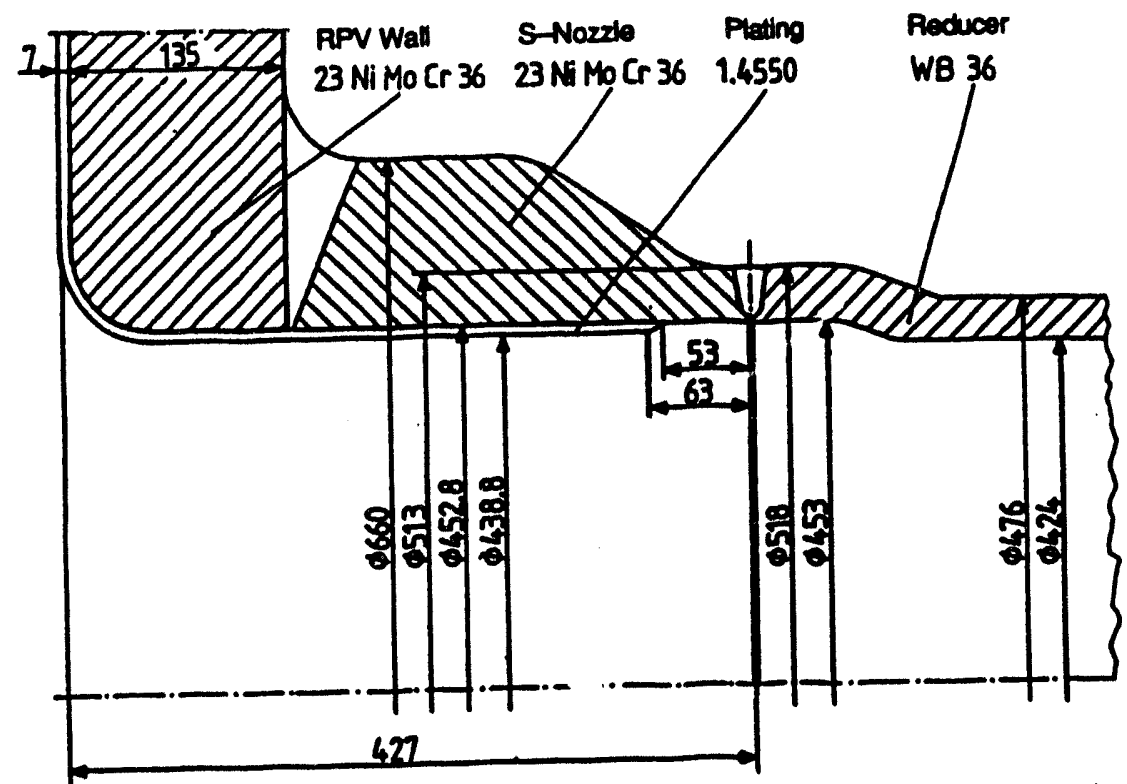

Figure 4.3 S-nozale at the reactor pressure vessel (RPV) (Units in mm)

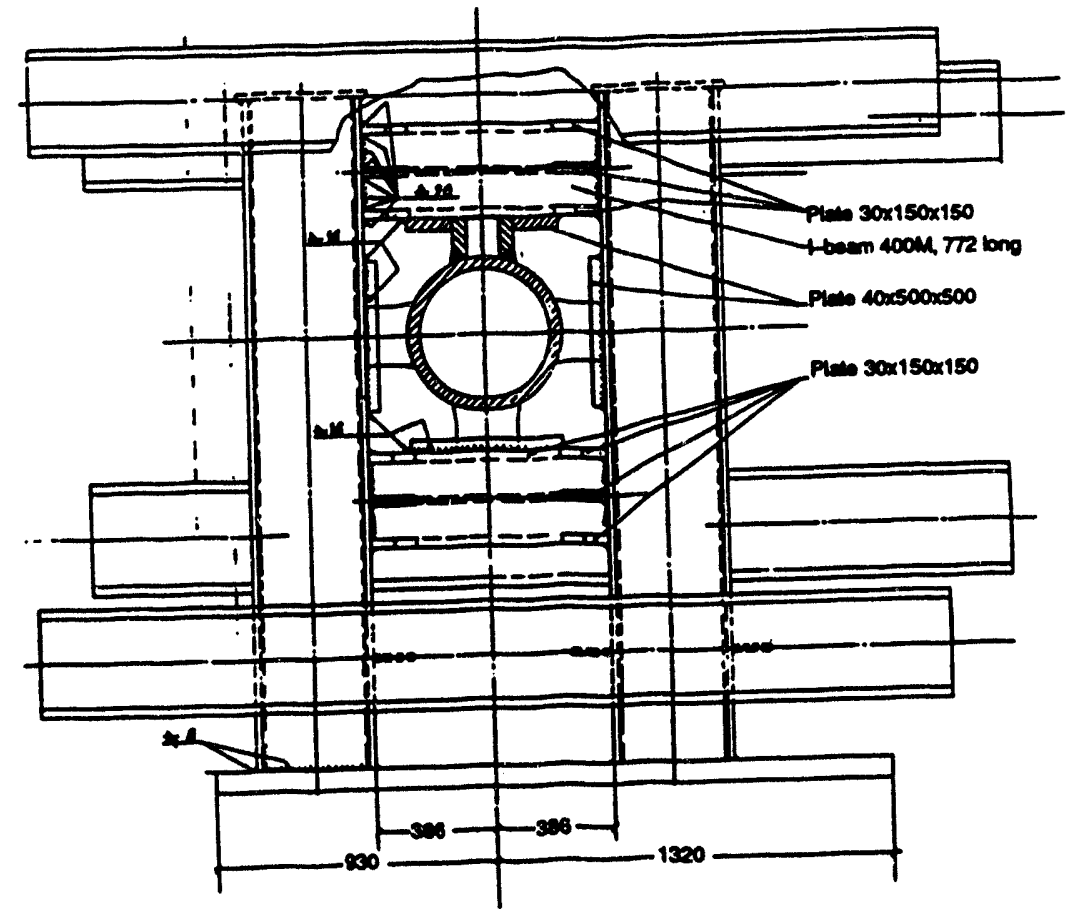

Figure 4.4 Fixed Point support (Units in mm) 

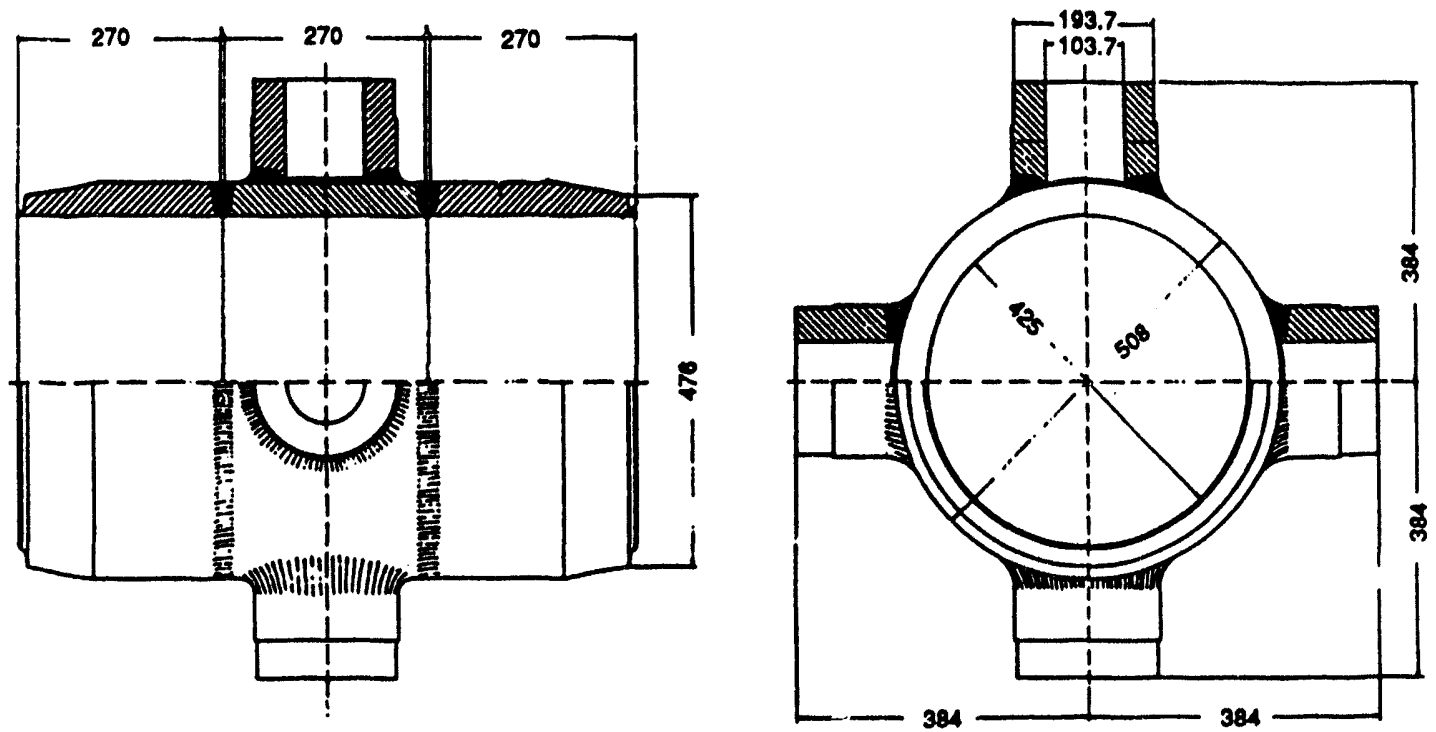

Material: WB 36

Figure 4.5 Pipe restraint section at the Fixed Point (Units in mm)
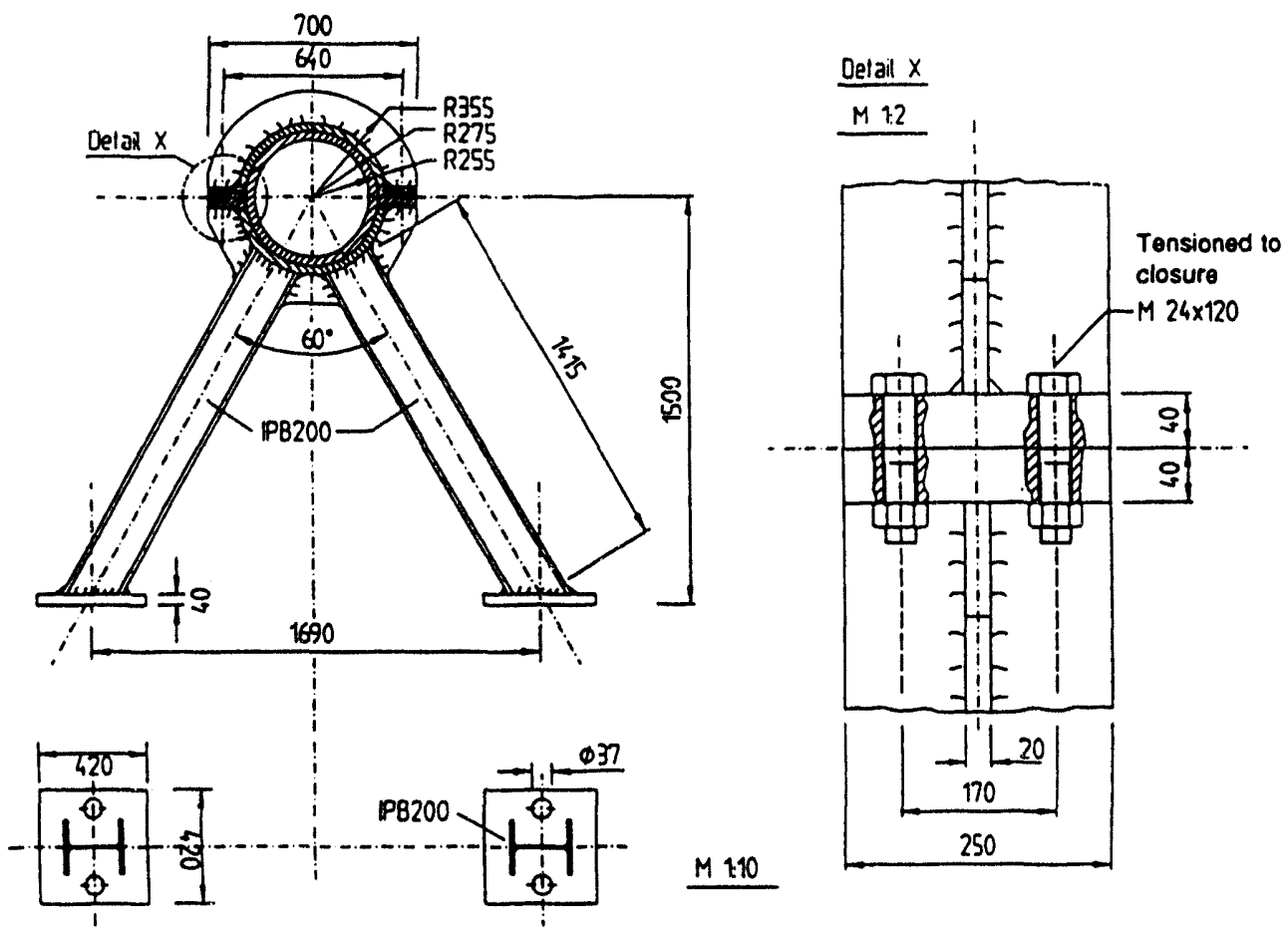

Figure 4.6 Rupture disc assembly support (Units in mm) 


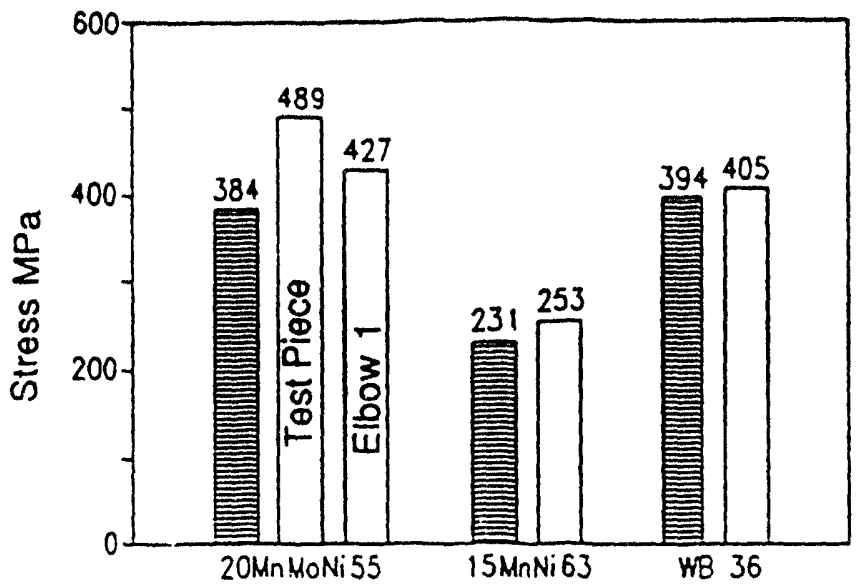

Yield Point

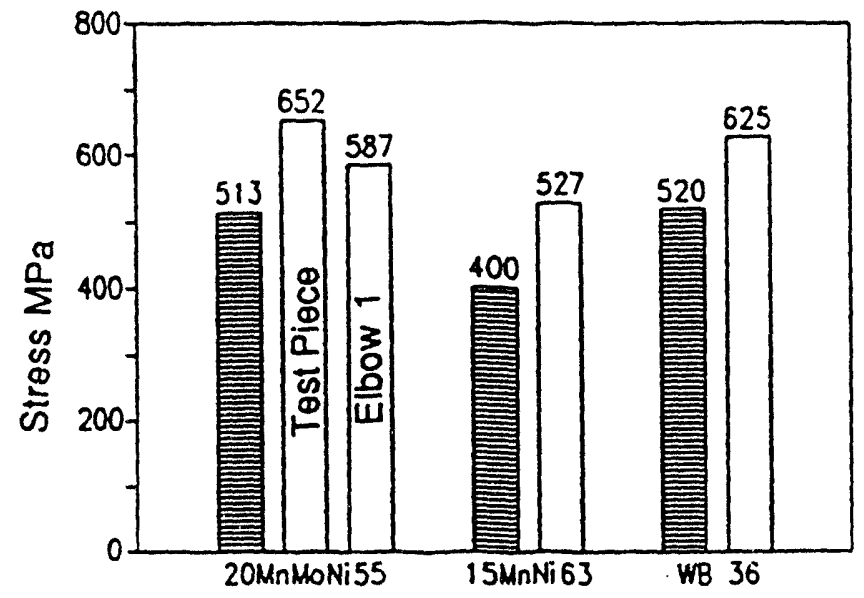

Tensile Strength
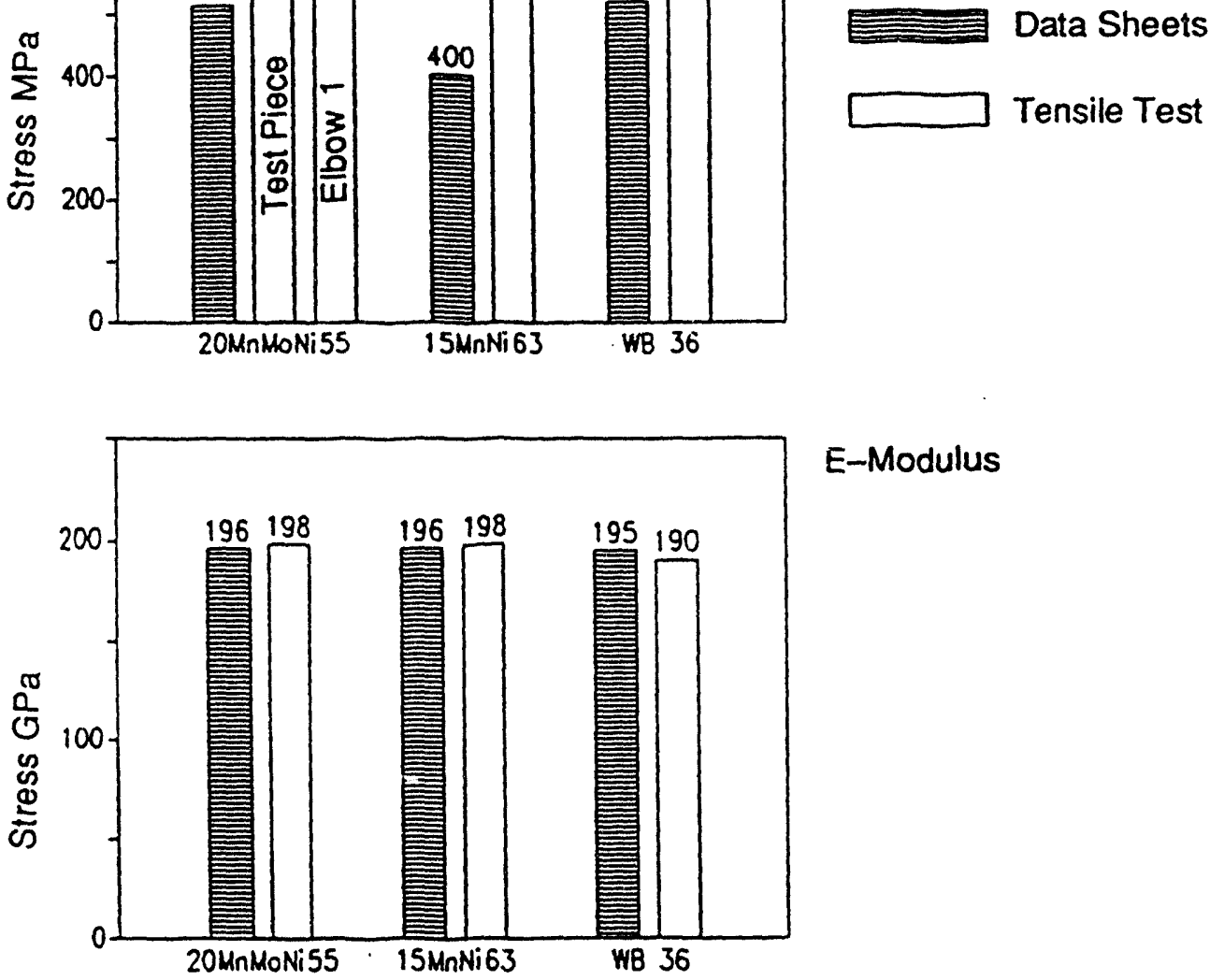

E-Modulus

Figure 4.7 Comparison of measured mechanical properties of the HDR-E31 pipe components with data sheet values at 240 C (464 F) 

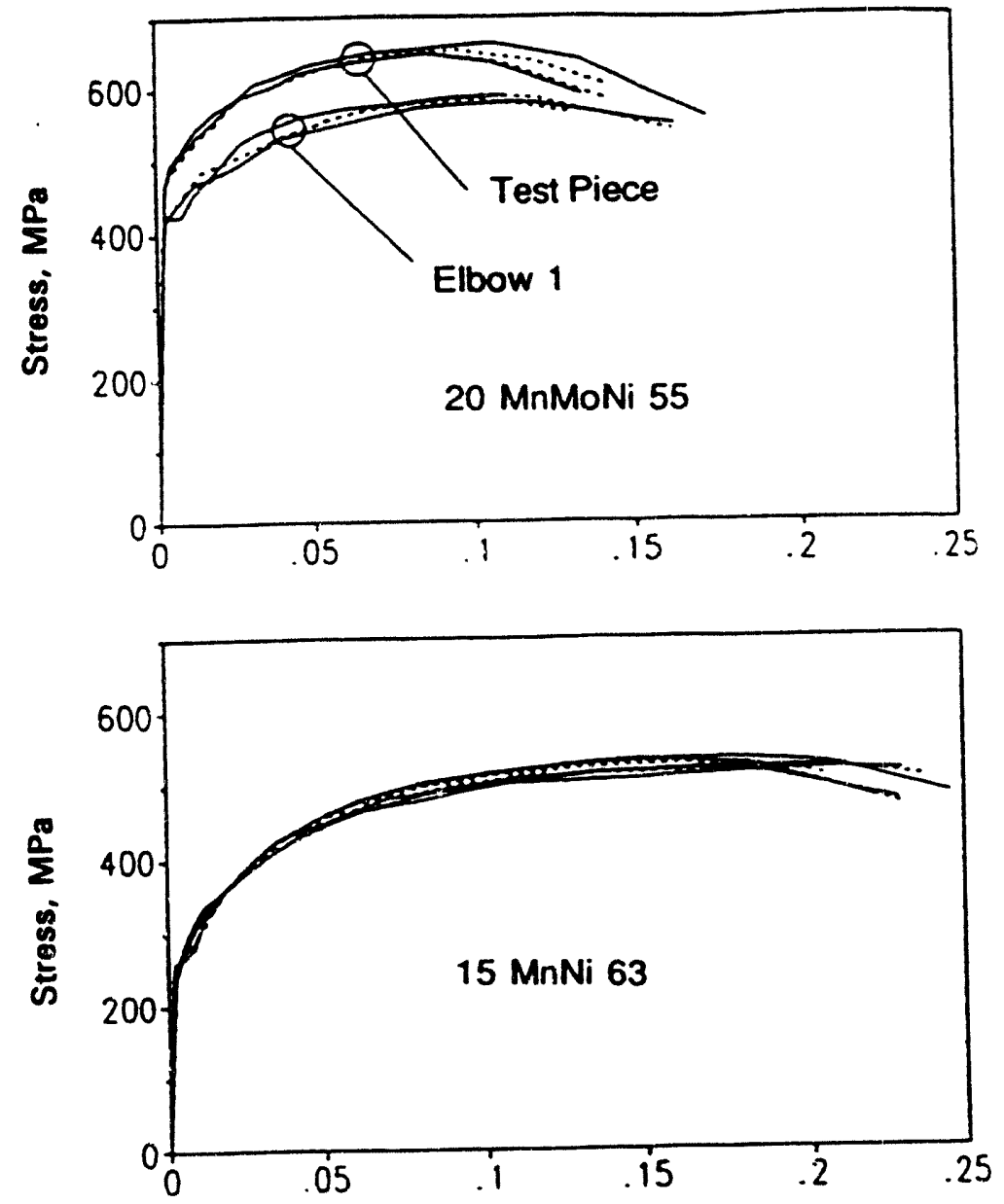

Longitudinal Samples

\section{Tangential Samples}

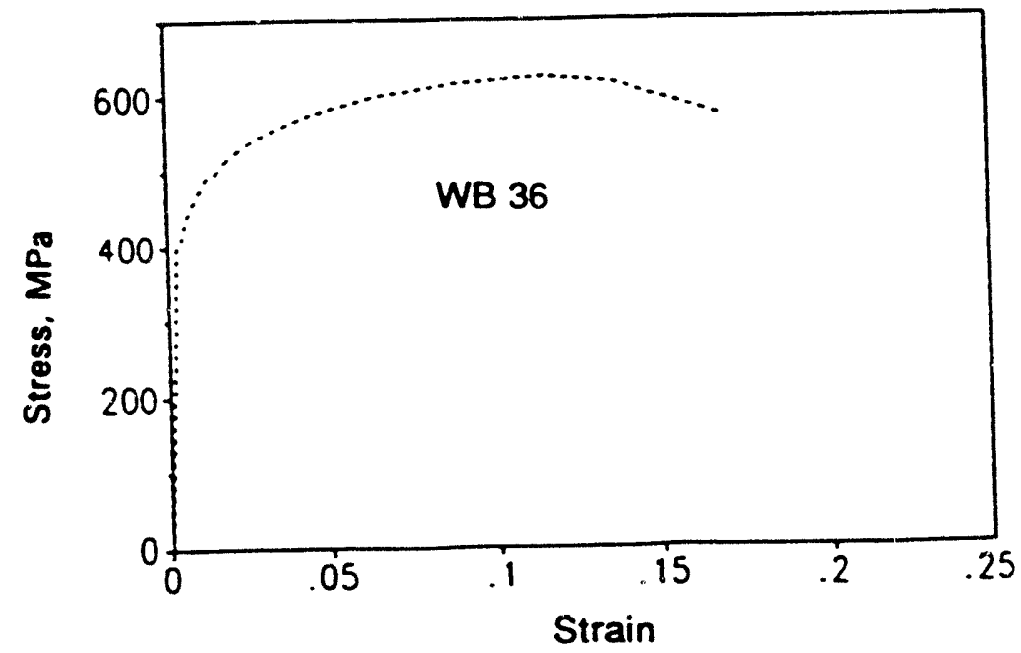

Figure 4.8 Stress-strain curves from tensile tests for the HDR-E31 pipe system materials at $240 \mathrm{C}$ (464 F) 


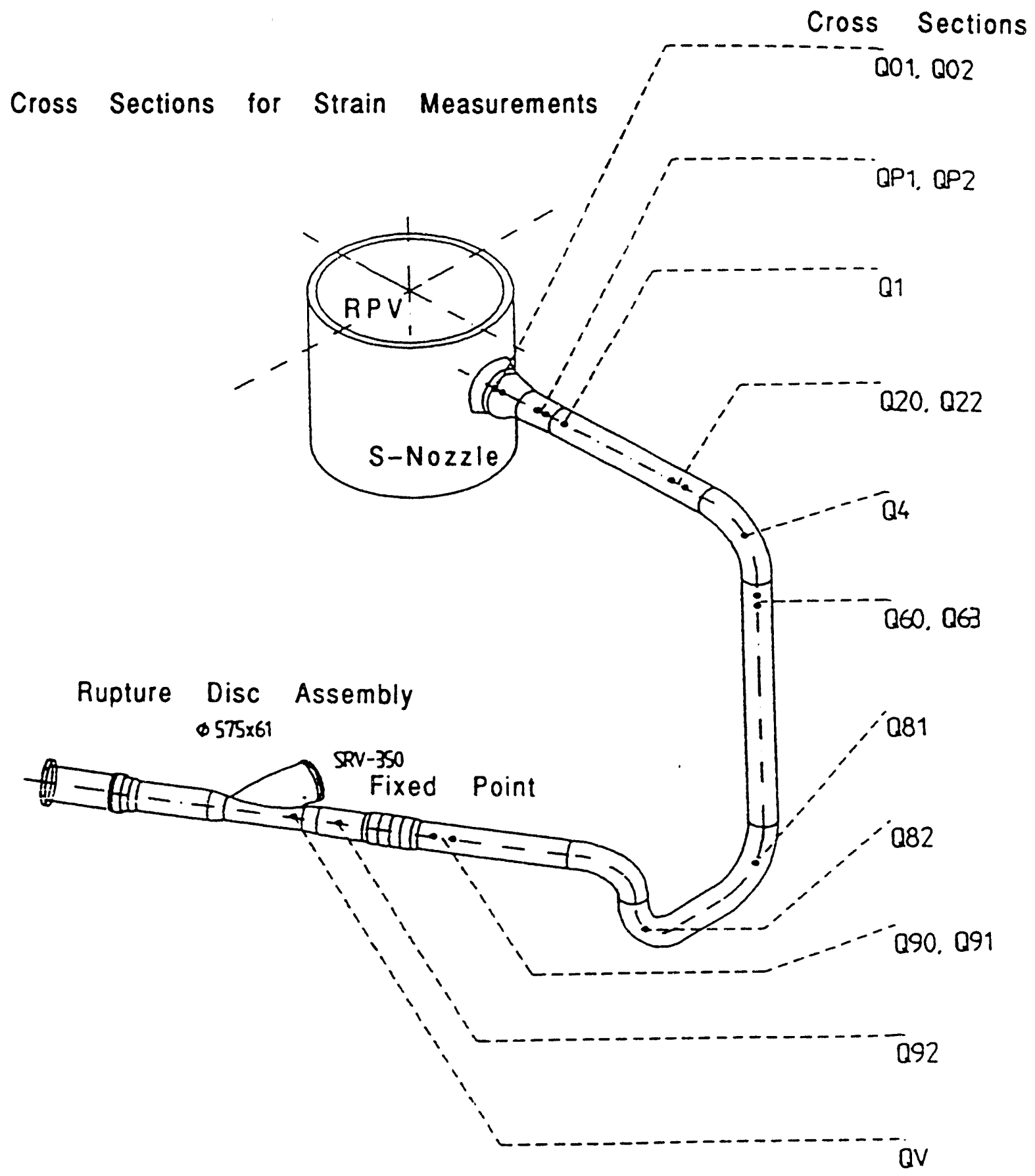

Note: Measurements at Q20, Q63 and QV were omitted in test E31.3

Figure 4.9 Strain measurement locations for the HDR-E31 tests 

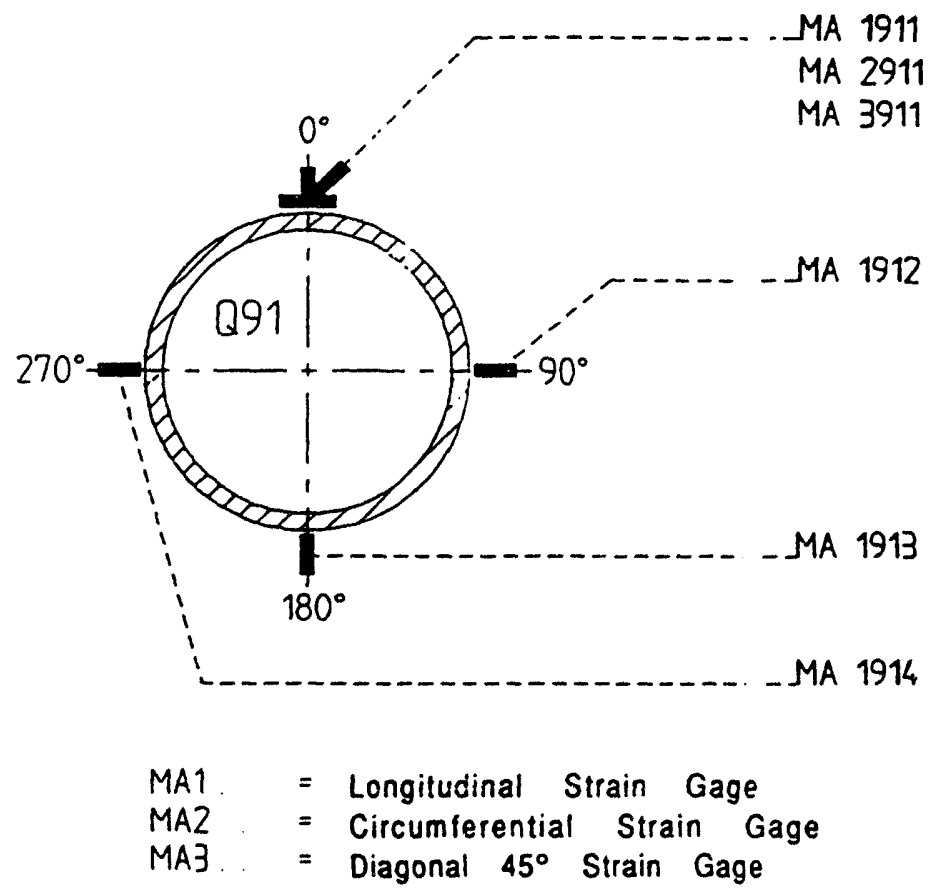

Figure 4.10 Typical strain gage installation in a straight pipe section (cross-section Q91 shown)

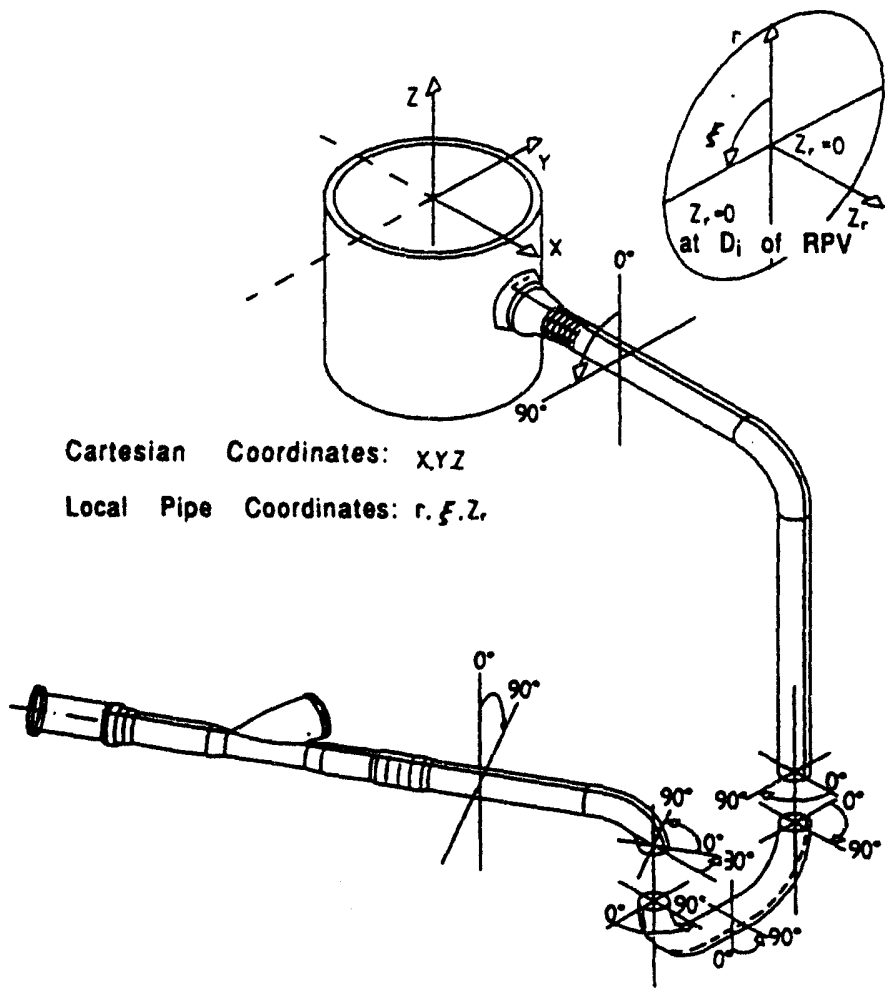

Figure 4.11 HDR-E31 piping coordinate systems 


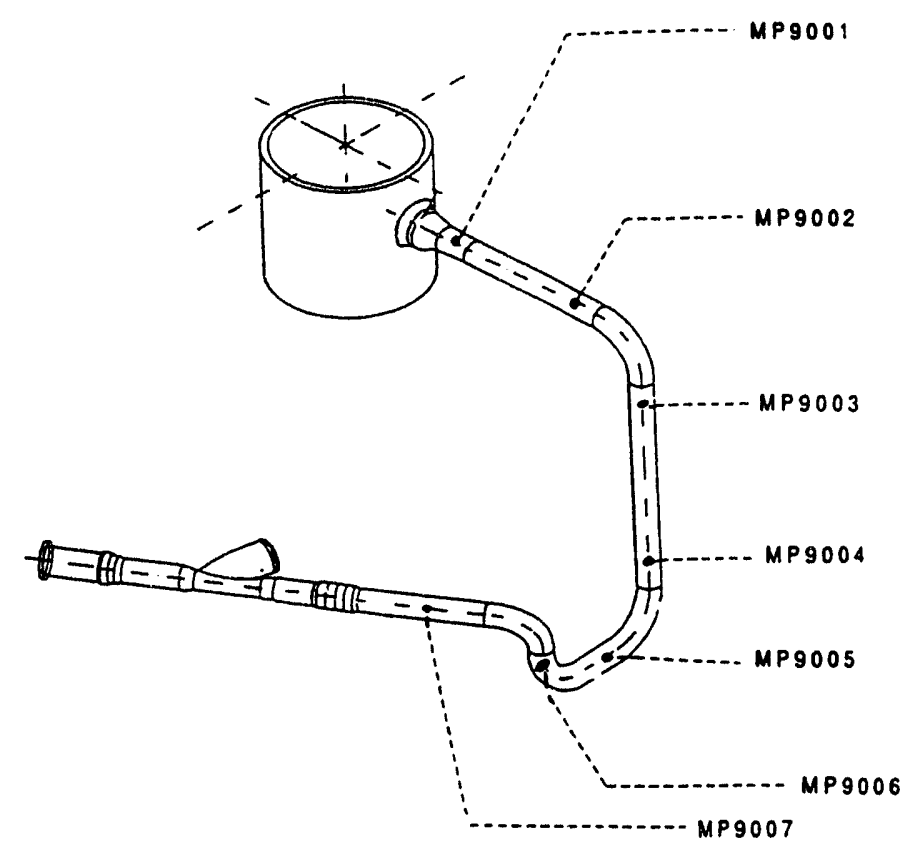

Note: For test E31.2 only MP9002. MP9004 and MP9007 were functional. Gage MPg002 was not used for lest E31.3.

Figure 4.12 Pressure gage locations for HDR-E31 tests

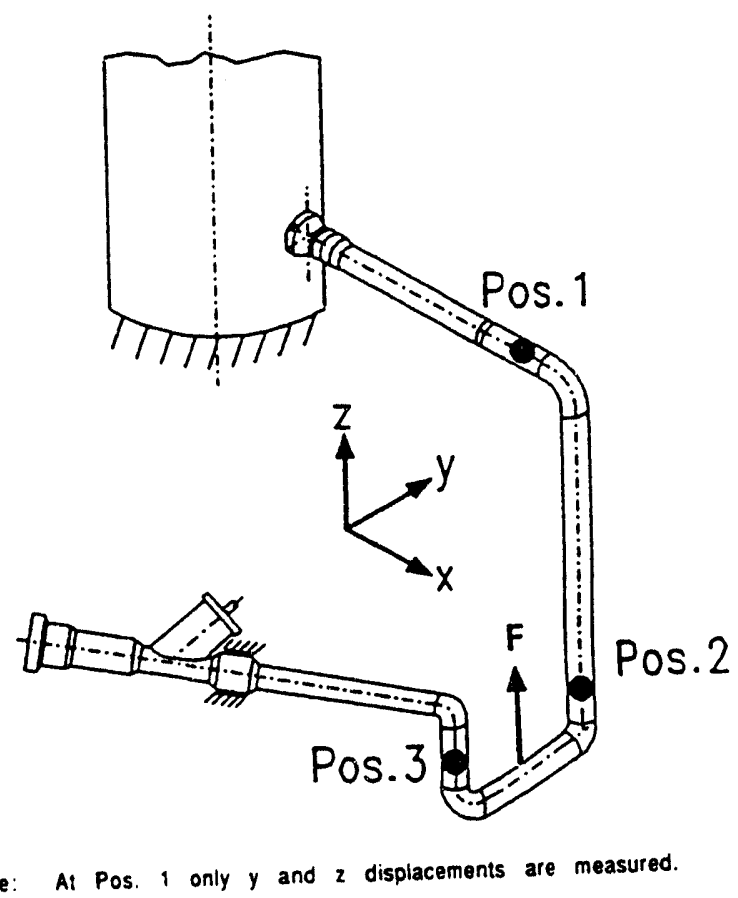

Figure 4.13 Displacement measurement locations for the HDR-E31 tests and point of static load application (F) 


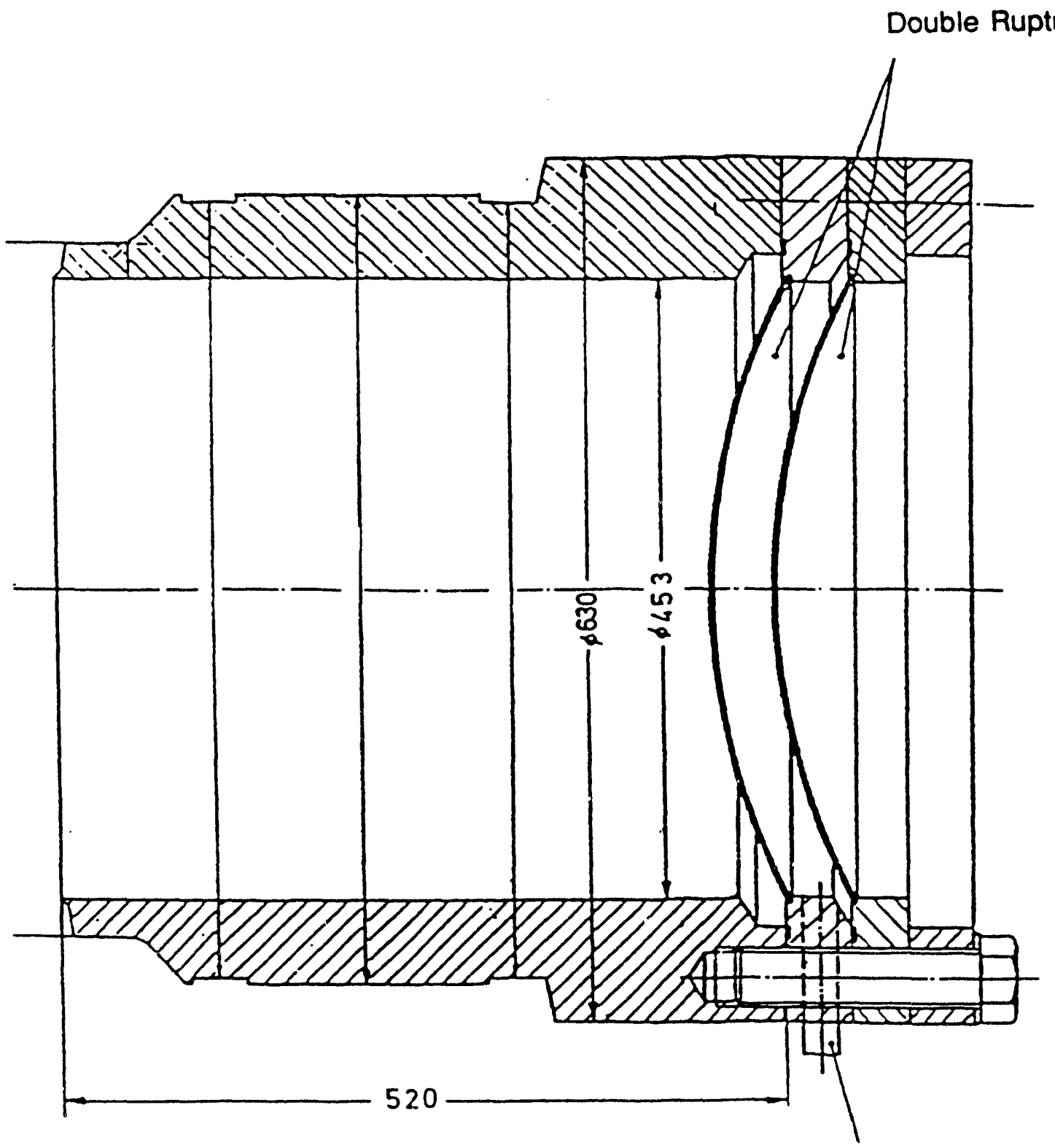

Burst Pressure Connection

WEIGHT (WITHOUT RUPTURE DISCS): APPR. $4220 \mathrm{~N}$

MATERIAL: $\quad 15 M 03$

Figure 4.14 Rupture disc assembly; nominal $450 \mathrm{~mm}$ diameter (Units in mm) 

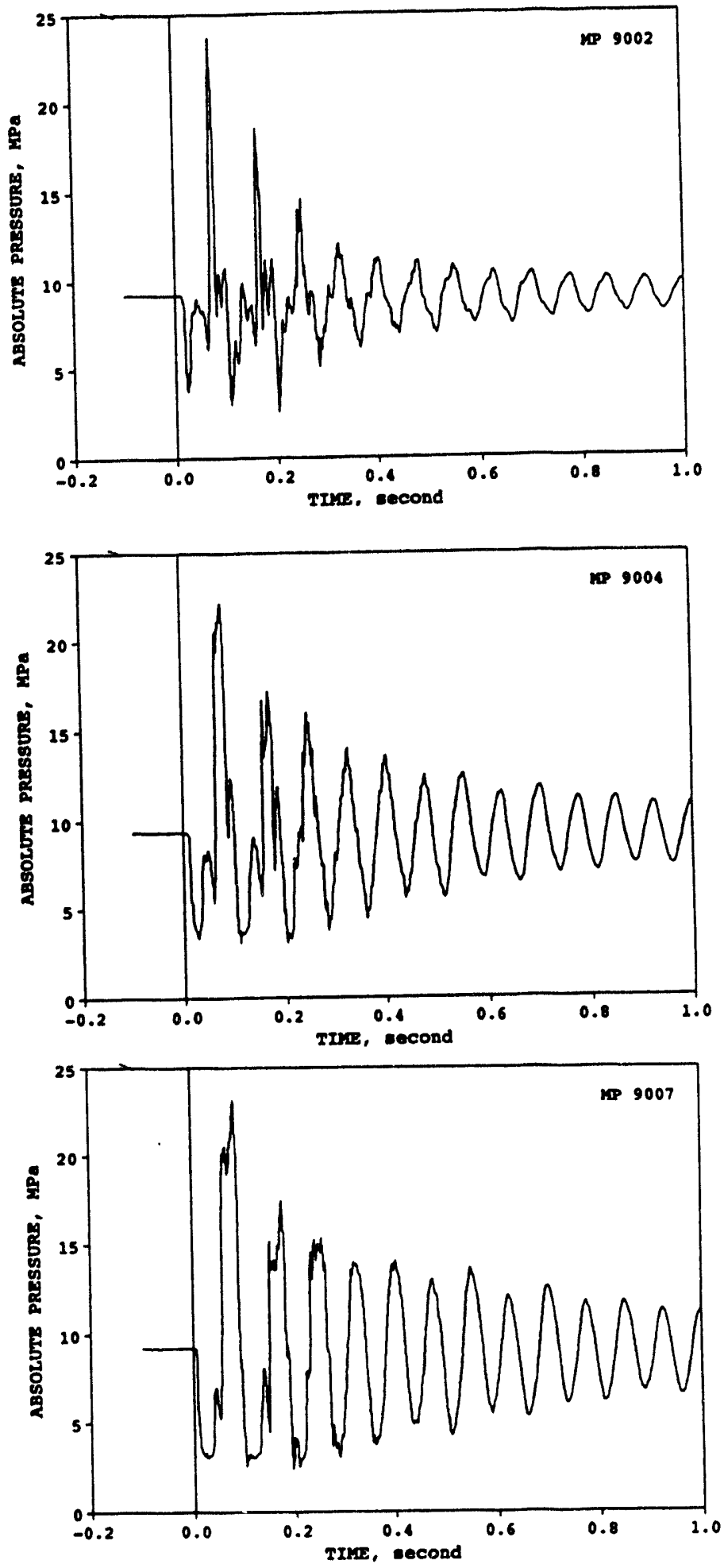

Figure 4.15 Pressures used for calculating elbow forces for HIDR-E31.2 

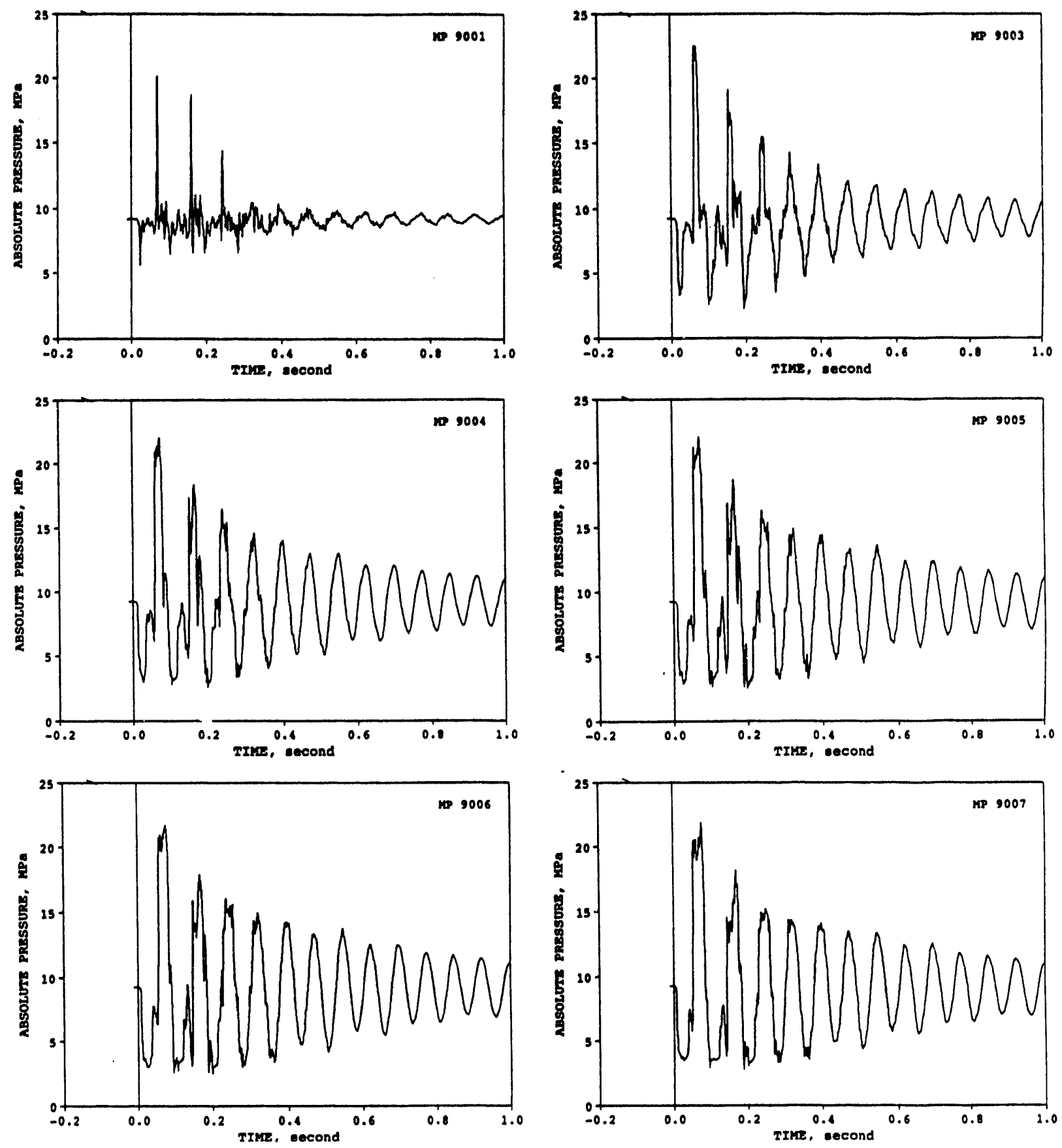

Figure 4.16 Pressures used for calculating elbow forces for HDR-E31.3 


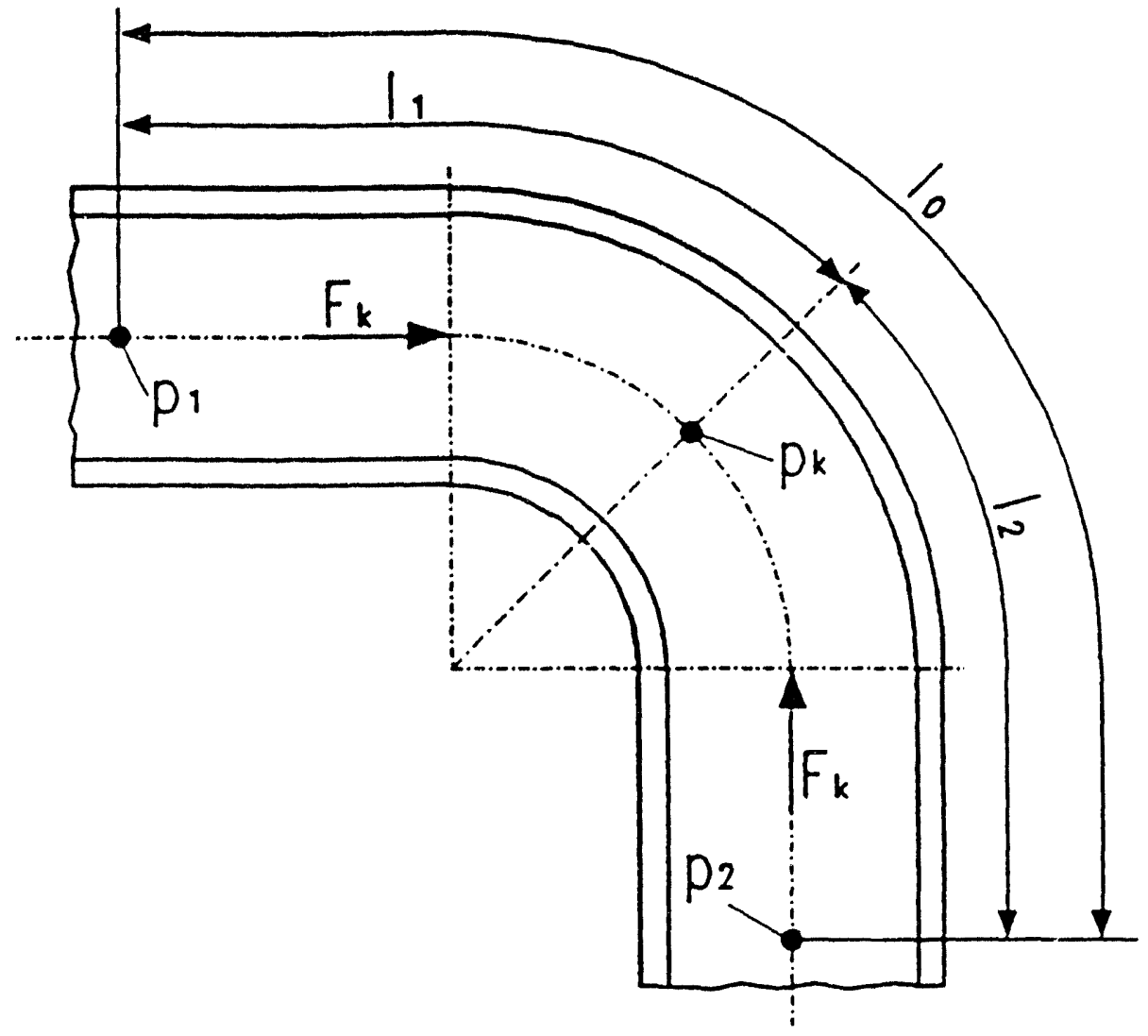

$p_{k}=\frac{l_{2}}{l_{0}} p_{1}+\frac{l_{1}}{l_{0}} p_{2}$

$F_{k}=A_{p} p_{k}$

Figure 4.17 Procedure for calculating equivalent elbow forces from elbow pressures 

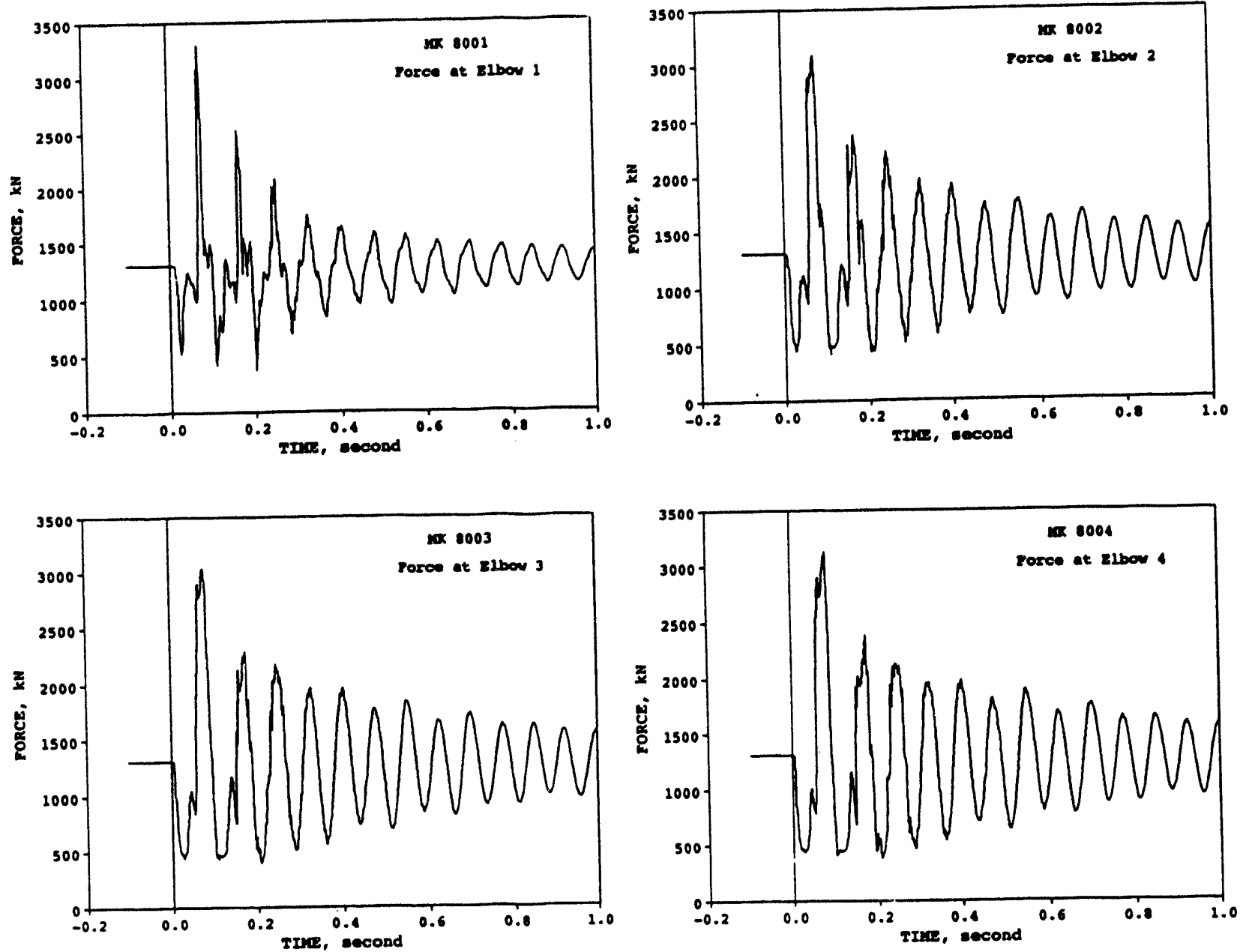

Figure 4.18 Elbow forces for HDR-E31.2 

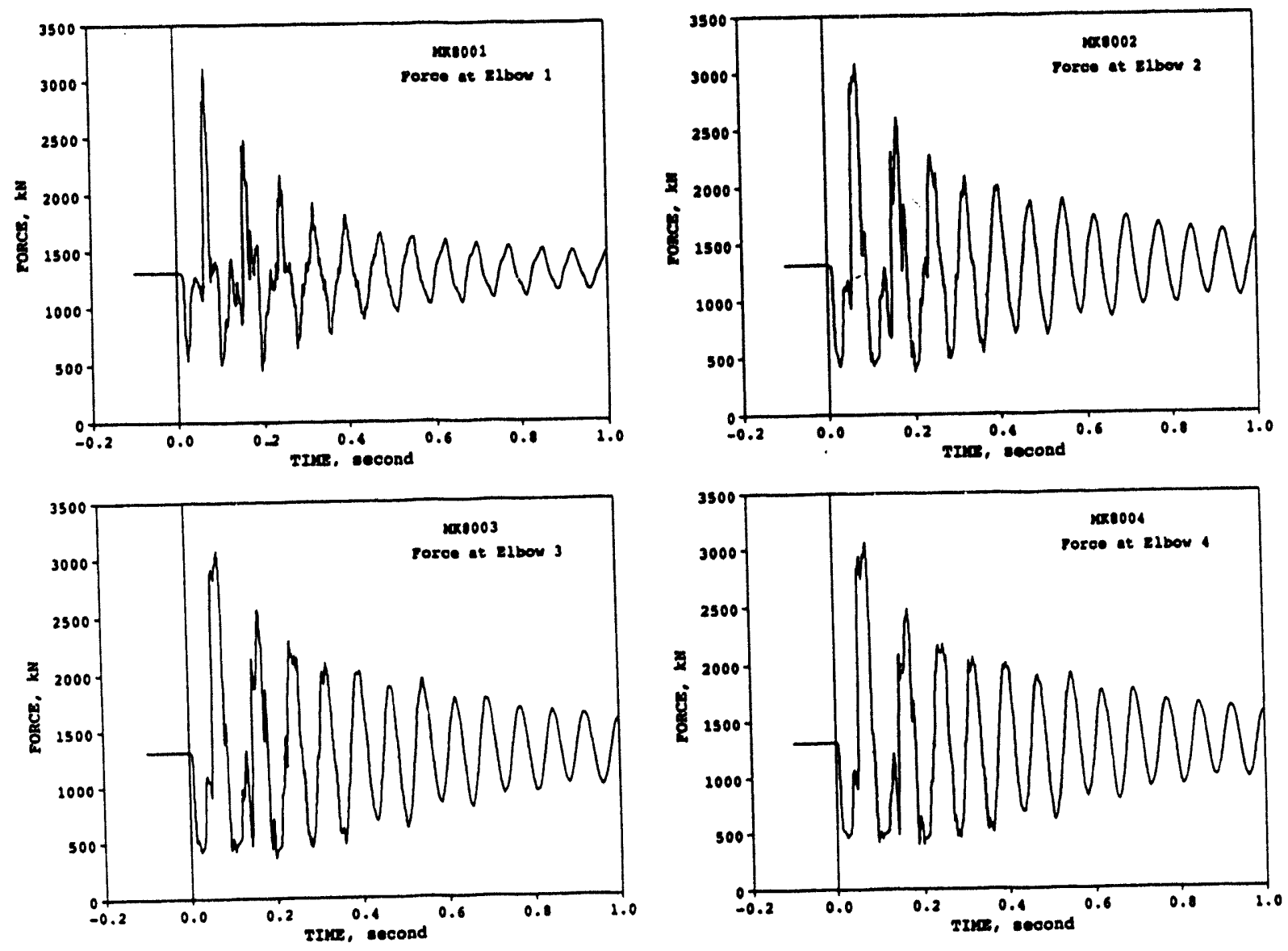

Figure 4.19 Elbow forces for HDR-E31.3 


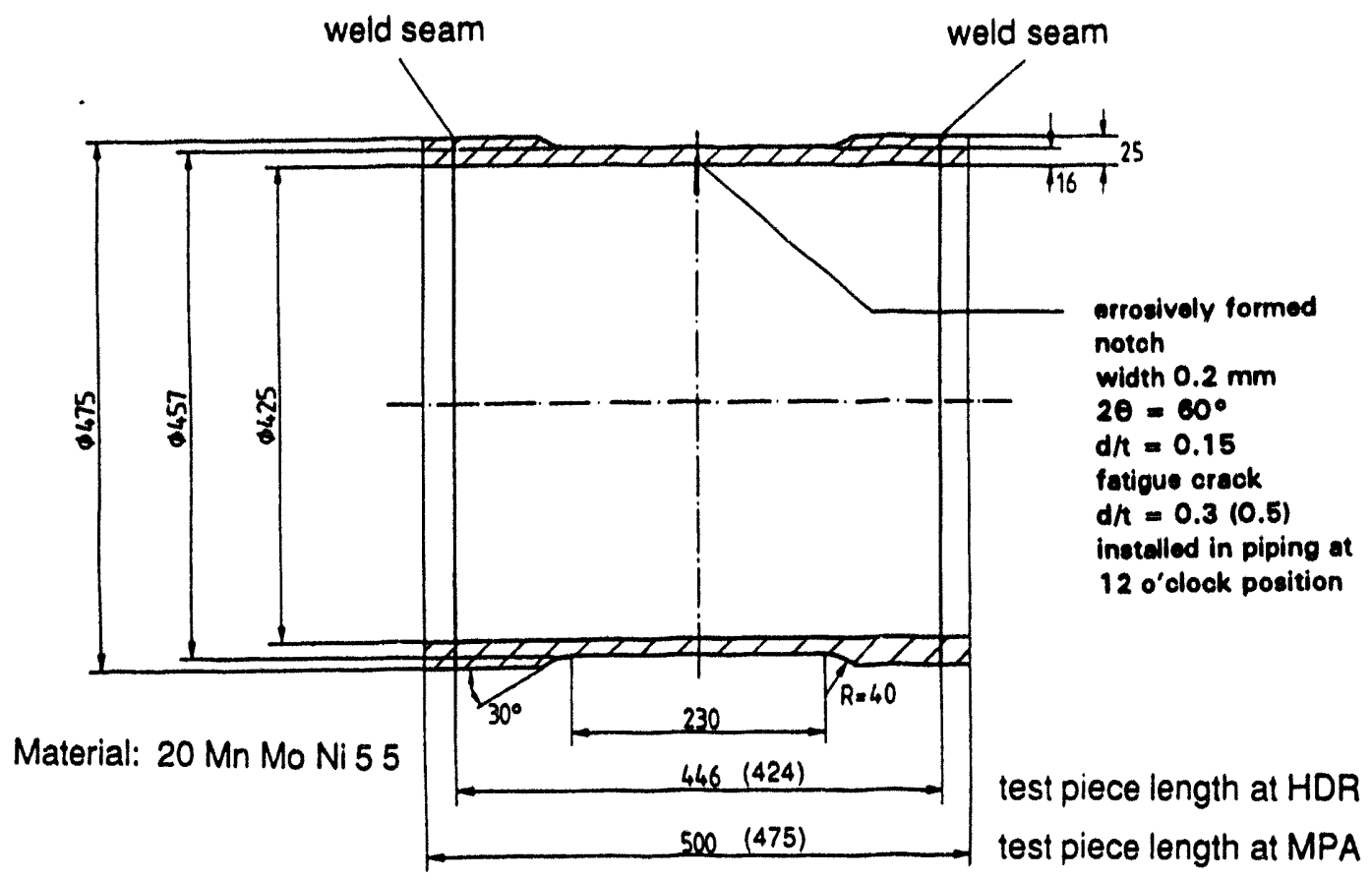

Figure 4.20 Test section with circumferential faw for the HDR-E31 tests (numbers in parenthesis indicate values for HDR-E31.3), units in mm

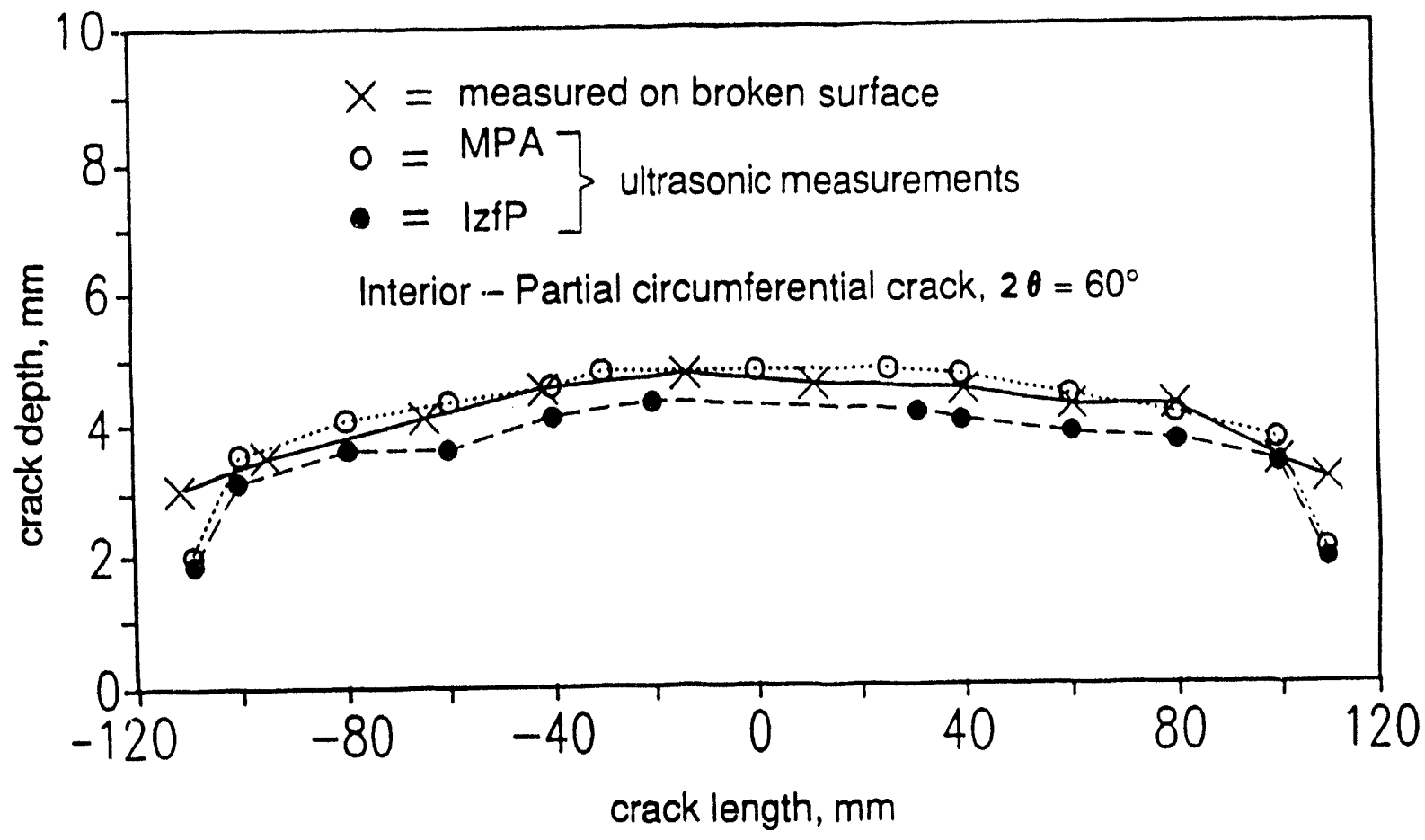

Figure 4.21 Initial tlaw profile for HDR-E31.2 


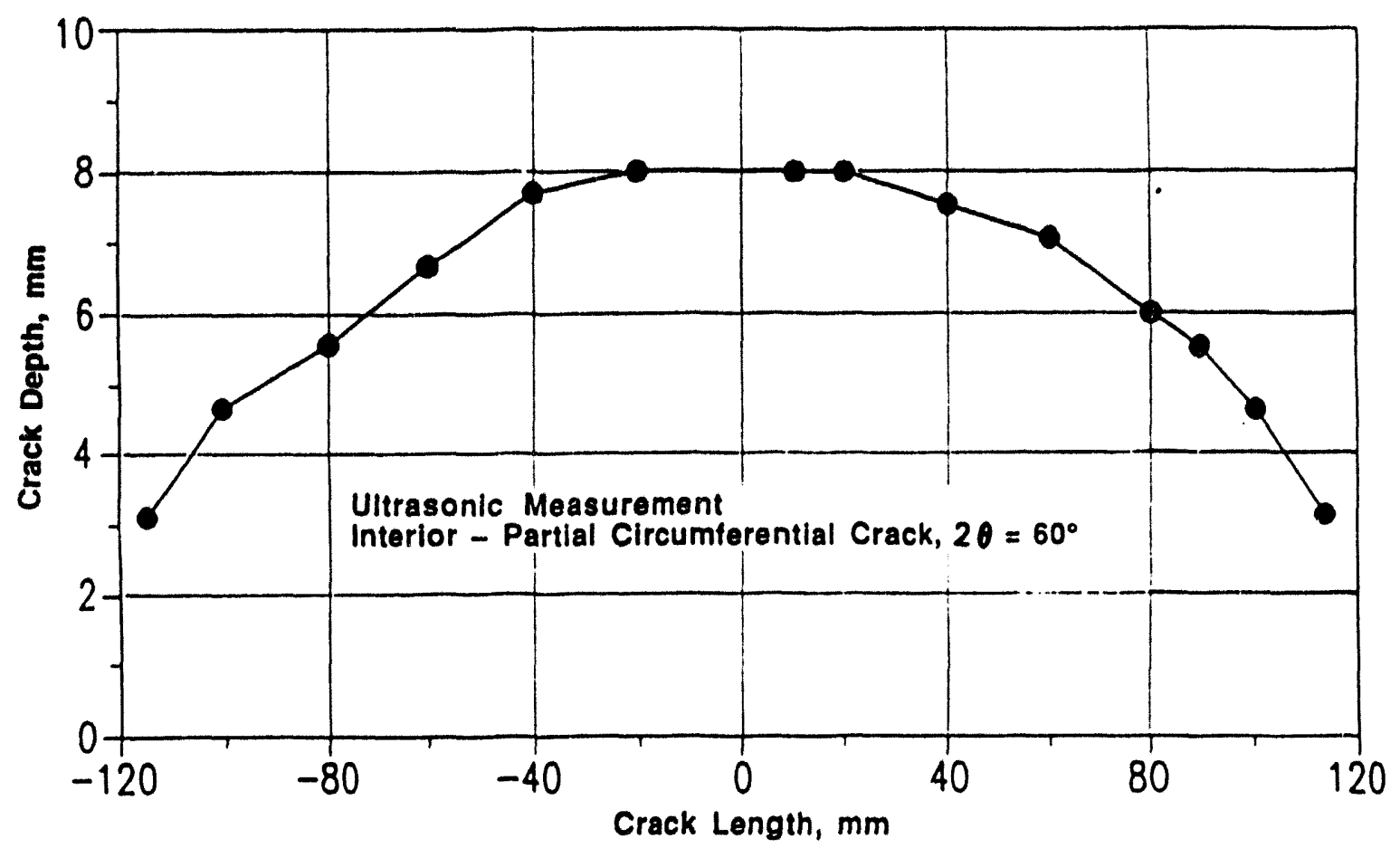

Figure 4.22 Initial flaw profile for HDR-E31.3

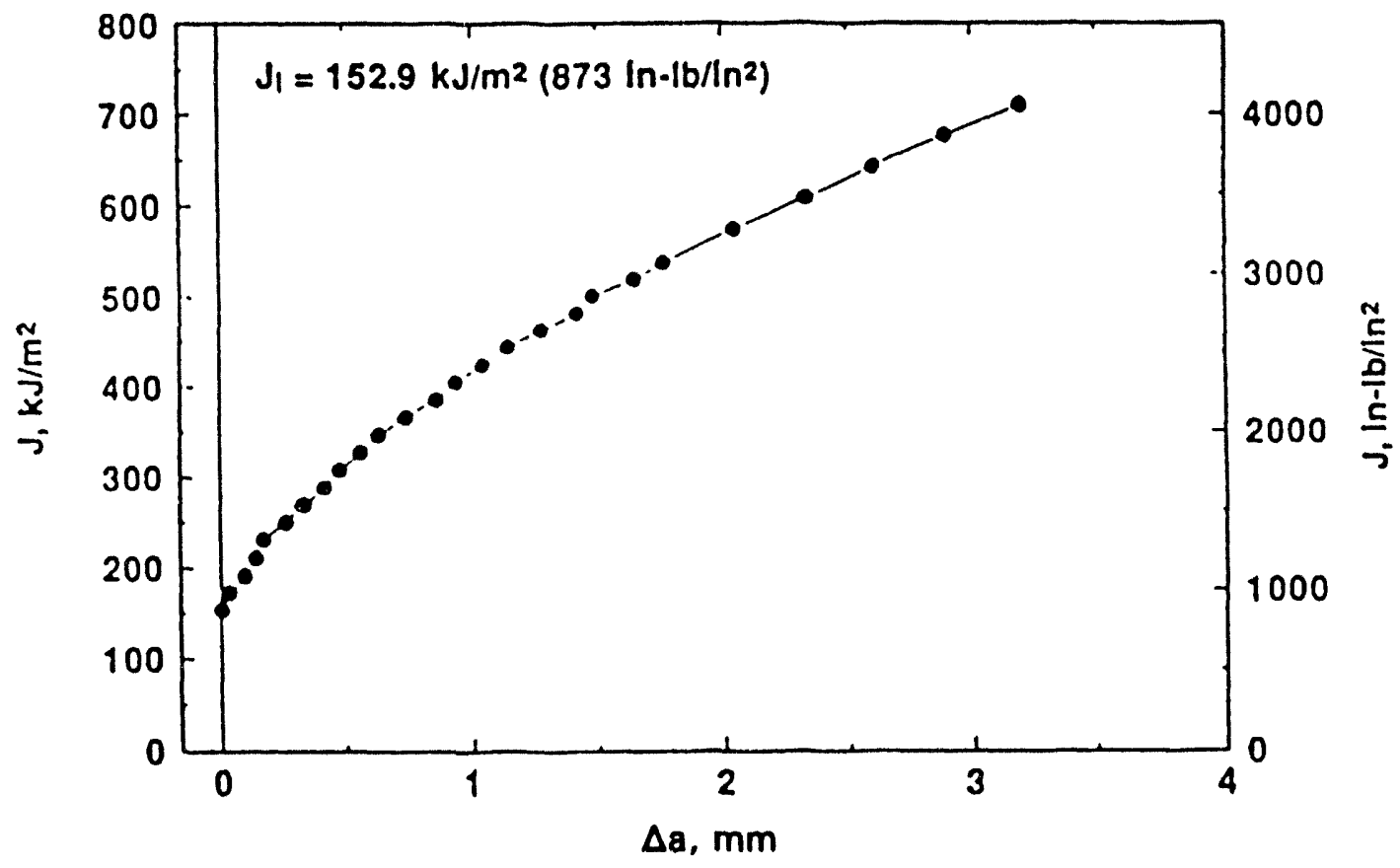

Figure 4.23 Typical J-R curve for test section material 20 MnMoNi 5 5, L-T orientation C(T) data 


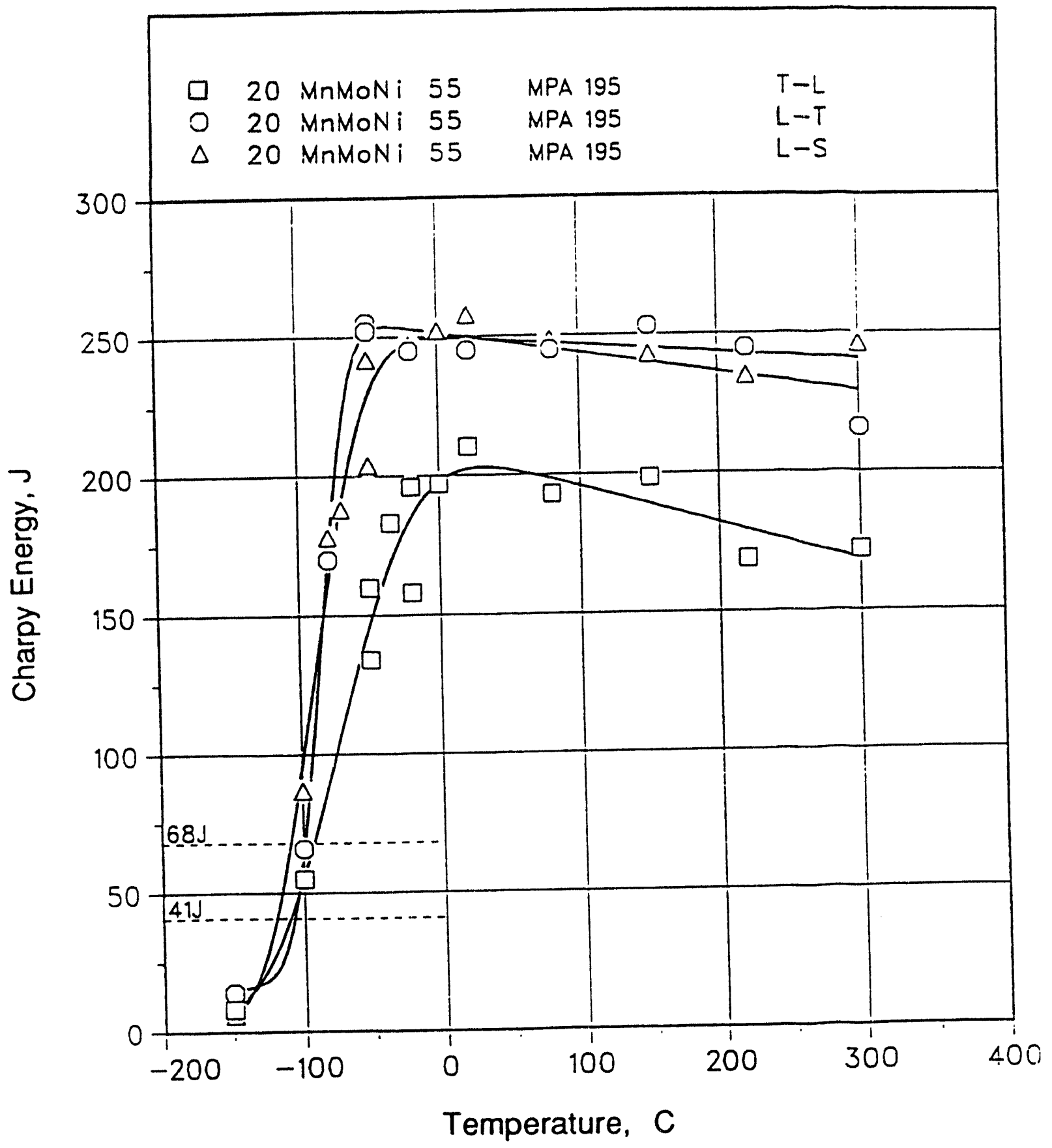

Figure 4.24 Charpy energy-temperature curves for test section material 20 MnMoNi 55 at various sample orientations 


\section{PREDICTIONS OF THE HDR-E31 EXPERIMENTS}

Prediction of the behavior of flawed piping requires a structural analysis to define the crack-driving force and a fracture analysis to determine if the crack resistance is exceeded. In the engineering fracture analysis, these two elements of the evaluation are assumed to be uncoupled. That is, a structural analysis is performed to find the maximum applied load, which is then used in a separate fracture analysis to determine if this load causes some fracture criterion to be exceeded. In the nonlinear FEA fracture analysis, the fracture criterion is an inherent part of the structural analysis.

In the section that follows, the previously discussed engineering fracture and nonlinear FEA fracture analyses are applied to prediction of the HDR-E31 experiments. Because the methodologies have already been discussed, the presentation for each mainly includes just a summary of the results. Assumptions needed to complete each analysis are also stated. Prior to presenting the fracture predictions, the basic structural modeling of the HDR test system is discussed, because it is an integral part of either analysis.

\subsection{Finite Element Modeling}

Prediction of the behavior of flawed piping sections is very much dependent upon the specific geometry, material properties, and globally applied loads of the piping system, i.e., to know the crack-driving force, the piping system response must be precisely estimated. Finite element piping stress analysis permits all of the essential features of a piping system to be rigorously included in a structural analysis, in a routine fashion.

\subsubsection{Finite Element Models}

Separate finite element models were developed to analyze HDR-E31.2 and -E31.3. The reason that separate models were developed was to include the modest section length variations between the two experiments. As appropriate, the models were modified for conducting modal analyses, static pointload analyses, and dynamic analyses of the uncracked piping system. In addition, a third, simplified engineering design model of the E31.2 pipe experiment was developed. The more detailed HDR models are referred to as refined models, while the less detailed model is called the engineering model. Eventually, the refined uncracked dynamic piping system models were modified to include the nonlinear-crack FEA fracture mechanics crack model.

In an attempt to produce a very high quality structural analysis, the pipe system was rigorously modeled to account for all of the pipe transitions, material changes, instrumentation locations, and boundary conditions. The models of the E31.2 and E31.3 experiments were developed using the HDR design reports for the specific experiment. Nodes were defined at locations where the material properties or pipe geometry changed and where instrumentation was applied during the experiments. Material properties were input as a function of temperature, when available. 
The refined system models were developed using ANSYS elastic pipe elements, a generalized mass element, and linear spring-damper elements. The straight pipe runs were modeled using the elastic pipe element, STIF16, and the four elbows vore modeled using elastic curved pipe elements, STIF18. The check valve was modeled using pipe elements with no material density and a generalized mass element, STIF21, located at the center of mass of the valve to account for its weight. Single degreeof-freedom spring-damper elements, STIF14, were used at the Fix Point support. A spring element was connected in each local degree-of-freedom to model the stifiness of the support. The secnnd support, at the rupture disc, was modeled by constraining the lateral and vertical translational motion of the piping system. Longitudinal translation and rotation of the pipe were allowed at this support. Over 275 elements were used in each refined model.

The refined piping system model used six different materials. A complete listing of the elemerts, including dimensions and element orientation, is provided in Appendix A. A table of the material properties used in the finite element analyses is also given in this appendix.

The third version of the HDR-E31 piping system model was a simplified model of the $\$ 31.2$ experiment. An engineering model, similar to that used for design purposes, was developed so that comparisons could be made with the results from the refined models. This model used the same ANSYS elastic pipe elements; however, only a few sets of average pipe geometric dimensions were considered. The wall thickness and diameter of the pipe elements were only changed at two locations in the piping system. The pipe element lengths were considerably longer in this engineering model than in the refined E31.2 model. Approximately 50 elements were used in the engineering model.

One set of material properties was applied to all of the pipe elements, except for the test section, in the engineering model. The boundary conditions at the reactor pressure vessel were fixed in all six deyrees-of-freedom, and the boundary conditions at the Fixed Point support were fixed against the lateral and vertical translational motions. The analysis using the engineering model was conducted under the same conditions of temperature and pressure as the E31.2 analyses.

Figures 5.1 and 5.2 show the basic HDR-E31 test system and the ANSYS finite element model, respectively.

\subsubsection{Modal Analyses}

A modal analysis was conducted for each model to deternnine the natural frequencies and mode shapes of the system. The modal analyses were conducted with the piping system at a temperature of $240 \mathrm{C}$ (464 F) and an internal pressure of 90 bar $(1,323 \mathrm{psi})$. The value of the internal fluid density was $844.6 \mathrm{~kg} / \mathrm{m}^{3}\left(52.07 \mathrm{lb} / \mathrm{ft}^{3}\right)$.

The modal analysis of Experiment E31.2 was conducted using two versions of the E31.2 finite element mod 1 . The first version used fixed-boundary conditions at the Fixed Point support, while the second analysis used the linear-spring elements previously described. The natural frequencies for the first five modes are shown in Table 5.1 for both versions of the E31.2 model. Plots of the mode shapes from the E31.2 model with the fixed-boundary conditions at the first support are shown in Figures 5.3 through 5.7. The plots of the mode shapes for the E31.2 model with the support stiffness showed no discernable differences from the plots in Figures 5.3 through 5.7. 
The modal analysis of the E31.3 finite element model was conducted under conditions identical to the E31.2 analysis, including the spring stiffnesses at the Fixed Point support. The natural frequencies calculated for the E31.3 model are also shown in Table 5.1. Modal analysis of the engineering model was also conducted, and the natural frequencies are listed in Table 5.1.

An additional analysis was conducted to determine if elbow flexibility influences the natural frequencies significantly. The reported ANSYS results used the standard ASME Section III elbow flexibility factors, Ref. 5.1. An alternative to Section III flexibility factors, Code Case N-319-2, Ref. 5.2, provides a different "approved" method to calculate elbow flexibility factors. If the Code Case flexibility goes up, the calculated natural frequencies using ASME Code Case N-319-2 should drop. The Code Case N-319-2 flexibility factors changed the flexibility factor from 4.05 to 3.19 for Elbow 1 and from 3.11 to 2.45 for the remaining elbows. The resulting change was a very slight increase in the calculated first natural frequency from $5.07 \mathrm{~Hz}$ to $5.17 \mathrm{~Hz}$. Because the natural frequency of the finite element model using the Code Case elbow flexibility factor was not significantly different when the Section III factor was used, the Section III flexibility factors were used in all subsequent analyses.

As a final effort, modal analysis of the HDR-E31.2 experiment was also conducted using the experimentally measured values of stiffness against vertical bending and horizontal bending at the Fixed Point support. A summary of the stiffness values is shown in Table 5.2. The design values for the translational stiffnesses and the stiffness against torsion were used in both analyses. The results showed a slight decrease in the frequency of the piping system for each mode; however, the change was typically less than one percent. The mode frequencies using each set of stiffness values are summarized in Table 5.3.

\subsubsection{Static Analyses}

The HDR-E31 uncracked piping system was analyzed with a static point load applied midway between the two elbows in the U-bend. All three versions of the HDR-E31 finite element model were used in. the analyses. The static point-load analyses were conducted at a temperature of $22 \mathrm{C} \mathrm{(72} \mathrm{F),} \mathrm{with} \mathrm{no}$ internal fluid pressure. An internal fluid density of $998.0 \mathrm{~kg} / \mathrm{m}^{3}\left(62.3 \mathrm{lb} / \mathrm{ft}^{3}\right)$ was used to account for the mass of the water. Displacements and moments at selected sections were calculated.

Figures 5.8 and 5.9 show the pipe system geometry and the location of calculated displacements and moments for the engineering and the HDR system models, respectively. The Sisplacements were measured at sections along the pipe system slightly up stream from each elbow. The bending moments were calculated at three locations in the pipe system. Section Q02 corresponds to Elements 5 and 26 in the engineering model and refined pipe system model, respectively. The flaw was located at Elements 8 and 43 in the respective models. The third set of moments was calculated at Section Q91, near the Fixed Point support, and corresponds to Elements 38 and 194 for the engineering and refined system models, respectively. Tables 5.4 to 5.8 present the static point load predictions. The results of the engineering model agree with those of the detailed pipe system models to within 10 percent. 


\subsubsection{Linear Dymamic Analysis}

Linear-elastic, time-history, uncracked pipe calculations were conducted using the finite element models previously described. These analyses were performed to provide inputs for the engineering fracture mechanics flaw assessments. Forces equivalent to the pressures, per the discussion presented in Section 4.2.4, were applied at the appropriate elbow nodes as a function of time. The analyses were conducted with pipe system material properties at a temperature of $240 \mathrm{C}$ (464 F). Moments and nodal displacements at the instrumentation locations were calculated.

The dynamic analyses were conducted using the ANSYS KAN $=4$ (Nonlinear Transient Dynamic Analysis) option. The $\mathrm{KAN}=4$ option was not required for the linear analyses but, because it must be used for the nonlinear FEA cracked pipe analysis, it was decided to utilize it for all analyses. $\mathrm{KAN}=4$ uses the Newmark direct-time-integration scheme. The default unconditionally stable integration parameters were used, and all linear elastic analyses were conducted using the complete 1.0 second force-time history with a time step of 0.0002 seconds.

Rayleigh damping (mass and stiffness damping) of 0.5-percent in the first and fourth modes was assumed in the analysis. This is justified on the basis of past experience with the IPIRG-1 pipe loop test system, Ref. 5.3, in which the measured damping in the pipe loop, which had no hangers (only hydrostatic pipe supports), was less than 0.5 -percent.

Force and displacement data were extracted from the finite element results during post-processing of the data. Moments were extracted at three locations along the pipe system: Section $\mathrm{Q02}$ in the reducer leading to the test piece, Section QP1 at the crack, and Section Q91 near the first support. Displacements were also extracted at three locations along the pipe system: near Elbows 1, 2, and 4. Figures 5.8 and 5.9 show schematics of the pipe system with the location of selected nodes and elements for the HDR E31.3 engineering and refined system models, respectively. The moments are at the end of the designated elements and the displacements are at the nodes.

Linear dynamic analysis results are plotted as a function of time using the engineering model and E31.3 loading in Figures 5.10 through 5.15. The corresponding results for the refined system model analyses are shown in Figures 5.16 through 5.21. As indicated in Section 4.2.4, the forces for the two experiments are slightly different, hence the two curves for the refined system model analysis results.

The maximum moment attained in the refined HDR-E31.2 linear analysis was $1,757 \mathrm{kN}-\mathrm{m}$ $\left(15.55 \times 10^{6}\right.$ in-lb). This moment occurred at 0.1084 seconds from initiation of the test. The maximum moment attained in the refined HDR-E31.3 linear analysis was slightly lower, 1,627 kN-m $\left(14.4 \times 10^{6}\right.$ in-lb), and it occurred at 0.1170 seconds from initiation of the test. As expected, the engineering model and the refined model results are virtually identical. The maximum moment data for all three analyses are summarized in Table 5.9.

It is important to point out that the "equivalent" water-hammer forces applied to the elbow elements in the dynamic finite element model do not include all of the load effects that pressure causes in an elbow. In almost all cases, a pressurized elbow will tend to "open", creating moments at the straight pipe to elbow junction. At the outset of this program, it was planned to use the measured pressures 
and the ANSYS pipe system pressure loading capability to induce the moments at the crack section. This did not work, and in the course of our investigation we discovered that pressure loading of elbows is not correct in ANSYS. The fall-back position that we adopted was to use the "equivalent" elbow forces, recognizing that some part of actual load is not being applied. In addition, it must also be pointed out that the "equivalent" elbow forces ignore static effects. This does not pose a problem in the analysis, however, because all of the measured strains and displacements are also dynamic.

\subsection{Engineering Fracture Predictions}

The basic procedure to utilize any of the engineering fracture mechanics assessment methodologies in a flaw evaluation is as follows.

(1) Conduct a linear elastic finite element analysis of the pipe system with no crack to find the moment at the flaw location. This analysis could be a time-history analysis or it could be a response spectrum analysis.

(2) Calculate the predicted flaw maximum moment-carrying capacity.

(3) Check the result of Step 2 against the applied moments determined in Step 1. If a timehistory analysis has been used in Step 1 and the maximum moment-carrying capacity has been exceeded, one can find the time when the flaw is predicted to "fail". If a responsespectrum analysis has been used in Step 1, then "failure" is a go/no go proposition.

(4) If "failure" is predicted in Step 3, a J/T or Energy Balance analysis can be performed to assess flaw stability.

\subsubsection{Analysis Assumptions}

There are several assumptions that are inherent to all the engineering fracture analyses. Among the important assumptions are:

- Flow stress has been taken as the average of yield plus ultimate from Specimens 195-1 and 195-2 (574.4 MPa [83.3 ksi]) in all but the ASME Section XI evaluation.

- For ASME Section XI, the Section III Code definition of $S_{m}$ for the material is supposed to be used in the analysis. Unfortunately, the test material, $20 \mathrm{MnMoNi} 5$ 5, is not in the ASME Section III Appendices, but it has been judged to be similar to A508 $\mathrm{Cl} 3$ material.

- An equivalent surface crack flaw size has been used in all of the analyses except the ASME Section XI evaluation. As can be seen in Figures 4.21 and 4.22, the flaw tapers at the edges, unlike the idealized radial edges shown in Figure 2.4. The equivalent flaw uses the actual maximum crack depth and a length that makes the actual crack area and 
equivalent crack areas equal. This has the effect of "shortening" the crack length, as measured on the inside diameter of the pipe.

- For ASME Section XI, crack length is prescribed to be based on the length of the crack at the inner pipe wall. Table 5.10 compares the flaw sizes used in the analyses.

- The initial size of the resulting through-wall crack is assumed to begin at the ends of the machined surface crack notch.

In addition to these important global assumptions, there are assumptions more specific to a particular analysis.

\subsubsection{R6 Assumptions}

In the R6 calculations, the quasi-static deformation J-R curve at the pipe test temperature was used. The yield strength used was an average value at the pipe test temperature. The cut-off point on the $S_{r}$ axis is the ratio of the flow stress to the yield strength, where the flow stress was the average of the yield and ultimate strengths.

\subsubsection{J-Estimation Scheme Assumptions}

The J-estimation scheme analysis follows the process described in Section 2.5. For this effort, the SC.TNP surface-cracked pipe J-estimation scheme, Ref. 5.4, implemented in Battelle's NRCPIPES computer program was used to predict the surface-crack behavior. Through-wall-crack behavior was predicted using the LBB.ENG2 method, Ref. 5.5, as implemented in Battelle's NRCPIPE throughwall-cracked pipe J-estimation scheme analysis computer program.

The data used as input to the SC.TNP analysis are the engineering estimate of the flaw geometry, see Table 5.10, and the material properties. Figures 5.22 and 5.23 show the stress-strain data and J-R curve data used in the analysis. Of particular interest in these figures is the fact that the RambergOsgood fitted stress-strain curve has a high " $n$ " value. Note the extremely good fit to the RambergOsgood curve. The " $n$ " value is very high compared to typical U.S. piping materials. In Figure 5.24 , the scatter band on the predictions was due to the difference in the Ramberg-Osgood fit of the stress-strain data in the low strain, high-strain or entire strain regions. The stainless steel pipe tests had a much larger scatter in the Ramberg-Osgood fits and predicted failure loads. The carbon steel pipe had a lower scatter and the experimental loads fell closer to the upper bounding curve. The HDR pipe material follows the Ramberg-Osgood curve very well, see Figure 5.22, hence it was expected that the upper bound curve in Figure 5.24 would give an accurate prediction of maximum loads. The measured J-R curve data are extrapolated using a power-law fit to the data out to many times the measured crack growth. (As a peripheral issue, $20 \mathrm{MnMoNi} 55$ was tested for susceptibility to dynamic strain aging. It was found not susceptible, as indicated by no anomalies in the hardness versus temperature curve, Figure 5.25, using the DSA screening criteria procedures developed in the NRC's Short Cracks in Piping and Piping Welds program, Ref. 5.6. Therefore, one would not expect crack jumps during flaw growth and the J-R curve should not be rate sensitive.) 
Comparisons between predictions using SC.TNP and experimental data suggest that, on average, SC.TNP tends to over predict the moment-carrying capacity of a given flaw, Figure 5.24, particularly at the $R_{i} / t$ ratio of the HDR test pipe, $R_{i} / t=13.3$. To remove this known bias, all of the raw SC.TNP data were scaled by a factor of 0.714 , the upper bound at $R_{i} / t=13.3$ in Figure 5.24. Pressure corrections were applied to the SC.TNP and LBB.ENG2 data per the discussions in Section 2.5.2.

\subsubsection{Energy Balance Stability Analysis Assumptions}

The data needed to perform an energy balance analysis are the moment-rotation prediction of the initially surface-cracked pipe, the moment-rotation prediction for the resulting through-wall-cracked pipe, and the elastic compliance of the pipe system. The moment-rotation predictions were made as described above. The pipe system compliance was determined with the ANSYS finite element computer program using the methodology outlined in Ref. 5.7.

For an Energy Balance Stability Analysis of a pipe system, it is necessary to identify load-controlled versus displacement-controlled moments. Displacement-controlled moments are moments which are relieved by pipe system deformation. Thermal expansion and anchor displacements cause displacement-controlled moments. Load-controlled moments, on the other hand, are moments which are not shed as a result of deformation. Dead-weight loading and eccentric axial forces from pressure caused load-controlled moments. For the HDR system case, the only significant load-controlled moment is the moment caused by the eccentric axial forces from the internal pressure. The deadweight loads are insignificant.

To account for the pressure induced moment, several possible approaches may be considered. One method is to incorporate the axial tensile forces in the calculations of the moment-rotation curves of the surface-cracked and through-wall-cracked pipe analyses. This is the most straight forward approach, but J-estimation schemes including pressure and bending of surface-cracked pipe have not been sufficiently validated to date. Another approach is to perform the moment-rotation calculations under pure bending, and then determine an equivalent load-controlled bending moment caused by the axial tensile load. This is the method that was used here. The equivalent bending moment, $M_{\text {eq, }}$ was determined by using the Net-Section-Collapse analysis:

$$
M_{o q}=M_{b}-M_{p+b}
$$

where $M_{b}$ is the moment calculated by the Net-Section-Collapse analysis at failure for pure bending of the through-wall crack, and $\mathrm{M}_{\mathrm{b}+\mathrm{p}}$ is the moment calculated by the Net-Section-Collapse analysis at failure for combined bending and pressure of the through-wall crack. This correction is also a function of crack size. It should be noted that $M_{e q}$ contains terms that include induced bending effects from the axial tension from the internal pressure. If the pipe system restrains the induced bending, then the $M_{e q}$ will be less. 


\subsubsection{Predictions}

Table 5.11 summarizes the results of the engineering fracture predictions for the HDR-E31 experiments. As expected, the E31.3 predictions are lower than the E31.2 predictions because of the deeper flaw. In addition, the ASME Section XI ferritic pipe evaluation procedure, with its conservative flaw size estimate, predicts the lowest moment-carrying capacity of all of the methods. Figure 5.26 shows the predicted moment-rotation behavior of the flaw from the J-estimation scheme analyses. (Note: rotation in this report is always the total rotation or rotation of the pipe on one side of the crack relative to the pipe on the other side of the crack, i.e., $2 \phi$.)

Strict application of ASME Section XI requires one to use $S_{m}$ from Section III of the Code and the inner wall crack length and maximum depth to define the flaw size. To explore the impact of these restrictions, two alternative interpretations were considered. First, the engineering flaw size was used. Because the length is shorter, Table 5.10, the moment-carrying capacity should go up. Second, the use of the $\mathrm{A} 508 \mathrm{Cl} 3 \mathrm{~S}_{\mathrm{m}}$ may be biasing the predictions downward. An alternative for defining $S_{m}$ is to calculate an $S_{m}$ based on actual properties. For ferritic steels, this $S_{m}$ value, called $S_{\mathrm{m} \text { (Actual) }}$, is the lowest of $\sigma_{\mathrm{u}} / 3$ at temperature, $0.9 \sigma_{\mathrm{y}}$ at temperature, or $2 \sigma_{\mathrm{y}} / 3$ at room temperature, per the ASME definitions. Using $S_{m \text { (Actual) }}$ accounts for material variability, and essentially considers the pipe as if it had minimum ASME Code properties. (It should be noted that the ASME Code is limited to lower strength ferritic steels, and that the HDR German piping steel has a higher strength than the ASME Code upper bound. Hence, strictly speaking, the ASME Code should not be applied to German piping steels.)

The impact of "lifting" some of the restrictions on ASME Section XI is shown in Table 5.12. The change is as great as 28-percent higher predicted capacity when actual $S_{m}$ and the engineering flaw size are used.

Comparing the predicted engineering fracture analyses maximum moment-carrying capacity of the flaws, Table 5.11, with the linear elastic finite element results, Table 5.9, all of the flaw evaluation methods would predict that the surface crack would easily penetrate the pipe wall, because the load capacity is much less than the applied moment. In light of the fact that all of the engineering analyses predict that the surface crack will penetrate the pipe wall, stability analyses were performed to predict the stability of the resulting through-wall crack.

The stability of the resulting through-wall cracks was assessed using both $\mathrm{J} / \mathrm{T}$ and Energy Balance analyses. Current $\mathrm{J} / \mathrm{T}$ analysis methods make a distinction between load-controlled and displacementcontrolled stresses, and are not able to consider combined stresses. Energy Balance, on the other hand, is able to consider the effect of each type of stress.

The applicable J/T solutions are EPFM solutions, Refs. 5.8 and 5.9. The analysis proceeds according to the discussion presented in Section 2.6.1, with both the load-controlled and displacement-controlled $\mathrm{J} / \mathrm{T}$ solutions utilizing the GE/EPRI h-functions. Unfortunately, the crack rotation $\mathrm{h}$-functions required for the displacement-controlled $\mathrm{J} / \mathrm{T}$ analysis are limited to Ramberg-Osgood " $n$ " values less than 7. Because the E31 experiment " $n$ " is beyond this limit, no displacement-controlled $J / T$ stability analysis can be performed. Load-controlled $\mathrm{J} / \mathrm{T}$ stability analyses can be conducted and are shown in Figure 5.27. In both cases, the through-wall crack is predicted to be unstable. 
Energy Balance stability assessments were performed according to the descriptions given in Sections 2.6.2 and 5.2.1.3. Figures 5.28 and 5.29 suggest that for both E31.2 and E31.3, the driving and absorbed energies can be balanced before the through-wall crack has run out of moment-carrying capacity. Because the balance point is well above the load-controlled moment of either the test pressure (90 Bar [1,323 psi]) or the saturation pressure at $240 \mathrm{C} \mathrm{(464} \mathrm{F)} \mathrm{and} 24$ Bar (353 psi), the cracks are predicted to arrest, after a limited instability.

\subsection{Nonlinear FEA Fracture Predictions}

The basic procedure to perform a nonlinear FEA fracture mechanics flaw evaluation is as follows:

(1) The geometry of the basic pipe system is modeled using finite elements.

(2) A J-estimation scheme analysis is performed to define the moment-rotation response of the crack. Moment-rotation response must be defined for the surface crack and the expected through-wall-crack after surface-crack penetration.

(3) The predicted moment-rotation response of the cracked section is implemented in the finite element model using nonlinear springs, a nonlinear truss, and a break-away element. The maximum force of the break-away element is set to a high value.

(4) Conduct a dynamic time-history analysis and note if and when the maximum surfacecrack moment is achieved. If the maximum surface-crack moment is not achieved, then the analysis terminates and the conclusion is that the surface crack does not penetrate the pipe wall. If maximum moment is attained, continue with Step 5.

(5) Restart the analysis at the time step of maximum moment of the surface crack with the correct break-away force in the break-away element. This will "remove" the surface crack from the subsequent load steps.

(6) Continue the analysis of the piping system as a through-wall crack problem. At some point, the moment capacity of the through-wall crack may be exhausted, in which case one would predict that a DEGB had occurred. If the through-wall crack unloads before reaching zero moment capacity, then continue with Step 7.

(7) At the point of crack unloading, determine the amount of crack growth and save the restart files for the dynamic analysis.

(8) At the given amount of through-wall-crack growth, conduct a J-estimation scheme through-wall-crack analysis with the new crack length and $J_{i}$ set very high. This has the effect of suppressing crack growth in the J-estimation scheme analysis, so that only material stress-strain nonlinearity is considered.

(9) At the given amount of through-wall-crack growth, conduct a J-estimation scheme through-wall-crack analysis with the new crack length and $\mathrm{J}_{\mathrm{i}}$ set to the value attained 
when the crack unloaded. This basically implements the change in compliance caused by the longer crack while retaining the correct moment-rotation response when the crack reinitiates.

(10) Restart the dynamic cracked-pipe analysis with new material properties. The tensile part of the moment-rotation curve comes from Step 9 and the compressive part comes from Step 8.

(11) Recycle to Step 6, as needed.

\subsubsection{Assumptions}

The principal assumptions needed to conduct a nonlinear FEA fracture mechanics analysis of the HDR-E31 experiments are the same ones listed in Section 5.2 for the J-estimation scheme analysis, i.e., use of the engineering flaw size, through-wall crack behavior begins with the crack tips at the ends of the surface crack machined notch, all of the assumptions associated with the J-estimation scheme analysis, no torsional loads, and moments are in a plane symmetric with the center of the surface crack.

In addition to the assumptions noted above, it was assumed that the surface crack moment-rotation response could be adequately represented with three linear segments and that the through-wall crack could be represented with five linear segments.

\subsubsection{Predictions}

The predicted moment-time and moment-rotation responses for the HDR-E31 experiments are shown in Figures 5.30 through 5.33. The interpretation of information presented in these figures is as follows; the E31.2 surface crack is predicted to penetrate the pipe wall at 0.1066 seconds and will propagate as a through-wall crack and arrest at an included angle of 83 degrees, while the E31.3 surface crack is predicted to penetrate the pipe wall at 0.1018 seconds and will propagate as a through-wall crack and arrest at an included angle of 85 degrees.

Review of the detailed outputs for the surface-crack portion of the analysis (through Step 4 in the procedure listed above), suggests that the E31.3 flaw and loading combination easily causes the surface crack to penetrate the pipe wall. E31.2, on the other hand, is quite marginal. The loading on the crack is only just sufficient to cause surface crack penetration. If the predicted maximum moment had been only 2- to 3-percent higher, surface-crack penetration would not be predicted to occur.

\subsection{References}

5.1 American Society of Mechanical Engineers Boiler and Pressure Vessel Code, Edition July 1989, Section III Article NB-3686.2.

5.2 American Society of Mechanical Engineers Boiler and Pressure Vessel Code, Edition 1992, Code Case N-319-2. 
5.3 R. A. Schmidt, G. M. Wilkowski, and M. Mayfield, "The International Piping Integrity Research Group (IPIRG) Program-An Overview", SMiRT-11 Proceedings, August 1991, Paper G23/1.

5.4 Scott, P. M., and Ahmad, J. A., "Experimental and Analytical Assessment of Circumferentially Surface-Cracked Pipes Under Bending", NUREG/CR-4872, April 1972.

5.5 Gilles, P., and Brust, F. W., "Approximate Methods for Fracture Analysis of Tubular Members Subjected to Combined Tensile and Bending Loads", ASME 8th OMAE Conference, The Hague, Netherlands, March 1989.

5.6 Wilkowski, G. M., and others, "Short Cracks in Piping and Piping Welds", Second Semiannual Report by Battelle, NUREG/CR-4599, Vol. 1, No. 2, April 1992.

5.7 Zahoor, A., and Gamble, R., "Leak Before Break Analysis for BWR Recirculation Piping Having Multiple weld Locations", EPRI report NP-3522-LD, April 1984.

5.8 Zahoor, A., "Ductile Fracture Handbook, Volume 1 - Section 5.9: Applied Tearing Modulus, Bending Moment, Load Control, EPFM", EPRI Report NP-6301-D, , June 1989, pp. 5-43 to 5-50.

5.9 Zahoor, A., "Ductile Fracture Handbook Volume 1 - Section 5.10: Applied Tearing Modulus, Bending Moment, Displacement Control, EPFM", EPRI Report NP-6301-D, June 1989, pp. 551 to 5-60. 
Table 5.1 Predicted natural frequencies of the HDR pipe system

\begin{tabular}{|c|c|c|c|c|}
\hline Mode & $\begin{array}{c}\text { E31.2 with } \\
\text { Fxed } \\
\text { Support, } \\
\text { Hz }\end{array}$ & $\begin{array}{c}\text { E31.2 with } \\
\text { Support } \\
\text { Stifness, } \\
\text { Hz }\end{array}$ & $\begin{array}{c}\text { E31.3 with } \\
\text { Support } \\
\text { Stifness, } \\
\text { Hz }\end{array}$ & $\begin{array}{c}\text { Engineering } \\
\text { Model, } \\
\text { Hz }\end{array}$ \\
\hline 1 & 5.250 & 5.105 & 5.105 & 5.223 \\
\hline 2 & 7.068 & 6.958 & 6.959 & 6.978 \\
\hline 3 & 8.951 & 8.954 & 8.955 & 9.197 \\
\hline 4 & 15.594 & 14.926 & 14.925 & 15.306 \\
\hline 5 & 21.356 & 20.428 & 20.429 & 21.036 \\
\hline
\end{tabular}

Table 5.2 Fixed point stiffness values for Experiment E31.2

\begin{tabular}{|c|c|c|}
\hline Stifness* & Design Report Stiffness & Measured Stiffness \\
\hline Cx, MN/mm & 2.56 & - \\
\hline$C y, M N / m m$ & 0.571 & - \\
\hline$C z, M N / m m$ & 0.77 & - \\
\hline$C x x, G N-m / r a d$ & 1.54 & - \\
\hline$C y y, G N-m / r a d$ & 0.457 & 0.409 \\
\hline$C z z, G N-m / r a d$ & 0.637 & 0.442 \\
\hline
\end{tabular}

* $0.17513 \mathrm{MN} / \mathrm{mm}=1.0 \times 10^{6}, 112.98 \mathrm{GN}-\mathrm{m} / \mathrm{rad}=1.0 \times 10^{12} \mathrm{in}-\mathrm{lb} / \mathrm{rad}$ 
Table 5.3 Mode frequencies for Experiment $\mathbf{B 3 1 . 2}$

\begin{tabular}{|c|c|c|}
\hline Mode & $\begin{array}{c}\text { Frequency Using Design } \\
\text { Surfiness Values, } \mathrm{Hz}\end{array}$ & $\begin{array}{c}\text { Frequency Using Measured } \\
\text { Stiffnes Values, Hz }\end{array}$ \\
\hline 1 & 5.105 & 5.068 \\
\hline 2 & 6.958 & 6.925 \\
\hline 3 & 8.954 & 8.947 \\
\hline 4 & 14.926 & 14.801 \\
\hline 5 & 20.428 & 20.316 \\
\hline
\end{tabular}

Table 5.4 Summary of displacements due to static loading*

\begin{tabular}{|c|l|c|c|c|}
\hline Model & \multicolumn{1}{|c|}{$\begin{array}{c}\text { Loading } \\
\text { Condition }\end{array}$} & $\begin{array}{c}\text { Displacement } \\
\mathbf{U}_{\mathrm{x}}, \mathrm{mm}\end{array}$ & $\begin{array}{c}\text { Displacement } \\
\mathbf{U}_{\mathrm{y}}, \mathrm{mm}\end{array}$ & $\begin{array}{c}\text { Displacement } \\
\mathbf{U}_{\mathrm{z}}, \mathrm{mm}\end{array}$ \\
\hline 1 & $\begin{array}{l}\mathrm{F}=100 \mathrm{kN} \\
\mathrm{g}=9.81 \mathrm{~m} / \mathrm{s}^{2}\end{array}$ & 3.323 & 0.377 & 3.891 \\
\hline 2 & $\begin{array}{l}\mathrm{F}=100 \mathrm{kN} \\
\mathrm{g}=0 \mathrm{~m} / \mathrm{s}^{2}\end{array}$ & 7.169 & 2.078 & 9.882 \\
\hline 3 & $\begin{array}{l}\mathrm{F}=0 \mathrm{kN} \\
\mathrm{g}=9.81 \mathrm{~m} / \mathrm{s}^{2}\end{array}$ & -3.846 & -1.701 & -5.991 \\
\hline
\end{tabular}

* $1,000 \mathrm{lb}=4.4482 \mathrm{kN} ; 1.0 \mathrm{~m} / \mathrm{s}=39.37 \mathrm{in} / \mathrm{s}, 25.4 \mathrm{~mm}=1.0 \mathrm{inch}$. 
Table 5.5 Moment and displacement results for the engineering finite element model with $F_{2}=100 \mathrm{kN}(22,481 \mathrm{lb} *)$

\begin{tabular}{|c|c|c|c|}
\hline $\begin{array}{l}\text { Location } \\
\text { (node) }\end{array}$ & $\begin{array}{l}\text { Displacement } U_{z} \\
\mathrm{~mm}\end{array}$ & $\underset{\mathrm{mm}}{\text { Displacemeat }} \mathbf{U}_{\mathbf{y}}$ & $\underset{\mathrm{mm}}{\underset{\mathrm{mm}}{\text { Displacement }}} \mathrm{U}_{\mathbf{z}}$ \\
\hline MN461 (14) & -0.008 & -0.977 & 8.560 \\
\hline MN471 (25) & 6.939 & 1.482 & 10.118 \\
\hline load point (30) & 6.544 & 2.245 & 8.634 \\
\hline MN481 (35) & 2.894 & 0.245 & 6.118 \\
\hline $\begin{array}{l}\text { Location } \\
\text { (clement) }\end{array}$ & & $\begin{array}{c}\text { Moment at } \xi=0^{\circ} \\
(\mathrm{N}-\mathrm{m})\end{array}$ & $\begin{array}{c}\text { Moment at } \xi=90^{\circ} \\
(N-m)\end{array}$ \\
\hline Q02 (5) & & $-176,160$ & $-13,880$ \\
\hline crack (8) & & $-164,865$ & $-13,920$ \\
\hline Q91 (38) & & $-173,540$ & $+40,150$ \\
\hline
\end{tabular}

* $25.4 \mathrm{~mm}=1.0 \mathrm{inch}, 0.11298 \mathrm{~N}-\mathrm{m}=1.0 \mathrm{in}-1 \mathrm{~b}$.

Table 5.6 Moment and displacement results for the E31.2 finite element model with $F_{2}=100 \mathrm{kN}(22,481 \mathrm{lb}) *$

\begin{tabular}{|c|c|c|c|}
\hline $\begin{array}{c}\text { Location } \\
\text { (node) }\end{array}$ & $\begin{array}{c}\text { Displacement } \mathrm{U}_{\mathbf{z}} \\
\mathrm{mm}\end{array}$ & $\begin{array}{c}\text { Displacement } \mathrm{U}_{\mathbf{y}} \\
\mathrm{mm}\end{array}$ & $\begin{array}{c}\text { Displacement } \mathrm{U}_{\mathbf{z}} \\
\mathrm{mm}\end{array}$ \\
\hline MN461 (93) & -0.009 & -0.920 & 8.653 \\
\hline MN471 (142) & 7.350 & 1.211 & 10.270 \\
\hline load point (153) & 6.940 & 1.838 & 9.004 \\
\hline MN481 (171) & 2.999 & -0.091 & 6.710 \\
\hline Location & & Moment at $\xi=0^{\circ}$ & Moment at $\xi=90^{\circ}$. \\
(element) & $(\mathrm{N}-\mathrm{m}$ ) & $-12,835$ \\
\hline Q02 (26) & & $-186,070$ & $-12,990$ \\
\hline crack (43) & & $-174,210$ & $+41,530$ \\
\hline Q91 (194) & & $-165,290$ & \\
\hline
\end{tabular}

* $25.4 \mathrm{~mm}=1.0 \mathrm{inch}, 0.11298 \mathrm{~N}-\mathrm{m}=1.0 \mathrm{in}-\mathrm{lb}$. 
Table 5.7 Moment and displacement results for the engineering finite element model with $F_{2}=110 \mathrm{kN}(24,729 \mathrm{lb}) *$

\begin{tabular}{|c|c|c|c|}
\hline $\begin{array}{c}\text { Location } \\
\text { (node) }\end{array}$ & $\begin{array}{c}\text { Displacement } U_{x} \\
\mathrm{~mm}\end{array}$ & $\begin{array}{c}\text { Displacement } U_{y} \\
\mathrm{~mm}\end{array}$ & $\begin{array}{c}\text { Displacement } U_{z} \\
\mathrm{~mm}\end{array}$ \\
\hline MN461 (14) & -0.009 & -1.075 & 9.416 \\
\hline MN471 (25) & 7.633 & 1.630 & 11.130 \\
\hline loed point (30) & 7.198 & 2.458 & 9.498 \\
\hline MN481 (35) & 3.183 & 0.270 & 6.730 \\
\hline $\begin{array}{c}\text { Location } \\
\text { (element) }\end{array}$ & & Moment at $\xi=0^{\circ}$ & Moment at $\xi=90^{\circ}$ \\
\hline Q02 (5) & $(\mathrm{N}-\mathrm{m})$ & $-15,265$ \\
\hline crack (8) & & $-193,780$ & $-15,310$ \\
\hline Q91 (38) & & $-181,350$ & $+44,165$ \\
\hline
\end{tabular}

* $25.4 \mathrm{~mm}=1.0 \mathrm{inch}, 0.11298 \mathrm{~N}-\mathrm{m}=1.0 \mathrm{in}-\mathrm{lb}$.

Table 5.8 Moment and displacement results for the E31.3 finite element model with $F_{z}=110 \mathrm{kN}(24,729 \mathrm{lb}) *$

\begin{tabular}{|c|c|c|c|}
\hline $\begin{array}{c}\text { Location } \\
\text { (node) }\end{array}$ & $\begin{array}{c}\text { Displacement } U_{x} \\
\mathbf{m m}\end{array}$ & $\begin{array}{c}\text { Displacement } \mathbf{U}_{\mathbf{y}} \\
\mathrm{mm}\end{array}$ & $\begin{array}{c}\text { Displacement } \mathbf{U}_{\mathbf{z}} \\
\mathrm{mm}\end{array}$ \\
\hline MN461 (93) & -0.010 & -1.011 & 9.517 \\
\hline MN471 (142) & 8.084 & 1.331 & 11.296 \\
\hline loed point (153) & 7.634 & 2.022 & 9.903 \\
\hline MN481 (171) & 3.299 & -0.101 & 7.381 \\
\hline $\begin{array}{c}\text { Location } \\
\text { (clement) }\end{array}$ & & Moment at $\xi=: 0^{\circ}$ & Moment at $\xi=90^{\circ}$ \\
\hline Q02 (26) & $(\mathrm{N}-\mathrm{m})$ & $-14,115$ \\
\hline crack (43) & & $-204,690$ & $-14,280$ \\
\hline Q91 (194) & & $-191,650$ & $+45,680$ \\
\hline
\end{tabular}

* $25.4 \mathrm{~mm}=1.0$ inch, $0.11298 \mathrm{~N}-\mathrm{m}=1.0 \mathrm{in}-\mathrm{lb}$. 
Table 5.9 Linear finite element piping stress analysis moment summary for the HDR-E31 test system

\begin{tabular}{|c|c|c|}
\hline Moded & Moximum moment, MN-m & Time, seconds \\
\hline Engineering & 1.796 & 0.1680 \\
\hline Refined E31.2 & 1.757 & 0.1084 \\
\hline Refined E31.3 & 1.627 & 0.1170 \\
\hline
\end{tabular}

* 1.0 MN-m $=8.85 \times 10^{6} \mathrm{in}-\mathrm{lb}$.

Table 5.10 Flaw sives used in the HDR-E31 fracture assessments

\begin{tabular}{|c|c|c|c|c|}
\hline \multicolumn{2}{|c|}{ Engineering Equivalent Size } & \multicolumn{2}{|c|}{ ASME Section III } \\
\cline { 2 - 5 } & $\mathbf{E 3 1 . 2}$ & $\mathbf{E 3 1 . 3}$ & $\mathbf{E 3 1 . 2}$ & $\mathbf{E 3 1 . 3}$ \\
\hline SC Depth, mm* & 4.56 & $\begin{array}{c}7.96 \\
200\end{array}$ & $\begin{array}{c}4.56 \\
230\end{array}$ & $\begin{array}{c}7.96 \\
260\end{array}$ \\
\hline Length, $\mathrm{mm}$ & 199 & 200 & \\
\hline
\end{tabular}

$* 25.4 \mathrm{~mm}=1.0$ inch.

Table 5.11 Engineering methods predictions

\begin{tabular}{|c|c|c|}
\hline Method & $\begin{array}{c}\text { E31.2 Predicted } \\
\text { Maximum Moment, } \\
\text { MN-m }\end{array}$ & $\begin{array}{c}\text { E31.3 Predicted Maximum } \\
\text { Moment, } \\
\text { MN-m }\end{array}$ \\
\hline NSC (NP-192) & 1.61 & 1.507 \\
\hline $\begin{array}{c}\text { ASME Section XI } \\
\text { (IWB-3650) }\end{array}$ & 0.652 & 0.575 \\
A508 C 3, Sec. II flaw & 1.521 & 1.307 \\
\hline R6, Rev 3, Option 1 & 1.158 & 1.083 \\
\hline DPZP screening criterion & 1.138 & 1.063 \\
\hline SC.TNP (Adjusted) & & \\
\hline
\end{tabular}

* $1.0 \mathrm{MN}-\mathrm{m}=8.85 \times 10^{6} \mathrm{in}-\mathrm{lb}$. 
Table 5.12 Comparison of IWB-3650 maximum moments for the HDR-E31 experiments with various haw and material assumptions*

\begin{tabular}{|c|c|c|c|c|c|}
\hline \multirow[b]{3}{*}{ S. Derinition } & \multirow[b]{3}{*}{$\mathbf{S}_{\mathbf{m}}, \mathbf{M P a}$} & \multicolumn{4}{|c|}{ Maximum Moment, kN-m } \\
\hline & & \multicolumn{2}{|c|}{ ASME Section XI Flaw Sixe } & \multicolumn{2}{|c|}{ Engineering Flaw Sive } \\
\hline & & $\begin{array}{c}\text { Experiment } \\
\text { E31.2 }\end{array}$ & $\begin{array}{c}\text { Experiment } \\
\text { E31.3 }\end{array}$ & $\begin{array}{c}\text { Experiment } \\
\text { E31.2 }\end{array}$ & $\begin{array}{c}\text { Experiment } \\
\text { E31.3 }\end{array}$ \\
\hline $\begin{array}{l}\text { ASME Code } S_{m} \\
\text { (A508 Cl 3) }\end{array}$ & 186.5 & 652 & 575 & 664 & 614 \\
\hline$S_{m(A c t u a n)} *$ & 218.53 & 783 & 695 & 797 & 740 \\
\hline
\end{tabular}

* $\quad 6.895 \mathrm{MPa}=1.0 \mathrm{ksi}, 1.0 \mathrm{kN}-\mathrm{m}=8,850 \mathrm{in}-\mathrm{lb}$.

** Based on actual properties. 


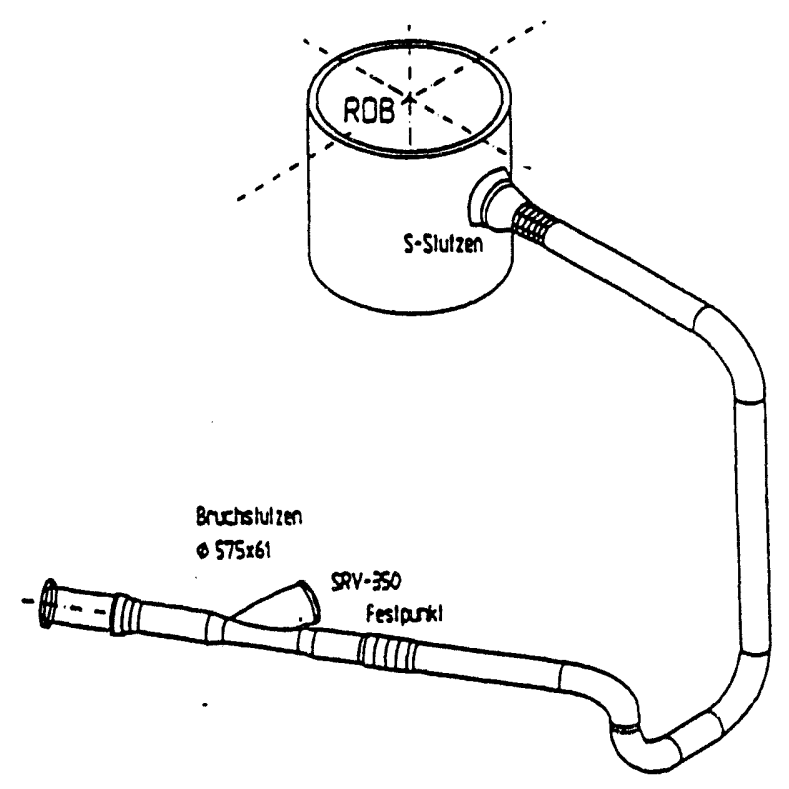

Figure 5.1 HDR-E31 experimental facility schematic (Units in mm)

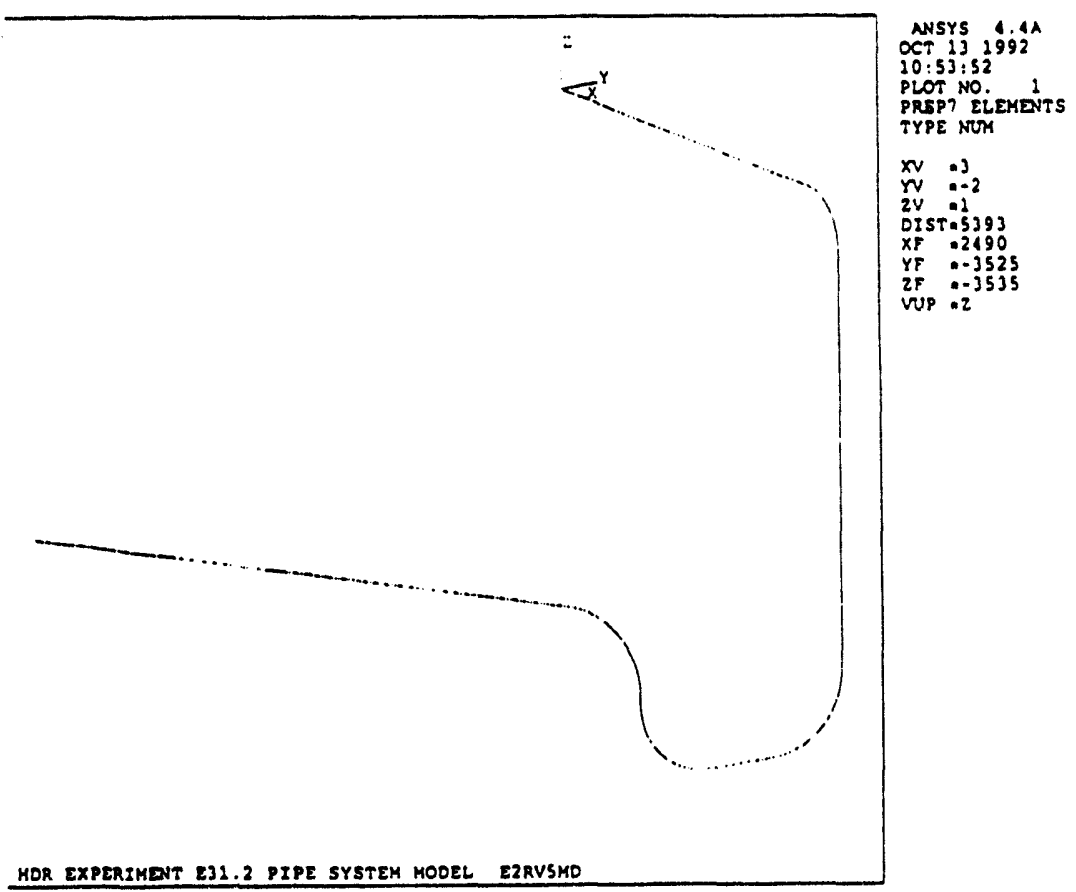

Figure 5.2 ANSYS finite element model of the HDR-E31 system 

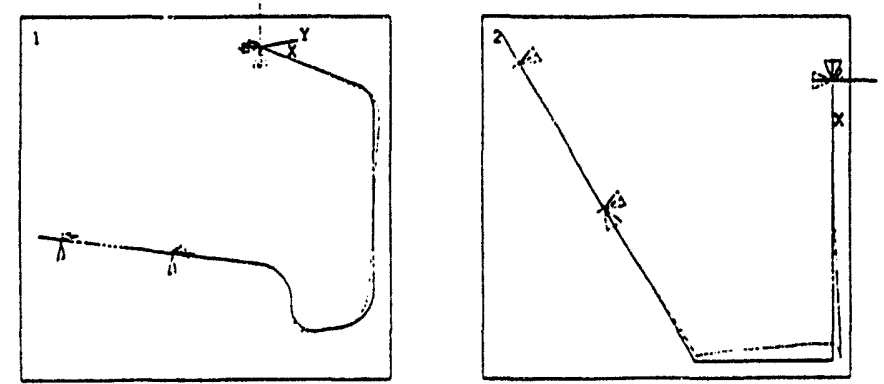

NH8Y8 4.4A

OCT 15,1992

PLOT No.

POST1 DIEPL.

STEP=!

ITER-1

DUX $=0.7925-04$

TDIs

DSCA $=0.681 E+07$

$x v-3$
$v v-0$

rv $=-2$

DI85-5393

$\begin{array}{ll}X F & -2490 \\ Y F & -3525\end{array}$

$27 \quad-3535$

vip $=2$

WIND-2

DSCA-0.493E+07
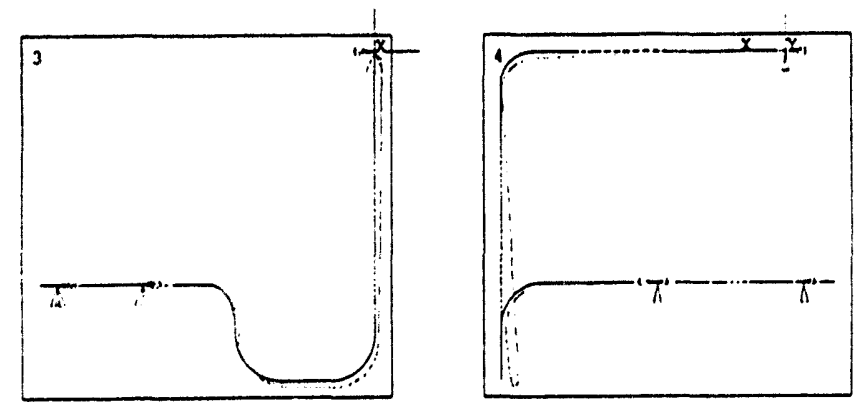

$8 V-1$

DIST $=3906$
$X F \quad-2490$

\begin{aligned}$x r & -2490 \\$\hline$r & -3525\end{aligned}$

ir $=-3535$

vor -2

HINDOM

DSCA=0.491E+07

HOR EXPERIMENT EJ1.2 PIPE SYSTEM MODEL E2RVBMD

Figure 5.3 Mode 1 of the HDR-E31 test system
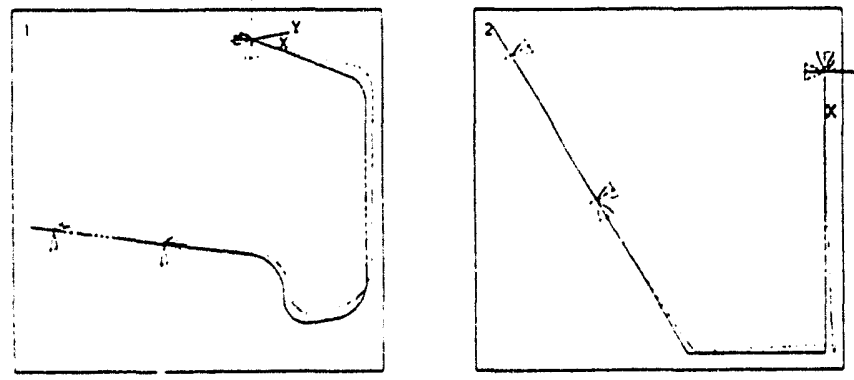

ANSYS 4.4A

16143103

PLOT NO.

POSTI OISPL.

STEP=!

ITER-2

TREO $=7.068$

DMX $-0.267 \varepsilon-04$

TDIS

DSCA-0.366E+OB

$x V=3$

$r v=-2$

zV $=1$

DIST-5393

$x F \quad-2490$

$\begin{array}{ll}x F & -3525 \\ 2 F & -3535\end{array}$

VUP -2

WINDO2

$D S C A=0.265 E+0 B$

ZV -1
DIST
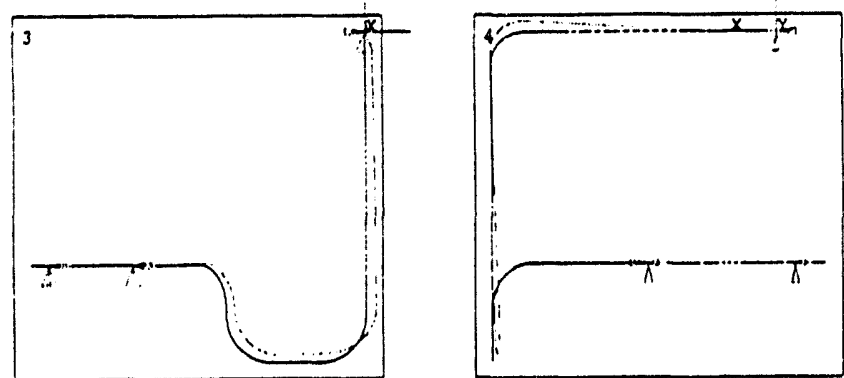

$X F=2490$

$X F=-3525$

$28-0353$

KIND=3

OSCA $=0.264 E+08$

$x v-1$

HDR EXPERIMENT E31.2 PIPE SYSTEM MODEL E2RVQMD

Figure 5.4 Mode 2 of the HDR-E31 test system 

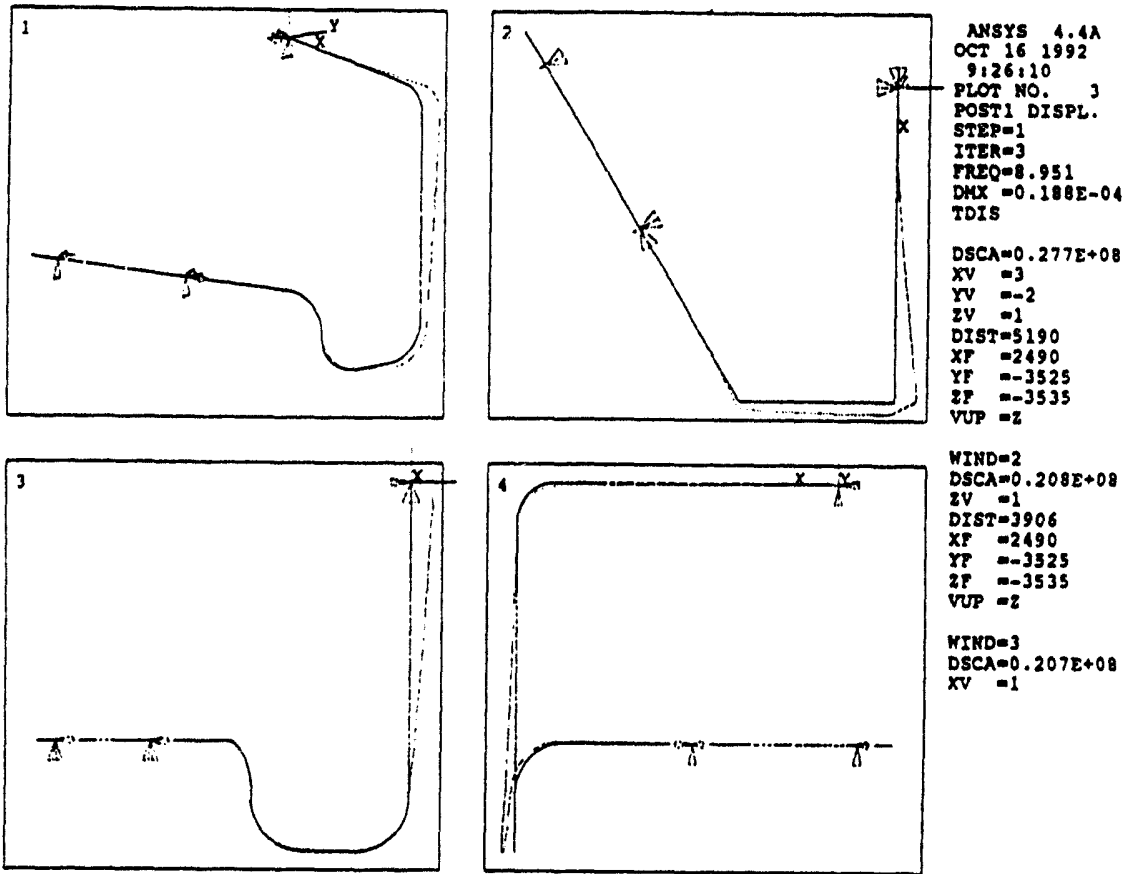

MTND=2

DSCA $=0.208 E+08$

iv -1

DIST $=3906$

$x z=249$

IF

vis -2

WIND $=3$

DSCA $0.2078+08$

$x v-1$

HDR EXPERIMENT E31.2 PIPE SYSTEM MODER E2RVEMD

Figure 5.5 Mode 3 of the HDR-E31 test system
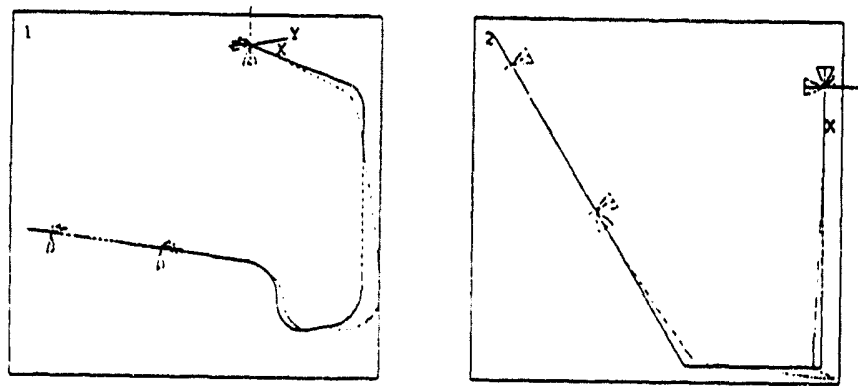

ANSYS $4.4 \lambda$

oct 151992

PLOT NO.

POSTI DISPL".

STEPMI

ITER=4

PREXO-15.594
DMX $=0.315 E-05$

TOIS

DSCA $=0.1718+09$

xv $=3$

iv

DI8T $=5393$

$X F=2490$

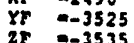

vir $=2$
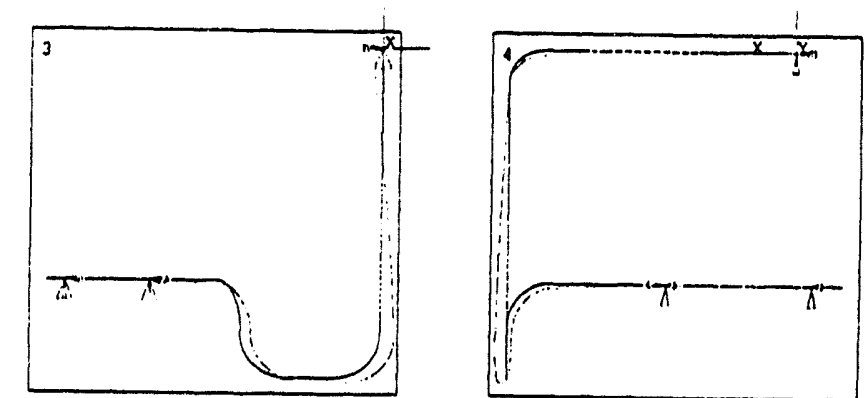

KIND $=2$

DSCA $=0.124 \Sigma+09$

$2 \mathrm{x}=1$

DIST-3906

XF -2490

if $=-3535$

VuP $=2$

HIND-3

DSCA $=0.123 E+09$

HDR EXPERIMENT EJ1.2 PIPE SYSTEM MODEL E2RVBMD

Figure 5.6 Mode 4 of the HDR-E31 test system 

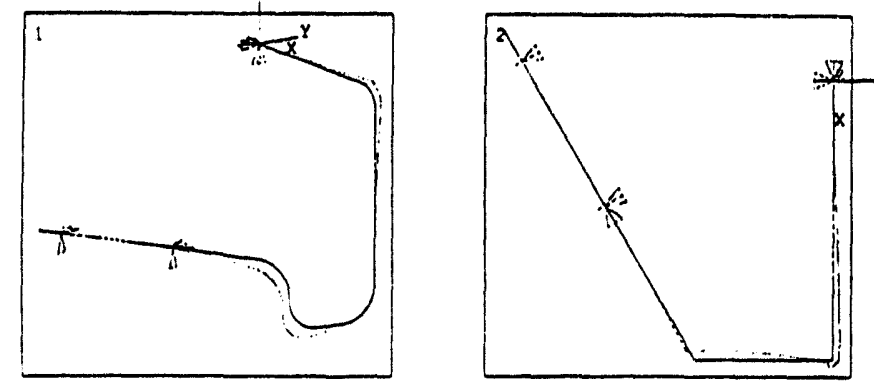

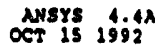

$16,166,18$

PLOT HO. 5

POST1 DISPL.

STzpar

Trencos 35

DMX $=0.313 \mathrm{E}-06$

ToIs

OSCA $=0.172 E+10$

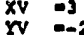

iv -1

DIST-5393

$X F$

YF $=-3525$

vip -28

WIND=2

DSCA $=0.1258+10$
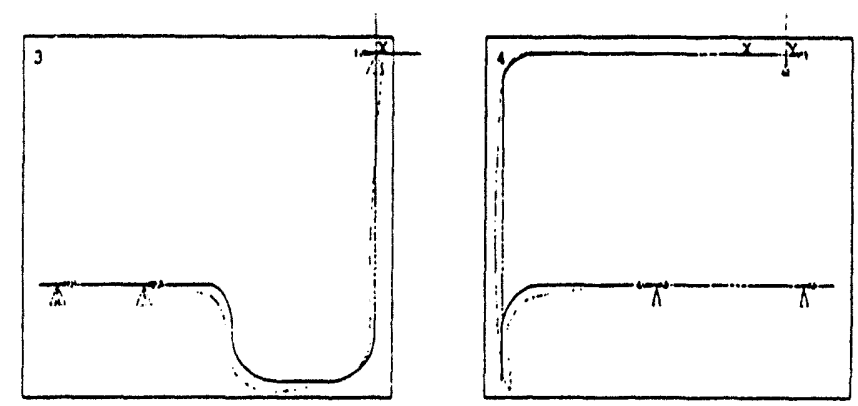

DIsT=-1906

$x=-2490$

YP $=-3325$

$28=-3535$

WIND=3

DSCA $=0.124 \Sigma+10$

$x V-1$

HDR EXPERIMENT E31.2 PIPE SYSTEM MODEL EZRUBMO

Figure 5.7 Mode 5 of the HDR-E31 test system
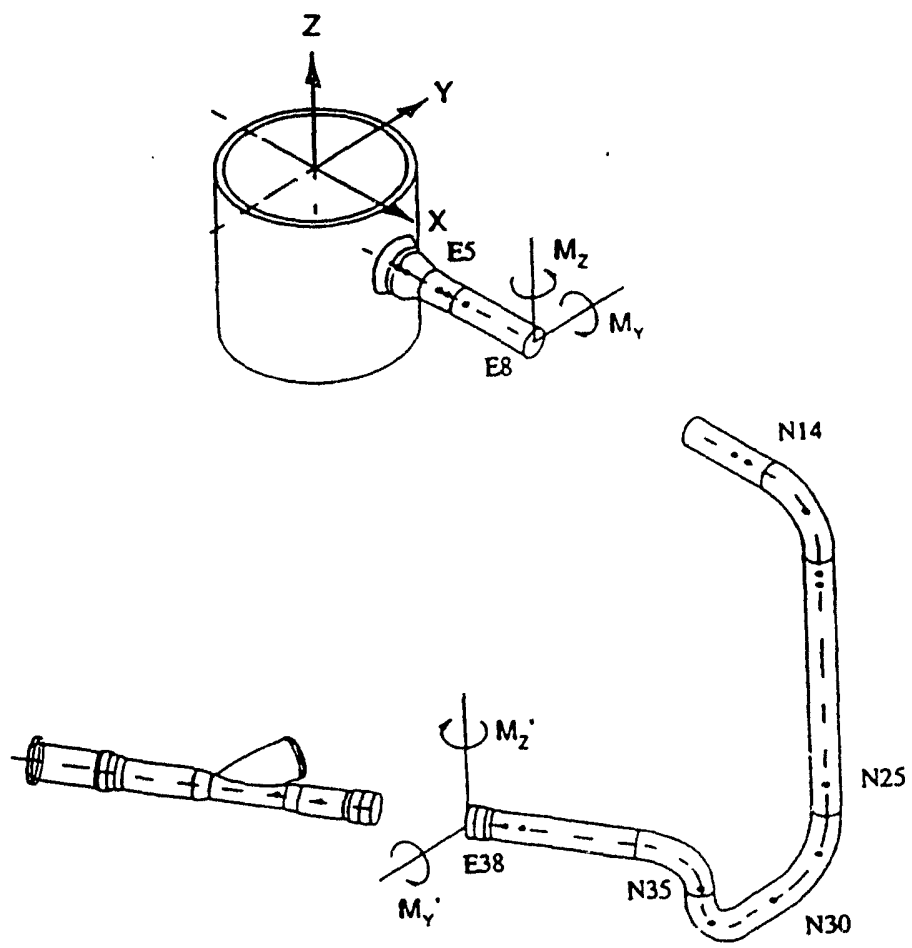

Figure 5.8 Selected nodes and elements in the engineering model 

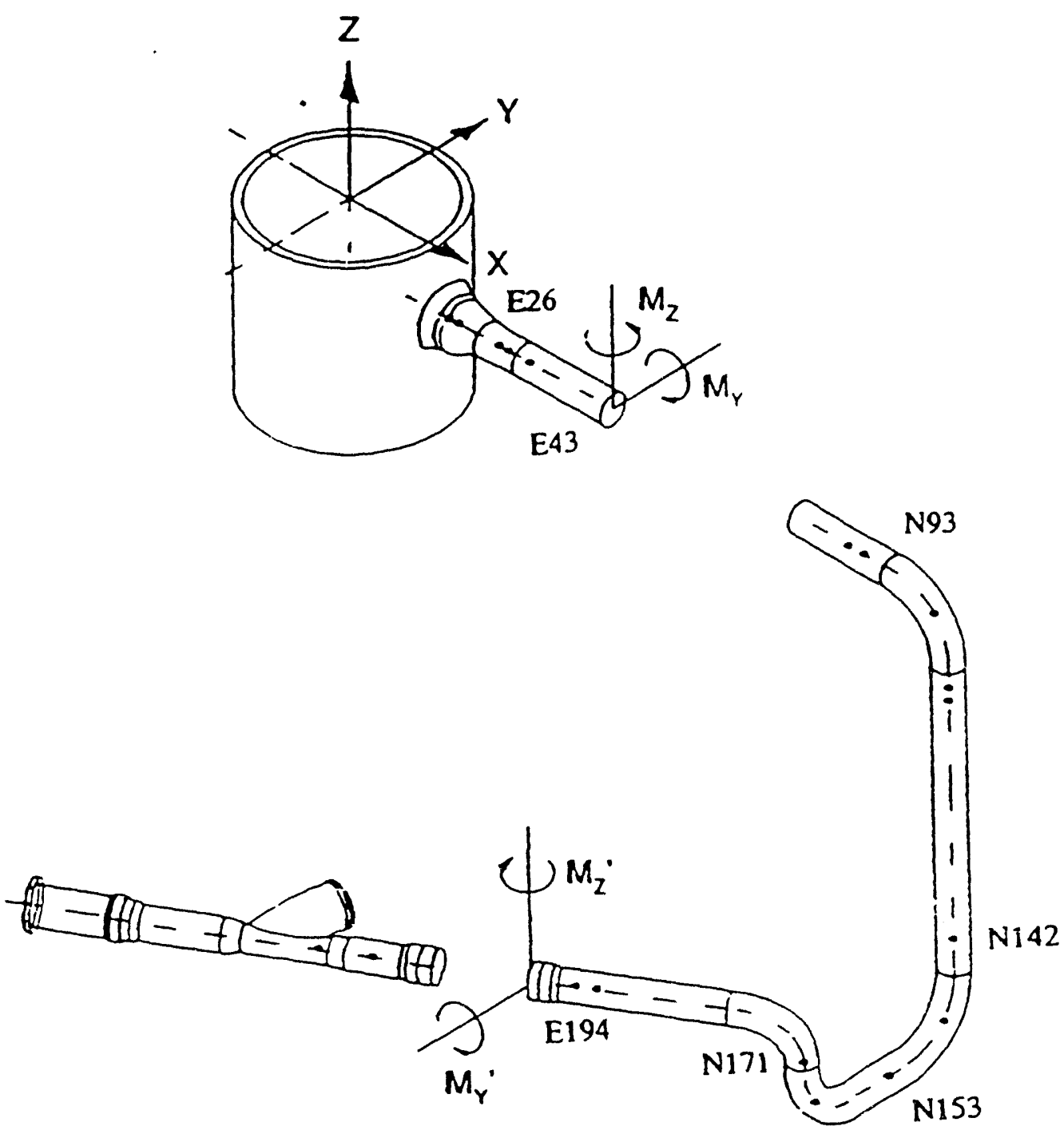

Figure 5.9 Selected nodes and elements in the refined system models 


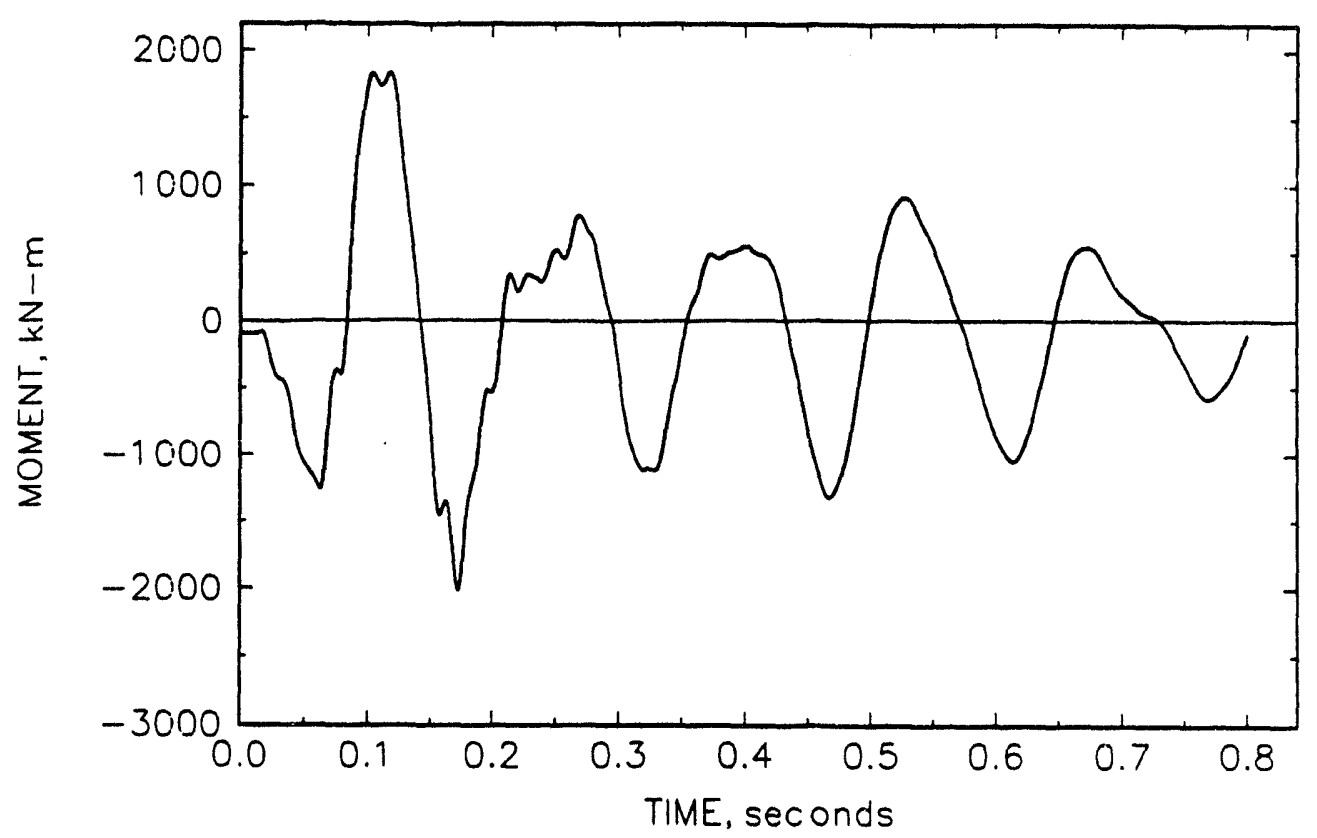

(a) Y-direction moments

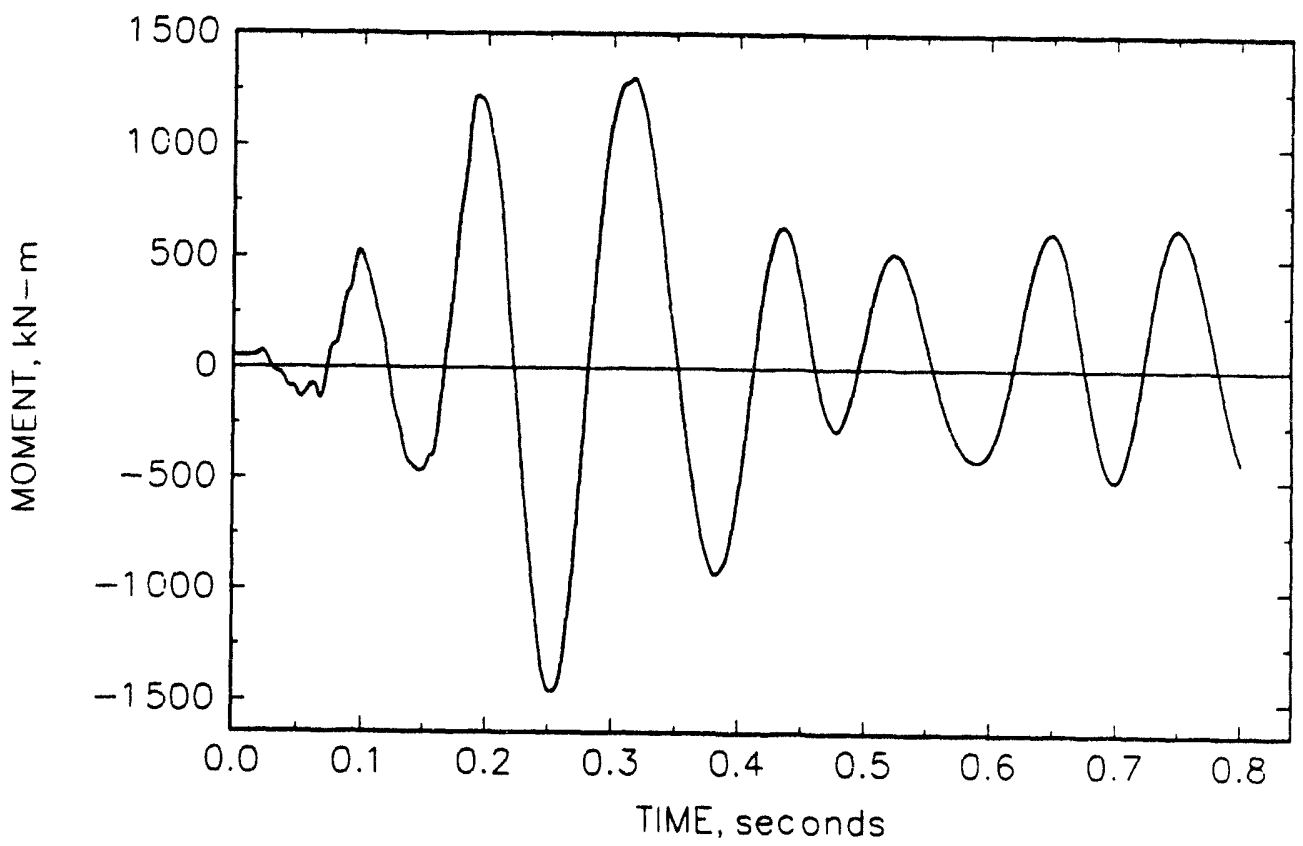

(b) Z-direction moments

Figure 5.10 Moments at Section Q02 (Element 5) in the engineering model (near the reactor pressure vessel) 


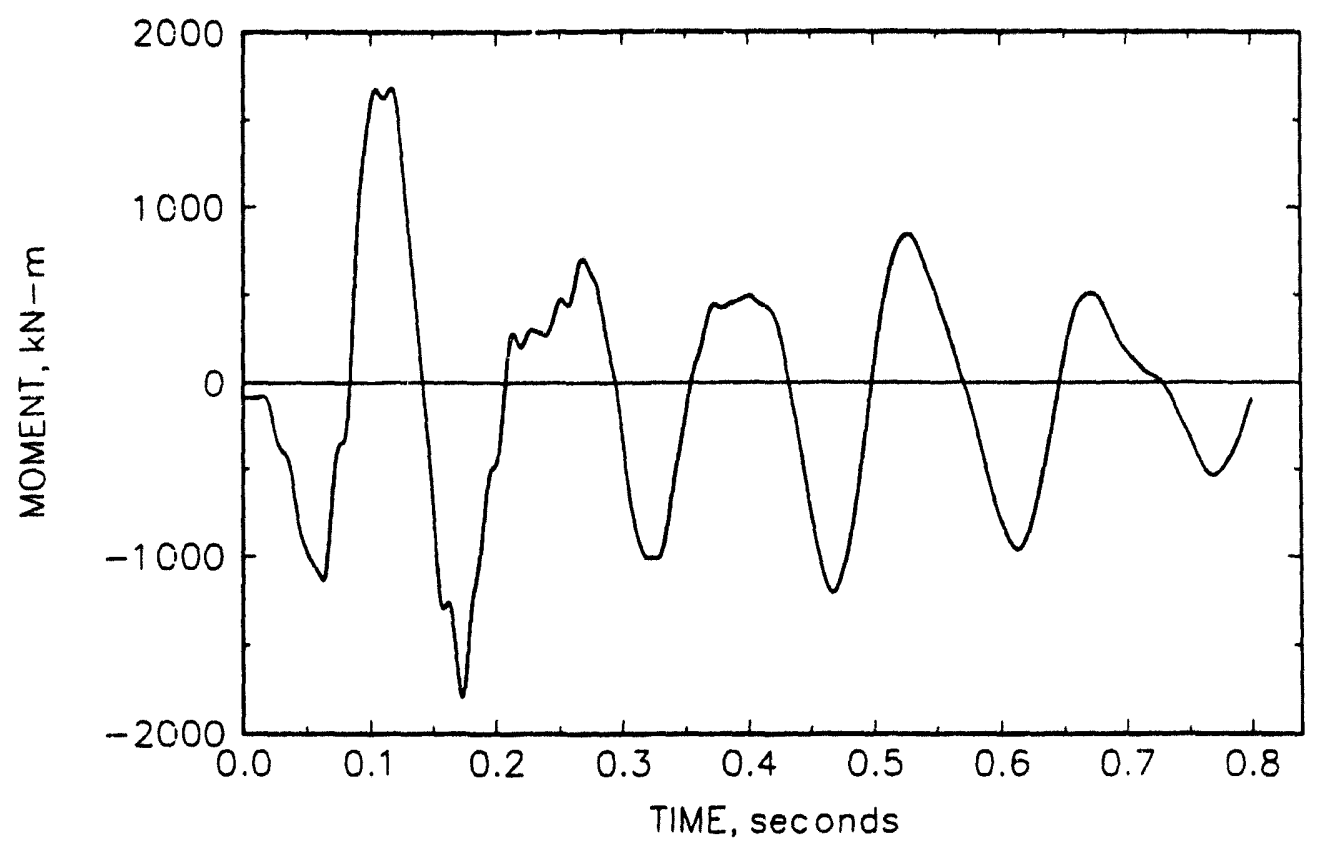

(a) Y direction (crack opening)

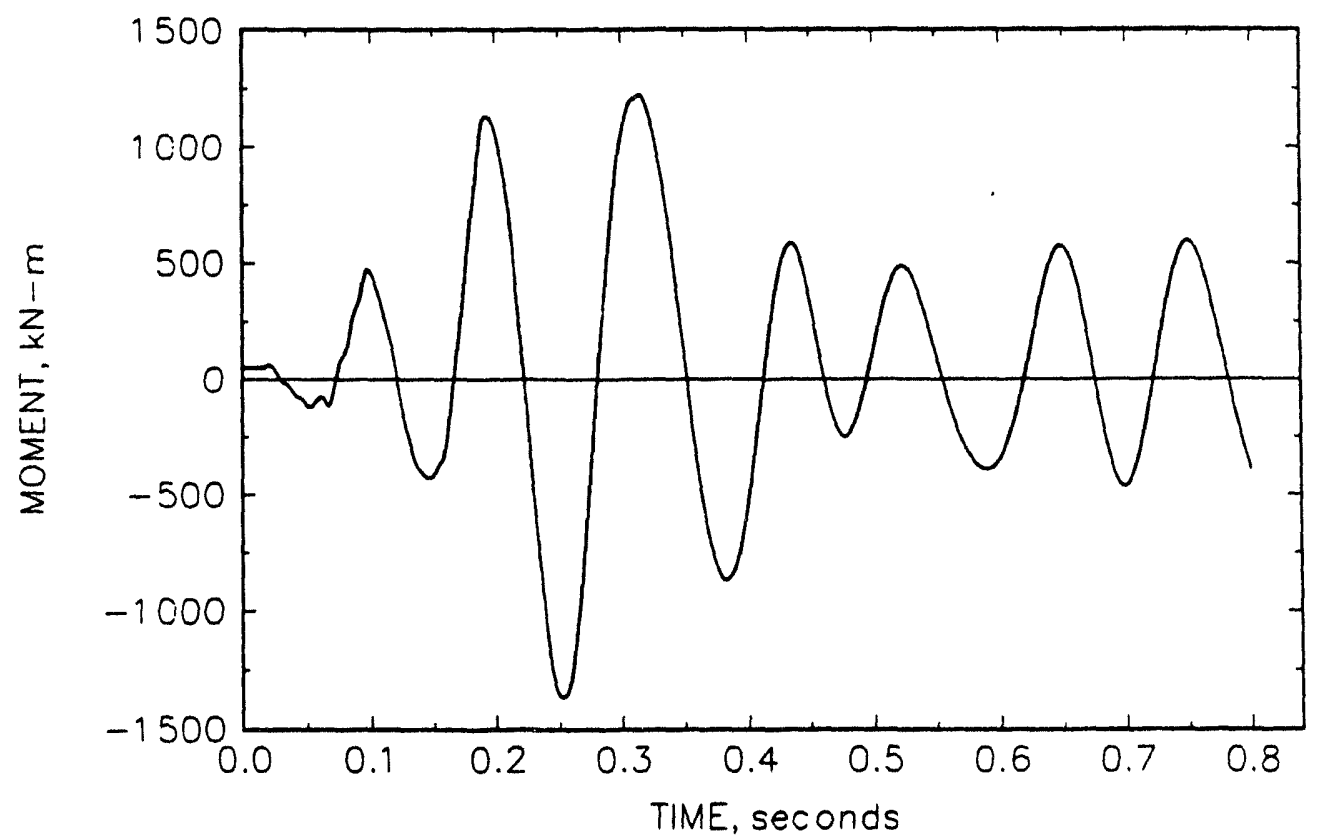

(b) $\mathbf{Z}$ direction

Figure 5.11 Moments at Section QP1 (Element 8) in the engineering model (crack location) 


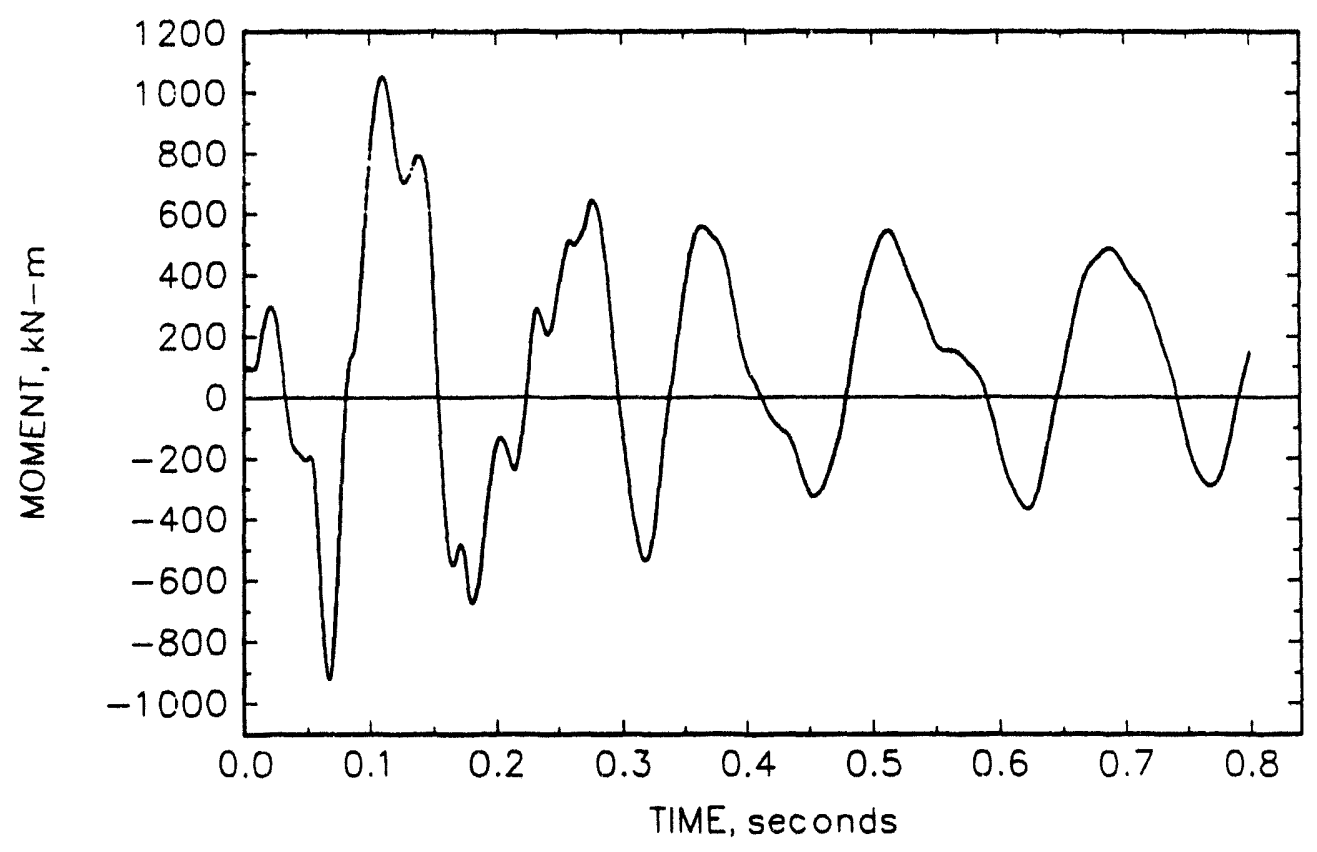

(a) $\mathbf{Y}$ direction

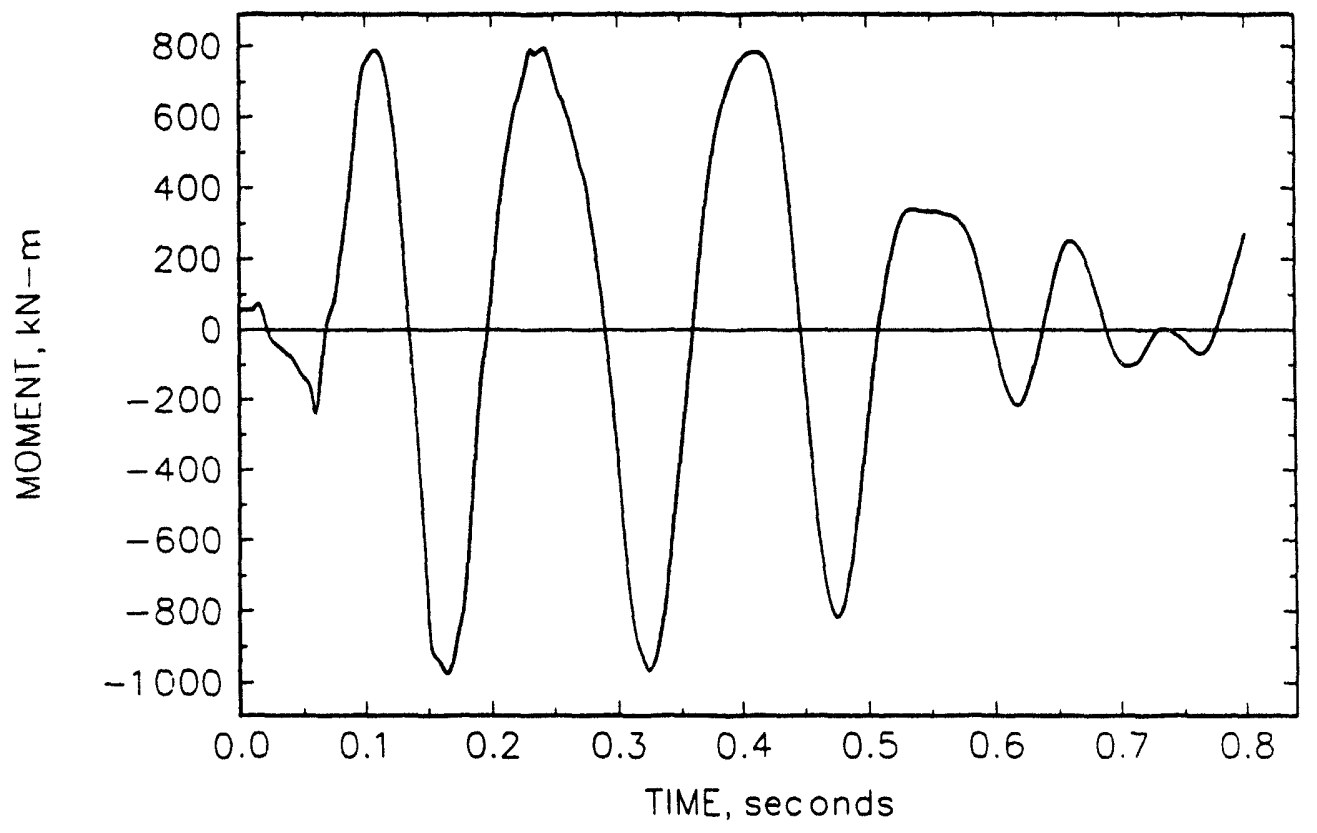

(b) $\mathbf{Z}$ direction

Figure 5.12 Moments at Section Q91 (Element 38) in the engineering model (near the Fixed Point support) 


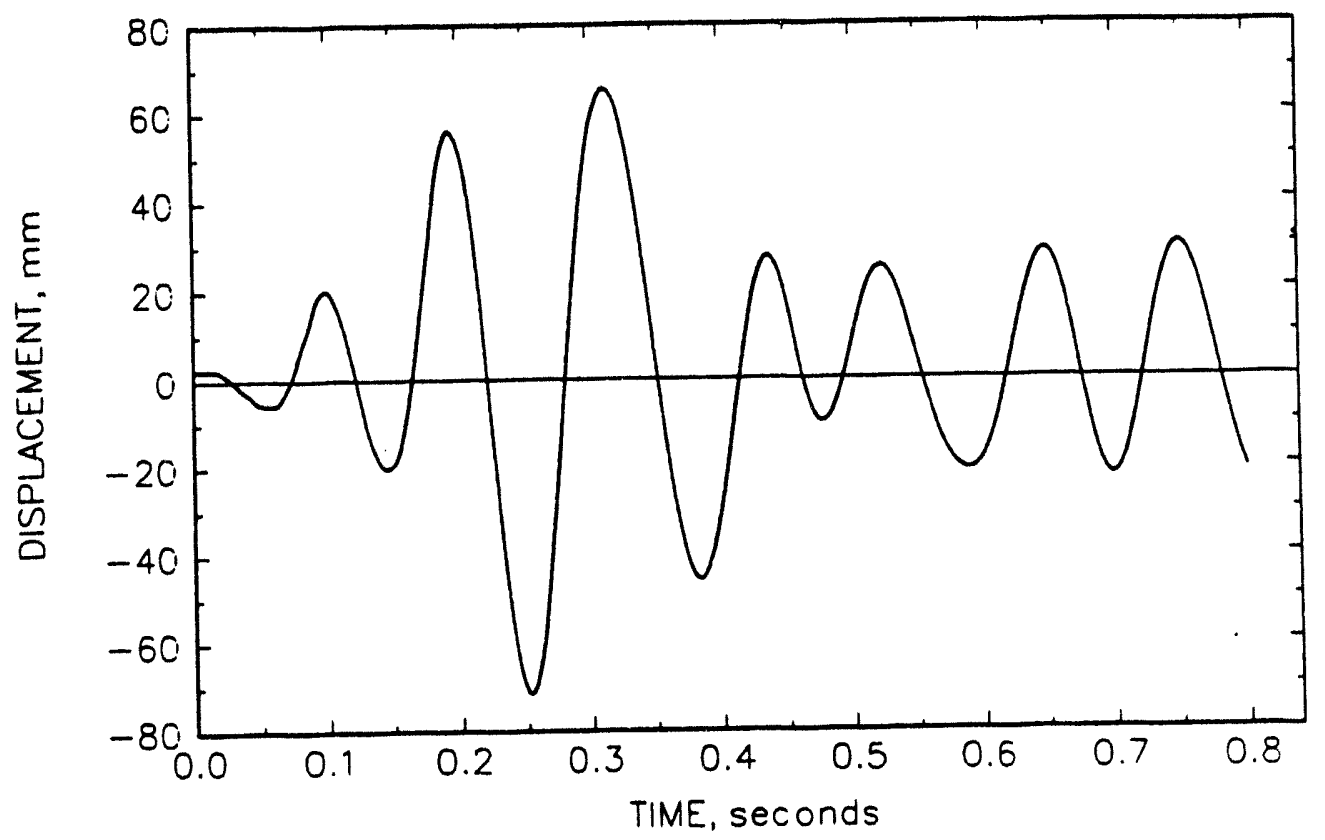

(a) $\mathbf{Y}$ direction

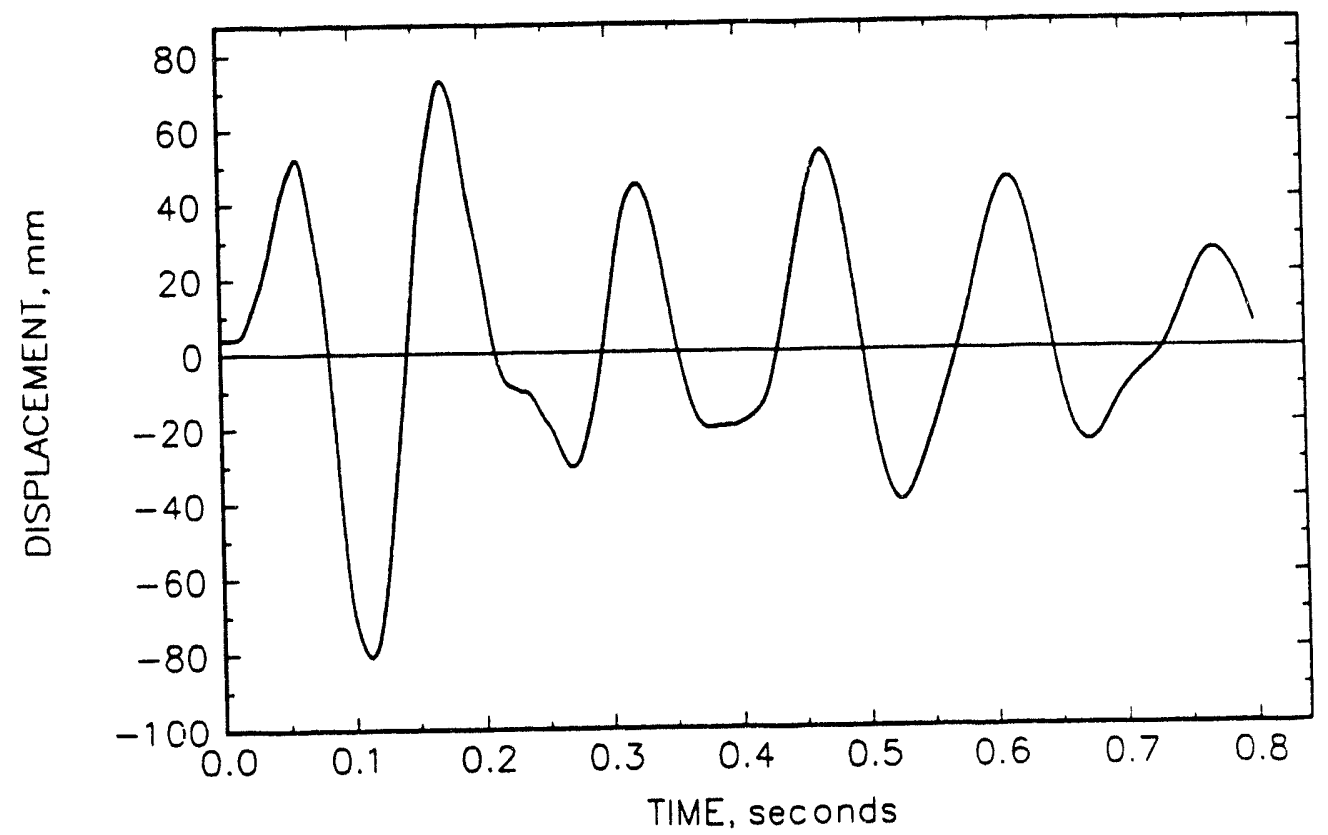

(b) $\mathbf{Z}$ direction

Figure 5.13 Displacements at Transducer MN461 (Node 14) in the engineering model (at the first elbow from the reactor pressure vessel) 


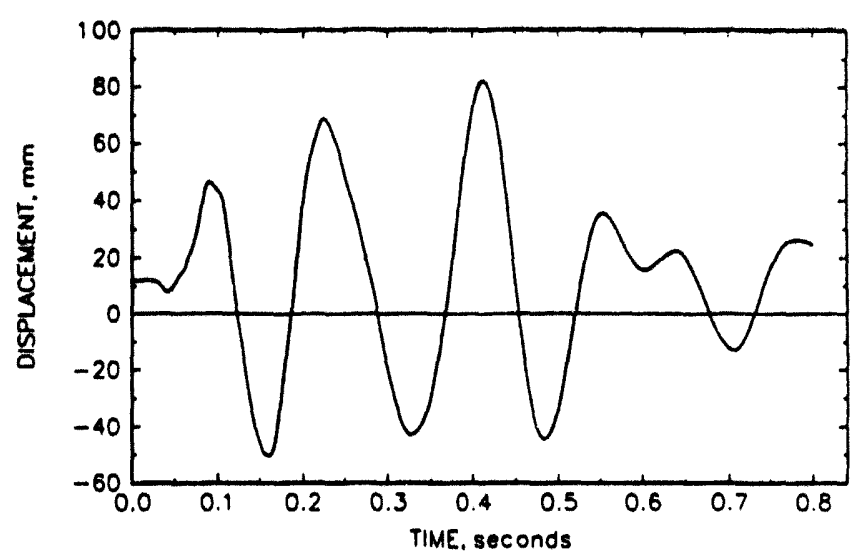

(a) $\mathrm{X}$ direction

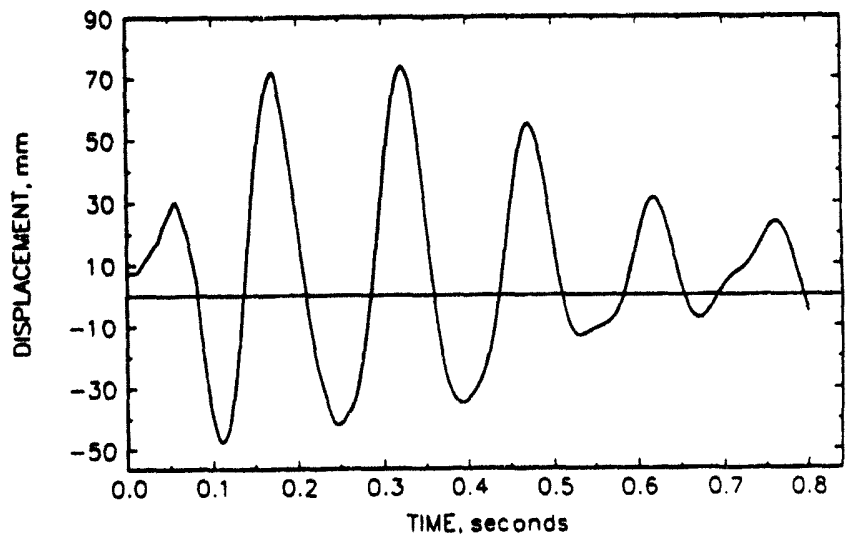

(b) $\mathbf{Y}$ direction

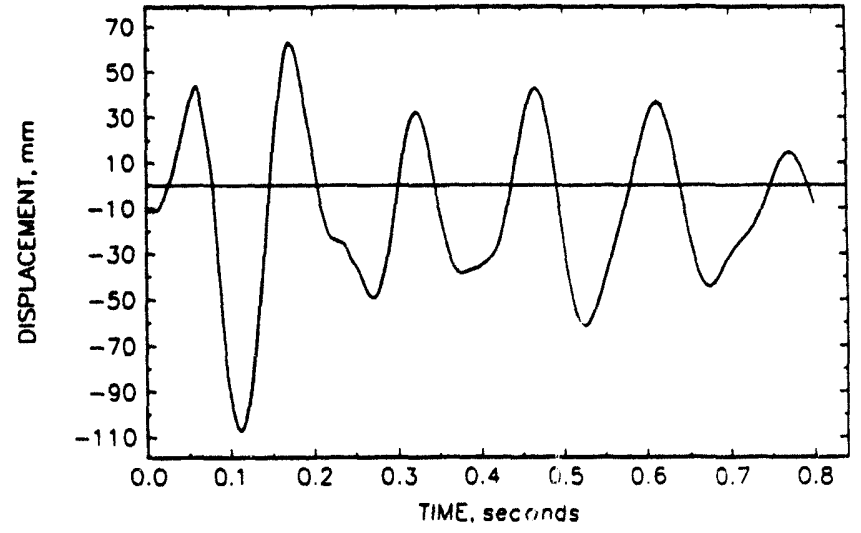

(c) $\mathbf{Z}$ direction

Figure 5.14 Displacements at Transducer MN471 (Node 25) in the engineering model (at the second elbow from the reactor pressure vessel) 


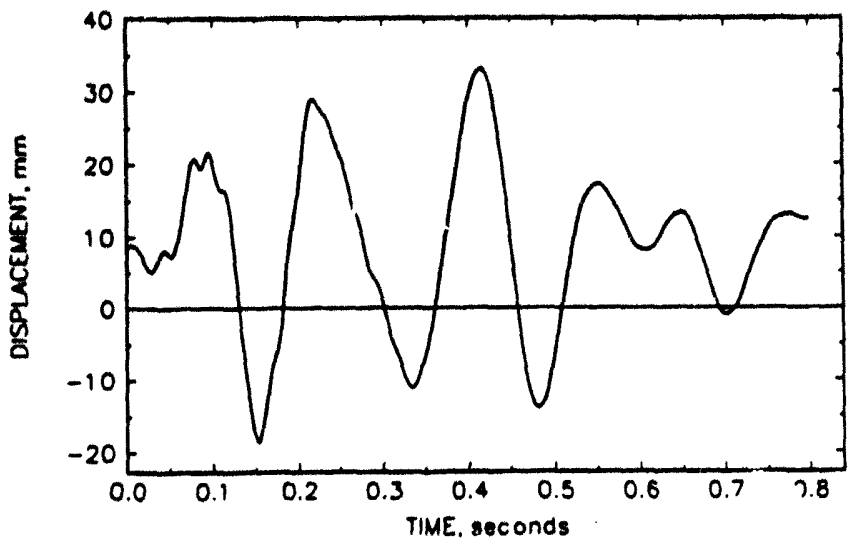

(a) $\mathrm{X}$ direction

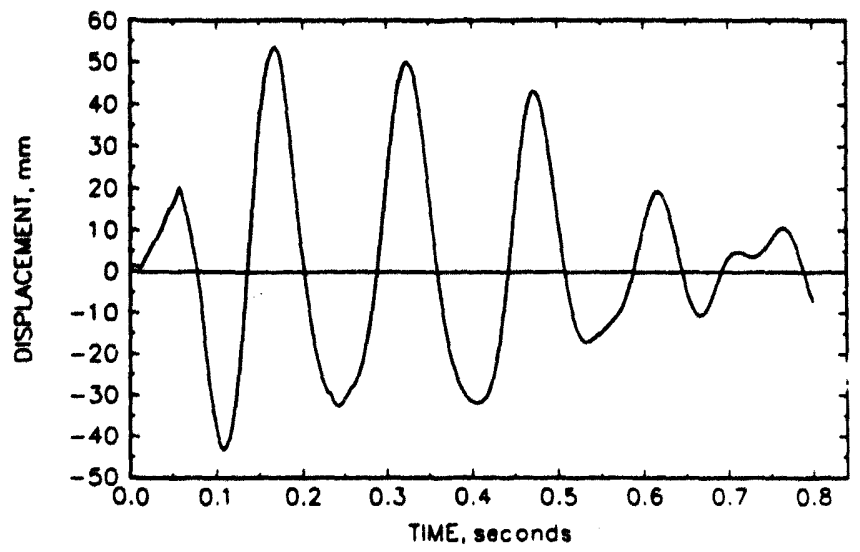

(b) $\mathbf{Y}$ direction

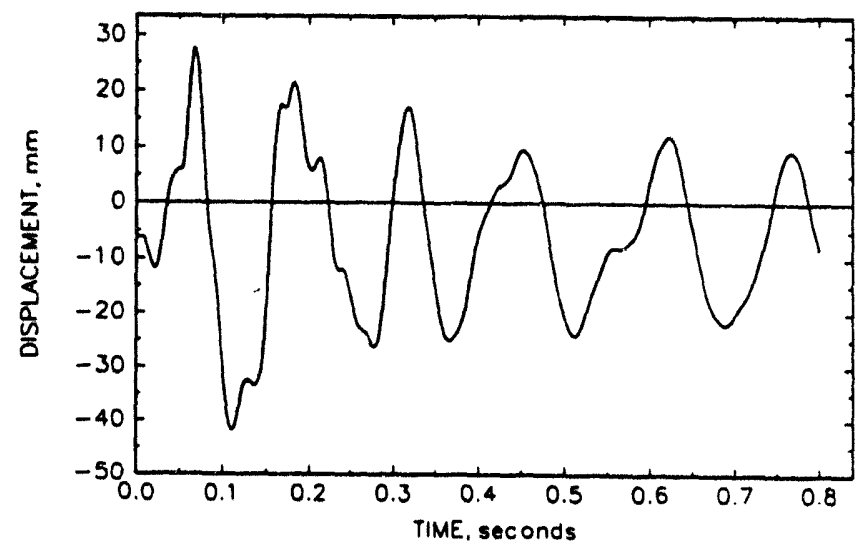

(c) $\mathbf{Z}$ direction

Figure 5.15 Displacements at Transducer MN481 (Node 35) in the engineering model (at the third elbow from the reactor pressure vessel) 


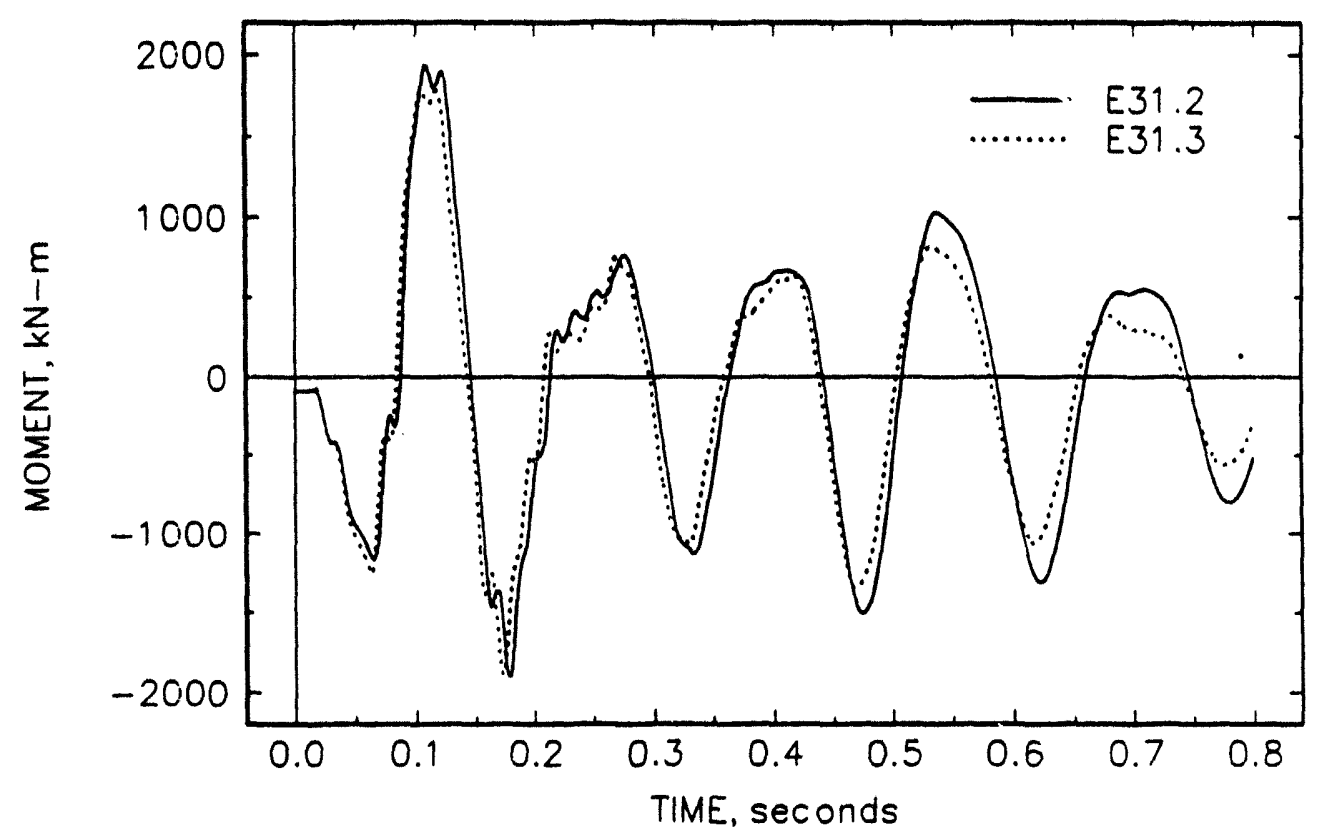

(a) $\mathbf{Y}$ direction

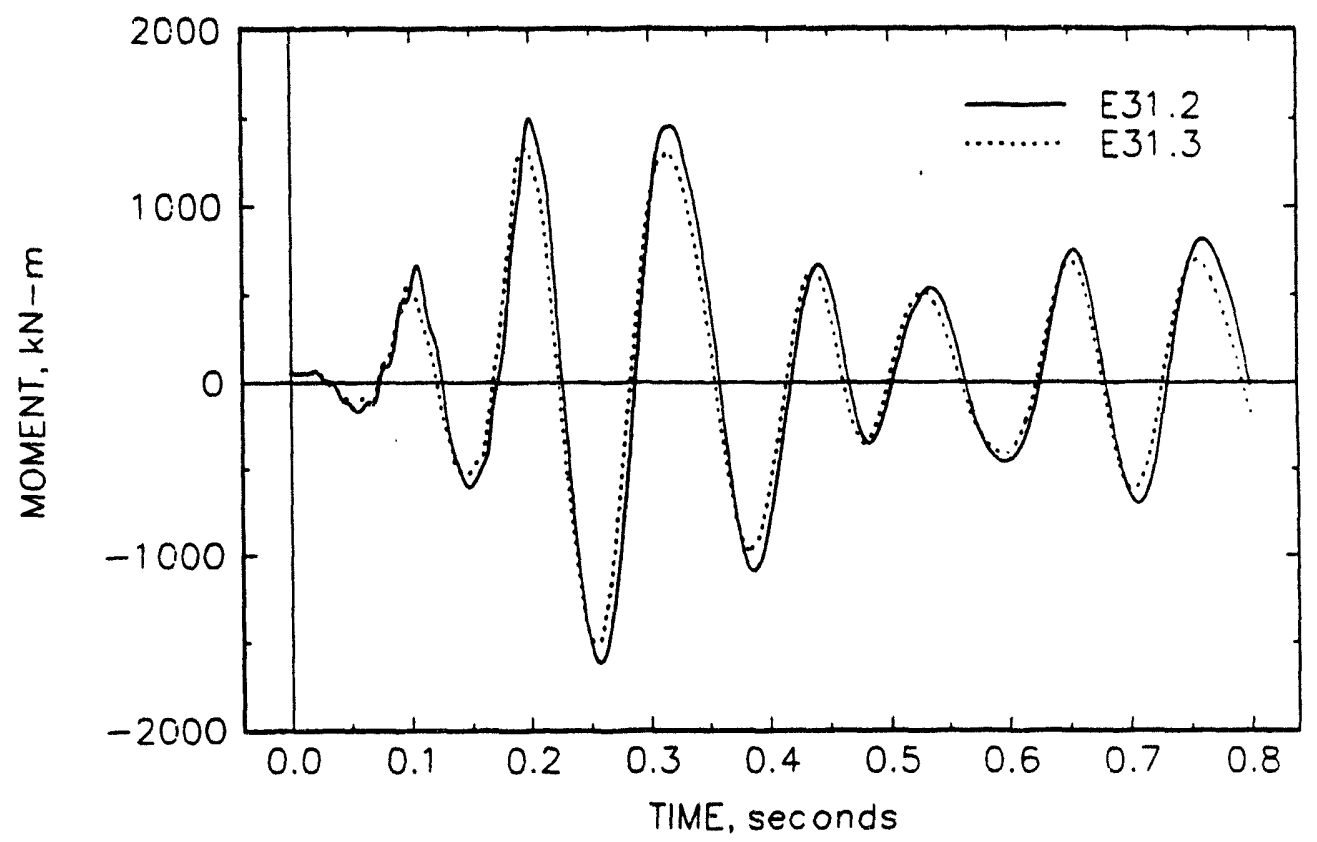

(b) $\mathbf{Z}$ direction

Figure 5.16 Moments at Section Q02 (Element 20) in the refined system models (near the reactor pressure vessel) 


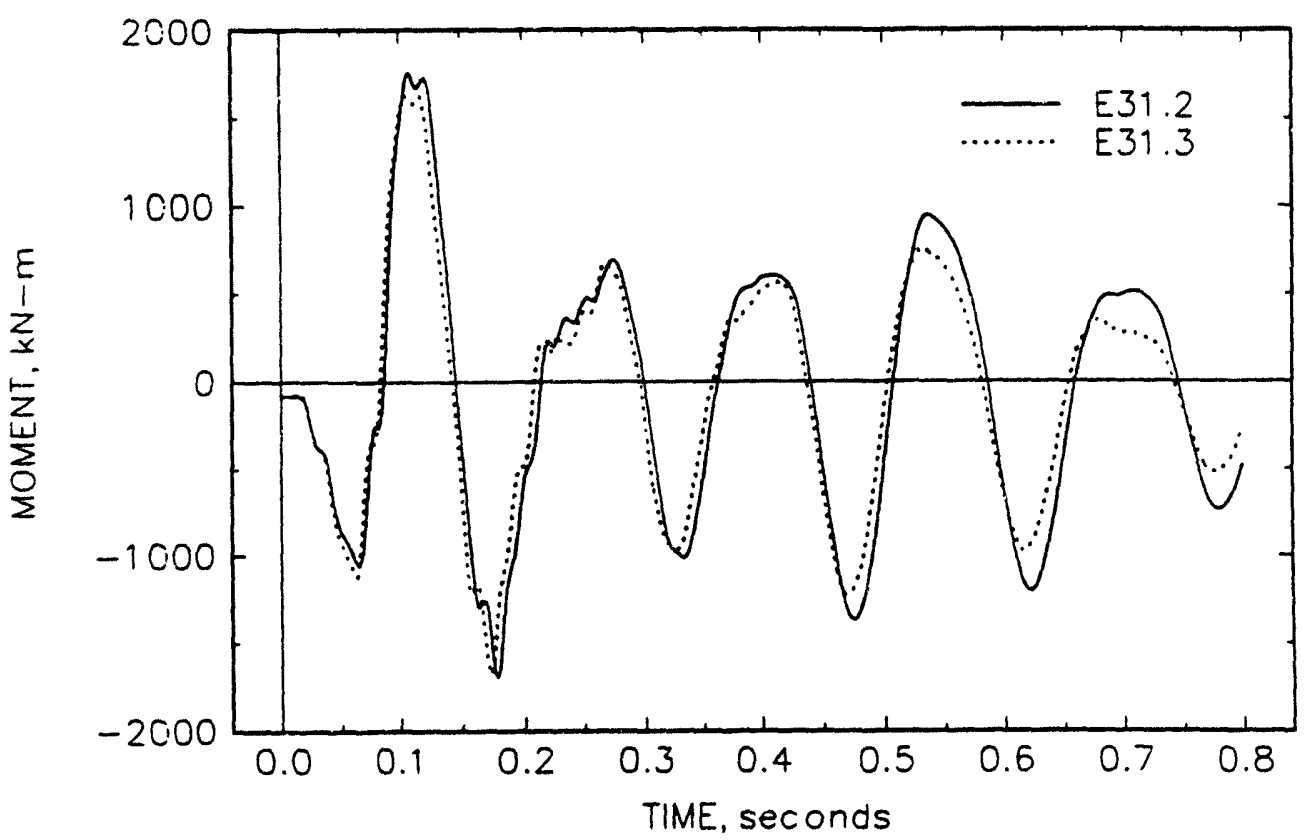

(a) $\mathbf{Y}$ direction

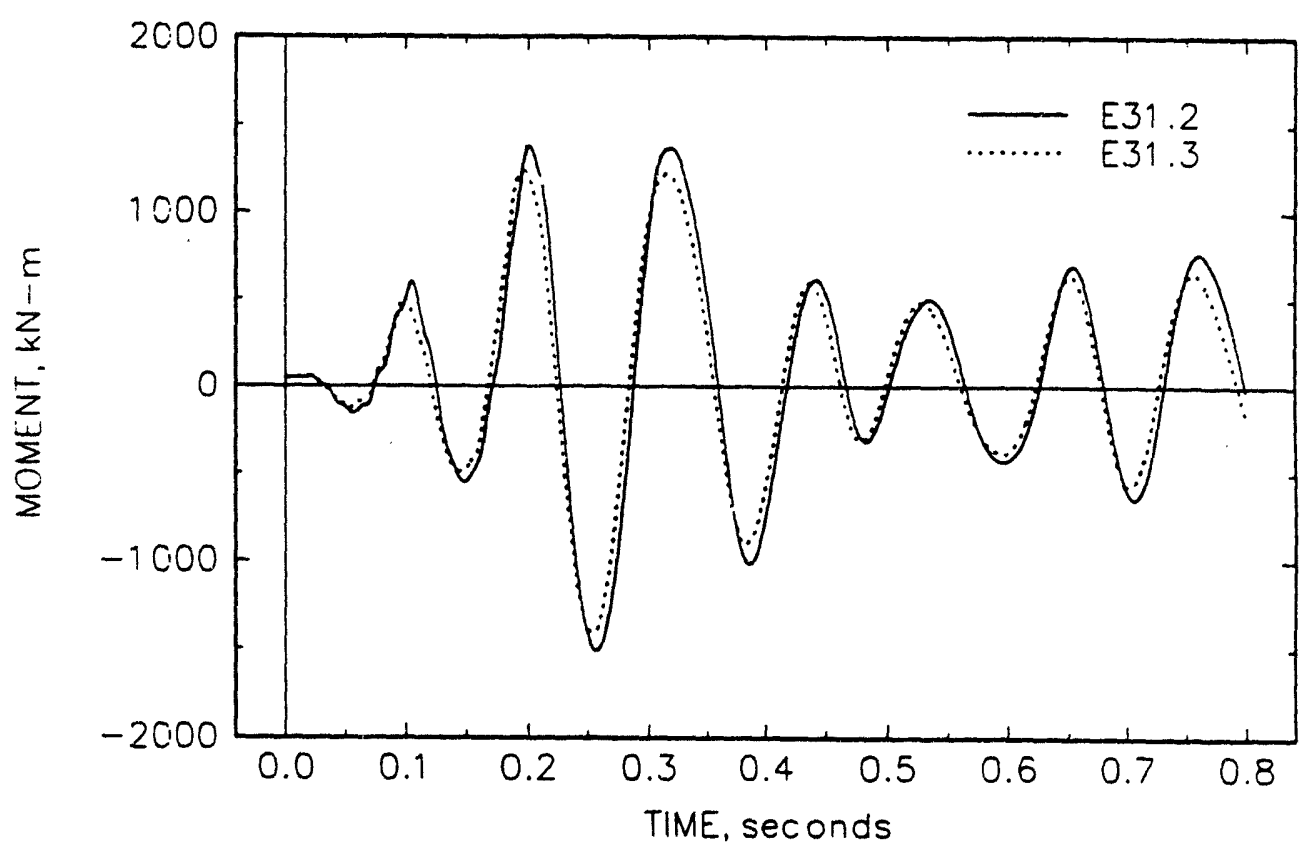

(b) $\mathbf{Z}$ direction

Figure 5.17 Moments at Section QP1 (Element 43) in the refined system models (crack location) 


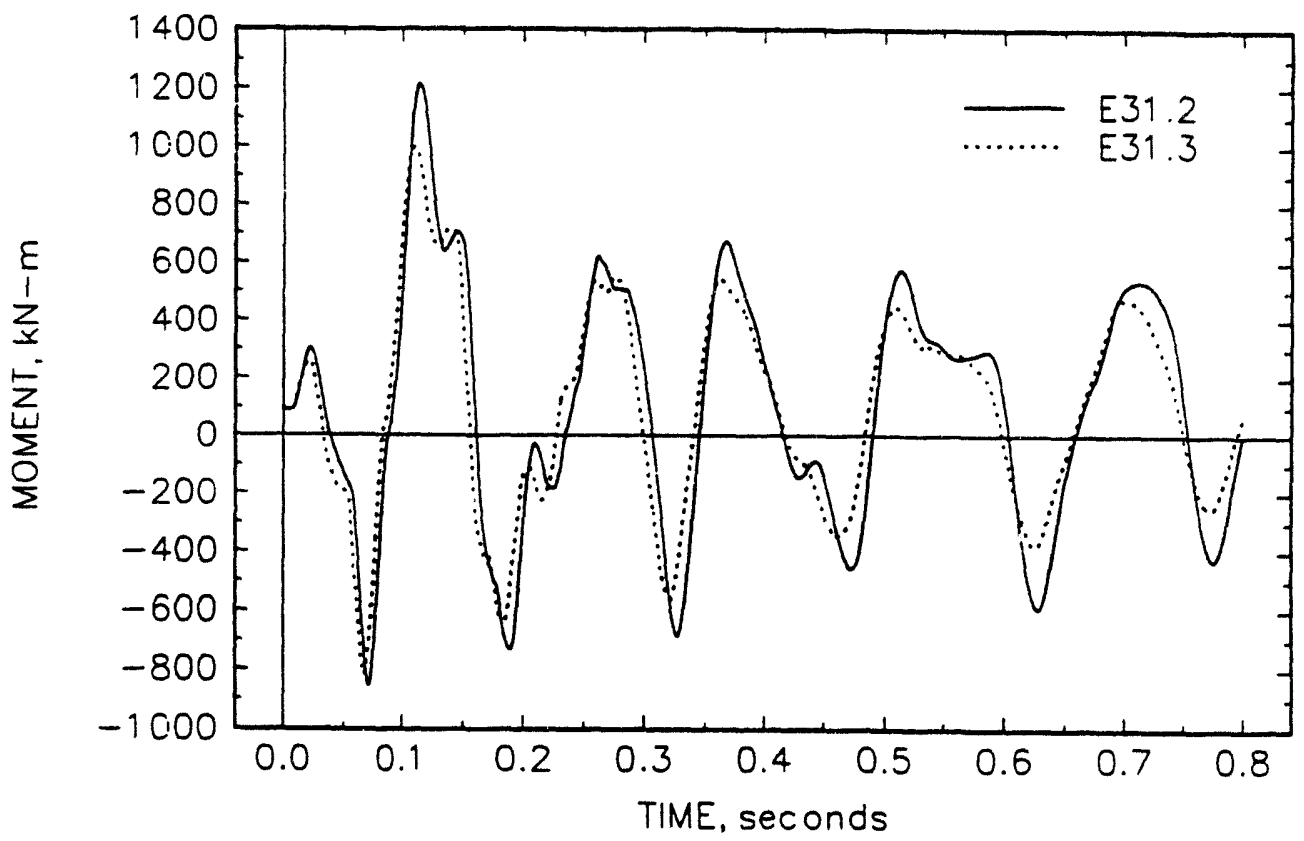

(a) $\mathbf{Y}$ direction

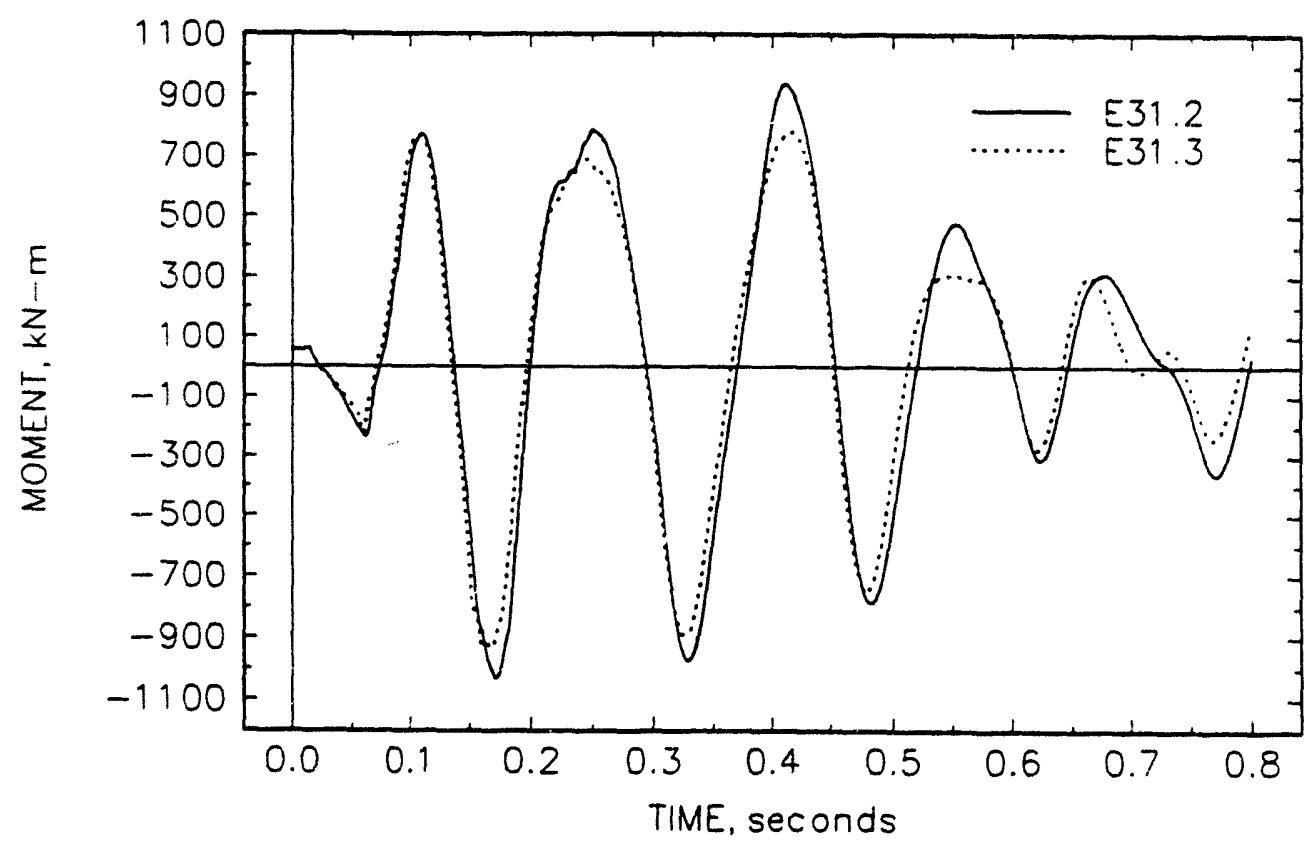

(b) $\mathbf{Z}$ direction

Figure 5.18 Moments at Section Q91 (Element 194) in the refined system models (near the Fixed Point support) 


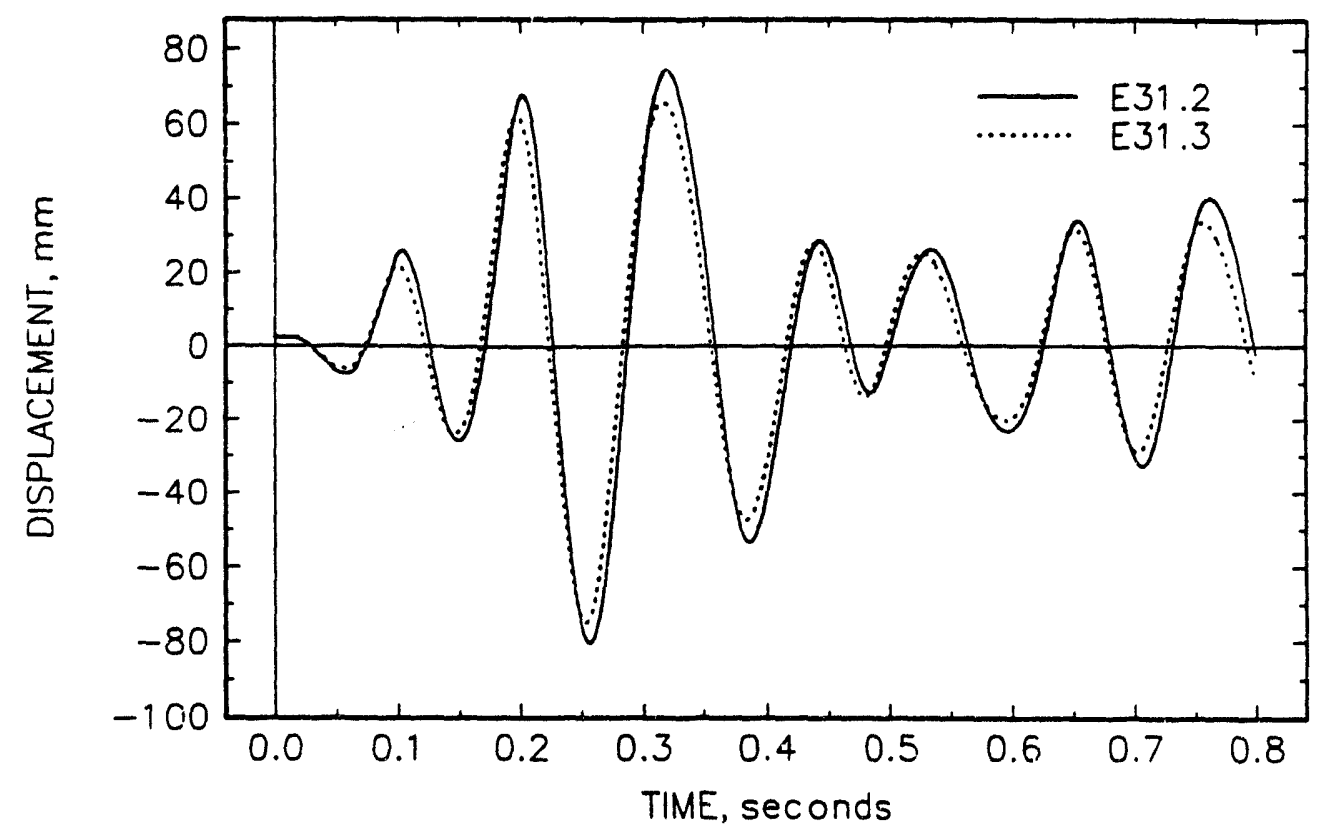

(a) $\mathbf{Y}$ direction

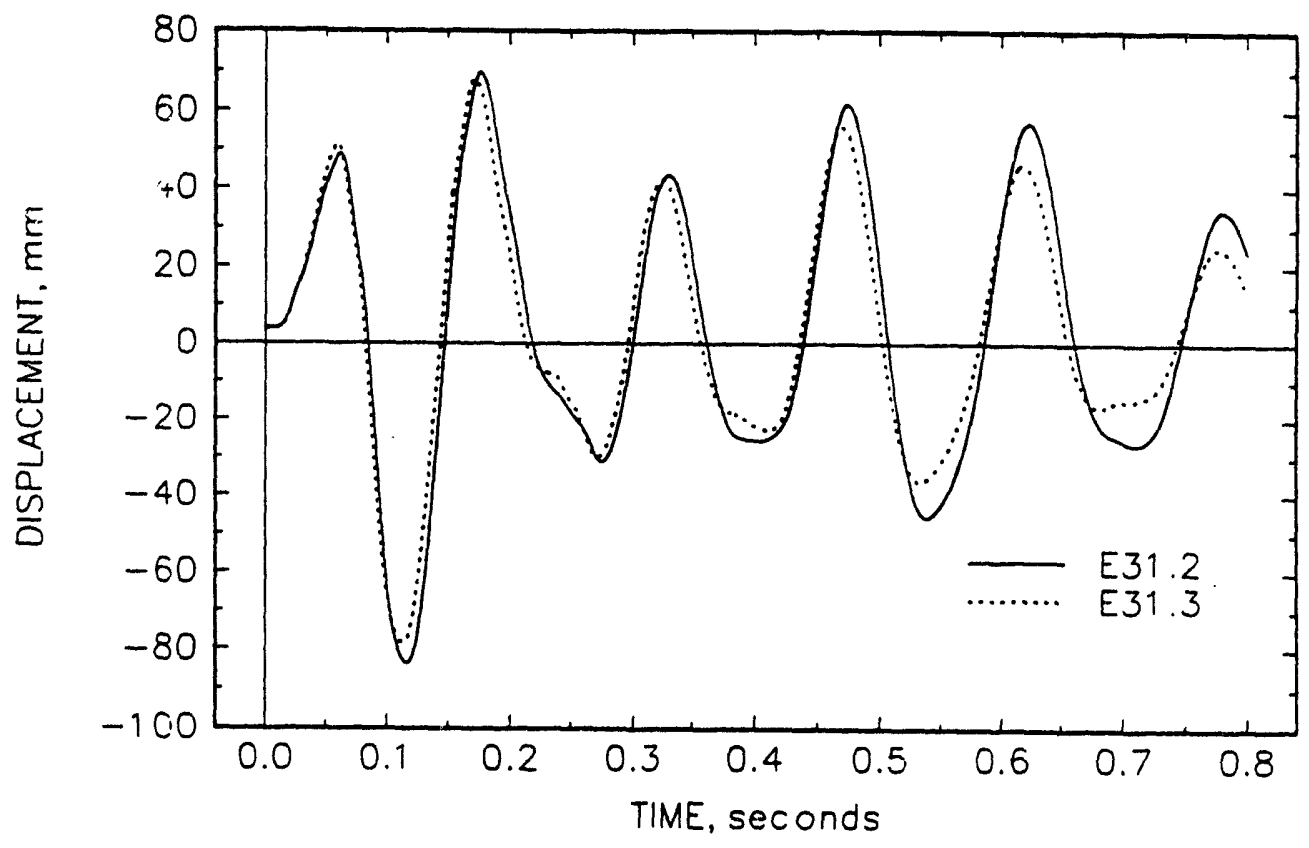

(b) $\mathbf{Z}$ direction

Figure 5.19 Displacements at Transducer MN461 (Node 93) in the refined system models (at the first elbow from the reactor pressure vessel) 


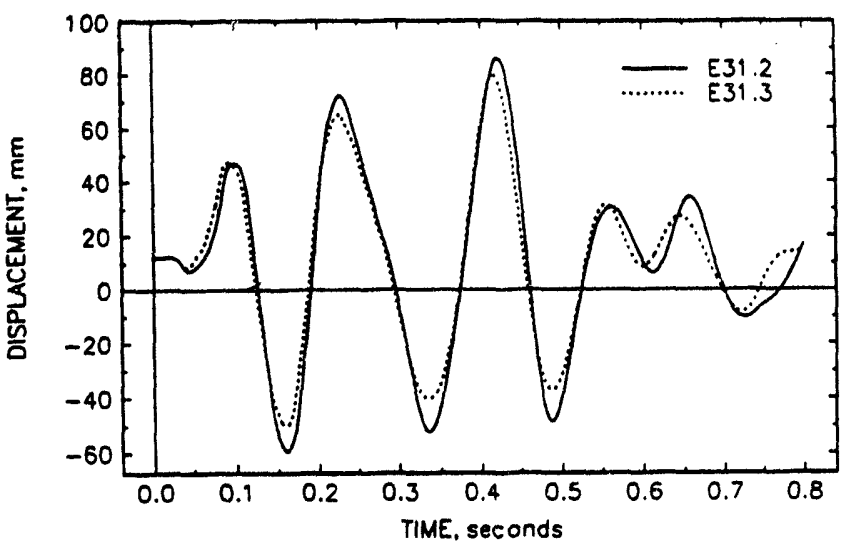

(a) $\mathrm{X}$ direction

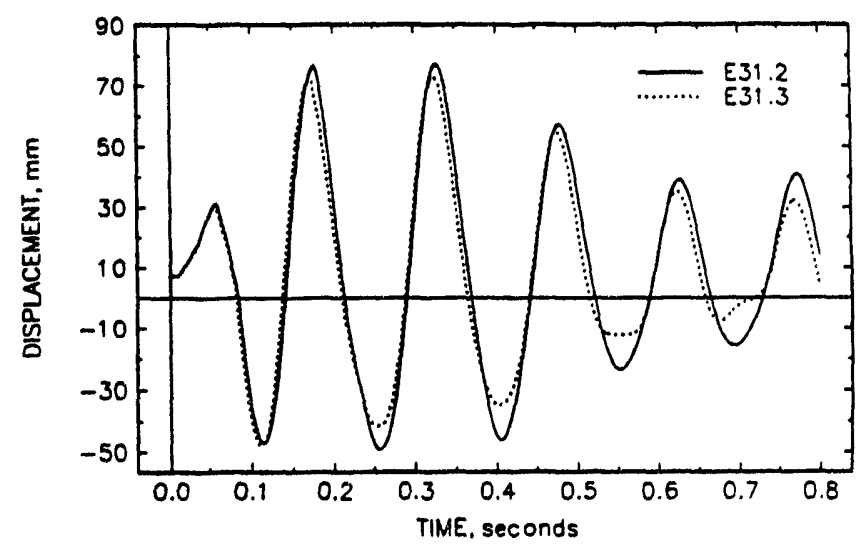

(b) $\mathbf{Y}$ direction

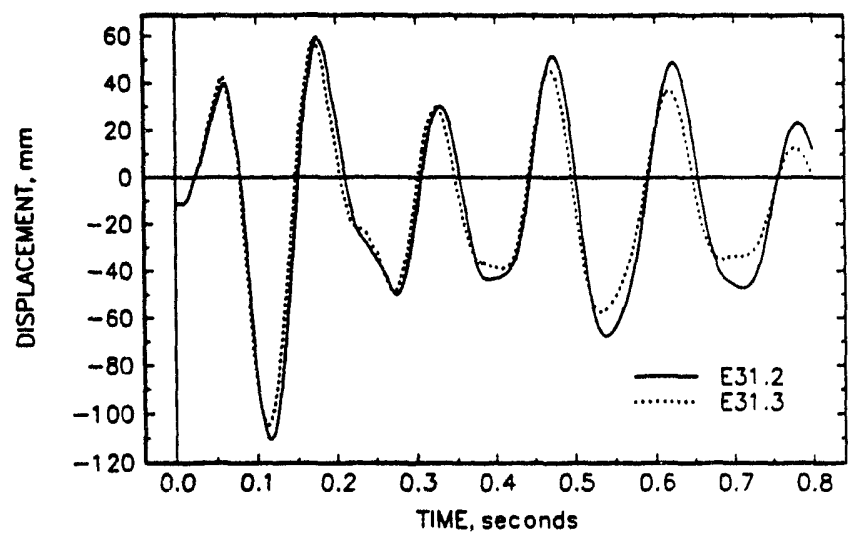

(c) $\mathbf{Z}$ direction

Figure 5.20 Displacements at Transducer MN471 (Node 142) in the refined system models (at the second elbow from the reactor pressure vessel) 


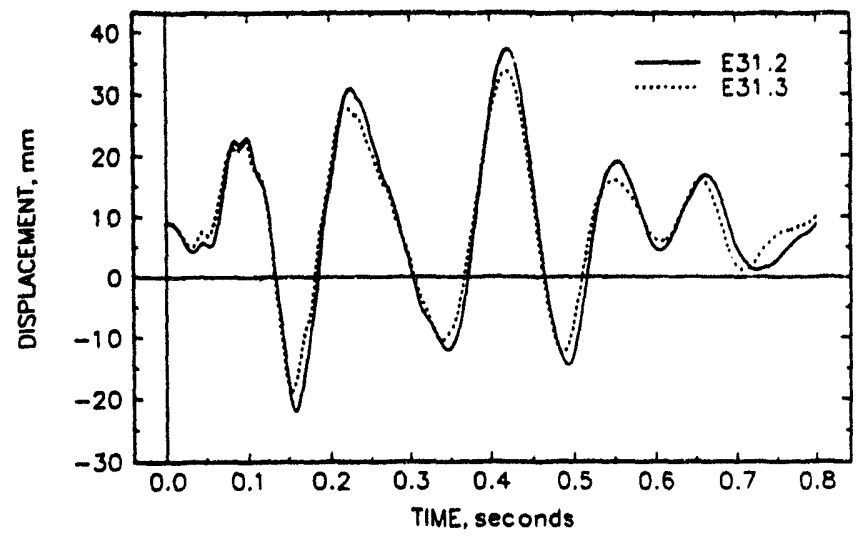

(a) $\mathrm{X}$ direction

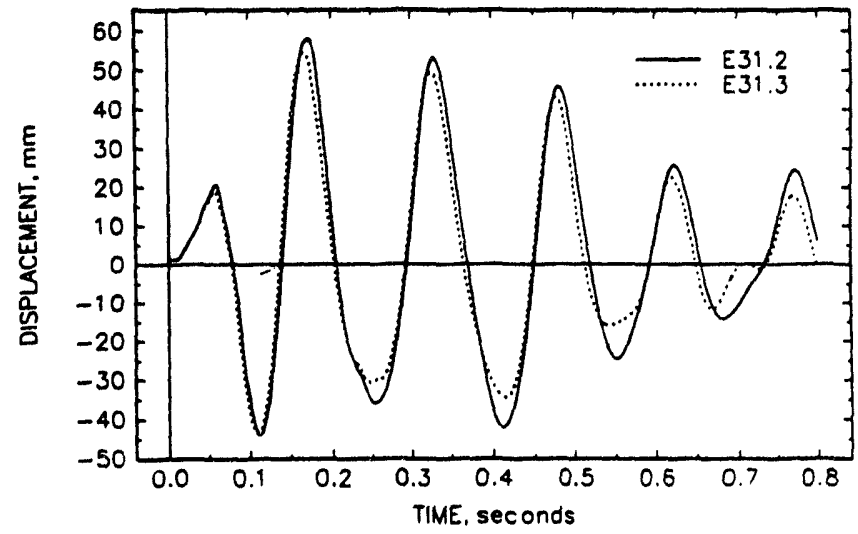

(b) Y direction

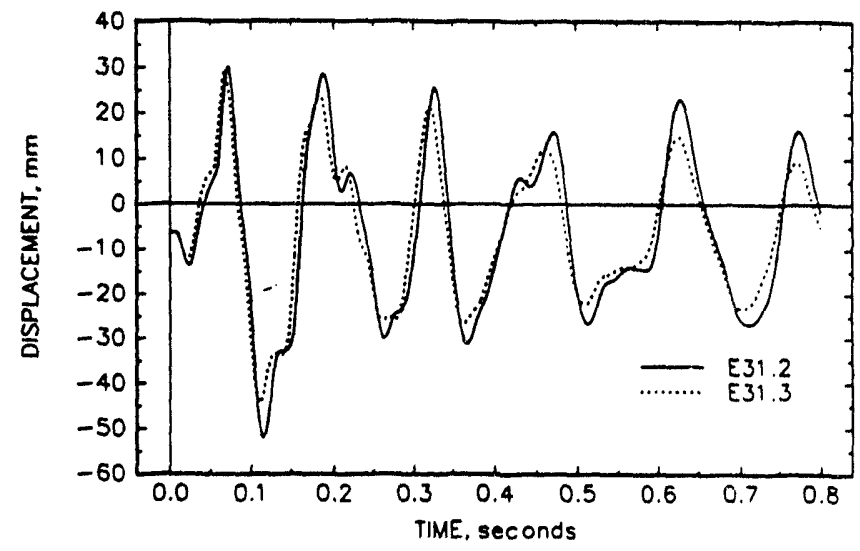

(c) $\mathbf{Z}$ direction

Figure 5.21 Displacements at Transducer MN481 (Node 171) in the refined system models (at the third elbow from the reactor pressure vessel) 


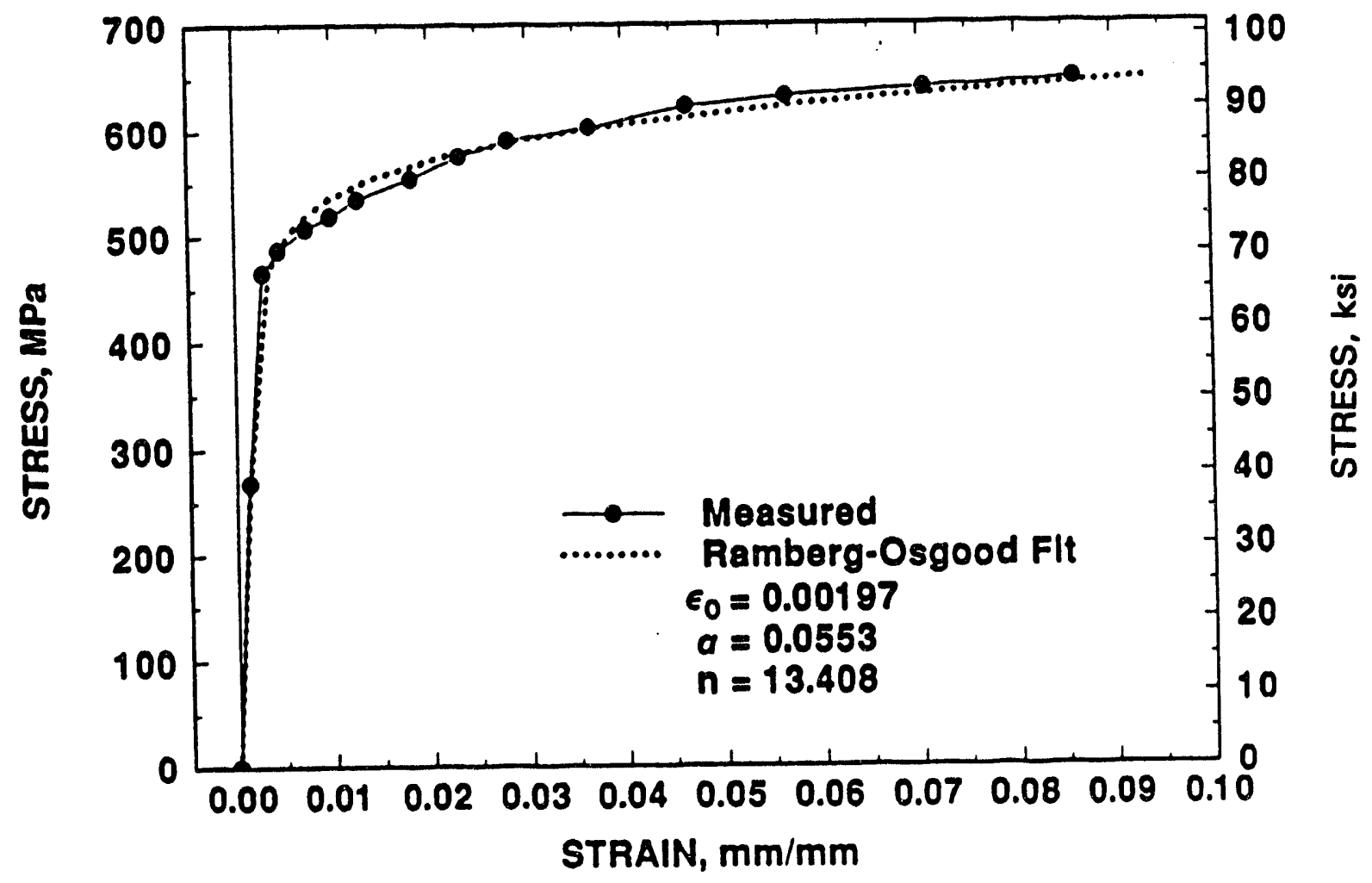

Figure 5.22 Stress-strain curve used in the J-estimation scheme analysis for 20 MnMoNi 55 test section material (Specimen HDR195-2) 


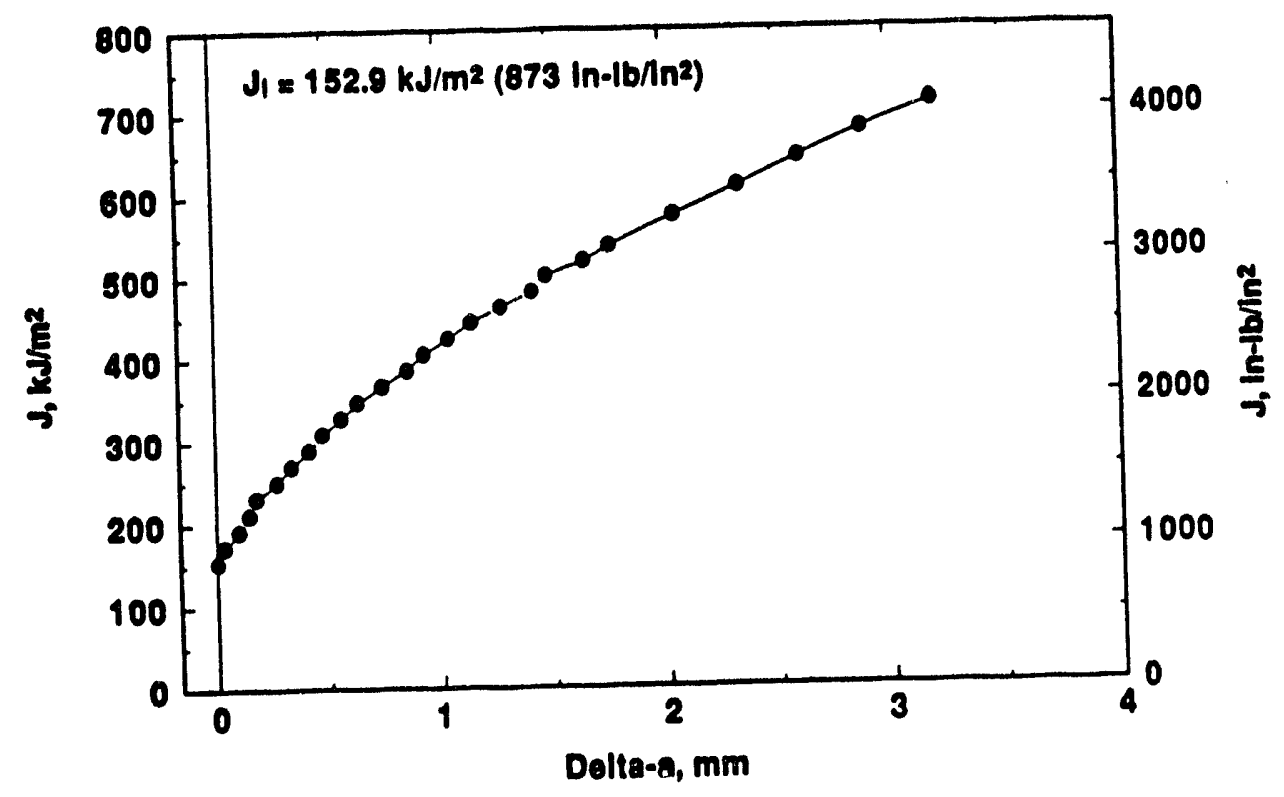

(a) L-T orientation $\mathrm{C}(\mathrm{T})$ data

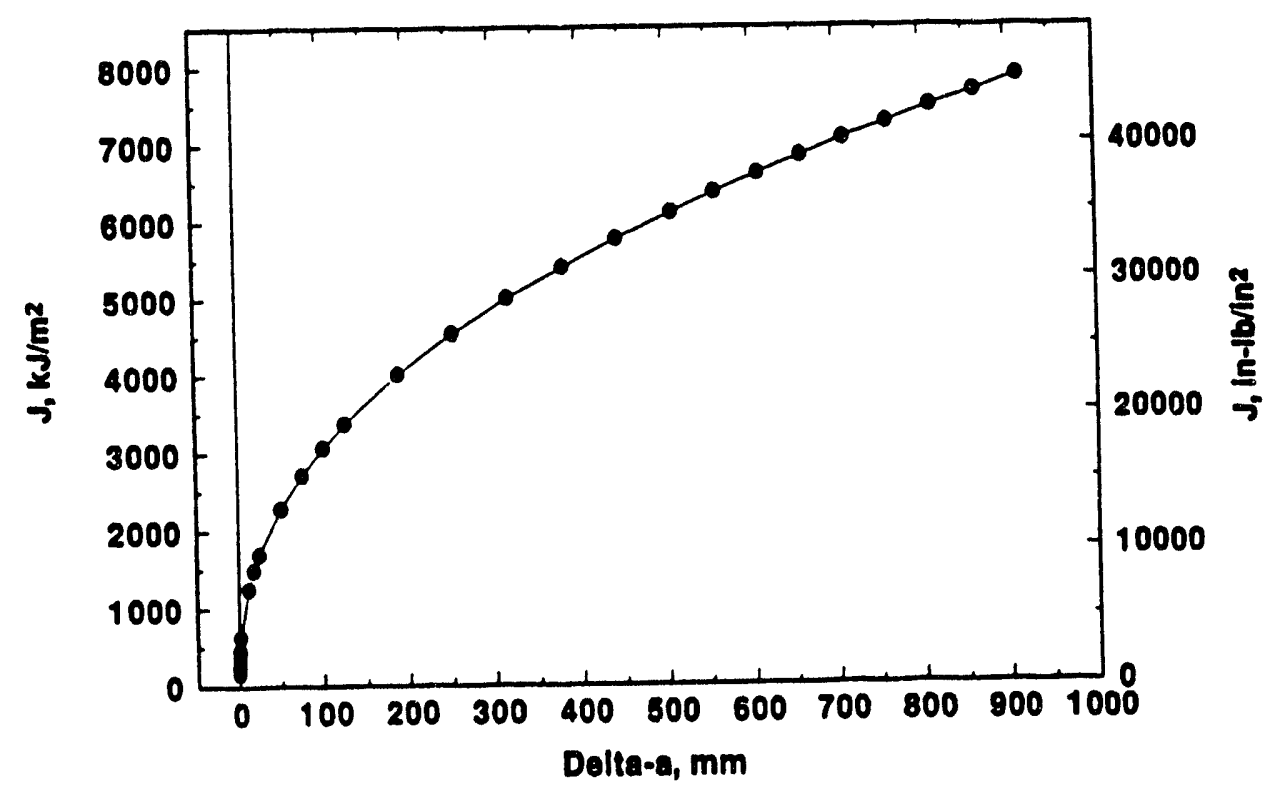

(b) Extrapolated to large crack growth

Figure 5.23 J-R curve used in the J-estimation scheme analysis for 20 MnMoNi 55 test section material (Specimen HDR195-2) 


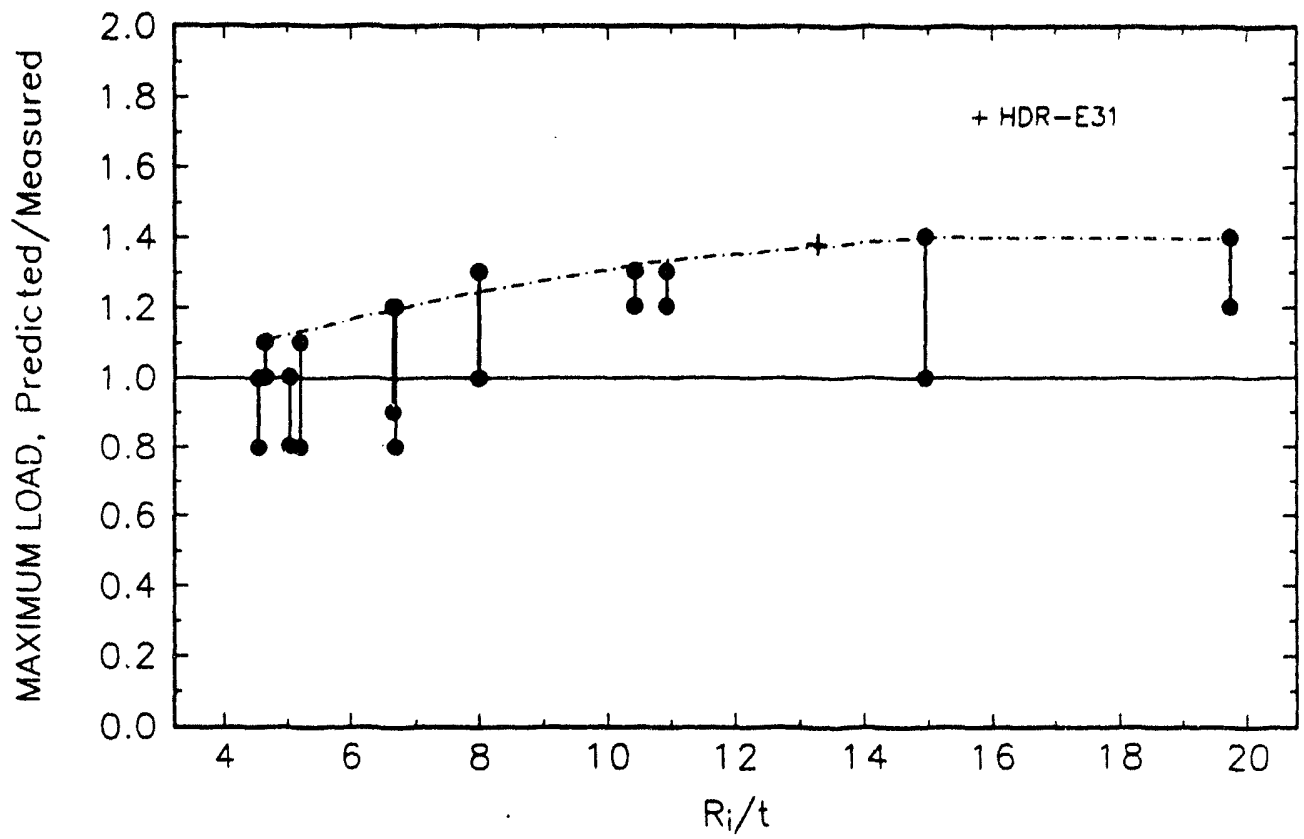

Figure 5.24 SC.TNP J-estimation scheme prediction accuracy for Degraded Piping Program experiments (Scatter due to Ramberg-Osgood fits in different strain regions.)

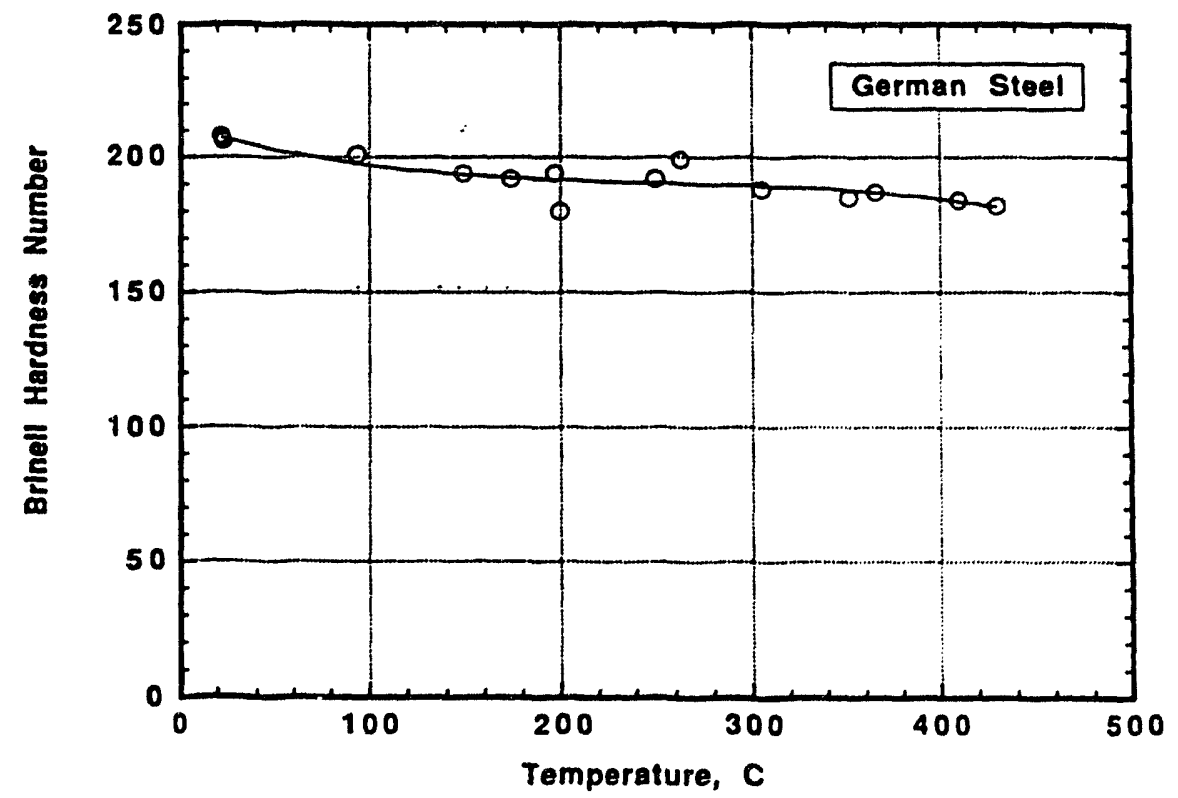

Figure 5.25 Dynamic strain-aging screening test data for 20 MnMoNi 55 test section material (Lack of a peak hardness indicates that the material is not sensitive to dynamic strain aging.) 


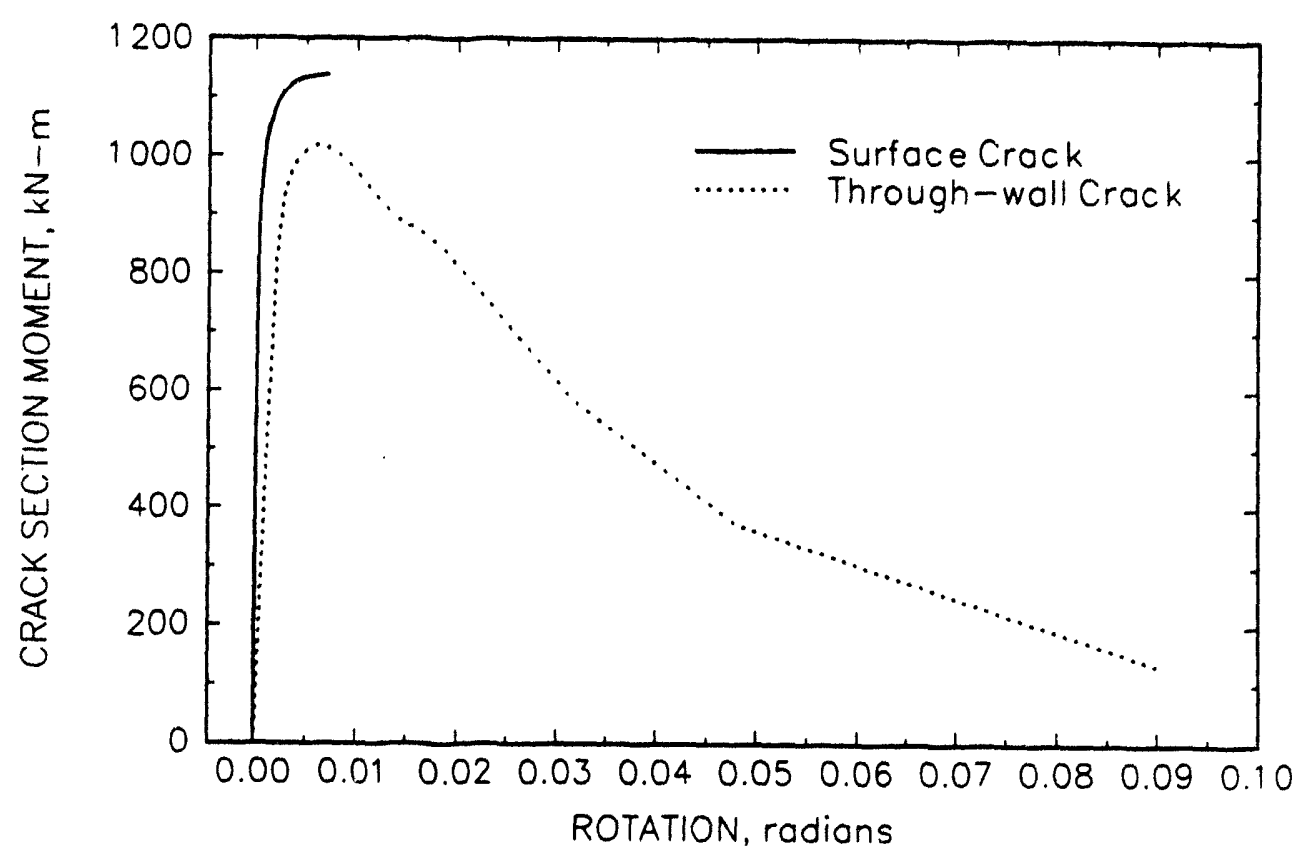

(a) E31.2

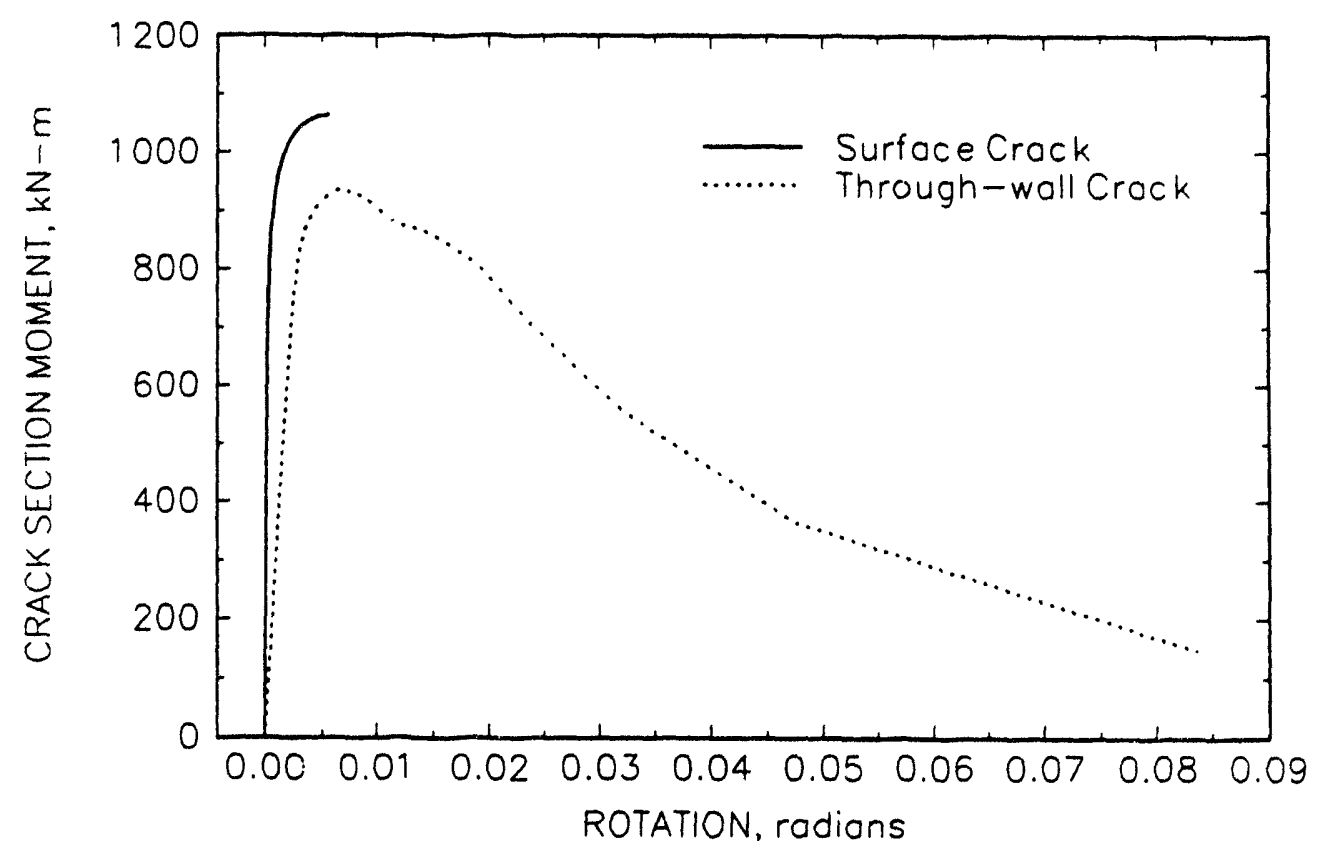

(b) $\mathbf{E 3 1 . 3}$

Figure 5.26 Predicted cracik behavior from J-estimation scheme analyses (Rotation is total rotation.) 


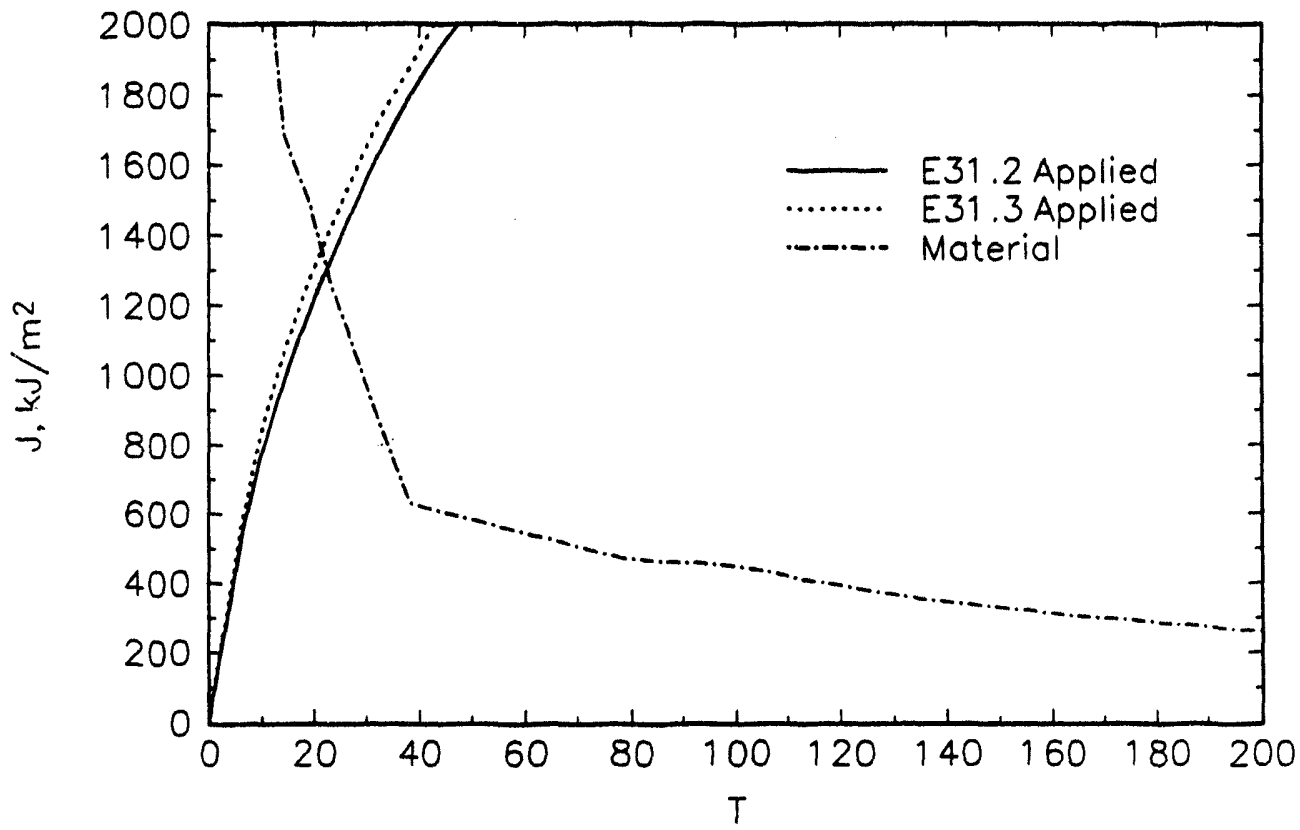

Figure 5.27 Load-controlled J/T stability analysis of HDR-E31 experiments

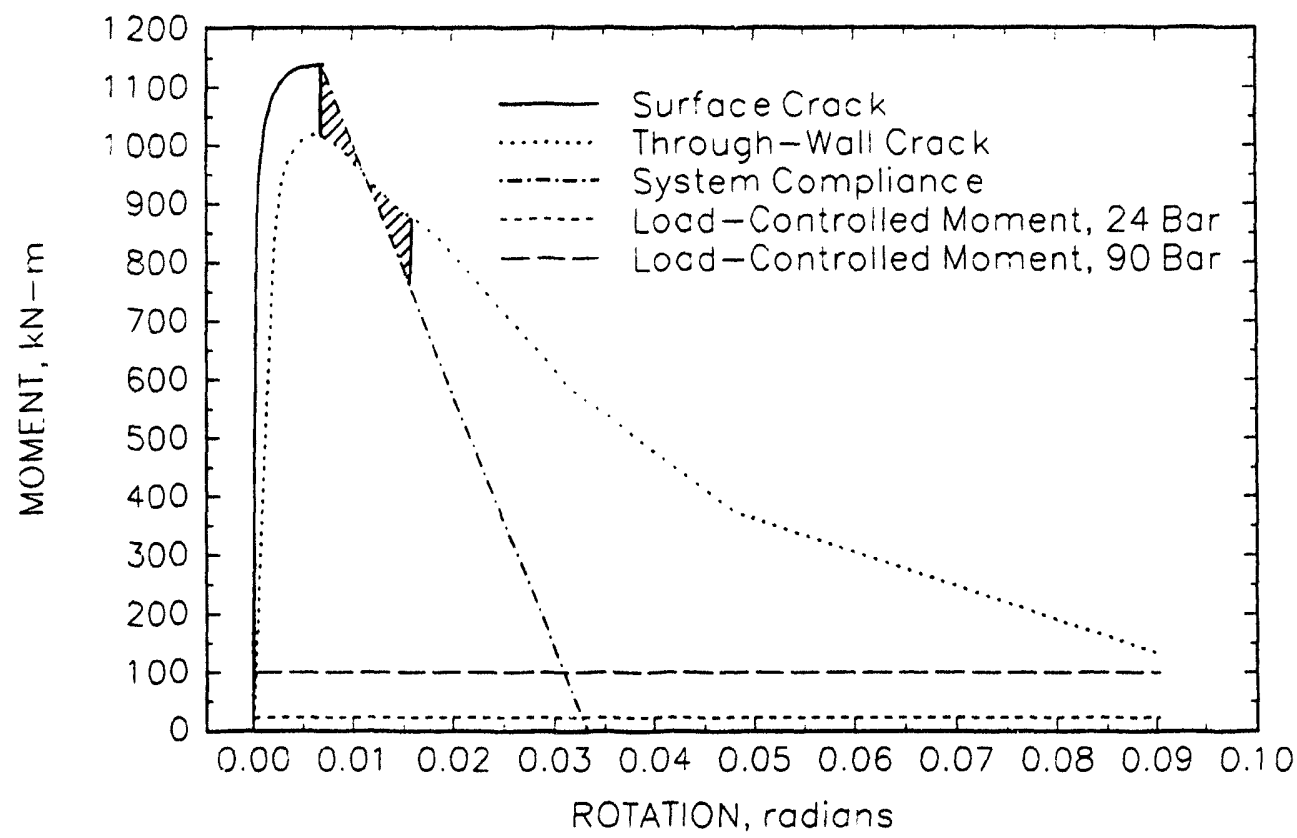

Figure 5.28 Energy Balance stability analysis of HDR-E31.2

(Rotation is total rotation.) 


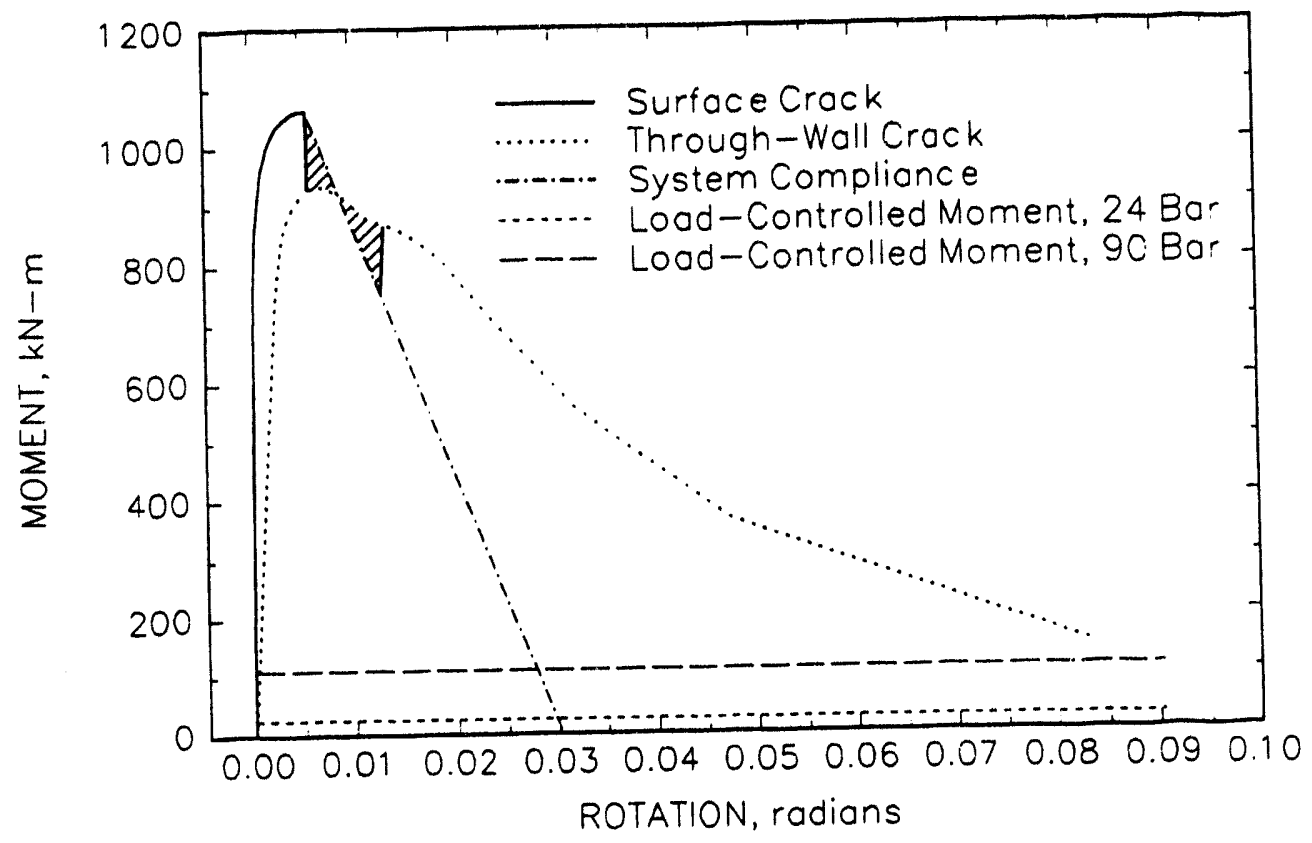

Figure 5.29 Energy Balance stability analysis of HDR-E31.3 (Rotation is total rotation)

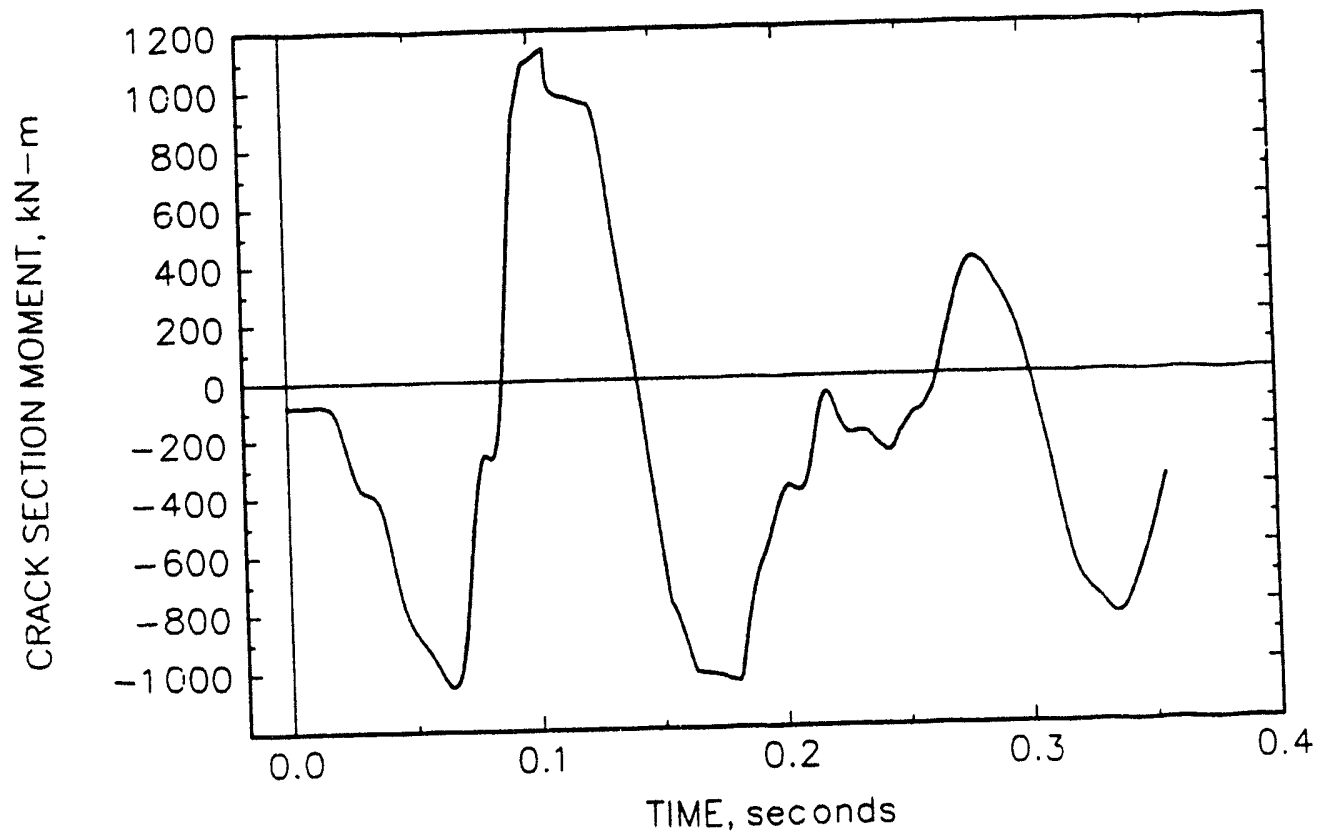

Figure 5.30 Nonlinear FEA fracture mechanics prediction of the moment-time response of the E31.2 naw (Rotation is total rotation) 


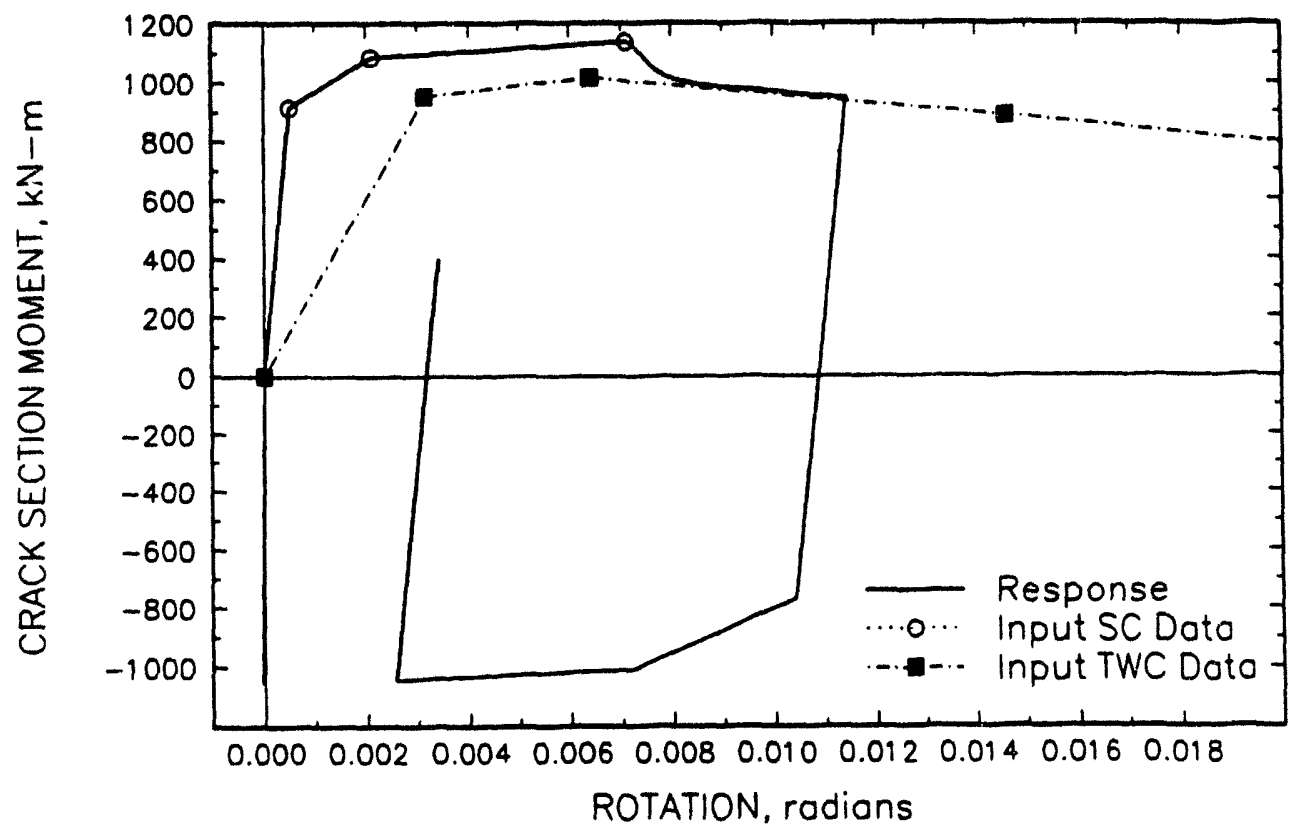

Figure 5.31 Nonlinear FEA fracture mechanics prediction of the moment-rotation response of the B31.2 naw (Rotation is total rotation)

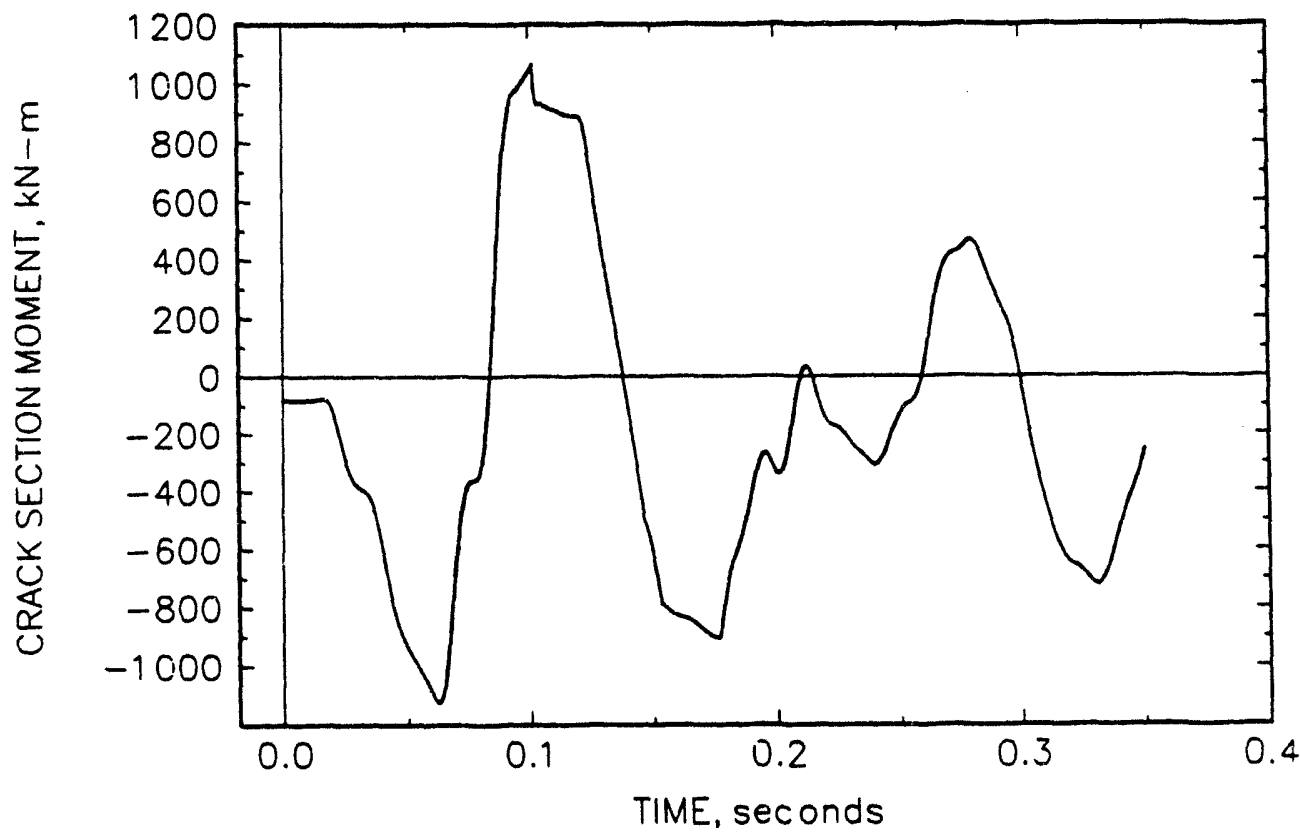

Figure 5.32 Nonlinear FEA fracture mechanics prediction of the moment-time response of the $\mathbf{E 3 1 . 3}$ naw 


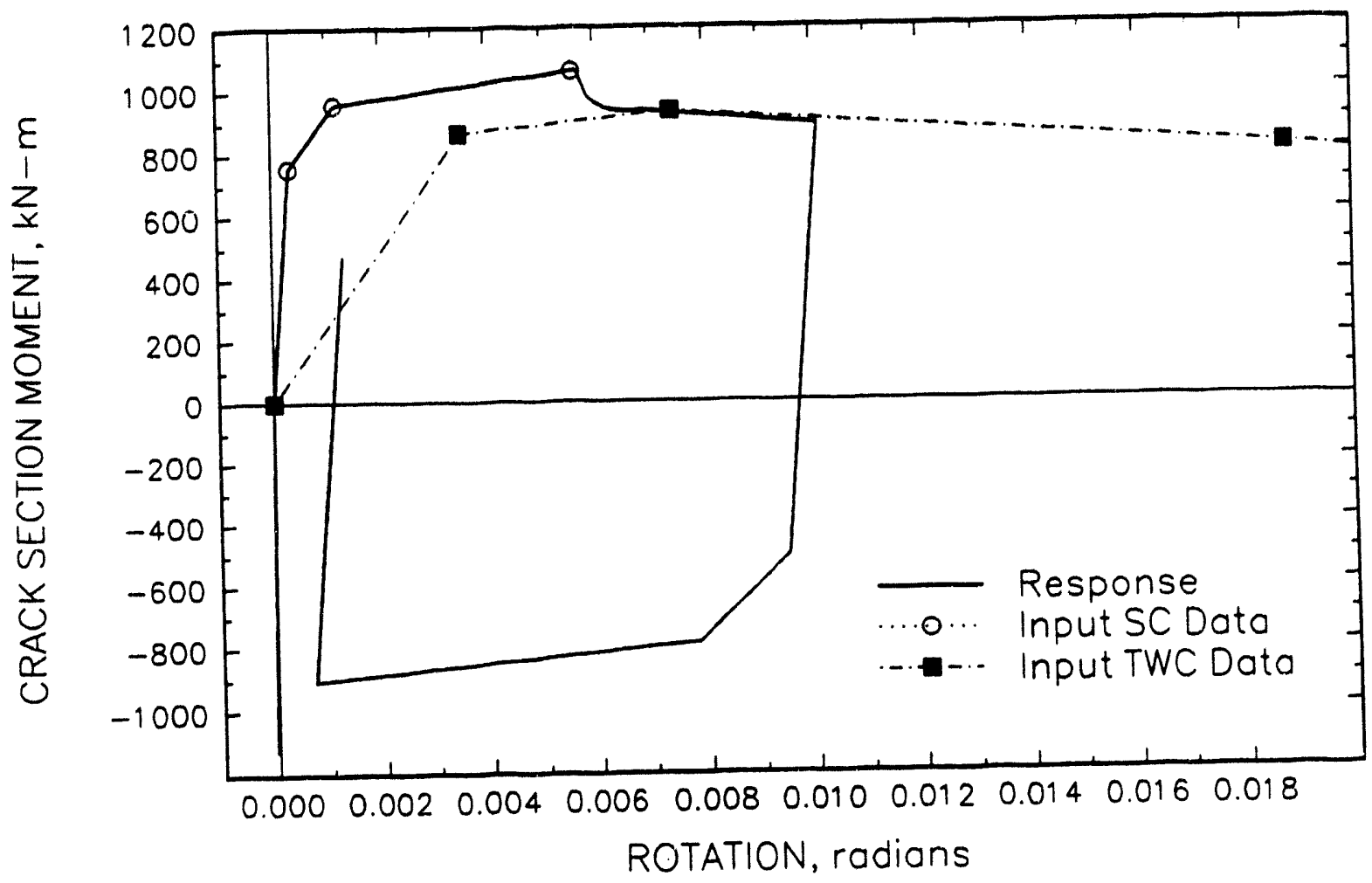

Figure 5.33 Nonlinear FEA fracture mechanics prediction of the moment-rotation response of the E31.3 naw (Rotation is total rotation) 


\section{COMPARISONS OF PREDICTIONS AND THE HDR-E31 EXPERIMENTS}

As indicated in Section 4 of this report, the HDR-31 test system was extensively instrumented. Data either directly recorded in the experiments or derived from the recorded data can be compared with the predictions presented in the previous section. The comparisons can then form the basis for assessing the margins that the various analysis schemes imply.

\subsection{Structural Behavior Comparisons}

\subsubsection{Eigenvalues}

Table 6.1 compares the predicted and measured natural frequencies of the HDR-E31 test system. The predicted and measured frequencies are quite similar, although the finite element results suggest that the piping system mndel is slightly too stiff. As previously discussed in Section 5.1.2, changing the elbow flexibility factors did not have a very significant impact on the natural frequencies. The fact the agreement is quite close, does suggest that the mass and stiffness of the piping system, for the most part, have been properly modeled.

\subsubsection{Static Behavior}

The static point load test of the HDR-E31 experiments provides a means to benchmark FEA analysis programs with measured experimental data. Tables 6.2 and 6.3 compare the displacements and moments at selected locations in the two experiments. The comparisons are quite good. In general, the static predictions, like the natural frequency predictions suggest that the models are slightly too stiff. This is the same result as the Brosi analyses, Ref. 6.1. Clearly, however, the fact that the measured and predicted results are so close indicates that the stiffness of the model is basically correct.

\subsubsection{Dynamic Time-History Response}

Dynamic time-history data from displacement transducers and moments calculated from measured strains on the test system can be compared with the predicted response of the system. By making these comparisoss, one can assess whether or not the dynamic finite element analyses capture the essential behavior of the test system.

As indicated in Section 5, linear and nonlinear analyses were performed. In addition, an engineering model and refined system models were developed. Rather than show results for all of the combinations of analyses, some selected subset will be presented. To provide a perspective for interpreting the comparisons, a brief summary of the outcome of the experiments is required; in E31.3, the surface crack penetrated the pipe wall at 0.110 seconds and grew a small amount as a through-wall crack, while in E31.2, the surface crack did not penetrate the pipe wall. 


\subsubsection{Displacement Comparisons}

Figures 6.1 through 6.3 compare predicted and experimental displacements for Experiment E31.2. In these figures, the predictions were based on linear elastic analyses. Figures 6.4 through 6.6 show similar comparisons for E31.3.

In reviewing these displacement data, it is clear that the finite element results bave the same character as the measured data, but that magnitudes and phasing are not precisely matched. The finite element analysis does make the correct distinction between the four peak event at transducer MN461 measuring the $y$-displacement, Figure 6.4a, and the three peak event at transducer MN471 measuring the $x$-displacement, Figure 6.5a. Some of the finer detail near the peaks and valleys, see Figure $6.2 b$, for instance, is missing in the finite element analysis.

All of the predictions match the experiments quite well for the first 0.1 seconds, but then deviate. It was expected that the linear E31.2 predictions would more closely match the experimental results because the E31.2 surface crack did not penetrate the pipe wall. In fact, transducer for transducer, the E31.3 predicted displacements appear to more closely track the measured data in this experiment. This may be due to a systematic error in the measured data in Test E31.2. In this test, the displacement gage attachment lugs, which are welded to the pipe, underwent considerable deformation (bending) due to interaction with the shifting insulating mats. The actual deformations during the test are unknown, but the measured post-test deformations range from 18 to $60 \mathrm{~mm}(0.709$ to 2.362 inches), Ref. 6.2.

\subsubsection{Moment Comparisons Remote from the Test Section}

Comparisons of moments at two sections remote from the crack location, one near the reactor pressure vessel, and one near the Fixed Point support are shown in Figures 6.7 to 6.10. The predictions in these cases are from nonlinear FEA analyses.

The agreement between the predicted and experimental moments is extremely good. There is occasional higher frequency detail in the measured data that is missed by the finite element results, but the general amplitudes and phasing of the moments are excellent.

Relative to the fracture event, Transducer $Q 02$ in the horizontal direction, $M_{y}$ in Figure 5.9, is the primary crack opening moment. Figures $6.7 \mathrm{a}$ and $6.9 \mathrm{a}$ suggest that the nonlinear finite element analysis predicts this behavior very well, although there is some finer detail in the measured data that is smoothed in the finite element results.

\subsection{Fracture Mechanics Comparisons}

\subsubsection{Loads and Stresses at Cracked Section}

The test section, including the crack location, in the E31 tests was heavily instrumented with strain gages. In addition, clip gages on the pipe interior monitored the crack opening. However, a number 
of strain gages close to the crack exceed their measurement range and failed in both tests. Hence, it is not possible to directly establish the cross-sectional loads and moments as well as stresses at the crack location. These must be inferred by extrapolation/interpolation techniques from measurements both upstream and downstream of the crack (Refs. 6.2 and 6.3).

Using this approach, as well as some of the individual strain measurements at the cracked section, it was found that the maximum moments and stresses exhibited an asymmetry relative to the crack center. The highest fictitious stress (assuming an undamaged crack cross-section) in Test E31.2 is located at 30 degrees to the crack center and has a value of $575 \mathrm{MPa}(83.4 \mathrm{ksi})$. The corresponding values for Test E31.3 are 20 degrees and $710 \mathrm{MPa}(103.0 \mathrm{ksi})$. In both tests, the locations radially opposite to the crack at 180 degrees experienced strong compressive deformations. The measured compressive strains were: -1.1 percent for Test E31.2 and -0.97 percent for Test E31.3.

In can also be established that high tensile loadings of the crack in both experiments are present only for a short time interval, namely, between $97 \mathrm{~ms}$ to $124 \mathrm{~ms}$ in Test E31.2 and between $90 \mathrm{~ms}$ to 130 $\mathrm{ms}$ in Test E31.3. The tensile loading is applied in a number of steps with load plateaus or reductions in between. The maximum bending moments at the cracked section, inferred from the measurements at adjacent locations, are shown in Table 6.4. As indicated earlier, in both tests, abrupt compressional deformations are observed at 180 degrees (opposite the crack, i.e., bottom of pipe) as the crack experiences its' highest tensile loading.

\subsubsection{Crack Response}

Following the tests, extensive fracture examinations of the cracked cross-sections were conducted. Stable crack growth was found to have occurred in both tests, but in Test E31.2 with the shallower starter crack, the crack arrested, while in Test E31.3 a through-wall crack (TWC) was formed. In both tests, there was no circumferential extension of the crack on the interior surface of the pipe beyond the initial circumferential flaw.

Video pictures taken during the tests at $\mathbf{4 0} \mathrm{ms}$ intervals (25 frames/s), show the first indication of a TWC in Test E31.3 as a small steam puff. The next frame shows no indication of leak, and the third picture shows a well developed steam jet. Following pictures show steam jets of increasing size indicating further crack opening, and by the 15th frame the picture is completely obscured by the steam accumulation in the room.

Based on the examination of the cracked-section specimen, it was found that in both tests there are two zones of stable crack growth. In the first zone, the crack is pulled apart while in the second zone the sides of the crack are nearly parallel. This second zone also bears evidence of having undergone strong compression. At the transition from the fatigue crack (formed in the laboratory prior to the tests) to the stable crack growth, a very clear "stretched zone" can be identified in both experiments. There are also indications of such a "stretched zone" between the first and second zone of siable crack growth.

The clip gage measurements in Test E31.3 indicate that the crack on the inner surface opened up to $4 \mathrm{~mm}(0.158 \mathrm{inch})$. The circumferential extent of the TWC is found to be 43.4 degrees or about 174 
$\mathrm{mm}$ (6.85 inches). Finally, in both tests there was necking (cross-sectional area reduction) at the cracked section. This necking was particularly strong in Test E31.3 and led to a relative radial displacement of the crack sides on the inner pipe surface of $1.1 \mathrm{~mm}(0.043 \mathrm{inch})$. The major crack characteristics for the two experiments, obtained from post-test examinations of crack-section specimen, are shown in Table 6.5.

\subsubsection{Comparison of Calculations and Test Results}

Tables 6.6 and 6.7 compare the predicted and measured fracture behavior of the E31 tests. In these tables, the measured values of moment are actually inferred from strains remote from the test section. All of the engineering methods (engineering fracture analysis plus linear finite element analysis) are conservative, in that they predict that the surface crack will easily penetrate the pipe wall for both experiments.

The nonlinear FEA fracture analysis method correctly predicts the outcome of E31.3, and conservatively predicts the behavior of E31.2. As mentioned in Section 5.3.2, the predictions for Experiment E31.2 appeared in the finite element analysis to be marginal, in terms of whether or not surface-crack penetration would occur. Because it was predicted to occur, the resulting through-wall crack analysis showed that the through-wall crack would propagate.

Flaw stability for the E31 experiments is summarized in Table 6.8. By virtue of having predicted surface-crack penetration, all of the methods were incorrect for Experiment E31.2. For Experiment E31.3, Energy Balance and nonlinear FEA both suggest that the crack will arrest. The conventional fully-plastic $J / T$ analysis, on the other hand, only can predict whether an instability will initiate and not if it will arrest, and hence it is usually assumed that a DEGB would occur. In these experiments, $\mathrm{J} / \mathrm{T}$ analysis predicted an instability for both experiments.

\subsection{Conclusions}

The conclusions regarding the comparisons are as follows:

- The basic finite element analysis does a good job of modeling the pipe system response. This is almost certainly a consequence of the boundary conditions being so simple.

- The engineering fracture analysis methods all tend to make conservative predictions.

- The nonlinear FEA fracture mechanics analysis did the most accurate job of predicting the fracture behavior of the E31 experiments, and using the current methodology was slightly conservative. 


\subsection{References}

6.1 Brosi, S., et al, "Precracked Pipe Under Waterhammer Action", Transactions of 12th SMiRT Conference, Volume GF, August 1993, pp. 405-410.

6.2 Schrammel, D., "Behavior of a Faulted Pipeline During a Simulated Loss of Coolant Accident with High Water-Hammer Loading", Quick Look Report, Test Group E31, Experiment E31.2 (In German), Technical Report PHDR 106-91, Kernforschungszentrum Karlsruhe, January 1991.

6.3 Schrammel, D., "Behavior of a Faulted Pipeline During a Simulated Loss of Coolant Accident with High Water-Hammer Loading", Quick Look Report, Test Group E31, Experiment E31.3 (In German), Technical Report PHDR 108-91, Kernforschungszentrum Karlsruhe, November 1991. 
Table 6.1 Natural frequencies of the HDR pipe system

\begin{tabular}{|c|c|c|c||}
\hline Mode & $\begin{array}{c}\text { E31.2 } \\
\text { Prediction, } \\
\text { Hz }\end{array}$ & $\begin{array}{c}\text { E31.3 } \\
\text { Prediction, } \\
\text { Hz }\end{array}$ & $\begin{array}{c}\text { Experimental } \\
\text { Results, } \\
\text { Hz }\end{array}$ \\
\hline 1 & 5.105 & 5.105 & 4.778 \\
\hline 2 & 6.958 & 6.959 & 6.525 \\
\hline 3 & 8.954 & 8.955 & 8.465 \\
\hline 4 & 14.926 & 14.925 & 13.348 \\
\hline 5 & 20.428 & 20.429 & N.D.(n) \\
\hline
\end{tabular}

(a) Not determined.

Table 6.2 Static loading results for Experiment E31.2, $\mathrm{F}_{\text {applied }}=100 \mathrm{kN}(22,481 \mathrm{lb}) *$

\begin{tabular}{|c|c|c|c|}
\hline $\begin{array}{c}\text { Location } \\
\text { (node) }\end{array}$ & Direction & $\begin{array}{c}\text { Prediction, } \\
\mathrm{mm}\end{array}$ & $\begin{array}{c}\text { Experiment, } \\
\mathrm{mm}\end{array}$ \\
\hline \multirow{2}{*}{ load point (153) } & $\mathrm{U}_{\mathrm{z}}$ & 9.0 & 10.3 \\
\cline { 2 - 4 } & $\mathrm{U}_{\mathrm{x}}$ & 6.9 & 7.4 \\
\hline $\mathrm{U}_{\mathrm{y}}$ & 1.8 & 1.2 \\
\hline MN461 (93) & $\mathrm{U}_{\mathrm{z}}$ & 8.65 & 9.07 \\
\hline MN471 (142) & $\mathrm{U}_{\mathrm{z}}$ & 10.3 & 10.6 \\
\hline MN481 (171) & $\mathrm{U}_{\mathrm{z}}$ & 6.7 & 6.0 \\
\hline \multirow{2}{*}{$\begin{array}{c}\text { Location } \\
\text { (element) }\end{array}$} & Direction & Predicted Moment, & $\begin{array}{c}\text { Experimental } \\
\mathrm{kN}-\mathrm{m}\end{array}$ \\
\hline \multirow{2}{*}{ Q02 (26) } & $\xi=0^{\circ}$ & -186.0 & -186.8 \\
\cline { 2 - 4 } & $\xi=90^{\circ}$ & -12.8 & -17.3 \\
\hline \multirow{2}{*}{ Q91 (194) } & $\xi=0^{\circ}$ & -165.3 & -158.8 \\
\cline { 2 - 5 } & $\xi=90^{\circ}$ & +41.5 & +42.9 \\
\hline
\end{tabular}

$* 25.4 \mathrm{~mm}=1.0 \mathrm{inch}, 0.11298 \mathrm{kN}-\mathrm{m}=1,000 \mathrm{in}-\mathrm{lb}$. 
Table 6.3 Static loading results for Experiment E31.3, $F_{\text {applied }}=110 \mathrm{kN}(24,729 \mathrm{lb}) *$

\begin{tabular}{|c|c|c|c|}
\hline $\begin{array}{c}\text { Location } \\
\text { (node) }\end{array}$ & Direction & $\begin{array}{c}\text { Prediction, } \\
\mathrm{mm}\end{array}$ & $\begin{array}{c}\text { Experiment, } \\
\mathrm{mm}\end{array}$ \\
\hline load point (153) & $\mathrm{U}_{\mathrm{z}}$ & 9.9 & 12.1 \\
\cline { 2 - 4 } & $\mathrm{U}_{\mathrm{x}}$ & 7.6 & 5.9 \\
\hline $\mathrm{U}_{\mathrm{y}}$ & 2.0 & 1.0 \\
\hline MN471 (142) & $\mathrm{U}_{\mathrm{z}}$ & 11.3 & 12.0 \\
\hline MN481 (171) & $\mathrm{U}_{\mathrm{z}}$ & 7.4 & 6.8 \\
\hline \multirow{2}{*}{$\begin{array}{c}\text { Location } \\
\text { (element) }\end{array}$} & Direction & $\begin{array}{c}\text { Predicted Moment, } \\
\mathrm{kN}-\mathrm{m}\end{array}$ & $\begin{array}{c}\text { Experimental } \\
\text { Moment, } \mathrm{kN}-\mathrm{m}\end{array}$ \\
\hline \multirow{2}{*}{ Q02 (26) } & $\xi=0^{\circ}$ & -204.7 & -217.3 \\
\cline { 2 - 4 } & $\xi=90^{\circ}$ & -14.1 & -20.9 \\
\hline Q91 (194) & $\xi=0^{\circ}$ & -181.8 & -160.1 \\
\hline & $\xi=90^{\circ}$ & +45.7 & +36.9 \\
\hline
\end{tabular}

* $25.4 \mathrm{~mm}=1.0 \mathrm{inch}, 0.11298 \mathrm{kN}-\mathrm{m}=1,000 \mathrm{in}-\mathrm{lb}$.

Table 6.4 Crack section behavior in the $\mathbf{E 3 1}$ experiments inferred from remote strain gage data

\begin{tabular}{|c|c|c|c|}
\hline Experiment & $\begin{array}{c}\text { Time, } \\
\mathrm{ms}\end{array}$ & $\begin{array}{c}\text { Angle, } \\
\text { degrees }\end{array}$ & $\begin{array}{c}\text { Bending Moment, } \\
\text { MN-m* }\end{array}$ \\
\hline E31.2 & $\sim 104$ & 28.5 & 1.262 \\
\hline E31.3 & $\sim 99$ & 27.3 & 1.383 \\
\hline
\end{tabular}

* $1.0 \mathrm{MN}-\mathrm{m}=8.85 \times 10^{6} \mathrm{in}-1 \mathrm{~b}$. 
Table 6.5 E31 experiment post-test crack examination results

\begin{tabular}{|l|c|c|c|c|}
\hline \multirow{2}{*}{ Crack Zone } & \multicolumn{2}{|c|}{ Experiment E31.2 } & \multicolumn{2}{c|}{ Experiment E31.3 } \\
\cline { 2 - 5 } & $\mathrm{d} / \mathrm{t}$ & depth, mm* & $\mathrm{d} / \mathrm{t}$ & depth, mm* \\
\hline Starter notch & 0.13 & 2.1 & 0.14 & 2.2 \\
\hline Fatigue crack & 0.30 & 4.8 & 0.53 & 8.5 \\
\hline 1st stable growth zone & 0.35 & 5.6 & 0.70 & 11.2 \\
\hline 2nd stable growth zone & 0.39 & 6.2 & 0.90 & 14.4 \\
\hline Shear lip (leading to leak) & - & - & 0.93 & 14.7 \\
\hline
\end{tabular}

$* 25.4 \mathrm{~mm}=1.0$ inch.

Table 6.6 Fracture predictions for Experiment E31.2

\begin{tabular}{|c|c|c|}
\hline Method & $\begin{array}{c}\text { Maximum Moment, } \\
\text { MN-m* }\end{array}$ & Comments \\
\hline Measured & 1.262 & no SC penetration \\
\hline Linear FEA & 1.757 & no crack in analysis \\
\hline $\begin{array}{c}\text { NSC } \\
\text { (NP-192) }\end{array}$ & 1.610 & SC penetration at $0.1034 \mathrm{sec}$ \\
\hline $\begin{array}{c}\text { ASME Sec XI } \\
\text { (TWB-3650) }\end{array}$ & 0.652 & SC penetration at $0.0910 \mathrm{sec}$ \\
A508 Cl 3, Sec. III flaw & 1.521 & SC penetration at $0.1016 \mathrm{sec}$ \\
\hline R6, Rev 3, Option 1 & 1.158 & SC penetration at $0.0956 \mathrm{sec}$ \\
\hline DPZP screening criterion & 1.138 & SC penetration at $0.0952 \mathrm{sec}$ \\
\hline SC.TNP & 1.138 & SC penetration at $0.1066 \mathrm{sec}$ \\
\hline nonlinear FEA & &
\end{tabular}

* $1.0 \mathrm{MN}-\mathrm{m}-8.85 \times 10^{6} \mathrm{in}-1 \mathrm{~b}$. 
Table 6.7 Fracture predictions for Experiment E31.3

\begin{tabular}{|c|c|c|}
\hline Method & $\begin{array}{c}\text { Maximum Moment, } \\
\text { MN-m* }\end{array}$ & \multicolumn{1}{|c|}{ Comments } \\
\hline Measured & 1.383 & SC penetration at $0.110 \mathrm{sec}$ \\
\hline Linear FEA & 1.627 & no crack in analysis \\
\hline $\begin{array}{c}\text { NSC } \\
\text { (NP-192) }\end{array}$ & 1.507 & SC penetration at $0.1002 \mathrm{sec}$ \\
\hline $\begin{array}{c}\text { ASME Sec XI } \\
\text { (IWB-3650) } \\
\text { A508 Cl 3, Sec. II flaw }\end{array}$ & 0.575 & SC penetration at $0.0874 \mathrm{sec}$ \\
\hline R6, Rev 3, Option 1 & 1.307 & SC penetration at $0.0966 \mathrm{sec}$ \\
\hline DPZP screening criterion & 1.083 & SC penetration at $0.0924 \mathrm{sec}$ \\
\hline SC.TNP & 1.063 & SC penetration at $0.0922 \mathrm{sec}$ \\
\hline nonlinear FEA & 1.063 & SC penetration at $0.1018 \mathrm{sec}$ \\
\hline
\end{tabular}

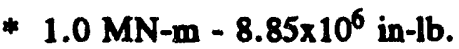

Table 6.8 Flaw stability predictions for the E31 experiments

\begin{tabular}{|c|c|c|}
\hline Method & E31.2 & E31.3 \\
\hline Experiment & no SC penetration & TWC growth to $2 \theta=43^{\circ}$ on OD \\
\hline $\begin{array}{c}\text { J } / T \\
\text { (load controlled) }\end{array}$ & unstable TWC & unstable TWC \\
\hline Energy Balance & TWC growth to $2 \theta=99^{\circ}$ & TWC growth to $2 \theta=94^{\circ}$ \\
\hline Nonlinear FEA & TWC growth to $2 \theta=83^{\circ}$ & TWC growth to $2 \theta=85^{\circ}$ \\
\hline
\end{tabular}




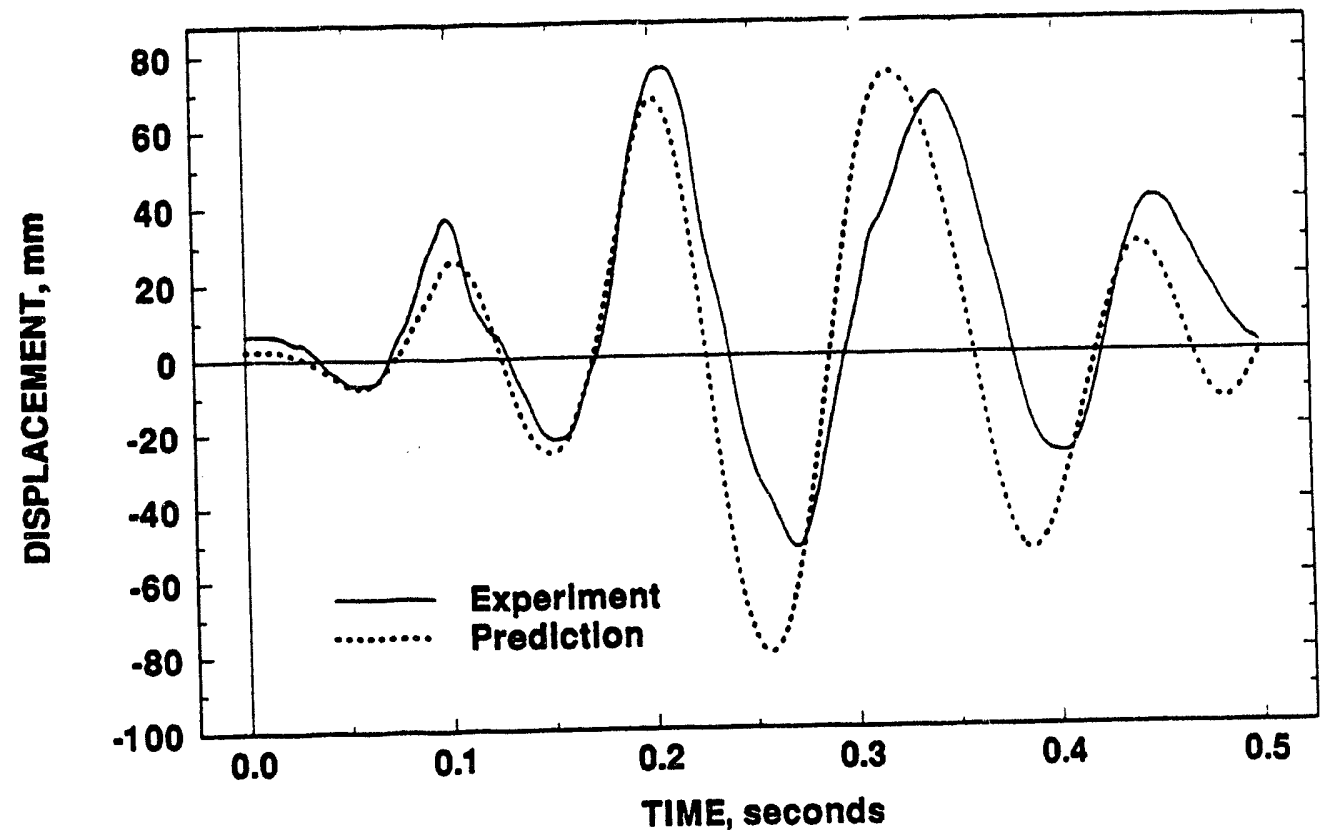

(a) $Y$ direction

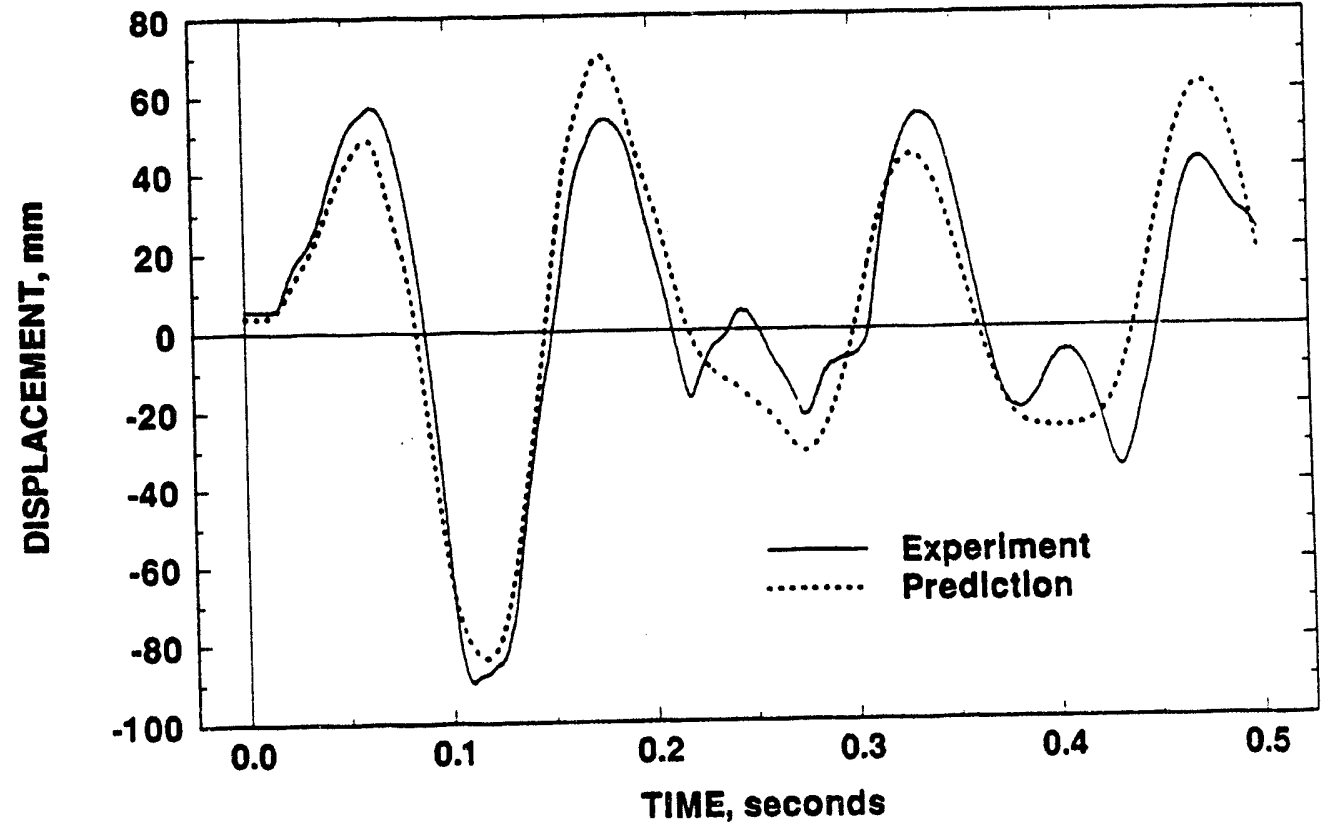

(b) $\mathbf{Z}$ direction

Figure 6.1 Displacements at Transducer MN461 (Node 93) for E31.2 (at the first elbow from the reactor pressure vessel) 


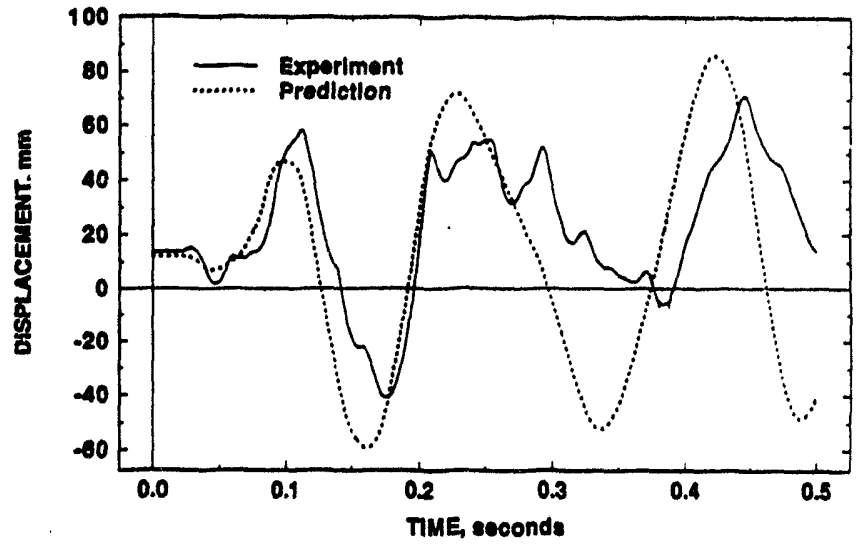

(a) $\mathrm{X}$ direction

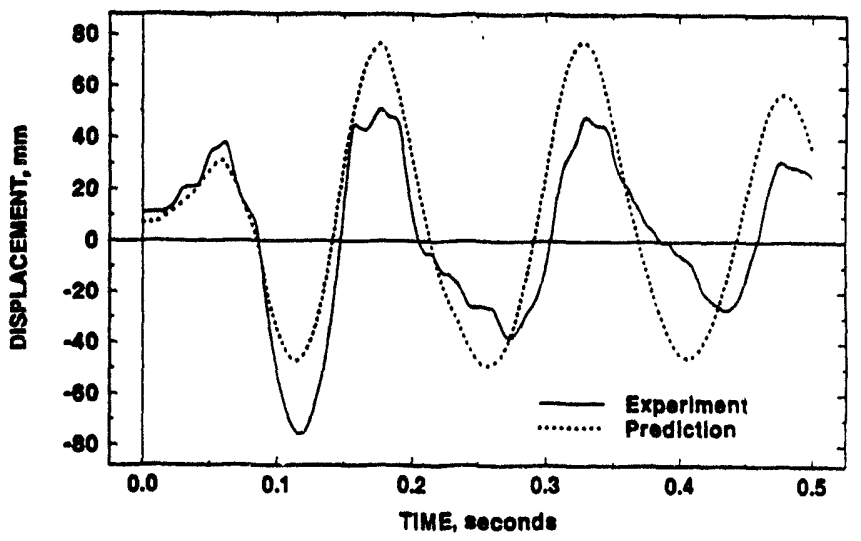

(b) $Y$ direction

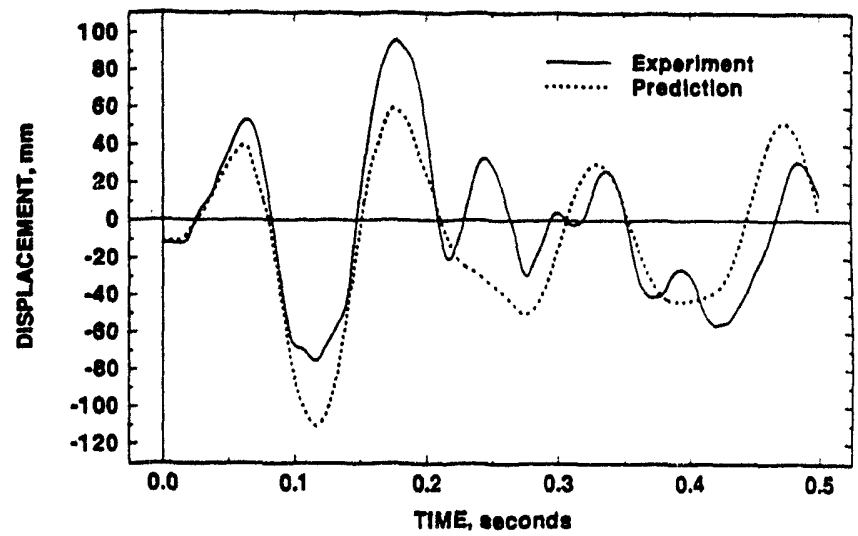

(c) $\mathbf{Z}$ direction

Figure 6.2 Displacements at Transducer MN471 (Node 142) for E31.2 (at the second elbow from the reactor pressure vessel) 


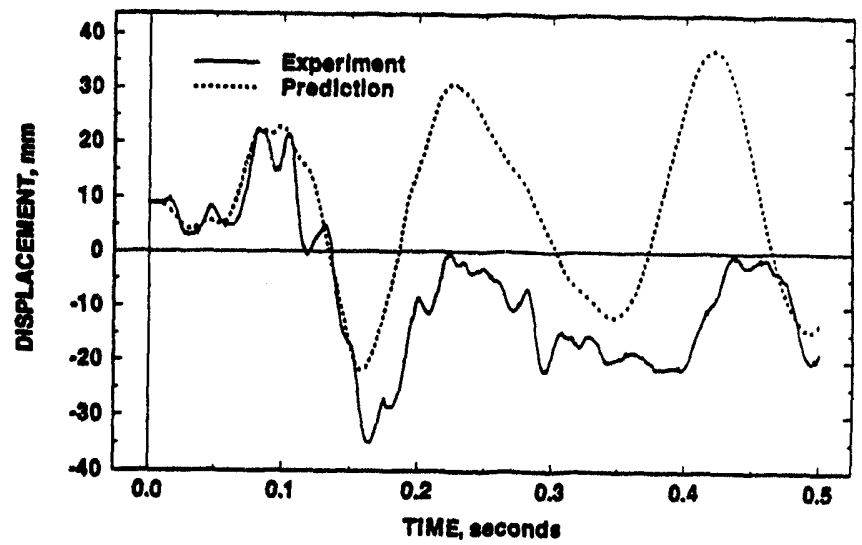

(a) $\mathrm{X}$ direction

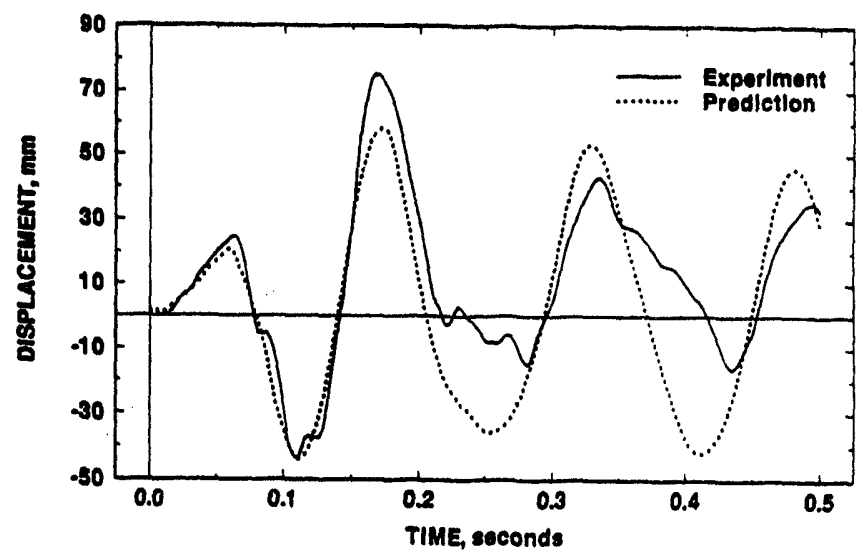

(b) $\mathbf{Y}$ direction

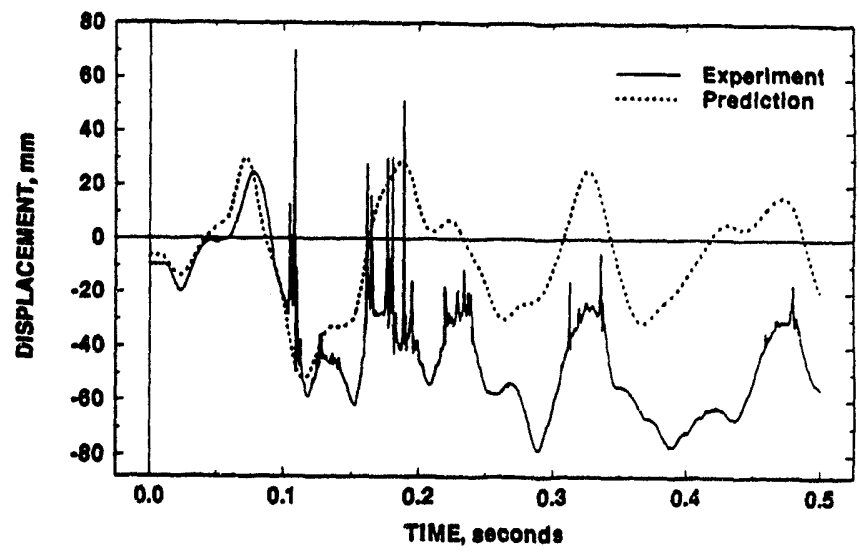

(c) $\mathbf{Z}$ direction

Figure 6.3 Displacements at Transducer MN481 (Node 171) for E31.2 (at the third elbow from the reactor pressure vessel) 


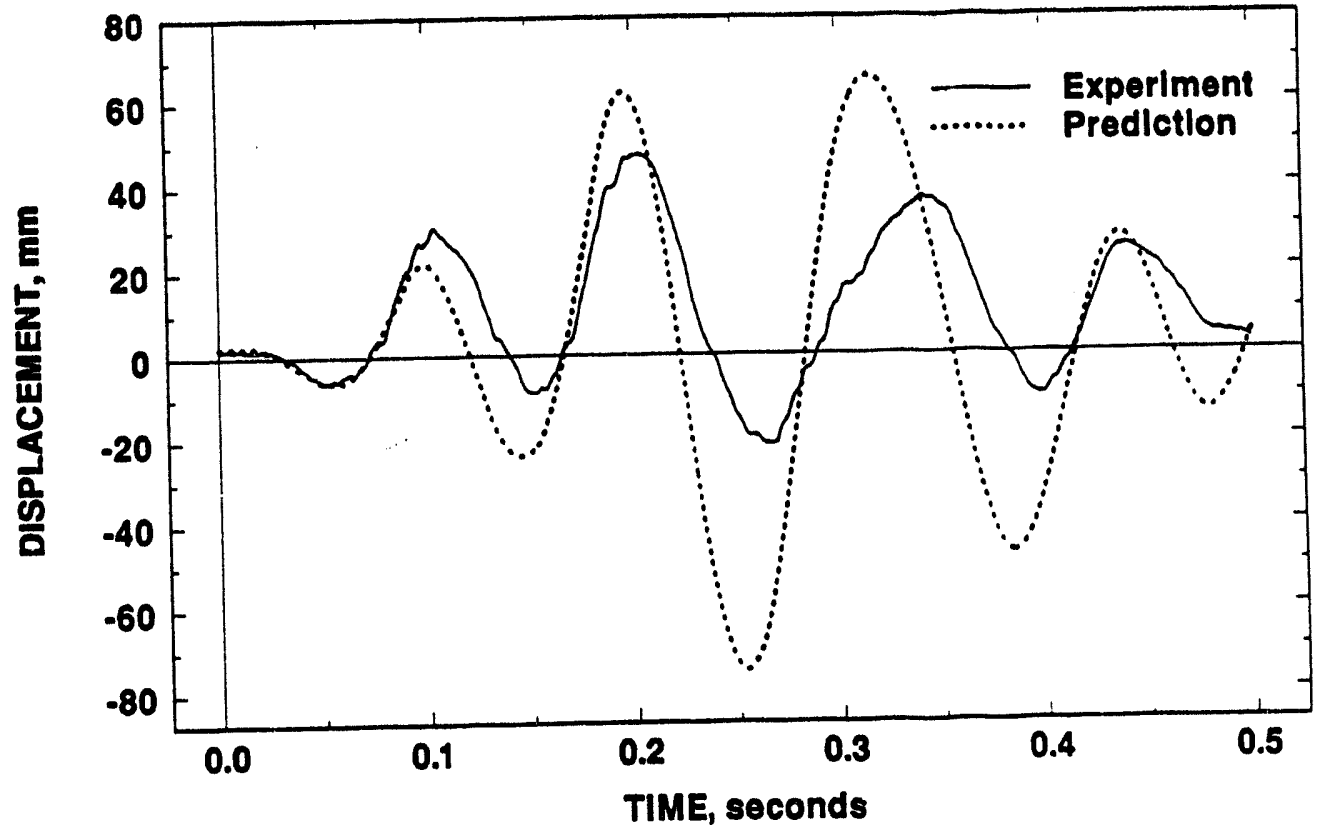

(a) $\mathbf{Y}$ direction

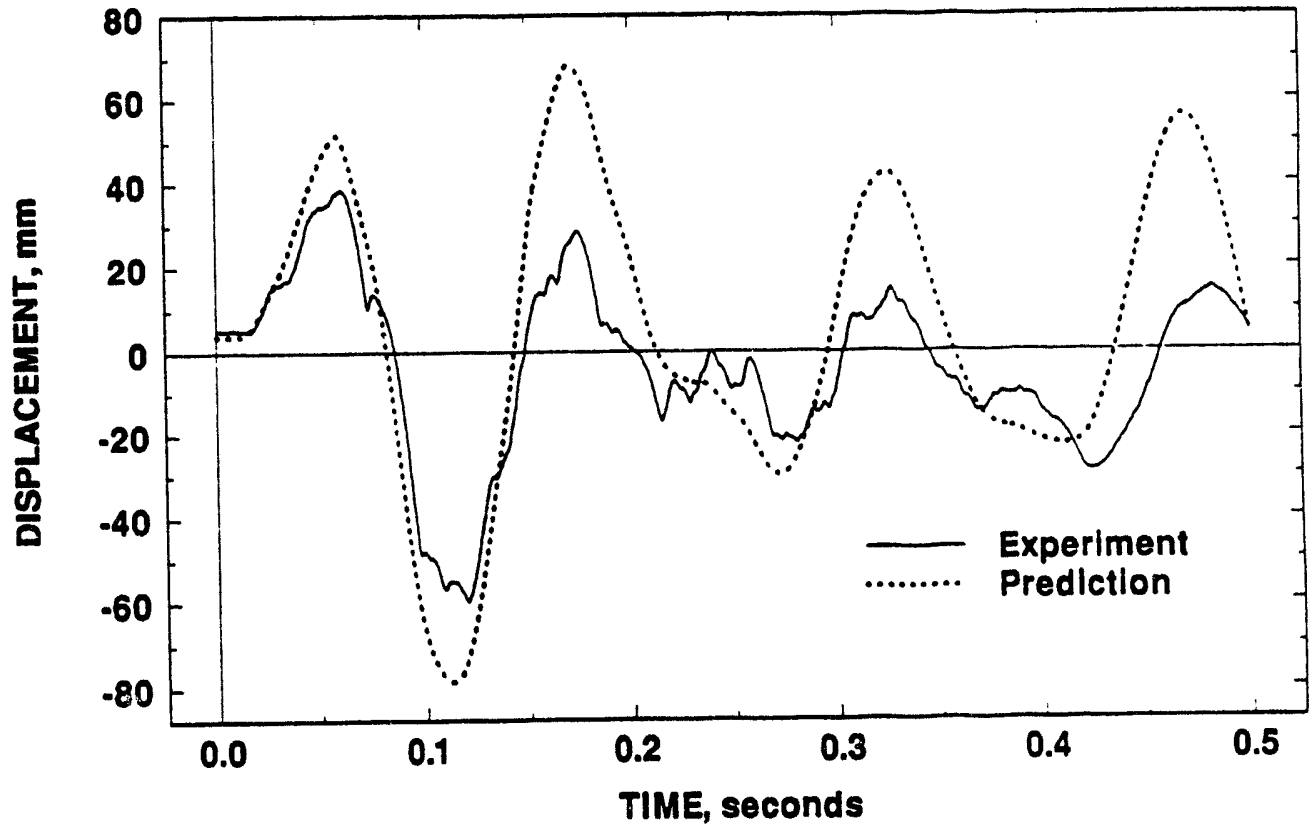

(b) $\mathbf{Z}$ direction

Figure 6.4 Displacements at Transducer MN461 (Node 93) for E31.3 (at the first elbow from the reactor pressure vessel) 


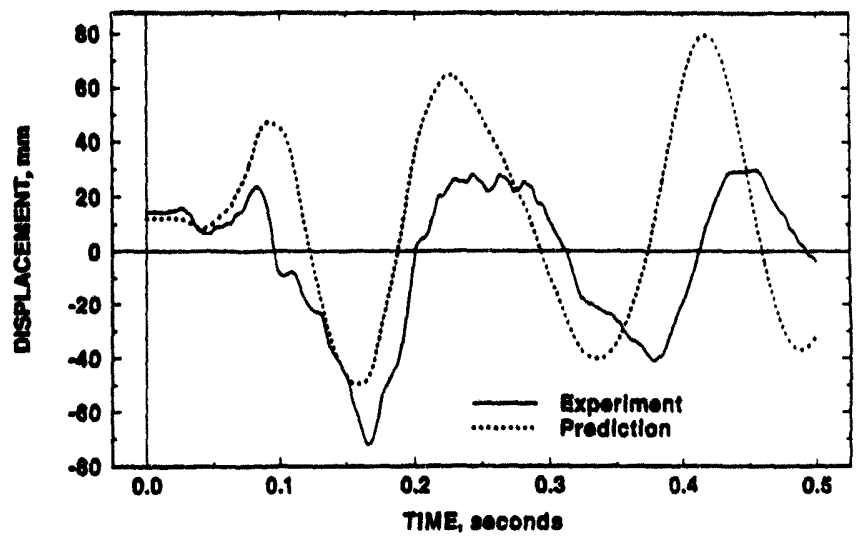

(a) $\mathrm{X}$ direction

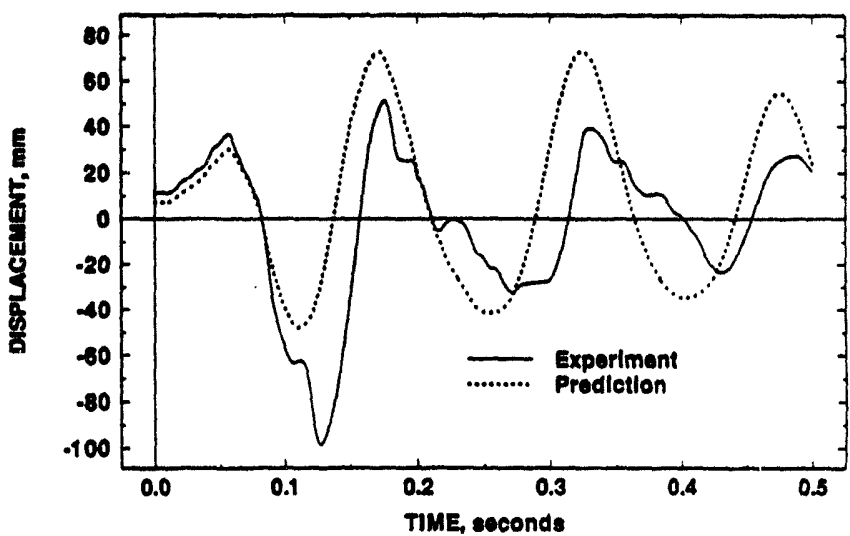

(b) $\mathbf{Y}$ direction

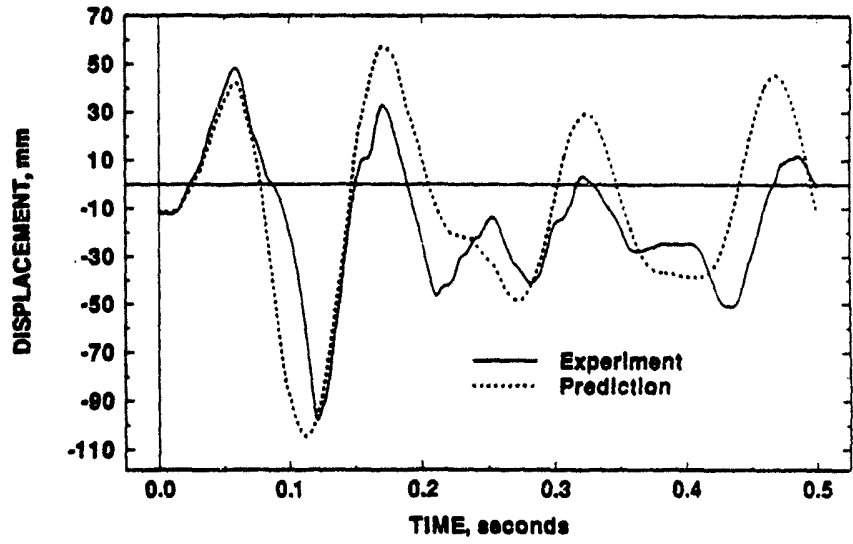

(c) $\mathbf{Z}$ direction

Figure 6.5 Displacements at Transducer MN471 (Node 142) for E31.3 (at the second elbow from the reactor pressure vessel) 


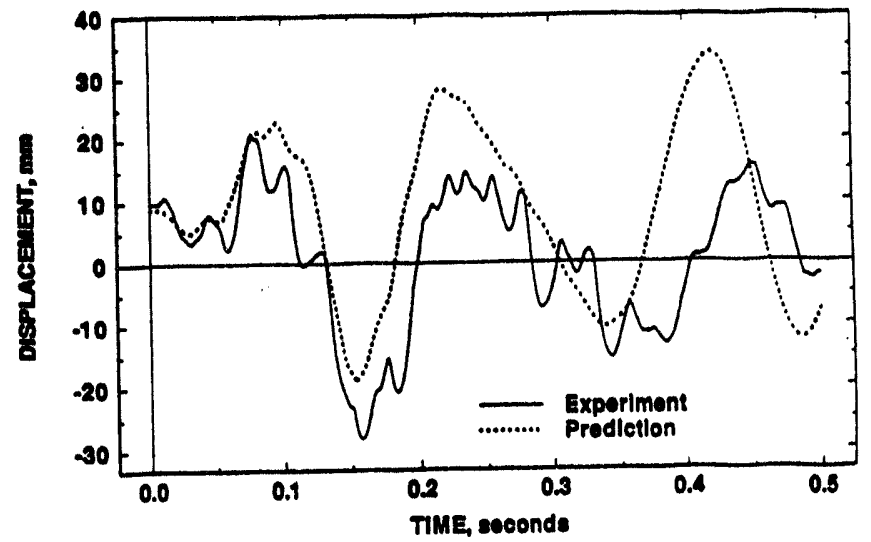

(a) $\mathrm{X}$ direction

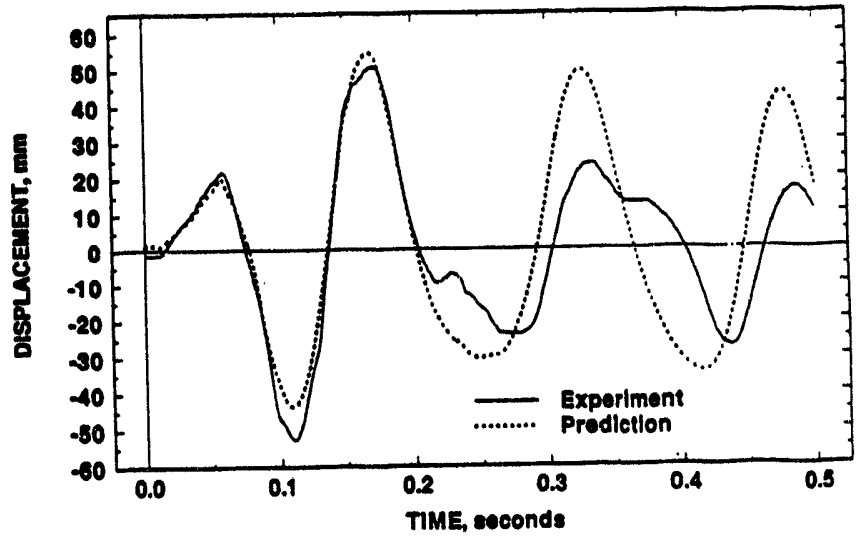

(b) $\mathbf{Y}$ direction

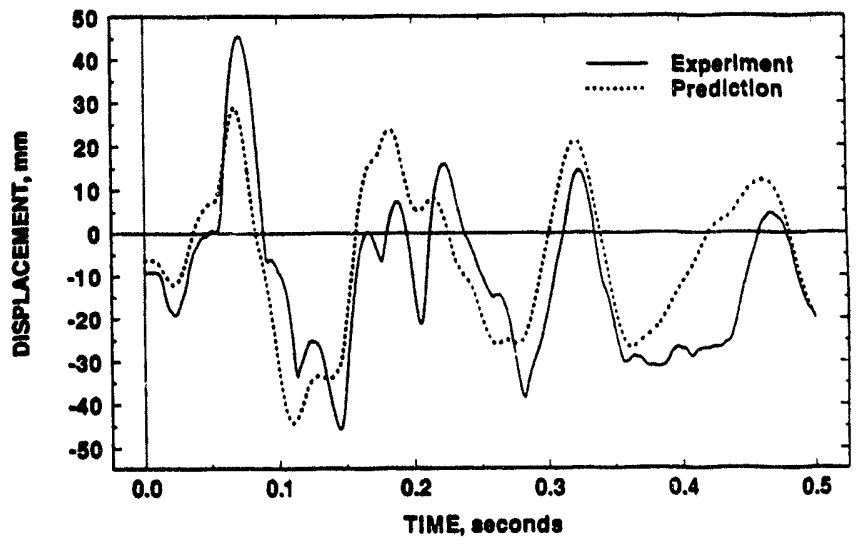

(c) $\mathrm{Z}$ direction

Figure 6.6 Displacements at Transducer MN481 (Node 171) for E31.3 (at the third elbow from the reactor pressure vessel) 

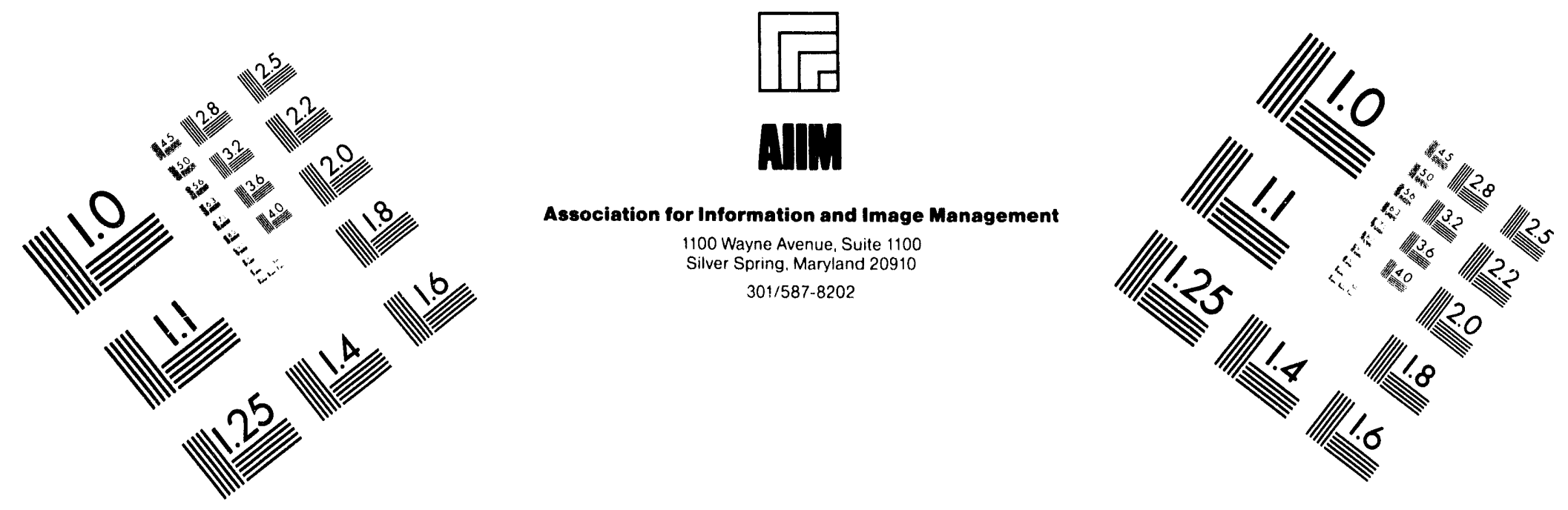

\section{Centimeter}

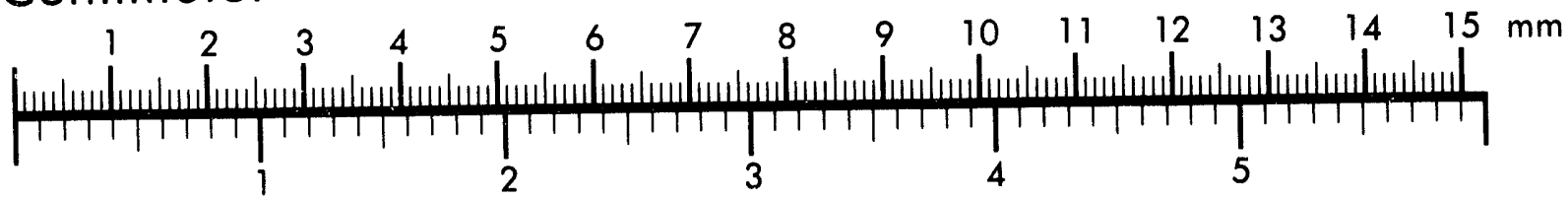

Inches
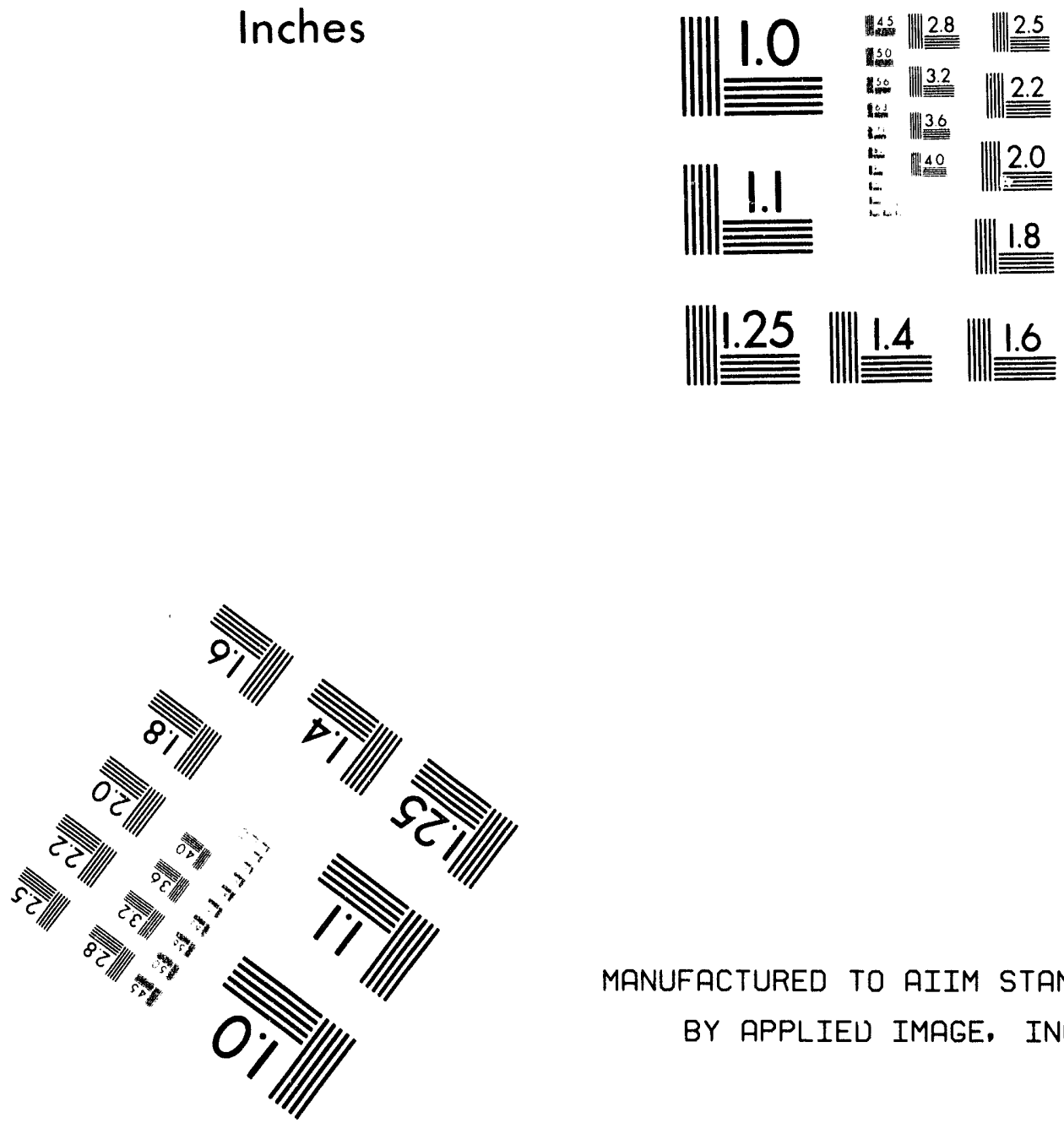

MANUFACTURED TO AIIM STANDARDS

BY APPLIEU IMAGE, INC.

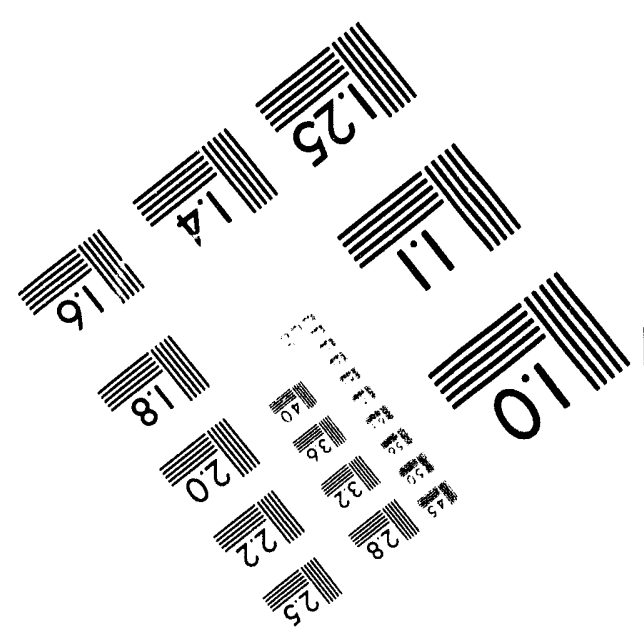



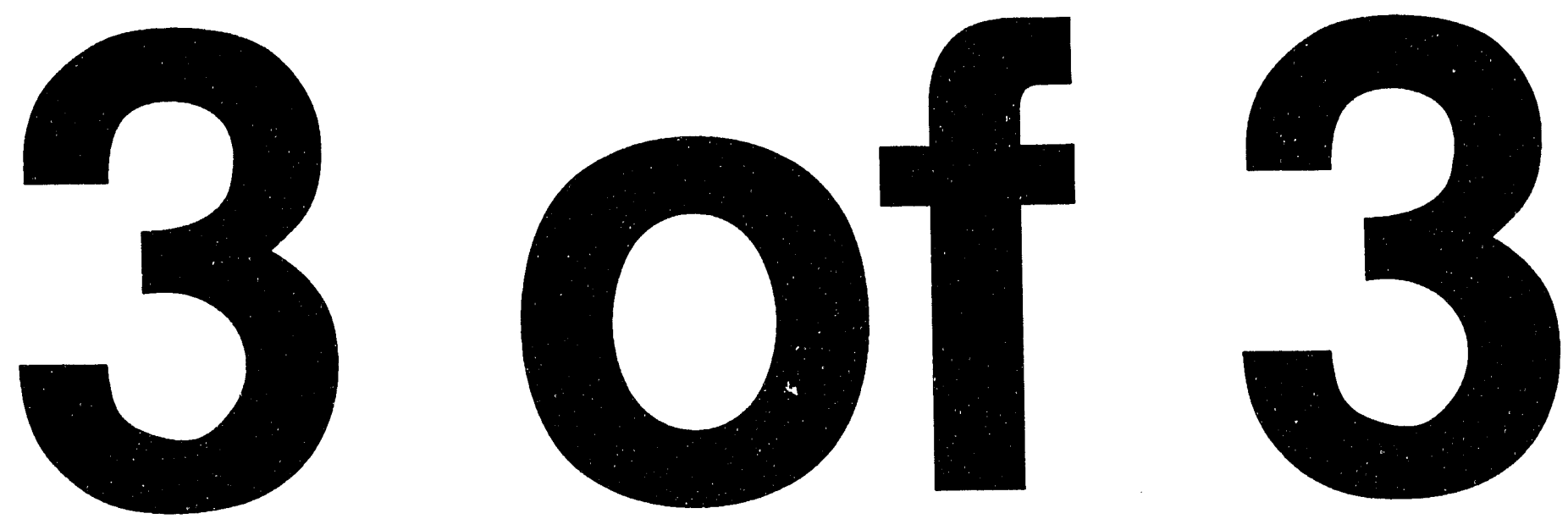


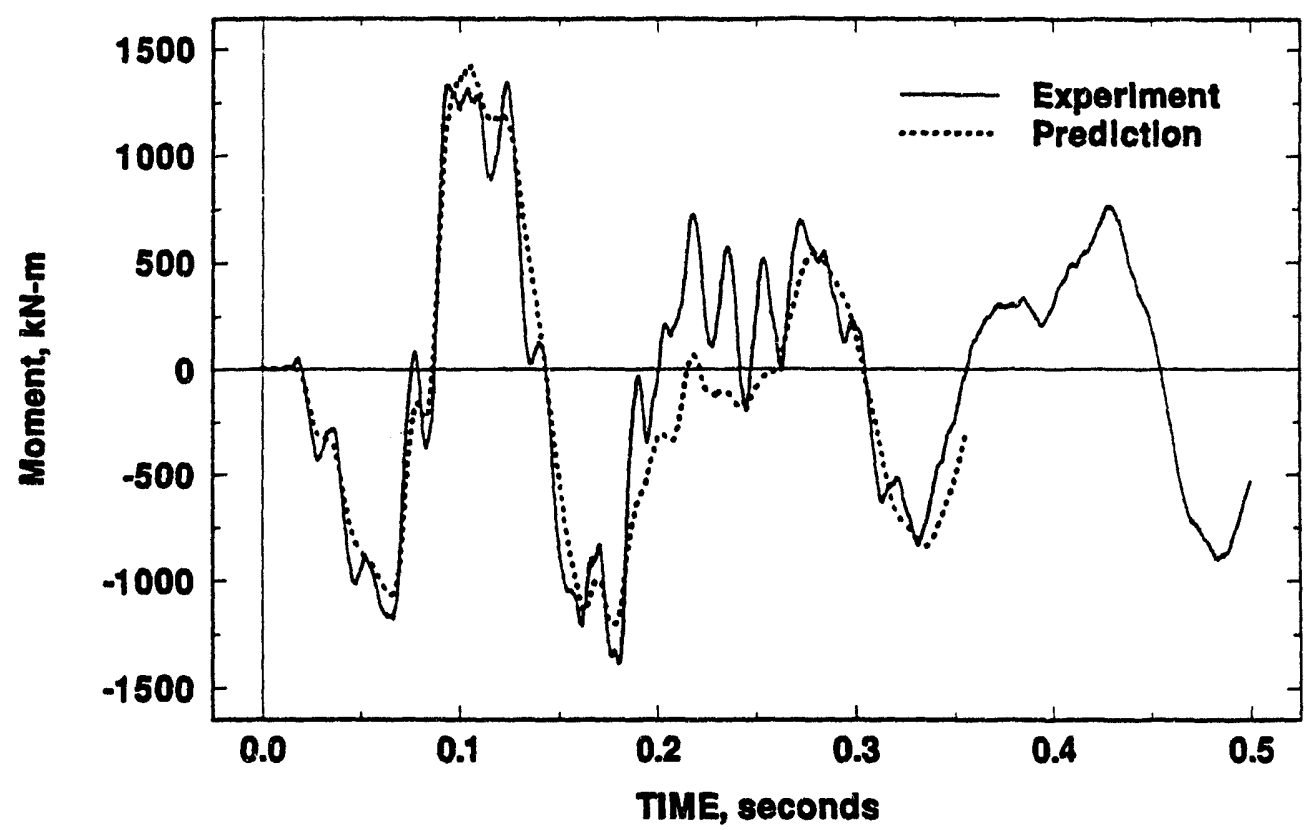

(a) horizontal

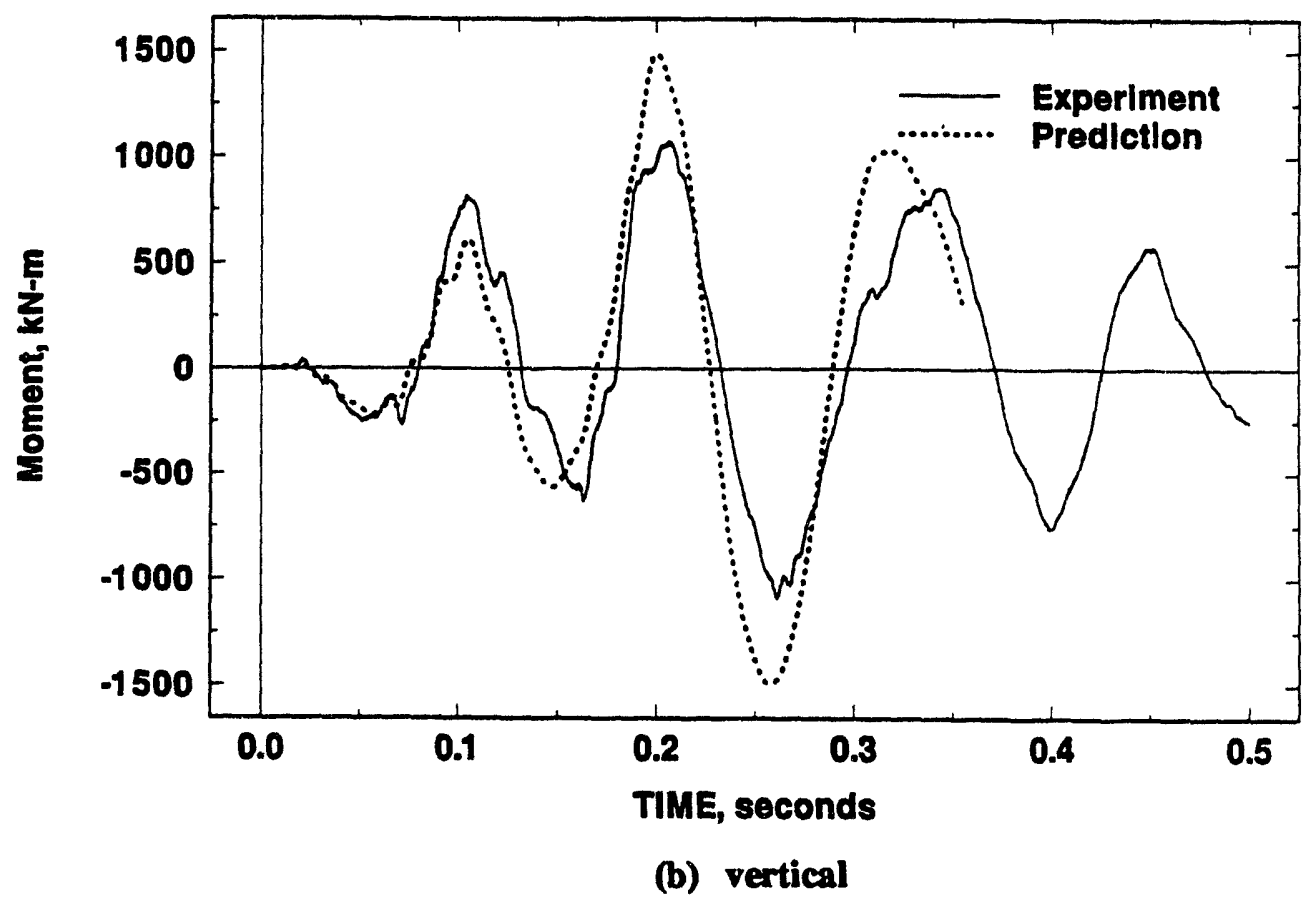

Figure 6.7 Moments at Section Q 02 (Element 20) for E31.2 (near the reactor pressure vessel) 


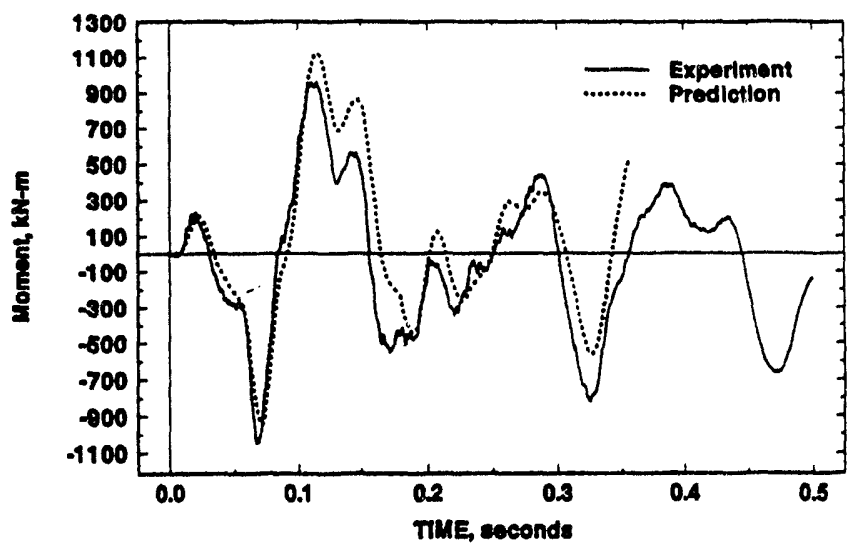

(a) horizontal

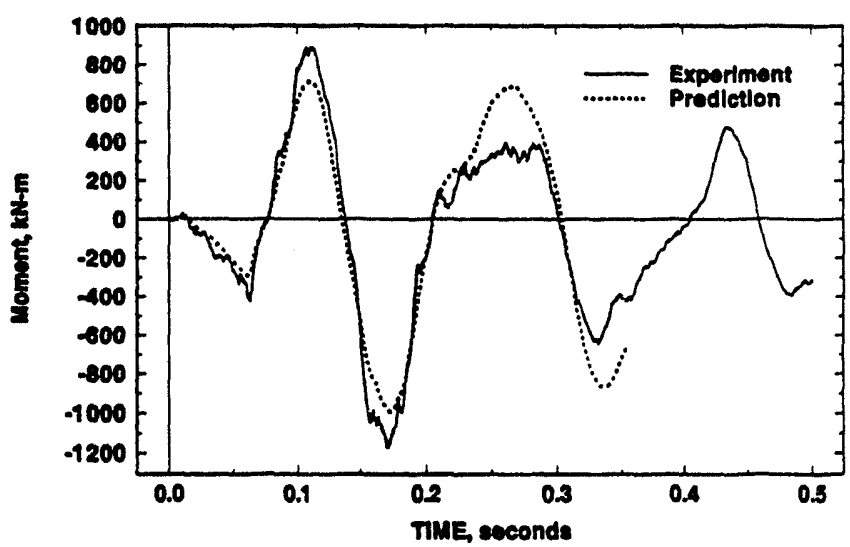

(b) vertical

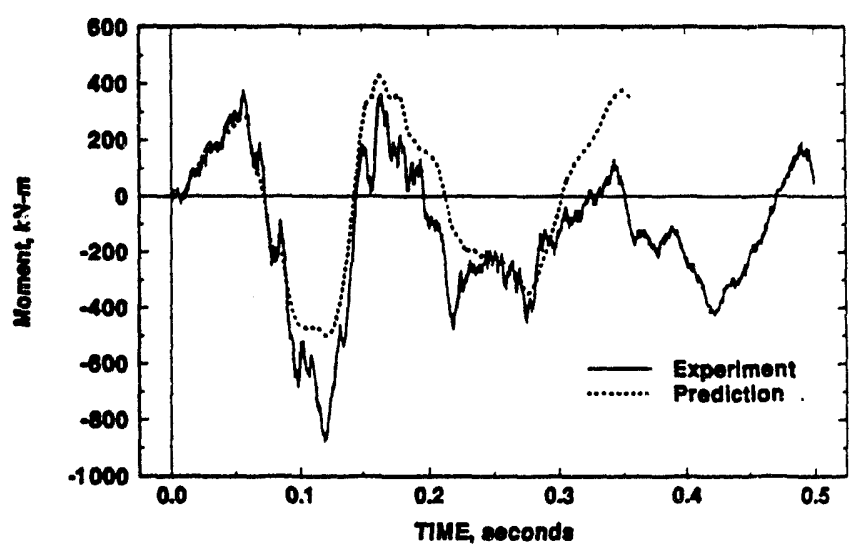

(c) torsion

Figure 6.8 Moments at Section Q91 (Element 194) for E31.2 (near the Fixed Point support) 


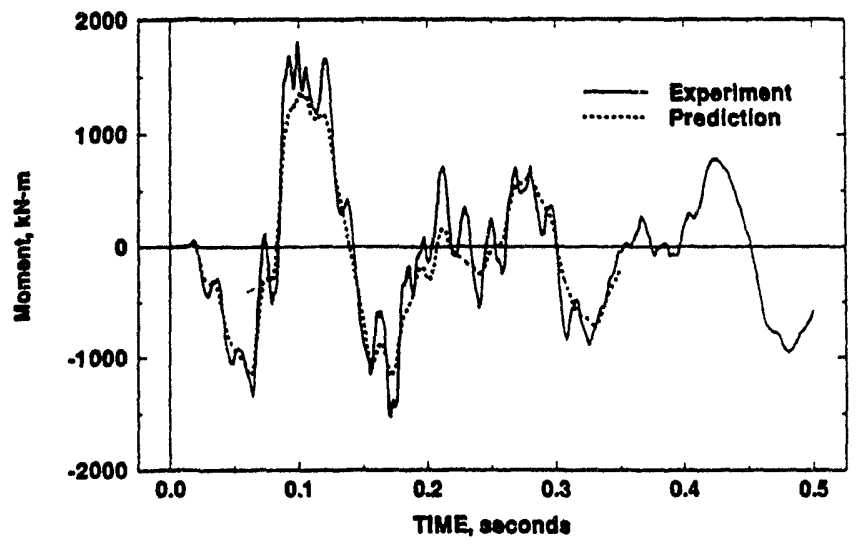

(a) horizontal

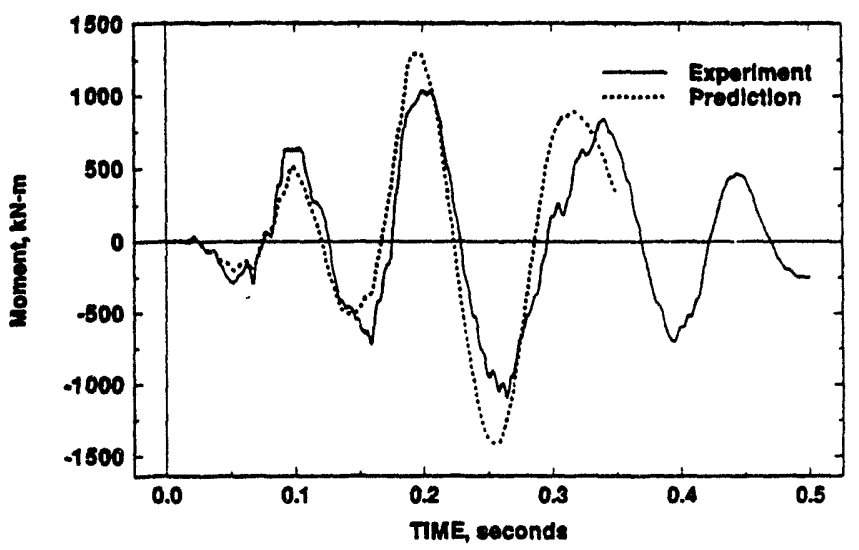

(b) vertical

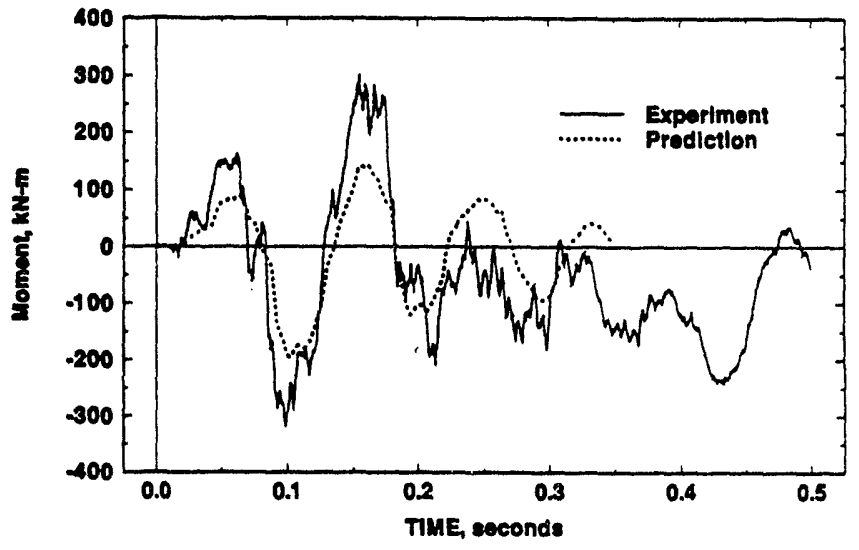

(c) torsion

Figure 6.9 Moments at Section Q02 (Element 20) for E31.3 (near the reactor pressure vessel) 


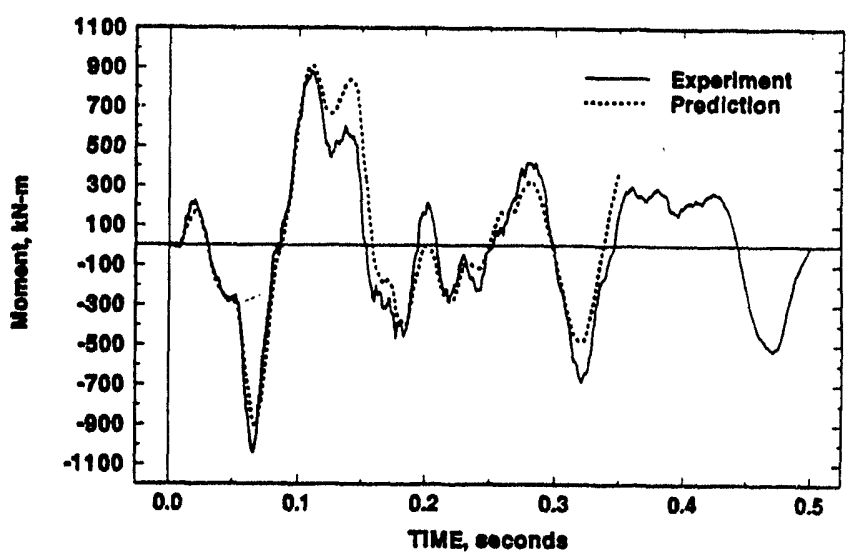

(a) horizontal

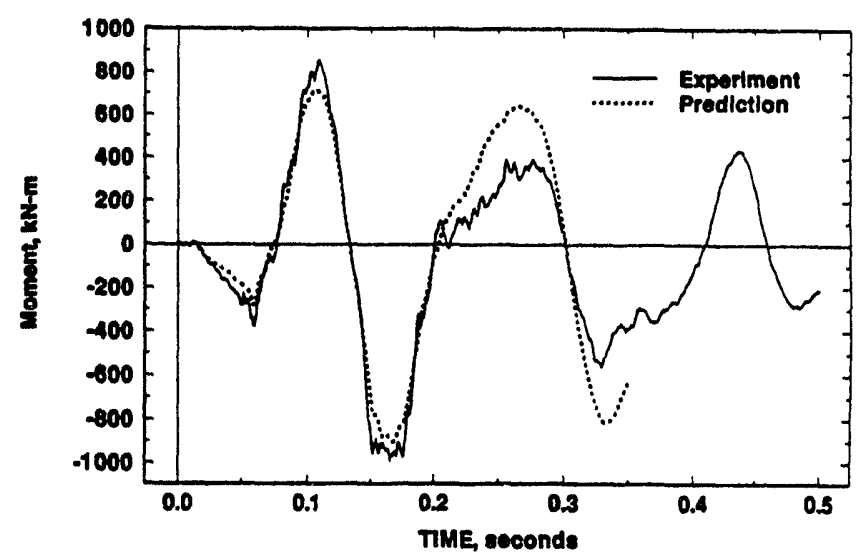

(b) vertical

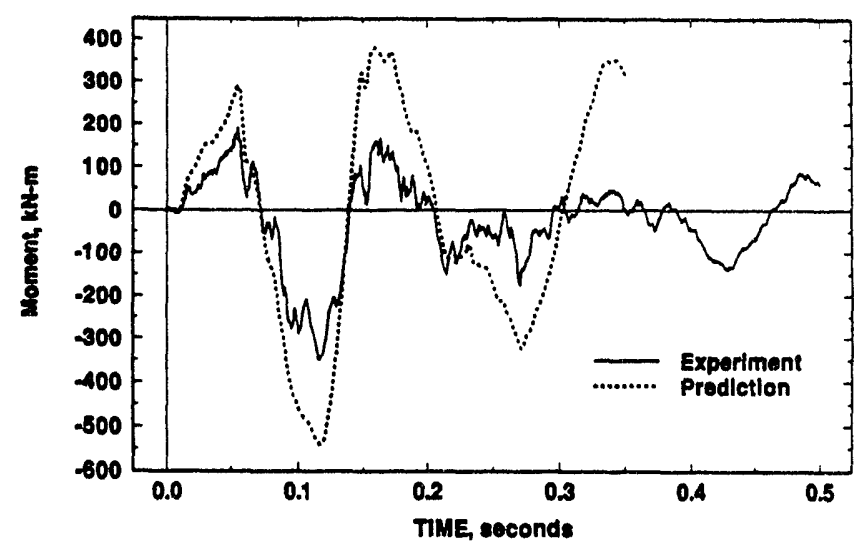

(c) torsion

Figure 6.10 Moments at Section Q91 (Element 194) for E31.3 (near the Fixed Point support) 


\section{SUMMARY, DISCUSSION, AND CONCLUSIONS}

The behavior of flawed piping under accident conditions is a major concern in the nuclear power industry, with significant resources devoted to developing and improving tools to predict such events. Simplified engineering methods have been developed as well as newer "state-of-the-art" fracture analysis methods. However, most of these analysis methods have only been validated with static experimental pipe fracture data. High-rate dynamic loading comparisons are rare because high-rate experimental data are scarce. Dynamic pipe loads are frequently classified as either repeating, i.e., seismic, or non-repeating (i.e., water hammer). Seismic loading evaluations are being conducted within the NRC's IPIRG program, Ref. 7.1.

The Test Group E31 series, part of a study of the behavior of flawed piping subjected to dynamic loads in the HDR Safety Program (PHDR) Phase III conducted by the Kernforschungszentrum Karlsruhe (KfK) in Germany, provided a unique opportunity to validate analytical and computational methods used in predicting the behavior of flawed piping. Argonne National Laboratory and Battelle have jointly conducted a research program for the USNRC to evaluate the ability of current engineering and a state-of-the-art analysis methods to predict the behavior of the E31 water-hammer experiments.

\subsection{Summary}

In this report, five major subjects were addressed. A brief summary of the important points is:

Review of Current Engineering Fracture Mechanics Analyses. The important concepts and equations for Net-Section-Collapse, ASME Section XI, Dimensionless Plastic-Zone Parameter, R6 Revision 3 Option 1, J-Estimation Scheme, and J/T and Energy Balance Stability engineering fracture methods were defined.

Description of the State-of-the-Art Fracture Analysis Method. The nonlinear-spring model of flawed piping was described in detail, as were three major advances in nonlinear FEA fracture analysis; modeling of crack behavior past maximum moment, surface-crack to throughwall-crack transition modeling, and modeling of cyclic ductile tearing with reinitiation. This involved validation with data from other programs. A noteworthy aspect, is that for the first time dynamic crack growth during a pipe instability test was modeled.

Description of the HDR-E31 Experiments. A very detailed description of the HDR-E31 test system geometry, boundary conditions, pipe system materials, loading, and test section flaws and material properties was presented.

Predictions of the HDR-E31 Experiments. Structural response and flaw behavior predictions for the HDR-E31 experiments were presented. The structural response predictions included static, modal, and dynamic linear analyses. Engineering method flaw behavior predictions were made using Net-Section-Collapse, ASME Section XI, Dimensionless Plastic-Zone 
Parameter, R6, and J-estimation scheme analyses. Nonlinear FEA fracture analysis was also used to predicted the experimental behavior.

Comparison of the Predictions and the Experiments. The structural and fracture behavior of the experiments was compared with the predictions. In general, the static, eigenvalue, and global dynamic predicted responses were slightly stiffer, but quite similar, to the measured behavior. All of the engineering fracture mechanics analyses, by virtue of the finite element analysis overestimating the applied moments and/or the fracture analysis underestimating the moment capacity suggested that both E31 surface cracks would penetrate the pipe wall and that the resulting through-wall cracks would be unstable. The nonlinear FEA fracture analysis indicated that both flaws would penetrate the pipe wall and that the through-wall cracks would propagate and then arrest. The behavior observed in the experiments was that the E31.3 flaw did penetrate the wall and then arrest, whereas the E31.2 flaw did not grow enough to penetrate the wall.

\subsection{Discussion}

\subsubsection{Accuracy of the Elastic Stress Analysis}

The accuracy of the elastic stress analysis was determined by dividing the moment from the elastic analysis by the experimentally determined moment at the crack location. Table 7.1 gives the ratio of the moment from the elastic stress analysis to the experimentally determined moment. In examining the results in Table 7.1, it can be seen that the moment ratio was greater than one, but less than 1.5. This suggests that the linear analysis overpredicts the moment. The moment ratios for the HDR-E31 tests are far less that the ratio of 15 to $\mathbf{3 0}$ observed in the EPRI/NRC Piping and Fitting Dynamic Reliability program on uncracked pipe, Ref. 7.2, but are close to the resuits observed in the IPIRG-1 Subtask 1.1 pure inertial loading experiments, and the IPIRG-1 pipe system experiments, Ref. 7.1. (Note, the precise manner of calculating the elastic stress analysis moment (or stress) ratio differed slightly between this program, the IPIRG-1 program, and the EPRI/NRC Piping and Fitting Dynamic Reliability program, but it is expected that they would give the same order of magnitude.)

The obvious question here is why do these different programs have different moment or stress ratios. To assess this, the following specific differences must be recognized.

First in the IPIRG-1 program, there were large cracks put in the piping system, so that the failure loads would be near, or below, yield in the uncracked pipe. Furthermore, the pipe system was mostly made from a high strength material so that it would behave elastically and hence, reuseable for multiple tests. Consequently, nonlinear behavior was limited to just the crack plane and elastic stress analysis did a reasonable job of calculating the stresses. Hence, the low elastic stress to experimental stress ratio was an artifact of the large flaws used and the higher strength pipe loop materials.

Secondly, for the EPRI/NRC Piping Reliability Program, there were no cracks in the piping system, so the loads were very high. The stress ratio in this EPRI program was the ratio of 
the elastically calculated stresses to the ASME code maximum allowable stresses, i.e., $3 S_{m}$ or $2 S_{y}$. The ASME stress indices at elbows, for instance, greatly increases the calculated elastic stresses. Here, the material was either A106 B or TP304 stainless steel, both having a low yield to ultimate strength ratio. Hence, the high ratios were due to no cracks being present, and the denominator in the stress ratio being the ASME Section III maximum allowable value rather than the actual stress.

Finally, for the HDR E31 experiments, the cracks were much smaller than the IPIRG-1 program pipe system cracks, but the material used had a much higher yield to ultimate strength ratio. Additionally, the cracked pipe section was a reduced thickness section of pipe (16-mm [0.630 inch] versus $25-\mathrm{mm}$ [ 1.0 inch] thick), so fracture occured at nominal stresses slightly above yield everywhere but in the cracked pipe section. Hence, the stress ratio for the elastic stress analysis in the HDR E31 experiments was similar in magnitude to the IPIRG-1 stress ratios.

Experiments with smaller cracks in pipe systems with low yield to ultimate strength piping (typical of U.S. materials), where yielding may occur other than at the crack section, have yet to be done. This is in part due to the expense of having to replace the pipe loop (or major portions of it) in every test. Hence, the margin in elastic stress analysis that might exist under higher stresses for shorter cracks has not been assessed experimentally by any of these programs. This could be assessed analytically, to some degree, with the capabilities developed in this and the IPIRG programs. This may be a more important issue with the potential changes to ASME Section III that propose to increase the maximum elastic design stresses from $3 \mathrm{~S}_{\mathrm{m}}$ to $4.5 \mathrm{~S}_{\mathrm{m}}$.

\subsubsection{Accuracy of the Fracture Analyses}

The inherent accuracy in the various fracture analyses was calculated by dividing the maximum moment in the experiment by the predicted maximum moment. This accuracy may be thought of as the margin on the pipe to resist fracture, whereas the elastic stress analysis ratio may be thought of as a margin on the stress or crack driving force. Table 7.2 summarizes the fracture prediction margins for the HDR-E31 experiments using the various engineering fracture analysis methodologies.

From Table 7.2, the following observations can be made about the various analyses.

- The Net-Section-Collapse analysis predicted load was 20 percent higher than the experimental loads. This is because the toughness is sufficiently low enough with the higher strength material and the reasonably large pipe diameter, that elastic-plastic failure is a possibility.

- The ASME Section XI flaw evaluation procedures for ferritic piping (IWB-3650) using the Code values of $S_{m}$ and Section XI flaw size definition, has the highest fracture ratio, i.e., it is the most conservative of all the analyses used. This fracture ratio does not include the ASME Code applied safety margins of 2.78 for normal and test conditions or 1.39 for emergency and faulted conditions. Inclusion of these factors would further increase the conservatism for this method. This large fracture ratio for the ASME 
Ferritic Pipe Flaw Evaluation criteria is consistant with past results in the IPIRG-1 and Degraded Piping Programs.

- The Dimensionless Plastic-Zone Parameter analysis is one of the simplest means of modifying the Net-Section-Collapse analysis for elastic-plastic fracture considerations. The fracture ratio was slightly greater than 1.0 for the two experiments, showing this method was slightly conservative in predicting the maximum moments.

- The R6 Revision 3. Option 1 analysis overpredicted the experimental failure stresses for Experiment E31.2 and underpredicted the failure moment for Experiment E31.3. Generally, the R6 Option 1 method underpredicts the failure stresses. Hence, the overpredicted load for Experiment E31.2 was surprising.

Note, that in our analysis, it was assumed that all the stresses were primary stresses. This is consistant with the R6 approach which would classify global secondary stresses like thermal expansion and seismic anchor motion stresses as primary stresses.

- The SC.TNP J-estimation analysis tended to give values which slightly underpredict the maximum load for both experiments. The predicted maximum moments are very close to the DPZP values.

A common thread with all these predictions was that the fracture ratios were lower for Experiment E31.2 than for Experiment E31.3. In examining the experimental data, there is the discrepancy that the reported experimental moment is lower for the shallower surface crack in Experiment E31.2. This fact, along with the applied dynamic forces being about 10 percent higher in Experiment E31.3 than Experiment E31.2, raises the question of the accuracy of the experimental moment data. MPA has indicated that they experienced some unexpected plasticity and failure of a strain gage in Experiment E31.3, and that they have done their best to adjust what data they have to estimate the moment at the cracked section. Assuming the MPA adjustment is correct, the only explanation for a lower maximum moment in the shallower E31.2 flaw is a difference in strength and/or material toughness between the two test sections.

\subsubsection{Limitations in Engineering Methods Stability Analyses}

The fully plastic $\mathrm{J} / \mathrm{T}$ and Energy Balance Stability analyses are quasi-static based analyses that assume that the loads remain essentially static during the fracture event. During the HDR-E31 experiments, the pipe pressure, after surface-crack penetration, does change and cause the loads to decrease at the crack. J/T and Energy Balance Stability analyses are also bending load driven formulations. An attempt has been made in the Energy Balance to incorporate the effect of the membrane stress by including a Net-Section-Collapse analysis pressure equivalent bending moment, but the legitimacy of handling the membrane stress this way has not been fully verified. In any event, neither of these stability analyses rigorously accounts for dynamics and membrane stresses.

Another limitation of the current quasi-static analyses is that they assume that there is no restraint of bending induced from the pressure loading. That is, virtually all piping fracture analyses assume the cracked sertions are free to rotate without restriction. In fact, in the HDR-E31 piping system and 
probably in most plant piping, the piping remote from the crack provides a significant restraint to free rotation of the cracked pipe section, thus making the through-wall crack much more stable than predicted by J/T or Energy Balance methods, although under normal operating conditions this restraint would reduce the crack opening and the subsequent leakage. Figure 7.1 shows an analytical assessment of the effect of restrained bending. Without induced bending from pressure loading, significantly longer flaws can be tolerated without failure. J/T and Energy Balance Stability analyses incorporate a piping system compliance feature, but in both cases, the piping system compliance is used to account for energy that could be used to drive the through-wall crack, rather than to incorporate bending restraint.

Two other aspects differentiate the J/T and Energy Balance Stability Analyses. First, the energy balance approach can predict not only the start of an instability, but also how far the crack may propagate. The $\mathrm{J} / \mathrm{T}$ analysis predicts only the start of an instability. The energy balance approach also can predict the surface to through-wall crack transition. Furthermore, under constant load or constant displacement conditions, the Energy Balance Stability Analysis was verified by dynamic FEA in this program. However, neither method can account for dynamically changing loads.

\subsubsection{Limitations in Nonlinear FEA Fracture Analysis Methods}

The nonlinear FEA fracture analysis method predicted the HDR-E31 experiments better than any of the engineering fracture analysis methods. The fact that so many of the first order effects in the fracture process and loading are an inherent part of the method accounts for the quality of the predictions. In spite of the superior accuracy of the nonlinear FEA fracture analysis, however, there are limitations that need to be mentioned.

First, there is the issue of the scaling factor on surface-crack moments. For this study, all of the SC.TNP J-estimation scheme moments, as stated in the list of assumptions, were scaled downward by a factor of 0.714 to account for the inherent conservatism in the method. The fact is, however, that some other scaling factor might be equally legitimate and may cause the analysis to be less accurate. For instance, a 1.0 scaling factor could be applied. Table 7.3 shows the effect on maximum moment that this assumption makes. Using the unscaled moment, neither of the E31 flaws would have been predicted to penetrate the pipe wall. The point is that the approach taken is acknowledged to be conservative, i.e., the maximum moment is the lowest of the options, and that the SC.TNP $J$-estimation scheme, although they are good, are not perfect.

The second limitation that must be acknowledged when the nonlinear FEA fracture analysis is evaluated is that the crack rotation data predicted by the SC.TNP J-estimation schemes has not been fully validated. The rotations are an essential element of the nonlinear FEA fracture analysis, because the crack is characterized as being nonlinear in moment-rotation coordinates. The amount of energy dissipated by the cracks in a dynamic analysis and crack growth are dominated by the rotations.

Most of the attention in the development of the SC.TNP J-estimation schemes has focussed on prediction of the initiation moment and the maximum moment. The rotations, on the other hand, have not been extensively evaluated, because there simply has not been a need and good experimental rotation data have not been routinely acquired in most pipe fracture experimental programs. With the emergence of the nonlinear FEA fracture analysis as a legitimate pipe fracture analysis tool, the need 
for accurate rotation predictions becomes apparent. The qualitative sense is that the SC.TNP Jestimation scheme predicted rotations are reasonably accurate, because of the good agreement found between nonlinear FEA fracture analyses and dynamic pipe system experiments. A systematic effort is required, however, to validate the predicted rotations. Such an effort is underway in the USNRC's Short Cracks in Piping and Piping Welds research program, Ref. 7.3, where improvements to the SC.TNP analysis and development of a new and independent finite-length circumferentially surfacecracked pipe J-estimation scheme are underway.

The final limitation of the nonlinear FEA fracture analyses is that surface-crack penetration is assumed to occur when the maximum moment is attained. The need to make this assumption is driven by limitations in the SC.TNP surface-crack J-estimation scheme; it has not been validated past maximum moment, and in fact, it frequently terminates the calculations just after maximum moment is predicted. As shown in Figure 7.2, surface cracks frequently experience some almost perfectly plastic displacement (rotation) after maximum moment, but before surface-crack penetration, and in fact the experiment in the Degraded Piping Program showed that the moment could be decreasing with increasing rotation during stable crack growth prior to surface-crack penetration. The J-estimation scheme crack growth estimates are consistent with this, in that the predicted radial crack growth estimates do not indicate growth through the wall at maximum moment. Assuming that surface-crack penetration occurs when the maximum moment is reached in the nonlinear FEA fracture analysis is conservative.

\subsubsection{The HDR-E31 Experiments as an Analysis Validation Tool}

The HDR-E31 water-hammer experiments are a very valuable data source for evaluating finite element and fracture analyses. Because the pipe system boundary conditions are very simple, finite element analysis results should compare very favorably with measured results. In fact, this has been demonstrated in this program. Concerning the fracture analysis, the loading on the flaws is only just adequate to achieve surface-crack penetration in the E31.3 experiment. Because of this, it is essential that the maximum moment, moment-rotation, and surface crack to through-wall-crack transition behavior be accurate, in addition to proper modeling of the basic system structural dynamics, to be able to make good predictions. If any of these elements of the analysis is not correctly modeled, the predictions will not match the experiments.

The marginal nature of the loading relative to the flaws became very apparent during the nonlinear FEA fracture analyses. The first analysis performed was for Experiment E31.3, the experiment with the deeper tlaw. It was apparent from the analysis results that the loading just barely caused the surface crack to penetrate the pipe wall. Having not examined the loading for the two different experiments closely, we assumed that they were identical, and thus expected that the E31.2 flaw would be predicted not to penetrate the pipe wall because of its higher moment-carrying capacity. In fact, the loading for E31.2 is different enough from E31.3 (and marginally larger) that it caused E31.2 to penetrate the pipe wall in our analysis. Thus, the subtle difference in the loading played a big role in the outcome of our analysis. 


\subsubsection{Other HDR-E31 Analysis Efforts}

The HDR-E31 experiments have been analyzed by other researchers. Brosi, et al., Ref. 7.4, performed extensive elastic and plastic global analysis of the piping system under static, modal, and dynamic loading. In general, he found reasonably good agreement between predictions and the global response in his plastic calculations. His elastic calculations, like ours, tend to be slightly stiffer than the measured values. Brosi modeled the crack in a separate 3-D brick element substructure analysis, using bending loads from the global structural analysis. Using approximately 2400 nodes and in excess of 400 elements, he predicted J-integral values along the crack front and predicted that the crack would initiate in Experiment E31.3 and grow only $0.5 \mathrm{~mm}(0.020 \mathrm{inch})$ radially, and that the crack would not even initiate in Experiment E31.2. Neither of these predictions was correct, and the error was on the nonconservative side. One of the interesting findings from Brosi is that $J$ along the crack front is not symmetric with respect to the centerline of the crack. The moment at 90 -degrees to the principal bending plane causes this.

Kussmaul, et al., Ref. 7.5, also did extensive finite element analysis of the global behavior of the system and found good agreement with the measured values. Like our nonlinear FEA fracture analysis n.odel, Kussmaul, et al., included the crack directly in their finite element piping system, after they had completed a series of uncracked piping analyses. In their case, shell elements and ABAQUS l'ne-spring elements were used to model the crack. Their cracked pipe analyses showed that the Experiment E31.2 crack would initiate. Experiment E31.3 was problematic for them because compression loading of the crack prior to the large crack-opening moment caused the line-spring elements to cease correctly evaluating J. Kussmaul et al., also did a 3D-brick substructure analysis of the crack area and essentially duplicated Brosi's asymmetric J behavior.

It is interesting to note that neither of the other researchers that have analyzed the E31 experiments have predicted the behavior as accurately as the nonlinear FEA fracture method that we have used. This is especially significant in light of the fact that Kussmaul, et al. indicates that CRAY2 supercomputers were used in both Brosi's and their work, and that several investigations had to be abandoned because costs were getting unmanageable. Our analyses were easily performed on a small Apollo DN5500 work station, basically a desk-top computer.

\subsection{Conclusions}

A great deal of effort has been spent in this program to evaluate current engineering fracture analysis methods and to advance the state-of-the-art in predicting pipe fracture behavior. From the work done in this study, the following conclusions can be made:

- The magnitudes of the maximum moments tend to be underpredicted for all analysis methods except the Net-Section-Collapse for both experiments and the R6 Option 1 analysis for Experiment E31.2.

- The engineering fracture methods combined with linear FEA is conservative. 
- The nonlinear FEA fracture analysis, in spite of its relative simplicity when compared with 3-D brick and shell models of cracks, does a good job of predicting crack behavior, and was extended to being able to make crack velocity predictions and the transition from a surface crack to a through-wall crack.

- The nonlinear FEA fracture analysis is the only method that currently can be used to assess the propensity for a DEGB, i.e., growth and possible arrest of the through-wall crack after surface-crack penetration.

- For the HDR-E31 experiments, slight changes in assumptions, i.e., the "equivalent" water-hammer road, or the J-estimation scheme scaling factor, could have a large impact on the margin between predictions and the experiments.

- Although "best engineering" practice was used to calculate the experimental moment for E31.3, the data are counter intuitive because the shallower E31.2 flaw has been reported to have a lower maximum moment than in Experiment E31.3. The only other explanation is differences in strength and toughness between the two flawed pipe sections in the E31.2 and E31.3 experiments.

\subsection{References}

7.1 R. A. Schmidt, G. M. Wilkowski, and M. Mayfield, "The International Piping Integrity Research Group (IPIRG) Program-An Overview", SMiRT-11 Proceedings, August 1991, Paper G23/1.

7.2 DeVita, V., "Seismic Fragility Pipe Testing", Transactions of 10th SMiRT Ccnference, Volume S, August 1989, pp. 81-86.

7.3 Wilkowski, G., et al, "Short Cracks in Piping and Welds, Semiannual Progress Report April 1992 - September 1992", NUREG/CR-4599, Vol 3 No 1, June 1993.

7.4 Brosi, S., et al, "Precracked Pipe Under Waterhammer Action", Transactions of 12th SMiRT Conference, Volume G, August 1993, pp. $405-410$.

7.5 Kussmaul, K., et al, "Leak-Before-Break Behavior of a Piping System DN 425 Subjected to Transient Loading by Water Hammer", Transactions of 12th SMiRT Conference, Volume G, August 1993, pp. 399-404.

7.6 Wilkowski, G. M., and others, "Degraded Piping Program - Phase II", Seventh Program Report, October 1987-December 1988, by Battelle Columbus Laboratories, NUREG/CR-4082, Vol. 7, March 1989. 
Table 7.1 Elastic stress analysis moment ratio at maximum moment for the HDR-E31 experiments

\begin{tabular}{|c|c|}
\hline Experiment & $\begin{array}{c}\text { Moment Ratio } \\
\text { (prediction/experiment) }\end{array}$ \\
\hline E31.2 & 1.38 \\
\hline E31.3 & 1.18 \\
\hline
\end{tabular}

Table 7.2 Experiment/predicted maximum moments for the HDR-E31 experiments

\begin{tabular}{|l|c|c|}
\hline \multicolumn{1}{|c|}{ Method } & Experiment/Predicted Maximum Moments \\
\cline { 2 - 3 } & E31.2 & E31.3 \\
\hline NSC & 0.78 & 0.90 \\
(NP-192) & & \\
\hline $\begin{array}{l}\text { ASME Sec XI } \\
\text { (IWB-3650) } \\
\text { A508 Cl 3, Sec. II flaw }\end{array}$ & 1.95 & 2.40 \\
\hline $\begin{array}{l}\text { R6, Rev 3, Option 1 } \\
\text { DPZP screening criterion }\end{array}$ & 0.84 & 1.06 \\
\hline J-estimation scheme analysis & 1.09 & 1.26 \\
\hline
\end{tabular}

Table 7.3 SC.TNP predicted maximum moments for HDR-E31 experiments

\begin{tabular}{|c|c|c|}
\hline & $\begin{array}{c}\text { E31.2 } \\
\text { Maximum Moment, } \\
\text { MN-m* }\end{array}$ & $\begin{array}{c}\text { E31.3 } \\
\text { Maximum Moment, } \\
\text { MN-m* }\end{array}$ \\
\hline Unscaled & 1.587 & 1.489 \\
\hline Scaled* & 1.138 & 1.063 \\
\hline
\end{tabular}

* $\quad 1.0 \mathrm{MN}-\mathrm{m}=8.85 \times 10^{6} \mathrm{in}-\mathrm{lb}$.

** Unscaled 0.714 based on past experimental data. 


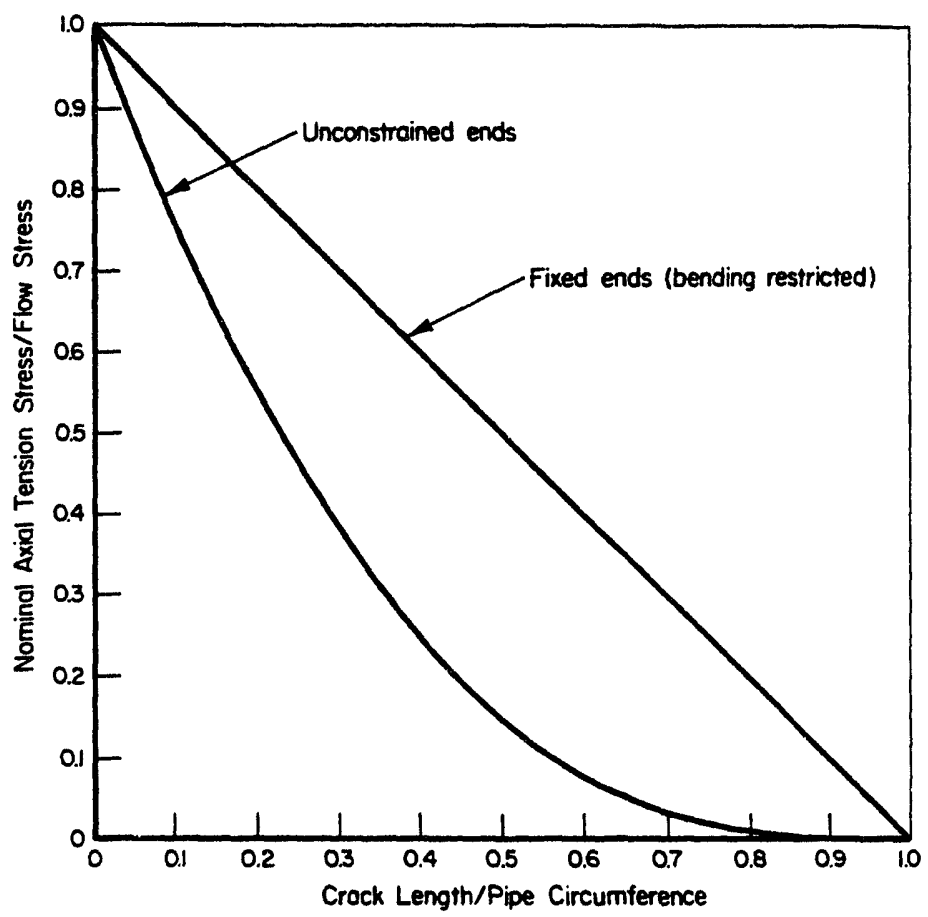

Figure 7.1 Net-Section-Collapse analysis predictions, with and without considering induced bending effects for through-wall cracks

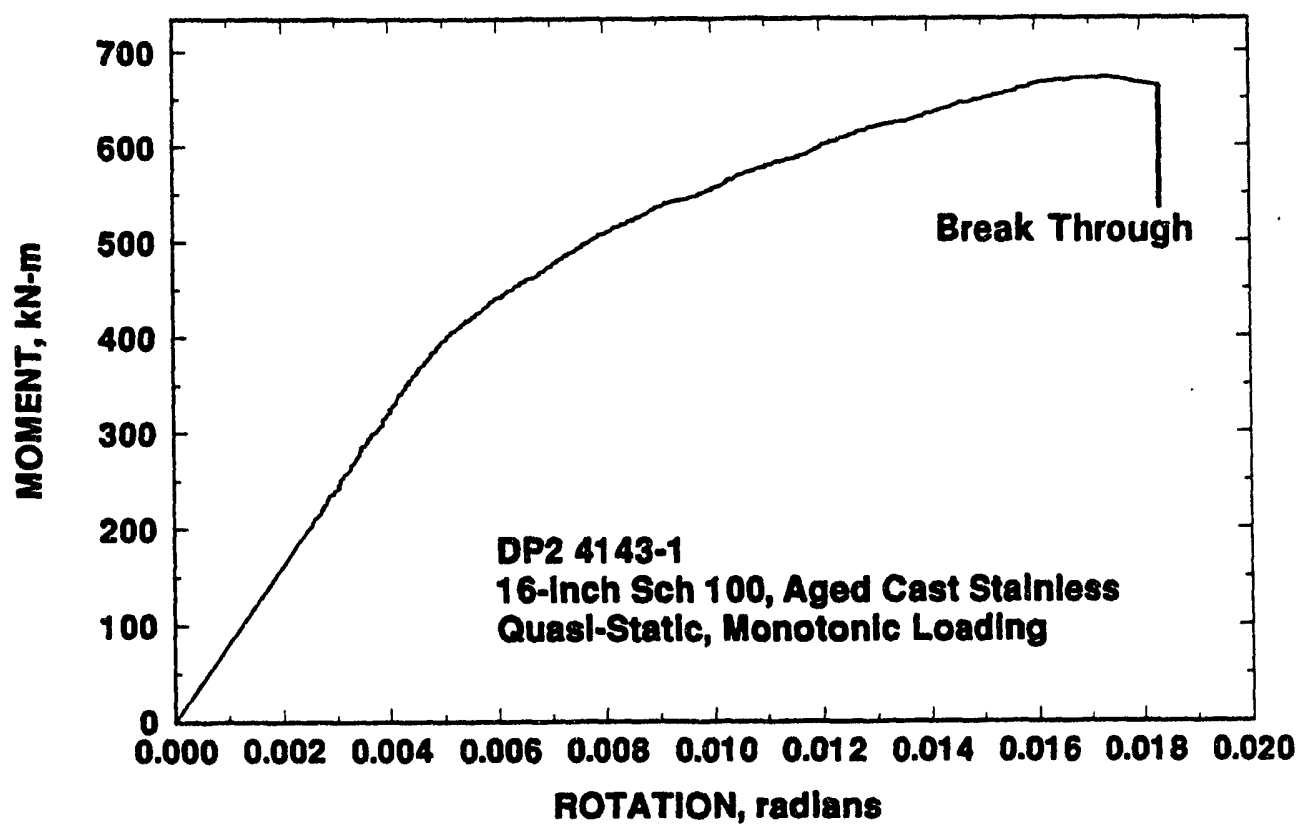

Figure 7.2 Experimental surface crack moment-displacement behavior showing the difference between maximum moment and surface crack penetration (From Ref. 7.6) 


\section{APPENDIX A}

HDR-E31 Finite Element Details 
Table A1. Material Property Data

\begin{tabular}{|c|c|c|c|}
\hline Material Property & Units & $20 \mathrm{C}$ & $200 \mathrm{C}$ \\
\hline \multicolumn{4}{|c|}{ Material 120 NiMoCr 36} \\
\hline Elastic Modulus & GPa & 185.0 & 185.0 \\
\hline Poisson's Ratio & & 0.285 & 0.285 \\
\hline Coefficient of & $1 / K$ & $12.9 \mathrm{E}-06$ & $12.9 \mathrm{E}-06$ \\
\hline Thermal Expansion & & & \\
\hline Density & $\mathbf{M g} / \mathrm{m}^{3}$ & 7.84 & 7.84 \\
\hline \multicolumn{4}{|l|}{ Material 2 GS C 25 u.a. } \\
\hline Elestic Modulus & $\mathbf{G P 2}$ & 200.0 & 200.0 \\
\hline Poisson's Ratio & & 0.285 & 0.285 \\
\hline Coefficient of & $1 / K$ & $13.1 \mathrm{E}-06$ & 13.1E-06 \\
\hline $\begin{array}{l}\text { Thermal Expansion } \\
\text { Density * }\end{array}$ & $\mathrm{Mg} / \mathrm{m}^{3}$ & 0 & \\
\hline & & 0 & 0 \\
\hline $\begin{array}{l}\text { Elastic Modulus } \\
\text { Poisson's Ratio }\end{array}$ & GPa & $\begin{array}{l}210.0 \\
0.285\end{array}$ & 198.0 \\
\hline $\begin{array}{l}\text { Poisson's Ratio } \\
\text { Coefficient of }\end{array}$ & & $\begin{array}{r}0.285 \\
12.8 \mathrm{E}-06\end{array}$ & 0.285 \\
\hline $\begin{array}{l}\text { Coefficient of } \\
\text { Thermal Expansion }\end{array}$ & $1 / K$ & $12.8 \mathrm{E}-06$ & $12.8 \mathrm{E}-06$ \\
\hline Density & $\mathrm{Mg} / \mathrm{m}^{3}$ & 7.84 & 7.84 \\
\hline \multicolumn{4}{|l|}{ Material $415 \mathrm{MnNi} 63$} \\
\hline Elastic Modulus & $\mathbf{G P a}$ & 211.0 & 199.0 \\
\hline Poisson's Ratio & & 0.285 & 0.285 \\
\hline Coefficient of & $1 / K$ & $12.9 \mathrm{E}-06$ & $12.9 \mathrm{E}-06$ \\
\hline $\begin{array}{l}\text { Thermal Expansion } \\
\text { Density }\end{array}$ & & & \\
\hline Density & $\mathrm{Mg} / \mathrm{m}^{3}$ & 7.84 & 7.84 \\
\hline \multicolumn{4}{|c|}{ Material 520 MnMoNi 55} \\
\hline Elastic Modulus & GPa & 211.0 & 199.0 \\
\hline Poisson's Ratio & & 0.285 & 0.285 \\
\hline Coefficient of & $1 / \mathrm{K}$ & $13.2 \mathrm{E}-06$ & $13.2 \mathrm{E}-06$ \\
\hline $\begin{array}{l}\text { Thermal Expansion } \\
\text { Density }\end{array}$ & $\mathrm{Mo} / \mathrm{m}^{3}$ & & \\
\hline Density & $\mathbf{M g} / \mathbf{m}^{3}$ & 7.84 & 7.84 \\
\hline \multicolumn{4}{|l|}{ Material 615 Mo 3} \\
\hline Elastic Modulus & $\mathbf{G P a}$ & 213.0 & 202.0 \\
\hline Poisson's Ratio & & 0.285 & 0.285 \\
\hline Coefficient of & $1 / K$ & $13.1 \mathrm{E}-06$ & $13.1 \mathrm{E}-06$ \\
\hline $\begin{array}{l}\text { Thermal Expansion } \\
\text { Density }\end{array}$ & $\mathrm{Mg} / \mathrm{m}^{3}$ & 7.85 & 7.85 \\
\hline
\end{tabular}

* Density of the check valve set to zero. Total mass of the check valve material applied as a point mass located at the center of mass. 
Table A2. Refined Model Geometry Data

\begin{tabular}{|c|c|c|c|c|c|c|}
\hline $\begin{array}{l}\text { Element } \\
\text { Number }\end{array}$ & $\begin{array}{c}\text { Global } \\
\text { Direction }\end{array}$ & Element Type & $\begin{array}{l}\text { Outside } \\
\text { Diameter } \\
\mathrm{mm}\end{array}$ & $\begin{array}{c}\text { Wall } \\
\text { Thickness } \\
\text { mm }\end{array}$ & $\begin{array}{c}\text { Element } \\
\text { Length } \\
\mathrm{mm}\end{array}$ & $\begin{array}{l}\text { Cummulative } \\
\text { Length } \\
\mathrm{mm}\end{array}$ \\
\hline \multicolumn{7}{|c|}{ RDB Wall, Material 1} \\
\hline 1 & $+\mathrm{X}$ & Straight Pipe & 1440 & 500.0 & 7.00 & 7 \\
\hline 2 & $+\mathrm{X}$ & Straight Pipe & 1440 & 500.0 & 27.00 & 34 \\
\hline 3 & $+\mathrm{X}$ & Straight Pipe & 1440 & 500.0 & 27.00 & 61 \\
\hline 4 & $+X$ & Straight Pipe & 1440 & 500.0 & 27.00 & 88 \\
\hline 5 & $+\mathrm{X}$ & Straight Pipe & 1440 & 500.0 & 27.00 & 115 \\
\hline 6 & $+x$ & Straight Pipe & 1440 & 500.0 & 27.00 & 142 \\
\hline \multicolumn{7}{|c|}{ Nozzle, Material 1} \\
\hline 7 & $+X$ & Straight Pipe & 660 & 111.0 & 25.00 & 167 \\
\hline 8 & $+\mathbf{X}$ & Straight Pipe & 660 & 111.0 & 25.00 & 192 \\
\hline 9 & $+\mathrm{X}$ & Straight Pipe & 660 & 111.0 & 25.00 & 217 \\
\hline 10 & $+\mathrm{X}$ & Straight Pipe & 660 & 111.0 & 25.00 & 242 \\
\hline 11 & $+\mathrm{X}$ & Straight Pipe & 660 & 111.0 & 25.00 & 267 \\
\hline 12 & $+\mathrm{X}$ & Straight Pipe & 660 & 111.0 & 25.00 & 292 \\
\hline 13 & $+x$ & Straight Pipe & 596 & 78.5 & 27.00 & 319 \\
\hline 14 & $+x$ & Straight Pipe & 596 & 78.5 & 25.00 & 344 \\
\hline 15 & $+\mathrm{X}$ & Straight Pipe & 596 & 78.5 & 25.00 & 369 \\
\hline 16 & $+\mathrm{X}$ & Stunight Pipe & 529 & 38.2 & 19.00 & 388 \\
\hline 17 & $+X$ & Straight Pipe & 529 & 38.2 & 20.00 & 408 \\
\hline 18 & $+X$ & Straight Pipe & 529 & 38.2 & 19.00 & 427 \\
\hline \multicolumn{7}{|c|}{ Reducer, Material 3} \\
\hline 19 & $+x$ & Straight Pipe & 518 & 32.5 & 19.00 & 446 \\
\hline 20 & $+x$ & Straight Pipe & 518 & 32.5 & 20.00 & 466 \\
\hline 21 & $+X$ & Straight Pipe & 518 & 32.5 & 19.00 & 485 \\
\hline 22 & $+x$ & Straight Pipe & 498 & 29.3 & 25.00 & 510 \\
\hline 23 & $+\mathrm{X}$ & Straight Pipe & 498 & 29.3 & 25.00 & 535 \\
\hline 24 & $+X$ & Straight Pipe & 476 & 26.0 & 12.00 & 547 \\
\hline 25 & $+x$ & Straight Pipe & 476 & 26.0 & 22.00 & 569 \\
\hline 26 & $+x$ & Straight Pipe & 476 & 26.0 & 22.00 & 591 \\
\hline 27 & $+X$ & Straight Pipe & 476 & 26.0 & 20.00 & 611 \\
\hline 28 & $+x$ & Straight Pipe & 476 & 26.0 & 20.00 & 631 \\
\hline \multicolumn{7}{|c|}{ Test Section, Material 5} \\
\hline 29 & $+\mathrm{X}$ & Straight Pipe & 476 & 26.0 & 28.00 & 659 \\
\hline 30 & $+x$ & Straight Pipe & 475 & 25.0 & 28.00 & 687 \\
\hline 31 & $+x$ & Straight Pipe & 475 & 25.0 & 27.00 & 714 \\
\hline 32 & $+x$ & Straight Pipe & 475 & 25.0 & 27.00 & 741 \\
\hline 33 & $+x$ & Straight Pipe & 475 & 25.0 & 15.00 & 756 \\
\hline 34 & $+x$ & Straight Pipe & 457 & 16.0 & 10.00 & 766 \\
\hline 35 & $+x$ & Straight Pipe & 457 & 16.0 & 10.00 & 776 \\
\hline 36 & $+x$ & Straight Pipe & 457 & 16.0 & 10.00 & 786 \\
\hline 37 & $+\mathrm{X}$ & Straight Pipe & 457 & 16.0 & 10.00 & 796 \\
\hline 38 & $+x$ & Straight Pipe & 457 & 16.0 & 10.00 & 806 \\
\hline
\end{tabular}


Table A2. Refined Model Geometry Data (continued)

\begin{tabular}{|c|c|c|c|c|c|c|}
\hline $\begin{array}{l}\text { Element } \\
\text { Number }\end{array}$ & $\begin{array}{c}\text { Global } \\
\text { Direction }\end{array}$ & Element Type & $\begin{array}{c}\text { Outside } \\
\text { Diameter } \\
\text { mm }\end{array}$ & $\begin{array}{c}\text { Wall } \\
\text { Thickness } \\
\text { mm }\end{array}$ & $\begin{array}{l}\text { Element } \\
\text { Loogth } \\
\text { mm }\end{array}$ & $\begin{array}{l}\text { Cummulative } \\
\text { Length } \\
\text { mm }\end{array}$ \\
\hline 39 & $+\bar{X}$ & Straight Pipe & 457 & 16.0 & 10.00 & 816 \\
\hline 40 & $+X$ & Straight Pipe & 457 & 16.0 & 10.00 & 826 \\
\hline 41 & $+X$ & Straight Pipe & 457 & 16.0 & 10.00 & 836 \\
\hline 42 & $+X$ & Straight Pipe & 457 & 16.0 & 10.00 & 846 \\
\hline 43 & $+x$ & Straight Pipe & 457 & 16.0 & 10.00 & 856 \\
\hline 999 & $+X$ & Nonlinear $\mathbf{M} \phi$ & & & 0.00 & 856 \\
\hline 44 & $+X$ & Straight Pipe & 457 & 16.0 & 10.00 & 866 \\
\hline 45 & $+X$ & Straight Pipe & 457 & 16.0 & 10.00 & 876 \\
\hline 46 & $+X$ & Straight Pipe & 457 & 16.0 & 10.00 & 886 \\
\hline 47 & $+X$ & Straight Pipe & 457 & 16.0 & 10.00 & 896 \\
\hline 48 & $+x$ & Straight Pipe & 457 & 16.0 & 10.00 & 906 \\
\hline 49 & $+x$ & Straight Pipe & 457 & 16.0 & 10.00 & 916 \\
\hline 50 & $+X$ & Straight Pipe & 457 & 16.0 & 10.00 & 926 \\
\hline 51 & $+X$ & Straight Pipe & 457 & 16.0 & 10.00 & 936 \\
\hline 52 & $+X$ & Straight Pipe & 457 & 16.0 & 10.00 & 946 \\
\hline 53 & $+X$ & Straight Pipe & 457 & 16.0 & 10.00 & 956 \\
\hline 54 & $+X$ & Straight Pipe & 457 & 16.0 & 15.00 & 971 \\
\hline 55 & $+X$ & Straight Pipe & 475 & 25.0 & 27.00 & 998 \\
\hline 56 & $+X$ & Straight Pipe & 475 & 25.0 & 27.00 & 1025 \\
\hline 57 & $+x$ & Straight Pipe & 475 & 25.0 & 28.00 & 1053 \\
\hline 58 & $+\mathrm{X}$ & Straight Pipe & 475 & 25.0 & 28.00 & 1081 \\
\hline \multicolumn{7}{|c|}{ Horizontal Straight Pipe Section, Material 4} \\
\hline 59 & $+x$ & Straight Pipe & 475 & 25.0 & 41.00 & 1122 \\
\hline 60 & $+\mathrm{X}$ & Straight Pipe & 475 & 25.0 & 100.00 & 1222 \\
\hline 61 & $+X$ & Straight Pipe & 475 & 25.0 & 54.00 & 1276 \\
\hline 62 & $+x$ & Straight Pipe & 475 & 25.0 & 55.00 & 1331 \\
\hline 63 & $+x$ & Straight Pipe & 475 & 25.0 & 41.00 & 1372 \\
\hline 64 & $+X$ & Straight Pipe & 475 & 25.0 & 200.00 & 1572 \\
\hline 65 & $+X$ & Straight Pipe & 475 & 25.0 & 200.00 & 1772 \\
\hline 66 & $+x$ & Straight Pipe & 475 & 25.0 & 200.00 & 1972 \\
\hline 67 & $+\mathbf{X}$ & Straight Pipe & 475 & 25.0 & 200.00 & 2172 \\
\hline 68 & $+\mathbf{X}$ & Straight Pipe & 475 & 25.0 & 200.00 & 2372 \\
\hline 69 & $+\mathbf{X}$ & Straight Pipe & 475 & 25.0 & 200.00 & 2572 \\
\hline 70 & $+X$ & Straight Pipe & 475 & 25.0 & 200.00 & 2772 \\
\hline 71 & $+X$ & Straight Pipe & 475 & 25.0 & 200.00 & 2972 \\
\hline 72 & $+\mathrm{X}$ & Straight Pipe & 475 & 25.0 & 200.00 & 3172 \\
\hline 73 & $+X$ & Straight Pipe & 475 & 25.0 & 200.00 & 3372 \\
\hline 74 & $+x$ & Straight Pipe & 475 & 25.0 & 200.00 & 3572 \\
\hline 75 & $+X$ & Straight Pipe & 475 & 25.0 & 200.00 & 3772 \\
\hline 76 & $+\mathbf{X}$ & Straight Pipe & 475 & 25.0 & 200.00 & 3972 \\
\hline 77 & $+X$ & Straight Pipe & 475 & 25.0 & 62.00 & 4034 \\
\hline 78 & $+X$ & Straight Pipe & 475 & 25.0 & 75.00 & 4109 \\
\hline 79 & $+X$ & Straight Pipe & 475 & 25.0 & 150.00 & 4259 \\
\hline
\end{tabular}


Table A2. Refined Model Geometry Data (continued)

\begin{tabular}{|c|c|c|c|c|c|c|}
\hline $\begin{array}{l}\text { Element } \\
\text { Number }\end{array}$ & $\begin{array}{c}\text { Global } \\
\text { Direction }\end{array}$ & Element Type & $\begin{array}{c}\text { Outside } \\
\text { Diameter } \\
\mathrm{mm}\end{array}$ & $\begin{array}{c}\text { Wall } \\
\text { Thickness } \\
\text { mm }\end{array}$ & $\begin{array}{c}\text { Elemeni } \\
\text { Length } \\
\mathrm{mm}\end{array}$ & $\begin{array}{l}\text { Cummulative } \\
\text { Length } \\
\mathrm{mm}\end{array}$ \\
\hline 80 & $+\mathrm{X}$ & Straight Pipe & 475 & 25.0 & 150.00 & 4409 \\
\hline 81 & $+X$ & Straight Pipe & 475 & 25.0 & 75.00 & 4484 \\
\hline 82 & $+\mathrm{X}$ & Straight Pipe & 475 & 25.0 & 58.00 & 4542 \\
\hline 83 & $+X$ & Straight Pipe & 475 & 25.0 & 62.00 & 4604 \\
\hline 84 & $+x$ & Straight Pipe & 475 & 25.0 & 62.00 & 4666 \\
\hline 85 & $+X$ & Straight Pipe & 475 & 25.0 & 62.00 & 4728 \\
\hline 86 & $+x$ & Straight Pipe & 475 & 25.0 & 62.00 & 4790 \\
\hline 87 & $+\mathbf{X}$ & Straight Pipe & 475 & 25.0 & 100.00 & 4890 \\
\hline 88 & $+X$ & Straight Pipe & 475 & 25.0 & 100.00 & 4990 \\
\hline 89 & $+X$ & Straight Pipe & 475 & 25.0 & 100.00 & 5090 \\
\hline 90 & $+x$ & Straight Pipe & 475 & 25.0 & 100.00 & 5190 \\
\hline 91 & $+x$ & Straight Pipe & 475 & 25.0 & 55.00 & 5245 \\
\hline 92 & $+x$ & Straight Pipe & 475 & 25.0 & 55.00 & 5300 \\
\hline \multicolumn{7}{|c|}{ Displacement Transducer MN 46XX } \\
\hline 93 & $+X$ & Straight Pipe & 475 & 25.0 & 24.00 & 5324 \\
\hline 94 & $+X$ & Straight Pipe & 475 & 25.0 & 24.00 & 5348 \\
\hline \multicolumn{7}{|c|}{ Elbow 1 , Material $5^{+X}$} \\
\hline 95 & $+X-Z$ & Elbow $\# 14^{\circ}$ & 489 & 29.6 & 544.00 & 5892 \\
\hline 96 & $+X-Z$ & Elbow $\# 14^{\circ}$ & 489 & 29.6 & 544.00 & 6436 \\
\hline \multicolumn{7}{|c|}{ Vertical Straight Pipe Section, Material 4} \\
\hline 97 & $-Z$ & Straight Pipe & 475 & 25.0 & 22.00 & 6458 \\
\hline 98 & $-\mathbf{Z}$ & Straight Pipe & 475 & 25.0 & 100.00 & 6558 \\
\hline 99 & $-\mathbf{Z}$ & Straight Pipe & 475 & 25.0 & 100.00 & 6658 \\
\hline 100 & $-\mathbf{Z}$ & Straight Pipe & 475 & 25.0 & 100.00 & 6758 \\
\hline 101 & $-\mathbf{Z}$ & Straight Pipe & 475 & 25.0 & 100.00 & 6858 \\
\hline 102 & $-\mathbf{Z}$ & Straight Pipe & 475 & 25.0 & 100.00 & 6958 \\
\hline 103 & $-\mathbf{Z}$ & Straight Pipe & 475 & 25.0 & 39.00 & 6997 \\
\hline 104 & $-\bar{z}$ & Straight Pipe & 475 & 25.0 & 69.00 & 7066 \\
\hline 105 & $-\mathbf{Z}$ & Straight Pipe & 475 & 25.0 & 100.00 & 7166 \\
\hline 106 & $-z$ & Straight Pipe & 475 & 25.0 & 100.00 & 7266 \\
\hline 107 & $-\bar{Z}$ & Straight Pipe & 475 & 25.0 & 69.00 & 7335 \\
\hline 108 & $-\mathbf{Z}$ & Straight Pipe & 475 & 25.0 & 75.00 & 7410 \\
\hline 109 & $-\bar{Z}$ & Straight Pipe & 475 & 25.0 & 100.00 & 7510 \\
\hline 110 & $-\mathbf{Z}$ & Straight Pipe & 475 & 25.0 & 100.00 & 7610 \\
\hline 111 & $-\mathbf{Z}$ & Straight Pipe & 475 & 25.0 & 100.00 & 7710 \\
\hline 112 & $-\mathbf{Z}$ & Straight Pipe & 475 & 25.0 & 75.00 & 7785 \\
\hline 113 & $-\bar{Z}$ & Straight Pipe & 475 & 25.0 & 75.00 & 7860 \\
\hline 114 & $-\mathbf{Z}$ & Straight Pipe & 475 & 25.0 & 250.00 & 8110 \\
\hline 115 & $-\mathbf{Z}$ & Straight Pipe & 475 & 25.0 & 250.00 & 8360 \\
\hline 116 & $-\bar{z}$ & Straight Pipe & 475 & 25.0 & 250.00 & 8610 \\
\hline 117 & $-\mathbf{Z}$ & Straight Pipe & 475 & 25.0 & 250.00 & 8860 \\
\hline 118 & $-\mathbf{Z}$ & Straight Pipe & 475 & 25.0 & 250.00 & 9110 \\
\hline 119 & $-z$ & Straight Pipe & 475 & 25.0 & 137.00 & 9247 \\
\hline
\end{tabular}


Table A2. Refined Model Geometry Data (continued)

\begin{tabular}{|c|c|c|c|c|c|c|}
\hline $\begin{array}{l}\text { Element } \\
\text { Number }\end{array}$ & $\begin{array}{c}\text { Global } \\
\text { Direction }\end{array}$ & Element Type & $\begin{array}{c}\text { Outside } \\
\text { Diameter } \\
\text { mm }\end{array}$ & $\begin{array}{c}\text { Wall } \\
\text { Thickness } \\
\text { mm }\end{array}$ & $\begin{array}{c}\text { Element } \\
\text { Length } \\
\mathrm{mm}\end{array}$ & $\begin{array}{l}\text { Cummulative } \\
\text { Length } \\
\mathrm{mm}\end{array}$ \\
\hline 120 & -2 & Straight Pipe & 475 & 25.0 & 84.00 & 9331 \\
\hline 121 & $-\mathbf{Z}$ & Straight Pipe & 475 & 25.0 & 250.00 & 9581 \\
\hline 122 & $-\mathbf{Z}$ & Straight Pipe & 475 & 25.0 & 250.00 & 9831 \\
\hline 123 & $-Z$ & Straight Pipe & 475 & 25.0 & 250.00 & 10081 \\
\hline 124 & $-\mathbf{Z}$ & Straight Pipe & 475 & 25.0 & 250.00 & 10331 \\
\hline 125 & $-\mathbf{Z}$ & Straight Pipe & 475 & 25.0 & 250.00 & 10581 \\
\hline 126 & $-\mathbf{Z}$ & Straight Pipe & 475 & 25.0 & 250.00 & 10831 \\
\hline 127 & $-\mathbf{Z}$ & Straight Pipe & 475 & 25.0 & 250.00 & 11081 \\
\hline 128 & $-\mathbf{Z}$ & Straight Pipe & 475 & 25.0 & 250.00 & 11331 \\
\hline \multicolumn{7}{|c|}{ U-Bend, Material 4} \\
\hline 129 & $-\mathbf{Z}$ & Straight Pipe & 475 & 25.0 & 82.00 & 11413 \\
\hline 130 & $-\mathbf{Z}$ & Straight Pipe & 475 & 25.0 & 50.00 & 11463 \\
\hline 131 & $-\mathbf{Z}$ & Straight Pipe & 475 & 25.0 & 25.00 & 11488 \\
\hline 132 & $-\mathbf{Z}$ & Straight Pipe & 475 & 25.0 & 25.00 & 11513 \\
\hline 133 & $-\mathbf{z}$ & Straight Pipe & 475 & 25.0 & 23.00 & 11536 \\
\hline 134 & $-\mathbf{Z}$ & Straight Pipe & 475 & 25.0 & 25.00 & 11561 \\
\hline 135 & $-z$ & Straight Pipe & 475 & 25.0 & 25.00 & 11586 \\
\hline 136 & $-\mathbf{z}$ & Straight Pipe & 475 & 25.0 & 50.00 & 11636 \\
\hline 137 & $-\mathbf{z}$ & Straight Pipe & 475 & 25.0 & 50.00 & 11686 \\
\hline 138 & $-\mathbf{Z}$ & Straight Pipe & 475 & 25.0 & 25.00 & 11711 \\
\hline 139 & $-\mathbf{Z}$ & Straight Pipe & 475 & 25.0 & 25.00 & 11736 \\
\hline 140 & $-\mathbf{Z}$ & Straight Pipe & 475 & 25.0 & 24.00 & 11760 \\
\hline \multicolumn{7}{|c|}{ Displacement Transducer MN 47XX } \\
\hline 141 & $-\mathbf{z}$ & Straight Pipe & 475 & 25.0 & 26.00 & 11786 \\
\hline 142 & $-\mathbf{Z}$ & Straight Pipe & 475 & 25.0 & 27.00 & 11813 \\
\hline 143 & $-Z-Y$ & Elbow $1245^{\circ}$ & 475 & 25.0 & 785.00 & 12598 \\
\hline 144 & $-Z \cdot Y$ & Elbow $\| 25^{\circ}$ & 475 & 25.0 & 785.00 & 13383 \\
\hline 145 & $-Y$ & Straight Pipe & 475 & 25.0 & 100.00 & 13483 \\
\hline 146 & $-\mathbf{Y}$ & Straight Pipe & 475 & 25.0 & 100.00 & 13583 \\
\hline 147 & $-Y$ & Straight Pipe & 475 & 25.0 & 100.00 & 13683 \\
\hline 148 & $-\mathbf{Y}$ & Straight Pipe & 475 & 25.0 & 75.00 & 13758 \\
\hline \multicolumn{7}{|c|}{ Displacement Transducer MN 49XX } \\
\hline 149 & $-\mathbf{Y}$ & Straight Pipe & 475 & 25.0 & 75.00 & 13833 \\
\hline 150 & $-\mathbf{Y}$ & Straight Pipe & 475 & 25.0 & 25.00 & 13858 \\
\hline \multicolumn{7}{|c|}{ Static load applied at node 153} \\
\hline 151 & $-Y$ & Straight Pipe & 475 & 25.0 & 25.00 & 13883 \\
\hline 152 & $-\mathbf{Y}$ & Straight Pipe & 475 & 25.0 & 19.00 & 13902 \\
\hline 153 & $-\mathbf{Y}$ & Straight Pipe & 475 & 25.0 & 50.00 & 13952 \\
\hline 154 & $-\mathbf{Y}$ & Straight Pipe & 475 & 25.0 & 100.00 & 14052 \\
\hline 155 & $-\mathbf{Y}$ & Straight Pipe & 475 & 25.0 & 100.00 & 14152 \\
\hline 156 & $-\mathbf{Y}$ & Straight Pipe & 475 & 25.0 & 50.00 & 14202 \\
\hline 157 & $-\mathbf{Y}$ & Straight Pipe & 475 & 25.0 & 20.00 & 14222 \\
\hline 158 & $-\mathbf{Y}$ & Straight Pipe & 475 & 25.0 & 20.00 & 14242 \\
\hline
\end{tabular}


Table A2. Refined Model Geometry Data (continued)

\begin{tabular}{|c|c|c|c|c|c|c|}
\hline $\begin{array}{l}\text { Element } \\
\text { Number }\end{array}$ & $\begin{array}{c}\text { Global } \\
\text { Direction }\end{array}$ & Element Type & $\begin{array}{c}\text { Outside } \\
\text { Diameter } \\
\text { mm }\end{array}$ & $\begin{array}{c}\text { Wall } \\
\text { Thickness } \\
\text { mm }\end{array}$ & $\begin{array}{l}\text { Element } \\
\text { Length } \\
\mathrm{mm}\end{array}$ & $\begin{array}{l}\text { Cummulative } \\
\text { Length } \\
\text { mm }\end{array}$ \\
\hline 159 & $-\bar{Y}$ & Straight Pipe & 475 & 25.0 & 40.00 & 14282 \\
\hline 160 & $-\mathbf{Y}$ & Straight Pipe & 475 & 25.0 & 50.00 & 14332 \\
\hline 161 & $-Y+Z$ & Elbow $1345^{\circ}$ & 475 & 25.0 & 785.00 & 15117 \\
\hline 162 & $-Y+Z$ & Elbow $\because 34^{\circ}$ & 475 & 25.0 & 720.00 & 15837 \\
\hline 163 & $-Y+Z$ & Elbow $\# 34^{\circ}$ & 475 & 25.0 & 65.00 & 15902 \\
\hline 164 & $+\mathbf{Z}$ & Straight Pipe & 475 & 25.0 & 37.00 & 15939 \\
\hline 165 & $+z$ & Straight Pipe & 475 & 25.0 & 32.00 & 15971 \\
\hline 166 & $+\mathbf{z}$ & Straight Pipe & 475 & 25.0 & 31.00 & 16002 \\
\hline \multicolumn{7}{|c|}{ Elbow 4, Material $4^{+Z}$} \\
\hline 167 & $+Z+X^{* * *}$ & Elbow $" 43^{\circ}$ & 475 & 25.0 & 48.00 & 16050 \\
\hline \multicolumn{7}{|c|}{$\begin{array}{c}167 \\
\text { Displacement Transducer } \mathrm{MN} 48 \mathrm{XX}\end{array}$} \\
\hline $\begin{array}{l}108 \\
169\end{array}$ & $+\mathbf{Z}+\mathbf{X}^{\prime}$ & Elbow $" 442^{\circ}$ & 475 & 25.0 & 737.00 & 16787 \\
\hline 170 & $+\mathbf{Z}+\mathbf{X}^{\prime}$ & Elbow $\# 445^{\circ}$ & 475 & 25.0 & 785.00 & 17572 \\
\hline 171 & $+\mathbf{X}^{\prime}$ & Straight Pipe & 475 & 25.0 & 100.34 & 17672 \\
\hline 172 & $+X^{\prime}$ & Straight Pipe & 475 & 25.0 & 100.34 & 17773 \\
\hline 173 & $+X^{\prime}$ & Straight Pipe & 475 & 25.0 & 49.74 & 17822 \\
\hline 174 & $+X^{\prime}$ & Straight Pipe & 475 & 25.0 & 49.74 & 17872 \\
\hline 175 & $+X^{\prime}$ & Straight Pipe & 475 & 25.0 & 49.74 & 17922 \\
\hline 176 & $+X^{\prime}$ & Straight Pipe & 475 & 25.0 & 57.80 & 17980 \\
\hline 177 & $+\mathbf{X}^{\prime}$ & Straight Pipe & 475 & 25.0 & 100.34 & 18080 \\
\hline 178 & $+X^{\prime}$ & Straight Pipe & 475 & 25.0 & 100.34 & 18180 \\
\hline 179 & $+X^{\prime}$ & Straight Pipe & 475 & 25.0 & 100.34 & 18281 \\
\hline 180 & $+X^{\prime}$ & Straight Pipe & 475 & 25.0 & 100.34 & 18381 \\
\hline 181 & $+X^{\prime}$ & Straight Pipe & 475 & 25.0 & 100.34 & 18481 \\
\hline 182 & $+X^{\prime}$ & Straight Pipe & 475 & 25.0 & 100.34 & 18582 \\
\hline 183 & $+X^{\prime}$ & Straight Pipe & 475 & 25.0 & 100.34 & 18682 \\
\hline 184 & $+X^{\prime}$ & Straight Pipe & 475 & 25.0 & 99.48 & 18782 \\
\hline 185 & $+X^{\prime}$ & Straight Pipe & 475 & 25.0 & 99.48 & 18881 \\
\hline 186 & $+X^{\prime}$ & Straight Pipe & 475 & 25.0 & 99.48 & 18981 \\
\hline 187 & $+X^{\prime}$ & Straight Pipe & 475 & 25.0 & 99.48 & 19080 \\
\hline 188 & $+X^{\prime}$ & Straight Pipe & 475 & 25.0 & 42.79 & 19123 \\
\hline 189 & $+X^{\prime}$ & Straight Pipe & 475 & 25.0 & 25.30 & 19148 \\
\hline 190 & $+X^{\prime}$ & Straight Pipe & 475 & 25.0 & 75.04 & 19223 \\
\hline 191 & $+X^{\prime}$ & Straight Pipe & 475 & 25.0 & 75.04 & 19298 \\
\hline 192 & $+X^{\prime}$ & Straight Pipe & 475 & 25.0 & 75.04 & 19373 \\
\hline 193 & $+X^{\prime}$ & Straight Pipe & 475 & 25.0 & 75.04 & 19448 \\
\hline 194 & $+X^{\prime}$ & Straight Pipe & 475 & 25.0 & 75.04 & 19523 \\
\hline 195 & $+\mathrm{X}^{\prime}$ & Straight Pipe & 475 & 25.0 & 24.44 & 19548 \\
\hline 196 & $+X^{\prime}$ & Straight Pipe & 475 & 25.0 & 24.44 & 19572 \\
\hline $\begin{array}{l}190 \\
197\end{array}$ & $+X^{\prime}$ & Straight Pipe & 475 & 25.0 & 75.04 & 19647 \\
\hline $\begin{array}{l}191 \\
198\end{array}$ & $+X^{\prime}$ & Straight Pipe & 475 & 25.0 & 75.04 & 19722 \\
\hline $\begin{array}{l}198 \\
199\end{array}$ & $+X^{\prime}$ & Straight Pipe & 475 & 25.0 & 75.04 & 19797 \\
\hline & $+X^{\prime}$ & Straight Pipe & 475 & 25.0 & 75.04 & 19872 \\
\hline
\end{tabular}


Table A2. Refined Model Geometry Data (continued)

\begin{tabular}{rrrrrrr}
\hline $\begin{array}{c}\text { Element } \\
\text { Number }\end{array}$ & $\begin{array}{c}\text { Global } \\
\text { Direction }\end{array}$ & Element Type & $\begin{array}{c}\text { Outside } \\
\text { Diameter } \\
\text { mm }\end{array}$ & $\begin{array}{c}\text { Wall } \\
\text { Thickness } \\
\text { mm }\end{array}$ & $\begin{array}{c}\text { Element } \\
\text { Length } \\
\text { mm }\end{array}$ & $\begin{array}{c}\text { Cummulative } \\
\text { Length } \\
\text { mm }\end{array}$ \\
\hline 200 & $+X^{\prime}$ & Straight Pipe & 475 & 25.0 & 75.04 & 19947 \\
201 & $+X^{\prime}$ & $\begin{array}{l}\text { Straight Pipe } \\
\text { Fixed Support Componeat, Material }\end{array}$ & 475 & 25.0 & 25.30 & 19973 \\
202 & $+X^{\prime}$ & Straight Pipe & 508 & 41.5 & 112.00 & 20085 \\
203 & $+X^{\prime}$ & Straight Pipe & 508 & 41.5 & 100.00 & 20185 \\
204 & $+X^{\prime}$ & Straight Pipe & 508 & 41.5 & 100.00 & 20285 \\
205 & $+X^{\prime}$ & Straight Pipe & 508 & 41.5 & 100.00 & 20385
\end{tabular}

Stiffness boundary condition applied to all 6 degrees-of-freedom at node 210

$\begin{array}{ll}300 & \text { Local X' } \\ 301 & \text { Local Y' } \\ 302 & \text { Local Z' } \\ 303 & \text { Local X' } \\ 304 & \text { Local Y' } \\ 305 & \text { Local Z' } \\ 206 & + \text { X' } \\ 207 & +X \\ 208 & +X \\ 209 & +X\end{array}$

Straight Section, Material 4

$\begin{array}{ll}210 & +X \\ 211 & +X \\ 212 & +X \\ 213 & +X \\ 214 & +X \\ 215 & +X \\ 216 & +X \\ 217 & +X\end{array}$

Reducer, Material 6

$\begin{array}{ll}218 & +X^{\prime} \\ 219 & +X^{\prime} \\ 220 & +X^{\prime} \\ 221 & +X^{\prime} \\ 222 & +X^{\prime} \\ 223 & +X^{\prime} \\ 224 & +X^{\prime} \\ 225 & +X^{\prime} \\ 226 & +X^{\prime} \\ 227 & +X^{\prime} \\ 228 & +X^{\prime}\end{array}$

Check Valve, Material 2

$229+\mathrm{X}$

$230+X^{\prime}$

232

\begin{abstract}
Ux Spring
Uy Spring

Uz Spring

$\theta \times$ Spring

Oy Spring

$\theta z$ Spring

Straight Pipe

Straight Pipe

Straight Pipe

Straight Pipe
\end{abstract}

Straight Pipe

Straight Pipe

Straight Pipe

Straight Pipe

Straight Pipe

Straight Pipe

Straight Pipe

Straight Pipe

Straight Pipe

Straight Pipe

Straight Pipe

Straight Pipe

Straight Pipe

Straight Pipe

Straight Pipe

Straight Pipe

Straight Pipe

Straight Pipe

Straight Pipe

Straight Pipe

Straight Pipe

Gen. Mass

$$
\begin{aligned}
& K=2.560 \times 10^{6} \mathrm{~N} / \mathrm{mm} \\
& K=0.571 \times 10^{6} \mathrm{~N} / \mathrm{mm} \\
& K=0.770 \times 10^{6} \mathrm{~N} / \mathrm{mm} \\
& K=1.540 \times 10^{12} \mathrm{~N}-\mathrm{mm} / \mathrm{rad} \\
& K=0.457 \times 10^{12} \mathrm{~N}-\mathrm{mm} / \mathrm{rad} \\
& K=0.637 \times 10^{12} \mathrm{~N}-\mathrm{mm} / \mathrm{rad}
\end{aligned}
$$

508

508

508

508

41.5

100.00

$41.5 \quad 100.00$

$41.5 \quad 100.00$

$41.5 \quad 112.00$

20385 


\section{A-8}

Table A2. Refined Model Geometry Data (continued)

\begin{tabular}{|c|c|c|c|c|c|c|}
\hline $\begin{array}{l}\text { Blement } \\
\text { Number }\end{array}$ & $\begin{array}{c}\text { Global } \\
\text { Direction }\end{array}$ & Element Type & $\begin{array}{c}\text { Outside } \\
\text { Diameter } \\
\text { mm }\end{array}$ & $\begin{array}{c}\text { Wall } \\
\text { Thickness } \\
\text { mm }\end{array}$ & $\begin{array}{l}\text { Element } \\
\text { Length } \\
\mathrm{mm}\end{array}$ & $\begin{array}{l}\text { Cummulative } \\
\text { Length } \\
\mathrm{mm}\end{array}$ \\
\hline 233 & $\overline{+X^{\prime}}$ & Straight Pipe & 406 & 17.5 & 184.99 & 22682 \\
\hline 234 & $+X^{\prime}$ & Straight Pipe & 406 & 17.5 & 135.07 & 22817 \\
\hline \multicolumn{7}{|c|}{ Reducer, Material 6} \\
\hline 235 & $+\mathbf{X}^{\prime}$ & Straight Pipe & 407 & 18.0 & 24.46 & 22841 \\
\hline 236 & $+X^{\prime}$ & Straight Pipe & 407 & 18.0 & 24.01 & 22865 \\
\hline 237 & $+X^{\prime}$ & Straight Pipe & 458 & 22.8 & 24.01 & 22889 \\
\hline 238 & $+X^{\prime}$ & Straight Pipe & 458 & 22.8 & 24.01 & 22913 \\
\hline 239 & $+X^{\prime}$ & Struight Pipe & 458 & 22.8 & 22.98 & 22936 \\
\hline 240 & $+\mathbf{X}^{\prime}$ & Stright Pipe & 458 & 22.8 & 22.45 & 22959 \\
\hline 241 & $+\mathbf{X}^{\prime}$ & Strnight Pipe & 458 & 22.8 & 24.01 & 22983 \\
\hline 242 & $+X^{\prime}$ & Struight Pipe & 458 & 22.8 & 24.01 & 23007 \\
\hline 243 & $+\mathbf{X}^{\prime}$ & Straight Pipe & 508 & 27.5 & 24.01 & 23031 \\
\hline 244 & $+X^{\prime}$ & Straight Pipe & 508 & 27.5 & 19.98 & 23051 \\
\hline 245 & $+X^{\prime}$ & Straight Pipe & 508 & 27.5 & 20.07 & 23071 \\
\hline \multicolumn{7}{|c|}{ Horizontal Straight Section, Material 6} \\
\hline 246 & $+X^{\prime}$ & Straight Pipe & 508 & 32.0 & 46.05 & 23117 \\
\hline 247 & $+X^{\prime}$ & Straight Pipe & 508 & 32.0 & 249.99 & 23367 \\
\hline 248 & $+X^{\prime}$ & Straight Pipe & 508 & 32.0 & 249.99 & 23617 \\
\hline 249 & $+X^{\prime}$ & Strnight Pipe & 508 & 32.0 & 249.99 & 23867 . \\
\hline 250 & $+X^{\prime}$ & Straight Pipe & 508 & 32.0 & 124.95 & 23992 \\
\hline \multicolumn{7}{|c|}{ Fixed boundary condition applied to 2 degrees-of-freedom at node $299, Y^{\prime}=0 \quad Z^{\prime}=0$} \\
\hline 299 & $+\mathbf{X}$ & Straight Pipe & 508 & 32.0 & 125.04 & 24117 \\
\hline \multicolumn{7}{|c|}{ Break Nozzle, Material 6} \\
\hline 251 & $+\mathbf{X}^{\prime}$ & Straight Pipe & 508 & 27.5 & 25.04 & 24142 \\
\hline 252 & $+\mathbf{X}^{\prime}$ & Straight Pipe & 508 & 27.5 & 24.51 & 24166 \\
\hline 253 & $+\mathrm{X}^{\prime}$ & Straight Pipe & 537 & 41.8 & 19.98 & 24186 \\
\hline 254 & $+X^{\prime}$ & Straight Pipe & 537 & 41.8 & 19.62 & 24206 \\
\hline 255 & $+X^{\prime}$ & Straight Pipe & 565 & 56.0 & 22.49 & 24228 \\
\hline 256 & $+\mathrm{X}$ & Straight Pipe & 565 & 56.0 & 21.95 & 24250 \\
\hline 257 & $+X^{\prime}$ & Straight Pipe & 575 & 61.0 & 24.37 & 24275 \\
\hline 258 & $+X^{\prime}$ & Straight Pipe & 575 & 61.0 & 39.96 & 24315 \\
\hline 259 & $+X^{\prime}$ & Straight Pipe & 575 & 61.0 & 40.05 & 24355 \\
\hline 260 & $+X^{\prime}$ & Straight Pipe & 575 & 61.0 & 39.96 & 24395 \\
\hline 261 & $+X^{\prime}$ & Straight Pipe & 575 & 61.0 & 24.01 & 24419 \\
\hline 262 & $+X^{\prime}$ & Straight Pipe & 565 & 56.0 & 22.54 & 24441 \\
\hline 263 & $+X^{\prime}$ & Straight Pipe & 565 & 56.0 & 21.95 & 24463 \\
\hline 264 & $+x^{\prime}$ & Straight Pipe & 630 & 88.5 & 16.48 & 24480 \\
\hline 265 & $+X^{\prime}$ & Straight Pipe & 630 & 88.5 & 40.05 & 24520 \\
\hline 266 & $+X^{\prime}$ & Straight Pipe & 630 & 88.5 & 39.96 & 24560 \\
\hline 267 & $+X^{\prime}$ & Straight Pipe & 630 & 88.5 & 40.05 & 24600 \\
\hline 268 & $+\mathbf{X}^{\prime}$ & Straight Pipe & 630 & 88.5 & 36.96 & 24637 \\
\hline \multicolumn{7}{|c|}{ Rupture Disk Assembly, Material 6} \\
\hline 269 & $+\mathbf{X}$ & Straight Pipe & 630 & 88.5 & 62.95 & 24700 \\
\hline
\end{tabular}




$$
\text { A-9 }
$$

Table A2. Refined Model Geometry Data (continued)

\begin{tabular}{ccccccc}
\hline $\begin{array}{l}\text { Element } \\
\text { Number }\end{array}$ & $\begin{array}{c}\text { Global } \\
\text { Direction }\end{array}$ & Element Type & $\begin{array}{c}\text { Outside } \\
\text { Diameter } \\
\mathrm{mm}\end{array}$ & $\begin{array}{c}\text { Wall } \\
\text { Thickness } \\
\mathrm{mm}\end{array}$ & $\begin{array}{c}\text { Element } \\
\text { Length } \\
\mathrm{mm}\end{array}$ & $\begin{array}{c}\text { Cummulative } \\
\text { Length } \\
\mathrm{mm}\end{array}$ \\
\hline 270 & $+\mathrm{X}$ & Straight Pipe & 630 & 88.5 & 72.04 & 24772 \\
\hline
\end{tabular}

* Local coordinate system of the last branch defined by a $210^{\circ}$ rotation of the X-Y plane about the global Z axis. Local coordinate system $\left(X^{\prime}, Y^{\prime}, Z^{\prime}\right)$ defined with $X^{\prime}$ along the pipe axis, $Y^{\prime}$ in the horizontal plane, and $Z^{\prime}$ vertical. $X^{\prime}=X^{*} \cos \left(210^{\circ}\right)+Y^{*} \sin \left(210^{\circ}\right), Y^{\prime}=-X^{*} \sin \left(210^{\circ}\right)+Y^{*} \cos \left(210^{\circ}\right), Z^{\prime}=$ Z. 


\section{Internal}

C. A. Kot (30)

TIS File

\section{External}

NRC, for distribution per RF, R5

ANL-E Library (2)

ANL-W Library

Manager, Chicago Operations Office, DOE

Mr. A. L. Hiser, Jr. (35)

Division of Engineering

Office of Nuclear Regulatory Research

U.S. Nuclear Regulatory Commission

Mail Stop T-10E10

Washington, DC 20555

Dr. G. M. Wilkowski (35)

Battelle

505 King Avenue

Columbus, $\mathrm{OH} 43201$ 

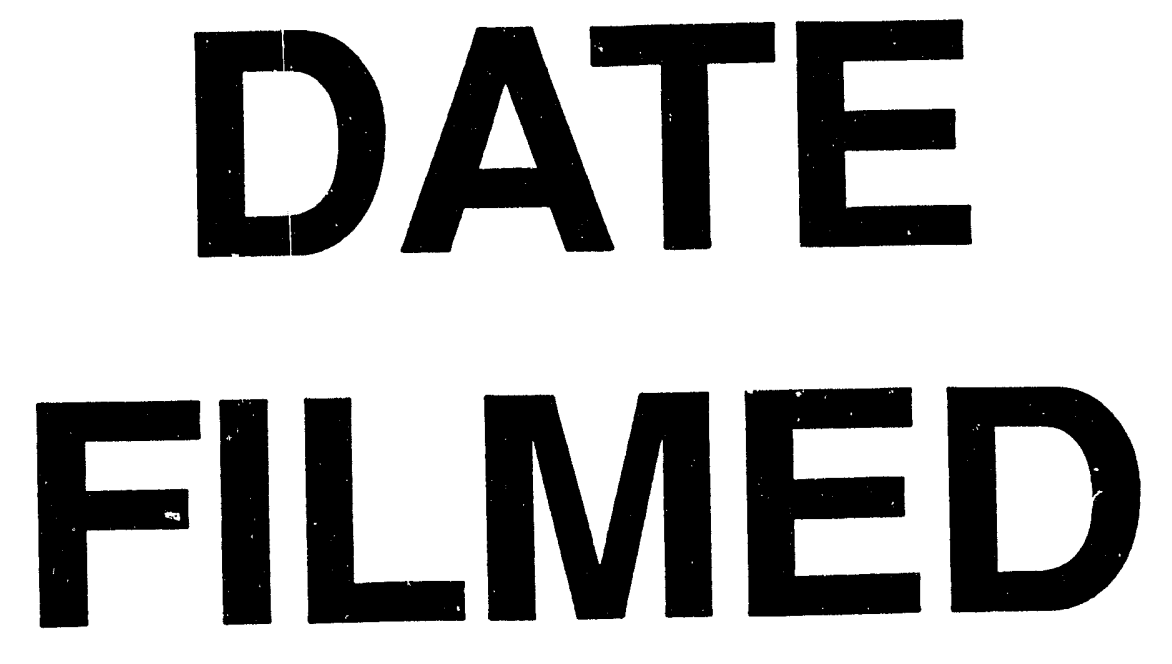

$10 / 24 / 94$
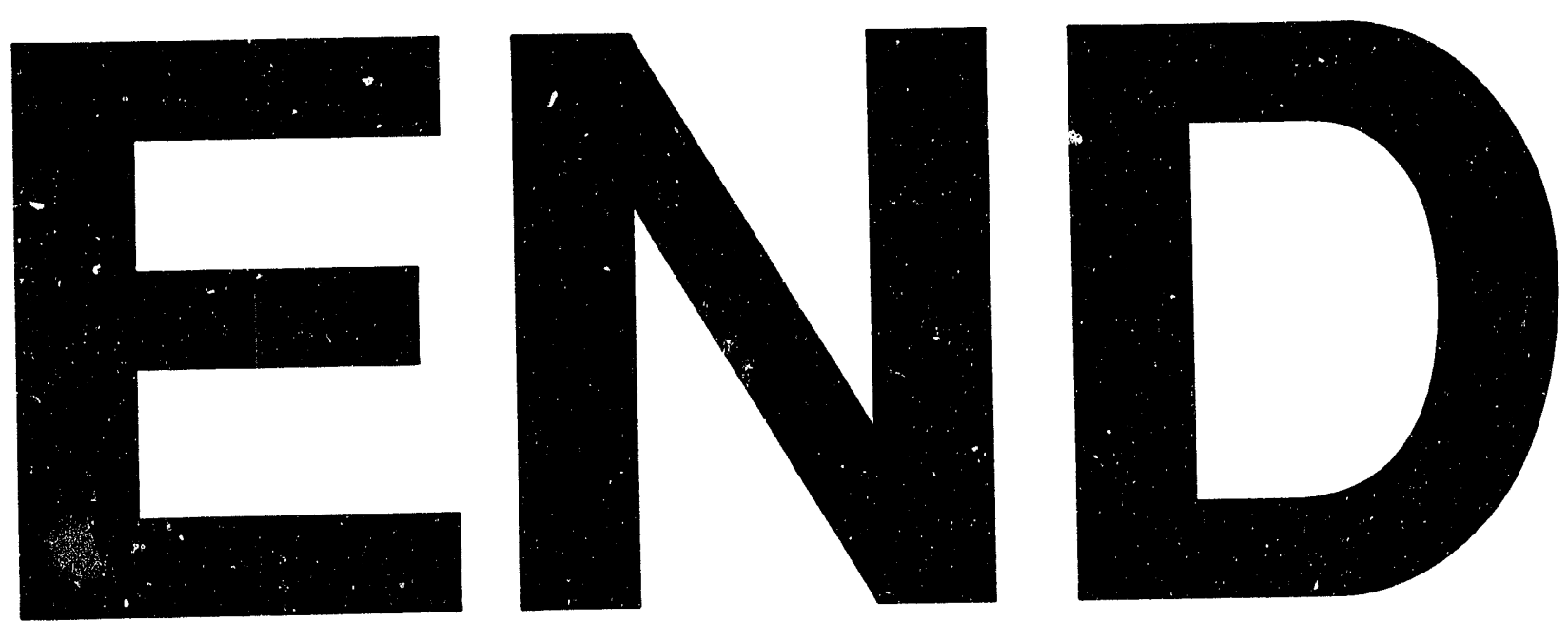
